$$
\begin{gathered}
\text { INTERMEDIATE } \\
\text { ANCIENT GREEK } \\
\text { LANGUAGE }
\end{gathered}
$$





\title{
INTERMEDIATE ANCIENT GREEK LANGUAGE
}

\author{
DARRYL PALMER
}

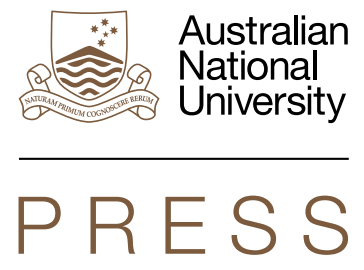




\section{ANU \\ PRES S \\ LANGUAGES}

Published by ANU Press

The Australian National University

Acton ACT 2601, Australia

Email: anupress@anu.edu.au

Available to download for free at press.anu.edu.au

ISBN (print): 9781760463427

ISBN (online): 9781760463434

WorldCat (print): 1241230170

WorldCat (online): 1241230169

DOI: 10.22459/IAGL.2021

This title is published under a Creative Commons Attribution-NonCommercialNoDerivatives 4.0 International (CC BY-NC-ND 4.0).

\section{(9) $(1) \Theta$}

The full licence terms are available at creativecommons.org/licenses/by-nc-nd/4.0/legalcode

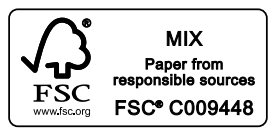

Cover design and layout by ANU Press

This edition (C) 2021 ANU Press 


\section{Contents}

Abbreviations and Symbols $\quad$ xiii

Introduction 1

1. Time and Aspect of the Indicative Mood 5

1.1. Tense 5

1.2. Forms and Functions $\quad 5$

1.3. Time and Aspect (Summary) 8

EXERCISE 1

2. Aspect in the Imperative, Subjunctive and Optative Moods 13

2.1. Introduction 13

2.2. Forms 13

2.3. Functions 14

EXERCISE 2 17

3. Infinitive 21

3.1. Introduction $\quad 21$

3.2. Forms 21

3.3. Functions $\quad 22$

3.4. Infinitive without Article $\quad 22$

3.5. Infinitive with Article $\quad 25$

EXERCISE $3 \quad 28$

4. Participles 31

4.1. Introduction 31

4.2. Forms $\quad 32$

4.3. Functions $\quad 32$

4.4. Negatives $\quad 36$

EXERCISE 4 36

5. Genitive Absolute 39

5.1. The Usual Construction $\quad 39$

5.2. Subject Unexpressed $\quad 40$

5.3. Improper Genitive Absolute $\quad 41$

EXERCISE 5

6. Accusative Absolute 45

6.1. Introduction $\quad 45$

6.2. So-Called Impersonal Verbs $\quad 45$

6.3. Verbs Used Impersonally in the Passive Voice 46

$\begin{array}{ll}\text { 6.4. Neuter Adjectives } & 47\end{array}$ 
6.5. Personal Accusative Absolute $\quad 48$

6.6. Note 49

EXERCISE $6 \quad 50$

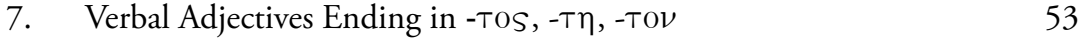

7.1. Introduction 53

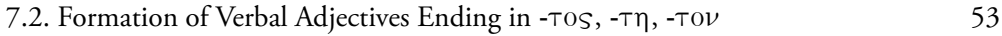

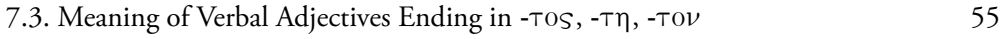

EXERCISE 7

8. Verbal Adjectives Ending in -TéOS, -Téa, -Téov 61

8.1. Formation of Verbal Adjectives Ending in -Téos, -Téa, -Téov 61

8.2. Usage of Verbal Adjectives Ending in -Téos, -Téa, -Téov 61

8.3. Impersonal Construction $\quad 62$

8.4. Personal Construction 63

8.5. Ambiguous Constructions $\quad 64$

8.6. Agent in Accusative $\quad 64$

8.7. Construction Continued with Infinitive 65

8.8. Impersonal Passive Construction $\quad 65$

EXERCISE 8

9. Voice 69

9.1. English $\quad 69$

9.2. Greek 69

9.3. Uses of the Middle Voice 70

9.4. The Development of the Middle Voice 74

EXERCISE 9

10. Commands 79

$\begin{array}{ll}\text { 10.1. Introduction } & 79\end{array}$

10.2. Negative Commands $\quad 79$

10.3. Virtual Commands $\quad 80$

10.4. Reported Commands $\quad 82$

EXERCISE 10

11. Wishes 89

11.1. Wishes for the Future 89

11.2. Unfulfilled Wishes for the Present and the Past 91

11.3. Reported Wishes 95

11.4. Reported Wishes Instead of Direct Wishes 95

11.5. Interrogative Wishes Combined with Deliberative Subjunctive 96

EXERCISE 11

12. Directly Reported Speech 101

12.1. Homer 101

12.2. Drama 102

12.3. Historiography 102

12.4. Prose Quotation Formulae 103

12.5. ÖTI and $\omega$ S as Quotation Markers $\quad 103$

$\begin{array}{ll}\text { EXERCISE } 12 & 104\end{array}$ 
13.1. Introduction

13.2. Reported Statements in Primary Sequence

13.3. Reported Statements in Past Sequence

13.4. Vivid Construction

EXERCISE 13

14. Reported Statements with Infinitive 113

14.1. Aspect of the Infinitive

14.2. Accusative and Infinitive Phrases

14.3. Nominative and Infinitive Phrases

14.4. Exceptional Accusative and Infinitive Phrases

14.5. Negative

14.6. Usage

14.7. Passive of $\lambda \hat{\epsilon} \gamma \in \mathrm{V}$

EXERCISE 14

15. Reported Knowledge and Perception

15.1. Introduction

15.2. Reported Knowledge or Perception with ötı or $\dot{\text { s }}$

15.3. Reported Knowledge or Perception with a Participial Phrase

15.4. Physical Perception

15.5. Reported Knowledge or Perception with an Infinitive Phrase

16. Reported Thoughts, Hopes, Promises and Oaths

16.1. Reported Thoughts

16.2. Reported Hopes and Promises

16.3. Reported Oaths

EXERCISE 16

17.1. Ordinary Questions

17.2. Alternative Questions

17.3. Questions with Interrogative Adjectives or Adverbs

17.4. Deliberative Questions

17.5. Rhetorical Questions

EXERCISE 17

18. Reported Questions

18.1. Reported Ordinary Questions

18.2. â $\rho a$ in Reported Questions

18.3. Reported Alternative Questions

146

18.4. Reported Questions with Interrogative Adjectives or Adverbs 148

18.5. Reported Deliberative Questions 149

EXERCISE 18 
19.1. Introduction

19.2. Open Conditions

19.3. Unfulfilled Conditions

19.4. Mixed Conditions

19.5. The Negative in If-Clauses

EXERCISE 19

20. Homeric Conditions 161

20.1. Introduction

20.2. Open Conditions

20.3. Unfulfilled Conditions

EXERCISE 20

21. Subordinate Clauses in Reported Discourse

21.1. Reported Complex Sentences

21.2. Reported Subordinate Clauses in Primary Sequence 169

21.3. Reported Subordinate Clauses in Past Sequence $\quad 170$

21.4. Assimilation of Construction $\quad 171$

21.5. Vivid Construction $\quad 172$

EXERCISE $21 \quad 173$

22. Result Constructions 175

22.1. Natural Result

22.2. Comparative Result

22.3. Actual Result

22.4. Adjectival Clauses of Result

22.5. Provisos

22.6. Antecedents for Result Constructions 179

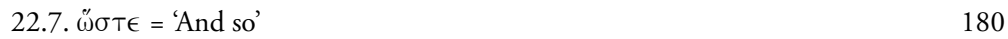

EXERCISE $22 \quad 180$

23. Causal Constructions 183

23.1. Adverbial Clauses of Cause $\quad 183$

23.2. Adjectival Clauses of Cause $\quad 186$

23.3. Causal Participles 186

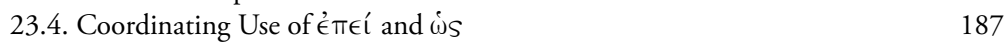

$\begin{array}{ll}\text { EXERCISE } 23 & 188\end{array}$

24. Constructions with Verbs of Effort and Caution 191

24.1. Introduction 191

24.2. Primary Sequence 191

24.3. Past Sequence 193

24.4. Variations of the Constructions in $\$ \$ 24.2$ and $24.3 \quad 196$

24.5. Infinitive Constructions 196

24.6. Omission of Main Clause 197

EXERCISE $24 \quad 198$ 
25.1. Introduction

25.2. Definite Clauses Introduced by ös

201

25.3. Indefinite Clauses Introduced by ös

25.4. Indefinite Clauses Introduced by ö $\sigma \mathrm{TIS}$

204

25.5. Coordinating Use of the Relative Adjective or Pronoun 206

25.6. Parenthetic ő $\sigma$ tıs Clause

206

25.7. Special Uses of ő $\sigma$ TIS and ôs ăv

207

EXERCISE 25

26. Concessive Constructions

26.1. Introduction

26.2. Concessive Participial Phrases

26.3. Concessive Clauses

EXERCISE 26

27. Purpose Constructions

27.1. Prepositions

27.2. Infinitive

27.3. Participles

27.4. Adjectival Clauses of Purpose

27.5. Adverbial Clauses of Purpose

EXERCISE 27

28. Clauses of Comparison

28.1. Introduction

28.2. Definite Comparison

28.3. Indefinite Comparison

28.4. Potential, Conditional and Temporal Constructions

28.5. Other Correlative Adjectives and Adverbs

EXERCISE 28

29. Expressions of Hindering, Forbidding, Denying and Failing

29.1. Introduction

29.2. Direct Object

29.3. Genitive of Separation

29.4. Infinitive after a Positive Expression

29.5. є̇ $\mu \pi о \delta \omega ́ v$

29.6. Infinitive after a Negative Expression

29.7. Result Construction

29.8. Effort Construction

29.9. Conditional Construction 
30. Temporal Constructions 1: Clauses in Primary Sequence

30.1. Introduction

30.2. Contemporaneous Action in Temporal Clause

30.3. Prior Action in Temporal Clause

30.4. Subsequent Action in Temporal Clause: Indefinite

31. Temporal Constructions 2: Clauses in Past Sequence

31.1. Introduction

31.2. Contemporaneous Action in Temporal Clause

31.3. Prior Action in Temporal Clause

31.4. Subsequent Action in Temporal Clause

EXERCISE 31

32. Temporal Constructions with $\pi \rho i v$

32.1. Introduction

32.2. $\pi \rho$ í $\nu$ with an Infinitive Phrase

32.3. $\pi \rho i v$ with a Finite Verb

EXERCISE 32

33. Adverbial Clauses of Place and Manner

33.1. Adverbial Clauses of Place

33.2. Adverbial Clauses of Manner

33.3. Adverbial Clauses of Place Expressing Purpose

33.4. Adverbial Clauses Distinguished from Noun Clauses

EXERCISE 33

34. Noun Clauses with Expressions of Emotion 269

34.1. Introduction

34.2. Verbs of Emotion

34.3. €i Clause as Subject

34.4. Negatives with ö $T \iota$ and $\epsilon i$ Clauses

34.5. General Comments

EXERCISE 34A

EXERCISE 34B

35. Expressions of Fearing

35.1. Introduction

35.2. Verbs of Fearing with Noun or Pronoun as Object

35.3. Verbs of Fearing with Infinitive Phrase as Object

35.4. Verbs of Fearing with a $\mu$ í Clause as Object

35.5. Fears that Something is (etc.) Actually Happening 285

35.6. Fears Expressed with Other Conjunctions 286

35.7. Introductory Noun Phrases $\quad 289$

35.8. Note 290

EXERCISE 35A $\quad 291$

EXERCISE 35B 292 
36.1. Nominative as Subject

36.2. Nominative as Complement

36.3. Predicate Nominative with Passive Verb

36.4. Quoted Nominative

36.5. Nominative Address

297

36.6. Nominative Exclamation

36.7. Vocative

298

36.8. Hanging Vocative

299

EXERCISE 36

37. Accusative Case

37.1. Accusative as Direct Object

37.2. Adverbial Uses of the Accusative

37.3. Accusative in Apposition to a Sentence

EXERCISE 37

38. Genitive Case 1

38.1. Introduction

38.2. Simple Possessive Genitive

38.3. Subjective Genitive

38.4. Objective Genitive

38.5. Partitive Genitive

38.6. Genitive of Definition (or Apposition)

38.7. Genitive of Description (or Quality)

38.8. Genitive of Material

38.9. Genitive of Measure

38.10. Genitive of Price or Value

EXERCISE 38

39. Genitive Case 2

39.1. Introduction

39.2. Possessive Genitive

39.3. Partitive Genitive

39.4. Genitive of Separation

39.5. Genitive with Compound Verbs

328

EXERCISE 39

40. Dative Case 1

40.1. Introduction

40.2. Dative of Interest

40.3. Dative of Accompaniment (or Sociative Dative) 334

EXERCISE 40

41. Dative Case 2 
42.1. Adverbs

42.2. Compound Verbs

42.3. Prepositions

42.4. Case Functions

42.5. Possessive Genitive with Preposition

42.6. Compound Verb with Preposition

42.7. Metaphorical Use of Prepositions

42.8. Accent and Position of Prepositions

42.9. Adverbial Accusative as Preposition

42.10. Pregnant Construction

42.11. 'Proper' and 'Improper' Prepositions

42.12. Hellenistic and Later Developments

EXERCISE 42A

EXERCISE 42B

43. Correlative Clauses 359

43.1. Introduction

43.2. Adjectival Clauses

43.3. Adverbial Clauses

43.4. Interrogative Antecedent

43.5. Mixed Adjectival and Adverbial Construction

43.6. Pronominal Idioms

43.7. Note

EXERCISE 43

44. Exclamations 367

44.1. Exclamatory Cries

44.2. A Cry with First Person Singular Pronoun

44.3. An Exclamation with a Causal Genitive

44.4. Exclamatory Infinitive Phrases

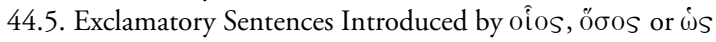

44.6. Interrogative Adjective or Adverb 


\section{Abbreviations and Symbols}

abs. absolute

Acc. Accusative

Act. Active

adj. adjective

adv. adverb

Aor. Aorist

(B)CE (Before) the Common Era

Dat. Dative

fem. feminine

Fut. Future

Gen. Genitive

Hist. Historic

Imperf. Imperfect

Impv. Imperative

Indic. Indicative

Infin. Infinitive
Intr. Intransitive

lit. literal(ly)

masc. masculine

Mid. Middle

neut. neuter

Nom. Nominative

Opt. Optative

Partc. Participle

Pass. Passive

Perf. Perfect

pers. person

pl. plural

Pres. Present

sg. singular

Subj. Subjunctive

Voc. Vocative

Angular brackets enclose words supplied in translation: <...>.

Square brackets enclose either brief explanatory notes or words not needing to be translated in Exercises: [...]. 



\section{Introduction}

This series of Lessons and Exercises is intended for students who have already covered all or most of an introductory course in the ancient Greek language. It aims to broaden and deepen students' understanding of the main grammatical constructions of Greek. Further attention is given to grammatical forms only to the extent necessary to illustrate their functions. With one exception, all Greek passages in the Lessons and Exercises (including English to Greek translation) are direct quotations from Greek authors. Some quotations are modified by the omission of a few words (marked by ellipses) for the sake of brevity, but without affecting the grammatical structure. In Lesson 19 on Conditions, brief model sentences have been employed to demonstrate more clearly the variety of conditional sentences.

In the Lessons, all Greek passages are translated into literal but reasonably idiomatic English. For the most part, passages in both the Lessons and the Exercises are drawn from main genres of the classical period (fifth to fourth centuries BCE) — tragedy, comedy, historiography (together with biography), oratory and philosophy. Non-dramatic lyric is not often used, since it is more difficult to understand a single sentence out of context in this genre. Didactic poetry (Hesiod) also appears seldom. Homer receives attention at particular points, mainly Homeric conditions (Lesson 20) and Homeric similes (Lesson 28 on clauses of comparison). In general, the focus is on the classical Attic dialect. Where Epic or Ionic forms occur, they are explained if necessary. Occasionally there are references forward to the Hellenistic period.

The first few Lessons have an emphasis on Time and Aspect in the Greek verbal system. After the Moods of the finite verb in Lessons 1 and 2, Infinitives and Participles are treated in Lessons 3 and 4. The absolute constructions of the Participles in the Genitive and Accusative Cases follow

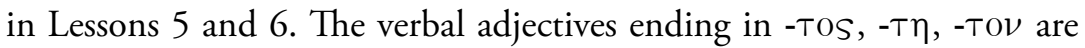
treated in Lesson 7, and those ending in -TÉos, -TÉa, -TÉov in Lesson 8. Lesson 9 is primarily concerned with the use of the Middle Voice in the classical period. Lesson 10 deals with commands and Lesson 11 with wishes. These two Lessons expand the concise treatment of Imperative, 
Subjunctive and Optative Moods in Main clauses in Lesson 2. In addition to the most basic constructions, Lessons 10 and 11 present the variety of ways in which commands and wishes may be expressed. These two Lessons also cover the subordinate constructions for reported commands and reported wishes.

Lesson 12 provides a brief and basic presentation of directly quoted statements. This leads on to the range of subordinate constructions, which begins with reported statements in Lessons 13 and 14, and extends to Lesson 35. This sequence is interrupted at two points. Lesson 17 on questions is followed by Lesson 18 on reported questions. Lesson 21 on subordinate clauses in reported discourse is placed intentionally in the midst of the sequence of subordinate constructions.

Discussion of the Cases has been deliberately placed late in the series at Lessons 36 to 41 . By this stage, students will be better prepared to analyse the Case usage with which they are now familiar. For the classical period, the consideration of prepositions in Lesson 42 naturally follows the treatment of the Cases. Lesson 43 on correlative clauses has numerous links with adjectival and adverbial constructions in previous Lessons. Finally, Lesson 44 deals with exclamations.

The majority of the Exercises comprise several passages for translation from Greek to English and one or more passages (depending on length) for translation from English to Greek. It is intended that students should use the full and most recent edition of $A$ Greek-English Lexicon originally compiled by H. G. Liddell and R. Scott. Alternatively, The Brill Dictionary of Ancient Greek, originally compiled by F. Montanari for Italian readers, is now available with American-English spellings (see Bibliography for both dictionaries). However, to save time for students, some vocabulary is provided for specific passages in each of the Exercises. Exercises 7 to 9 and Exercises 36 to 42 involve translation from Greek to English only, but do require brief analytical comment. Exercise 20 on Homeric conditions involves translation from Greek to English only, but requires no further comment. Alternative Exercises (A and B) are provided for Lessons 34, 35 and 42 . Exercises are of approximately equal length. 
Accent marks indicate how a pitch accent was probably pronounced in Classical Greek. No separate Exercises are provided for this purpose. But the books of Allen (1987) and Probert (2003) are recommended. The table near the end of Lesson 1 and the accompanying list of Tenses largely correspond to those of the Joint Committee on Grammatical Terminology (1911) as modified by Masterman (1962). Masterman (1962, p .72) began his article with the following words:

It is over fifty years now since the formation of the Joint Committee on Grammatical Terminology, and the presentation of its Report; and it seems to be high time that teachers of languages considered, first, how successful they have been in carrying out its recommendations, and secondly, what modifications are called for in the light of more recent knowledge.

Since Masterman's article was published, over 50 more years have passed, and it seems high time that a new intermediate Greek language textbook be made available. The grammars of Ancient Greek by Goodwin (1889) and Smyth (1956) remain the most convenient in English, despite their age. 



\section{LESSON 1 \\ Time and Aspect of the Indicative Mood}

\subsection{Tense}

Tense may be regarded as the combination of the Time and Aspect of a Greek verb. In classical usage, there are three Times-Present, Past, Future—and three Aspects_-Imperfect, Perfect, Aorist.

The main functions of the Aspects are as follows:

- Imperfect expresses continuous or repeated action.

- Perfect expresses completed action or the state resulting from completed action.

- Aorist expresses momentary action or sums up a whole period as a single action.

- Aspect is not inherent in an action but expresses the point of view of the speaker or writer.

(Palmer regards 'durative' as an inadequate description of the function of the Imperfect Aspect and prefers to think of it as the 'eye-witness aspect'.)

The combination of three Times and Aspects would give a theoretical nine Tenses. But Greek does not have separate forms for each of the nine theoretical possibilities.

\subsection{Forms and Functions}

By way of illustration, the first person singular forms of the Indicative Active are given in the following list. The Active Voice of mav́eIV is normally used transitively (i.e. with a direct Object). 


\subsubsection{Present Time}

Present

\begin{tabular}{ll}
\hline Taúw & I am stopping \\
& I stop (repeatedly or regularly) \\
\hline
\end{tabular}

This Tense form is properly Present Imperfect. However, there is no separate form for Present Aorist. So tav́w also covers the meaning 'I stop' (momentarily), and the Tense is usually called simply 'Present'. The Aorist function of the Present is most obvious in the Historic Present usage, where a Present Indicative vividly expresses a past action.

\section{Present Perfect}

пе́таטка I have stopped

It is generally agreed that, at the earliest stage of its development, the Perfect Aspect expressed a state resulting from previous action. In the classical period, this is especially noticeable with the Present Perfect forms of certain verbs used with Present meaning, for example: oî $\delta \alpha$, 'I have come to know', hence 'I know'; or Ë $\sigma \tau \eta \kappa \alpha$, 'I have taken my stand', hence 'I am standing'. By the later classical period, the emphasis on completed action had become more prominent and new Perfect forms with this resultative force were invented. But this emphasis had declined again by the first century CE. The Present Perfect and the Past Aorist Indicatives became increasingly interchangeable during the first three centuries CE. By the fourth century CE, the Present Perfect had been superseded by the Present (replacing its stative force) and by the Past Aorist (replacing its resultative force).

\subsubsection{Past Time}

In the classical period, all three Past Tenses were marked by the augment $\epsilon$ and had endings different to the Present and Future Tenses. Verbs with an initial short vowel in the Present Tense (e.g. i $\in \in T \in \hat{v} \omega$ with short ı)

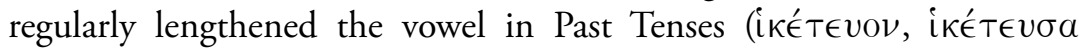
with long $\mathrm{l}$ ). 


\section{Past Imperfect}

Étravov I was stopping, I used to stop

\section{Past Perfect}

\begin{tabular}{|c|c|}
\hline 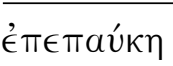 & I had stopped \\
\hline$\eta$ & I had come to know, (hence) I knew \\
\hline$\epsilon i \sigma \tau \eta ́ \kappa \eta$ & I had stood, (hence) I was standing \\
\hline
\end{tabular}

\section{Past Aorist}

\begin{tabular}{|c|c|}
\hline$\epsilon^{\prime} \pi \alpha v \sigma \alpha$ & I stopped \\
\hline 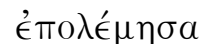 & I fought \\
\hline
\end{tabular}

'Stopping' is by nature a momentary action. 'Fighting' a battle or a war is by nature a continuous action. In the following passage, neither the composition of the account of the Peloponnesian war nor the actual fighting of the war was a momentary action. But both actions are summed

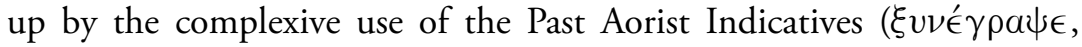

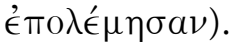

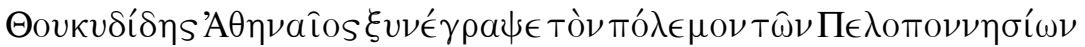

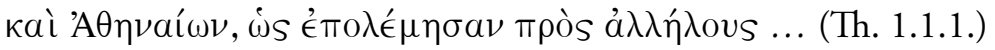

Thucydides the Athenian wrote an account of the war of the Peloponnesians and the Athenians, how they fought against each other ...

\subsubsection{Future Time}

\section{Future}

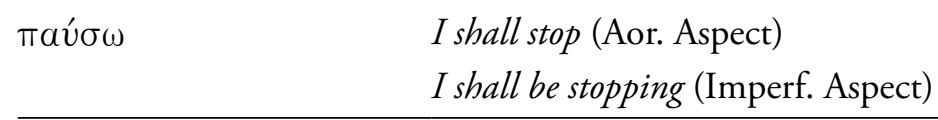

There are not separate forms for Future Imperfect and Future Aorist. The Future is primarily Aoristic in function. Some scholars explain the Future Indicative as derived from an Aorist Subjunctive with a sigma suffix. Tav́ $\sigma \omega$ is an ambivalent form: 'I shall stop' (Fut. Indic.); 'I am to stop', 'let me stop' (Aor. Subj.). Palmer (1980) prefers to explain the 
Future as a desiderative Mood in origin. Alternatively, the Future could be regarded as an Intentive Aspect in function. (Cf. the other common English idiom for expressing futurity: 'I am going to stop'.)

\section{Future Perfect}

\begin{tabular}{ll}
\hline$\pi \in \pi a v \xi_{\omega}$ & $\begin{array}{l}\text { I shall have stopped } \\
\text { I shall have stopped } \\
\text { (periphrastic, the usual form) }\end{array}$ \\
\hline
\end{tabular}

Actual forms of the Future Perfect Active are rare; they occur especially in two verbs that are regularly used in the Perfect with an Imperfect meaning.

\begin{tabular}{ll}
\hline$\dot{\epsilon} \sigma \top \hat{\eta} \xi \omega$ & I shall have stood, (hence) I shall stand \\
$\tau \in \theta \nu \hat{\eta} \xi_{\omega}$ & I shall have died, (hence) I shall be dead \\
\hline
\end{tabular}

Those verbs that form a regular Future Perfect Middle/Passive mostly prefer either a Middle or a Passive meaning. The Passive meaning is more common.

Emphatic reduplicated Futures such as $\delta \in \delta \delta^{\prime} \xi_{\mathrm{o}}$ al 'I shall certainly receive' (Hom.Il. 5.238) constituted a model for the formation of Future Perfects from the Present Perfect base. Conversely, Future Perfect forms can sometimes be translated appropriately as emphatic Futures.

\subsection{Time and Aspect (Summary)}

\begin{tabular}{|c|c|c|c|}
\hline & Aspect & & \\
\hline Time & Imperfect & Perfect & Aorist \\
\hline \multirow[t]{2}{*}{ Present } & $\pi a v ́ \omega$ & пе́таика & $(\pi \alpha \hat{v} \omega)$ \\
\hline & 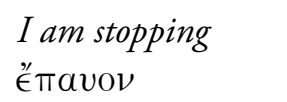 & $\begin{array}{l}\text { I have stopped } \\
\epsilon \pi \epsilon \pi \text { aúkn }\end{array}$ & $\begin{array}{l}\text { I stop } \\
\text { ÉTav } \sigma a\end{array}$ \\
\hline Past & $\begin{array}{l}\text { I was stopping } \\
(\pi \alpha v ́ \sigma \omega)\end{array}$ & $\begin{array}{l}\text { I had stopped } \\
\pi \in \pi a v ́ \xi \omega\end{array}$ & 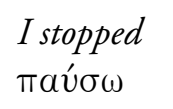 \\
\hline Future & I shall be stopping & 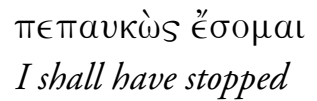 & I shall stop \\
\hline
\end{tabular}


In the Lessons and Exercises, the following terminology will be used for the Tenses of the Indicative Mood (Cf. Masterman, 1962, 76).

\begin{tabular}{|c|c|}
\hline$\pi a v ́ \omega$ & Present \\
\hline те́тачка & Present Perfect \\
\hline ÉTavov & Past Imperfect \\
\hline 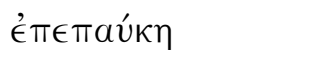 & Past Perfect \\
\hline $\mathscr{e}^{\prime} \pi \alpha v \sigma \alpha$ & Past Aorist \\
\hline$\pi a v ́ \sigma \omega$ & Future \\
\hline 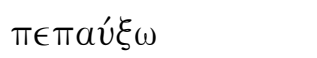 & Future Perfect \\
\hline 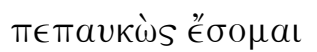 & Future Perfect (periphrastic) \\
\hline
\end{tabular}

\section{References}

Goodwin (1889), Syntax of the moods and tenses of the Greek verb, $\$ \$ 19-84$.

Masterman (1962), On grammatical terminology and aspect in particular, Greece and Rome, 9, 72-86.

Palmer (1980), The Greek language, pp. 261, 292-307, 310-311.

Smyth (1956), Greek grammar, \$\$355-380, 1850-1858, 1875-1965.

\section{EXERCISE 1}

Translate the following passages into English or Greek as appropriate, giving particular attention to the Time and Aspect of the Indicative verbs.

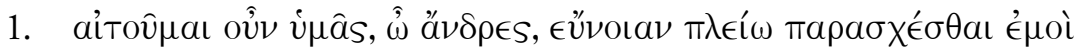

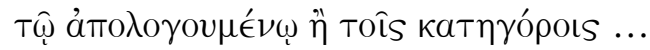

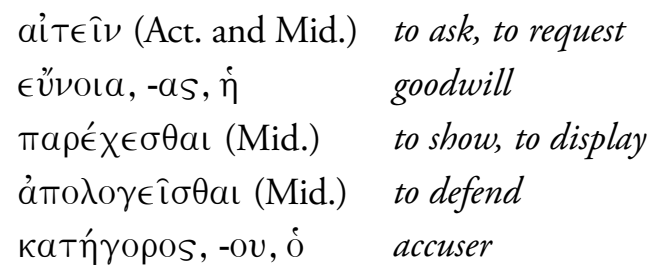




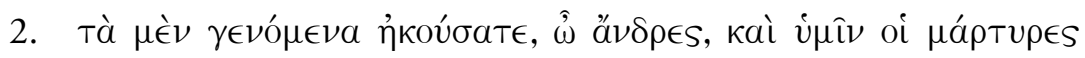
$\mu \in \mu \alpha \rho т$ ри́кабเv.

\begin{tabular}{ll}
\hline$\mu \epsilon^{\prime} \nu$ & $\begin{array}{l}\text { Anticipates a following } \delta \epsilon ́ \text { and should not } \\
\text { be translated. } \\
\text { to testify (to) (+ Dat.) }\end{array}$ \\
\hline
\end{tabular}

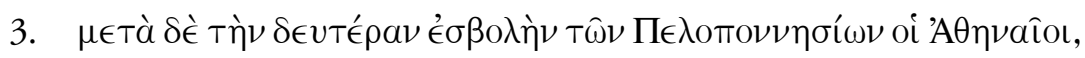

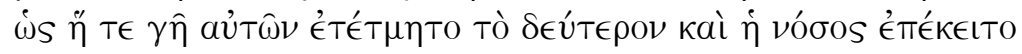

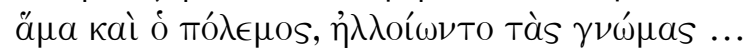

\begin{tabular}{|c|c|}
\hline$\delta \in U ́ T \epsilon \rho O S,-\alpha,-o \nu$ & second \\
\hline$\dot{\epsilon} \sigma \beta o \lambda \eta \dot{\eta},-\hat{\eta} s, \dot{\eta}$ & invasion \\
\hline is & as (Temporal + Causal) \\
\hline$T \epsilon$ & $\begin{array}{l}\text { Anticipates the following kaí and should } \\
\text { not be translated. }\end{array}$ \\
\hline 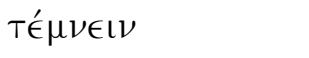 & to ravage \\
\hline vóoos, -ov, $\dot{\eta}$ & plague \\
\hline$\grave{\epsilon} \pi \iota \kappa \in \hat{\imath} \sigma \theta a \iota$ (Mid.) & $\begin{array}{l}\text { to have been laid upon (The Imperf. Mid. is } \\
\text { equivalent to the Perf. Pass. of É } \pi \text { เTı } \theta \text { Éval.) }\end{array}$ \\
\hline 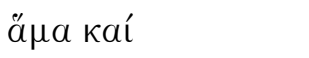 & at the same time as \\
\hline 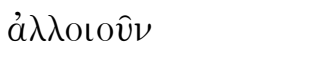 & to change (here Pass. + Acc. of Respect) \\
\hline$\gamma \nu \omega ́ \mu \eta,-\eta s, \dot{\eta}$ & attitude \\
\hline
\end{tabular}

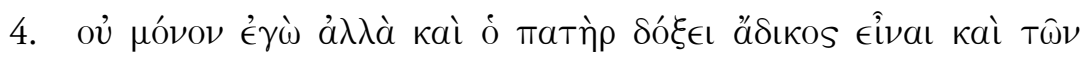

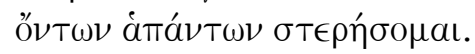

\begin{tabular}{|c|c|}
\hline ठокєิ̂े & to seem \\
\hline 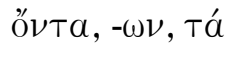 & possessions, property (Partc.) \\
\hline$\sigma \tau \epsilon \rho \in \hat{\imath} \nu$ & to deprive (here Fut. Mid. in Pass. sense) \\
\hline
\end{tabular}

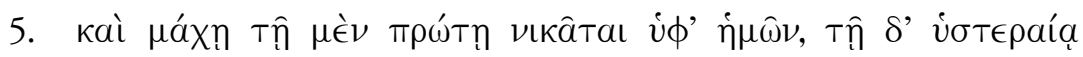

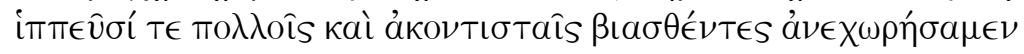
ÉS Tà TÉ́xๆ.

\begin{tabular}{ll}
\hline$\mu a ́ x \eta,-\eta s, \dot{\eta}$ & battle \\
$\mu \in ́ v$ & Cf. 2 above
\end{tabular}




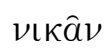

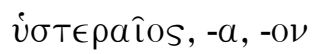

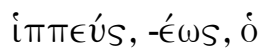

to beat, to defeat

next

horseman; (pl.) cavalry (here personal Dat.

of Means)

$\tau \epsilon$

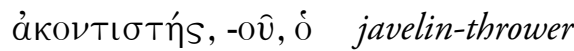

$\beta \iota a ́ \zeta \in \mathrm{t \nu}$

to overpower

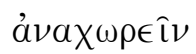

to withdraw (Intr.)

És inside, within (+ Acc. of motion)

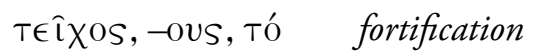

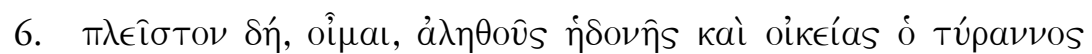

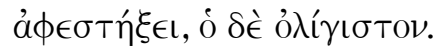

$\pi \lambda \epsilon \hat{\imath} \sigma \tau \mathrm{T}$ (neut. Acc.) most (i.e. furthest) (adv.)

$\delta n^{\prime}$ so, therefore

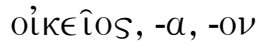
genuine

túpavvos, -ov, $\dot{0} \quad$ absolute ruler

o $\delta \epsilon ́$ and he (referring to the philosopher-king)

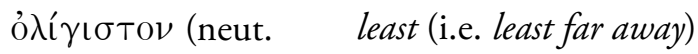

Acc.)

7. And yet what was I intending, if I informed against my father, as these [men] say, but was entreating my father to stay and suffer something from me?

\begin{tabular}{|c|c|}
\hline and yet & кaítoı \\
\hline to intend & $\beta o u ́ \lambda \in \sigma \theta a \mathrm{r}$ \\
\hline to inform against & $\mu \eta \nu v ́ \in ı$ катá (+ Gen.) \\
\hline$[m e n]$ & $\begin{array}{l}\text { Words in square brackets need not } \\
\text { be translated. }\end{array}$ \\
\hline to entreat & 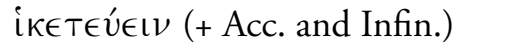 \\
\hline to stay & $\mu \in ́ \nu \in \iota \nu$ \\
\hline to suffer & $\pi a ́ \sigma \chi \in \mathrm{X} \nu$ \\
\hline from & ن்mó (+ Gen.) \\
\hline
\end{tabular}





\section{LESSON 2 \\ Aspect in the Imperative, Subjunctive and Optative Moods}

\subsection{Introduction}

As a general principle, the Moods of the Greek verb other than the Indicative have Aspect but not Time. This generalisation is valid, provided that the so-called 'Future' Optative is treated as belonging to a fourth, 'Intentive' Aspect. (This will also apply to the 'Future' Infinitive and Participle.) At any rate, there are forms for Imperative, Subjunctive and Optative Moods in the Imperfect, Perfect and Aorist Aspects. There are no forms for Imperative and Subjunctive Moods in Present, Past or Future Time. The 'Future' or 'Intentive' Optative is mostly limited to reported discourse in Past sequence, where it represents an original Future Indicative of direct discourse. It is occasionally used in the same way after verbs of effort. The terminology 'Present' Imperative, Subjunctive and Optative has often been used (misleadingly) for what is in fact the Imperfect Aspect of these Moods.

\subsection{Forms}

The usual paradigms for Imperative, Subjunctive and Optative in the Active Voice begin as follows.

\section{Imperfect Aspect}

\begin{tabular}{|c|c|c|}
\hline Imperative & $\pi a \hat{v} \epsilon$ & 2nd pers. sg. \\
\hline Subjunctive & $\pi a v ́ \omega$ & 1st pers. sg. \\
\hline Optative & таv́oı $\mu \iota$ & 1st pers. sg. \\
\hline
\end{tabular}


Perfect Aspect

\begin{tabular}{|c|c|c|c|}
\hline & Regular Forn & & Periphrastic Form \\
\hline Imperative & $\pi \dot{\pi} \pi \alpha \cup \kappa \epsilon$ & 2nd pers. sg. & 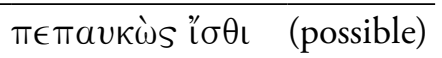 \\
\hline Subjunctive & $\pi \in \pi a v ́ \kappa \omega$ & 1 st pers. sg. & $\pi \in \pi \alpha v \kappa \grave{\omega} \hat{\omega}$ \\
\hline Optative & $\pi \in \pi \alpha \dot{\kappa} \kappa \iota \iota \iota$ & 1 st pers. sg. & 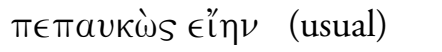 \\
\hline
\end{tabular}

Aorist Aspect

\begin{tabular}{lll}
\hline Imperative & $\pi a \hat{v} \sigma o \nu$ & 2nd pers. sg. \\
Subjunctive & $\pi a v ́ \sigma \omega$ & 1st pers. sg. \\
Optative & $\pi a v ́ \sigma a \iota \mu \iota$ & 1st pers. sg. \\
\hline
\end{tabular}

'Future'/Intentive Aspect

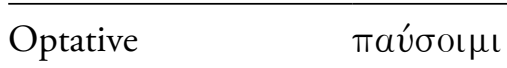

\subsection{Functions}

This section gives a brief survey of the uses of the non-Indicative Moods. Most of these uses will receive further attention in later Lessons on particular topics.

\subsubsection{Imperative}

The Imperative expresses commands. Imperfect Aspect expresses continuing or repeated action. Aorist Aspect expresses momentary action. Perfect Aspect is less common in the Imperative. It generally emphasises the state resulting from a completed action. (See Lesson 10 on Commands.) However, as with the Indicative Mood, some verbs by their very meaning express a momentary action. Thus $\pi \alpha \hat{v} \epsilon$, although an Imperative form of the Imperfect Aspect, may express a command requiring instant action.

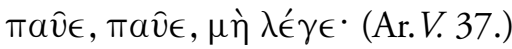

Stop, stop, do not say <any more $>$.

\section{Imperfect Aspect}

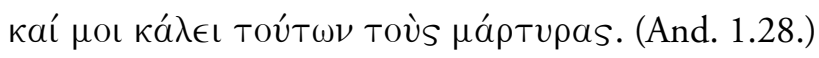

Now please summon the witnesses of these <matters $>$. 


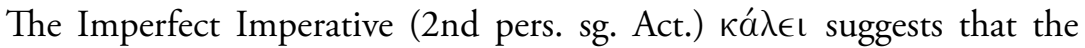
summoning may take a while. However, it would not be idiomatic to translate it as 'be summoning'.

\section{Aorist Aspect}

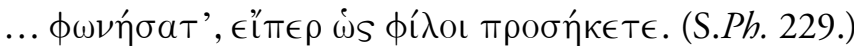

... speak, if indeed you have come as friends.

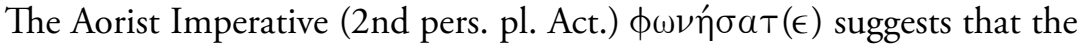
speaking should be brief and prompt.

\section{Perfect Aspect}

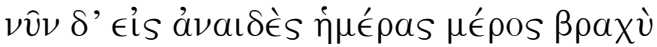

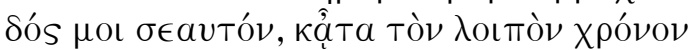

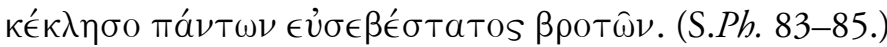

But for the present please give yourself to recklessness

for a brief part of a day, and then for the rest of time

be called the most pious of all mortals.

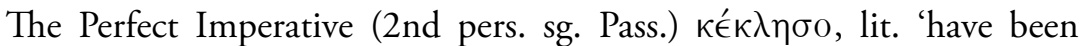
called', implies 'have the ongoing reputation of'. This stative force, expressing the result of completed action, is emphasised by the adverbial phrase 'for the rest of time'.

\subsubsection{Subjunctive}

Despite differences of terminology, the following usages are all basically of the same type, expressing an exhortation or command. The negative for each usage is $\mu \eta \dot{\eta}$, except that ov may negate a particular word other than the Subjunctive verb.

\section{Hortatory}

The hortatory use occurs in the first person, usually plural.

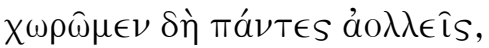

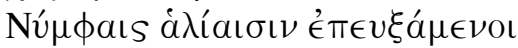

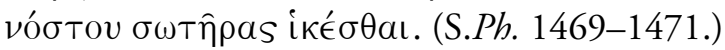

Now let us go all together

(after) praying to the Nymphs of the sea

that they come as guarantors of our return. 


\section{Jussive}

In the classical period, this construction occurs primarily in the negative with the second person singular or plural of the Aorist Subjunctive. Hence, the usage is often called 'Prohibitive'. The positive use at S.Ph. 300 is exceptional in the classical period, although further positive examples occur in the Hellenistic period. (See Lesson 10 on Commands.)

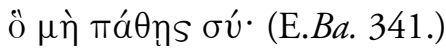

And you are not to suffer this.

Ö is a coordinating relative pronoun: 'And ... this'.

The third person of the Aorist Subjunctive used in a prohibition is usually indefinite and equivalent to the second person. (The Imperfect Subjunctive is rare in this usage.)

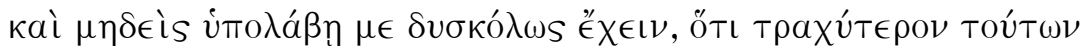

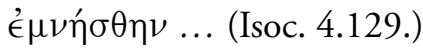

And let no one suppose that I am discontented, because I recounted these points rather harshly...

\section{Deliberative}

The Deliberative Subjunctive is an interrogative use of the Hortatory Subjunctive. Instead of stating 'Let us do this', a Deliberative question asks 'What are we to do?'. Deliberative questions occur in Imperfect or Aorist Aspect, primarily in the first person, rarely in the second person (repeating a question) and in the indefinite third person. (See Lesson 17 on Questions.)

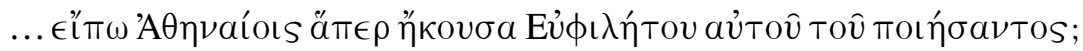
(And. 1.51.)

... am I to tell the Athenians what I heard from Euphiletus himself who did $<i t>$ ?

\subsubsection{Optative}

\section{Wishes}

Without $\stackrel{\alpha}{\nu} \nu$, the Optative in a Main clause expresses a wish for the future.

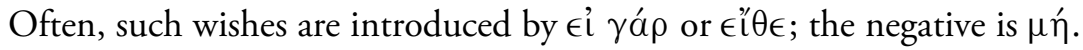
(See Lesson 11 on Wishes.) 


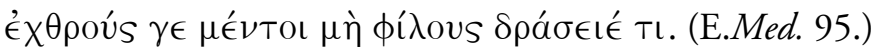

However, may she do something to her enemies, not to her friends.

\section{Potential}

With o̊ $v$ the Optative in a Main clause is potential; the negative is ov.

\begin{tabular}{|c|c|}
\hline & Éró; \\
\hline & 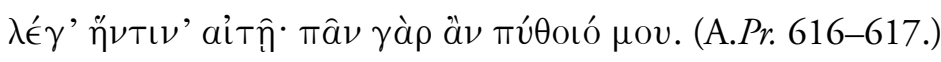 \\
\hline & Would you not, then, grant this gift to me? \\
\hline & $\begin{array}{l}\text { Say what <gift> you are requesting; for you would learn everything } \\
\text { from me. }\end{array}$ \\
\hline
\end{tabular}

\section{References}

Goodwin (1889), Syntax of the moods and tenses of the Greek verb, \$\$233-242, 250-293, 720-728.

Smyth (1956), Greek grammar, \$\$1795-1811, 1814-1842, 1859-1864, 2212.

\section{EXERCISE 2}

Translate the following passages. Give particular attention to the Aspect of the non-Indicative verbs, so far as idiomatic translation allows. The Exercise is concerned with the use of non-Indicative verbs in Main clauses.

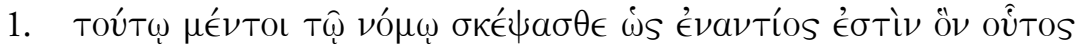

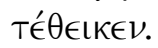

\begin{tabular}{|c|c|}
\hline$\mu \operatorname{é}_{\nu T O \mathrm{~L}}$ & so (Progressive) \\
\hline$\sigma \kappa \in ́ \pi \tau \in \sigma \theta a l$ & to consider, to examine \\
\hline$\dot{\omega s}$ & how (Modifies évavtíos.) \\
\hline öv & Understand $\nu$ ó $\mathrm{os}_{\mathrm{S}}$ as antecedent. \\
\hline 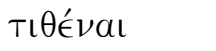 & to propose (a law) \\
\hline
\end{tabular}




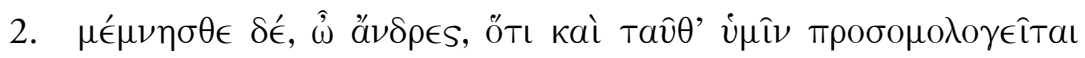
ăтаvта.

\begin{tabular}{ll}
\hline$\mu \epsilon ́ \mu \nu \eta \sigma \theta \epsilon$ & Perf. Impv. with Imperf. meaning: remember \\
$\pi \rho \circ \sigma \circ \mu о \lambda о \gamma \epsilon \hat{\imath} \nu$ & to admit, to confess (here Pass.) \\
\hline
\end{tabular}

3.

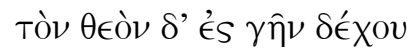

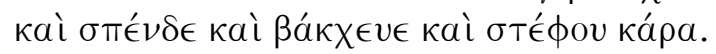

$\sigma \tau \in \operatorname{\phi } \phi \in \mathrm{\nu}$ (Act. and to wreathe

Mid.)

кápa, Tó (irregular) head

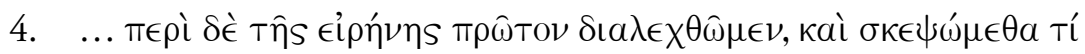

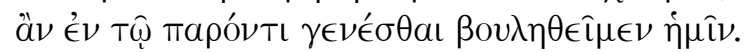

$\delta \iota a \lambda \epsilon ́ \gamma \in \sigma \theta a \iota$ (Mid.) to discuss (Aor. Pass. in Act. sense)

парóv, -óvтos, тó the present< <ituation> (neut. Partc.)

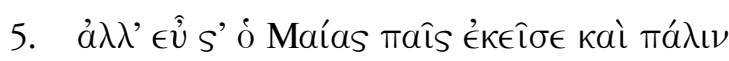

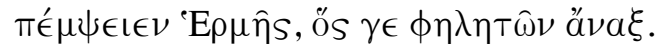

$\dot{\alpha} \lambda \lambda(\alpha)$

Maîa, -as, $\dot{\eta}$

$\pi \epsilon ́ \mu \pi \epsilon \mathrm{L \nu}$

$\phi \eta \lambda \eta ́ \tau \eta \mathrm{s},-o v, \dot{o}$ well (introducing a prayer: Denniston, 1954, p. 15)

Maia (mother of Hermes)

to escort

thief

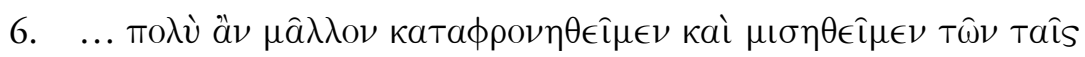

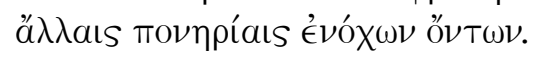

\begin{tabular}{|c|c|}
\hline$\kappa a \tau a \phi \rho о \nu \in \hat{\imath} \nu$ & to despise \\
\hline$\mu \iota \sigma \in \hat{\imath} \nu$ & to hate \\
\hline 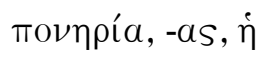 & wickedness \\
\hline ÉvOXOS, -OV & liable (for) (+ Dat.) \\
\hline
\end{tabular}




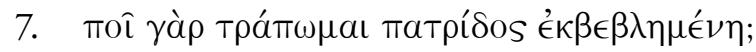

$\tau \rho \epsilon ́ \pi \epsilon \sigma \theta \alpha$ เ (Mid.) to turn (Intr.)

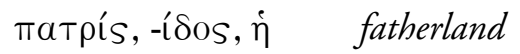

$\dot{\epsilon} \kappa \beta a ́ d \lambda \lambda \in \mathrm{LV} \quad$ to cast out

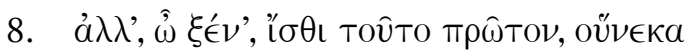

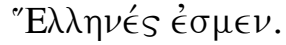

\begin{tabular}{|c|c|}
\hline 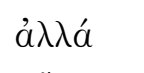 & well (assentient: Denniston, 1954, p. 18) \\
\hline 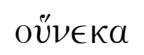 & that \\
\hline
\end{tabular}

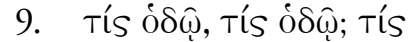

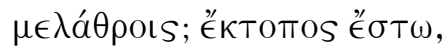

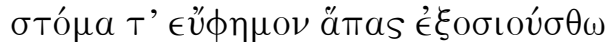

\begin{tabular}{|c|c|}
\hline$\mu \epsilon^{\prime} \lambda \alpha \theta \rho o \nu,-o v$, тó & hall \\
\hline ÉКтотоS, -OV & out of doors \\
\hline$\sigma \tau o ́ \mu \alpha,-\alpha T o s$, Tó & speech \\
\hline$\epsilon \ddot{v} \phi \eta \mu o s,-o \nu$ & holy \\
\hline 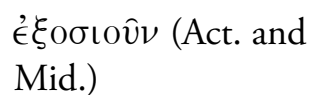 & to keep pure \\
\hline
\end{tabular}

10. And who would try to learn from another these [things], which he knows from his own nature?

\begin{tabular}{|c|c|}
\hline to try & 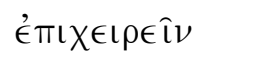 \\
\hline to learn & $\mu a \nu \theta a ́ \nu \in \mathrm{I} \nu$ \\
\hline from & 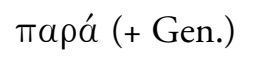 \\
\hline to know & $\epsilon \in \pi i ́ \sigma \tau a \sigma \theta a \iota$ \\
\hline nature & $\phi \dot{\sigma} \sigma \mathrm{s},-\epsilon \omega s, \dot{\eta}$ \\
\hline
\end{tabular}





\section{LESSON 3 \\ Infinitive}

\subsection{Introduction}

The Infinitive is the verbal noun, that is, the name of the verb. The Infinitive expresses Aspect but not Time. The apparent exception is the so-called 'Future' Infinitive. As with the 'Future' Optative, the 'Future' Infinitive may be regarded as expressing an Intentive Aspect rather than Future Time.

\subsection{Forms}

By way of illustrating the Aspect of Infinitives, only Active forms are listed here.

\section{Imperfect}

Tav́elV to be stopping

\section{Perfect}

тєாаטкéval to have stopped

\section{Aorist}

$\pi a \hat{\sigma} \sigma a \mathrm{l}$

to stop

\section{'Future'/Intentive}

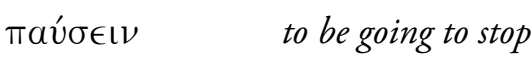

A 'Future Perfect' Infinitive form $\mu \epsilon \mu \nu \eta \dot{\sigma} \sigma \sigma \theta a$ ı (Mid./Pass.) occurs in Homer and in Attic prose. But that is the 'Future' of a Perfect verb with Imperfect meaning; it means 'to be going to remember' (Intentive). 


\subsection{Functions}

As a verb, the Infinitive may take any construction which finite parts of the verb may take.

As a noun, the Infinitive may be used without the definite article:

- as the Subject or Object of another verb

- in dependence on certain adjectives, adverbs and even nouns (especially when these parts of speech denote ability or suitability)

- to express Purpose with certain verbs.

The Infinitive with the neuter definite article (or 'articular Infinitive') may also be used in the Nominative or Accusative Case respectively as Subject or Object of a verb. In addition, the Infinitive with the definite article may be used in various constructions in the Genitive or Dative Cases, and after prepositions governing Accusative, Genitive or Dative Cases. (See further the Lessons on the Cases.)

The negative for all Infinitive constructions in this Lesson is regularly $\mu$ in. There are three examples in $\$ \$ 3.5 .3$ and 3.5.4 below.

The use of the Infinitive in reported speech and thought and in Temporal and Result constructions will be treated in other Lessons.

\subsection{Infinitive without Article}

\subsubsection{Infinitive as Subject}

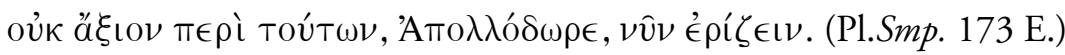
To quarrel about this now, Apollodorus, <is> not worthwhile.

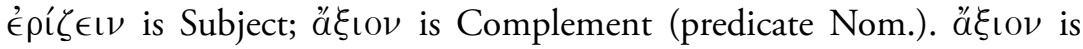
neuter Gender in reference to the Infinitive as a neuter singular noun. The more usual form of English expression for this sentence is: 'It is not worthwhile quarrelling about this now, Apollodorus'. 'It' is in anticipatory apposition with 'quarrelling'. As in this example, the verb 'to be' is not always expressed in Greek. 


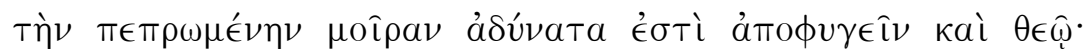
(Hdt. 1.91.1.)

It is impossible even for a god to escape one's appointed fate.

(lit. 'To escape one's appointed fate is impossible even for a god'.) Here, the neuter plural form ásúvata is used as Complement of the Nominative Infinitive phrase; and the verb 'to be' ('́đTí) is expressed.

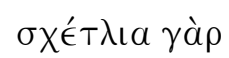

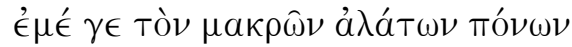

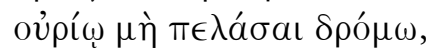

... (S.Aj. 887-889.)

$$
\text { For }<\text { it is }>\text { wretched }
$$

that I the wanderer through lengthy labours

should not approach a favourable course

(lit. 'For that $I$ the wanderer through lengthy labours should not approach a favourable course <is $>$ wretched...'.) Here, the Subject is an Accusative and Infinitive phrase; and the verb 'to be' is not expressed in Greek.

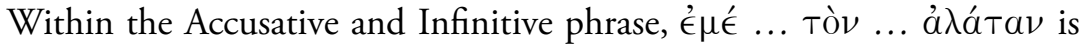
the Subject of the Infinitive $\pi \in \lambda a ́ \sigma a l$. And the neuter plural adjective $\sigma \chi \epsilon ́ T \lambda \iota a$ is the Complement of the Infinitive phrase.

\subsubsection{Infinitive as Object}

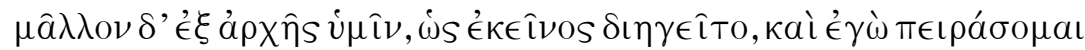

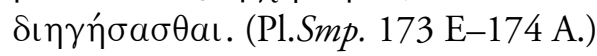

But rather, as he was relating <the matter>, I too shall attempt to relate <it> to you from the beginning.

$\delta ı \eta \eta \dot{\sigma a \sigma \theta a \iota ~ i s ~ d i r e c t ~ O b j e c t ~ o f ~ \pi \epsilon ı \rho a ́ \sigma o \mu a ı . ~}$

\subsubsection{Infinitive Expressing Purpose}

The use of the Infinitive with certain verbs, nouns, adjectives and adverbs reflects its Indo-European background as a Dative verbal noun expressing Purpose. 


\subsubsection{Infinitive with Verbs}

The Infinitive may express Purpose, mostly with verbs used transitively, and in prose especially with verbs of giving, receiving and choosing.

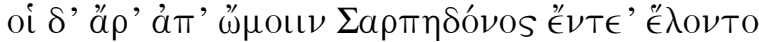

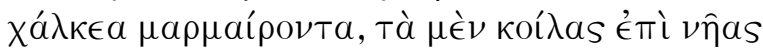

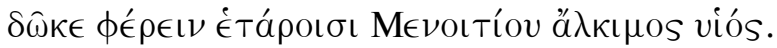
(Hom.Il. 16.663-665.)

But then from the shoulders of Sarpedon they took the shining bronze armour, which the brave son of Menoitius gave to his companions to carry to the hollow ships.

The Infinitive $\phi \epsilon ́ \rho \in I \nu$ expresses the Purpose of the verb $\delta \hat{\omega} \kappa \epsilon$ (without augment).

\subsubsection{Infinitive with Nouns}

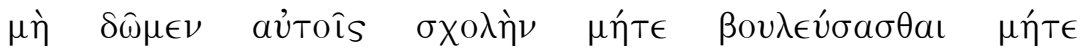

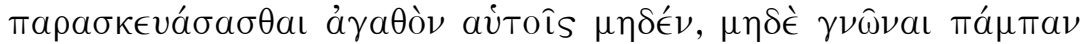

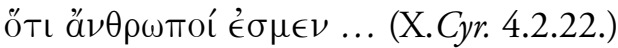

let us not give them leisure for deliberating or preparing any benefit for themselves, nor for realising at all that we are humans ...

The Infinitives $\beta o v \lambda \epsilon \hat{\sigma} \sigma \alpha \sigma \theta a \mathrm{l}, \pi \alpha \rho a \sigma \kappa \in v a ́ \sigma \alpha \sigma \theta a \mathrm{l}$ and $\gamma \nu \hat{\omega} \nu a \mathrm{l}$ express the Purpose of the noun $\sigma \chi 0 \lambda \eta \dot{\nu}$.

\subsubsection{Infinitive with Adjectives}

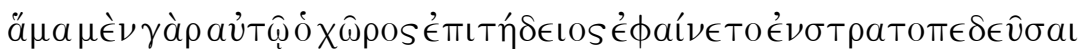
... (Th. 2.20.4.)

For at the same time the place appeared to him suitable for encamping ...

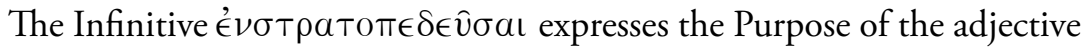

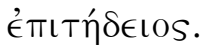

\subsubsection{Infinitive with Adverbs}

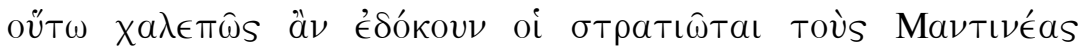

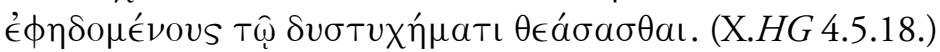

The soldiers would be thinking it so difficult to look upon the Mantineans exulting over their misfortune. 
The Infinitive $\theta \epsilon a ́ \sigma \alpha \sigma \theta a$ l expresses the Purpose of the adverb $\chi \alpha \lambda \epsilon \pi \hat{\omega} s$. (The adverb has been translated as an adjective for the sake of English idiom. But English idiom itself sometimes allows an adverb where an adjective would be expected: 'all is well that ends well'.)

\subsection{Infinitive with Article}

\subsubsection{Infinitive as Subject (Nominative)}

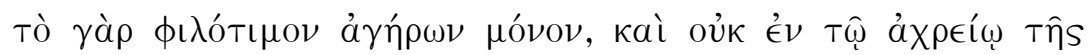

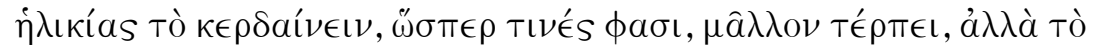

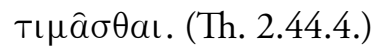

For love of honour alone <is> unaffected by age, and in the ineffective <stage> of life <it is $>$ not making a profit, as some say, <which > gives more enjoyment, but being honoured.

Tò $\kappa \in \rho \delta a i ́ \nu \in \iota \nu$ and Tò Tı $\mu a ̂ \sigma \theta a \iota$ are (contrasted) Subjects of Té $\rho \pi \epsilon \iota$.

\subsubsection{Infinitive as Object (Accusative)}

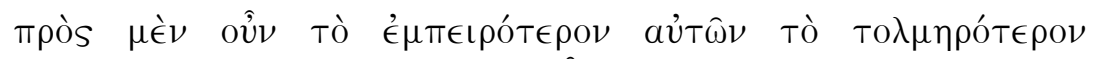

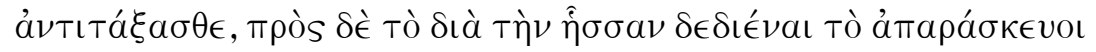

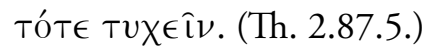

Therefore, against their greater experience set <your $>$ greater daring, and against <your $>$ being afraid because of <your $>$ defeat $<$ set $>$ the fact that you happened to be unprepared then.

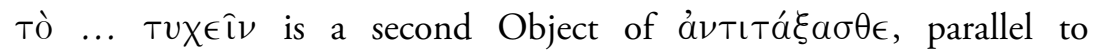

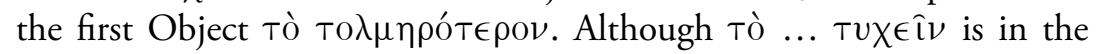

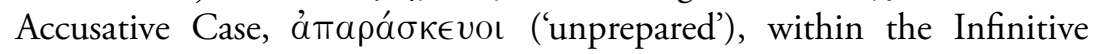
phrase, is Nominative, because it refers to the Subject of the Main verb

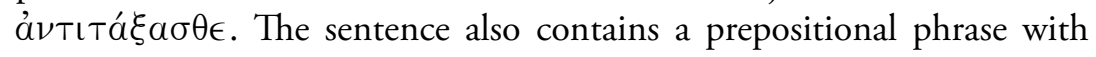
articular Accusative Infinitive phrase (for this usage see $\$ 3.5 .5$ below).

\subsubsection{Genitive}

The following examples illustrate the main ways in which the Genitive of the articular Infinitive is used. 


\section{Objective}

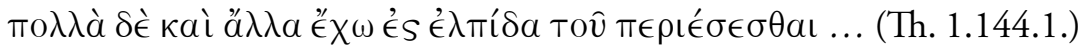

And I have many other <arguments> relevant to the hope of being successful

\section{Partitive}

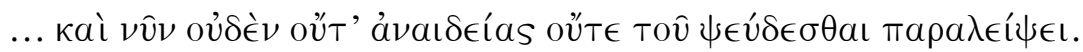

(D. 37.45.)

... even now he will leave out no <aspect $>$ of shamelessness nor of being deceitful.

\section{Comparative}

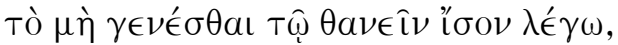

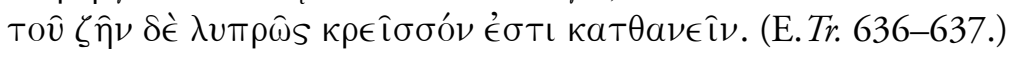

Not to be born I count as equal to dying,

but dying is better than living in grief.

\section{Separation}

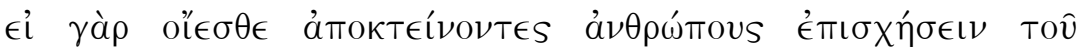

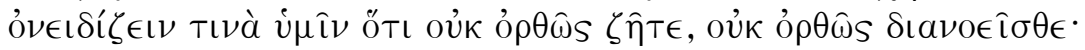
(Pl.Ap. 39 D.)

For if you think that by putting people to death you will prevent anyone from criticising you because you do not live properly, you do not think properly.

\section{Purpose}

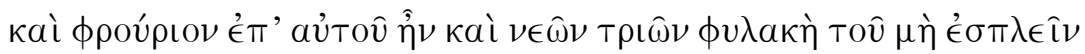

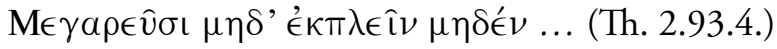

And there was a fort on it and a protective force of three ships, so that nothing might sail in nor sail out for the Megarians...

av่Tov̂ ('it') refers to the point of the island of Salamis.

This construction is usually left unexplained in Greek grammars. And to say that the Genitive articular Infinitive has been separated from any governing noun or verb does not clarify the usage. The idiom occurs first and especially in Thucydides and is often negative. As in the present example, a number of instances in Thucydides and Xenophon are close to a construction of 'preventing' with Genitive of Separation. (Cf. Lesson 29.6.8.) 


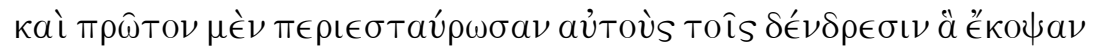

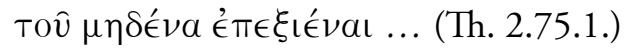

And in the first place they [= Spartans] stockaded them [= Plataeans] with trees which they had felled

a. <to prevent $>$ any one from going out against $<$ them $>$... [Prevention]

b. <so that $>$ no one might go out against <them $>$... [Purpose]

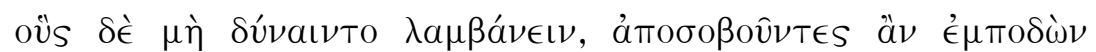

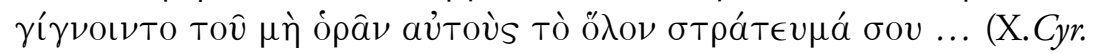
2.4.23.)

and those whom they could not catch, they would scare off

a. and get in the way of their seeing your whole contingent ... [Prevention]

b. and get in their way, so that they might not see your whole contingent ... [Purpose]

\subsubsection{Dative}

The Dative articular Infinitive is especially used to express Cause, means or instrument.

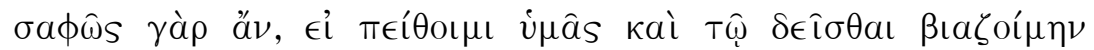

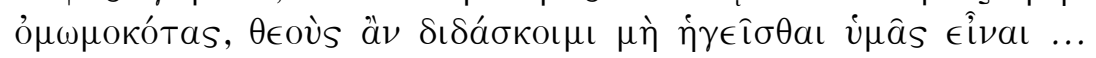
(Pl.Ap. 35 D.)

For clearly, if I were to persuade you and by begging were to force you when you have sworn an oath, I would be teaching you not to believe that gods exist ... $\tau \hat{\omega} \delta \in \hat{\imath} \sigma \theta a \iota$ is Dative of Means.

\subsubsection{Prepositions}

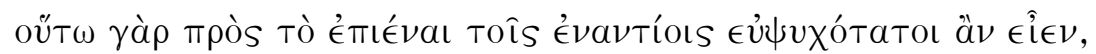

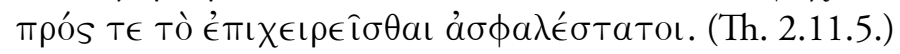

For in this way they would be most courageous with regard to assaulting their opponents, and most steadfast with regard to being attacked. 


\section{References}

Goodwin (1889), Syntax of the moods and tenses of the Greek verb, \$\$741-750, 758-775, 788-814.

Palmer (1980), The Greek language, p. 314.

Smyth (1956), Greek grammar, \$\$1966-2015, 2025-2037.

\section{EXERCISE 3}

Translate the following sentences. Give particular attention to the Aspect of the Infinitives, so far as idiomatic translation allows.

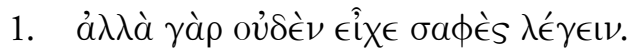

\begin{tabular}{|c|c|}
\hline à $\lambda \lambda \grave{a} \gamma \alpha{ }^{\prime} \rho$ & but really \\
\hline$\epsilon^{\prime} X \in \mathrm{X}$ & to be able (+ Infin.) \\
\hline
\end{tabular}

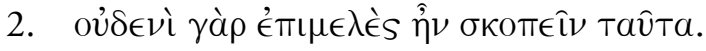

\begin{tabular}{|c|c|}
\hline 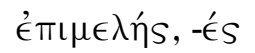 & $<a$ matter $>$ of concern \\
\hline$\sigma \kappa O \pi \epsilon \hat{\imath} \nu$ & to examine \\
\hline
\end{tabular}

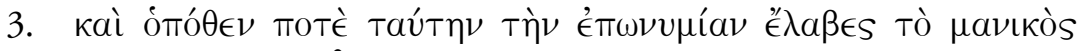

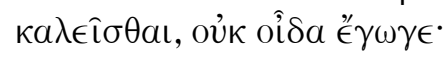

\begin{tabular}{|c|c|}
\hline$\dot{\epsilon} \pi \omega \nu v \mu i ́ a,-a s, \dot{\eta}$ & name, reputation \\
\hline 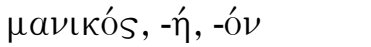 & $\operatorname{mad}$ \\
\hline 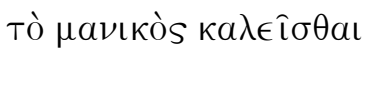 & 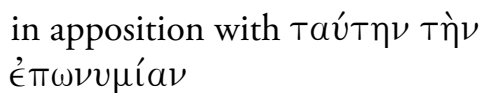 \\
\hline
\end{tabular}

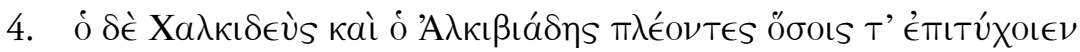

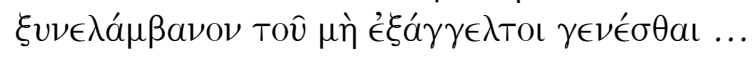

\begin{tabular}{|c|c|}
\hline 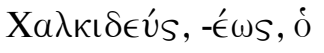 & personal proper name \\
\hline$\pi \lambda \in \hat{\imath} \nu$ & to sail \\
\hline$T(\epsilon)$ & Omit: anticipates a following kaí. \\
\hline 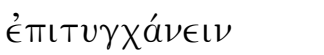 & to encounter (+ Dat.) \\
\hline
\end{tabular}


$\xi v \lambda \lambda \alpha \mu \beta a ́ v \in เ \nu$

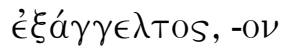

to arrest

reported

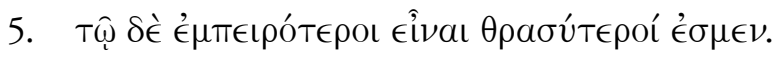

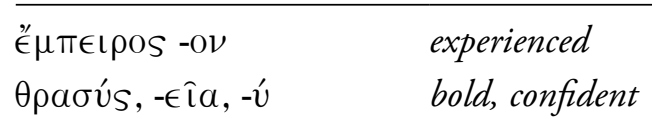

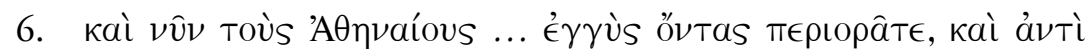

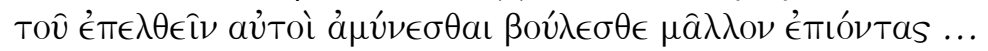

\begin{tabular}{|c|c|}
\hline$\pi \epsilon \rho ı \rho \rho \hat{\nu} \nu$ & to overlook (here Indic.) \\
\hline àvтí (+ Gen.) & instead of \\
\hline 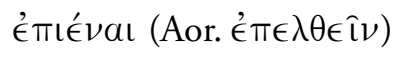 & to attack \\
\hline 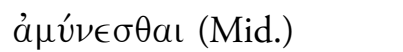 & to ward off (+ Acc.) \\
\hline
\end{tabular}

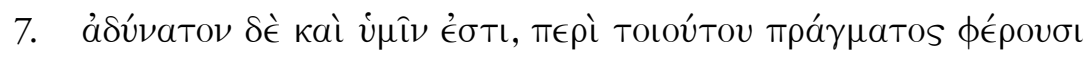

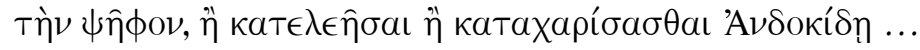

\begin{tabular}{|c|c|}
\hline SÈ kaí & and indeed \\
\hline àsúvatos, -оv & impossible \\
\hline$\phi \in ́ \rho \in I \nu$ & to cast (here Dat. pl. Partc.) \\
\hline$\psi \hat{\eta} \phi o s,-o v, \dot{\eta}$ & vote \\
\hline$\kappa a T \in \lambda \in \epsilon \hat{\imath} \nu$ & to pity (+ Acc., not expressed here) \\
\hline 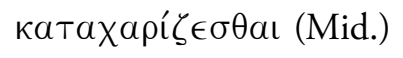 & to show favour (to) (+ Dat.) \\
\hline 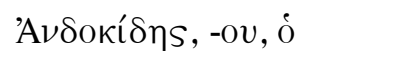 & Andocides \\
\hline
\end{tabular}

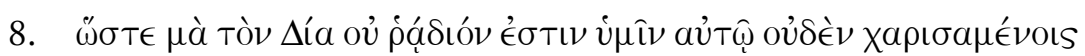

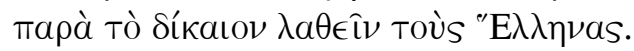

\begin{tabular}{|c|c|}
\hline$\ddot{\omega} \sigma \tau \epsilon$ & $\begin{array}{l}\text { and so (used as coordinating } \\
\text { conjunction) }\end{array}$ \\
\hline$\mu \grave{a}$ Tòv $\Delta$ ía & by Zeus (oath formula) \\
\hline 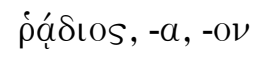 & easy \\
\hline 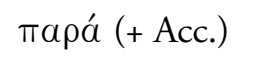 & contrary to \\
\hline$\lambda \alpha \nu \theta a ́ v \in \mathrm{I} \nu$ & $\begin{array}{l}\text { to escape the notice of someone (Acc.) } \\
\text { in doing something (Partc.) }\end{array}$ \\
\hline
\end{tabular}




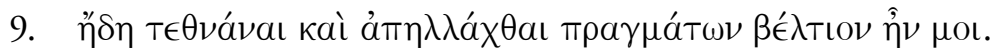

\begin{tabular}{ll}
\hline$\dot{a} \pi \alpha \lambda \lambda \hat{\alpha} \sigma \sigma \in \mathrm{I \nu}$ & to free, to release \\
$\pi \rho \hat{\alpha} \gamma \mu \alpha,-\alpha \tau \mathrm{Tos}, \tau o ́$ & trouble, problem \\
$\beta \in \lambda \tau i ́ \omega \nu,-\mathrm{-O \nu}$ & better
\end{tabular}

10. For you are the most appropriate [person] to be reporting your companion's discussions.

\begin{tabular}{|c|c|}
\hline appropriate & Síkaısos, $(-a)-,о \nu$ \\
\hline to report & $\dot{a} \pi a \gamma \gamma \in \dot{\epsilon} \lambda \lambda \in \mathrm{I \nu}$ \\
\hline companion & ÉTaîpos, -ov, ó \\
\hline discussion & 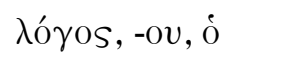 \\
\hline
\end{tabular}

11. having expelled those [people], they did not dare to expropriate their lands ...

\begin{tabular}{|c|c|}
\hline to dare & то $\lambda \mu \hat{\alpha} \nu$ \\
\hline to expropriate & $\epsilon^{\epsilon} \xi \iota \delta ı ૦ \hat{v} \sigma \theta a \iota$ (Mid.) \\
\hline land & $\chi \omega \dot{\omega} \rho a,-a s, \dot{\eta}$ \\
\hline
\end{tabular}




\section{LESSON 4 \\ Participles}

\subsection{Introduction}

Participles are verbal adjectives. As a verb, a Participle may take any construction that finite parts of the verb may take. As an adjective, a Participle may be used in any appropriate Case, Gender and Number.

As a general principle, Participles express Aspect but not Time. The Aspect of the Participle expresses the type of action in relation to the verbal form to which it is subordinate. Most simply, a Participle may be subordinate to a finite verb in the Indicative Mood. But it may also be subordinate to a finite verb in a non-Indicative Mood, or to an Infinitive, or even to another Participle. The subordination of a Participle to another verb form applies more readily to the adverbial functions of circumstantial and supplementary Participles than to the adjectival function of attributive Participles.

The Imperfect Participle expresses continuous or repeated action contemporary with the action of the verbal form to which it is subordinate.

The Perfect Participle expresses (the state resulting from) action which is completed in relation to the verbal form to which it is subordinate.

The Aorist Participle expresses momentary action, which may be either prior to or contemporary with the action of the verbal form to which it is subordinate. If the context allows it, an Aorist Participle may (but need not) be translated 'after stopping' or 'having stopped'. But such

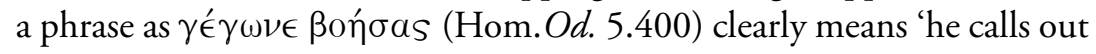
with a shout', not 'having shouted he calls out'.

The so-called 'Future' Participle expresses an intention and may be subordinated to any Tense of an Indicative verb. The Participle has no Time reference in itself but is subordinate to the Time reference of the Indicative verb, whether Present, Past or Future. Thus, the 'Future' Participle needs to be regarded as an Intentive Participle, analogous to 
the Intentive ('Fut.') Optative and Infinitive (Lessons 2.1 and 3.1). Like other Participles, this Intentive Participle may be subordinated not only to a finite Indicative verb, but to a non-Indicative verb, an Infinitive or another Participle.

\subsection{Forms}

The usual paradigms for the Participles in the Active Voice begin as follows (Nom. masc. sg.).

\section{Imperfect}

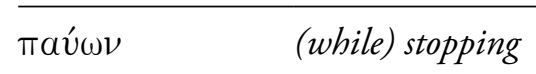

Perfect

$\pi \in \pi$ avkús havingstopped

Aorist

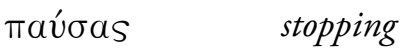

\section{'Future'/Intentive}

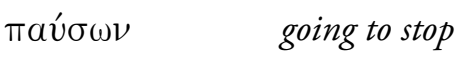

The only certain example of a Future Perfect Participle in classical Greek is the Passive form $\delta\llcorner a \pi \epsilon \pi o \lambda \epsilon \mu \eta \sigma o ́ \mu \epsilon \nu \nu \nu$ 'going to have been fought out' (Th. 7.25.9.)

\subsection{Functions}

\subsubsection{Attributive Participle (Adjectival)}

Like other adjectives, a Participle may be used attributively; it is then normally placed between the definite article and the noun to which it refers.

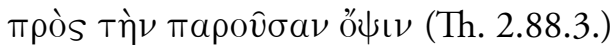

in face of the present sight 
A longer Participial phrase may sometimes be placed only partly between article and noun.

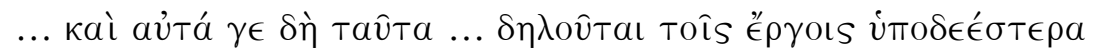

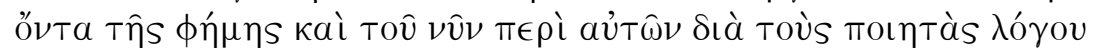

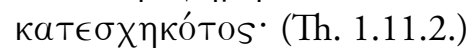

$\ldots$ and this <campaign $>$ itself [the Trojan war] ... is shown by the actions $<$ undertaken > to be inferior to its reputation and to the assessment which has now come to prevail concerning it on account of the poets.

The attributive Participle катєбХฤко́тоs stands outside article and noun,

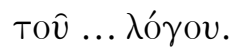

The Participle may be used attributively after the definite article even without a noun.

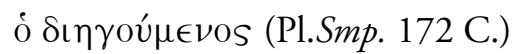

the <person $>$ narrating, the narrator

\subsubsection{Circumstantial Participle (Adverbial)}

A Participle may be used to express the circumstances under which an action takes place, usually the action of the Main verb of a sentence. A circumstantial Participle expresses an adverbial relation such as Time, Cause, Condition, Concession, Manner, Means or Purpose. Such a Participle is not used with its own definite article. If it agrees with a noun which has an article, the Participle stands in the predicate position,

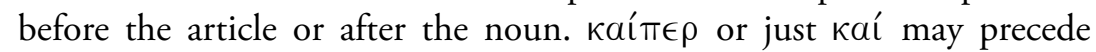
Participles expressing concession (see also Lesson 26). is may precede Participles expressing Cause (Lesson 23) or Purpose (Lesson 27).

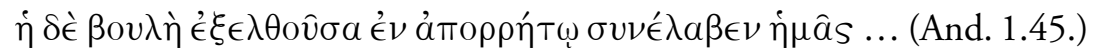
And the council, <after $>$ adjourning, secretly arranged to arrest us ...

$\epsilon \in \xi \in \lambda \theta$ ov̂ $\sigma \alpha$ expresses time.

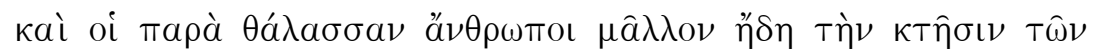

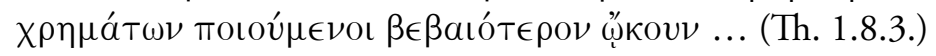

and the people by the sea, <ince they were> now, rather, achieving the acquisition of resources, were living more securely...

Toเoú $\mu \in \nu$ ol expresses Cause. 


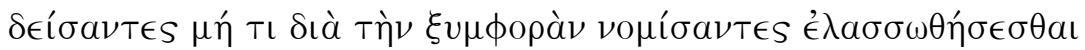

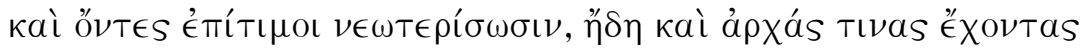

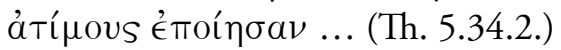

fearing that, if they thought that they would be downgraded because of the disaster and if they remained enfranchised, they would revolt, they disenfranchised them, even some currently holding office ...

$\nu 0 \mu i ́ \sigma \alpha \nu T \epsilon S$ and ${ }^{\prime} \nu T \epsilon S$ express condition.

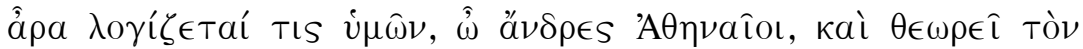

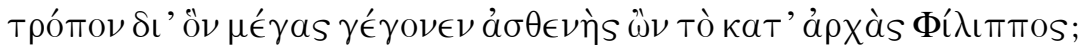
(D. 1.12.)

Does any one of you, $O$ men of Athens, take account and observe the means through which Philip, though being weak at first, has become great?

๘ँv expresses concession.

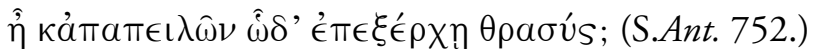

Do you thus boldly go to extremes in actually making threats?

$€ \in \pi \alpha \pi \epsilon \mathrm{\lambda} \hat{\omega} \nu$ expresses manner.

\begin{tabular}{|c|c|}
\hline $\begin{array}{l}\text { K } \rho . \\
\text { At. }\end{array}$ & 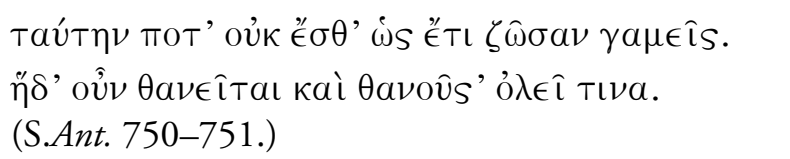 \\
\hline Creon: & $\begin{array}{l}\text { It is not possible that you will ever marry this girl while } \\
\text { she is still living. }\end{array}$ \\
\hline Haemon: & $\begin{array}{l}\text { She will therefore die and by dying she will destroy } \\
\text { someone. }\end{array}$ \\
\hline
\end{tabular}

$\theta$ avov̂ $(\alpha)$ expresses means.

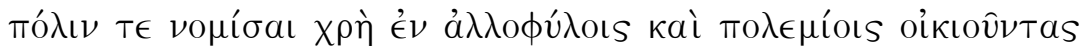
iéval ... (Th. 6.23.2.)

And <we> should acknowledge that we are going in order to found a city among foreign and hostile <people $>$...

oikıôvvtas ('Fut.'/Intentive Partc.) expresses Purpose, as may the Imperfect Participle. 


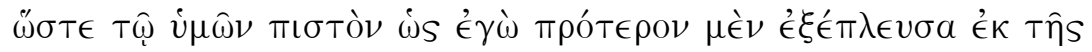

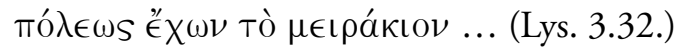

And so to which one of you <is it> credible that I previously sailed out from the city having the boy <with me...?

ÉX $\chi \nu$ expresses attendant circumstances in general.

\subsubsection{Supplementary Participle (Adverbial)}

A supplementary Participle is regularly used in idiomatic phrases with a significant number of verbs such as the following. Although the Greek construction is adverbial, the corresponding English idiom most often uses a gerund (verbal noun) as direct Object of the finite verb.

\begin{tabular}{|c|c|}
\hline$\ddot{a} \rho x \in \sigma \theta a \iota$ & to begin (doing something) \\
\hline$\delta\llcorner a T \in \lambda \in \hat{\imath} \nu$ & to continue (doing something) \\
\hline$\eta ँ \delta \in \sigma \theta a \iota$ & to enjoy (doing something), to be pleased (to do something) \\
\hline$\pi a v ́ \in \sigma \theta a \iota$ & to stop (doing something) \\
\hline 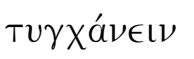 & to happen (to be doing something) \\
\hline
\end{tabular}

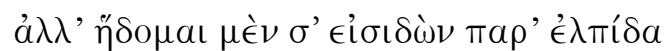

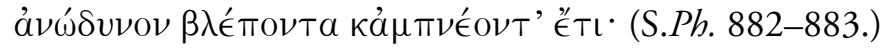

Well, I am pleased to see you contrary to expectation

free from pain <and > still alive and breathing.

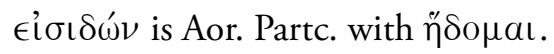

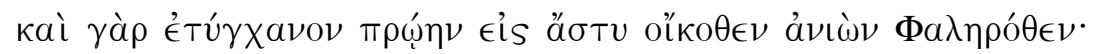
(Pl.Smp. 172 A.)

For I happened to be going up during the early morning to town from home at (lit. 'from') Phalerum.

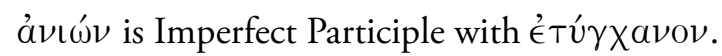




\subsection{Negatives}

In the classical period, ov negates a Participle with factual force and $\mu$ ' negates a Participle with indefinite or conditional force. In the Hellenistic period, $\mu \eta$ is increasingly used with all types of Participial phrase.

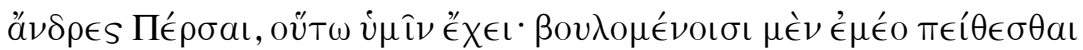

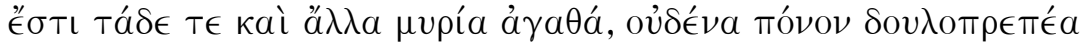

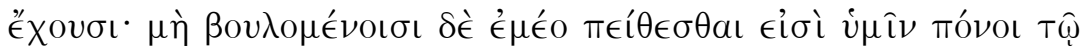

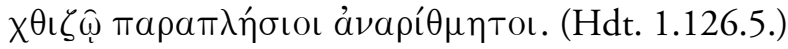

Men of Persia, this is the situation for you: if you are willing to obey me, there are these and ten thousand other benefits for you while having no slave labour; but if you are not willing to obey me, there are unnumbered labours like yesterday's for you.

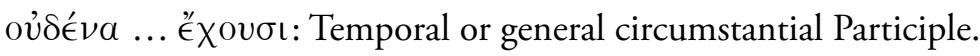

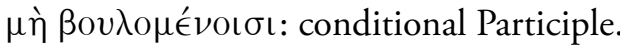

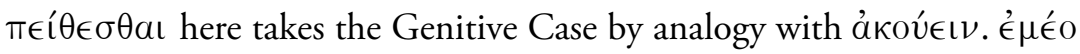
(Ionic) = '́ $\mu \mathrm{ov}$ (Attic).

\section{References}

Goodwin (1889), Syntax of the moods and tenses of the Greek verb, $\$ \$ 138-153$, 213-217, 224, 821-846, 877-901.

Smyth (1956), Greek grammar, $\$ \$ 1166-1167,2039-2056,2060-2069,2079-$ 2105, 2110-2119, 2123-2148, 2720-2734.

\section{EXERCISE 4}

Translate the following passages. Give particular attention to the Aspect of the Participles, so far as idiomatic translation allows.

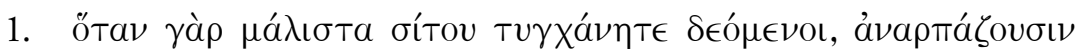

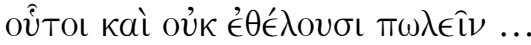

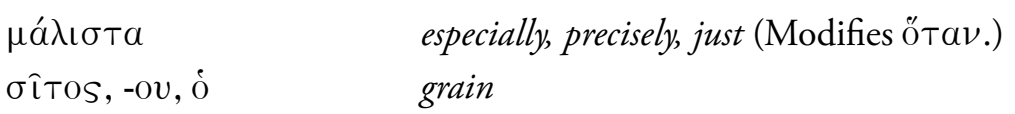


$\delta \in \hat{\imath} \sigma \theta a \iota$

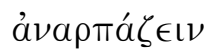

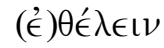

$\pi \omega \lambda \epsilon \hat{\imath} \nu$ to be in need (of) (+ Gen.)

to snatch up

to be willing (+ Infin.)

to sell

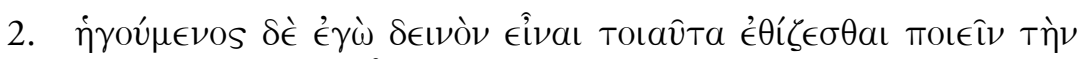

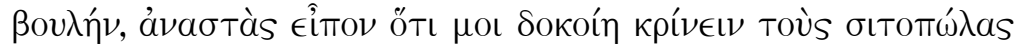
катà Tòv vó $\mu \mathrm{o \nu} . .$.

\begin{tabular}{|c|c|}
\hline$\overline{\dot{\eta} \gamma \in \hat{\imath} \sigma \theta a \iota \text { (Mid.) }}$ & to think (+ Acc. and Infin.) \\
\hline$\delta \in \iota \nu o ́ s,-\eta ́$, -óv & terrible \\
\hline $\mathfrak{\epsilon}^{\prime} \theta \dot{\zeta} \zeta \in \mathrm{I \nu}$ & $\begin{array}{l}\text { to accustom; (Pass.) to become accustomed } \\
\text { (+ Infin.) }\end{array}$ \\
\hline 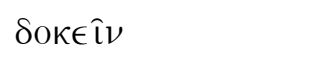 & to seem (right) \\
\hline$\kappa \rho i ́ \nu \in \mathrm{l} \nu$ & to judge \\
\hline 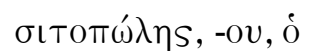 & grain-seller \\
\hline
\end{tabular}

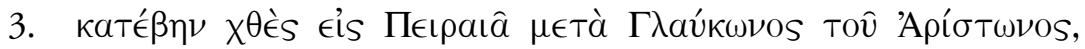

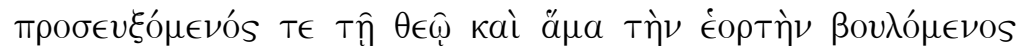

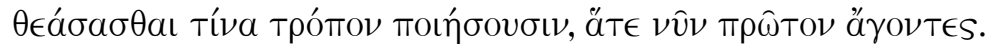

\begin{tabular}{|c|c|}
\hline катаßаíveıv & to go down \\
\hline$\chi \theta \dot{s}$ & yesterday \\
\hline$\Pi \in \iota \rho a(\iota) \in \dot{s}, \dot{o}$, Acc. $-\hat{a}$ & Piraeus \\
\hline 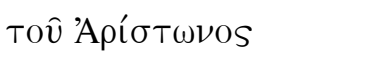 & the $<$ son $>$ of Ariston \\
\hline$\pi \rho 0 \sigma \in \dot{x} \chi \sigma \theta a \mathrm{r}$ & to pray (to) (+ Dat.) \\
\hline غ̇орти́, -ทิs, $\dot{\eta}$ & festival \\
\hline$\theta \in \hat{a} \sigma \theta a ı$ (Mid.) & to see \\
\hline ät€ (+ Partc.) & $\begin{array}{l}\text { inasmuch as (doing something), since } \\
\text { (they are/were doing something) }\end{array}$ \\
\hline$a ̈ \gamma \in \mathrm{L} \nu$ & to celebrate (a festival) \\
\hline
\end{tabular}

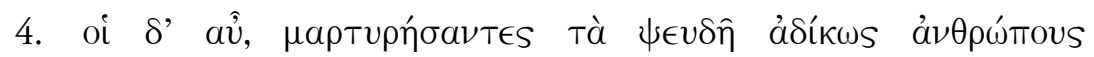

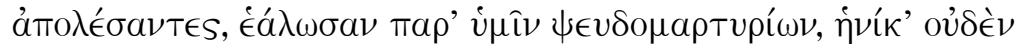

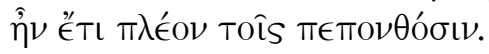

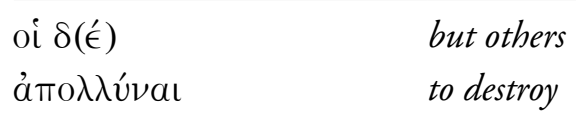


$\dot{\alpha} \lambda i ́ \sigma \kappa \in \sigma \theta a \mathrm{l} \quad$ to be convicted of (+ Gen.; Intr. 2nd Aor. $\dot{\alpha} \lambda \hat{\omega} \nu a \mathrm{~L})$

$\dot{\eta} v \cos ^{\prime}(\alpha) \quad$ when

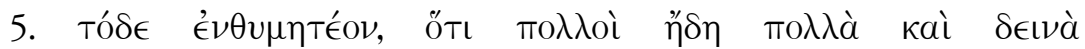

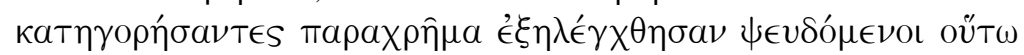

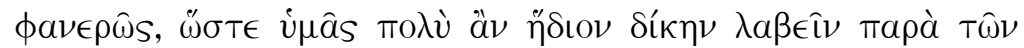

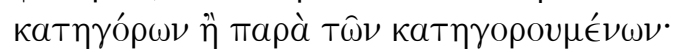

\begin{tabular}{|c|c|}
\hline 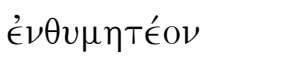 & $<$ it is $>$ necessary to keep in mind (+ Acc.) \\
\hline ÖTı & that (expanding Tó $\delta \epsilon$ ) \\
\hline kaí & $\begin{array}{l}\text { When joining an adj. of size or number } \\
\text { with a descriptive adj., kaí is regularly } \\
\text { omitted in English translation. }\end{array}$ \\
\hline 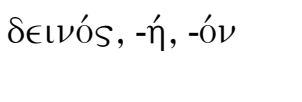 & 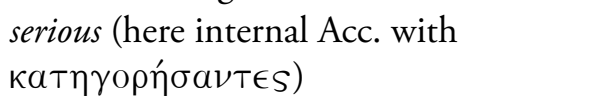 \\
\hline$\pi \alpha \rho a \chi \rho \hat{\eta} \mu \alpha(\mathrm{adv})$. & promptly, immediately \\
\hline $\mathfrak{\epsilon}^{\prime} \xi \in \lambda \epsilon^{\prime} \gamma \chi \in I \nu$ & $\begin{array}{l}\text { to prove someone (Acc.) guilty (of doing } \\
\text { something) (+ Partc.) }\end{array}$ \\
\hline$\psi \in \hat{v} \delta \in \sigma \theta a \iota$ (Mid.) & to speak falsely, to lie \\
\hline$\phi a \nu \in \rho \hat{\omega} s(\mathrm{adv})$. & openly, obviously \\
\hline 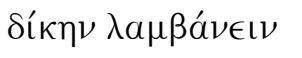 & to exact punishment \\
\hline
\end{tabular}

6. For since these [men] were attributing the responsibility to those [men], we, having summoned the magistrates, were questioning [them].

\begin{tabular}{|c|c|}
\hline to attribute .... to & $\grave{a} \nu a \phi \epsilon^{\prime} \rho \in \iota^{\prime}(+$ Acc. and $\epsilon \dot{i} S+$ Acc.) \\
\hline responsibility & aitía, -as, $\dot{\eta}$ \\
\hline to summon & 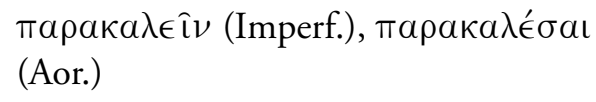 \\
\hline magistrate & $a ́ \rho \chi \omega \nu,-o \nu T o s, o ́$ (Partc. as noun) \\
\hline to question & $\epsilon^{\epsilon} \rho \omega T \hat{\alpha} \nu$ \\
\hline these [men] & Refers to grainsellers \\
\hline those [men], [them] & Refer to magistrates \\
\hline
\end{tabular}




\section{LESSON 5 \\ Genitive Absolute}

\subsection{The Usual Construction}

A Participle may be used with its own Subject in the Genitive Case, where that Subject does not normally appear elsewhere in the same clause. The Participles in a Genitive absolute have a more restricted range of meaning than a circumstantial Participle agreeing with a noun in any Case or agreeing with the unexpressed Subject of a verb (as indicated by the ending of the verb).

\subsubsection{Time}

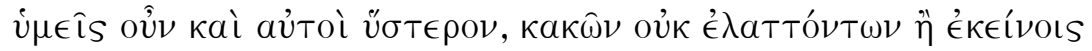

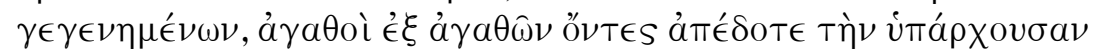

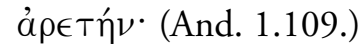

So subsequently, when troubles no less serious had happened than <had happened $>$ to those <men>, you yourselves, being good <men $>$ descended from good <ancestors $>$, displayed their traditional virtue.

Negative oủk.

\subsubsection{Cause}

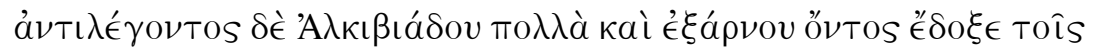

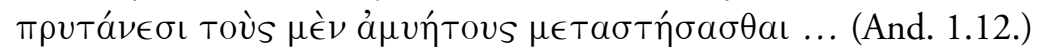

And since Alcibiades was speaking at length in opposition and was denying $<$ the accusation $>$, the members of the standing committee decided to remove the uninitiated... 


\subsubsection{Condition}

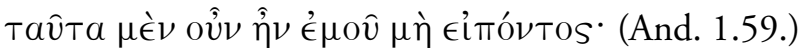

Well then, this was <the situation $>$, if I did not speak.

Negative $\mu$ п́.

\subsubsection{Concession}

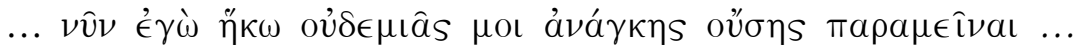
(And. 1.2.)

... now I have come, although there is no compulsion for me to stay here ...

Negative ở (compound).

\subsubsection{Attendant Circumstances in General}

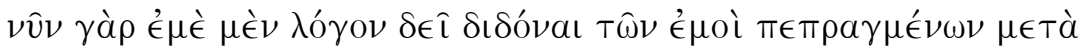

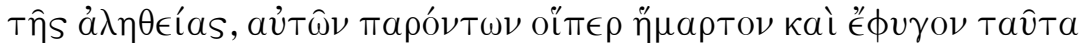

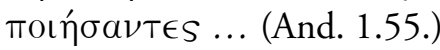

For now I must truthfully give an account of what has been done by me, when there are present the very <men $>$ who did wrong and went into exile after doing this...

\subsection{Subject Unexpressed}

A Participle is sometimes used in the Genitive absolute without an expressed Genitive Subject. This may occur when the Subject is easily understood from the context, or is general (and sometimes deliberately vague), or when the Participle is used impersonally with a öTı clause or an Accusative and Infinitive phrase as its Subject.

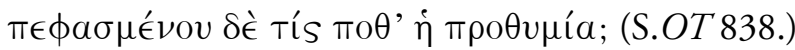

And when <he> has appeared, what at such time <will be> your desire?

The unexpressed Subject of $\pi \epsilon \phi a \sigma \mu \epsilon \operatorname{cov}$ is 'the herdsman' of the previous

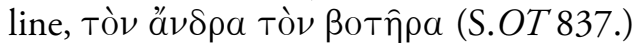

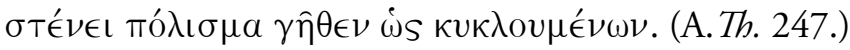

The city groans from the earth, since $<$ people $>$ are surrounding $<i t>$. 
Those who are besieging Thebes are more generally indicated solely by the

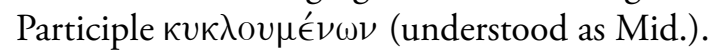

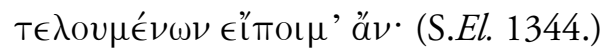

When <things> are being brought to an end, I would tell <you>.

Here, the neuter Participle contains a deliberately vague reference to the plan to kill Clytemnestra and Aegisthus.

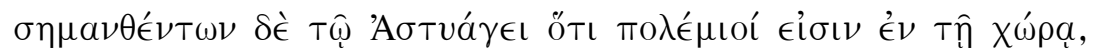

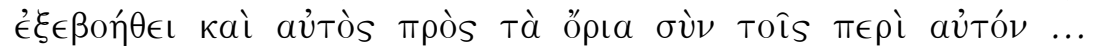
(X.Cyr. 1.4.18.)

But when it was indicated to Astyages that there were enemy in the country, he himself went out to the borders with his attendants to help...

In this impersonal construction, the öTı clause is the Subject of the

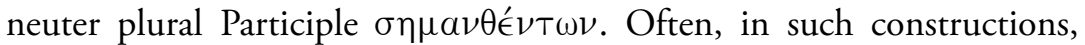
the Participle is artificially plural in keeping with a plural Subject of the ǑTı clause.

\subsection{Improper Genitive Absolute}

Improper Genitive absolute constructions occur where the Subject of the Genitive phrase is the same as a Nominative, Accusative or Dative of the main construction. An improper Genitive absolute usually precedes the Main verb. This irregular construction, which emphasises the idea expressed by the Genitive absolute, became more common in the Hellenistic period.

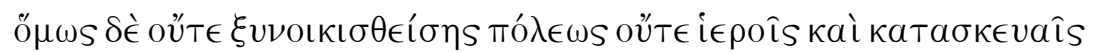

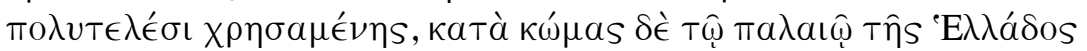

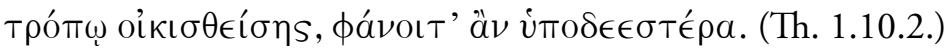

Nevertheless, since the community had not been combined into a single <city>, and did not have the use of temples and expensive structures, but had been settled as a group of villages in the early manner of Greece, it would appear rather deficient.

The 'community' of Sparta is the Subject of three successive Participles in an improper Genitive absolute construction, but then becomes the Nominative Subject of the Main verb фávoıto. 


\section{References}

Goodwin (1889), Syntax of the moods and tenses of the Greek verb, $\$ \$ 847-850$.

Smyth (1956), Greek grammar, \$\$2058, 2070-2074.

\section{EXERCISE 5}

Translate the following passages.

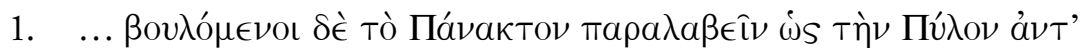

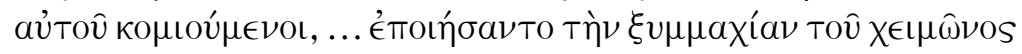

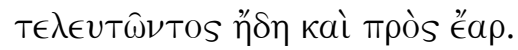

\begin{tabular}{|c|c|}
\hline$\pi \alpha \rho \alpha \lambda \alpha \mu \beta a ́ \nu \in \mathrm{t \nu}$ & to acquire \\
\hline 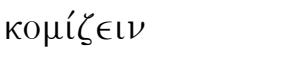 & to obtain (with Fut. Mid.) \\
\hline$x \in \iota \mu \omega^{\prime} \nu,-\hat{\omega} \nu 0 s, \dot{o}$ & winter \\
\hline Є́$\alpha \rho, \hat{\eta} \rho o s$, Tó & spring \\
\hline
\end{tabular}

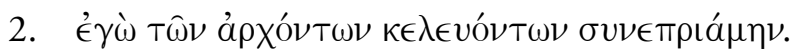

$a ́ \rho x \omega \nu,-$ ovTos, $\dot{o} \quad$ magistrate (as in Exercise 4.6)

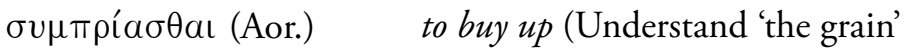
as Object.)

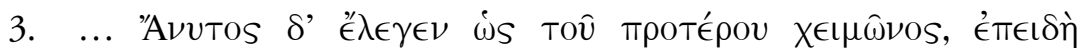

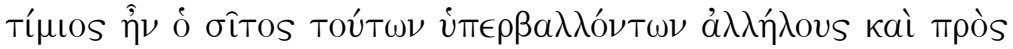

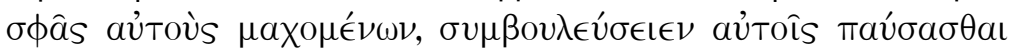

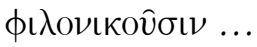

\begin{tabular}{|c|c|}
\hline$\chi \in \iota \mu \omega ́ \omega,-\hat{\omega} \nu \mathrm{os}, \dot{o}$ & winter \\
\hline Tíftos, $(-a)-,0 \nu$ & expensive, at a high price \\
\hline 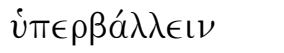 & to outbid \\
\hline$\mu a ́ x \in \sigma \theta a \iota$ & to fight \\
\hline$\sigma v \mu \beta o v \lambda \epsilon u ́ \in t \nu$ & to advise (+ Dat. and Infin.) \\
\hline$\phi ı \lambda о \nu ı к \in \hat{\imath} \nu$ & $\begin{array}{l}\text { to squabble (here Dat. pl. Partc. with } \\
\text { aưtoîs) }\end{array}$ \\
\hline
\end{tabular}


4.

Évíote (adv.)

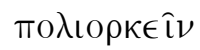

sometimes (Modifies то入ıокои́ $\mu \in \theta$.)

to besiege

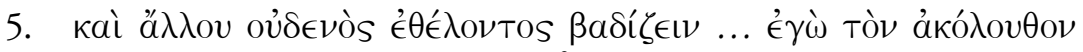

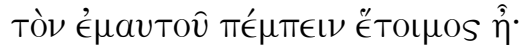

\section{$\beta a \delta i \zeta \zeta \in I \nu$}

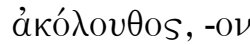

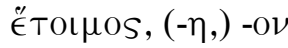

to go

attendant (adj. used as noun)

ready, prepared

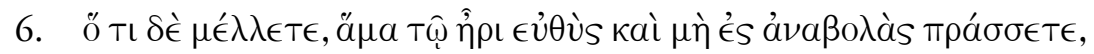

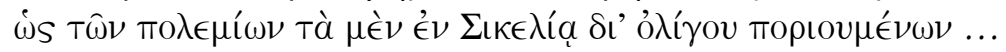

\begin{tabular}{|c|c|}
\hline$\mu \epsilon^{\prime} \lambda \lambda \in \mathrm{I \nu}$ & to intend \\
\hline$\ddot{a} \mu \alpha(\mathrm{adv})$. & $\begin{array}{l}\text { at the same time as (+ Dat.), at the } \\
\text { beginning of }\end{array}$ \\
\hline$\epsilon \dot{u} \theta \dot{s}$ (adv.) & immediately \\
\hline 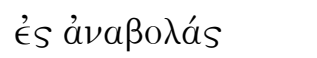 & with (respect to) delay(s) \\
\hline Tà ... É $\nu \Sigma ı$ เ $\in \lambda i ́ a ̣$ & the $<$ forces $>\ldots$ in Sicily \\
\hline$\delta \iota^{\prime}$ ò $\lambda i ́ \gamma o v$ & within a short <time>, shortly \\
\hline торі́ $\zeta \in \sigma \theta a \iota$ (Mid.) & to procure \\
\hline
\end{tabular}

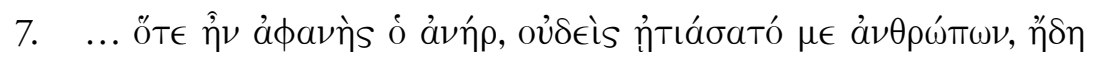

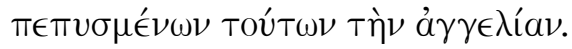

\begin{tabular}{|c|c|}
\hline 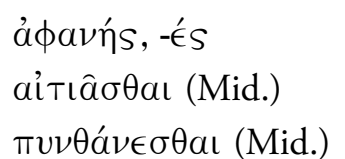 & $\begin{array}{l}\text { unseen, missing } \\
\text { to blame } \\
\text { to learn (by inquiry) }\end{array}$ \\
\hline
\end{tabular}

8. For they make most profit then, when, after something bad has been reported to the city, they sell the grain at a high price.

\begin{tabular}{|c|c|}
\hline most & $\pi \lambda \epsilon \hat{\imath} \sigma \tau \alpha$ (neut. Acc. pl.) \\
\hline to make profit & 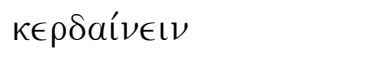 \\
\hline when (indef.) & ÖTav (+ Subj.) \\
\hline after ... reported & Use Gen. abs. \\
\hline
\end{tabular}





\section{LESSON 6 \\ Accusative Absolute}

\subsection{Introduction}

Instead of a Genitive absolute, an Accusative absolute is used:

1. with Participles of so-called impersonal verbs

2. with Participles of verbs which are used impersonally in the Passive Voice

3. with neuter adjectives which are used with the Participle of the verb 'to be'

4. and sometimes with a Participle which has an explicit Subject other than an Infinitive phrase.

These four categories will be treated separately in the following sections.

The Participles in the Accusative absolute have the same restriction of meaning as those in the Genitive absolute. $к a i t \pi \epsilon \rho$ is not used with the Accusative absolute constructions, although they may have a Concessive force.

\subsection{So-Called Impersonal Verbs}

Some common verbs, which are usually designated 'impersonal', are $\delta \in \hat{\imath}$, meaning 'it is necessary'; and ' $\epsilon^{\prime} \xi \in \tau \iota$ and $\pi \alpha ́ \rho \in \sigma \tau \iota$, both meaning 'it is possible', 'it is permissible'. Such verbs are often described as being 'followed by' an Infinitive. These verbs are not 'impersonal' in the sense that they do not have a grammatical Subject. Rather, they may have an

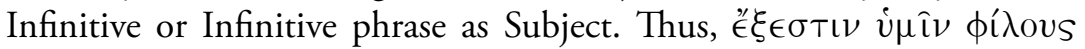
$\gamma \in \nu^{\prime} \in \theta$ a (Th. 4.20.3) may be translated 'it is possible for you to become

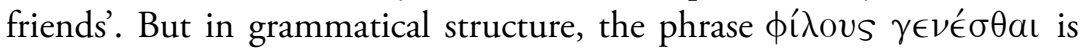
Subject of ' $\epsilon \in \in \sigma \tau \iota \nu$, 'to become friends is possible for you'. (Cf. Lesson 3.4.1.) 
Such verbs use a neuter singular Accusative absolute of the Participle instead of a Genitive absolute. The construction is first attested in Herodotus (Ionic) and in Attic prose writers of the fifth century BCE. The Participles are most often used in the Imperfect Aspect. Apart from $\delta$ ó $\xi a v$ and TuXóv (and their compounds), the Aorist Participle rarely appears.

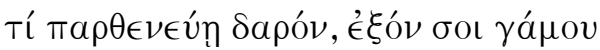

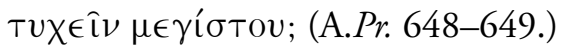

Why do you so long remain a virgin, when it is possible for you to obtain the greatest marriage?

However, an impersonal verb does not always have an Infinitive phrase as Subject, either with a finite verb form or in an Accusative absolute.

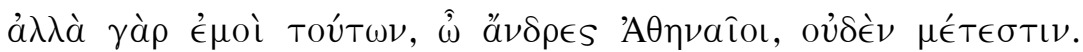
(Pl.Ap. 19 C.)

But really, $O$ men of Athens, I am not involved in these matters [lit. there is no share for me of these matters].

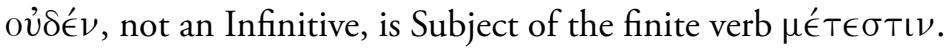

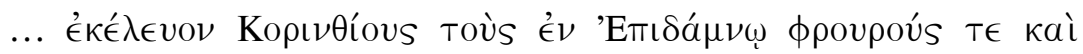

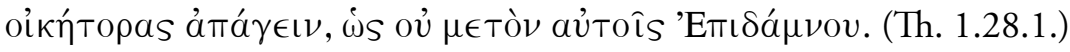

... they were ordering the Corinthians to withdraw their garrison members and colonists in Epidamnus, on the grounds that they had no claim to Epidamnus [lit. there not being a share for them of Epidamnus].

There is no Subject for the neuter Accusative Participle $\mu \in T o ́ \nu$. is emphasises that the grounds are alleged by the Corinthians, not by the writer Thucydides.

\subsection{Verbs Used Impersonally in the Passive Voice}

The Accusative absolute construction also occurs with the Participles of verbs which are used impersonally in the third person singular Indicative Passive. Some of the more common examples are in the Perfect Aspect; the Aorist Passive Participle occurs more rarely. 


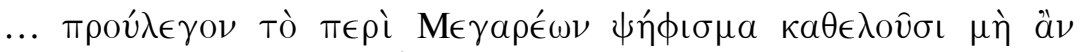

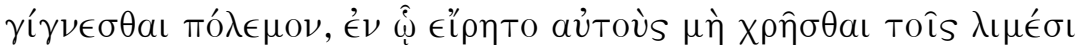

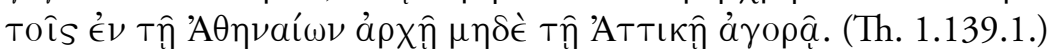

... they declared <to them $>$ that a war would not occur, if they rescinded the decree about the Megarians, in which it had been stated that they were not to use the ports in the control of the Athenians nor the Athenian market-place.

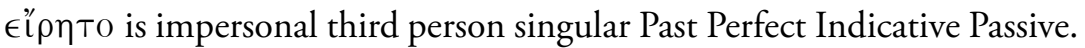

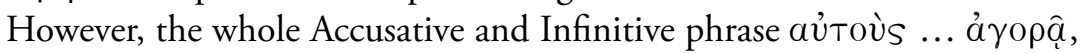
is the Subject of $\epsilon$ l’ $\eta т 0$. Compare $\$ 6.2$ above. (The negatives in the passage are $\mu \eta$, because $\pi \rho 0 u ́ \lambda \epsilon \gamma o \nu$ represents an ultimatum and $\epsilon " \rho \eta \tau o$ refers to a decree.)

The following example uses the Perfect Passive Participle of the same verb in the neuter singular Accusative absolute.

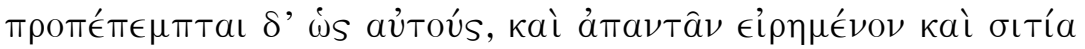

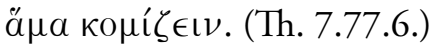

And <instructions> have been sent ahead to them, since it has been stated both that <they $>$ are to meet and that $<$ they $>$ are to bring provisions at the same time.

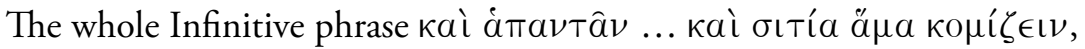

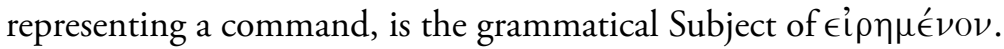

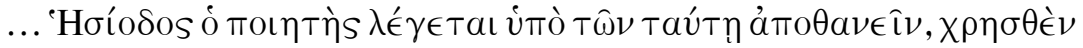

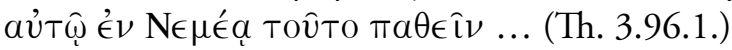

... Hesiod the poet is said to have been killed by the people here, when it had been prophesied to him that he <was to $>$ suffer this in Nemea...

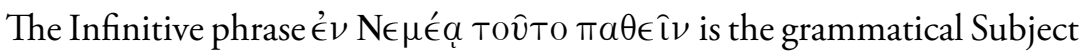
of the Aorist Passive Participle $\chi \rho \eta \sigma \theta \in ́ \nu$.

\subsection{Neuter Adjectives}

Some neuter adjectives are used impersonally with the Indicative of the

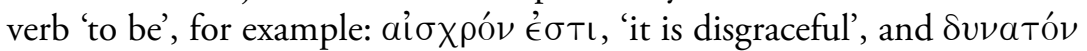
É$\sigma \tau \iota$, 'it is possible'. Such adjectives may be used in an Accusative absolute construction with the Participle of the verb 'to be'. 


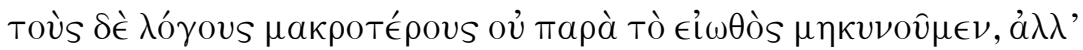

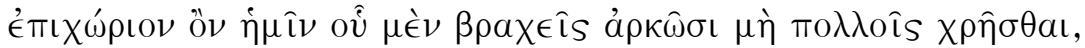

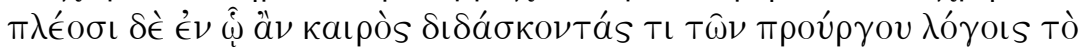

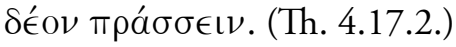

And we shall prolong our words at greater length not contrary to our custom, but because it is characteristic for us not to use many <words $>$ when few are sufficient, but to achieve what is necessary when there is opportunity by explaining something of what is useful in more words.

In this passage, the whole section ổ $\mu \grave{\epsilon} \nu \ldots \chi \rho \hat{\eta} \sigma \theta a \mathrm{l}$ is the grammatical

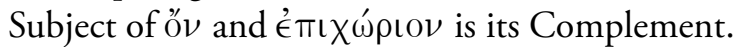

In this construction, the adjective and the Participle are in the neuter singular, but in the following example, the adjective and Participle are plural, despite the fact that the grammatical Subject of the Participle is the (singular) Infinitive phrase $\pi a \nu \tau i ̀ ~ . . . ~ \pi \iota \sigma \tau \epsilon \hat{v} \sigma \alpha \iota$.

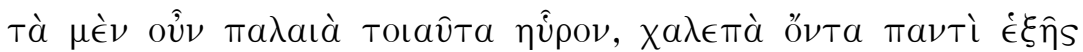

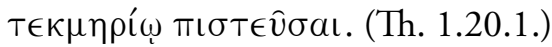

Well then, I found the early <events to be> such, although it was difficult to rely on every inference along the way.

\subsection{Personal Accusative Absolute}

Sometimes, a personal construction is used in the Accusative absolute: the Participle has an Accusative Subject other than an Infinitive phrase. is or $\tilde{\sigma} \sigma \pi \epsilon \rho$ generally introduces this construction. The Participle is usually in the neuter Gender and is often derived from a verb which is used impersonally. But this personal construction may occur with any Gender or Number.

\subsubsection{With $\dot{\omega}$ or $\dddot{\omega} \sigma \pi \epsilon \rho$}

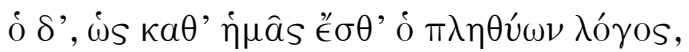

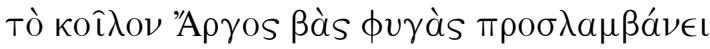

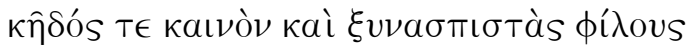

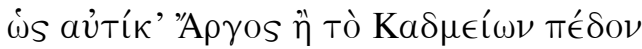

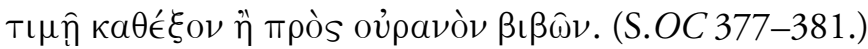


But he, as the current story among us is, having gone as an exile to the valley of Argos, is taking on a new relationship and companions in arms as friends, on the understanding that presently Argos either will occupy the Cadmeans' land in honour or will exalt it to heaven.

is is used with 'A $\rho$ yos as Accusative Subject of the Intentive ('Fut.')

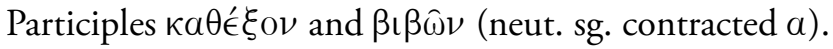

\subsubsection{Without $\dot{\omega} s$ or $\ddot{\omega} \sigma \pi \epsilon \rho$}

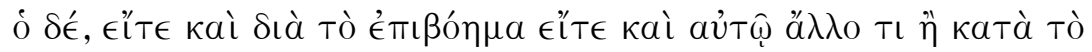

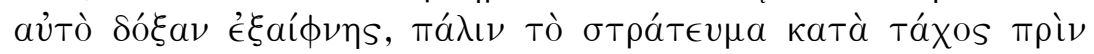
$\xi v \mu \mu \epsilon \hat{\imath} \xi a \iota \grave{a} \pi \hat{\eta} \gamma \in \nu$. (Th. 5.65.3.)

But he, whether actually on account of the shout or rather because some other $<$ course of action $>$ than the one he was currently following suddenly seemed right to him, began to lead the army away again in haste before making contact with < the enemy>.

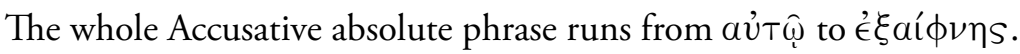

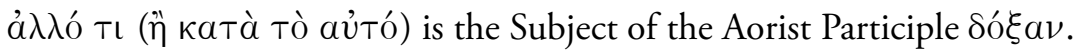

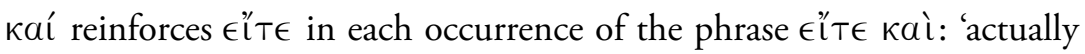
... rather'.

катà Tò aưTó means literally 'in accordance with the same'.

\subsection{Note}

In the Hellenistic period, the Accusative absolute is partly replaced by

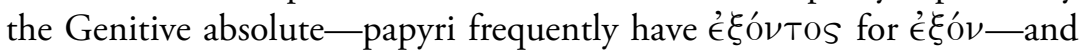
partly drops out of use altogether.

\section{References}

Goodwin (1889), Syntax of the moods and tenses of the Greek verb, \$\$851-854.

Smyth (1956), Greek grammar, \$\$2059, 2076-2078, 2086d, 2087, cf. 905, 932935 (impersonal verbs). 


\section{EXERCISE 6}

Translate the following passages.

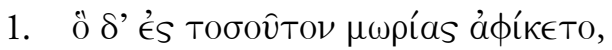

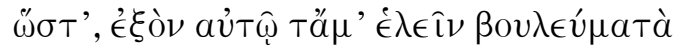

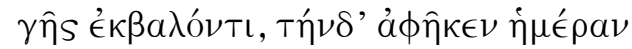
$\mu \in \hat{\imath} \nu a i ́ ~ \mu ’ . .$.

\begin{tabular}{|c|c|}
\hline$\ddot{O}$ & be \\
\hline 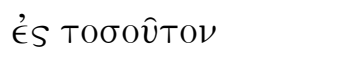 & to so great (a degree of) (+ Gen.) \\
\hline$\mu \omega \rho i ́ a,-a s, \dot{\eta}$ & foolishness \\
\hline тá $\mu^{\prime}$ & 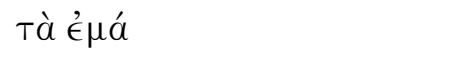 \\
\hline$\dot{\epsilon} \lambda \in \hat{\imath} \nu$ (Aor.) & to destroy, to ruin \\
\hline$\beta$ oú $\lambda \in v \mu a,-\alpha$ Tos, тó & purpose, intention \\
\hline 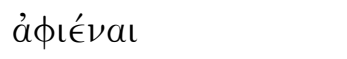 & to allow \\
\hline$\mu^{\prime}$ & $\mu \epsilon$ \\
\hline
\end{tabular}

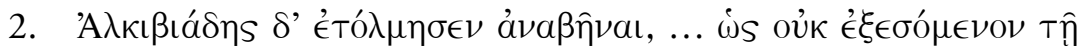

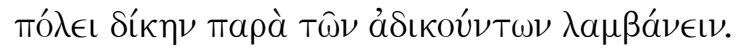

\begin{tabular}{ll}
\hline$\alpha \nu a \beta a i ́ v \in ı \nu$ & to mount (a horse) \\
$\alpha \dot{\delta} \delta \kappa \in \hat{\imath} \nu$ & to do wrong
\end{tabular}

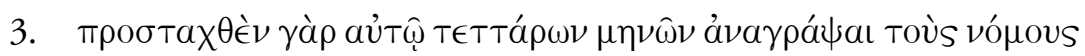

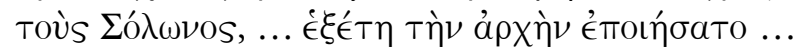

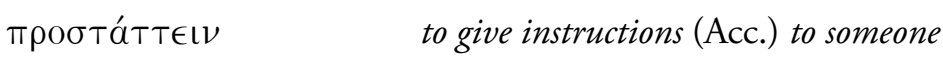
(Dat.) to do (Infin.)

$\mu \in$ ís or $\mu \eta \dot{\eta} \nu, \mu \eta \nu$ ós, $\dot{o} \quad$ month

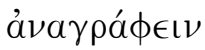
to write uplout, to record $\dot{\epsilon} \xi \dot{\epsilon} T \eta S,-\epsilon S$ (here) lasting six years; (usually) six years old

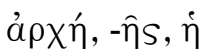
office, appointment 


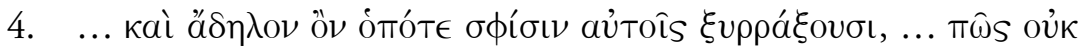

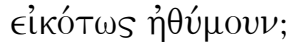

$\xi v \rho \rho a ́ \sigma \sigma \in \mathrm{IV}$

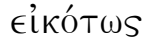

$\dot{a} \theta v \mu \epsilon \hat{\imath} v$ to fight with, to clash with (+ Dat.) reasonably, with (good) reason to be disheartened (here 3rd pers. pl.)

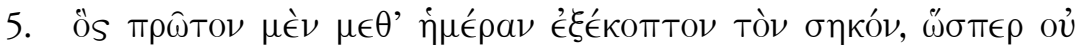

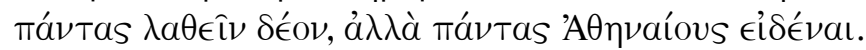

\begin{tabular}{|c|c|}
\hline Ös & For ... I (coordinating relative pronoun) \\
\hline$\pi \rho \hat{\omega} T \mathrm{\nu}$ & in the first place \\
\hline$\mu \in \theta^{\prime} \dot{\eta} \mu \epsilon^{\prime} \rho \alpha \nu$ & by day, in the day-time \\
\hline 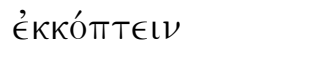 & to cut out \\
\hline$\sigma \eta \kappa o ́ s,-o \hat{v}, \dot{o}$ & olive-stump \\
\hline$\ddot{\omega} \sigma \pi \epsilon \rho$ & as if \\
\hline$a ́ \nu T a s \lambda a \theta \in \hat{\imath} \nu$ & $\pi \alpha ́ \nu \tau a S$ is Object of $\lambda a \theta \in \hat{\imath} \nu$. \\
\hline 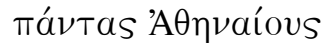 & Subject of $\epsilon i \delta \in ́ v a l$ \\
\hline
\end{tabular}

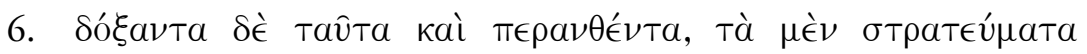
$\dot{a} \pi \hat{\eta} \lambda \theta \in \ldots$

$\pi \in \rho a i ́ v \in \mathrm{L} \nu \quad$ to bring to an end, to finish

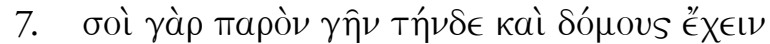

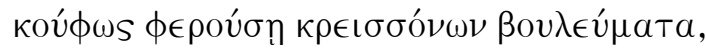

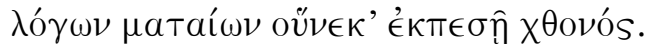

\begin{tabular}{|c|c|}
\hline $\mathscr{E}^{\prime} X \in \mathrm{L}$ & to inhabit, to live in \\
\hline 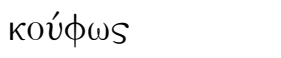 & lightly \\
\hline на́таıоs, - -,- -оv & rash \\
\hline oüvยKa & because of (after Gen.) \\
\hline$\dot{\epsilon} \kappa \pi i ́ \pi T \in \iota \nu$ & Used instead of Pass. of é $\kappa \beta a ́ d \lambda \lambda \in \iota \nu$. \\
\hline
\end{tabular}


8. But if we are taking revenge later, although it was necessary to take revenge long ago, he gains the time during which he was living, although it was not appropriate for him [to do so] ...

\begin{tabular}{|c|c|}
\hline to take revenge & $\tau \iota \mu \omega \rho \in \hat{\imath} \sigma \theta a \iota$ (Mid.) \\
\hline later & vँ $\sigma \tau \epsilon \rho O \nu$ \\
\hline $\begin{array}{l}\text { although it was necessary } \\
\text { long ago }\end{array}$ & $\begin{array}{l}\text { Use Acc. abs. } \\
\text { тádaı }\end{array}$ \\
\hline time & xpóvos, -ov, ò \\
\hline during & Use Acc. of extent. \\
\hline he was living & $\iota^{\prime} \zeta \eta$ \\
\hline to be appropriate (for) & $\pi \rho о \sigma \eta ́ \kappa \in \iota \nu$ (+ Dat.) Use Acc. abs. \\
\hline
\end{tabular}




\section{LESSON 7

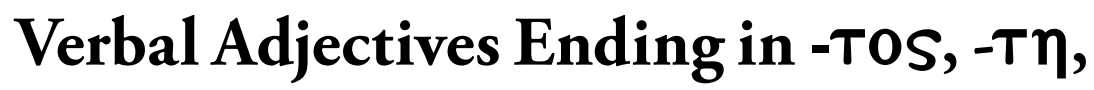 \\ - TOV}

\subsection{Introduction}

In addition to Participles, which are a standard component of the Greek verbal system, there are two other sets of verbal adjectives. These sets use the endings of the first and second declensions. The forms are listed separately in dictionaries. Lesson 7 deals with verbal adjectives ending in

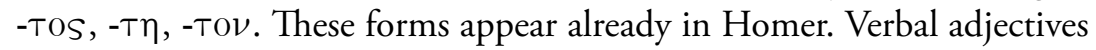
ending in -TÉos, -TÉa, -TÉov will be treated in Lesson 8.

\subsection{Formation of Verbal Adjectives Ending

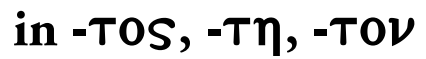

The letter $T$ was often used as a suffix to form adjectives, for example, $\dot{a}-\gamma \in \rho a \sigma-\tau o S$, 'without a prize' (Hom.Il. 1.119.). It was usually added to the shortest form of the root of a word. Thus, $\theta \in$-Tós ('placed') is cognate

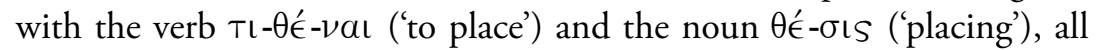
incorporating the root $\theta \epsilon$. And verbal adjectives, which are related to verbs with reduplicated Imperfect stems, have the short form of the root.

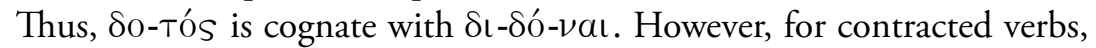
-TOS is usually added after the lengthened form of the theme vowel. Thus,

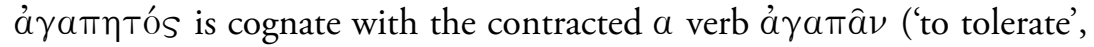
'to accept', 'to desire'), which has $\eta$ in Tenses other than Present and

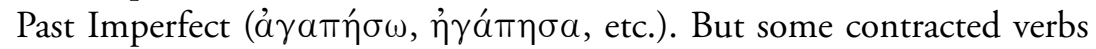
use the short form of the theme vowel in some Tenses. And this short theme vowel may appear in the related verbal adjective. Thus, ai $\rho \in T o ́ s$ is cognate with ai $\rho \in \hat{\imath} \nu$ ('to take'), which has $\eta$ in some Tenses (e.g. Fut. Act.

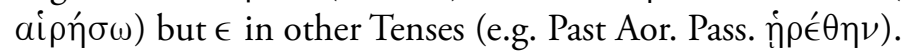


But contracted $\alpha$ verbs, whose base ends in $\rho$ or a short vowel $\epsilon$ or $\mathrm{I}$ (and sometimes 0 ), often retain $\alpha$ in the Tenses other than Present and Past Imperfect. Examples are $\pi \epsilon \rho \hat{\alpha} \nu$ ('to cross'; $\pi \epsilon \rho a ́ \sigma \omega, ~ \epsilon ̇ \pi \epsilon ́ \rho a \sigma \alpha$, etc.),

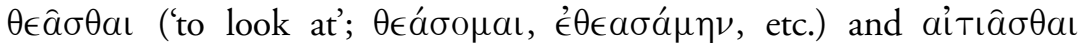

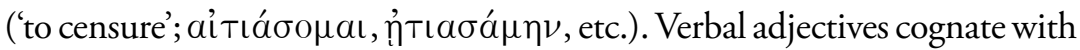

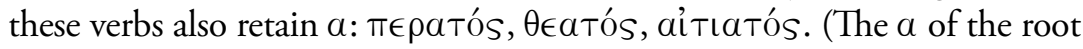
is long in all the forms cited, both in the verbs and in the verbal adjectives. But there are some exceptions to this pattern; cf. Smyth, 1956, \$488.)

Following the regular pattern, $\phi ı \lambda \eta \tau o ́ s ~(' l i k a b l e ')$ is cognate with the contracted $\epsilon$ verb $\phi \iota \lambda \in \hat{\imath} \nu$ ('to like'), which has $\eta$ in Tenses other than Present and Past Imperfect ( $\phi i \lambda \dot{\eta} \sigma \omega, \dot{\epsilon} \phi i ́ \lambda \eta \sigma \alpha$, etc.). And $\delta \eta \lambda \omega \tau o ́ s$ ('able to be shown') is cognate with the contracted o verb $\delta \eta \lambda$ ov̂ $\nu$ ('to show'), which has $\omega$ in tenses other than the Present and Past Imperfect

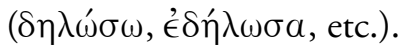

In practice, the stem of the verbal adjectives (both in -Tos and in -TÉOS) is usually most easily recognisable from the Aorist Passive of the cognate verb. For example, $\sigma \pi a \rho$ Tós ('sown') is cognate with the verb $\sigma \pi \epsilon i ́ \rho \in I \nu$ ('to sow'), whose (second) Aorist Passive is $\sigma \pi a \rho \eta v \nu a ı$ ('to be sown'). The $\theta$ at the end of the base of first Aorist Passive verbs does not appear in the cognate verbal adjectives. But where a verb has $\sigma$ before $\theta$ in first Aorist Passive verbs, this $\sigma$ appears before $\tau$ in the verbal adjective:

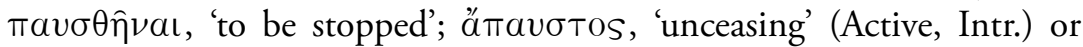
'unstoppable' (Passive). The insertion or omission of $\sigma$ may vary with different occurrences of the same verb or verbal adjective (e.g. $\gamma \nu \omega T$ ós or $\gamma \nu \omega \sigma T o ́ s)$, and different manuscripts may vary in the spelling of the same term in the same context (e.g. $\gamma \nu \omega(\sigma)$ Tós [A.Ch. 702; S.OT 396]). (In the 1st Aor. Pass. of $\tau \imath \theta \epsilon \in \nu a l$, the root $\theta \epsilon$ has been modified to $\tau \epsilon$ before the following $\theta$; thus, $\tau \in-\theta \hat{\eta} \nu a \iota$ instead of $\theta \epsilon-\theta \hat{\eta} \nu a \iota$.)

Verbal adjectives ending in -Tos, which are uncompounded (as $\phi \iota \lambda \eta т o ́ s)$

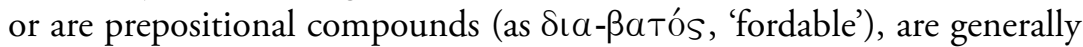
accented on the final syllable and often (but not always) have all three gender endings: -ós, - -́, -ó $\nu$. Other compound verbal adjectives regularly have recessive accent and use the ending -os for both masculine and feminine genders. Thus, $\nu v \kappa \tau i ́-\pi \lambda a \gamma \kappa T O S$, -Ov ('causing to wander at night') is formed from the root of $\pi \lambda a ́ \zeta \in \mathrm{L} \nu$ ('to cause to wander'; 1 st Aor. Pass. $\pi \lambda a \gamma \chi \theta \hat{\eta} \nu a \mathrm{l})$. Negative $\alpha$ is common in these compounds. Simple $a$ - precedes a consonant ( $\alpha$ - $\phi \cup \kappa T O S$, 'unable to escape' [Act.]; 'inescapable' 


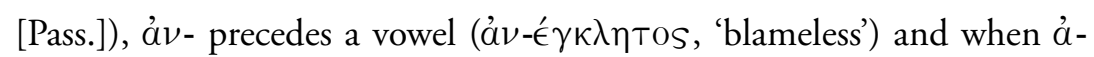
precedes $\rho$, the $\rho$ is doubled (á $\rho-\rho \eta \kappa T$, 'not broken', 'not to be broken'; cf. Smyth, 1956, \$80).

\subsection{Meaning of Verbal Adjectives Ending in -TOS, $-T \eta,-T O \nu$}

It is likely that originally these verbal adjectives were not specifically Active or Passive but merely indicated relevance to the sphere of meaning of the

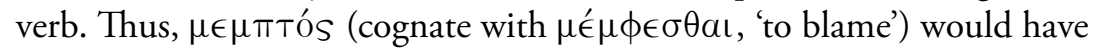
indicated relevance to blaming. In the classical period, this word may have either Active or Passive force. (Cf. ämavotos in $\$ 7.2$ above.)

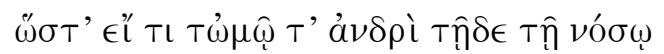

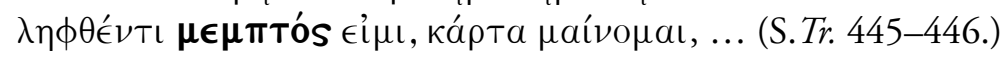

And so, if I am blaming my husband at all for getting caught

by this disease, I am surely mad, ...

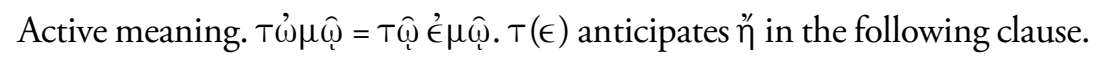

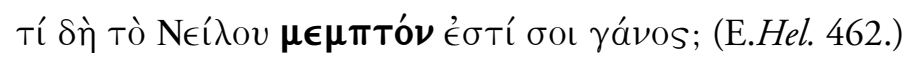

Just why is the bright-water of the Nile blamed by you?

Passive meaning.

The Passive force of these verbal adjectives is more common. But verbal adjectives with Passive force can be used to indicate either what is (already) done or what may or must be done. Some verbal adjectives are used in only one of these ways in extant Greek literature, but others are used

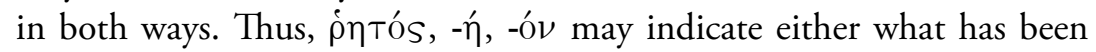
stated or what may be stated.

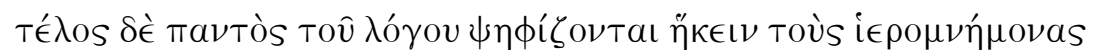

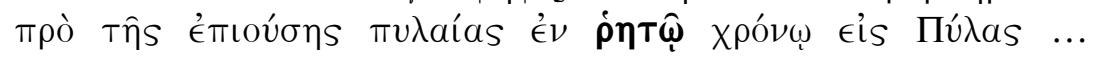
(Aeschin. 3.124.)

And as the conclusion of all the discussion they voted [Hist. Pres.] that the representatives should come to Thermopylae at a stated time before the next amphictyonic-meeting...

The verbal adjective indicates what has been done. 


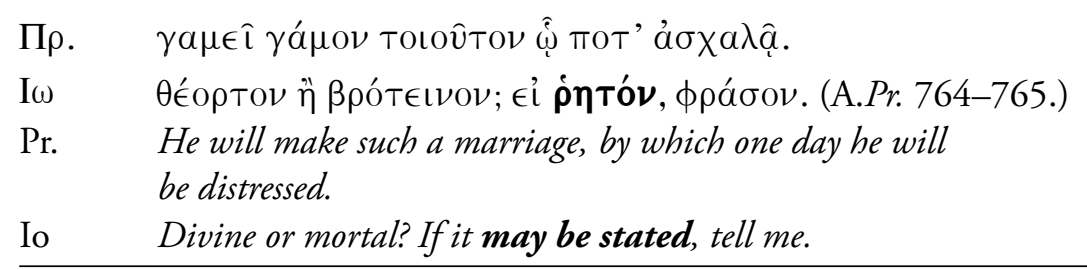

The verbal adjective indicates what may be done.

When an Infinitive phrase is the Subject of the verb 'to be' (expressed or understood), a neuter verbal adjective may be Complement, mostly singular as in the preceding examples (E.Hel. 462; A.Pr. 765), but sometimes plural. (Cf. Lesson 3.4.1.)

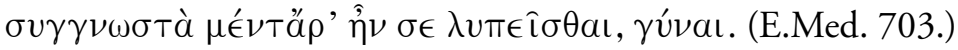

It was understandable, therefore, that you should be upset, lady.

Lit. 'That you should be upset, therefore, was understandable, lady'. Here, an Accusative and Infinitive phrase is the Subject of $\hat{\eta} \nu$. Within the Accusative and Infinitive phrase, $\sigma \in$ is Subject of the Passive Infinitive $\lambda v \pi \epsilon \hat{\imath} \sigma \theta \alpha$. And the neuter plural $\sigma v \gamma \gamma \nu \omega \sigma \tau \alpha$ is the Complement of the Infinitive phrase. (The crasis of $\mu \epsilon ́ \nu T O \iota$ ă $\rho \alpha$ accounts for the apparent double accent.)

A Dative of Interest, implying Agency, may be used with verbal adjectives in their Passive sense.

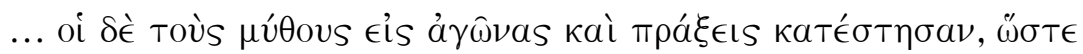

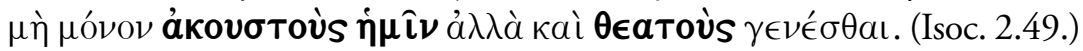

... but they put the stories into conflicts and actions, so as to become not only beard by us but also seen.

(The passage refers to early tragedians, by contrast with Homer who put into stories the conflicts and wars of the demigods.)

\section{References}

Palmer (1980), The Greek language, pp. 256-257, 314.

Smyth (1956), Greek grammar, \$\$80, 358, 425.c, 471-472, 488, 1003.a, 1052, 1488. 


\section{EXERCISE 7}

1. Translate the following passages.

2. For each passage:

a. write down the Nominative masculine singular of any verbal

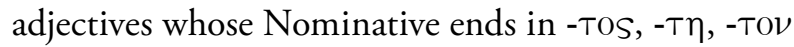

b. indicate any negative $\dot{\alpha}(v)$ - prefixes by inserting a hyphen

c. write the Imperfect Infinitive of the verb to which the verbal adjective is etymologically related

d. mark accents and breathings correctly.

3. Montanari (2015), The Brill dictionary of Ancient Greek, or the full edition of Liddell and Scott (1996), A Greek-English lexicon, should be used.

\section{Example}

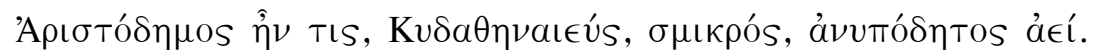
(Pl.Smp. 173 B.)

It was a certain Aristodemus of Kydathenaeum, a small <man>, always unshod [i.e. barefoot].

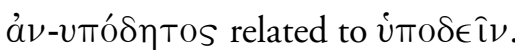

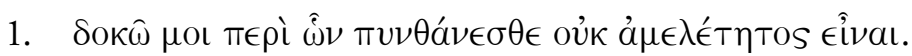

\begin{tabular}{|c|c|}
\hline 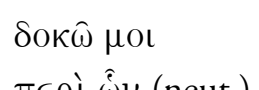 & lit. I seem to me (i.e. it seems to me that I) \\
\hline$\pi \epsilon \rho \grave{i} \hat{\omega} \nu$ (neut.) & 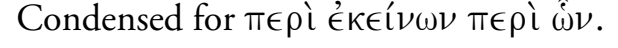 \\
\hline
\end{tabular}

2.

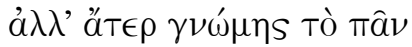

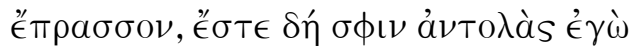

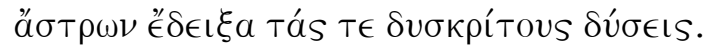

\begin{tabular}{|c|c|}
\hline ăt $T \rho$ (+ Gen.) & without \\
\hline$\stackrel{\prime}{\epsilon} \sigma T \epsilon$ & until \\
\hline$\dot{a} \nu(\alpha) \tau o \lambda \dot{\eta},-\hat{\eta} s, \dot{\eta}$ & rising \\
\hline$\delta \dot{\sigma} \sigma s,-\epsilon \omega s, \dot{\eta}$ & setting \\
\hline
\end{tabular}




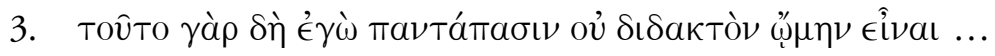

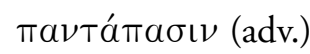

olı $\sigma \theta a \iota$

\section{altogether}

to think (Mid. with Aor. Pass.;

œै $\mu \eta \nu=\omega$ ó $\mu \eta \nu$, Past Imperf.)

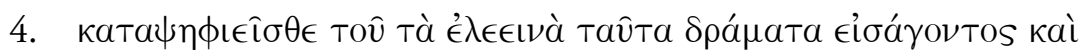

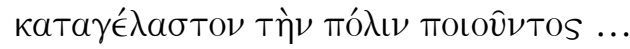

\begin{tabular}{|c|c|}
\hline 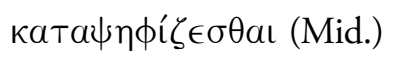 & to vote in condemnation of $(+\mathrm{Gen})$. \\
\hline 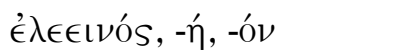 & pitiful, pitiable \\
\hline
\end{tabular}

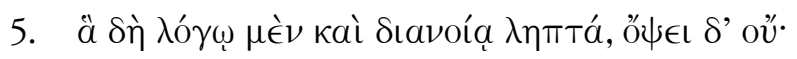

á

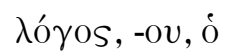

And these (coordinating relative pronoun)

Sıávoıa, -as, $\dot{\eta}$

ő\&ss, - $\epsilon \omega S, \dot{\eta}$ reason

thought

sight

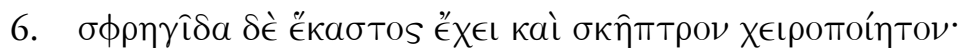

$\sigma \phi \rho \eta \gamma i ́ s,-i \delta o s, \dot{\eta}$ (Ionic) seal (Attic $\sigma \phi \rho a \gamma i ́ s)$

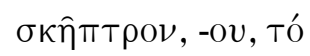

staff

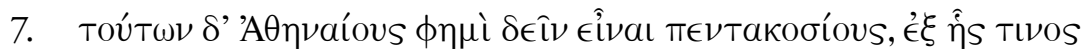

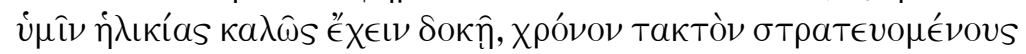
...

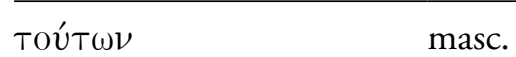

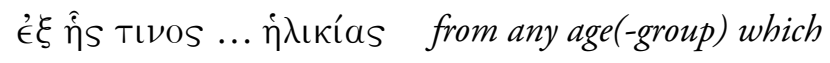

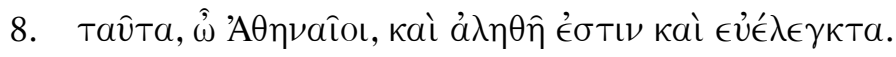




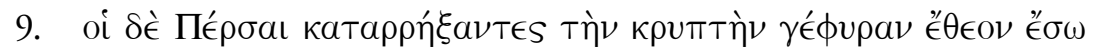
ÉS TÒ TỄXOS.

\begin{tabular}{|c|c|}
\hline 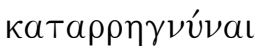 & to break down \\
\hline$\gamma{ }^{\prime} \phi \cup \rho a,-a s, \dot{\eta}$ & bridge \\
\hline$\theta \in ́ \in \in \nu$ (Ionic) & to run (Attic $\theta \in \hat{\imath} \nu)$ \\
\hline
\end{tabular}

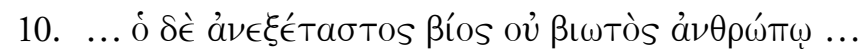

Understand '̇́Tí. 



\section{LESSON 8 \\ Verbal Adjectives Ending in -Téos, -Téa, -Téov}

\subsection{Formation of Verbal Adjectives Ending in -Téos, -Téa, -Téov}

According to Palmer (1980), the verbal adjectival suffix -Téo- is derived from the action suffix ${ }^{*}$-ti- inherited from Indo-European. In Greek,

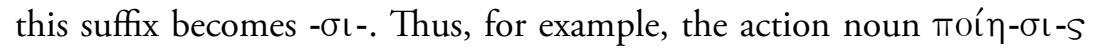

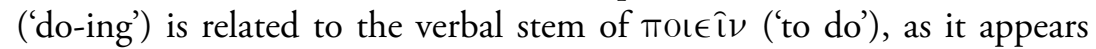

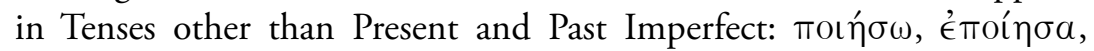
etc. The corresponding verbal adjective is moın-Téos. Where a verb has $\sigma$ before $\theta$ in First Aorist Passive, this $\sigma$ appears before $\tau$ in the verbal

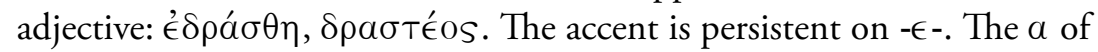
the feminine ending is long.

Verbal adjectives formed with a suffix -TÉO- are listed separately in dictionaries. If only a Passive use of a particular verbal adjective occurs in extant classical Greek, the word is listed alphabetically in Liddell and Scott (1996) with the ending -Téos. If only an Active use occurs, the word is listed with the ending -Téov. Where both Passive and Active uses occur, the Active form is listed first in Montanari (2015), but there is some inconsistency in Liddell and Scott (1996) as to which form is listed first.

\subsection{Usage of Verbal Adjectives Ending in -Téos, -Téa, -TÉov}

The verbal adjectives ending in -Téos do not occur at all in Homer. They are in general use from the fifth century BCE onwards. (The earliest

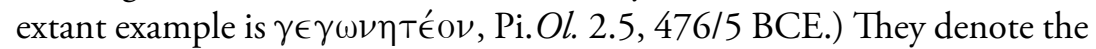
necessity of the action of the cognate verb. 
When these verbal adjectives are used personally, they may appear in any gender (-TÉOS, -TÉa, -TÉOV) and they have a Passive meaning, indicating that something is to be done. But they are more often used impersonally, mainly in the neuter singular (-TÉOV), but sometimes in the neuter plural (-TÉa). The plural occurs especially in Thucydides among prose writers. The impersonal use regularly has an Active meaning, indicating that it is necessary to do something; and the verb 'to be' is usually omitted ('<it is $>$ necessary to do'). However, in reported discourse the Infinitive of the verb 'to be' may be included for the sake of clarity. And for an exceptional impersonal Passive usage, see $\$ 8.8$ below.

The Agent for both personal and impersonal constructions is normally expressed in the Dative Case. Examples are given in $\$ \$ 8.3$ and 8.4.1 below.

In both personal and impersonal constructions, the verbal adjective generally appears in the Nominative Case in direct discourse. In reported discourse, the verbal adjective regularly appears in the Accusative Case with Infinitive or Participle as appropriate. For a usage with the definite article in any Case, see $\$ 8.4 .2$ below.

In so far as these verbal adjectives regularly occur in statements (direct or reported), the negative used with them is ov. However, in the impersonal Active construction, ov moınTéov means not ' $<\mathrm{It}$ is $>$ not necessary to do', but '<It is $>$ necessary not to do'. Although negative $a$ is common as a prefix to verbal adjectives ending in -Tós, -Tク́, -Tó $\nu$, it appears as a prefix to verbal adjectives ending in -TÉos, -TÉa, -TÉov only in some 11 forms cognate with verbs which contain the negative $\alpha$. Alphabetically,

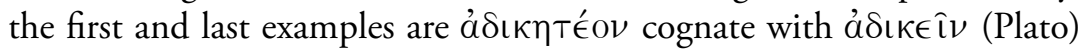
and $\dot{a} \sigma \iota t \eta T \hat{O} O \nu$ cognate with $\dot{a} \sigma \iota t \in \hat{\imath} \nu$ (Galen).

\subsection{Impersonal Construction}

In the following example, the relation of the form of the verbal adjective to the cognate verb is indicated by citing the verbal adjective itself, the Imperfect Active Infinitive and the Aorist Passive Infinitive.

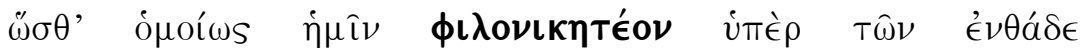

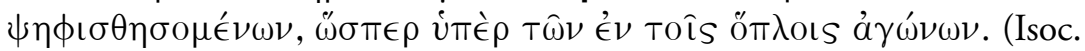
6.92.)

And so in a similar way <it is > necessary for us to campaign for what is going to be voted on here, just as for contests under arms. 


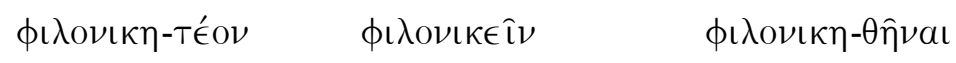

$\dot{\eta} \mu \hat{\imath} \nu$ is Dative of Interest implying Agency: the 'campaigning' is to be done 'by us'.

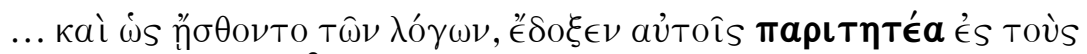

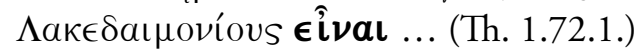

... and when they had heard the speeches, it seemed to them to be necessary to appear (lit. 'to come forward') before the Spartans ...

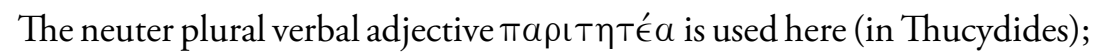

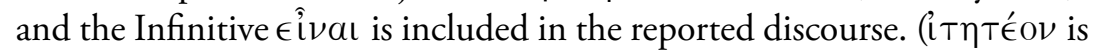
equivalent to iTéOV in function and meaning.)

\subsection{Personal Construction}

\subsubsection{Regular Usage}

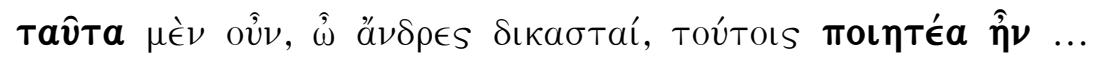
(And. 1.136.)

Well then, $O$ men of the jury, this was (bound) to be done by these $<$ men $>\ldots$

In the personal construction, тоıпте́a is Nominative neuter plural in agreement with тâ̂Ta. Toútoıs is Dative of Interest implying Agency.

\subsubsection{Usage with Article}

The personal usage of the verbal adjective occasionally appears with the definite article to form a noun phrase. This idiom is not restricted to the Nominative Case.

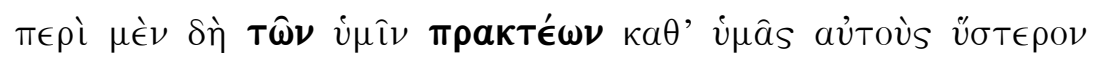

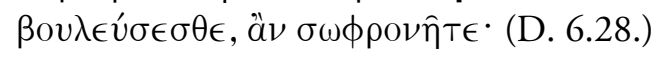

Indeed, concerning what is to be done by you, you will subsequently deliberate by yourselves, if you are sensible. 


\subsection{Ambiguous Constructions}

When the entire verbal adjectival phrase is neuter, it is often difficult to decide whether a neuter noun or pronoun is Subject of a personal construction or Object of an impersonal construction.

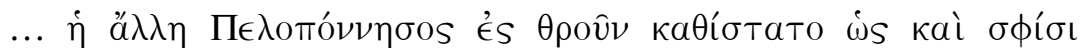

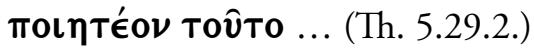

... the rest of the Peloponnese was getting into a discussion, that <it was $>$ necessary for them too to do this ... [OR: that this <was> to be done by them too ....]

Tov̂To may be either Object of moınTéov (used impersonally) or Subject of moıntéov (used personally). But the absence of the verb 'to be' makes it more likely that the construction should be understood as impersonal here.

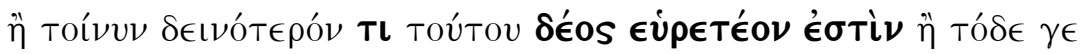

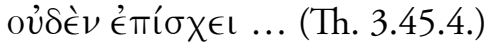

Either, therefore, some cause-of-fear more fearsome than this [= death] is to be found or this [= cause-of-fear] restrains nothing ...

[OR: Either, therefore, it is necessary to find some cause-of-fear more fearsome than this or this causes no restraint ...]

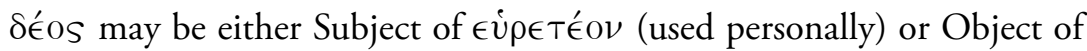

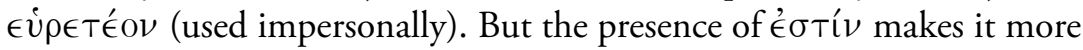
likely that the construction should be understood as personal here.

\subsection{Agent in Accusative}

Sometimes, the Agent of a verbal adjective appears in the Accusative Case instead of the Dative, apparently by analogy with $\delta \in \hat{\imath}$ or $\chi \rho \eta \dot{~ w i t h ~ t h e ~}$ Accusative (and Infinitive).

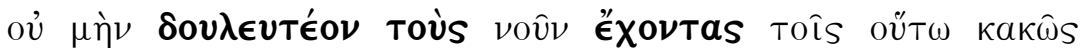

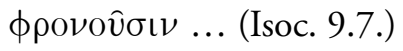

$<$ It is> certainly necessary that those who have sense (should) not be subject to people with so bad an attitude... 


\subsection{Construction Continued with Infinitive}

The construction of verbal adjectives becomes more closely assimilated to the pattern of $\delta \in \hat{\imath}$ or $\chi \rho \eta$, when an initial verbal adjective is followed by a second phrase with an Infinitive, which is dependent on the notion of necessity contained in the verbal adjective. In the following sentence,

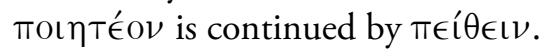

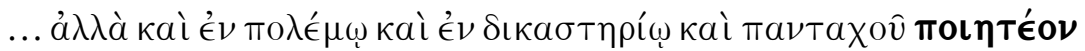

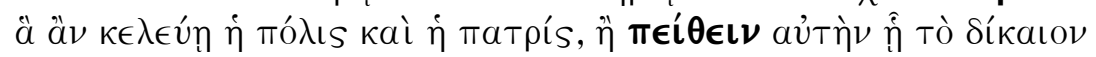
те́фטкє ... (Pl.Cri. $51 \mathrm{~B}-\mathrm{C}$.)

... but both in war and in law-court and everywhere <it is> necessary to do what the city and the fatherland commands, or to persuade it where justice lies...

\subsection{Impersonal Passive Construction}

Contrary to the usual practice, an impersonal construction with Passive

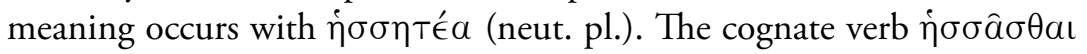
occurs only in the Middle/Passive in the classical period. The Genitive of Comparison, which is used with the verb and the verbal adjective, implies Agency: 'to be inferior (compared with)', 'to be defeated (by)'.

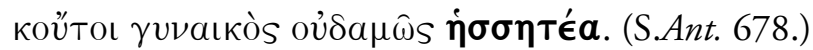
And <it is> certainly necessary by no means to be defeated by a woman.

But the impersonal Passive construction is not limited to verbal adjectives cognate with verbs which are used only in the Passive Voice. In the

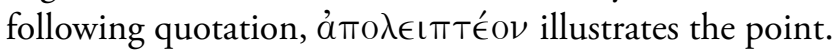

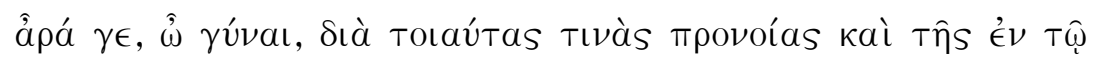

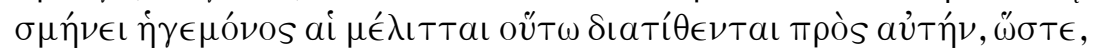

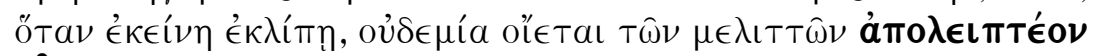

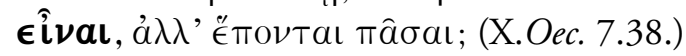

(Is it), O wife, on account of some such caring-actions even of the leader in the hive (that) the bees are so disposed towards her, that, when she quits $<$ the hives, none of the bees thinks that it is necessary to be left bebind, but they all follow? 


\section{References}

Goodwin (1889), Syntax of the moods and tenses of the Greek verb, $\$ \$ 920-926$.

Palmer (1980), The Greek language, pp. 257, 314.

Smyth (1956), Greek grammar, $\$ \$ 358,425 . c, 471$, 1003.a, 1052, 1488, 21492152.

\section{EXERCISE 8}

1. Translate the following passages.

2. For each passage:

a. write down, in the form in which they appear, any verbal adjectives of the type whose Nominative singular ends in -Téos, -Téa, -TÉOV

b. write the Imperfect Infinitive of the verb to which each of these adjectives is related

c. state whether the particular use is personal Passive or impersonal Active

d. if the construction appears to be ambiguous, indicate whether there are grounds for preferring an Active or Passive interpretation

e. mark accents correctly.

3. Montanari (2015), The Brill dictionary of Ancient Greek, or the full edition of Liddell and Scott (1996), A Greek-English lexicon, should be used.

\section{Example}

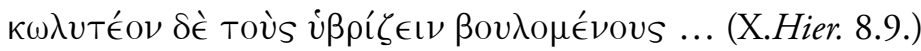

and $<$ it is $>$ necessary to prevent those wanting to act violently ...

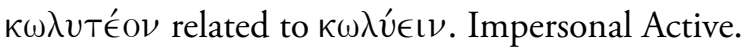




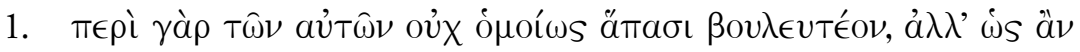

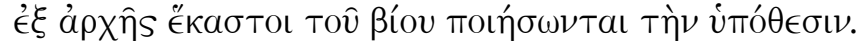

\begin{tabular}{|c|c|}
\hline 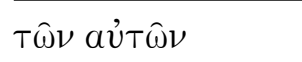 & neut. \\
\hline$\dot{\omega} s \not u$ & $\begin{array}{l}\text { Introduces a clause of indefinite } \\
\text { comparison. }\end{array}$ \\
\hline caбтоı (pl.) & each group \\
\hline$\pi o ́ \theta \in \sigma \iota s,-\epsilon \omega s, \dot{\eta}$ & basis (qualified by Tov̂ ßíov) \\
\hline
\end{tabular}

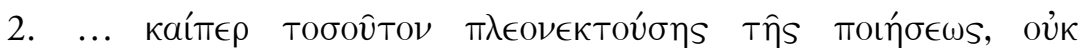

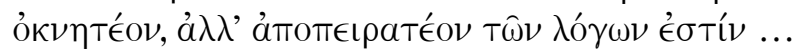

\begin{tabular}{|c|c|}
\hline$\pi \lambda \in O \nu \in \kappa T \in \hat{\imath} \nu$ & to have an advantage \\
\hline 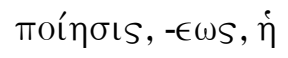 & poetry \\
\hline oi $\lambda o ́ \gamma o t$ & prose (lit. the words) \\
\hline
\end{tabular}

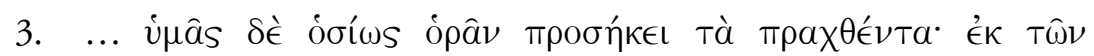

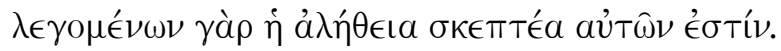

\begin{tabular}{|c|c|}
\hline óoíws & conscientiously \\
\hline$\pi \rho о \sigma \eta ́ \kappa \in \iota \nu$ & $\begin{array}{l}\text { to be appropriate (here with Acc. } \\
\text { and Infin.) }\end{array}$ \\
\hline$\dot{\epsilon}_{\mathrm{K}}$ & on the basis of \\
\hline 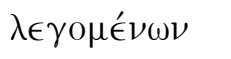 & neut. Pass. \\
\hline aưT $\hat{\nu} \nu$ (neut.) & Refers to Tà $\pi \rho a \chi \theta^{\prime} \in \tau T a$. \\
\hline
\end{tabular}

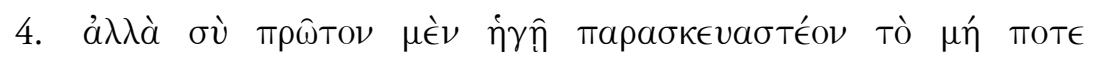

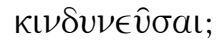

\begin{tabular}{ll}
\hline$\dot{\eta} \gamma \in \hat{i} \sigma \theta a \mathrm{\iota}$ (Mid.) & to think \\
$\kappa \iota \nu \delta v \nu \in \cup \in \in \iota \nu$ & to run a risk, to be in danger \\
\hline
\end{tabular}

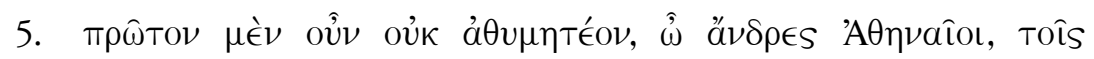

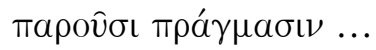




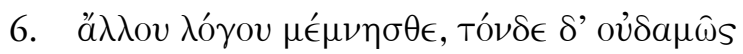

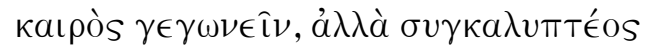

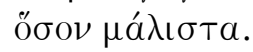

\begin{tabular}{|c|c|}
\hline$\lambda \operatorname{có}_{\mathrm{os}},-\mathrm{ov}, \dot{o}$ & subject, topic \\
\hline$\mu \epsilon \mu \nu \hat{\eta} \sigma \theta a \iota$ (Mid.) & $\begin{array}{l}\text { to make mention of (+ Gen.; Perf. with } \\
\text { Imperf. meaning; here Impv.) }\end{array}$ \\
\hline$\tau o ́ \nu \delta \epsilon$ & Understand $\lambda o ́ \gamma o \nu$. \\
\hline$\gamma \in \gamma \omega \nu \in \hat{\imath} \nu$ & to declare \\
\hline 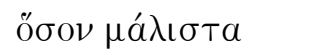 & so far as possible \\
\hline
\end{tabular}

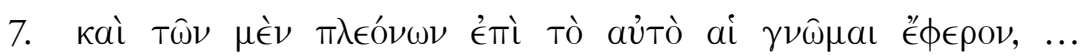

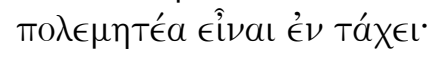

$\phi \in ́ \rho \in \mathrm{L} \nu$ (Intr.) to tend (to), to incline (to)

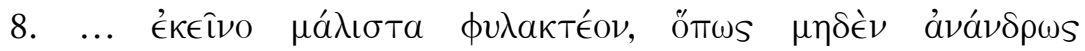

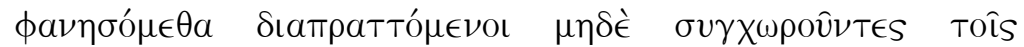

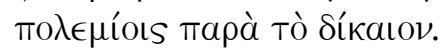

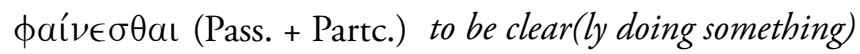

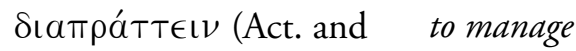

Mid.)

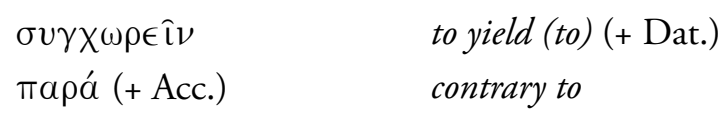




\section{LESSON 9 \\ Voice}

\subsection{English}

Both in classical Greek and in modern English, Voice is a function of the verb including not only finite forms of the verb but also Infinitives (verbal nouns) and Participles (verbal adjectives). In English, there are two Voices: Active and Passive. The Active forms are simple, being expressed by a single form of a verb; Passive forms are compound, being expressed with the help of auxiliary verbs.

He had a good time. (Act.)

A good time was had by all. (Pass.)

Active verbs may be used transitively or intransitively, that is, with or without a direct Object.

He turned the handle of the lounge-room door. (Transitive)

I turned, and saw below

The same shape twisted on the banister ... (Intr.) (T. S. Eliot, Ash Wednesday, III.2-3.)

The (grammatical) Subject performs the action expressed by an Active form of a verb. The Subject experiences (suffers, receives) the action expressed by a Passive form of a verb.

The hoplite hurled his spear with all his strength. (Act.)

The first spear was hurled by a hoplite in the front rank. (Pass.)

\subsection{Greek}

In the classical period of Ancient Greek, there are three Voices of the verb: Active, Middle and Passive. The forms and functions of the Active Voice are relatively straightforward and will not be treated further here. In most 
Tenses of the Indicative, there are not separate forms for the Middle and Passive Voices. The function of such forms needs to be determined in each context. An expressed Agent is a pointer to a Passive function: 'The spear is hurled by a hoplite'.

Separate forms for Middle and Passive Voices do occur in the Future and Past Aorist Tenses of the Indicative Mood, and likewise for the Aorist Subjunctive and Optative, and for the Intentive ('Fut.') Optative.

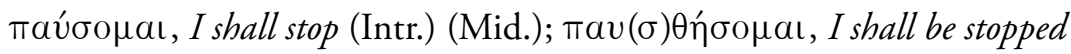
(Pass.).

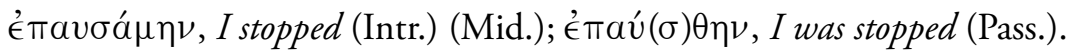

In English, it is not appropriate to apply the category of Voice to verbs such as 'to be', 'to become', 'to seem', which may have a (Subjective) Complement. The same restriction would apply to eival in Greek. But the status of $\gamma(\hat{\prime} \gamma \nu \in \sigma \theta a \mathrm{l}$ and $\delta о \kappa \in \hat{\imath} \nu$ is not simply equivalent to that of

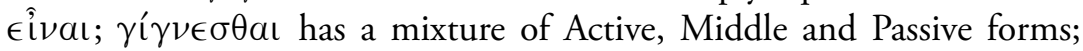

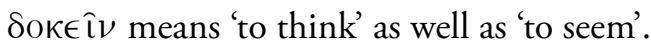

\subsection{Uses of the Middle Voice}

\subsubsection{In General}

The Middle Voice expresses greater interest or involvement of the Subject in the action of the verb than would be expressed by the Active Voice.

\begin{tabular}{ll}
\hline ai $\rho \in \hat{\imath} \nu$ (Act.) & to take \\
ai $\rho \in \hat{\imath} \sigma \theta a \mathrm{\iota}$ (Mid.) & to take for oneself, to choose \\
\hline
\end{tabular}

Often verbs of emotion, thought and perception are used especially or solely in the Middle Voice.

\begin{tabular}{|c|c|}
\hline$\alpha \mathfrak{\imath} \delta \in \hat{\imath} \sigma \theta a \iota$ & to be ashamed \\
\hline$\nu 0 \epsilon \hat{\imath} \sigma \theta a \mathrm{l}$ & to think \\
\hline$\alpha \grave{\imath} \sigma \theta a ́ \nu \in \sigma \theta a \iota$ & to perceive \\
\hline
\end{tabular}


Likewise, verbs denoting bodily activity.

\begin{tabular}{ll}
\hline o" $\chi \in \sigma \theta a \mathrm{l}$ & to go, to have gone \\
$\epsilon \prime \pi \in \sigma \theta a \mathrm{l}$ & to follow
\end{tabular}

Similar to the last two groups are Active verbs which use the Middle Voice in the Future Tense only, without any distinction of meaning.

\begin{tabular}{|c|c|}
\hline ăкои́єı & to hear, to be going to hear (perception) \\
\hline 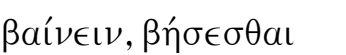 & to walk, to be going to walk (physical activity) \\
\hline
\end{tabular}

\subsubsection{Causative}

In the following example, Croesus caused the action of 'making' to take place but did not himself 'make' the image of the lion.

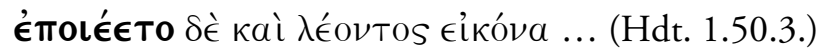

And he had an image of a lion made also ...

But this causative force may also be expressed by the Active Voice. In the following example, the Subject (Artaphrenes) causes something to be done but does not personally execute the Persians.

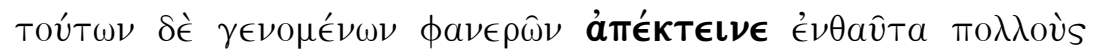

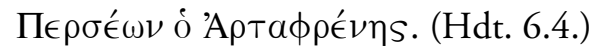

And when <the identity of $>$ these men became known, Artaphrenes promptly had many of the Persians put to death.

\subsubsection{Reflexive}

The Middle Voice in itself may have a reflexive force.

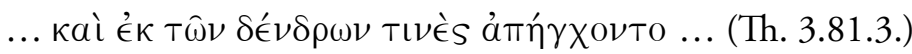

$\ldots$ and some hanged themselves from the trees ...

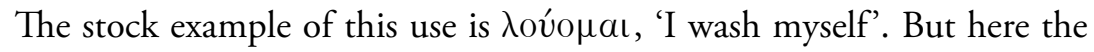
force may rather be 'I wash' (Intr.), in the sense 'I have a wash', 'I am having a wash'. Likewise with many other such Middle forms.

A definitely reflexive construction is more often expressed by an Active verb with a reflexive pronoun as direct Object. 


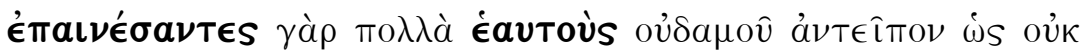

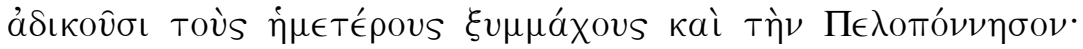
(Th. 1.86.1.)

For although praising themselves at length, they nowhere denied that they were maltreating our allies and the Peloponnese.

However, this Transitive construction may also occur with a verb in the Middle Voice.

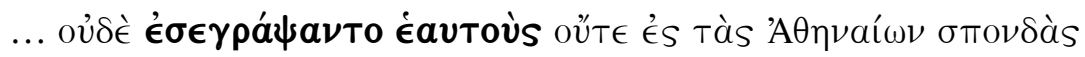
oúte ÉS Tàs $\Lambda a \kappa \in \delta a l \mu o v i ́ \omega \nu$. (Th. 1.31.2.)

... nor <had $>$ they enrolled themselves either in the treaty with the Athenians or in that with the Spartans.

\subsubsection{Reciprocal}

A reciprocal use of the Middle Voice has often been proposed.

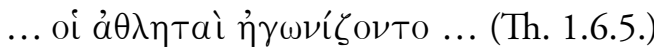

... the contestants used to compete (with one another) ...

In the context of this example, however, Thucydides is discussing continuity and change in social practice, including clothing in general and for sport. He is not making a point about competition, mutuality or reciprocity. Moreover, $\dot{a} \gamma \omega \nu v^{\prime} \zeta \in \sigma \theta a$ เ is used only in the Middle and occasionally the Passive (usually Perf. Pass.) Voices throughout the ancient period (apart from the Act. in an inscription of uncertain date).

$\mu a ́ x \in \sigma \theta a$ ı (only Middle), 'to fight (with one another)' is also cited as an example of reciprocal use of the Middle Voice. But $\pi 0 \lambda \epsilon \mu \epsilon \hat{\imath} \nu$, which has a similar meaning, is not used in the Middle but only in the Active Voice apart from a few Passive instances.

Some verbs are used in both Active and Middle Voices without any significant difference regarding reciprocity.

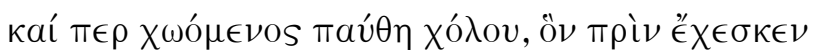

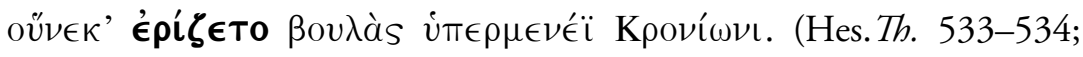
Middle.) 
Although being angry he [= Zeus] ceased from the anger, which he previously had

because he [= Prometheus] contended in his designs with the mighty son of Kronos.

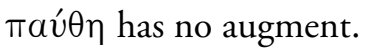

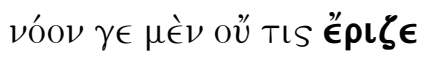

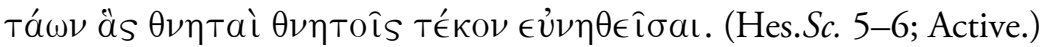

And indeed in intellect there contended with <her> no one of the <girls>, whom mortal women when brought to bed bore to mortal men.

The Middle Voice of some verbs compounded with Sıá and oúv is often assigned a reciprocal force.

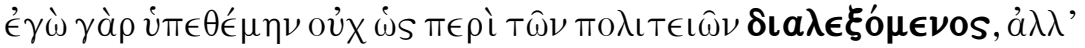

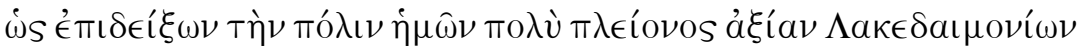

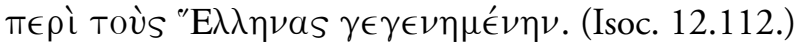

For I proposed <my topic> not in order to bave a discussion about constitutions, but in order to show that our city had been worth much more than <that> of the Spartans with regard to the Greeks.

In this example, however, any suggestion of reciprocity or mutual involvement may be due to the prefix as much as to the Middle Voice of $\delta\llcorner\alpha-\lambda \epsilon \xi o ́ \mu \epsilon \nu$ os.

A genuinely reciprocal expression is more clearly formed by the reciprocal pronoun as Object of an Active verb (or as another component of the predicate).

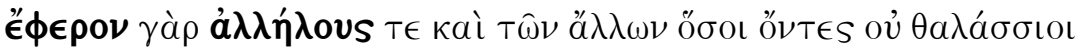

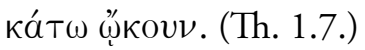

For they used to plunder each other and as many of the rest as, although not being seagoing, lived on the coast.

However, the reciprocal pronoun may also be used with the Middle Voice.

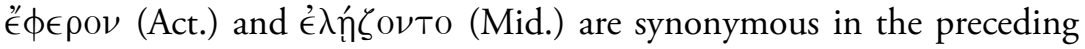
and following sentences.

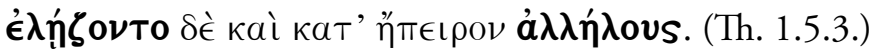
And they used to plunder each other on the mainland also. 
In short, it is not clear that there is a specifically reciprocal use of the Middle Voice. Rather, in some contexts some verbs may be used in the Active Voice with the reciprocal pronoun, or in the Middle Voice with or without the reciprocal pronoun, to express reciprocity. The Middle Voice is used in a general way in such contexts to convey the interest or involvement of the Subject.

\subsection{The Development of the Middle Voice}

It is generally, but not universally, agreed that in Indo-European there were two Voices: Active and Middle. 'The active verb was used to present an activity proceeding from a subject outwards: when the event took place within the subject or was reflected on the subject, then the middle voice was used' (Palmer, 1980, p. 292).

In Homer, second Aorist verb forms ending in $-\eta \nu$ in first person singular are generally Intransitive Active, not Passive. Thus, from daívelv, to show:

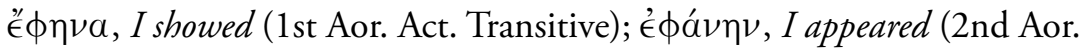
Act. Intr.).

Most (about three-quarters) of first Aorists ending in $-\theta \eta \nu$ in first person singular are also Active Intransitive in Epic:

É$\phi a ́ \nu \theta \eta \nu$, I appeared (Act. Intr. in Epic); I was shown (Pass. in Attic).

This feature is still evident in some forms which are used in Attic tragedy with Middle force.

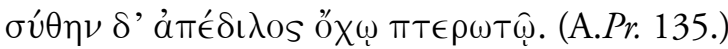

And I rushed off without my shoes on a winged conveyance.

$\sigma u ́ \theta \eta \nu$ has no augment.

Future forms ending with $-\sigma o \mu \alpha \mathrm{l}$ in first person singular may still have both Middle and Passive force in the classical period. Passive Futures ending in $-(\theta) \eta$ бo $\sigma a \mathrm{l}$ in first person singular, which were formed on the basis of first and second Aorist Passives ending in $-(\theta) \eta \nu$, are largely a development of the fifth century BCE. (It cannot safely be maintained

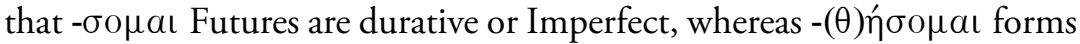
are Aoristic.) 
In the Hellenistic period, the Active Voice tends to supplant the Middle. In particular, Active verbs with Middle Futures now begin to use Active

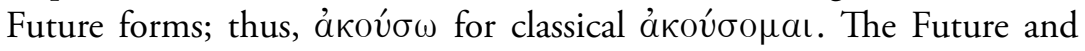
Past Aorist Tenses of the Middle Voice, which in the classical period were distinguished from the Passive, tend to disappear. Middle verbs with Active meaning now prefer Passive forms; thus, for 'he replied', $\alpha \pi \epsilon \kappa \rho i ́ \theta \eta$

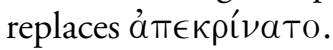

\section{References}

Gildersleeve (1900), Syntax of classical Greek from Homer to Demosthenes (Vol. 1), pp. 61-79.

Moorhouse (1982), The syntax of Sophocles (Mnemosyne Supplement 75), pp. 176-180.

Palmer (1980), The Greek language, pp. 292-293, 298-299, 302-303, 311-312.

Rijksbaron (1994), The syntax and semantics of the verb in classical Greek, pp. 131160.

Smyth (1956), Greek grammar, $\$ \$ 800-821,1703-1758$.

\section{EXERCISE 9}

Identify all Middle or Passive verb forms (including Infinitives and Participles) in the passage of Euripides Alcestis 29-31, 42-64. (Do not include any parts of $\epsilon \hat{i} \nu a \mathrm{l}$.)

1. Write the line number in the left margin.

2. Write the form which appears in the Greek text.

3. Parse the form.

For finite verb forms, state the person, Number, Tense (of Indicative forms) or Aspect (of non-Indicative forms), Mood and Voice (indicating whether Middle or Passive).

For Infinitives, state the Aspect and Voice.

For Participles, state the Aspect, Voice, Case, Gender and Number.

Give the Imperfect Active Infinitive form of the verb (if the Active form does not occur in classical Greek, give the Middle or Passive form). 
Give the English meaning of the quoted Imperfect Infinitive which is relevant to the context (not the whole range of possible meanings).

4. Montanari (2015), The Brill dictionary of Ancient Greek or the full edition of Liddell and Scott (1996), A Greek-English lexicon, should be used.

\section{Example}

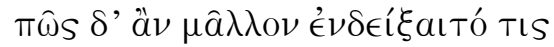

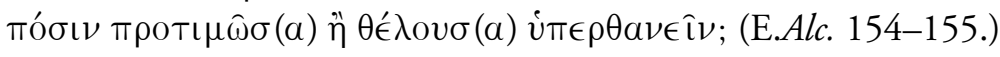

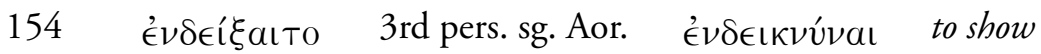
Opt. Mid.

\section{Euripides Alcestis 29-31, 42-64}

$\Theta=\Theta A N A T O \Sigma$

$\mathrm{A}=\mathrm{A} \Pi \mathrm{O} \Lambda \Lambda \Omega \mathrm{N}$

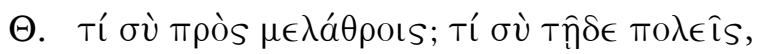

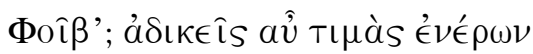

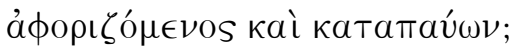

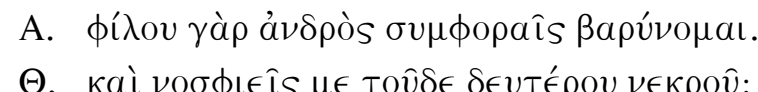

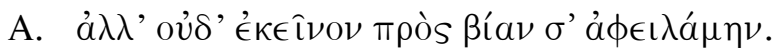

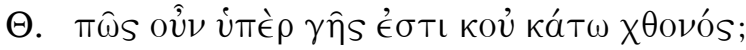

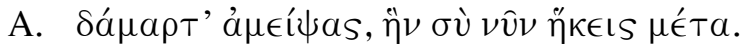

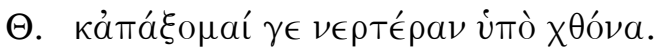

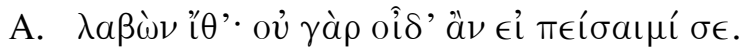

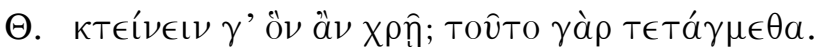

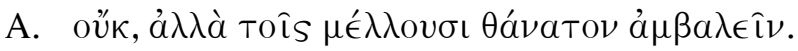

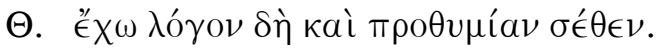

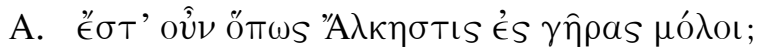

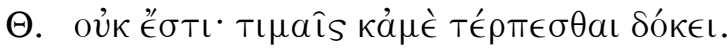

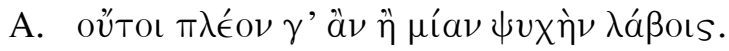

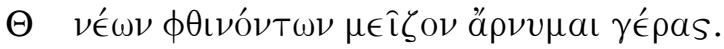

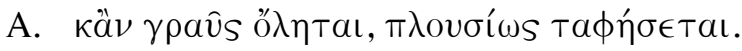




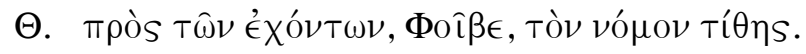

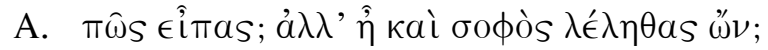

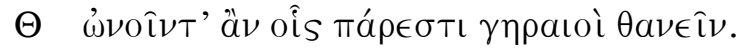

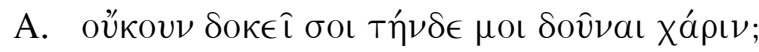

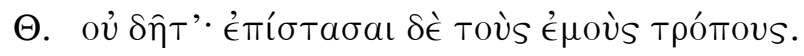

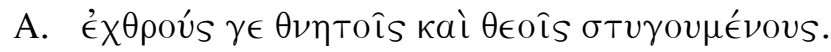

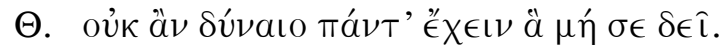

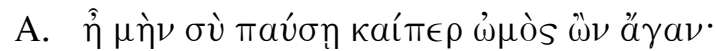





\section{LESSON 10 \\ Commands}

\subsection{Introduction}

Positive commands are normally expressed by the Imperative Mood. Negative commands are normally expressed by $\mu$ n with the Imperfect Imperative, or by $\mu$ ' with the Aorist Subjunctive. The Imperfect Aspect expresses continuous or repeated action. The Aorist Aspect expresses momentary action. The Perfect Aspect is used especially with verbs, whose Perfect Aspect has an Imperfect meaning, for example, "̈́ $\sigma \eta \kappa \alpha$, 'I have taken my stand', hence 'I am standing'; $\mu$ '́ $\mu \nu \eta \mu a$, 'I have recalled', hence 'I remember'. (Cf. Lesson 2.1 and Lesson 2.3.1.)

\subsection{Negative Commands}

The Aorist Imperative is not normally used in negative commands; it occurs occasionally in the third person, and rarely (and only in poetry) in the second person. The Imperfect Subjunctive is not normally used in negative commands; it occurs not at all in the second person, and only rarely in the third person.

This apparently arbitrary distinction of Moods (Imperative for Imperfect action, Subjunctive for Aorist action) had already developed in the classical period and has continued through Hellenistic usage up to modern Greek.

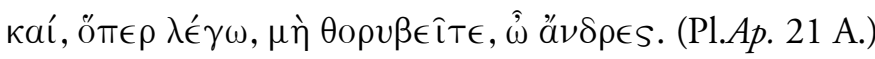

And, as I say, do not be making a disturbance, $O$ men.

Imperfect Imperative.

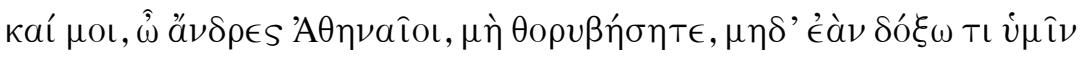

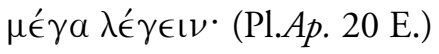

And please, $O$ men of Athens, do not make a disturbance, not even if I seem to you to be telling something exaggerated. 
Aorist Subjunctive.

It is sometimes suggested that $\mu$ í with the Imperfect Imperative implies a command to stop doing something, while $\mu$ in with the Aorist Subjunctive implies a command not to start doing something. This view sometimes suits the circumstances of a particular passage, but the basic principle seems to be the usual distinction of Aspects, as stated above. Moreover, there does not always seem to be any significant difference in function between Imperfect Imperative and Aorist Subjunctive in negative commands. An author's choice may depend partly on established idiom and partly on the meaning of a particular word, as well as on the distinction of Aspect.

\subsection{Virtual Commands}

Various idioms using Future Indicative, Aorist Subjunctive, and Imperfect or Aorist Optative may have the function of commands.

\subsubsection{Future Indicative (Positive)}

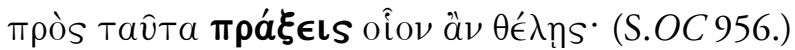

In view of this [you will] do what you like.

\subsubsection{Future Indicative (Negative: o $\mathbf{u}$ )}

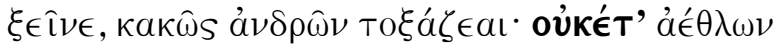

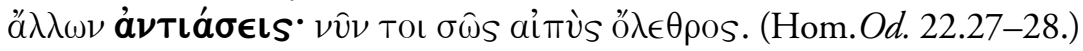

Stranger, wrongly you shoot at men; never again [will you] take part in other contests; now indeed your sheer destruction <is> assured.

\subsubsection{Future Indicative (Negative Interrogative: ov̉ ...;)}

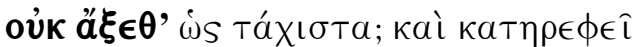

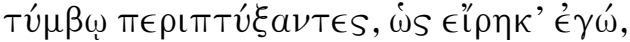

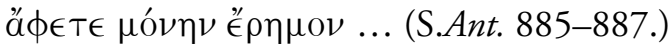

[Will you not] take <her> as quickly as possible[?] And surrounding $<$ her $>$ with a vaulted tomb, as I have said, leave her alone, deserted ...

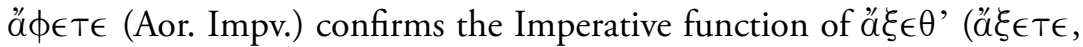
Fut. Indic.). 


\subsubsection{Future Indicative (Double Negative Interrogative:

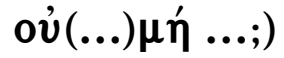

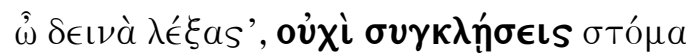

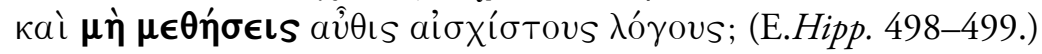

$O<$ you>, having said terrible things, will you not shut up your mouth and not emit most shameful words again?

Future Indicative occurs in both coordinate clauses, which are joined by kaí. The first negative (oủk) negates the whole sentence. The second negative $\left(\mu \eta^{\prime}\right)$ is functionally subordinate to the first negative and negates the second clause: 'Will you not shut up ... and will you not not emit ...?' (i.e. 'Shut up $\ldots$ and do not emit ...').

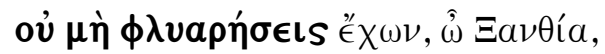

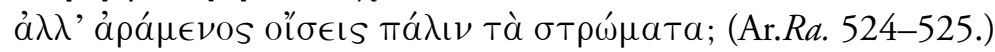

Do not keep on being silly, O Xanthias, but pick up and carry the trappings back.

Lit. 'Will you not not keep on being silly ..., but will you not carry ...?' Again, ov negates the whole sentence, $\mu$ ' further negates the first coordinate clause and the second clause is introduced by à $\lambda \lambda a ́$ (not kaí).

\subsection{5. ở $\mu$ ń with Aorist Subjunctive}

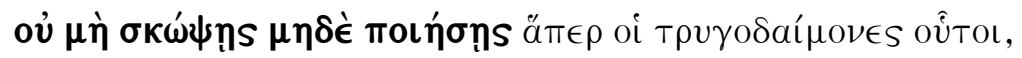
à $\lambda \lambda^{\prime} \in \dot{v} \phi \hat{n} \mu \in l^{\cdot}$ (Ar.Nu. 296-297.)

Do not joke nor do what these comic poets do, but keep silent.

In this sentence, after an initial negative command with ov $\mu$ í and the Aorist Subjunctive, a second negative command is added by $\mu \eta \delta \epsilon \in$ (also with Aor. Subj.), and a contrasting positive command follows with à $\lambda \lambda \alpha$ and Imperfect Imperative.

The origin and explanation of the constructions in $\$ \$ 10.3 .4$ and 10.3.5 are disputed. The issue is complicated by variant readings in manuscripts and emendations by editors, for example, $-\eta n$ and $-\epsilon I S$. 


\subsubsection{Optative with ă}

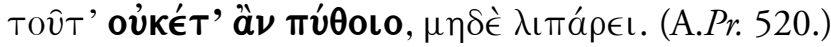

[You would] no longer make this enquiry, and do not persist.

The Imperative form $\lambda \iota \pi \alpha ́ \rho \in t$ in the second clause confirms the Imperative function of the Optative with $\stackrel{\alpha}{\nu} v$ in the first clause. Negative ov is used with this potential Optative.

Such sentences having Optative with ă $\nu$ are usually punctuated as statements, although they would often make sense as questions.

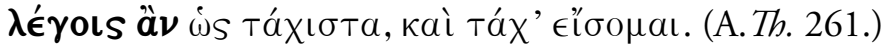
[Would you] speak as soon as possible[?] And I shall soon know.

\subsection{Reported Commands}

\subsubsection{Reported Commands with Infinitive}

Commands, requests and exhortations are most often reported in an Infinitive phrase as direct Object of a verb of commanding. Most verbs of commanding have a second direct Object in the Accusative, denoting the person who is commanded to do something. Instead of this second direct Object, particular verbs may have a Genitive of Separation or a Dative indirect Object.

The Aspect of the Infinitive in a reported command reflects the Aspect of the Imperative in the presumed direct command. And the Number of the noun or pronoun in the Accusative Object (or Genitive or Dative) of the reported command reflects the Number of the Imperative of the presumed direct command. The negative with the Infinitive is $\mu$ '

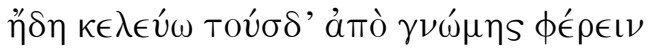

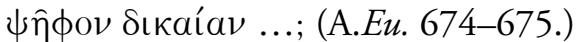

Do I now command these <jurors $>$ to cast a just vote on the basis of their judgment ...?

Acc. (pl.) and (Imperf.) Infin.

Direct form: $\phi \epsilon \in € \in T \epsilon$. 


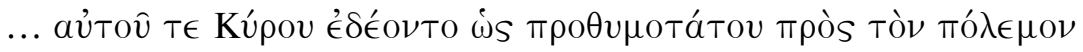

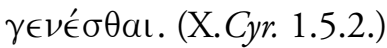

... and they begged Cyrus himself to become as enthusiastic as possible for the war.

Genitive (sg.) and (Aor.) Infinitive.

Direct form: $\gamma \in \nu 0 \hat{v}$.

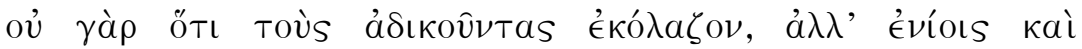

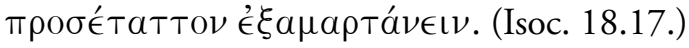

For they were not only not punishing those acting unjustly, but they were actually instructing some to do wrong.

Dative (pl.) and (Imperf.) Infinitive.

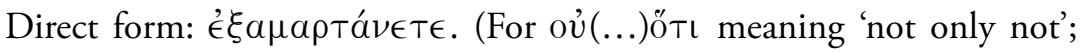
see Smyth, 1956, \$2763.b.)

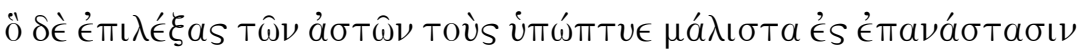

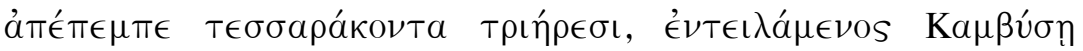

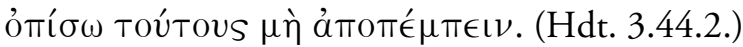

And he, having picked out from the citizens those whom he most suspected with respect to an uprising, sent them away on forty triremes, instructing Cambyses not to send these <men > back again.

Dative (sg.) and (Imperf.) Infinitive with negative $\mu \eta_{\text {. }}$

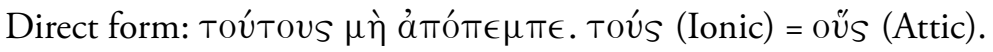

\subsubsection{Reported Commands with ö $\pi \omega S$}

In addition to the more common Infinitive construction, some verbs of commanding may sometimes have as their Object a clause introduced by

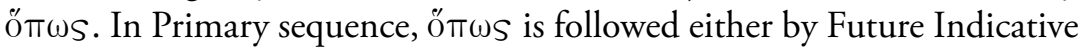
or by the Subjunctive (sometimes with ö $\nu$ ). In Past sequence, ötw is followed by the Optative. Vivid constructions, using Subjunctive or Future Indicative in Past sequence, also occur. The negative is $\mu \eta \dot{n}$. 
As the Object of a verb of commanding, these ötws clauses are noun clauses. Contrary to Smyth $(1956, \$ 2218)$, the ötws clause is best understood as merely stating the content of the command, not 'the purpose in giving it' as well. Purpose clauses with ö $\pi \omega s$ are adverbial clauses, not noun clauses.

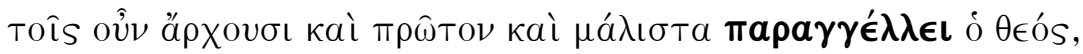

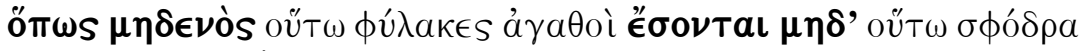

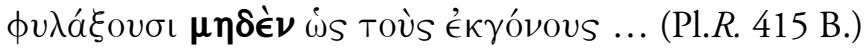

Therefore the god both first and foremost commands the rulers to be good guardians of nothing so much as the children, and to guard carefully nothing so much <as them $>$...

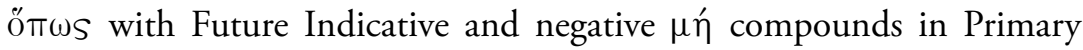
sequence.

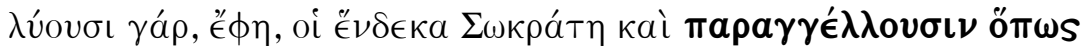

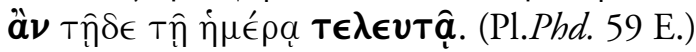

'For the Eleven', he said, 'are unchaining Socrates and are giving orders that be is to die on this day'.

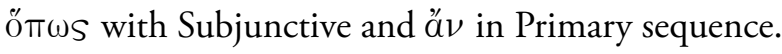

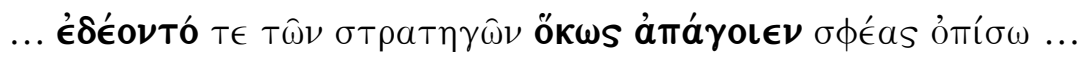
(Hdt. 9.117.)

... and they begged their generals to lead [OR: that they should lead] them away <and take them > back again ...

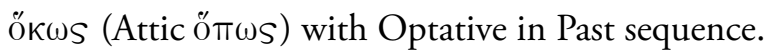

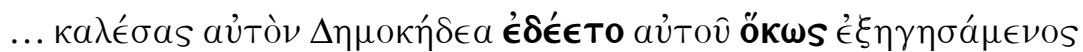

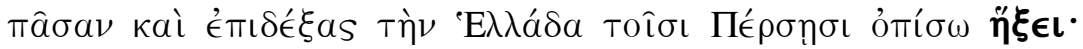
(Hdt. 3.135.2.)

... summoning Democedes himself, he required of him that, when he had shown the way and had displayed all Greece to the Persians, he should come back.

Vivid construction with Future Indicative in Past sequence.

Hom.Od. 3.327 seems to be the only instance of i $\nu a+$ Subjunctive expressing a reported request or command prior to the later classical or Hellenistic periods. 


\section{References}

Goodwin (1889), Syntax of the moods and tenses of the Greek verb, $\$ \$ 237,250-251$, 259-260, 294, 297-298, 355-357, 746-747, Appendix II (pp. 389-397).

Smyth (1956), Greek grammar, $\$ \$ 1800,1830,1835-1836,1840-1841,1918-$ 1919, 1991-1992, 1996-1998, 2155, 2210, 2218, 2754, 2756-2757.

Goodwin (1889, Appendix II) has not convinced all his contemporaries nor all subsequent scholars.

\section{EXERCISE 10}

Translate the following passages. The Imperative function of virtual commands should be made clear in translation.

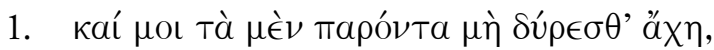

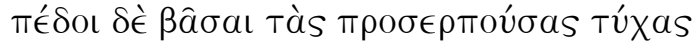
áкоú $\sigma a \theta^{\prime} . .$.
(o) $\delta u ́ p \in \sigma \theta a \iota$
to lament (for) (+ Acc.)
ăxos, -ous, Tó
pain

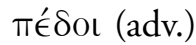
(on) to the ground
$\pi \rho 0 \sigma \epsilon ́ \rho \pi \epsilon \mathrm{L} \nu$
to approach
åkoú $\sigma \alpha \theta$ '

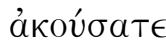

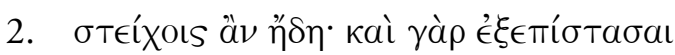

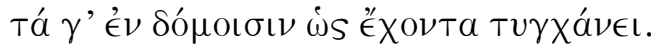

\begin{tabular}{|c|c|}
\hline is & 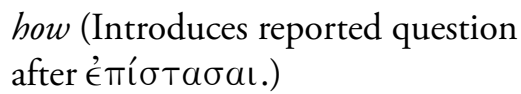 \\
\hline
\end{tabular}

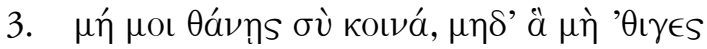

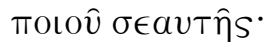

\begin{tabular}{|c|c|}
\hline кoıvá (adverbial Acc. neut.) & $\begin{array}{l}\text { in common (with), jointly (with) } \\
\text { (+ Dat.) }\end{array}$ \\
\hline$\mu \eta \delta \epsilon^{\prime}$ & and (...) not \\
\hline$\theta \iota \gamma \gamma \alpha ́ \nu \in \iota \nu$ & to touch, to handle \\
\hline тоıє & $\begin{array}{l}\text { to make, to claim as; to regard as } \\
\text { (here + Possessive Gen.) }\end{array}$ \\
\hline
\end{tabular}




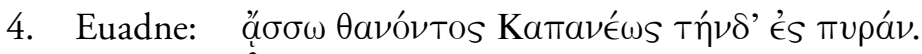

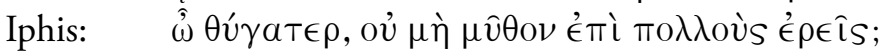

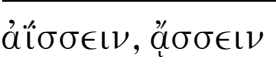

Kamaveús, -'́ws, ò

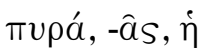

$\mu \hat{v} \theta$ os, - ov, ò

є̇mí (+ Acc.) to move quickly, to hurry

here Possessive Gen.

pyre

statement, announcement

before, in the presence of (Some editors emend to $\hat{\epsilon} s$.)

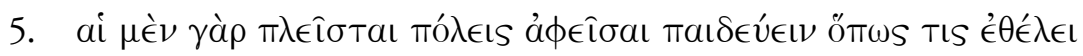

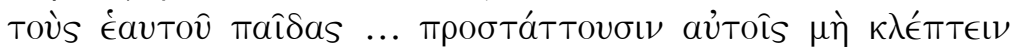
$\mu \eta \delta \hat{~} \dot{\rho} \rho \pi a ́ \zeta \epsilon \in \nu . .$.

\begin{tabular}{|c|c|}
\hline 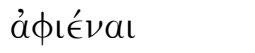 & to allow \\
\hline 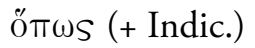 & as \\
\hline
\end{tabular}

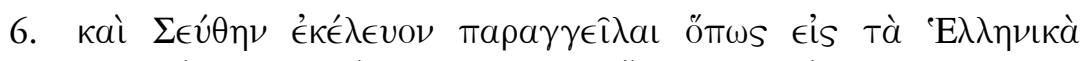

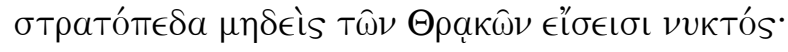

\begin{tabular}{|c|c|}
\hline kaí & And (Links whole sentence to preceding.) \\
\hline$\Sigma \in \dot{\theta} \theta \eta s,-o v, \dot{O}$ & Seuthes \\
\hline ÉKÉ $\lambda \in \cup O \nu$ & 3rd pers. pl. \\
\hline 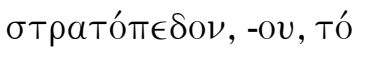 & $\operatorname{camp}$ \\
\hline Eioléval & $\begin{array}{l}\text { to go into, to enter (Pres. Indic. } \\
\text { equivalent to Fut.) }\end{array}$ \\
\hline
\end{tabular}

7. Therefore, from a distance catching sight of us having set off for home, Polemarchus the son of Cephalus told his slave to run and tell [us] to wait for him. And the slave, catching me from behind by the cloak, said, 'Polemarchus tells you [pl.] to wait'.

\begin{tabular}{|c|c|}
\hline from a distance & тó $\rho \rho \omega \theta \in \nu$ \\
\hline to catch sight of & 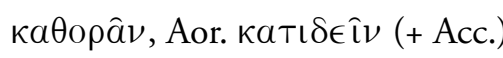 \\
\hline to set off & $\dot{o} \rho \mu \hat{a} \sigma \theta a \iota$ \\
\hline Polemarchus & 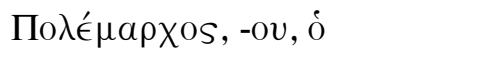 \\
\hline Cephalus & 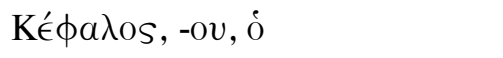 \\
\hline to run & $\tau \rho \epsilon ́ \chi \in \iota \nu$, Aor. $\delta \rho a \mu \epsilon \hat{\imath} \nu$ \\
\hline
\end{tabular}




\begin{tabular}{|c|c|}
\hline to wait (for) & 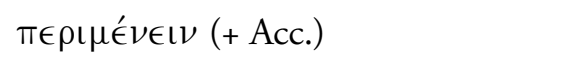 \\
\hline $\begin{array}{l}\text { to catch (someone) } \\
\text { by (something) }\end{array}$ & $\lambda a \mu \beta a ́ \nu \in \sigma \theta a \iota$ (Mid.) (+ double Gen.) \\
\hline from behind & 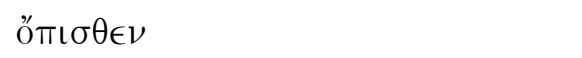 \\
\hline cloak & 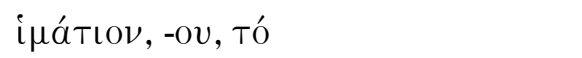 \\
\hline 'Polemarchus tells...' & Use direct speech in Greek. \\
\hline
\end{tabular}





\section{LESSON 11 \\ Wishes}

\subsection{Wishes for the Future}

Wishes for the future are regularly expressed by a verb in the Optative Mood. The usual Aspects are either Imperfect for continuous action or Aorist for momentary action. The Perfect Aspect is normally limited to verbs which are used in the Perfect with an Imperfect meaning. The Intentive ('Fut.') Optative is not used for wishes. Introductory particles often occur with this construction. The negative is $\mu \eta$.

\subsubsection{Optative Alone}

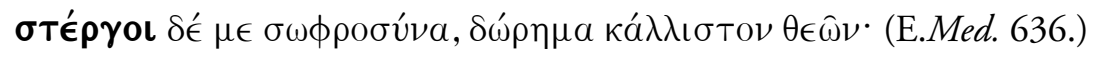
And may moderation, finest gift of the gods, favour me.

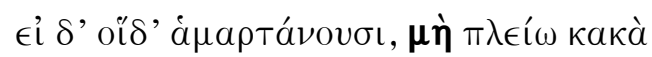

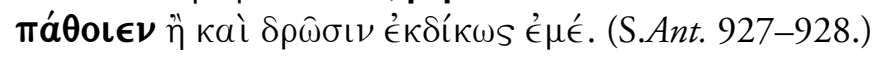

But if these men are making a mistake, may they suffer no more harm than they are unjustly causing me.

Negative $\mu \eta \dot{n}$.

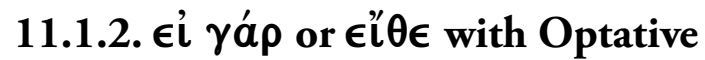

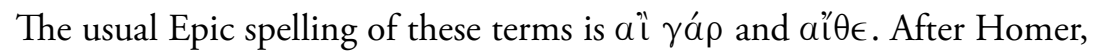
$\epsilon \mathfrak{l} \gamma a ́ \rho$ is found mainly in tragedy and especially in responses.

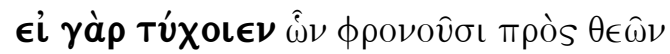

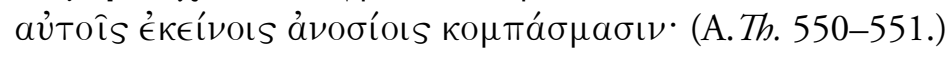

May they obtain from the gods what they intend, by reason of those very boasts $\langle$ so $>$ impious.

$\hat{\omega} \nu=\tau o u ́ \tau \omega \nu \ddot{\alpha}$. 


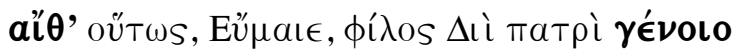

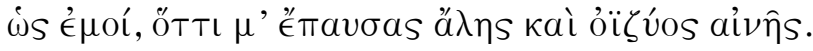
(Hom.Od. 15.341-342.)

May you, Eumaeus, become so dear to father Zeus as to me, because you stopped me from my wandering and my dreadful misery!

\subsection{3. $\epsilon$ ' or $\dot{\omega} S$ with Optative}

The use of $\epsilon \hat{l}$ or $\dot{\omega} s$ with Optative is more restricted. $\epsilon \hat{l}$ alone occurs mainly in poetry, including Homer. An exclamatory use of $\dot{\omega} s$ also occurs in poetry, especially Homer.

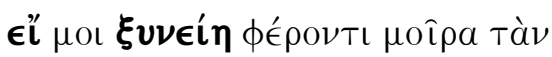

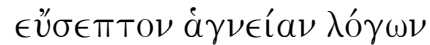

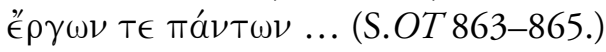

May destiny be with me as I attain

reverent purity in all

words and actions...

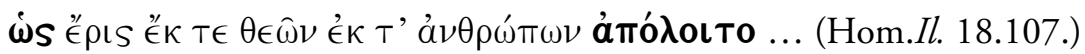
May strife perish from among gods and men ...

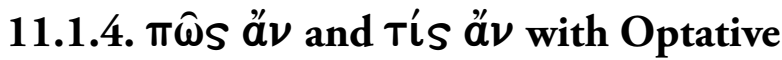

Sentences, which are in form questions introduced by $\pi \hat{\omega} s$ äv or Tís äv with the Optative, may function as wishes. The question 'How would I ...?' is equivalent to the wish 'May I ...'. And the question 'Who would ...?' is equivalent to the wish 'May someone .... The negative in these virtual wishes is $\mu$ ', not o $\mathcal{u}$ as in genuine potential Optative constructions.

$\hat{\omega} \mathrm{Z} \in \hat{v}, \pi \rho \circ \gamma o ́ \nu \omega \nu \pi \rho 0 \pi \alpha ́ \tau \omega \rho$,

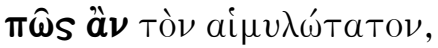

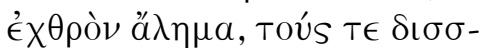

ápxas ỏ $\lambda \epsilon ́ \sigma \sigma a s \beta a \sigma i \lambda \hat{s}$,

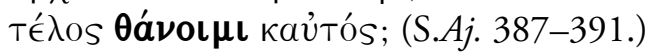

$O$ Zeus, forefather of my forbears,

may I, after destroying that most wily man,

a hateful trickster, and the jointly

ruling kings, <may I>

finally die myself. 


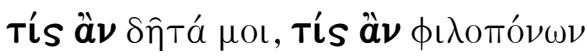

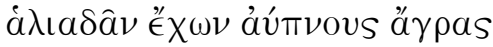

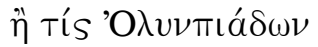

$\theta \in \hat{a} \nu, \grave{\eta} \dot{\rho} v T \hat{\omega} \nu$

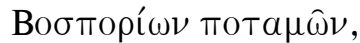

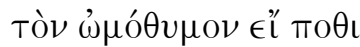

$\pi \lambda a \zeta o ́ \mu \epsilon \nu \nu \nu \lambda \epsilon \hat{v} \sigma \sigma \omega \nu$

ámúoı; (S.Aj. 879-887.)

May some one, then, some one of the hard-working

fishermen maintaining sleepless searches

or one of the Olympian

goddesses, or of the rivers

flowing into the Bosporus,

if seeing the savage-hearted man

wandering somewhere,

tell me.

\subsection{Unfulfilled Wishes for the Present and the Past}

The negative in all the following constructions is $\mu \eta$.

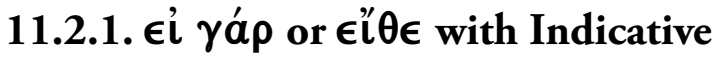

This Indicative construction does not yet occur in Homer.

\subsubsection{Wishes for the Present}

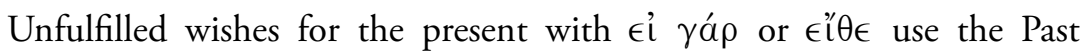
Imperfect Indicative.

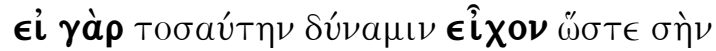

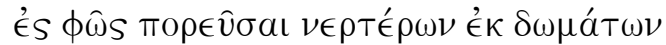

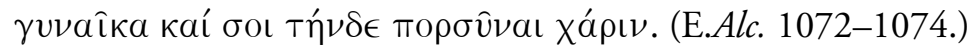

If only I had (now) enough strength to convey your wife to the light from the dwellings below and to provide this favour for you. 


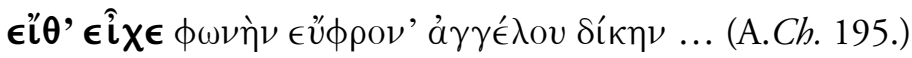

If only it had (now) a kindly voice in the manner of a messenger ...

(Electra speaks about the lock of hair found at Agamemnon's tomb.)

\subsubsection{Wishes for the Past}

Unfulfilled wishes for the past with $\epsilon \dot{l}$ yá $\rho$ or $\epsilon^{\prime} \theta \in$ use the Past Aorist Indicative.

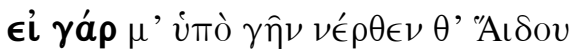

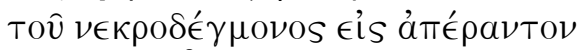

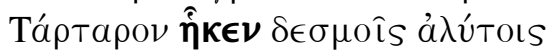

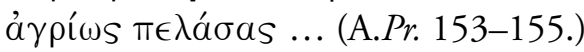

If only, having savagely put me in inescapable bonds,

be had sent me under the earth

and beneath Hades, who receives the dead,

to boundless Tartarus...

ì̀ $\Lambda$ aî́EL

$\epsilon^{\prime \prime} \theta \epsilon \sigma^{\prime} \epsilon^{\prime \prime} \theta \epsilon \sigma \epsilon$

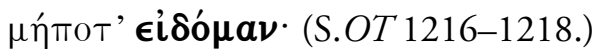

Ab! O child of Laius,

if only, if only

I had never seen you.

\subsection{2.}

Unfulfilled wishes for the present or the past may also be expressed by

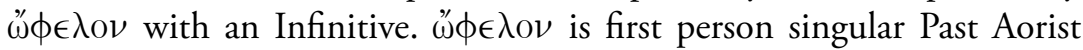
Indicative of ó $\phi \in \epsilon^{\prime} \lambda \in \mathrm{L} \nu$ 'to owe'. The idiomatic English equivalent of ઢ $\phi \in \lambda o \nu$ is 'I ought'. 'Ought' is itself a past form of 'owe' in English, and functions as an Imperfect Subjunctive ('would owe'). In Homer, besides the Past Aorist Indicative $\dddot{\omega} \phi \in \lambda o \nu$, the Past Imperfect Indicative ऍ $\phi \in \lambda \lambda \mathrm{o \nu}$ occurs; both forms may appear without augment, ő $\phi \in \lambda \mathrm{o \nu}$, ö $\phi \in \lambda \lambda \mathrm{o \nu}$. Other forms besides first person singular occur.

\subsubsection{Wishes for the Present}

Unfulfilled wishes for the present with $\dddot{\phi} \phi \in \lambda \mathrm{\nu}$ use the Imperfect Infinitive. 


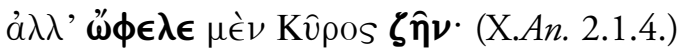

Oh, if only Cyrus were alive.

Lit. 'Oh, Cyrus ought to be alive'.

\subsubsection{Wishes for the Past}

Unfulfilled wishes for the past with $\dddot{\phi} \in \in \mathrm{O} \nu$ generally use the Aorist Infinitive, rarely the Perfect Infinitive. If the reference is to past continuous or repeated action, the Imperfect Infinitive may be used.

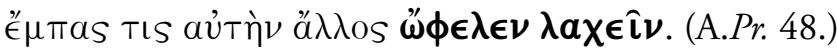

Nevertheless, if only someone else had obtained it.

$\lambda a \chi \in \hat{\imath} \nu$ (Aor. Infin.) is the usual construction. aưTív refers to

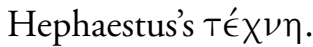

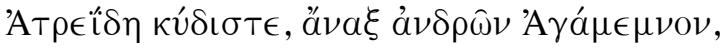

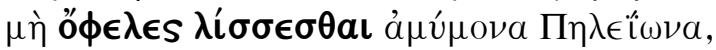

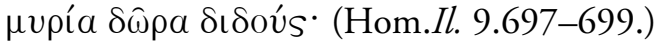

Most honoured son of Atreus, lord of men Agamemnon, if only you had not entreated the blameless son of Peleus, offering ten thousand gifts.

Lit. '...you ought not to have entreated...'; $\lambda$ í $\sigma \sigma \epsilon \sigma \theta a \iota$ (Imperf. Infin.) alludes to repeated or continuous action in the past.

\subsubsection{Introductory Particles with $̋ \phi \in \lambda(\lambda) 0 \nu$}

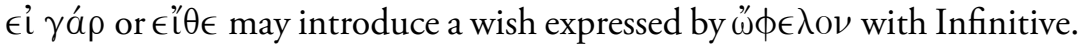
is is also often used in Homer and rarely in Attic poetry.

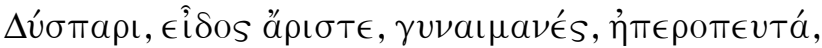

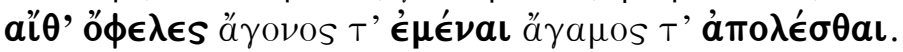
(Hom.Il. 3.39-40.)

Bad Paris, excellent in appearance, mad for women, deceiver, if only you were unborn and had perished unmarried.

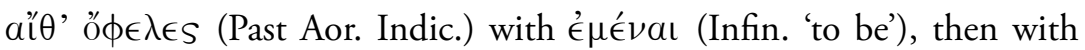
ámo $\lambda \epsilon ́ \sigma \theta$ aı (Aor. Infin.), expresses an unfulfilled wish for the present, then for the past. 


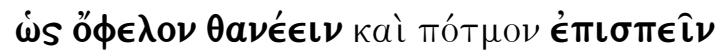

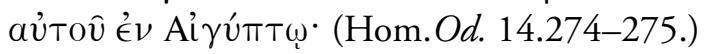

\section{If only I had died and had met my fate}

there in Egypt!

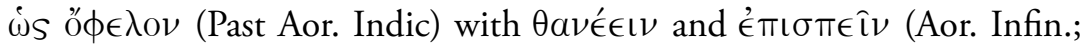
Imperf. 'ं申́́ $\pi \epsilon \iota \nu)$.

Lit. 'How I ought to have died...!'

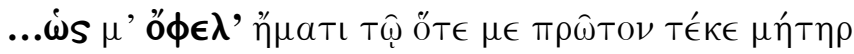

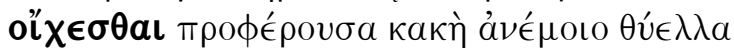

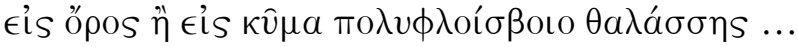

(Hom.Il. 6.345-347.)

...if only on that day, when first my mother bore me, a bad squall of wind had carried me off and gone

into a mountain or into the swell of the loud-roaring sea...

is ... ő $\phi \in \lambda(\epsilon)$ (Past Aor. Indic.) with ol’ $\chi \in \sigma \theta$ aı (Imperf. Infin. with Perf. sense).

Lit. 'how a bad squall ... ought to have gone ...'

\subsubsection{An Additional Homeric Construction}

In Homer, although the constructions in $\$ 11.2 .1$ are not yet used, unfulfilled wishes for the Present are sometimes expressed by the Imperfect Optative. These wishes are usually introduced by $\epsilon \dot{l}$ yá $\rho$ or $\epsilon^{\prime} \theta \epsilon$.

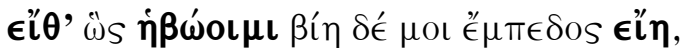

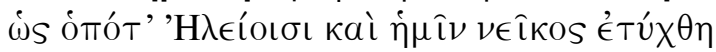

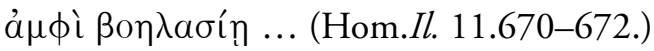

If only I were thus young and my strength were firm, as when a quarrel arose between the Eleans and us over cattle-rustling ... 


\subsection{Reported Wishes}

Wishes may be reported in an Infinitive phrase after verbs such as $\beta o v ́ \lambda \epsilon \sigma \theta a \mathrm{l},(\dot{\epsilon}) \theta \epsilon \in \lambda \in \mathrm{I} \nu$ and $\zeta \eta \tau \epsilon \hat{\imath} \nu$. When the Subject of the Infinitive is the same as the Subject of the verb of wishing, it is usually not expressed in Greek. If it is expressed, it is Nominative as in $\$ 11.4$, second example (where $\kappa \dot{a} \gamma\left(\dot{\omega}=\kappa a \grave{\imath} \hat{\epsilon}^{\prime}(\dot{\omega})\right.$. When the Subject of the Infinitive is different to the Subject of the verb of wishing, it is expressed in the Accusative.

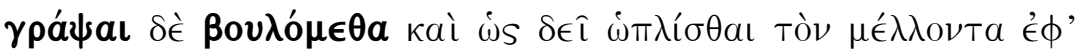

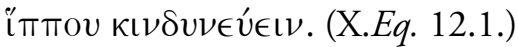

And we want to describe also how the man, who is going to face danger on horseback, needs to have been armed.

$\beta o u ́ \lambda \epsilon \sigma \theta a \mathrm{l}+$ Infinitive only.

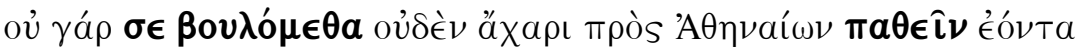

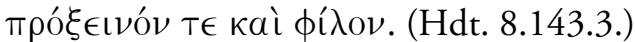

For we do not want you to suffer anything unpleasant from the Athenians, since you are our patron and friend.

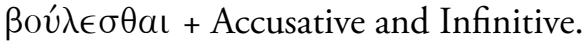

\subsection{Reported Wishes Instead of Direct Wishes}

An unfulfilled wish for the present or the past is occasionally expressed by the Past Imperfect Indicative '́ß $\beta$ ou ó $\mu \eta \nu$ with Imperfect Infinitive (referring to the present) or Aorist Infinitive (referring to the past). This idiom expresses the wish less directly and therefore more gently.

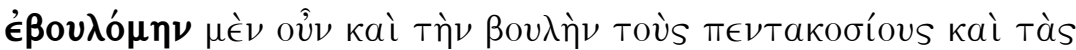

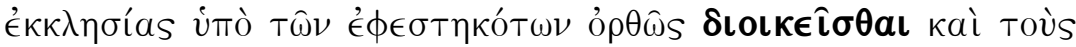

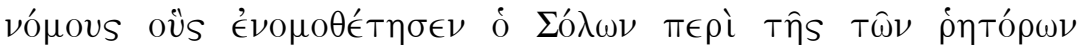

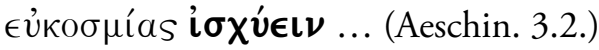

Well then, I wish that both the council of the five hundred and the assemblies were (now) being properly organised by those in charge, and that the laws which Solon framed concerning the proper behaviour of public speakers were (now) in force...

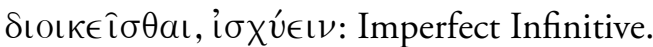




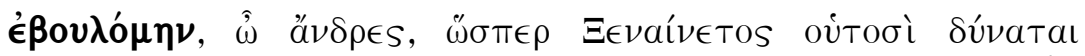

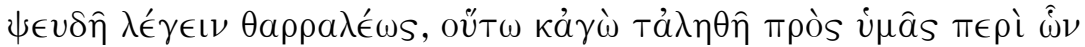
$\dot{\alpha} \mu \phi ı \sigma \beta \eta т о \hat{\mu} \mu \epsilon \nu \in \mathrm{i} \pi \epsilon \hat{\imath} \nu \delta \boldsymbol{v} \nu \eta \theta \hat{\eta} \nu a l \cdot($ Is. 10.1.)

I wish, $O$ men, that, just as Xenaenetus here can confidently tell lies, so I too could have told you the truth about the points on which we disagree.

$\delta v \nu \eta \theta \hat{\eta} \nu a \iota:$ Aorist Infinitive.

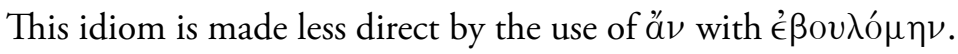

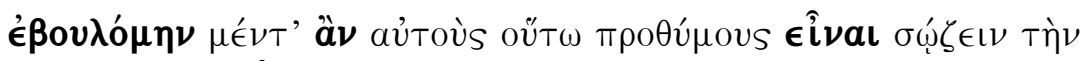

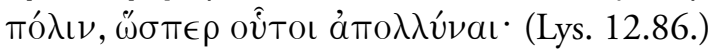

But I wish that they were (now) so eager to save the city, as these men $<$ are eager $>$ to destroy it.

Lit. 'But I would (now) be wishing ...'

\subsection{Interrogative Wishes Combined with Deliberative Subjunctive}

Classical Greek uses a particular idiom corresponding to the English question: 'Do you want me to do this?' The verb of wishing is regularly second person (sg. or pl.) and the verb of doing is regularly first person (sg. or pl.). In prose, $\beta$ oú $\lambda \epsilon \sigma \theta a$ is used as the verb of wishing; in verse,

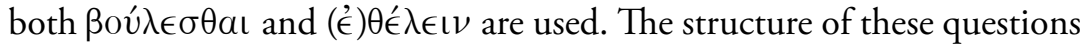
is coordinate (paratactic) — 'Do you wish it? Am I to do it?'

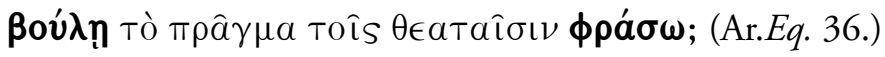

Do you want me to tell the matter to the spectators?

Lit. 'Do you want? Am I to tell ...?'

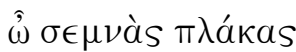

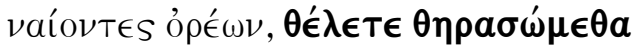

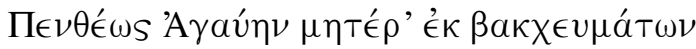

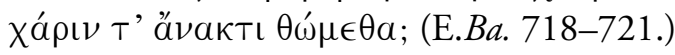




\section{$O<$ you $>$, inhabiting}

the holy plateaus of the mountains, do you want us to bunt

Agaue mother of Pentheus from her Bacchic rites

and do a favour to our master?

Lit. 'Do you want? Are we to hunt ...?'

\section{References}

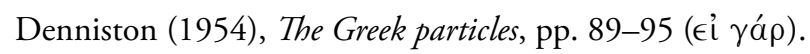

Goodwin (1889), Syntax of the moods and tenses of the Greek verb, $\$ \$ 246,287-288$, 720-739.

Smyth (1956), Greek grammar, $\$ \$ 1780-1782,1789,1806,1814-1815,1832$, 2156.

\section{EXERCISE 11}

Translate the following passages. All expressions which may have the function of a wish should be translated as wishes.

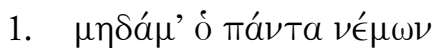

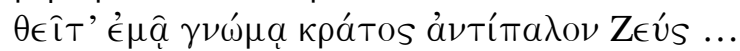

\begin{tabular}{|c|c|}
\hline$\mu \eta \delta a \mu a ́$ & never (accent affected by elision) \\
\hline$\nu \in ́ \mu \in \iota_{\nu}$ & to control, to manage \\
\hline$\gamma \nu \omega \dot{\mu} \eta,-\eta s, \dot{\eta}$ & will (here with Doric spelling) \\
\hline 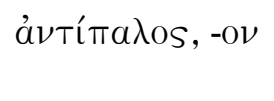 & $\begin{array}{l}\text { in opposition to, against (+ Dat.) } \\
\text { (here predicative) }\end{array}$ \\
\hline
\end{tabular}

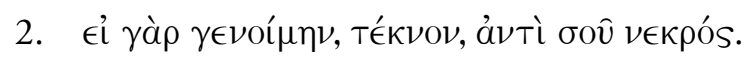

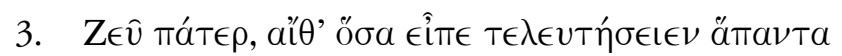

'A $\lambda$ кívoos.

'A入кívoos, -ov, ò

Alcinous 


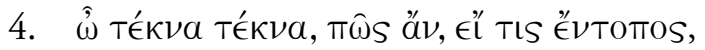

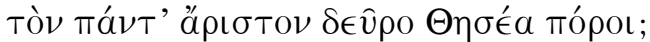

\begin{tabular}{|c|c|}
\hline ÉVTOTOS, -OV & at hand \\
\hline$\pi \alpha ́ \nu \tau(\alpha)$ & neut. pl. adj. as Acc. of Respect \\
\hline 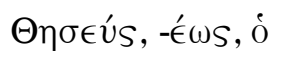 & Theseus \\
\hline$\pi о \rho \in \hat{\imath} \nu$ (Aor.) & to bring (usually, to provide) \\
\hline \multicolumn{2}{|c|}{ 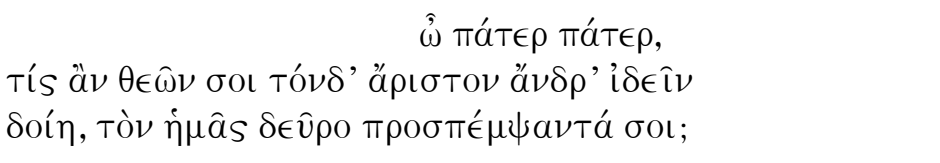 } \\
\hline 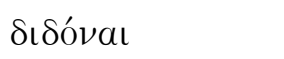 & to grant, to allow (+ Dat. and Infin.) \\
\hline$\pi \rho о \sigma \pi \epsilon ́ \mu \pi \epsilon \iota \nu$ & to conduct (to) (+ Dat.) \\
\hline
\end{tabular}

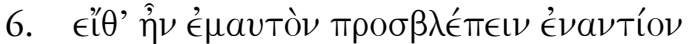

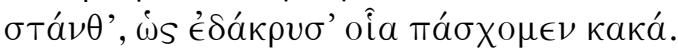

\begin{tabular}{|c|c|}
\hline$\epsilon \hat{\imath \nu} a \iota$ & to be <possible $>$ \\
\hline 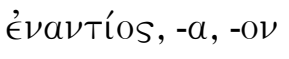 & opposite \\
\hline$\sigma \tau a^{\prime} \nu \theta^{\prime}$ & бтávта (Acc. sg. masc.) \\
\hline 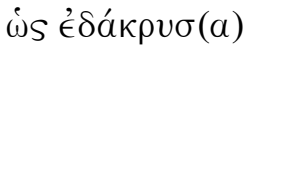 & $\begin{array}{l}\text { so that I might lament (Unfulfilled } \\
\text { Purpose clause with Indic., dependent } \\
\text { on unfulfilled wish [Smyth, 1956, } \\
\$ 2185 . c \text {; Goodwin, } 1889, \$ 333] \text { ). }\end{array}$ \\
\hline
\end{tabular}

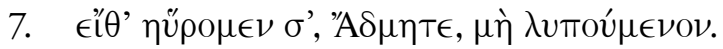

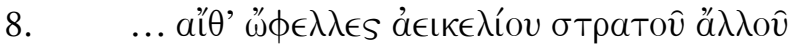

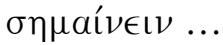

\begin{tabular}{|c|c|}
\hline 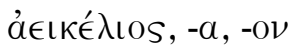 & inferior \\
\hline$\sigma \eta \mu a i ́ \nu \in t \nu$ & mmand (of) $(+\mathrm{Ge}$ \\
\hline
\end{tabular}

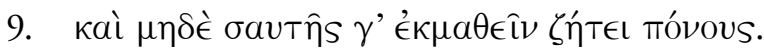

\begin{tabular}{ll}
\hline$\mu \eta \delta \epsilon^{\prime}$ & not ... either \\
тóvos, -ov, o & trouble \\
\hline
\end{tabular}


10. Astyages, wishing the boy to dine as pleasantly as possible, was setting all sorts of foods before him.

\begin{tabular}{|c|c|}
\hline Astyages & 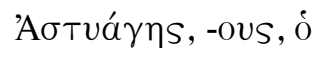 \\
\hline to dine & $\delta \in \iota \pi \nu \in \hat{\imath} \nu$ \\
\hline to set (Acc.) before (Dat.) & $\pi \rho 0 \sigma a ́ \gamma \in \mathrm{t} \nu$ \\
\hline all sorts of & 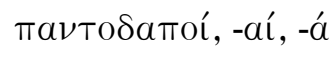 \\
\hline food & $\beta \rho \hat{\omega} \mu \alpha,-\alpha$ тоs, тó \\
\hline
\end{tabular}

11. And I [would] wish, O council, that Simon had the same attitude as I...

I [would] wish

Use Past Imperf. Indic. of $\beta$ oú $\lambda \in \sigma \theta a \iota$ with $\stackrel{\alpha}{\nu}$.

\begin{tabular}{|c|c|}
\hline Simon & $\Sigma i ́ \mu \omega \nu,-\omega \nu 0 s, \dot{o}$ \\
\hline same ... as & aưTós, -ń, -óv (+ Dat.) \\
\hline attitude & $\gamma \nu \omega_{\mu} \eta,-\eta s, \dot{\eta}$ \\
\hline
\end{tabular}

12. Do you [pl.], therefore, want me ... to converse with you to the accompaniment of the flute?

\begin{tabular}{|c|c|}
\hline to converse (with) & $\begin{array}{l}\delta ı a \lambda \epsilon ́ \gamma \epsilon \sigma \theta a \iota \text { (Mid.; also Aor. Pass.) } \\
\text { (+ Dat.) }\end{array}$ \\
\hline to the accompaniment of & vंmó + Acc. \\
\hline flute & aừós, -ov̂, ó \\
\hline
\end{tabular}





\section{LESSON 12 \\ Directly Reported Speech}

All speaking or writing may be directly reported in the exact words of the original speaker or writer. The following sections quote examples from a range of genres and periods.

\subsection{Homer}

Normally, the speeches in the Homeric epics were formally introduced. And either their conclusion was marked, or the immediate response of the next speaker was introduced.

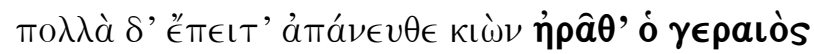

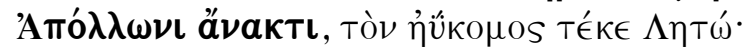

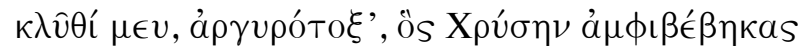

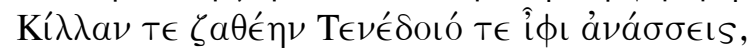

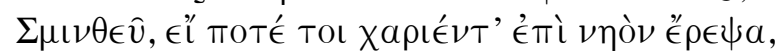

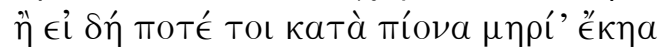

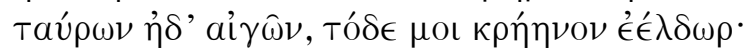

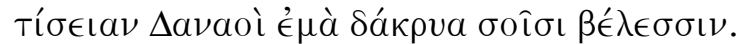

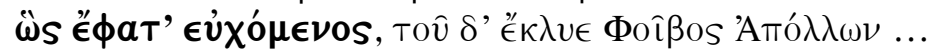

(Hom.Il. 1.35-43.)

And then, going far away, be, the old man, earnestly prayed

to lord Apollo, whom lovely-haired Leto bore:

'Hear me, you with the silver bow, who have taken your stand over Chryse

and sacred Cilla and rule with strength over Tenedos,

Smintheus, if ever I roofed over a shrine pleasing to you,

or if indeed ever I burned up for you fat thighs

of bulls and goats, fulfil this wish for me:

may the Danaans pay for my tears by your arrows.

So he spoke as he prayed, and Phoebus Apollo heard him ... 


\subsection{Drama}

All dramatic dialogue is, by its nature, direct speech; but it is not directly reported speech. However, in drama short passages of direct speech may be quoted within a longer speech. Most commonly, this may occur within a messenger's speech.

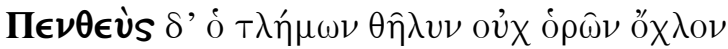

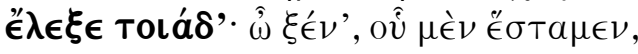

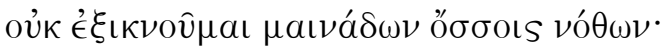

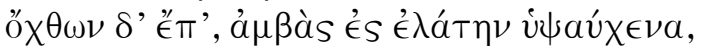

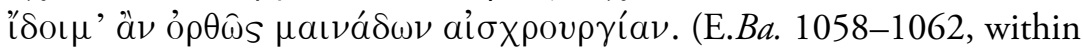
the speech 1043-1152.)

But Pentheus, the poor man, not seeing the female crowd, spoke in the following way: 'O stranger, <from> where we are standing I do not reach with my eyes the spurious maenads; but on a mound, getting up into a stately fir-tree, I would see properly the disgraceful-behaviour of the maenads.

\subsection{Historiography}

The first passage of directly reported speech in Thucydides's History of the Peloponnesian War is formally introduced, begins with an elaborate opening sentence, continues for five chapters and has its conclusion formally marked.

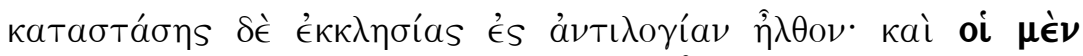

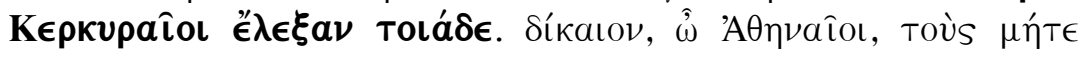

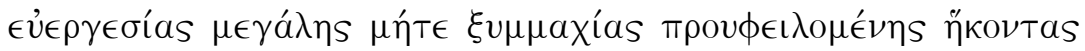

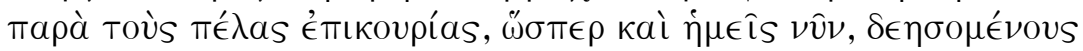

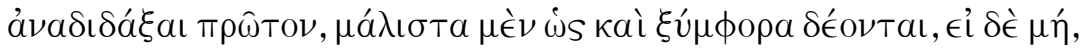

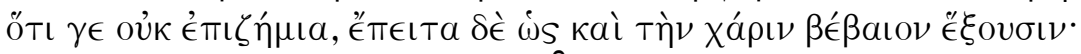

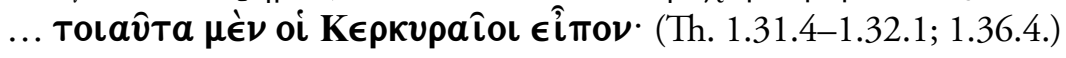

And when an assembly had been arranged, they came to put their arguments; and the Corcyreans spoke in the following way. '<It is > (only) fair, $O$ Athenians, that those, who have come to their neighbours, when there is prior indebtedness neither for a great benefit nor for an alliance, to ask for aid, just as indeed we <have $>$ now, should first explain, especially that they are actually making a request that is advantageous [i.e. to those who are asked], but 
otherwise, that at least $<$ it is $>$ one that is not disadvantageous $<$ to them $>$, and secondly that they [= providers] will get gratitude that is sure; ...' Such $<$ were the words which> the Corcyreans spoke.

\subsection{Prose Quotation Formulae}

In prose, short passages of reported speech are often marked by the insertion of a form of фával ('to say') after an opening word, phrase or clause.

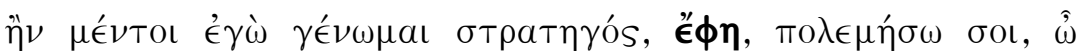

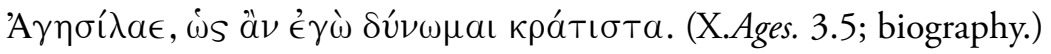

'But if I become general', he said, 'I shall make war on you, O Agesilaus, as forcefully as I possibly can'.

$\epsilon^{\prime} \phi \eta \nu$ is listed in Liddell and Scott (1996) as (Past) second Aorist. In some grammars and in Montanari (2015), this form is treated as Past Imperfect. According to Smyth (1956, \$788), é $\phi \eta \nu$ is both (Past) Imperfect and (Past) Aorist. Even those grammars which present the É $\phi \eta \nu$ forms as Past Imperfect may translate these forms as 'I said', etc. It is indeed usual to translate the é $\phi \eta \nu$ forms into English by a simple Past Tense, 'I said', etc.

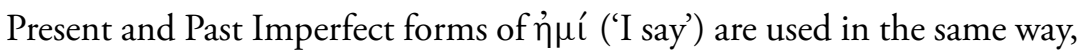
but they occur only in first person singular and third person singular. These forms are regularly followed by $\delta(\epsilon)$ (which serves no function) and then by the first and third person singular pronouns é $\gamma \dot{\omega}$ and ös, The Past Imperfect forms function as a general Past Tense.

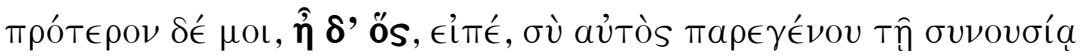
тaúṭฺ ทे oü; (Pl.Smp. 172 B; philosophical dialogue.)

'But first tell me', he said, 'did you yourself attend this gathering or not?'

\section{5. öTl and $\dot{\omega} s$ as Quotation Markers}

In prose, ǑTl (rarely $\dot{\omega}$ ) is sometimes used immediately before a passage of directly reported speech. In this usage, ö $T \iota$ has the function of quotation marks and should not be translated. This idiom is colloquial; it first occurs at Hdt. 2.115.4-6. The fact that the following example contains a directly reported statement, and not just a Vivid indirectly reported statement, is confirmed by the second person pronouns $\dot{v} \mu \hat{a} s$ and $\dot{v} \mu \hat{\omega} \nu$. 


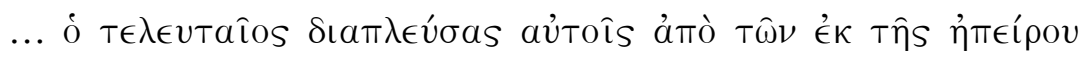

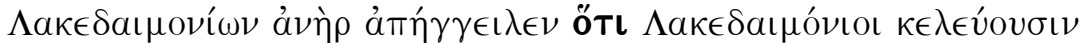

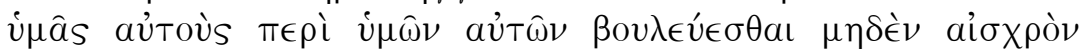
пoloûvtas' (Th. 4.38.3.)

... the last man to sail across to them from the Spartans on the mainland reported: 'The Spartans order you yourselves to decide concerning yourselves, provided that you do nothing shameful'.

\section{References}

Goodwin (1889), Syntax of the moods and tenses of the Greek verb, $\$ \$ 662,711$.

Smyth (1956), Greek grammar, \$\$2589-2590.

\section{EXERCISE 12}

Translate the following passages.

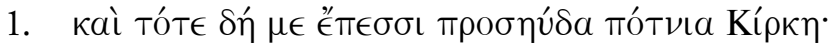

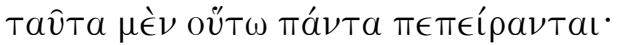

$\pi \rho 0 \sigma a v \delta a ̂ \nu$

to address

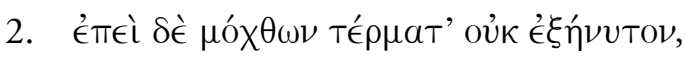

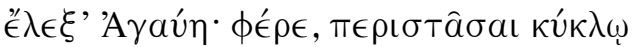
тто́ $\rho \theta$ ov $\lambda a ́ \beta \in \sigma \theta \epsilon, \mu a \iota v a ́ \delta \in S, . .$.

\begin{tabular}{|c|c|}
\hline 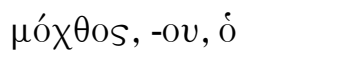 & labour \\
\hline$\epsilon^{\epsilon} \xi \alpha \nu v^{\prime}(\tau) \in \mathrm{L} \nu$ & to accomplish, to attain \\
\hline$\phi \epsilon ́ \rho \epsilon$ & come on! (sg. Impv. used also for pl.) \\
\hline$\pi \tau o ́ \rho \theta o s,-o v, \dot{o}$ & sapling \\
\hline$\lambda \alpha \mu \beta a ́ \nu \in \sigma \theta a \iota$ (Mid.) & to take hold (of) (+ Partitive Gen.) \\
\hline
\end{tabular}




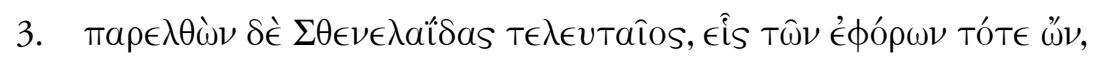

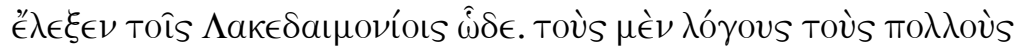

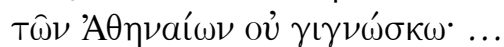

$\pi a \rho \in \lambda \theta \in \hat{\imath} \nu$ (Aor.) to come forward

$\Sigma \theta \in \nu \in \lambda a i ̂ \delta a s,-o v, \dot{O} \quad$ Sthenelaidas

є́фopos, -ov, ó

ephor (one of five annual magistrates at Sparta)

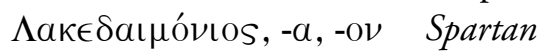

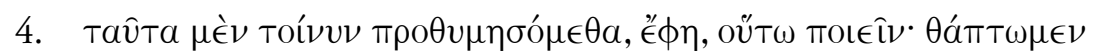

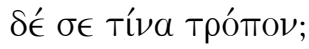

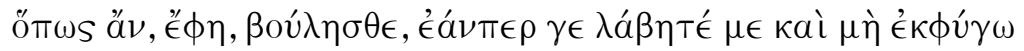
ùuâs.

\begin{tabular}{|c|c|}
\hline Toívuv & well then \\
\hline$\pi \rho o \theta v \mu \epsilon i \sigma \theta a \iota$ (Mid.) & to be eager, to be keen (+ Infin.) \\
\hline$\theta a ́ \pi T \in I \nu$ & to bury \\
\hline тíva (тро́тор) & delayed interrogative \\
\hline
\end{tabular}

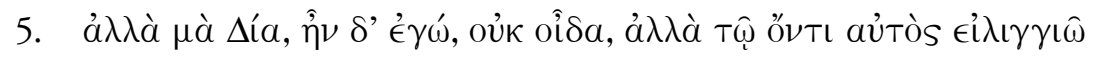

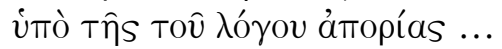

\begin{tabular}{|c|c|}
\hline 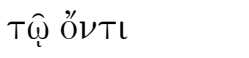 & in reality \\
\hline$(\epsilon)^{\imath} \lambda \iota \gamma \gamma \iota \hat{\alpha} \nu$ & to be(come) dizzy \\
\hline ن்тó (+ Gen.) & under (the influenceleffect of) \\
\hline àторі́a, -as, i் & difficulty \\
\hline
\end{tabular}

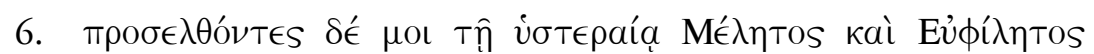

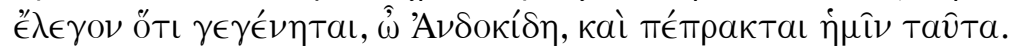

\begin{tabular}{|c|c|}
\hline 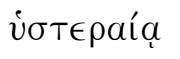 & 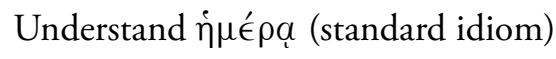 \\
\hline 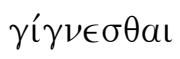 & to happen \\
\hline$\dot{\eta} \mu \hat{\imath} \nu$ & Dat. of Agent with Perf. Pass. verb \\
\hline
\end{tabular}


INTERMEDIATE ANCIENT GREEK LANGUAGE

7. 'I know', he said, 'both that you had been born a private citizen, and that you are now a monarch'.

\begin{tabular}{|c|c|}
\hline to have been born & $\gamma \in \gamma \in \nu \hat{\eta} \sigma \theta a \iota$ (Perf. Pass.) \\
\hline private citizen & 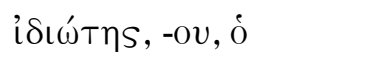 \\
\hline monarch & Túpavvos, -ov, ó \\
\hline
\end{tabular}




\section{LESSON 13 \\ Reported Statements with öTl or $\dot{\omega} s$}

\subsection{Introduction}

This Lesson deals with reported statements in the form of a Simple sentence and of the Main clause of a Complex sentence. The negative for these reported statements is regularly ovं. (Subordinate clauses in reported discourse will be treated in Lesson 21.)

A statement may be reported indirectly after a verb of saying by means of a Subordinate clause introduced by öTı or $\dot{\omega} s$. ÖTl is generally used after a positive leading verb. $\dot{\omega}$ s is likely to be used when the reported statement is open to doubt. ÖTı and $\dot{\omega}$ s are regularly used with $\lambda \epsilon ́ \gamma \in \mathrm{V} \nu$

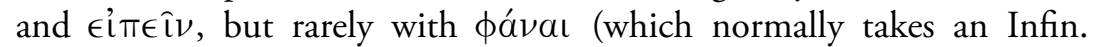
phrase; see Lesson 14).

\subsection{Reported Statements in Primary Sequence}

In Primary sequence, that is, after a verb of saying in Present or Future Time, the original Mood and Tense of direct speech are retained in the reported clause after ötı or $\dot{\omega}$. There may, however, be a change of person as in English idiom.

Directly reported statement: He says, 'I am the king'.

Indirectly reported statement: He says that he is the king.

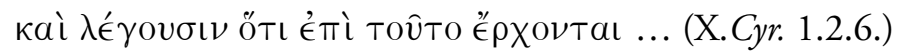

And they say that they come for this purpose...

Direct form: ÉpXovTal, 'They come'; Present Indicative retained in reported form.

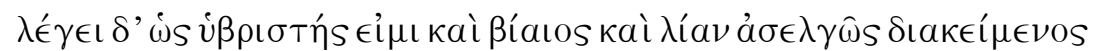
... (Lys. 24.15.)

And he says that I am insolent and violent and have a very outrageous attitude... 


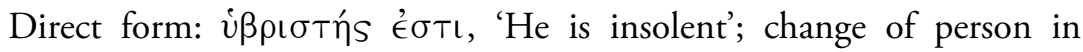
reported form. Here, the speechwriter uses $\omega$ s rather than ö $T \iota$, since he does not want his client to appear to admit the allegations against him.

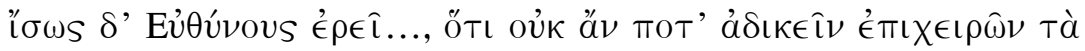

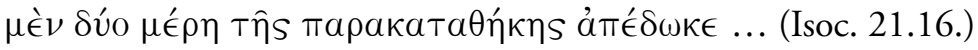

But perhaps Euthynus will say ..., that, if attempting to do wrong, he would not ever have paid back two-thirds of the deposit...

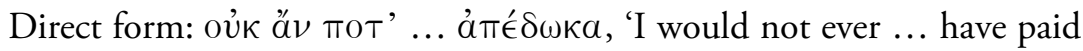
back'; Past Aorist Indicative with ő $v$ retained; change of person.

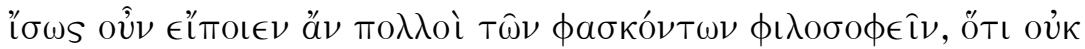

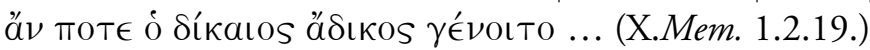

Perhaps, therefore, many of those who claim to be philosophers would say, that the just <man > would not ever become unjust ...

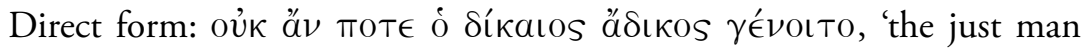
would not ever become unjust'; Optative retained.

\subsection{Reported Statements in Past Sequence}

In Past sequence, that is, after a verb of saying in Past Time:

- Primary and Past Aorist Tenses of the Indicative are changed to the same Aspect of the Optative

- Past Aorist Indicative with ăv denoting potentiality is retained

- Past Imperfect and Past Perfect Indicatives are usually retained

- all Optatives are retained.

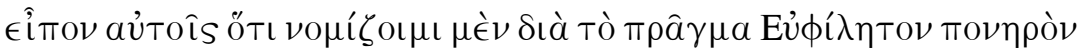
€îvaı ... (And. 1.64.)

I told them that I thought that Euphiletus was wicked because of the action ...

Direct form: $\nu \circ \mu i \zeta \omega$, 'I think'; Imperfect Aspect is retained in reported form.

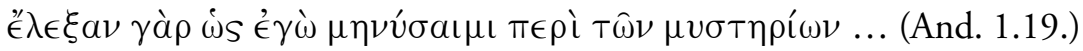
For they said that I had lodged information concerning the mysteries ... 
Direct form: '̇ $\mu \eta ́ \eta v \sigma \epsilon$, 'He lodged information'; Aorist Aspect is retained in reported form, with change of person. Here, Andocides uses is, since he does not admit the allegation.

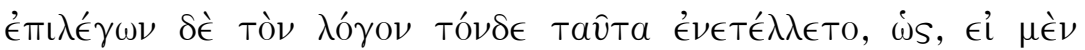

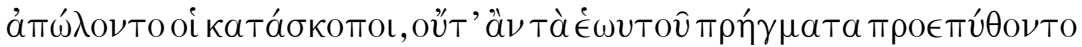

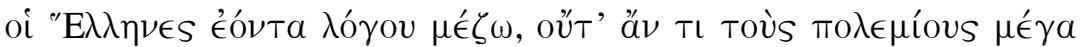

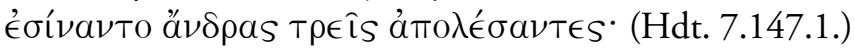

And he was giving this command while explaining that, if the scouts had perished, neither would the Greeks have learnt in advance that his own importance was greater than common report, nor would they [= Persians] have done any great harm to their enemy by destroying three men.

Past Aorist Indicative with $\stackrel{\alpha}{\nu} v$ retained in reported form. The use of $\dot{\omega}$ may be influenced by the potential nature of the expression.

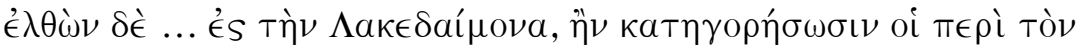

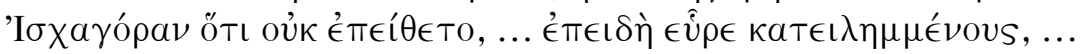

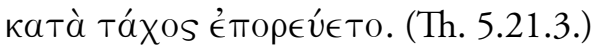

And coming ... to Sparta, in case the followers of Ischagoras made an accusation that he had not been obedient, ... when he found that they [= Spartans] had been bound <by the agreement $>$,... he moved on with haste.

Direct form: oủk émtí $\theta \in T O$, 'He was not obedient'; Past Imperfect Indicative is retained in reported form.

Although the Past Imperfect Indicative of direct speech is usually retained in reported speech after ö $T \iota$ or $\dot{\omega}$, the Imperfect Optative does sometimes occur where the context is clear.

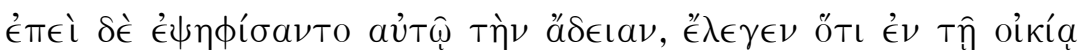

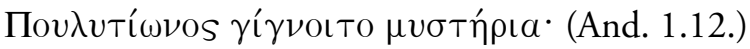

And when they had voted immunity to him, he said that mysteries had been celebrated in the house of Poulytion.

In the context, it is clear that the speaker (in court) did not mean that mysteries were currently being celebrated, but that they had previously been (being) celebrated. Thus, the Imperfect Optative can be used without ambiguity. 


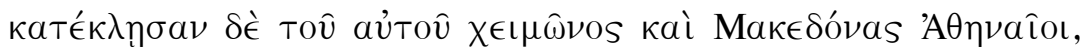

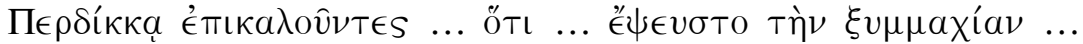
(Th. 5.83.4.)

And within the same winter the Athenians also blockaded the Macedonians, bringing an accusation against Perdiccas ..., that ... he had cheated the alliance...

Original Past Perfect Indicative is retained in the reported form.

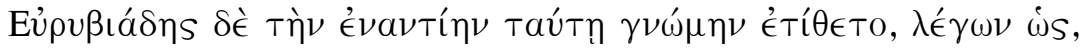

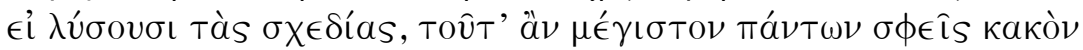

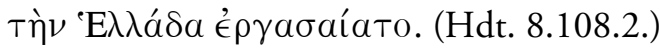

But Eurybiades put forward the opinion opposite to this one, saying that, if they disconnected the pontoons, they would thereby wreak the greatest trouble of all upon Greece.

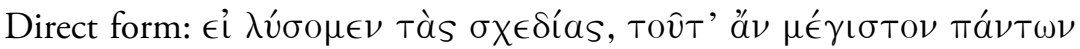

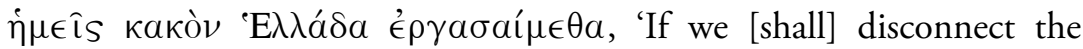
pontoons, we would thereby wreak ...' (Mixed Fut. Open, Fut. Unfulfilled Condition). Original potential Optative with ŏ $\nu$ is retained. Tov̂T(o)

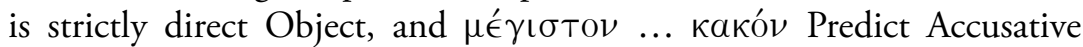

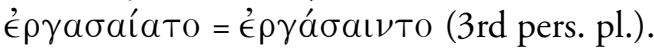

\subsection{Vivid Construction}

The Optative Mood in Past sequence in reported statements is just beginning to be used in Aeschylus (earlier fifth century BCE). By the time of the late fifth to early fourth century BCE, usage still depends on the preference of the writer. Thus, Thucydides more often than not uses the Vivid construction, retaining the Mood and Tense of the direct form of speech. But the orators and Plato and Xenophon prefer the Optative. Both constructions may even occur within the same sentence written by the same author.

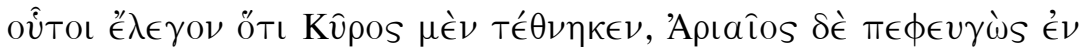

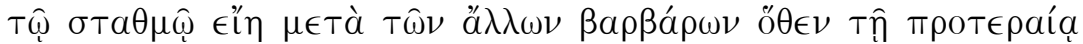

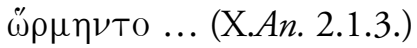

These <men > said that Cyrus had died, but that Ariaeus having fled was with the rest of the natives at the stopping-point from where they had set out on the previous day... 


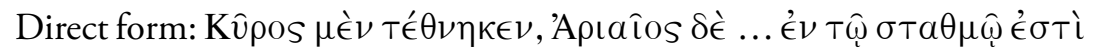
... ö $\theta \in \nu \dot{\omega} \rho \mu \eta \dot{\eta} \mu \in \theta$. 'Cyrus has died, but Ariaeus ... is at the stoppingpoint ... from where we had set out ...'. In Xenophon's actual form, the original Mood and Tense has been retained in Té $\theta \nu \eta \kappa \in \nu$ (Vivid); Optative has been used in $\epsilon$ II (normal Past sequence); and Past Perfect Indicative has been retained in $\dot{\omega} \rho \mu \eta \dot{\eta} \mu \in \theta$ (the usual Vivid construction for this Mood and Tense).

\section{References}

Goodwin (1889), Syntax of the moods and tenses of the Greek verb, \$\$662-676, 681.

Smyth (1956), Greek grammar, \$\$2574-2600, 2613-2615, 2623.

\section{EXERCISE 13}

Translate the following passages.

1.

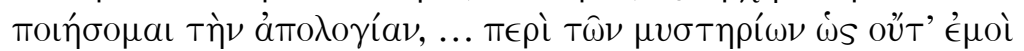

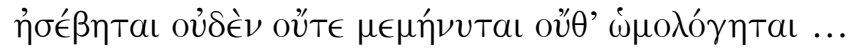

\begin{tabular}{|c|c|}
\hline$\pi \rho 0 \epsilon \mathrm{I} \pi \epsilon \hat{\imath} \nu$ (Aor.) & to mention previously (here 1st pers. sg.) \\
\hline$\dot{a} \sigma \in \beta \in \hat{\imath} \nu$ & to commit impiety \\
\hline$\mu \eta \nu u ́ \in \iota \nu$ & to lay information \\
\hline$\dot{o} \mu о \lambda о \gamma \in \hat{\imath} \nu$ & to make a confession \\
\hline
\end{tabular}

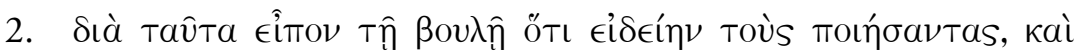

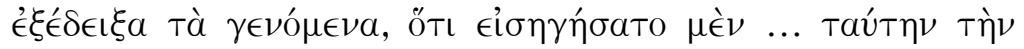

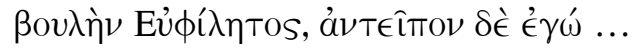

\begin{tabular}{|c|c|}
\hline$\beta o v \lambda \eta \dot{\eta},-\hat{\eta} s, \dot{\eta}$ & council (1st instance); plan (2nd instance) \\
\hline 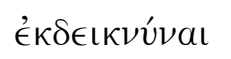 & to reveal \\
\hline$\epsilon \mathfrak{i} \sigma \eta \gamma \in \hat{\imath} \sigma \theta a \iota$ & to introduce \\
\hline
\end{tabular}




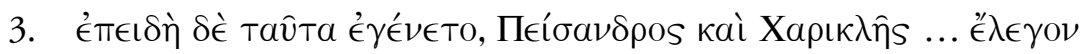

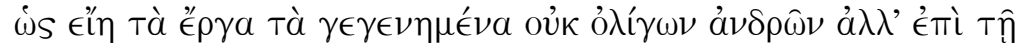

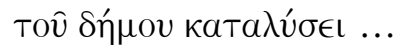
$\delta \hat{\eta} \mu \mathrm{os},-\mathrm{ov}, \dot{o}$
democracy

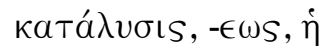
dissolution, overthrow

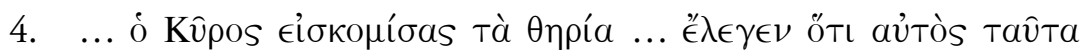
$\theta \eta \rho a ́ \sigma \in \mathrm{\epsilon} \in \mathrm{V}$...

\begin{tabular}{|c|c|}
\hline $\begin{array}{l}\epsilon \dot{\mathrm{i} \sigma \kappa о \mu i ́ \zeta \epsilon \iota \nu} \\
\theta \eta \rho i ́ o \nu,-o v, \text {,ó } \\
\theta \eta \rho \hat{\nu} \nu\end{array}$ & $\begin{array}{l}\text { to carry in } \\
\text { (wild) animal } \\
\text { to hunt }\end{array}$ \\
\hline
\end{tabular}

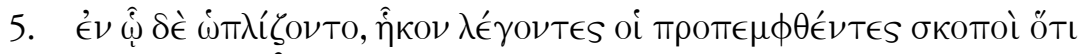

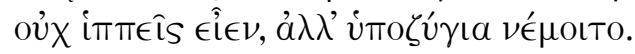

\begin{tabular}{|c|c|}
\hline 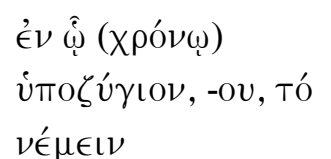 & $\begin{array}{l}\text { in which (time) (i.e. while) } \\
\text { pack-animal } \\
\text { (Mid., of animals) to feed, to graze (Intr.) }\end{array}$ \\
\hline
\end{tabular}

6. And he went there and said, that he was a freeman and a Milesian by birth, and [that] Pasion had sent him there to explain about the money.

\begin{tabular}{|c|c|}
\hline And he & ös (coordinating relative pronoun) \\
\hline free(man) & $\epsilon^{\epsilon} \lambda \epsilon \hat{U} \theta \epsilon \rho o s,-o v$ (masc. adj.) \\
\hline Milesian & 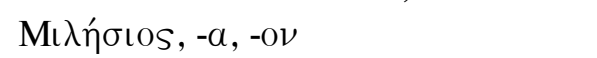 \\
\hline birth & 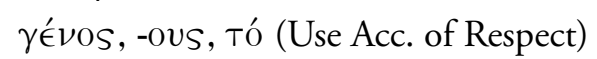 \\
\hline Pasion & 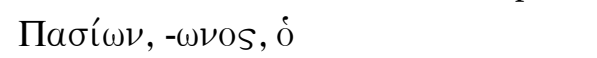 \\
\hline to send there & $\epsilon i \sigma \pi \epsilon ́ \mu \pi \epsilon \iota \nu$ \\
\hline to explain & $\delta \iota \delta a ́ \sigma \kappa \in \iota \nu$ (Use Intentive/'Fut.' Partc.) \\
\hline money & 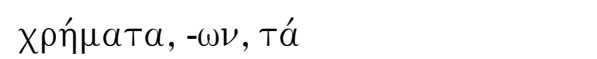 \\
\hline
\end{tabular}




\section{LESSON 14 \\ Reported Statements with Infinitive}

\subsection{Aspect of the Infinitive}

In classical Greek, some verbs of saying (especially фávaı) report a statement by means of an Infinitive phrase. In this construction, the Infinitive preserves the Aspect of the direct form of the statement. Thus, an Imperfect Infinitive generally represents either a Present Imperfect or a Past Imperfect Indicative of the original statement. A Future (or 'Intentive') Infinitive represents an original Future Indicative. An Aorist Infinitive generally represents a Past Aorist Indicative. And a Perfect Infinitive generally represents either a Present Perfect or a Past Perfect Indicative. Where an original potential statement with ó $v$ and the Indicative is reported, $a ̂ v$ is retained in the Infinitive phrase. In addition, an original potential statement with ö $v$ and the Optative may be reported in an Infinitive phrase with ŏ $\nu$; the Infinitive preserves the Aspect of the original Optative.

\subsection{Accusative and Infinitive Phrases}

Where the Subject of the direct statement is different to the Subject of the verb of saying, it appears in the Accusative Case as the Subject of the Infinitive. The whole Accusative and Infinitive phrase is the Object of the verb of saying. In the following examples, the Subject of the Infinitive is in the Accusative Case. These examples also illustrate the Aspect of the Infinitive (as noted in \$14.1).

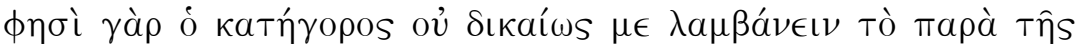

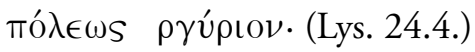

For my accuser says that I am unjustly receiving the money from the state.

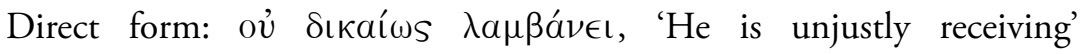
(Pres. Imperf.). There is a change from third person $(\lambda \alpha \mu \beta a ́ \nu \in \mathrm{l}$, 'he is receiving') of the direct form to first person ( $\mu \epsilon$, 'I') of the reported form. 


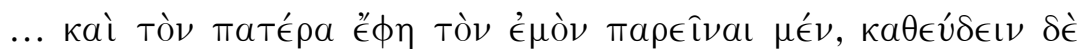

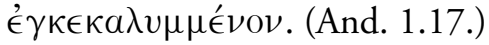

... and he said that my father had been present, but had been asleep covered $u$.

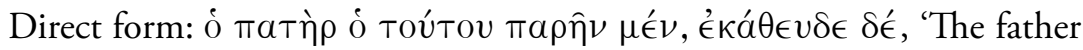
of this <man> was present, but was sleeping' (Past Imperf.). There is a change from third person (Tov́Tov, 'of this $<$ man>') in the direct form to

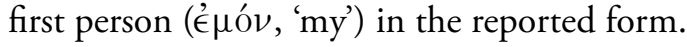

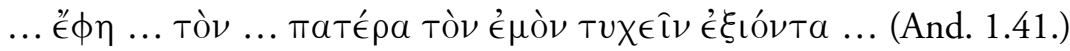
... he said that my father had happened to be going out ...

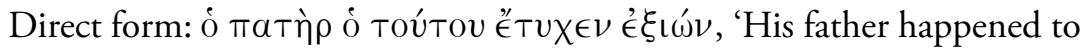
be going out' (Past Aor.). There is a change of person as in the previous example.

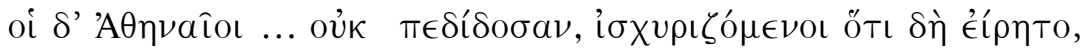

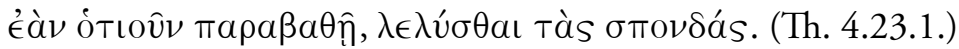

But the Athenians ... were not giving back < the ships>, affirming that it had indeed been stated, that, if any infringement at all had occurred, the treaty had been broken.

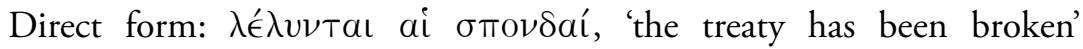
(Pres. Perf.).

\subsection{Nominative and Infinitive Phrases}

The Subject of an Infinitive phrase is normally omitted when it is the same as the Subject of the verb of saying. An attribute or Complement of the Subject of the Infinitive appears in the Nominative Case.

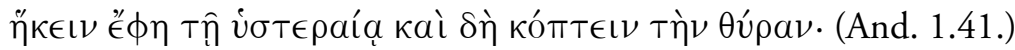

He said that he had come on the following day and actually had been knocking on the door.

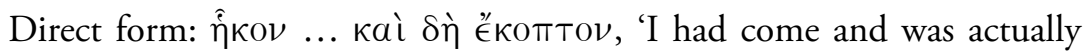
knocking' (Past Imperf.). The Subject of the two Infinitives in the reported form is omitted because it is the same as the Subject of "ै $\phi \eta$. 


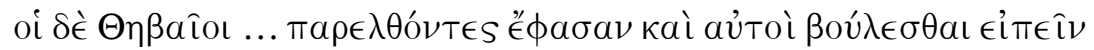
... (Th. 3.60.)

And the Thebans ... coming forward said that they themselves also wanted to speak ...

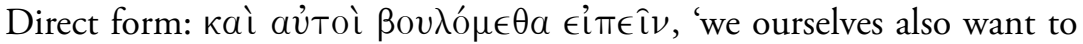
speak' (Pres.). The attribute au่Toí ('-selves') remains Nominative in the reported form, because it refers to the Subject of "̈ $\phi \alpha \sigma \alpha \nu$. The change of person of the verb in the English reported form is not evident in Greek because of the change of construction from Indicative to Infinitive.

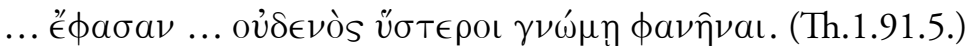

... they said ... that they had appeared inferior to none in judgment.

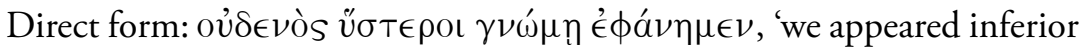
to none in judgment' (Past Aor.). The Complement ú $\sigma \tau \epsilon \rho o r$ remains Nominative in the reported form, because it refers to the Subject of

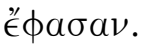

\subsection{Exceptional Accusative and Infinitive Phrases}

For emphasis, an Accusative and Infinitive phrase is sometimes used, even when the Subject of the Infinitive is the same as the Subject of the leading verb. This usually occurs where a contrast or comparison is expressed or implied. (The same phenomenon also appears with verbs of thinking and hoping, and with Acc. and Partc. after verbs of perception.)

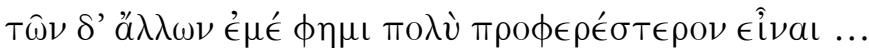
(Hom.Od. 8.221.)

But I say that I am much more proficient than the rest ...

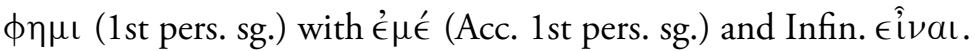




\subsection{Negative}

The negative for statements reported by Infinitive phrases is regularly ou and its compounds. The negative is usually placed before forms of $\phi a ́ v a l$, unless it negates a particular word within the reported statement as in the first example in $\$ 14.2$ above.

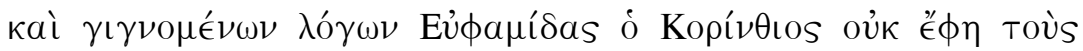

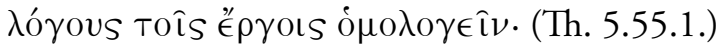

And while discussions were taking place, Euphamidas the Corinthian said that their discussions did not correspond with their actions.

The sentence does not mean: 'he did not say that their discussions corresponded with their actions'.

\subsection{Usage}

Among the verbs which introduce reported statements, whereas $\lambda \epsilon ́ \gamma \in \mathrm{V} \nu$ and $\epsilon i \pi \in \hat{\imath} \nu$ are usually followed by öTı or $\dot{\omega}$, фávaı is usually followed by an Infinitive phrase (see Lesson 13.1). When $\lambda \epsilon \in \gamma \in \nu$ and verbs of saying other than $\phi a ́ v a l$ are followed by an Infinitive, the meaning is usually 'to command', 'to tell someone to do something'. And in keeping with the reported command, the negative is $\mu \eta$.

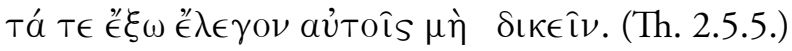

and they told them not to maltreat those outside.

\subsection{Passive of $\lambda \epsilon^{\prime} \gamma \in \mathrm{\nu} \nu$}

A statement may be reported by the Passive of $\lambda \hat{\epsilon} \gamma \in \mathrm{\iota} \nu$ used either personally or impersonally with an Infinitive phrase. The personal construction is the more usual.

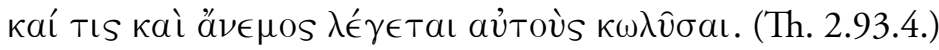

And a certain wind also is said to have hindered them.

Personal: Nominative and Infinitive. 


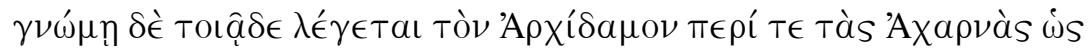

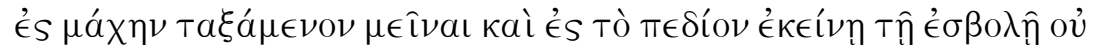

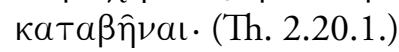

And it is said that with such an intention Archidamus formed his army as for battle and remained around Acharnae, and did not descend to the plain at the time of that invasion.

Impersonal: Accusative and Infinitive. Structurally, the whole Accusative and Infinitive phrase is Subject of $\lambda \epsilon^{\prime} \gamma \in T a \iota$ (cf. Lessons 3.4.1 and 6.2).

\section{References}

Goodwin (1889), Syntax of the moods and tenses of the Greek verb, \$\$683-685, 753-754.

Smyth (1956), Greek grammar, $\$ \$ 1866-1867,1982,2016-2017,2616,2722-$ 2723.

\section{EXERCISE 14}

Translate the following passages.

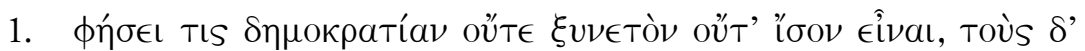

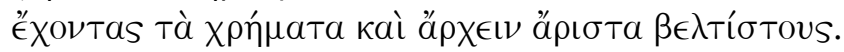

\begin{tabular}{|c|c|}
\hline 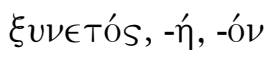 & intelligent, wise \\
\hline$\epsilon \hat{\imath \nu}$ & 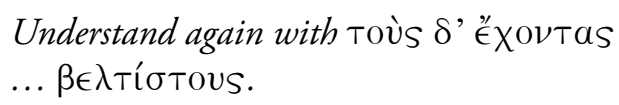 \\
\hline кaí & also \\
\hline$a ̊ \rho x \in I \nu$ & $\begin{array}{l}\text { Depends on } \beta \in \lambda \text { Tíotous; } \\
\text { see Lesson 3.4.3.3. }\end{array}$ \\
\hline
\end{tabular}

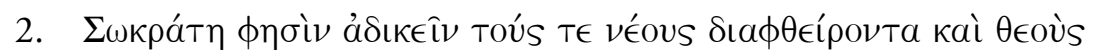

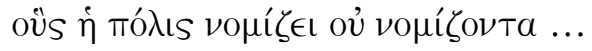

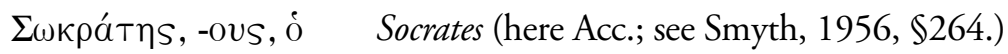

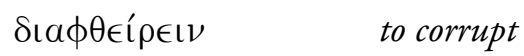

$\nu \mathrm{o} \mu \mathrm{i} \zeta \in \mathrm{L} \nu$ to believe in $(+$ Acc. $)$ 


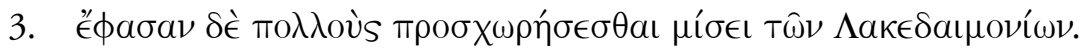
$\pi \rho 0 \sigma \chi \omega \rho \in \hat{\imath} \nu$ to come over (to another side) (Mid. in Fut.)

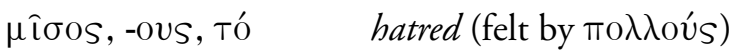

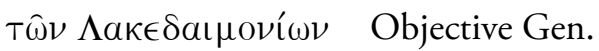

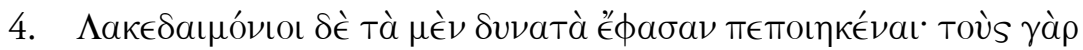

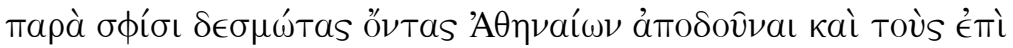

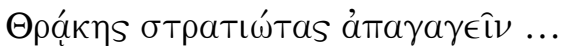

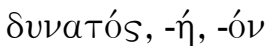
possible

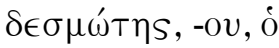
prisoner

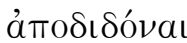
to give over

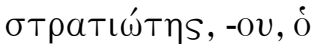
soldier

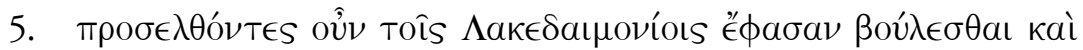

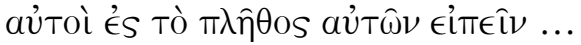

$\stackrel{\epsilon}{\mathrm{S}}$

to, before (persons, with verbs of speaking)

$\pi \lambda \hat{\eta} \theta$ os, -ous, тó assembly

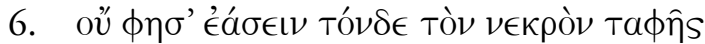

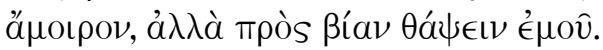

$\phi \eta \sigma(i ́)$ The Subject is masc.

тафиं, -ทिs, $\dot{\eta}$ burial

ärotpos, -ov without a share (in) (+ Gen.)

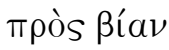
in spite (of), in defiance (of) (+ Gen.)

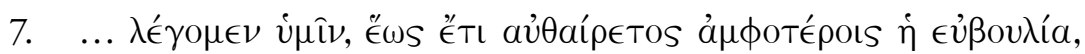

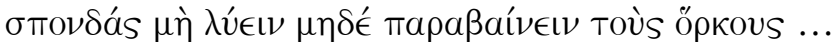

\begin{tabular}{|c|c|}
\hline 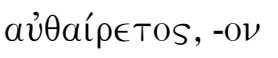 & available \\
\hline$\epsilon \cup ̛ ß o u \lambda i ́ a,-a s, \dot{\eta}$ & prudence \\
\hline
\end{tabular}


8. ... he said that he desired to impose punishment on him ...

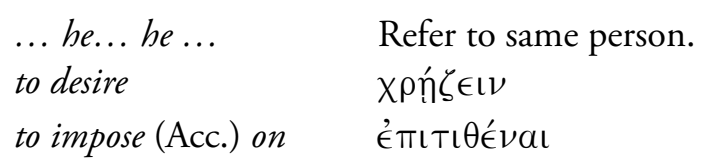

(Dat.)

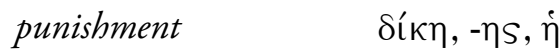

9. And the Locrians are said to have established only this law in more than two hundred years.

\begin{tabular}{|c|c|}
\hline Locrians & 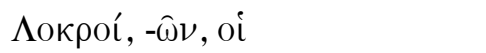 \\
\hline are said & Use personal construction. \\
\hline to establish & тí $\theta \in \sigma \theta a \iota$ (Mid.; use Aor. Infin.) \\
\hline law & vómos, -ov, ó \\
\hline in & $\stackrel{\epsilon}{\mathrm{V}}(+$ + Dat. $)$ \\
\hline more (adv. Acc.) & $\pi \lambda \in \hat{\imath} \nu($ for $\pi \lambda \epsilon \hat{\imath} O \nu)$ \\
\hline two bundred & 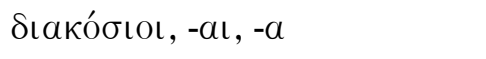 \\
\hline year & ÉTOS, -OUS, Tó \\
\hline
\end{tabular}





\section{LESSON 15 \\ Reported Knowledge and Perception}

\subsection{Introduction}

Verbs of knowing and perceiving may take either öTı or $\dot{\omega}$ with a Subordinate clause, or a Participial phrase (or occasionally an Infin. phrase). The negative for reported knowledge and perception, both after ŐTı or $\dot{\omega} s$ and with Participial and Infinitive phrases, is normally ov่. For the occasional use of $\mu$ n with Participial or Infinitive phrases, see the examples at the end of $\$ 15.3$ below.

\subsection{Reported Knowledge or Perception with öTl or ஸ்s}

Reported knowledge or perception with ötı or $\dot{\omega}$ is expressed in the same way as reported statements. For Primary sequence, see Lesson 13.2. For Past sequence, see Lesson 13.3; a Vivid construction may also be used for reported knowledge or perception.

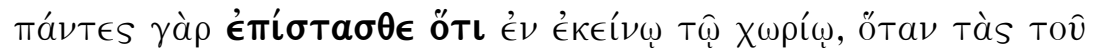

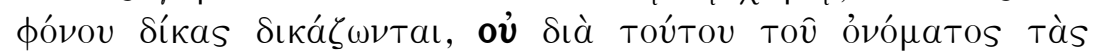

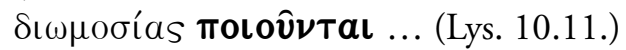

For you all know that in that place, when they try cases of murder, they do not make sworn-statements by means of this term ...

In Primary sequence, the verbs in the reported form have the same Mood and Tense as in the direct form. There is no change of person in this particular sentence. The negative is oú.

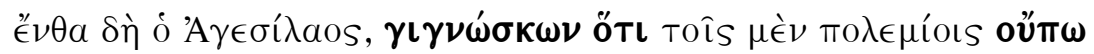

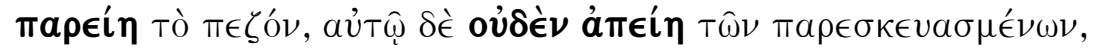

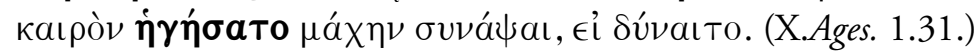


Then indeed Agesilaus, realising that the infantry were not yet present for the enemy, but for himself nothing of what had been prepared was missing, thought it the time to join battle, if he could.

In Past sequence, the verbs in the reported form appear in the Optative Mood instead of the Indicative Mood of the direct form. The Past sequence is set by the Main verb iं $\gamma\llcorner\gamma \nu \omega$ ' $\sigma \kappa \omega \nu$ ('realising') is subordinate. The negatives are ov compounds.

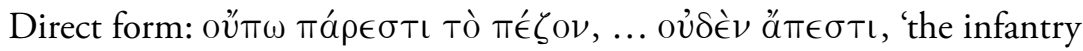
are not yet present, ... nothing is missing'.

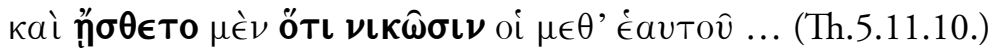

And he perceived that those with him were victorious ...

Vivid construction: in Past sequence the direct form $\nu \iota \kappa \omega \hat{\sigma} \sigma \nu$ (Pres. Indic.) is retained, instead of being changed to Optative.

\subsection{Reported Knowledge or Perception with a Participial Phrase}

With verbs of knowing and (intellectually) perceiving, the content of knowledge or perception may be expressed by a Participial phrase, analogous to the Infinitive phrase with verbs of saying such as pával. Like the Infinitive, the Participle preserves the Aspect of the direct form of expression. (Cf. Lesson 14.1.) The regular constructions are as follows.

Where the Subject of reported knowledge or perception is different to the Subject of the verb of knowing, it appears in the Accusative Case with an Accusative Participle.

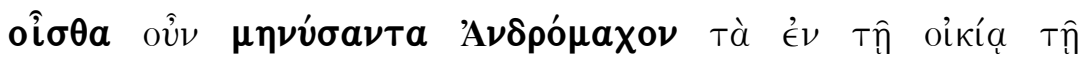

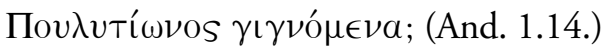

So do you know that Andromachus reported what had been going on in Poulytion's house?

Direct form: '́ $\mu \eta \dot{\eta} \nu v \sigma \in \nu$ 'A $\nu \delta \rho o ́ \mu a \chi o s$, 'Andromachus reported'. In the reported form, the Participle $\mu \eta \nu v ́ \sigma a \nu \tau a$ retains the Aspect of the direct form. 
Where the Subject of a Participial phrase is the same as the Subject of the verb of knowledge or perception, it is omitted, and the Participle itself and any attribute or Complement appears in the Nominative Case.

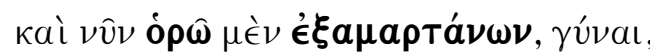

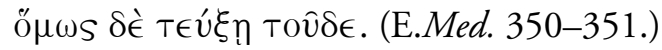

And now I see that I am making a mistake, woman, but nevertheless you will obtain this.

Direct form: $€ \dot{\xi} \xi \alpha \mu \alpha \rho \alpha^{\alpha} \nu \omega$, 'I am making a mistake'. In the reported form, the Participle retains the Aspect of the direct form.

Besides the regular constructions, the following variations also occur.

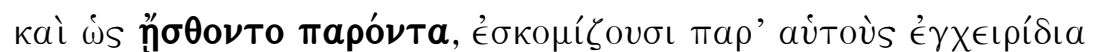

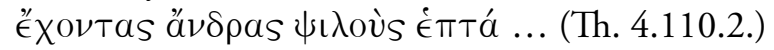

and when they realised that $<$ he $>$ was present, they brought in [Hist. Pres.] to their presence seven light-armed men holding daggers ...

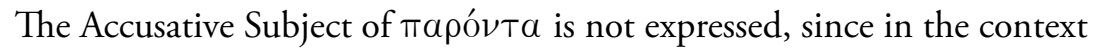
the Participle clearly refers to 'him' (Brasidas). The pronoun to be

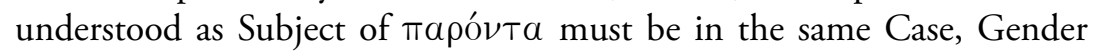
and Number as the Participle, thus aưTóv.

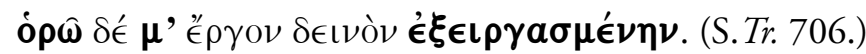

But I see that I have done a terrible deed.

Although the Subject of the Participle $\mathfrak{\epsilon}^{\prime} \xi \in \mathrm{\epsilon} \rho \gamma \alpha \sigma \mu \epsilon^{\prime} \nu \eta \nu$ is the same as the Subject of $\dot{\rho} \hat{\omega}$, it is expressed and is in the Accusative Case. The construction implies a greater degree of objectivity in the one who 'see(s)'.

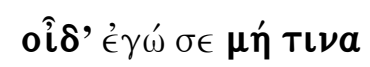

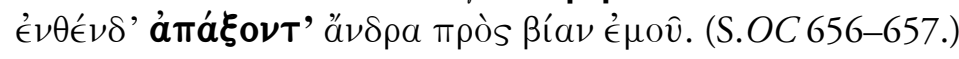

\section{I know that no man}

will take you away from here in defiance of me.

Accusative and Participle with negative $\mu \eta \dot{\eta}$. Indefinite Subject ( $\tau \iota \nu \alpha)$ and reference to a future situation. 


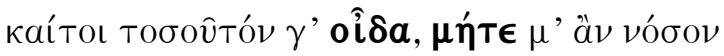

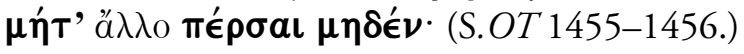

And yet so much I know, that neither would plague

nor anything else destroy me.

Accusative and Infinitive with negative $\mu \eta$. Reference to a potential situation.

\subsection{Physical Perception}

A Participle may also be used with a verb expressing physical perception.

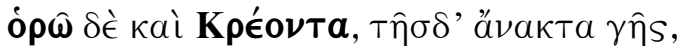

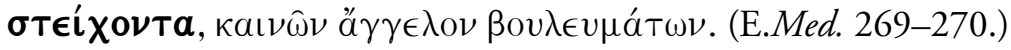

But I see Creon, lord of this land, approaching, messenger of new intentions.

ó $\hat{\omega}$ has a direct Object K $\rho$ ÉovTa followed by a supplementary Participle $\sigma \tau \in \dot{\chi} \chi 0 \nu \tau a$.

The difference in function between physical and intellectual perception is clear with verbs which normally take the Genitive Case.

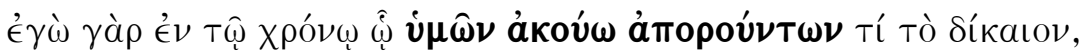

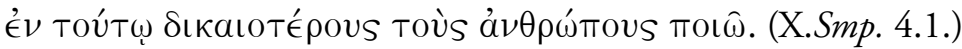

For in the time in which I bear you puzzling as to what justice <is>, meantime I am making people more just.

Physical perception: Genitive and supplementary Participle after ảkoúєı

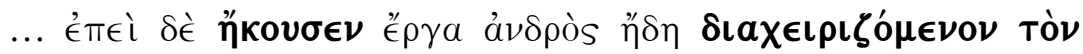

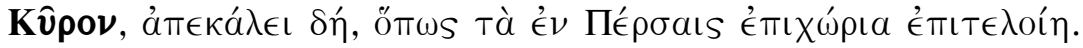
(X.Cyr. 1.4.25.)

... and when he heard that Cyrus was already managing the actions of a man, he proceeded to recall <him>, so that he might complete the <training> customary among the Persians.

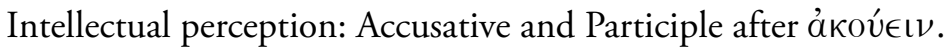




\subsection{Reported Knowledge or Perception with an Infinitive Phrase}

A common view is that the Infinitive construction expresses perception of what is hypothetical or possible, whereas the Participial construction expresses perception of what is actual.

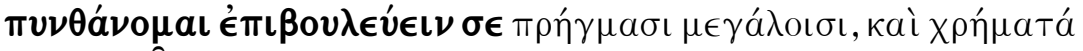

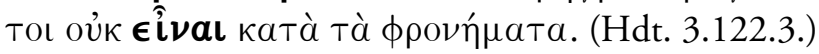

I hear that you are planning for great projects, and that you do not have financial resources in accordance with your ideas.

Tol (Ionic) $=\sigma o \iota$ (Attic), Possessive Dative with $\epsilon \hat{\imath} \nu a \iota$.

Thus, Montanari (2015) introducing ákov́elv 1.C states that the Participle usually expresses real indirect perception, the Infinitive generic perception. On the other hand Goodwin $(1889, \$ 914)$ states that many verbs which have the Participle in reported discourse may also take the Infinitive 'in nearly or quite the same sense'. Similarly, Smyth (1956, $\$ 2144)$ gives a list of verbs which take Participle or Infinitive in reported discourse 'with no (or only slight) difference in meaning'. The following phrases from the same paragraph of Herodotus would support this view.

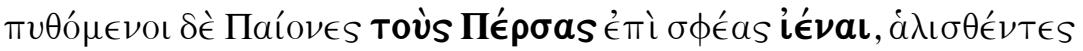

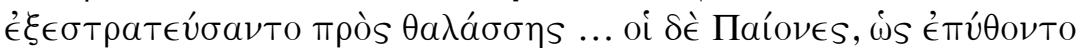

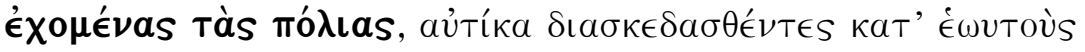

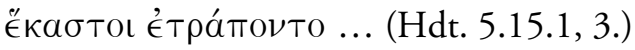

And the Paeonians, learning that the Persians were coming against them, gathered together and marched to the sea... And the Paeonians, when they learned that their towns were occupied, immediately scattered and each turned to his own way...

There is also variation of usage between one author and another. The following statistics are limited to a sample of three words and to three authors. Only the Accusative plus Participle and Accusative plus Infinitive in reported discourse are considered. For Xenophon, only Anabasis, Cyropaedia and Historia Graeca are considered. 
INTERMEDIATE ANCIENT GREEK LANGUAGE

\begin{tabular}{|c|c|c|c|c|c|c|}
\hline & \multicolumn{2}{|c|}{$a \imath \sigma \theta a ́ v \in \sigma \theta a \iota$} & \multicolumn{2}{|c|}{ 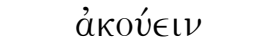 } & \multicolumn{2}{|c|}{$\pi v \nu \theta a ́ \nu \in \sigma \theta a \iota$} \\
\hline & $\begin{array}{l}\text { Acc. + } \\
\text { Partc. }\end{array}$ & $\begin{array}{l}\text { Acc. + } \\
\text { Infin. }\end{array}$ & $\begin{array}{l}\text { Acc. + } \\
\text { Partc. }\end{array}$ & $\begin{array}{l}\text { Acc. + } \\
\text { Infin. }\end{array}$ & $\begin{array}{l}\text { Acc. + } \\
\text { Partc. }\end{array}$ & $\begin{array}{l}\text { Acc. + } \\
\text { Infin. }\end{array}$ \\
\hline Hdt. & 1 & 0 & 1 & 7 & 34 & 40 \\
\hline Th. & 28 & 2 & 1 & 0 & 10 & 9 \\
\hline X. & 10 & 0 & 0 & 23 & 2 & 1 \\
\hline
\end{tabular}

\section{References}

Goodwin (1889), Syntax of the moods and tenses of the Greek verb, \$\$669, 687$688,884,914$.

Smyth (1956), Greek grammar, \$\$1874, 2106-2114, 2123, 2144-2145, 2576, 2614-2616, 2727, 2729-2731.

\section{EXERCISE 15}

Translate the following passages.

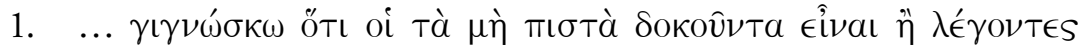

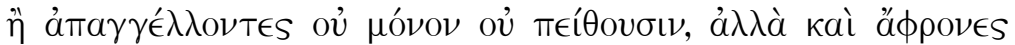

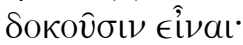

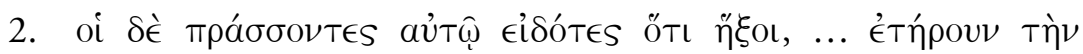

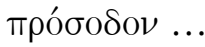

\begin{tabular}{|c|c|}
\hline$\pi \rho a ́ \sigma \sigma \in \mathrm{t} \nu$ & to deal with (+ Dat.) \\
\hline 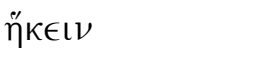 & to (have) come \\
\hline$\tau \eta \rho \in \hat{\imath} \nu$ & to watch for (+ Acc.) \\
\hline 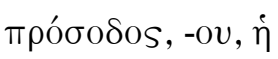 & approach \\
\hline
\end{tabular}

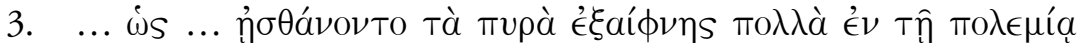

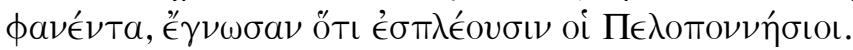

\begin{tabular}{|c|c|}
\hline is & when \\
\hline 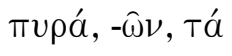 & (watch-)fires \\
\hline
\end{tabular}




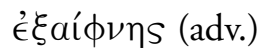

$\pi о \lambda \epsilon \mu i ́ a,-a s, \dot{\eta}$

$\hat{\epsilon} \sigma \pi \lambda \epsilon \hat{\imath} \nu$ suddenly

enemy <territory > (fem. adj. as noun)

to sail in

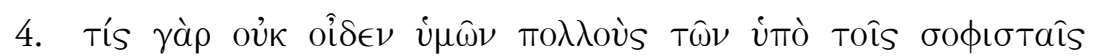

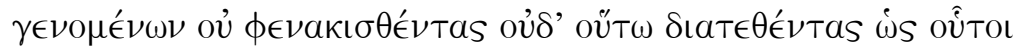
$\lambda \operatorname{ć} \gamma O v \sigma \nu \ldots$;

\begin{tabular}{|c|c|}
\hline$\dot{v} \mu \hat{\omega} \nu$ & Partitive Gen. with Tís \\
\hline 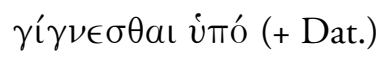 & to come under (the influence of) \\
\hline$\phi \in \nu a \kappa i \zeta \zeta \in \mathrm{I} \nu$ & to cheat \\
\hline$\delta ı а т \imath \theta \in ́ v a \iota$ & to treat \\
\hline
\end{tabular}

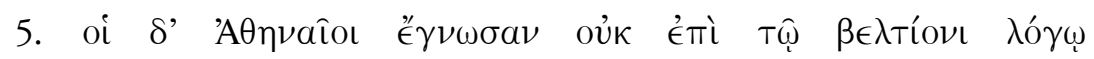

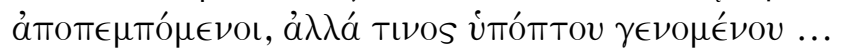

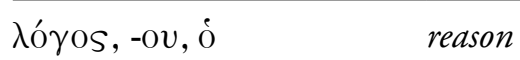

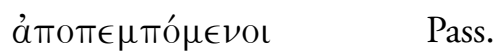

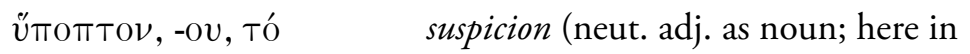

Gen. abs.)

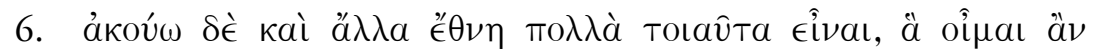

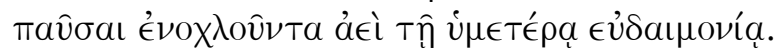

\begin{tabular}{ll}
\hline É$\theta \nu$ OS, -ous, Tó & tribe \\
$\epsilon \in \nu \circ \chi \lambda \in \hat{\imath} \nu$ & to cause trouble (for) (+ Dat.) \\
\hline
\end{tabular}

7. And immediately they all realised that [the Persian] king had been encamping somewhere nearby.

\begin{tabular}{|c|c|}
\hline that & Use öTı. \\
\hline to encamp & 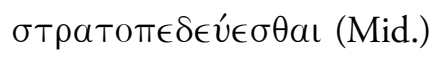 \\
\hline somewhere & Tov (enclitic) \\
\hline nearby & 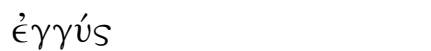 \\
\hline
\end{tabular}


INTERMEDIATE ANCIENT GREEK LANGUAGE

8. ... when they realised that the army had come in and that it was impossible to take the city by force, they withdrew ...

\begin{tabular}{ll}
\hline that & Use Acc. and Partc. \\
to take & aí $\rho \in \hat{\imath} \nu$, Aor. $\dot{\epsilon} \lambda \in \hat{\imath} \nu$ \\
force & Bía, -as, $\dot{\eta}$
\end{tabular}




\section{LESSON 16 \\ Reported Thoughts, Hopes, \\ Promises and Oaths}

\subsection{Reported Thoughts}

The usual construction with verbs of thinking is an Infinitive phrase. Where the Subject of the reported thought is different to the Subject of the verb of thinking, it appears in the Accusative Case. Where the Subject of the reported thought is the same as the Subject of the verb of thinking, it is usually omitted. In this construction, an attribute or Complement of the Subject of the reported thought appears in the Nominative Case. For comparison or contrast the Subject of the Infinitive is sometimes expressed in the Accusative, even when it is the same as the Subject of the leading verb. The Infinitive preserves the Aspect of the direct form of thought. An Infinitive with ăv represents a direct form of thought with öv and potential Indicative or Optative. The usual negative is ov. The negative may precede the leading verb, rather than be attached to the Infinitive (cf. Lesson 14.5).

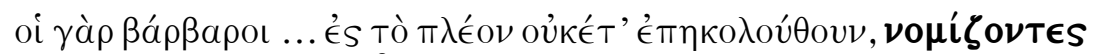

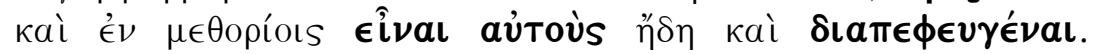
(Th.4.128.2.)

For the foreigners ... for the most part no longer pursued, thinking both that they were on the borders by now and that they had escaped.

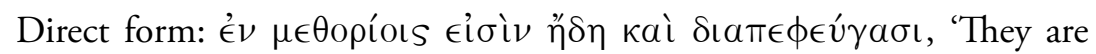
on the borders by now and have escaped'. aútoús (Acc.) shows that

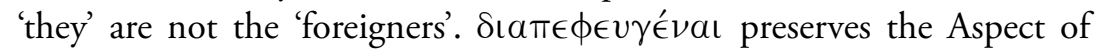

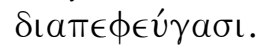

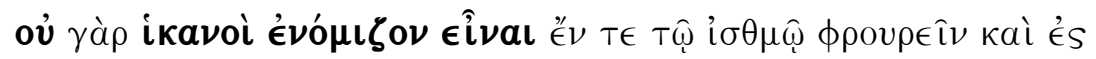

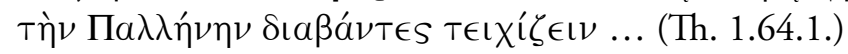

For they thought that they were not competent to keep watch on the isthmus and to cross over to Pallene and build a wall ... 


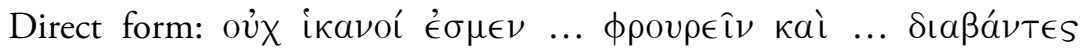
$\tau \in I X i \zeta \in I \nu$, "We are not competent to keep watch ... and ... to cross over and build a wall'. In the reported form, the Subject of the Infinitives is omitted, since it is the same as the Subject of É ${ }^{\prime} \mu \iota \zeta o \nu$; and the

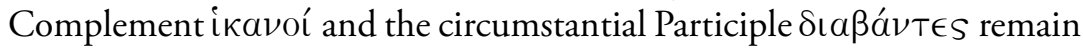
in the Nominative Case. The negative oú precedes évó $\mu \iota \zeta o \nu$ (as does the Complement ikavoú in this instance).

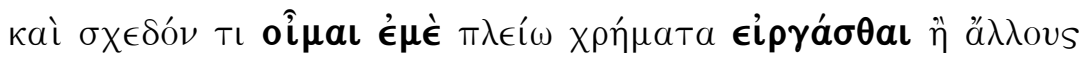

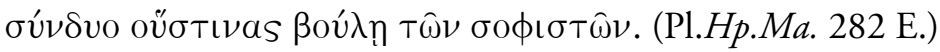

And $\mathbf{I}$ just about think that $\mathbf{I}$ have made more money than any other two together of the sophists whom you wish < to name $>$.

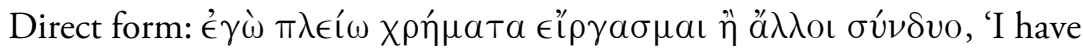
made more money than any other two together'. For comparison of

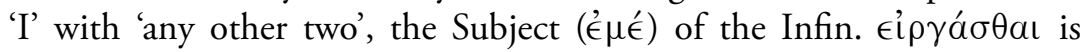
expressed in the Accusative Case, although it is the same as the Subject of the leading verb (oî $\mu a \mathrm{l})$.

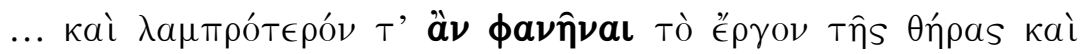

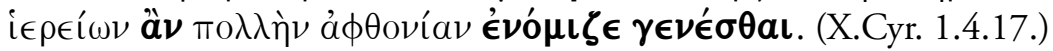

... and be thought that the action of the hunt would appear more illustrious and that there would turn out to be a great abundance of animals for slaughter.

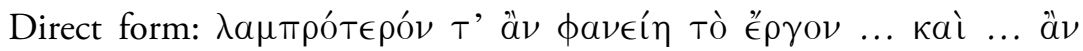

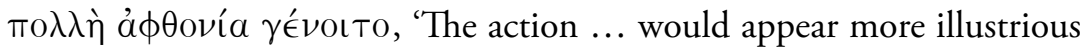
and there would turn out to be a great abundance'. ä $v$ used with the potential Optative in the direct form is retained with the Infinitive in the reported form.

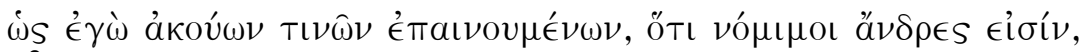

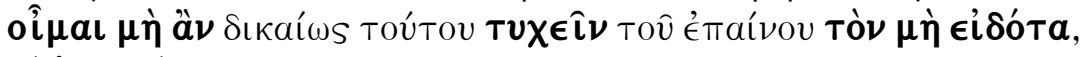
Tí éoTı vópos. (X.Mem. 1.2.41.)

For, when I hear some people assigning praise, because men are law-abiding, I think that the <man>, who does not know what a law is, would not justly obtain this praise. 
In this sentence, $\mu \eta n$ with $\alpha$ $\nu$ and the Infinitive may be influenced by the

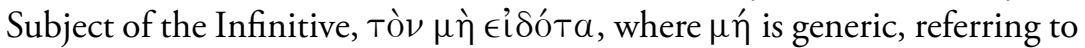
'anyone who does not know'. (For the coordinating use of $\dot{\omega} s$ and $\epsilon \epsilon \epsilon i$, see Lesson 23.4.)

\subsection{Reported Hopes and Promises}

In most respects, expressions of hoping (or expecting) and promising follow the pattern of reported thoughts $(\$ 16.1)$. Because of their meaning, hopes and promises are most often used with an Intentive ('Fut.') Infinitive.

However, hopes and promises may also be reported with an Imperfect Infinitive expressing continuous action or with an Aorist Infinitive expressing momentary action. Occasionally, the Aorist Infinitive reports a hope that something had previously happened. And sometimes manuscripts are divided in reading an Aorist or an Intentive Infinitive.

Frequently, in reported hopes, and regularly in reported promises, the negative used with the Infinitive is $\mu \eta$; but ov does also occur.

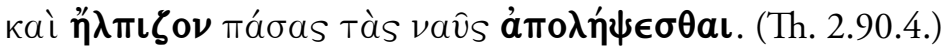

and they were boping that they would cut off all their ships.

Direct form: åmo $\lambda \eta \psi o ́ \mu \epsilon \theta a$, 'We shall cut off. The Intentive ('Fut.') Infinitive of the reported form corresponds to the Future Indicative of the direct form.

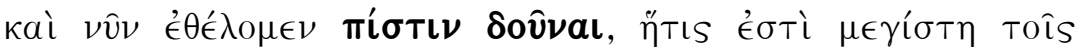

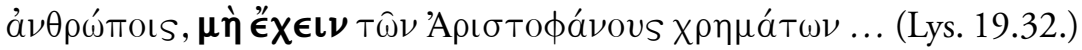

and now we are willing to give a pledge, which is the most serious for human beings, that we do not hold <any parts> of the property of Aristophanes...

Direct form: oúk '́X $\chi \mu \in \nu$, 'We do not hold'. The Imperfect Infinitive and negative $\mu \eta$ of the reported form correspond to the Present Indicative and negative ou of the direct form.

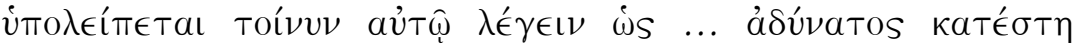

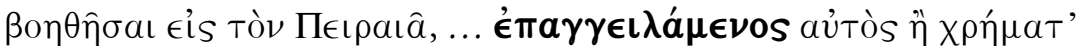

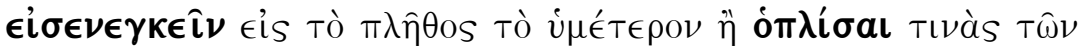

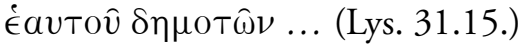


It remains, therefore, for him to state that ... he became incapable of helping at the Piraeus ... although promising either to contribute money himself to your community or to arm some of his fellow-citizens...

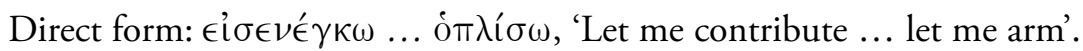
The hortatory Aorist Subjunctive could be postulated as the equivalent direct form. But at any rate the Aorist Infinitives $\in \dot{i} \sigma \in \nu \in \gamma \kappa \in \hat{\imath} \nu \ldots$

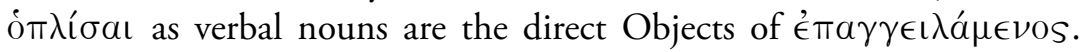
(Some scholars classify such Infinitives as 'not in indirect discourse'.) And the promise relates to action subsequent to the time at which it was made.

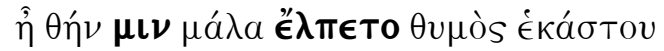

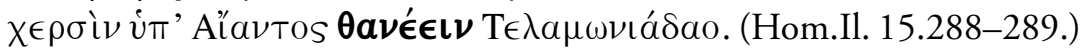

Certainly the heart of each firmly hoped

that he had died under the hands of Ajax, son of Telamon.

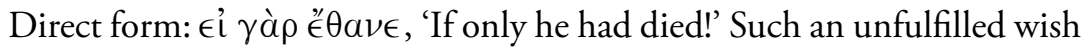
for the past is perhaps the closest approximation to a direct form of this reported hope (cf. Lesson 11.2.1.2.). Unlike the previous example, the Aorist Infinitive here relates to action prior to the time at which the hope was reported.

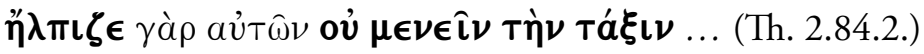

For he hoped that their battle-line would not remain $<$ intact> ...

Here, the negative ov is used with the Infinitive $\mu \in \nu \in \hat{\imath} \nu$, rather than the more usual $\mu$ ' as in Lys. 19.32 above.

\subsection{Reported Oaths}

Like hopes and promises, oaths about an intended action are most commonly reported with an Intentive ('Fut.') Infinitive, and oaths about a continuing action may be reported with an Imperfect Infinitive or oaths about an action viewed as momentary may be reported with an Aorist Infinitive. Again, the Aorist Infinitive may report an oath about an intended action (swear to do something) or an oath about a prior action (swear that one did something). An oath about completed action may also be reported with a Perfect Infinitive. As with reported thoughts, hopes and promises, $\stackrel{\alpha}{\nu}$ is sometimes used to express potentiality. 


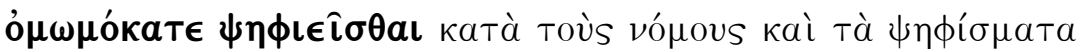

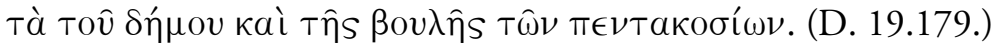

You have sworn that you will vote according to the laws and the decrees of the people and of the council of the five hundred.

The Subject of the Intentive Infinitive is not expressed since it is the same as the Subject of the leading verb.

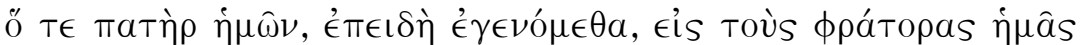

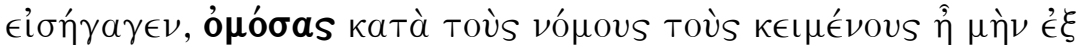

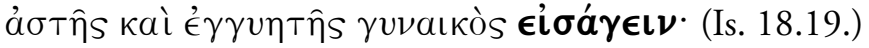

And our father, when we had been born, introduced us to the clansmen, swearing in accordance with the established customs, that assuredly he was introducing <children $>$ from a married [and] Athenian woman.

The Imperfect Infinitive expresses a continuing action.

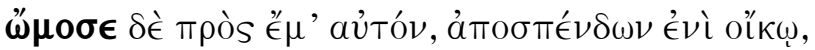

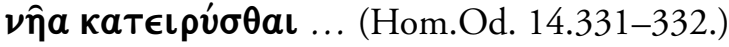

And he swore to me myself, as he poured a libation in his house, that the ship had been drawn down ...

The Accusative and Perfect (Pass.) Infinitive expresses completed action.

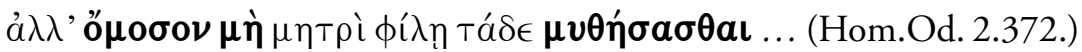
But swear not to tell this to my dear mother...

The Aorist Infinitive expresses intended action.

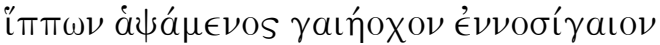

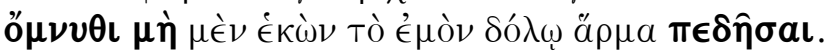

(Hom.Il. 23.584-585.)

laying a hand on your horses, swear by the one who holds the earth <and> shakes the earth that you certainly did not intentionally impede my chariot by trickery.

The Aorist Infinitive expresses prior action, with negative $\mu$ ท́. 


\section{References}

Goodwin (1889), Syntax of the moods and tenses of the Greek verb, \$\$204-212, 683-686, 751-752.

Smyth (1956), Greek grammar, \$\$1845-1849, 1868, 2018, 2022-2024, 2580, 2692, 2722-2723, 2725-2726.

\section{EXERCISE 16}

Translate the following passages.

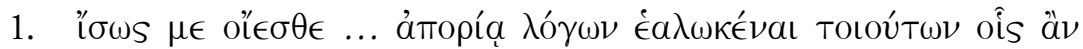

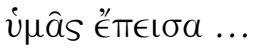

ámopía, -as, $\dot{\eta}$

lack

ol̈ $\sigma \theta a \mathrm{\iota}$

to think (Mid. with Aor. Pass.)

à $\lambda i ́ \sigma \kappa \in \sigma \theta a \iota$

to be convicted (Intr. Aor. and Perf. Act.

forms have Pass. sense)

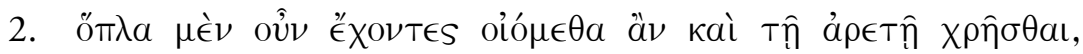

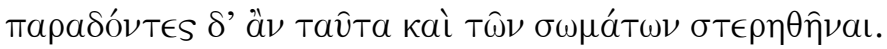

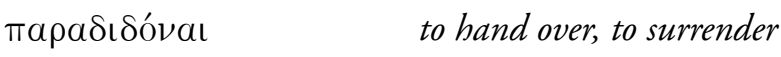

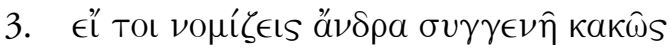

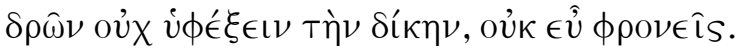

نंTé $\chi \in \mathrm{IV} \quad$ to suffer

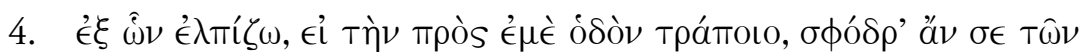

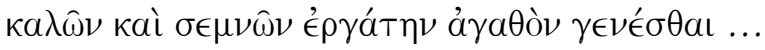

\begin{tabular}{|c|c|}
\hline$\epsilon \xi \hat{\omega} \nu$ & $\begin{array}{l}\text { And as a result of this ( } \hat{\omega} \nu \text { : coordinating } \\
\text { relative pronoun) }\end{array}$ \\
\hline 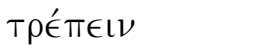 & to turn \\
\hline$\sigma \phi o ́ \delta \rho(\alpha)$ & certainly \\
\hline 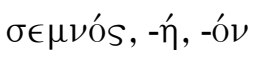 & noble (here neut., as also $\kappa a \lambda \hat{\omega} \nu)$ \\
\hline 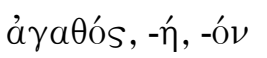 & beneficial \\
\hline
\end{tabular}




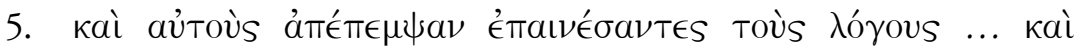

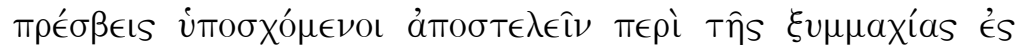
"A

$\pi \rho \epsilon ́ \sigma \beta \in \mathrm{IS},-\epsilon \omega \nu$, oi ambassadors (here Acc.)

$\dot{a} \pi$ Tобт́́ $\lambda \lambda \in \mathrm{LV} \quad$ to send out

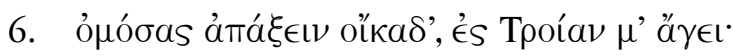

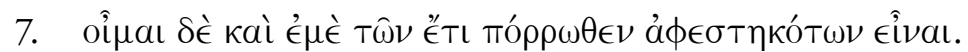

Tó $\rho \rho \omega \theta \in \nu \quad$ far off (no emphasis on $-\theta \in \nu$ here)

8. But I think that I shall quickly make clear that we would not even be able to establish this sovereignty.

\begin{tabular}{ll}
\hline to make clear & $\delta \eta \lambda \mathrm{ov} v$ \\
to establish & $\kappa a \theta \iota \sigma \tau a ́ \sigma \theta a ı$ (rarely Middle in this sense) \\
sovereignty & $\dot{\alpha} \rho x \dot{\eta},-\eta \hat{s}, \dot{\eta}$ \\
\hline
\end{tabular}

9. But when he had arrived in Nemea, he delayed there, hoping that he would catch the Athenians as they were going past ...

\begin{tabular}{|c|c|}
\hline Nemea & $\mathrm{N} \epsilon \mu \dot{\epsilon} \alpha,-\alpha_{S}, \dot{\eta}$ \\
\hline to arrive in & $\left.\gamma^{\prime}{ }^{\prime} \gamma \nu \in \sigma \theta a \iota\right)$ \\
\hline to delay & 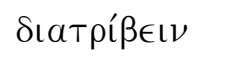 \\
\hline to catch & $\lambda a \mu \beta a ́ v \in t \nu$ \\
\hline to go past & 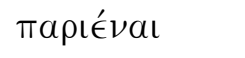 \\
\hline
\end{tabular}





\section{LESSON 17}

\section{Questions}

\subsection{Ordinary Questions}

Ordinary questions may be expressed with or without an introductory interrogative particle. The particles are normally the first element in a sentence. Interrogative phrases, which include the negative oú, generally expect a positive answer. Interrogative phrases, which include $\mu$, are more emotionally charged, but do not necessarily expect a negative answer.

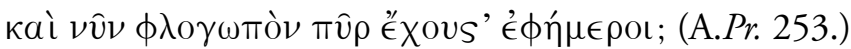

And now do ephemeral <mortals $>$ have flaming fire?

No interrogative particle.

$$
\text { ทें } \theta \epsilon \omega p \eta ́ \sigma \omega \nu \text { тúxas }
$$

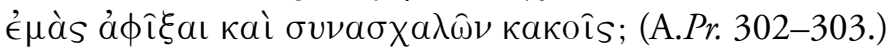

Have you come to see

my fortunes and to sympathise with my troubles?

Question with $\hat{\eta}$ is neutral.

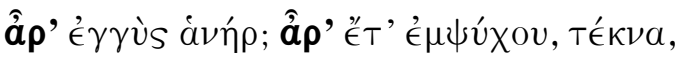

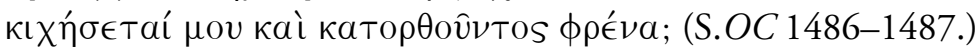

$<I s>$ the man near? Will he find me, children, still alive and in my right mind?

These questions with $\hat{\alpha} \rho \alpha$ are neutral.

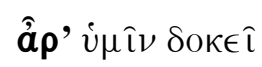

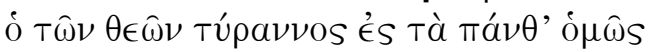

Bíalos €ivval; (A.Pr. 735-737.)

Does it (not) seem to you

that the ruler of the gods in all respects alike is violent? 
This question with $\hat{\alpha} \rho \alpha$ expects a positive answer.

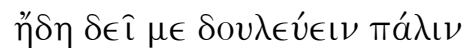

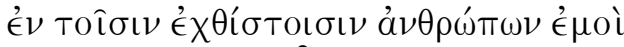

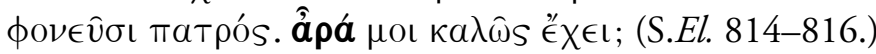

Now I must be a slave again

among the people most hateful to me,

the murderers of my father. Does it go well with me?

This question with $\hat{\alpha} \rho \alpha$ expects a negative answer.

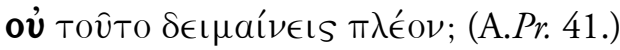

Do you not fear this more?

Question with oủ expects a positive answer.

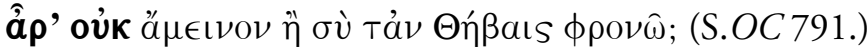

Do I not understand the <situation > in Thebes better than you?

Question with â $\rho$ ' oủk expects a positive answer.

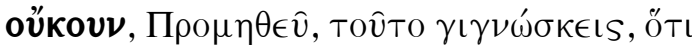

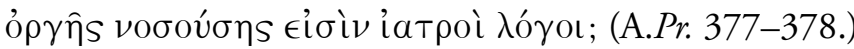

Do you not know this, Prometheus, that

words are healers of the disease of anger?

oükovv with paroxytone accent emphasises the negative, and the question expects a positive answer.

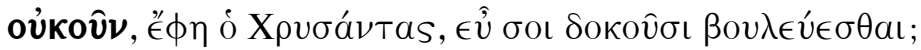
(X.Cyr. 7.1.8.)

'Therefore do they not', said Chrysantas, 'seem to you to be laying their plans well?'

oúkov̂v with perispomenon accent emphasises the inferential force of ovv $v$, while maintaining the negative value of oúk, and the question expects a positive answer.

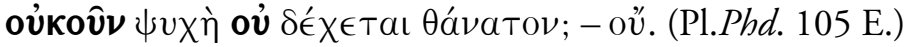

Therefore the soul does not admit of death? - No. 
The question with oúkov̂v ... oú expects (and receives) a negative answer. For the accent on oú, see the comment preceding the second example in $\$ 17.2$ below.

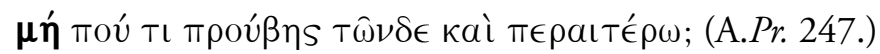

Did you perhaps go even somewhat further than this?

$\mu \eta$ gives a worried tone to the question.

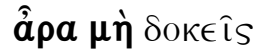

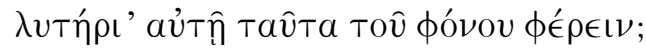

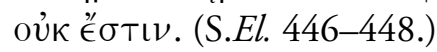

\section{Do you really think}

that you are bringing these things as a deliverance for her from the murder? It is not possible.

Despite her own attitude, Electra does not expect her sister Chrysothemis to answer 'No'. â $\rho \alpha \mu$ in indicates Electra's emotion in opposing her sister's action.

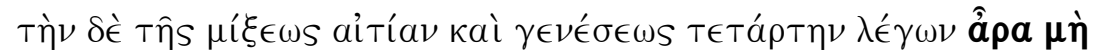

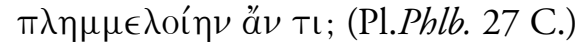

And I would not be making any mistake in calling the cause of mixing and generation the fourth <cause>, would I?

This question with $\hat{\alpha} \rho \alpha \mu \eta^{\prime}$ (delayed) expects a negative answer. $\hat{\alpha} \rho \alpha \mu$, used in this and the preceding example, is not common in classical Greek.

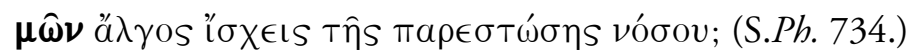

Do you have pain from your current sickness?

$\mu \hat{\omega} \nu$ (derived from $\mu \grave{\eta}$ oûv) expresses Neoptolemus's concern at Philoctetes's pain.

\subsection{Alternative Questions}

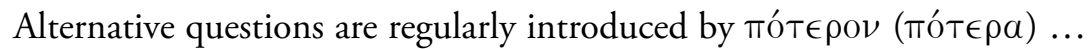
$\eta$. .. ; Further alternatives may be added by repetition of $\eta$. The initial тó $T \in \rho O \nu(-\alpha)$ is often omitted in Greek. And an initial 'whether' is no longer used in direct alternative questions in English. 


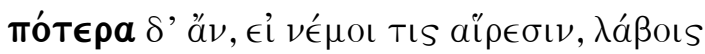

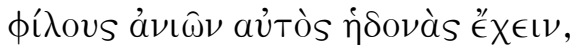

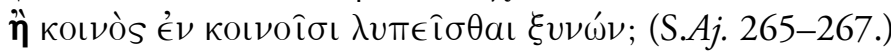

And, if someone were to give <you > choice, would you choose [lit. accept] to have pleasure yourself while distressing your friends,

or to be grieved while being together as a partner among partners?

The second alternative is sometimes a mere negative. If ou is immediately followed by punctuation at the end of a clause or sentence, it has an oxytone accent, oú.

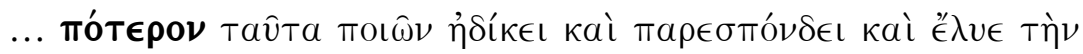

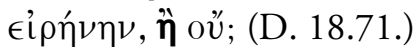

... in doing these things was he acting wrongly and was he violating the treaty and was he breaking the peace, or not?

In the following example, continuous with the preceding, the Infinitive construction with '́X $\chi \hat{\eta} \nu$ justifies $\mu$ '́ as the negative for the second alternative. (Cf. Smyth, 1956, \$2714.)

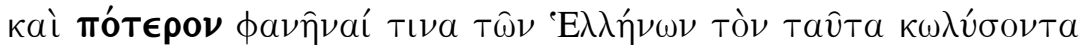

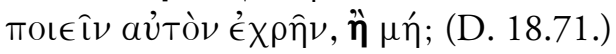

And was it right that one of the Greeks should appear as the one to prevent him doing this, or not?

\subsection{Questions with Interrogative Adjectives or Adverbs}

Questions may be introduced by interrogative adjectives or adverbs. The adjectives may be used with or without a noun. Without a noun, they function as pronouns.

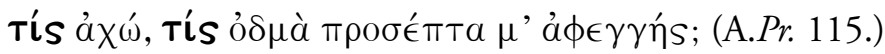

What sound, what smell came upon me, unseen?

Tís is used as an interrogative adjective. 
Tís $\hat{\omega} \delta \in \tau \lambda \eta \sigma ı \alpha a ́ \rho \delta ı s$

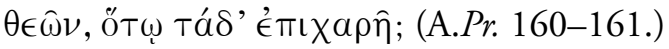

Who $<i s>$ so hard-hearted

among the gods, that this <is> a joy to him?

Tís is used as an interrogative pronoun.

$\pi \hat{\omega} s$ ÉTó $\lambda \mu \eta \sigma a s, \lambda ı \pi \omega ̀ \nu$

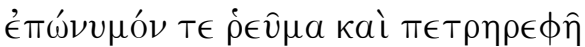

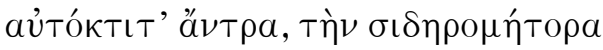

É $\lambda \theta \in \hat{\imath} \nu$ És aîav; (A.Pr. 299-302.)

How did you dare, leaving

the stream named after you and rock-vaulted caverns formed by yourself, to come to this iron-producing land?

$\pi \omega \hat{S}$ is an interrogative adverb.

\subsection{Deliberative Questions}

Deliberative questions normally occur in the first person singular or plural, and ask, for example: 'Am I to do this?' or 'What are we to do?' or 'Where are we to go?' They may be addressed to oneself, or to some other person. The Mood is Subjunctive, and the negative is $\mu$ '́.

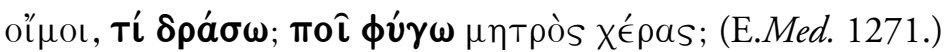
Alas, what am I to do? Where am I to flee from my mother's hands?

Deliberation may also be expressed by the Future Indicative, by the modal expressions $\delta \in \hat{\imath}$ or $\chi \rho \eta$, or by the verbal adjectives expressing necessity.

\subsection{Rhetorical Questions}

Rhetorical questions have the form of a question, but the function of a statement or a command. Thus, either they do not expect any answer or an answer is provided by the speaker. Rhetorical questions differ from other questions only in function, not in form. 


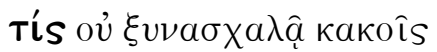

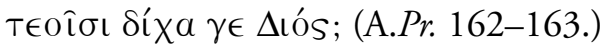

Who does not sympathise with your

troubles, apart from Zeus at least?

Function: There is nobody who does not sympathise ... (Statement).

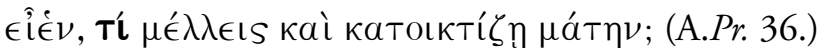

Enough! Why do you delay and pity <him $>$ in vain?

Function: Do not delay ... (Command).

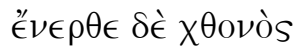

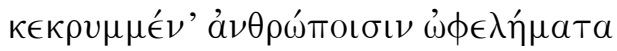

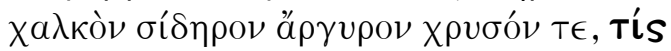

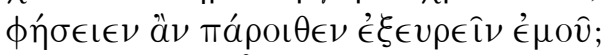

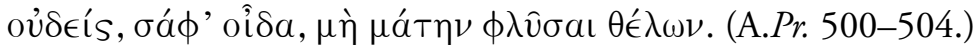

$$
\text { And < as for }>\text { aids }
$$

for mankind hidden beneath the earth,

bronze, iron, silver and gold, who

would say that he discovered <them $>$ before me?

No one, I am sure, unless wishing to babble on in vain.

The question is answered by the speaker, who thereby shows that the question is equivalent to a statement: No one would say that he discovered ... before me.

\section{References}

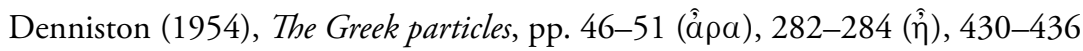

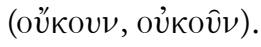

Goodwin (1889), Syntax of the moods and tenses of the Greek verb, $\$ \$ 287-293$.

Smyth (1956), Greek grammar, $\$ \$ 1805,1807-1809$, 2636-2662.

The present Lesson agrees with Denniston (1954) and Humbert (1954) on the

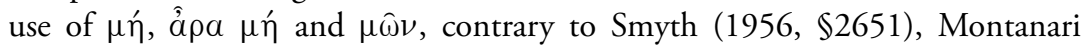
(2015) and Liddell and Scott (1996). Smyth (1956) in $\$ 2657$ has misquoted D. 18.71 , which should be placed in $\$ 2656$. 


\section{EXERCISE 17}

Translate the following passages.

1.

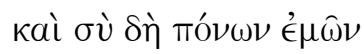

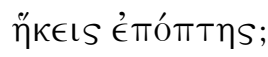

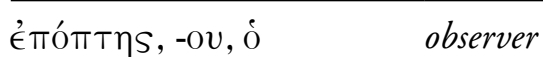

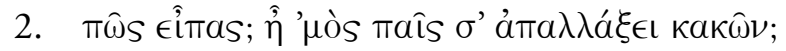

\begin{tabular}{ll}
\hline$\lambda \epsilon ́ \gamma \in \mathrm{L}, \epsilon i \pi \epsilon \hat{\imath} \nu$ & to say; to mean \\
$\dot{a} \pi \alpha \lambda \lambda a ́ \sigma \sigma \in \mathrm{IV}$ & to release
\end{tabular}

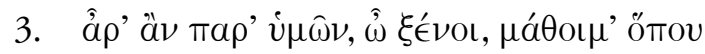

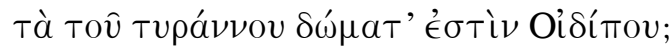

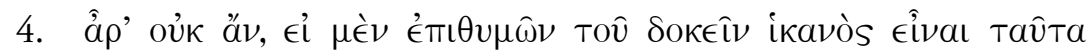

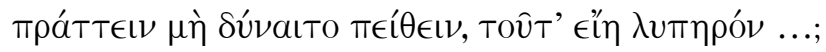

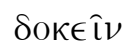

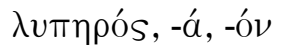

\section{to seem}

distressing

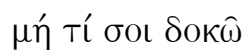

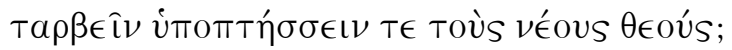

\begin{tabular}{|c|c|}
\hline $\begin{array}{l}\tau \alpha \rho \beta \in \hat{\imath} \nu \\
\dot{v} \pi \rho \pi \tau \dot{n} \sigma \sigma \in \| \nu\end{array}$ & $\begin{array}{l}\text { to be fearful } \\
\text { to cower before }(+A c c)\end{array}$ \\
\hline
\end{tabular}

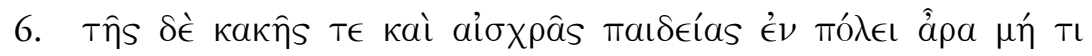

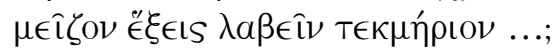

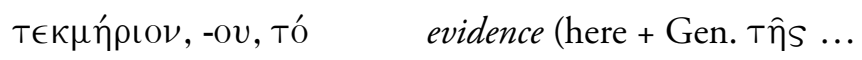

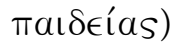

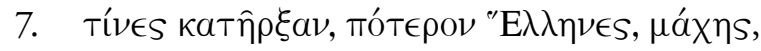

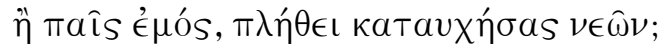

\begin{tabular}{ll}
\hline$\kappa a \tau a ́ \rho x \in \mathrm{L} \nu$ & to begin (+ Gen.) \\
$\kappa a \tau a v \chi \in \hat{\imath} \nu$ & to be overconfident
\end{tabular}




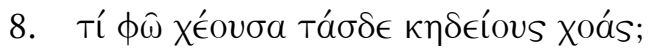

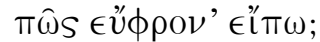

\begin{tabular}{|c|c|}
\hline$x \in \hat{\imath} \nu$ & to pour \\
\hline 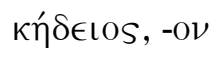 & (funereal, sepulchral;) for the dead \\
\hline 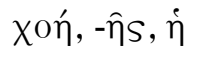 & (pouring out;) drink-offering \\
\hline$\epsilon \ddot{U} \phi \rho \omega \nu,-0 \nu$ & gracious \\
\hline
\end{tabular}

9. Therefore, the names of the men, against whom that [man] laid information, are these?

\begin{tabular}{ll}
\hline against & кaTá (+ Gen.) \\
to lay information & $\mu \eta \nu u ́ \in \iota \nu$ \\
\hline
\end{tabular}

10. Does Aeschines seem to you, $\mathrm{O}$ men of Athens, to be an employee or a guest-friend of Alexander?

\begin{tabular}{|c|c|}
\hline Does... or & 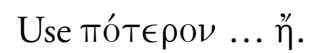 \\
\hline Aeschines & 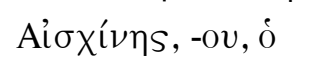 \\
\hline employee & 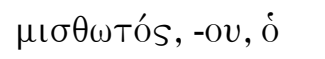 \\
\hline guest-friend & 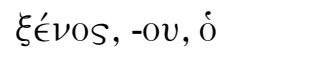 \\
\hline Alexander & 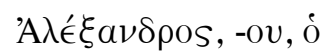 \\
\hline
\end{tabular}




\section{LESSON 18 \\ Reported Questions}

\subsection{Reported Ordinary Questions}

The verbs in reported questions have the same usage of Mood and Tense as in reported statements with ötı or $\dot{\omega}$ s. See Lessons 13.2 and 13.3. Reported ordinary questions are regularly introduced by the conjunction $\epsilon \hat{l}$ in the sense 'whether'. ov or $\mu$ ' may be retained from the presumed direct form of a reported question. The whole reported question is the direct Object of the leading verb.

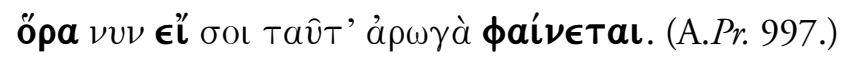

Come now, see whether this seems helpful to you.

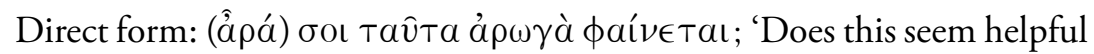
to you?' In Primary sequence, the Mood and Tense of the verb in the reported form are the same as in the direct form.

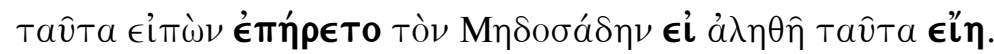
(X.An. 7.2.25.)

After saying this he asked Medosades in addition, whether this was true.

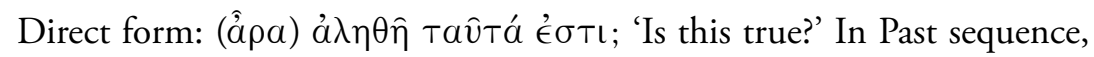
the Indicative of the direct form becomes Optative in the reported form.

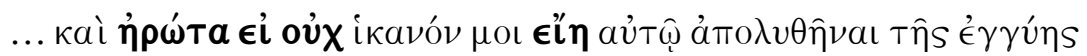

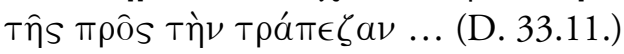

... and he asked whether it was not enough for me to be released myself from the security-paid to the bank...

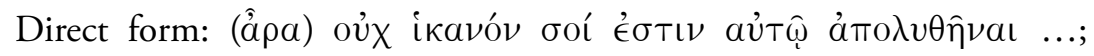
'Is it not enough for you yourself to be released ...?' oúx of the direct form is retained in the reported form and implies the expectation of a positive answer. 


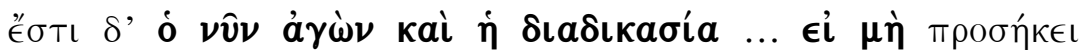

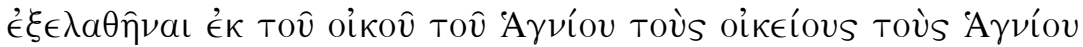
... (D. 43.61.)

And the present lawsuit and dispute are <about $>$... whether it is really appropriate that the kinsmen of Hagnias should be driven out of the household of Hagnias ...

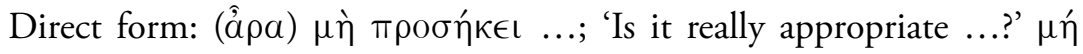
of the direct form is retained in the reported form, and lends a more emotional tone to the question ('really'). $\mu$ ' does not in itself imply the expectation of a negative answer.

\section{2. ấa in Reported Questions}

Sometimes, $\hat{\alpha} \rho \alpha$ seems to be used to introduce a reported ordinary question. A noticeable proportion of the examples of this usage are exhortations to 'examine' whether something is the case, especially with forms of the verb $\sigma \kappa \epsilon \in \pi \tau \epsilon \sigma \theta a$. As in the following example, it is frequently ambiguous whether the question is reported or actually direct.

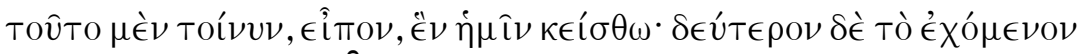

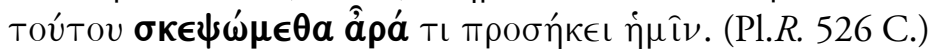

Reported: 'Let this one point, therefore', I said, 'be assumed for us; and let us consider a second, following from this one, (as to) whether it is of any concern to us'.

Direct: 'and let us consider a second, following from this one. Is it of any concern to us?'

\subsection{Reported Alternative Questions}

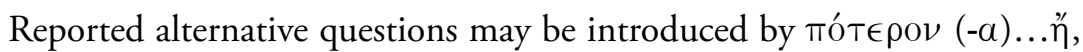

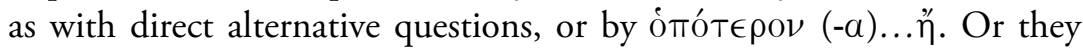
may be introduced by several other combinations of conjunctions, as in the following examples. Where the second alternative is negative, $\mu \eta$ is sometimes used, rather than ovं, without any obvious syntactical justification. 


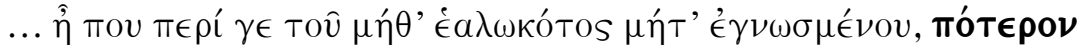

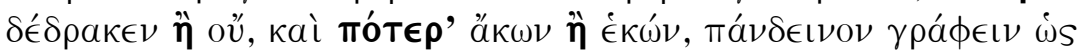

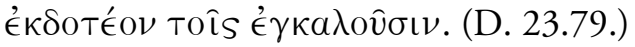

... surely in the case of a man who has been neither convicted nor judged as to whether he has done <something > or not, and whether accidentally or deliberately, <it is $>$ outrageous to draft $<a$ law $>$, that it is necessary to hand $<$ him $>$ over to his accusers.

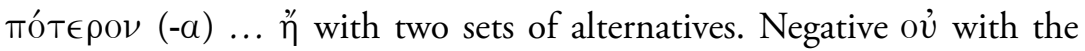
second alternative of the first set.

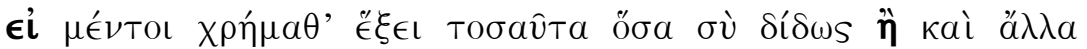

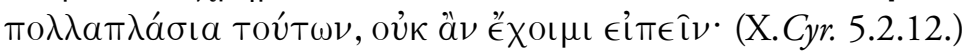

But whether he will have so much money as you are offering or actually other $<$ funds> many times more than this, I would not be able to say.

$\epsilon \mathfrak{l}$...ク gives preference to the second alternative, here reinforced by kaí.

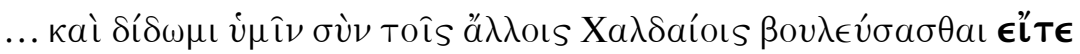

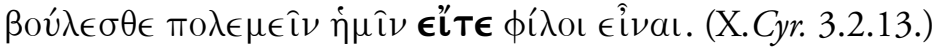

... and I am allowing you to consult with the rest of the Chaldaeans as to whether you want to go to war with us or to be friends.

$\epsilon^{\prime} T \epsilon \ldots \in \epsilon^{\prime} T \epsilon$ gives equal value to each alternative.

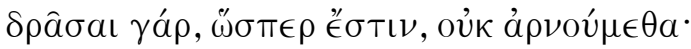

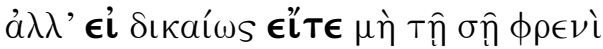

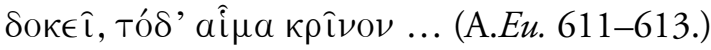

For, as it is, we do not deny that we did it.

But judge this murder, as to whether to your mind it seems justly <done> or not ...

$\epsilon i . . . \epsilon l T \epsilon$ also gives equal value to each alternative. Negative $\mu \eta \dot{n}$ is used with the second alternative. 


\subsection{Reported Questions with Interrogative Adjectives or Adverbs}

Reported questions may be introduced by the indirect form of interrogative adjectives or adverbs. Corresponding to the direct forms Tís ('Who?'), $\pi \omega \hat{s}$ ('How?') and so on, are the indirect forms ö $\sigma \tau t s$, ö $\pi \omega s$ and so on. However, quite often the direct forms are also used to introduce reported questions. And sometimes the relative forms ös, $\dot{\omega}$ and so on are used.

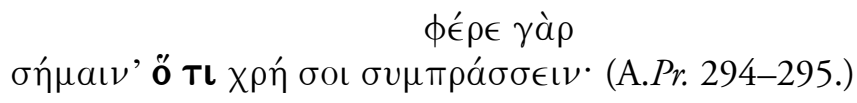

So come,

indicate what $<I>$ should do to help you.

Indirect interrogative pronoun ö $\mathrm{Tl}$.

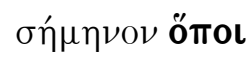

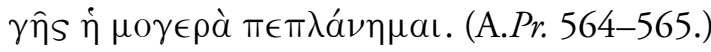

\section{Indicate to where}

on earth I poor girl have wandered.

Indirect interrogative adverb öTot.

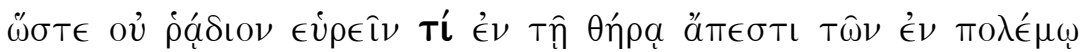
паро́ $\nu T \omega \nu$. (X.Cyr. 1.2.10.)

And so <it is> not easy to find out which of the <elements> present in war is absent in hunting.

Direct interrogative pronoun $\tau i ́$ in reported question.

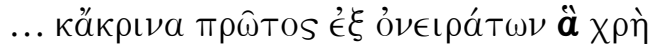

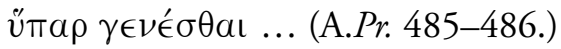

... and I first discerned among dreams, which ones should become reality ...

Relative adjective $\alpha$ in reported question.

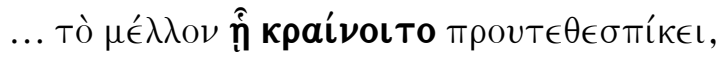

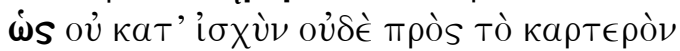

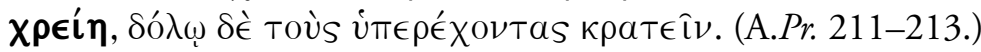


... (she) had foretold in what way the future was being brought to pass,

how not by strength nor with force

should the winners prevail, but by cunning.

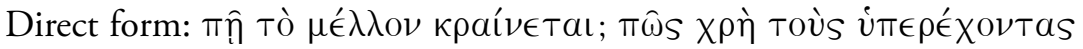

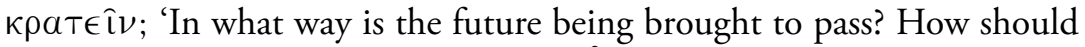
the winners prevail?' Relative adverbs $\hat{\eta}$ and $\dot{\omega}$ in reported questions.

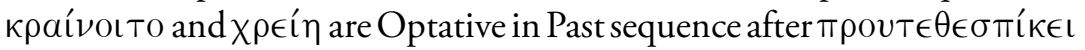
(Past Perf.).

\subsection{Reported Deliberative Questions}

Reported Deliberative questions follow a pattern of usage similar to that of other types of reported discourse.

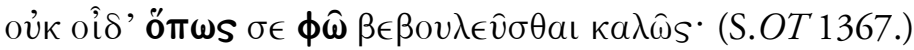

I do not know how I am to say that you have made a good decision.

Direct form: $\pi \hat{\omega} s \phi \hat{\omega}$...; 'How am I to say ...?' In Primary sequence, the Mood and Aspect of the verb in the reported form is the same as in the direct form.

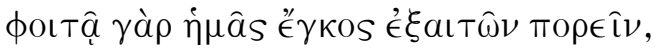

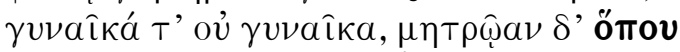

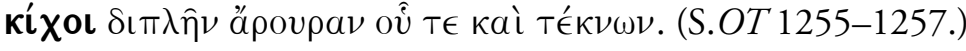

For he was wandering around, asking us to provide a sword, and where he was to find the wife that was no wife, and the double maternal field of himself and his children.

Direct form: пov̂ kí $\chi \omega . . . ;$ 'Where am I to find ...?' In Past sequence, the Subjunctive of the direct form becomes Optative in the same Aspect in the reported form.

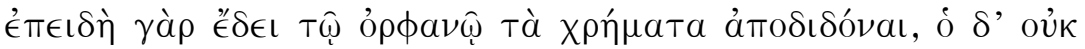

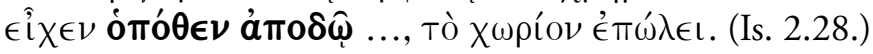

For when it had become necessary to pay back the money to the orphan, and he did not know from where he was to pay <it> back..., he was <in favour of selling the property.

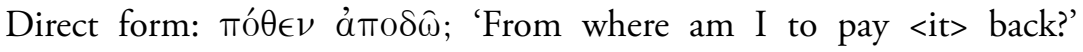
In a Vivid construction in Past sequence, the Mood and Aspect of the direct form are retained in the reported form. 


\section{References}

Goodwin (1889), Syntax of the moods and tenses of the Greek verb, $\$ \$ 665,667$, 669-672, 677-681.

Smyth (1956), Greek grammar, \$\$2663-2679.

\section{EXERCISE 18}

Translate the following passages. For the Exercise, $\epsilon \dot{\imath}$ should preferably be translated as 'whether'.

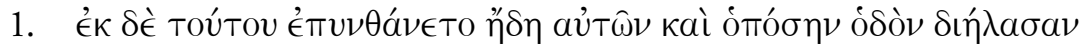

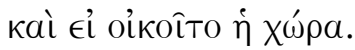

\begin{tabular}{|c|c|}
\hline$\stackrel{\epsilon}{K} K$ & after \\
\hline$\pi v \nu \theta a ́ \nu \in \sigma \theta a \iota$ & $\begin{array}{l}\text { to inquire (of someone) (+ Gen. and } \\
\text { reported questions) }\end{array}$ \\
\hline kaí ... kaí ... & also $\ldots$ and ... \\
\hline$\delta ı \in \lambda a u ́ v \in ı \nu$ & to ride over \\
\hline
\end{tabular}

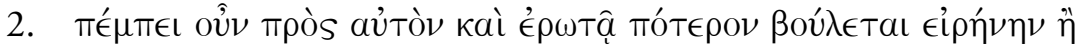

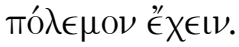

\begin{tabular}{|c|c|}
\hline$\pi \epsilon ́ \mu \pi \epsilon \mathrm{.} . . \dot{\epsilon} \rho \omega T \hat{\alpha} \ldots$ & Hist. Pres. \\
\hline$\beta o u ́ \lambda \in T a \iota$ & Vivid construction \\
\hline
\end{tabular}

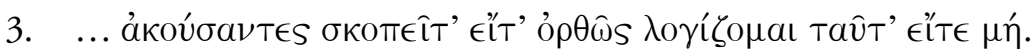

$\begin{array}{ll}\sigma \kappa о \pi \epsilon \hat{\imath}(\epsilon) & \text { Impv. } \\ \lambda о \gamma(\hat{\zeta} \zeta \in \theta \text { aı (Mid.) } & \text { to assess }\end{array}$

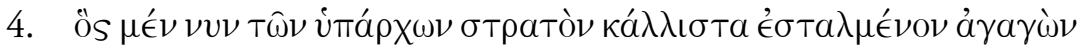

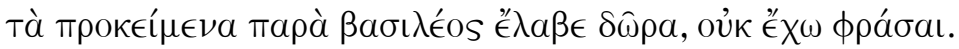

\begin{tabular}{|c|c|}
\hline$\mu \epsilon ́ \nu \nu v \nu$ & well now (transitional phrase) \\
\hline 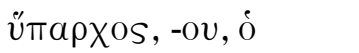 & commander \\
\hline 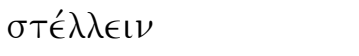 & to equip \\
\hline$\pi \rho о к \epsilon \hat{\imath} \sigma \theta \alpha \iota$ & to be proffered \\
\hline 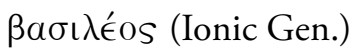 & $\beta a \sigma ı \lambda \epsilon^{\prime} \omega s$ (Attic) \\
\hline
\end{tabular}




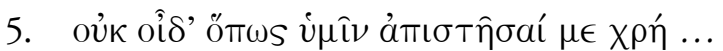

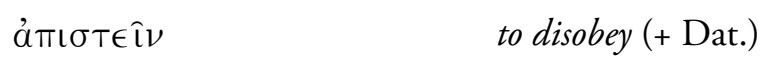

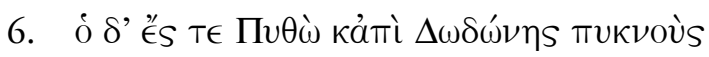

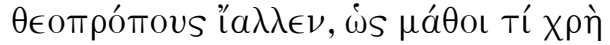

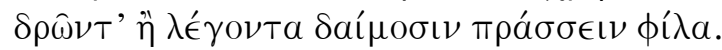

$\dot{o} \delta\left(\dot{\epsilon}^{\prime}\right)$

$\Pi v \theta \dot{\omega},-o v \hat{s}, \dot{\eta}$

є̇mí (+ Gen.)

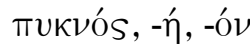

$\theta \in$ отро́тоs, -ov, ó

iá $\lambda \lambda \in \iota \nu$

$\phi i ́ \lambda a$ (n. pl. Acc.) and he

Pytho (region around Delphi)

in the direction of, to

frequent

messenger (adj. as noun)

to send

pleasing (to) (+ Dat.)

7. And all the aliens who are residents will know whether unjustly they are excluding the thirty from the[ir] cities, or justly.

\begin{tabular}{|c|c|}
\hline all ... who & öбol (+ Indic.) \\
\hline alien & $\xi \in \epsilon^{\prime} \nu \mathrm{OS},-\mathrm{OU}, \dot{O}$ \\
\hline to be a resident & $\epsilon \in \pi \iota \eta \eta \mu \epsilon \hat{\imath} \nu$ \\
\hline to exclude (by proclamation) & 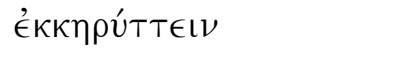 \\
\hline thirty (tyrants) & 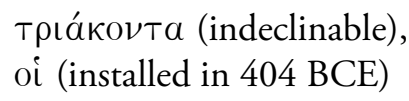 \\
\hline
\end{tabular}

8. And on hearing this, Clearchus asked the messenger approximately how big the country between the Tigris and the canal was.

\begin{tabular}{|c|c|}
\hline Clearchus & 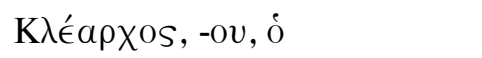 \\
\hline approximately how big & $\begin{array}{l}\text { Use TIS (enclitic) in agreement } \\
\text { with (and after) the appropriate } \\
\text { gender of }(\dot{0}) \text { móoos. }\end{array}$ \\
\hline between & '́ $\nu \mu \epsilon^{\prime} \sigma \omega(+$ Gen.) \\
\hline Tigris & 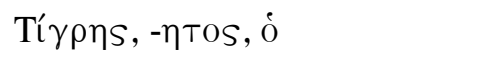 \\
\hline canal & $\delta \iota \hat{\omega} \rho v \xi,-v x o s, \dot{\eta}$ \\
\hline
\end{tabular}





\section{LESSON 19 \\ Conditions}

\subsection{Introduction}

In the study of Greek syntax, various schemes of classification have been used for Conditions. The following scheme is intended to be as simple and clear as possible. It classifies the usual practice of the classical period, according to type of Condition, with subdivisions according to time reference. (Homeric Conditions show some differences; see Lesson 20.) The negative in all types of Conditional clause is regularly $\mu \eta^{\prime}$.

Conditional clauses are adverbial clauses, which modify the verb in the clause on which they depend. Most commonly, the leading clause is the Main clause of a sentence. But a Conditional clause may depend on another Subordinate clause, as in $\$ 19.4 .1$ below.

\subsection{Open Conditions}

Open Conditions leave it 'open' whether the Condition is, or is likely to be, fulfilled.

\subsubsection{Particular}

Open Particular Conditions refer to 'particular' circumstances and, therefore, use $\epsilon \mathfrak{l}$ with Indicative in the if-clause, and Indicative in the Main clause (if the Main clause is a statement).

\section{Present}

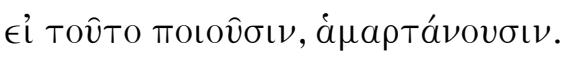

If they are doing this, they are making a mistake.

\section{Past}

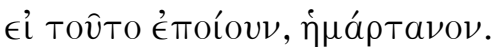

If they were doing this, they were making a mistake. 
Past Imperfect Indicative denotes continuous or repeated action.

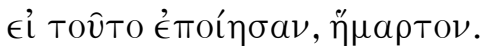

If they did this, they made a mistake.

Past Aorist Indicative denotes momentary action.

\section{Future}

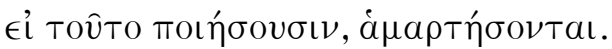

If they do this, they will make a mistake.

In English idiom, a Present form is regularly used in the if-clause of a Future Open Condition (so also in $\$ 19.2 .2$ below). Future Open Particular Conditions, with Indicative in the if-clause, are less common but more emphatic than Future Open General Conditions. They are used especially in threats or warnings.

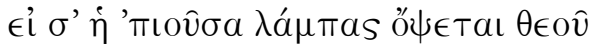

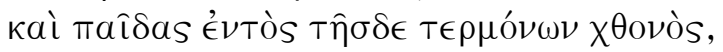

$\theta a \nu \hat{n} \cdot$ (E. Med. 352-354.)

If the coming light of god sees you

and your children within the limits of this land, you will die.

\subsubsection{General}

Open General Conditions all refer to the circumstances of the Condition in a 'general' or 'indefinite' way. Parallel to other indefinite constructions, they therefore use éá $\nu$ with Subjunctive in Primary sequence in if-clauses, and $\epsilon \dot{l}$ with Optative in Past sequence. Alternative forms for $\epsilon$ áv also occur: $\dddot{\eta} \nu, \grave{\alpha} \nu$ (with long $\alpha$ ).

\section{Present}

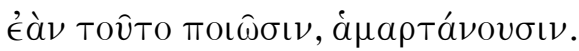

If (ever) they do this, they are making a mistake.

Éáv + Subjunctive in if-clause; Indicative in Main clause.

\section{Past}

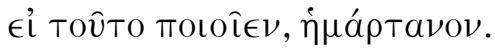

If (ever) they were doing this, they were making a mistake. 
Imperfect Optative and Past Imperfect Indicative denote continuous or repeated action.

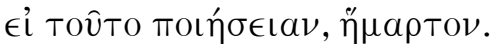

If (ever) they did this, they made a mistake.

Aorist Optative and Past Aorist Indicative denote momentary action.

In both Past examples, $\in \hat{\imath}+$ Optative in if-clause; Indicative in Main clause.

\section{Future}

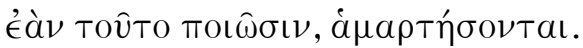

If (ever) they do this, they will make a mistake.

$€ \in a ́ v+$ Subjunctive in if-clause; Indicative in Main clause.

\subsection{Unfulfilled Conditions}

Unfulfilled Conditions imply that the circumstances of the if-clause are contrary to fact or 'unfulfilled'. From a chronological point of view, any Future Condition is necessarily unfulfilled. But the term 'unfulfilled' is not applied to other Future Conditions. Future Unfulfilled Conditions are unlikely to be fulfilled. They belong to the same category of Condition as Present and Past Unfulfilled Conditions.

Especially in the scheme of Unfulfilled Conditions, it should be noted that the headings 'Present', 'Past' and 'Future' indicate the time reference of the Conditions, not necessarily the Tense of the Indicative verbs, and certainly not the Aspect of the Optative verbs. The form of the Past continuous Unfulfilled Condition is the same as the form of the Present Unfulfilled Condition. In the if-clause of English Present and Future Unfulfilled Conditions, 'were' is a Subjunctive form, not a Past Indicative form.

\section{Present}

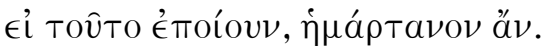

If they were (now) doing this, they would be making a mistake.

$\epsilon \hat{\imath}+$ Past Imperfect Indicative in if-clause; Past Imperfect Indicative with $a ̈ \nu$ in Main clause. 


\section{Past}

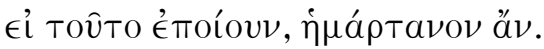

If they had been doing this, they would have been making a mistake.

$\epsilon \hat{l}+$ Past Imperfect Indicative in if-clause; Past Imperfect Indicative with $a ̊ v$ in Main clause; continuous.

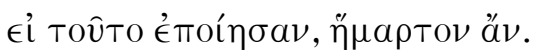

If they had done this, they would have made a mistake.

$\epsilon \grave{l}+$ Past Aorist Indicative in if-clause; Past Aorist Indicative with ö $v$ in Main clause; momentary.

\section{Future}

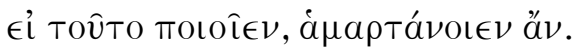

If they were to (be) do(ing) this, they would be making a mistake. Imperfect Aspect; continuous.

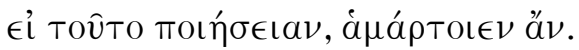

If they were to do this, they would make a mistake. Aorist Aspect; momentary.

(Often expressed as: If they did this, ...)

In both Future examples, $\epsilon \dot{\imath}+$ Optative in if-clause; Optative with å $v$ in Main clause.

\subsection{Mixed Conditions}

\subsubsection{Mixed Times and Types}

In some Conditional sentences, there may be a difference of time reference or of type of Condition (or both) between the Main clause and the if-clause, as in the following sentence.

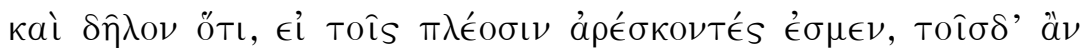

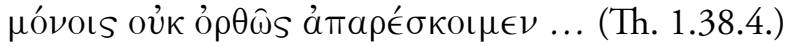

And $<$ it is $>$ clear that, if we are acceptable to the greater number, we would not rightly be unacceptable to these $<$ people $>$ alone ...

Present Open Particular if-clause, Future Unfulfilled Main clause. 


\subsubsection{General Principles (with Primary Time Reference)}

Open General Conditions, expressing a general principle, may sometimes have Optative (rather than Subjunctive) in the if-clause, and Indicative in the Main clause. The Indicative of the Main clause is usually Present (sometimes with Future implications), sometimes Future, or rarely Present Perfect. And sometimes, in the Main clause the verb 'to be' is unexpressed.

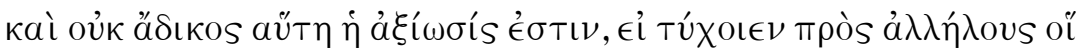

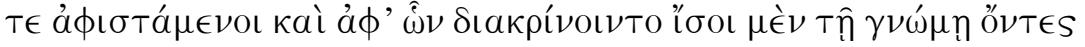
кaì єủvoía ... (Th. 3.9.2.)

And this assessment is not unfair, if those who secede <from an alliance $>$ and $<$ those $>$ from whom they are separated [were to] happen to be on an equal footing towards each other in attitude and good will ...

In English style, it would be natural to omit the words '[were to]'. But then the distinctive form of the Greek construction is lost in translation.

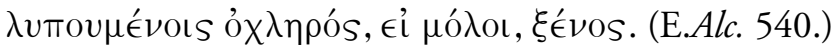

$A$ visitor, if he were to come, <is> annoying to people who are grieving.

The verb 'to be' is unexpressed in the Main clause in Greek. Again, in English style it would be natural to say 'comes' rather than 'were to come'.

\subsubsection{Iterative Past Conditions}

There is also an iterative form of Past Open General Condition, using $\epsilon \hat{\imath}$ + Optative in the if-clause, and $\alpha ّ v$ with either Past Imperfect Indicative or Past Aorist Indicative in the Main clause. The term 'iterative' indicates repeated action.

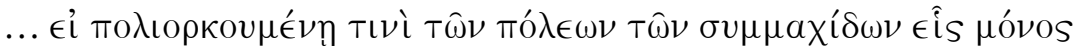

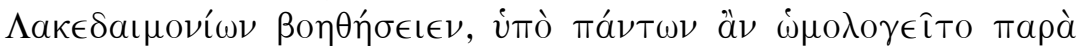

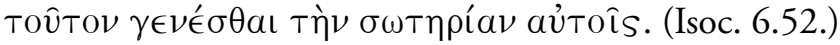

... if a single one of the Spartans came to help one of our allied cities when it was under siege, it used to be agreed by all that due to this man safety had come to them.

Past Imperfect Indicative in Main clause denotes continuous action. 


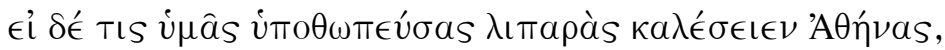

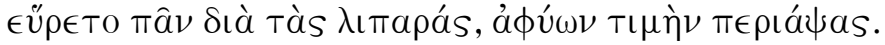
(Ar.Ach. 639-640.)

And if anyone, using flattery, called you 'shining Athens', he obtained everything on account of that 'shining', by surrounding small fry with honour.

Past Aorist Indicative in Main clause denotes momentary action.

\subsection{The Negative in If-Clauses}

The negative in if-clauses is regularly $\mu \eta \dot{~(a s ~ n o t e d ~ i n ~} \$ 19.1$ above). In particular circumstances, ov may occur:

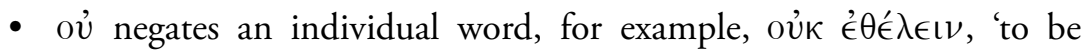
un-willing'

- the factuality of a condition is emphasised

- ov́ negates one of two contrasted clauses, which are introduced by a single $\epsilon \hat{l}$ with Indicative

- with expressions of emotion, ov may occur in a clause where 'if' is equivalent to 'that' (Lesson 34.4)

- oú may negate a clause, in which 'if' is virtually Causal, meaning 'since', 'because' (Lessons 23.1 and 1.1).

\section{References}

Goodwin (1889), Syntax of the moods and tenses of the Greek verb, $\$ \$ 162,378-513$.

Smyth (1956), Greek grammar, \$\$2280-2368, 2696-2698, 2701.

The analyses of Goodwin (1889) and Smyth (1956) are more complex than that which has been attempted here, and their terminology is different in part. 


\section{EXERCISE 19}

Translate the following passages.

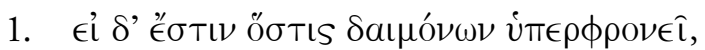

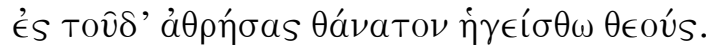

\begin{tabular}{ll}
\hline$\dot{v} \pi \epsilon \rho \phi \rho 0 \nu \in \hat{\imath} \nu$ & to look down on, to despise (+ Gen.) \\
$\dot{\alpha} \theta \rho \in \hat{\imath} \nu \hat{~} \mathrm{~S}_{\mathrm{S}}(+\mathrm{Acc})$. & to look at, to observe \\
$\dot{\eta} \gamma \in \hat{\imath} \sigma \theta a \mathrm{l}$ & to believe in (+ Acc.)
\end{tabular}

2.

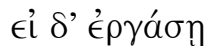

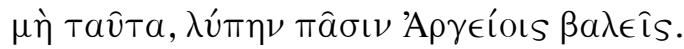

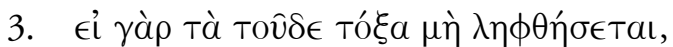

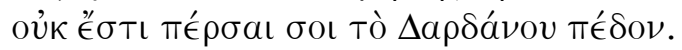

\begin{tabular}{|c|c|}
\hline Tóka, - $\omega \nu$, Tá & bow \\
\hline$\pi \epsilon ́ \rho \theta \in \iota \nu$ & to ravage, to sack \\
\hline$\Delta a ́ p \delta a v o s,-o v, \dot{o}$ & $\begin{array}{l}\text { Dardanus (mythical ancestor of kings } \\
\text { of Troy) }\end{array}$ \\
\hline 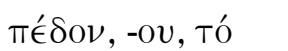 & land \\
\hline
\end{tabular}

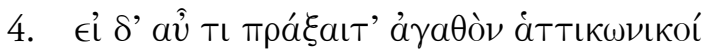

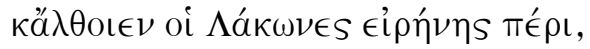

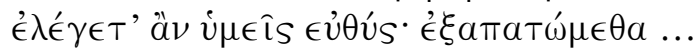

\begin{tabular}{|c|c|}
\hline$\delta^{\prime} a \hat{v}$ & and/but again (often enumerating) \\
\hline 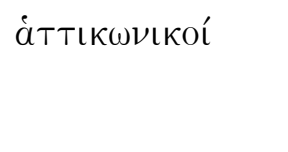 & 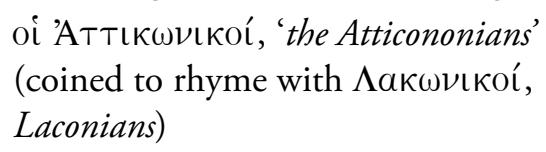 \\
\hline$\kappa a ̈ \lambda \theta \theta \mathrm{ot \epsilon \nu}$ & кaì é $\lambda \theta o ı \in \nu$ \\
\hline$\Lambda a ́ k \omega \nu \in S,-\omega \nu$, oi & Laconians \\
\hline$\epsilon^{\epsilon} \xi \alpha \pi a \tau \hat{\alpha} \nu$ & $\begin{array}{l}\text { to deceive (here Pass., and beginning } \\
\text { direct speech) }\end{array}$ \\
\hline
\end{tabular}




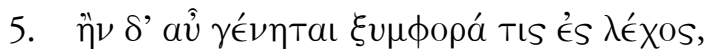

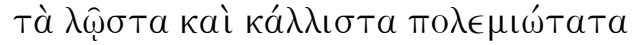
тí $\theta \in \sigma \theta \epsilon$.

\begin{tabular}{|c|c|}
\hline 入ÉXOS, -ous, Tó & (bed, often referring to) marriage \\
\hline$\lambda \hat{\omega} \sigma \tau$ Tos, $-\eta,-$ ov & best \\
\hline тí⿴囗⿱一一 $\sigma \theta a \iota$ (Mid.) & to regard (as) (here Indic.) \\
\hline
\end{tabular}

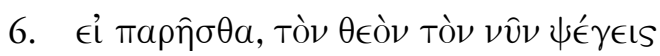
$\epsilon \dot{v} x a \hat{\imath} \sigma \iota \nu \grave{\alpha} \nu \mu \in T \hat{\eta} \lambda \theta \in S$...

\begin{tabular}{|c|c|}
\hline Tóv (2nd instance) & öv \\
\hline$\psi \psi^{\prime} \gamma \in \mathrm{I \nu}$ & to criticise \\
\hline$\epsilon \dot{v} \times \dot{\eta},-\hat{\eta} s, \dot{\eta}$ & prayer \\
\hline$\mu \in T \in \lambda \theta \in \hat{\imath} \nu$ (Aor.) & $\begin{array}{l}\text { to approach (someone: Acc.) with } \\
\text { (something. Dat.) }\end{array}$ \\
\hline
\end{tabular}

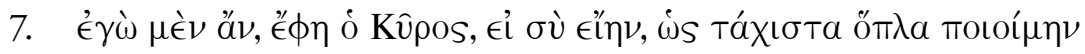

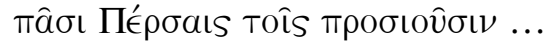

пробı'́val to approach, to come (here)

(in friendly sense)

8. And perhaps I would have been put to death because of this, if the government had not been quickly dissolved.

\begin{tabular}{|c|c|}
\hline perhaps & lows \\
\hline to be put to death = to die & $\dot{a} \pi \circ \theta \nu \eta ̣ \sigma \kappa \in \iota \nu$ \\
\hline government & 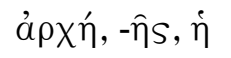 \\
\hline to dissolve & 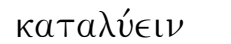 \\
\hline
\end{tabular}

9. For I would not be speaking, if I did not care greatly for the whole of Greece.

to care (for) кń $\delta \in \sigma \theta a \mathrm{l}$ (Mid.; + Gen.)




\section{LESSON 20 \\ Homeric Conditions}

\subsection{Introduction}

In the Homeric poems, Conditional sentences have not yet attained the regularity of the classical period. Some Homeric Conditions have the same form as those of the classical period. Some may be explained as mixed types. But some Homeric constructions no longer appear in the classical period. On the other hand, some classical constructions have not yet developed at the stage of the Homeric poems. The Doric and Aeolic form a $\mathrm{l}$ may be used instead of $\epsilon \hat{l}$ in Homer. And the enclitic $\kappa \in$ may be used instead of $\alpha \nu$. When $\kappa \epsilon$ occurs before a word beginning with a vowel, either movable $\nu$ may be added, or $\epsilon$ may be elided.

The following sections of this Lesson contain some representative examples of Homeric constructions which differ from the classical standard. At the risk of anachronism, but for the sake of comparison, the same categories are used as in Lesson 19. However, scholars do not always agree in the classification or translation of Homeric Conditions.

\subsection{Open Conditions}

\subsubsection{Open Particular Conditions}

Open Particular Conditions normally have the same form in Homer as in the classical period. However, in addition to the usual form of Future Open Particular Condition ( $\epsilon \mathfrak{l}+$ Indic. in if-clause, Indic. in Main clause), $\kappa \in$ may appear with the Indicative in the if-clause in Homer.

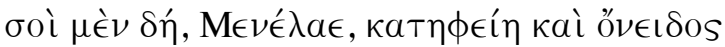

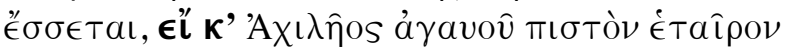

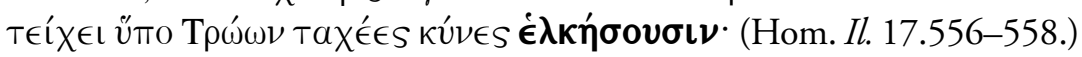


For you indeed, Menelaus, there will be dejection and reproach, if swift hounds tear apart the trusted companion of noble Achilles under the wall of the Trojans.

\subsubsection{Open General Conditions}

\subsubsection{Present}

In Present Open General Conditions, Homer regularly uses $\in \dot{l}$ ( $a \grave{i}$ ) alone and the Subjunctive without $\stackrel{\alpha}{\nu} \nu$ or $\kappa \epsilon$.

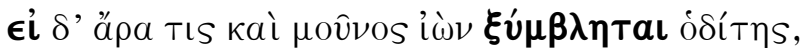

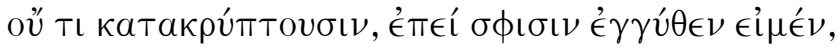

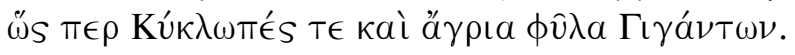
(Hom.Od. 7.204-206.)

And if, then, any one going alone as a wayfarer meets up with <them>, they do not conceal at all, since we are near to them, just as the Cyclopes and the wild tribes of the Giants.

$\xi \dot{v} \mu \beta \lambda \eta \tau a \iota$ is third person singular Aorist Subjunctive Middle of $\sigma v \mu \beta a ́ \lambda \lambda \in \mathrm{l} \nu$.

A classical equivalent of the Homeric construction occurs in the following example.

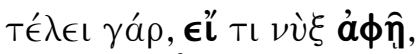

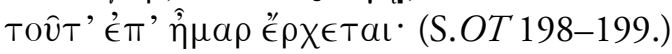

For, if night leaves anything out,

this day comes on for completion.

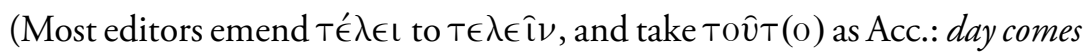
on to complete this. On either reading $\hat{\epsilon} \pi(\hat{\mathrm{l}})$ is an adv. not a preposition.)

\subsubsection{Future}

a. Future Open General Conditions are far more common in Homer than Future Open Particular Conditions. (This tendency continues into the classical period.) Homer most often uses $\epsilon \dot{l}$ (ai) and the Subjunctive with $\kappa \in$ (or occasionally ő $\nu$ ), equivalent to classical €́á $\nu$ and the Subjunctive, in the if-clause, and Future Indicative in the Main clause. For the if-clause, ฑ๊v is also frequent; but the forms éáv and $\alpha$ $v$ (with long $\alpha$ ) do not occur in Homer. 


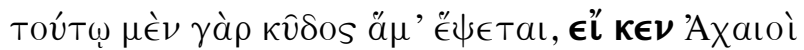

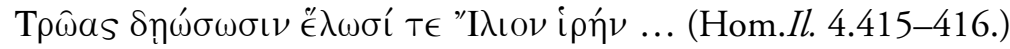

For renown will follow after this $<$ man $>$, if the Achaeans cut down the Trojans and capture sacred Ilios ...

Future Indicative in Main clause, $\epsilon l k \in \nu$ with Subjunctive in if-clause.

b. Instead of the usual Future Indicative of the Main clause of a Future

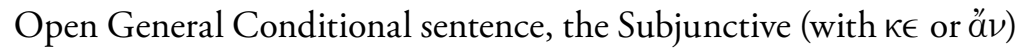
may occur in Homer. However, this usage is equivalent in function to the Future Indicative, and is to be translated as a Future Indicative.

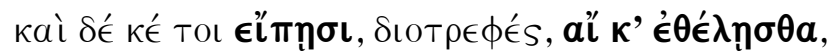

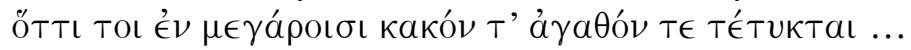
(Hom.Od. 4.391-392.)

And he will also tell you, $<O$ man $>$ favoured by Zeus, ifyou are willing, what evil and what good has been done in your halls...

$\epsilon$ Main clause. $T O \mathrm{~L}=\sigma \mathrm{Ol}$.

c. A variation of this form is a mixed Condition, which uses $\epsilon \hat{l}$ with Optative for the if-clause and $\kappa \epsilon$ or ${ }^{\prime \prime} \nu$ with Subjunctive in the Main clause. The if-clause has the form of a Future Unfulfilled Condition, but is to be translated as a Future Open General Condition (Pres. Indic. in English). And the Main clause, again, is to be translated by a Future Indicative in English. This form occurs especially in threats or warnings; and the negative with the Subjunctive in the Main clause is ov, not $\mu$ í.

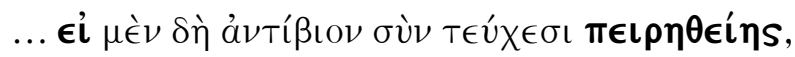

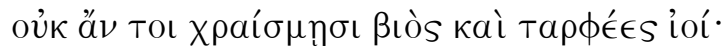

(Hom.Il. 11.386-387.)

... if indeed in opposition you [were to] make an attempt with weapons,

your bow and dense <shower of $>$ arrows will not protect you.

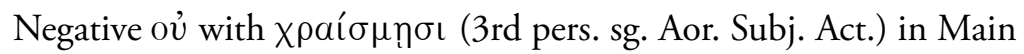
clause. 
d. $\epsilon \hat{l}$ alone without $\alpha$ $\nu$ or $\kappa \in$ is occasionally used with the Subjunctive in Future Open General Conditions in Homer.

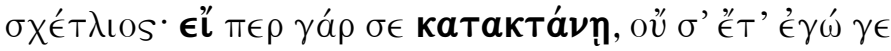

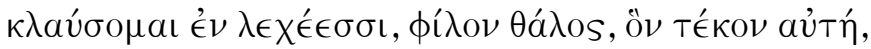

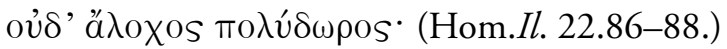

$<$ He is $>$ cruel. For if indeed he kills you, I for my part shall no longer lament for you on your deathbed, dear child, whom I myself bore, nor will your gifted wife.

A classical equivalent of the Homeric construction occurs in the following example.

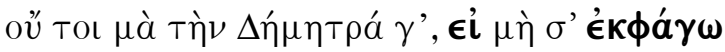

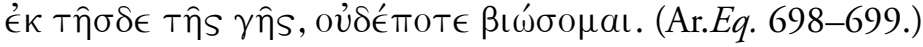

No indeed by Demeter, if I do not eat you up out of this land, I shall not even ever live.

(The reading of the earliest manuscript is given for line 698. Some other manuscripts read $\epsilon$ á $\nu$ for $\epsilon \hat{l}$ and adjust the metre. But it is unlikely that an original classical construction would have been altered to a Homeric one.)

\subsection{Unfulfilled Conditions}

\subsubsection{Present}

There seem to be no Unfulfilled Conditional sentences in Homer, where both the if-clause and the Main clause refer to the present. However, there are mixed Conditions, in which the if-clause is Past Unfulfilled with $\in \dot{l}$ and Past Aorist Indicative, whereas the Main clause is Present Unfulfilled with Optative and $\kappa \in(\nu)$ (not Past Imperf. Indic. with ő $\nu$ ).

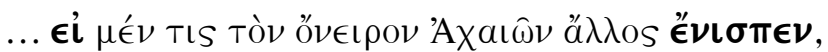

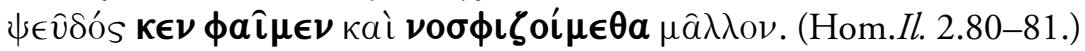

... if any other of the Achaeans had reported this dream, we would be calling <it $>$ a falsehood and would rather be turning away from $<i t>$. 


\subsubsection{Past}

Past Aorist Indicative is used in Past Unfulfilled Conditions in Homer as in classical Attic. But Past Imperfect Indicative in Unfulfilled Conditions in Homer always refers to past continuous action, and does not express a Present Unfulfilled Condition.

Occasionally, Homer uses Indicative in the if-clause, but Optative with $\kappa \in(\nu)$ in the Main clause of a Past Unfulfilled Condition. (There are further examples of Main clauses of this type, without any if-clause.)

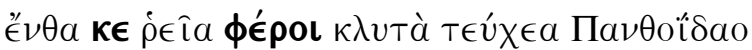

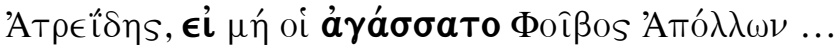
(Hom.Il. 17.70-71.)

Then easily would the son of Atreus have been carrying off the splendid armour

of the son of Panthoüs, if Phoebus Apollo had not envied him.

\subsubsection{Future}

For Future Unfulfilled Conditions, Homer does use the same construction as writers of the classical period: $\epsilon \hat{l}$ with Optative in the if-clause and Optative with ăv $(\kappa \in)$ in the Main clause. But he also uses $\epsilon \dot{l}$ (al) with $\kappa \in(\nu)$ and Optative in the if-clause.

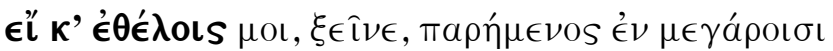

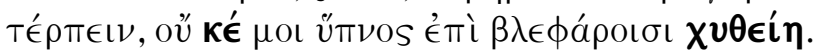
(Hom.Od. 19.589-590.)

Ifyou were to be willing, stranger, to sit by me in my halls and cheer me up, sleep would not be poured over my eyelids.

\section{References}

Goodwin (1889), Syntax of the moods and tenses of the Greek verb, $\$ \$ 434-443$, 450-454, 460-461, 468-471, 474, 488.

Smyth (1956), Greek grammar, \$\$2311, 2327, 2334. 


\section{EXERCISE 20}

Translate the following passages.

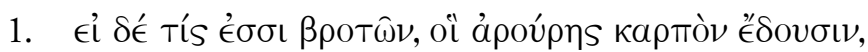
$\hat{\alpha} \sigma \sigma O \nu{ }^{\prime} \theta^{\prime}{ }^{\prime} \ldots$

\begin{tabular}{|c|c|}
\hline$\dot{\epsilon} \sigma \sigma \iota$ (enclitic) & $\epsilon \hat{\imath}($ Attic $)$ \\
\hline$a ̈ \rho o v \rho a,-a s, \dot{\eta}$ & earth, land \\
\hline карто́s, -оv̂, ó & roduce, harvest \\
\hline$\epsilon^{\prime} \delta \in \iota \nu$ & 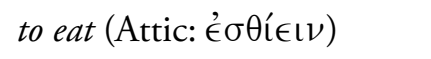 \\
\hline$\hat{\alpha} \sigma \sigma o \nu$ (adv.) & earer (comparative of ä $\gamma \chi \mathrm{l}$ ) \\
\hline$\imath^{\prime} \theta$ & ¿ $\theta \iota$ \\
\hline
\end{tabular}

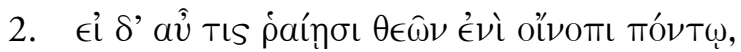

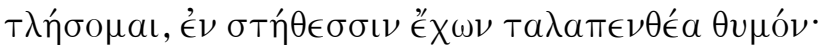

\begin{tabular}{|c|c|}
\hline$\dot{\rho} a i ́ \in I \nu$ & to cause a shipwreck \\
\hline 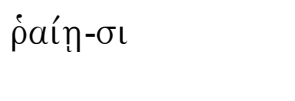 & $\begin{array}{l}\text { 3rd pers. sg. Imperf. Subj. Act. } \\
\text { with suffix }\end{array}$ \\
\hline Éví & $\dot{\epsilon} V$ \\
\hline 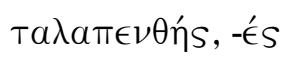 & long-suffering \\
\hline
\end{tabular}

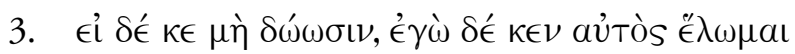

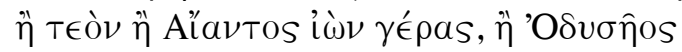
ă $\xi_{\omega} \dot{\epsilon} \lambda \omega \nu^{\prime}$.

\begin{tabular}{|c|c|}
\hline$\delta \omega^{\prime} \omega \sigma \iota v$ & Attic: $\delta \hat{\omega} \sigma \mathrm{l}(\nu)$ \\
\hline$\delta \in ́$ (2nd instance) & $\begin{array}{l}\text { then (apodotic after preceding } \\
\text { Conditional clause) }\end{array}$ \\
\hline 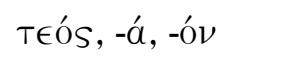 & Attic: $\sigma o ́ s, \sigma \eta ́, \sigma o ́ v$ \\
\hline Al̈as, -avтos, $\dot{o}$ & $\operatorname{Ajax}$ \\
\hline
\end{tabular}


4.

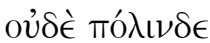

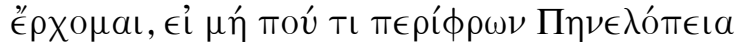

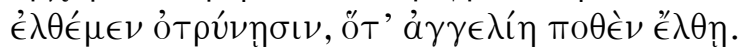

\begin{tabular}{|c|c|}
\hline$\pi o ́ \lambda ı \nu-\delta \epsilon$ & $-\delta \epsilon$, adv. suffix: motion towards \\
\hline Toú Tı & perhaps \\
\hline$\dot{\epsilon} \lambda \theta \epsilon ́ \mu \epsilon \nu$ & $\dot{\epsilon} \lambda \theta \epsilon \hat{\imath} \nu$ (Attic) \\
\hline 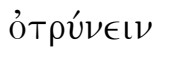 & to urge \\
\hline 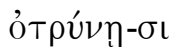 & 3rd pers. sg. Aor. Subj. Act. with suffix \\
\hline ÖT' & ÖT€ \\
\hline
\end{tabular}

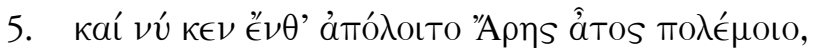

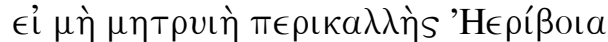

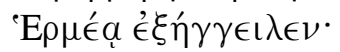

\begin{tabular}{|c|c|}
\hline$\nu U$ (enclitic) & indeed \\
\hline 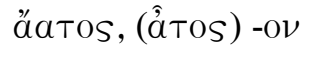 & insatiable (in) (+ Gen.) \\
\hline 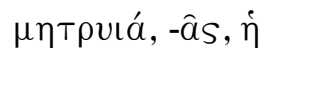 & $\begin{array}{l}\text { stepmother (of the sons of Aloeus, } \\
\text { just mentioned) }\end{array}$ \\
\hline$\pi \epsilon \rho \iota к a \lambda \lambda \eta \dot{s},-\epsilon ́ s$ & very beautiful \\
\hline E $\rho \mu \hat{n} s,-o \hat{v}, \dot{o}$ & Hermes (here Dat. uncontracted) \\
\hline
\end{tabular}

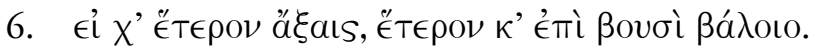

\begin{tabular}{|c|c|}
\hline àjvúvaı & to break \\
\hline$\stackrel{\prime}{\epsilon} T \epsilon \rho O \nu$ & Refers to one of two ploughs ( \\
\hline
\end{tabular}

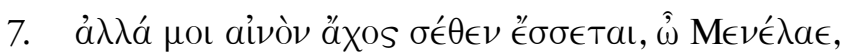

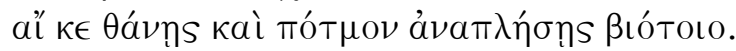

\begin{tabular}{|c|c|}
\hline aivós, -á, -óv & terrible \\
\hline áxos, -ous, tó & distress \\
\hline 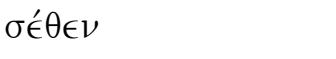 & бov̂ (as Objective Gen.) \\
\hline$\stackrel{\epsilon}{\epsilon}^{\prime} \sigma \sigma \in \mathrm{T} \alpha \mathrm{l}$ & 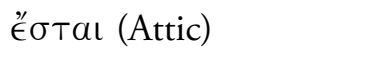 \\
\hline Bíotos, -ov (-olo), ó & life \\
\hline
\end{tabular}




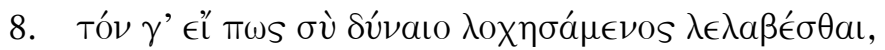

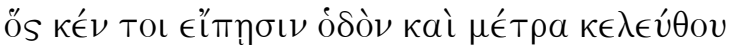

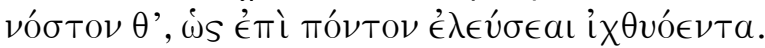

\begin{tabular}{|c|c|}
\hline Tóv & him \\
\hline$\lambda o x \hat{\alpha} \nu$ & to ambush \\
\hline$(\lambda \epsilon) \lambda \alpha \beta \epsilon ́ \sigma \theta a \imath$ & reduplicated Aor. Mid. Infin. \\
\hline ös & he \\
\hline Tol (Epic) & $\sigma o l$ (Attic) \\
\hline$\epsilon l \pi \eta\rceil-\sigma \iota \nu$ & 3rd pers. sg. Aor. Subj. Act. with suffix \\
\hline is & how \\
\hline ÉTí & over \\
\hline$\dot{\epsilon} \lambda \in \dot{v} \sigma \epsilon a l$ & 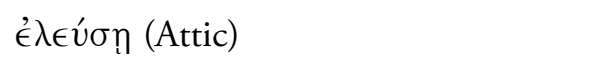 \\
\hline 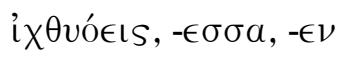 & fish-filled \\
\hline
\end{tabular}




\section{LESSON 21 \\ Subordinate Clauses in Reported Discourse}

\subsection{Reported Complex Sentences}

A Complex sentence has a Main clause and one or more Subordinate clauses. When a Complex sentence is reported, the Main clause has the construction of a reported Simple sentence; any Subordinate clauses have one of the following constructions in Primary (Pres. or Fut.) and Past sequence respectively ( $\$ \$ 21.2$ and 21.3 below). The possible constructions are the same, whether the Subordinate clauses depend on original statements, questions, commands, knowledge, thoughts, hopes, promises or oaths. And in reported statements, these constructions are the same, whether the original Main clause is reported after ötı or $\dot{\omega}$, or in an Infinitive phrase or a Participial phrase.

\subsection{Reported Subordinate Clauses in Primary Sequence}

In reported Subordinate clauses in Primary sequence, the verb has the same Mood and Tense (for Indic. verbs) or the same Aspect (for non-Indic. verbs) as in the direct form of expression.

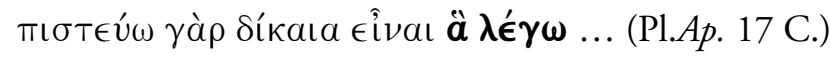

For I believe that what I am saying is just ...

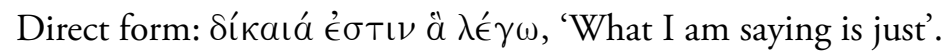




\subsection{Reported Subordinate Clauses in Past Sequence}

Reported Subordinate clauses in Past sequence are treated as follows.

Primary Tenses of the Indicative and all Subjunctives are regularly changed to the same Aspect of the Optative.

All Past Tenses of the Indicative are retained.

All Optatives are retained.

$\dddot{a} \nu$ with a subordinate Subjunctive in direct expression is omitted, when the Subjunctive is changed to Optative in Past sequence. Thus, éáv,

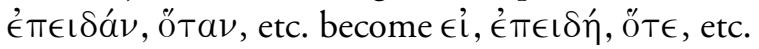

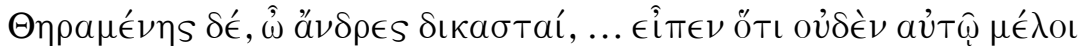

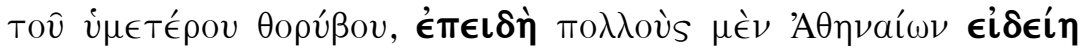

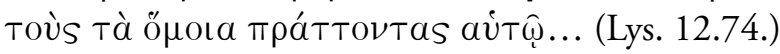

And Theramenes, $O$ men of the jury, ... said that he had no concern about your uproar, since be knew many of the Athenians who were doing the same thing as himself...

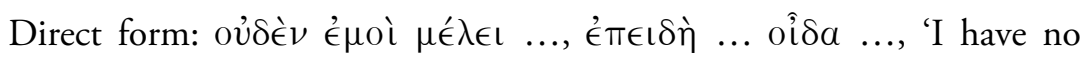
concern ..., since I know ...'

Indicative oî $\delta a$ becomes Optative $\epsilon \hat{i} \delta \in \epsilon^{\prime} \eta$ (with change of person) in the reported form.

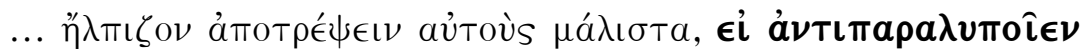

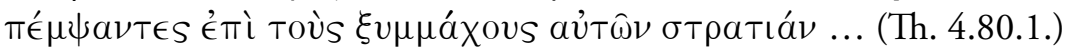

... they [Spartans] hoped that they would best deter them [Athenians], if they annoyed them in turn by sending an army against their allies ...

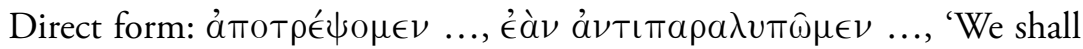
deter ..., if we annoy them in turn ...'

Ł́á $\nu$ with Subjunctive becomes $\epsilon \dot{l}$ with Optative (with change of person) in the reported form. 


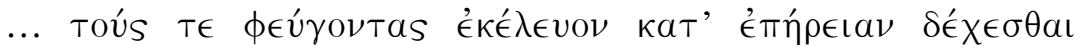

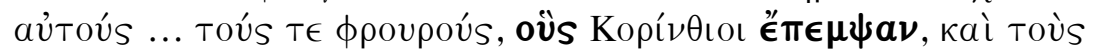
оікท́тораs àmoт́́ $\mu \pi \epsilon \iota \nu$. (Th. 1.26.3.)

... they peremptorily ordered them to receive the exiles ... and to send away the garrison members, whom the Corinthians had sent, and the colonists.

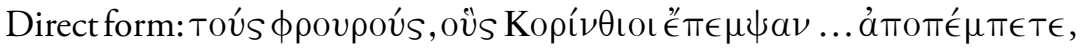
'Send away the garrison members whom the Corinthians sent ...'

Past (Aor.) Indicative $\epsilon^{\prime} \pi \epsilon \mu \psi \alpha \nu$ is retained in the reported form. (The first $\tau \in$ anticipates the second.)

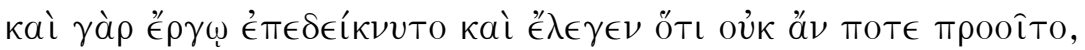

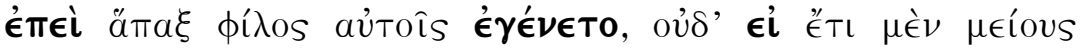

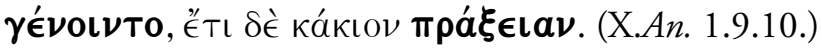

For he showed in action and stated that he would not ever abandon $<$ them $>$, when once he had become a friend to them, not even if they became even fewer and fared even worse.

прооіто: third person singular second Aorist Middle Optative of $\pi \rho 0-$ iéval.

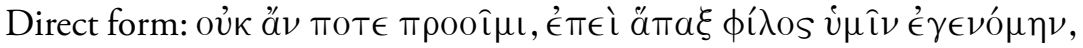

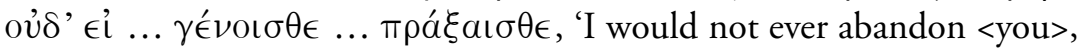
when once I had become a friend to you, not even if ... you became [OR: were to become] ... and fared [OR: were to fare] ...'

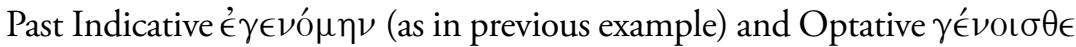
and $\pi \rho \alpha \dot{\xi} \xi \iota \iota \theta \Theta \in$ are retained (all with appropriate change of person).

\subsection{Assimilation of Construction}

Normally, all Subordinate clauses, in both direct and reported discourse, have a finite verb. However, in reported discourse, where an original Main clause is reported in an Infinitive phrase, the Subject and verb of a Subordinate clause are sometimes assimilated to the Accusative and Infinitive construction of the reported Main clause. 


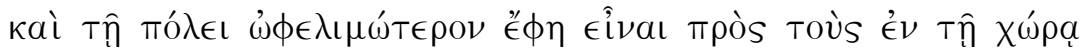

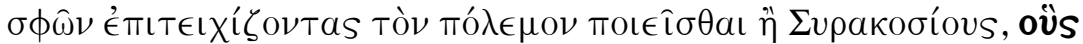

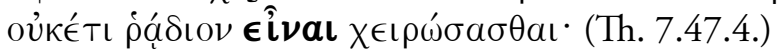

And he said that it was more helpful for the city to carry on the war against those who were building fortifications in their own country than against the Syracusans, whom it was no longer easy to defeat.

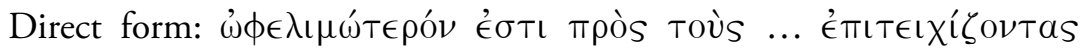

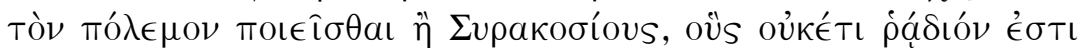
$\chi \in \iota \rho \omega ́ \sigma \alpha \sigma \theta \alpha$, 'it is more helpful to carry on the war against those who are building fortifications ... than <against> the Syracusans, whom it is no longer easy to defeat'.

\subsection{Vivid Construction}

The Optative is not always used to represent Primary Indicatives and any Subjunctives in Subordinate clauses in Past sequence. Sometimes a Vivid construction, retaining the Mood of direct expression, is used.

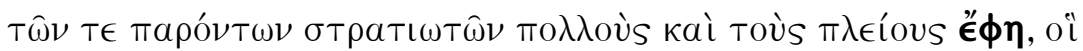

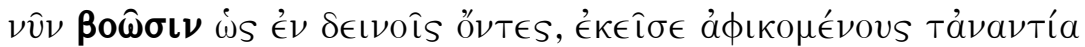

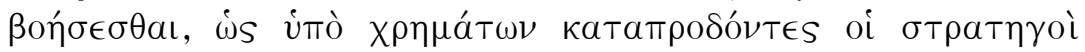
ảm $\lambda \lambda \theta 0 \nu$. (Th. 7.48.4.)

And he said that many, indeed the majority, of the soldiers present [in Sicily], who now were crying out on the grounds that they were in dire straits, on arriving there [at Athens] would cry out the opposite, that under the influence of money the generals had left them in the lurch and had gone away.

Indicative $\beta \circ \omega \sigma \iota \nu$ is retained, instead of being converted to Optative.

\section{References}

Goodwin (1889), Syntax of the moods and tenses of the Greek verb, \$\$689-693, 755.

Smyth (1956), Greek grammar, \$\$2617-2620, 2623, 2625, 2631-2632. 


\section{EXERCISE 21}

Translate the following passages.

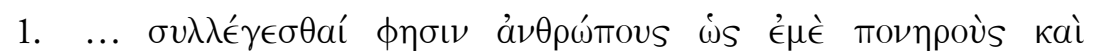

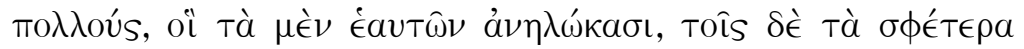

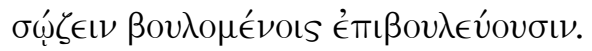

$\sigma v \lambda \lambda \epsilon^{\prime} \gamma \in \mathrm{I \nu}$

to gather together (Mid.: Intr.)

is (+ Acc. of motion)

to (a person)

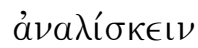

to use up, to spend

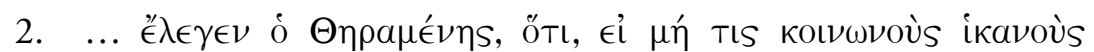

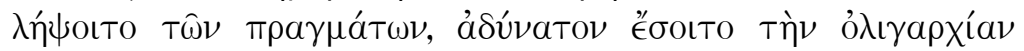

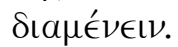

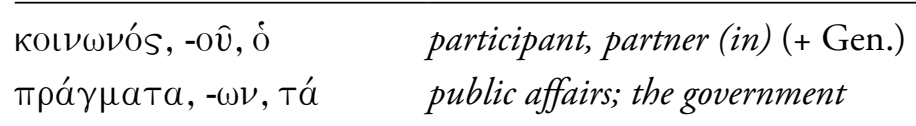

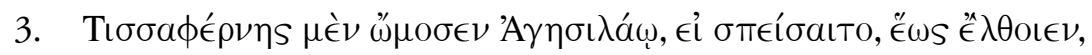

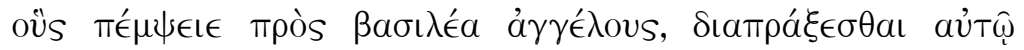

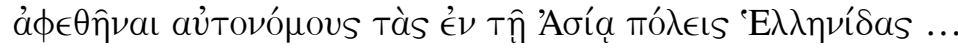

\begin{tabular}{ll}
\hline$\sigma \pi \epsilon ́ \nu \delta \in \sigma \theta a \iota$ (Mid.) & to keep a truce \\
$\delta ı \alpha \pi \rho a ́ \sigma \sigma \in \sigma \theta a \iota$ & to bring about, to accomplish (here + \\
acc. and Infin.) \\
to set free
\end{tabular}

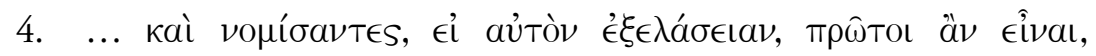

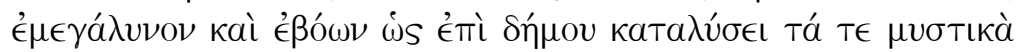

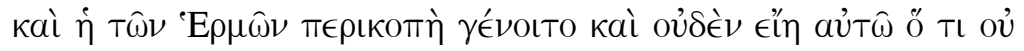

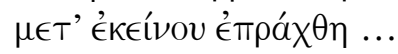

\begin{tabular}{|c|c|}
\hline 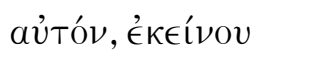 & Both terms refer to Alcibiades. \\
\hline $\mathfrak{\epsilon}^{\prime} \xi \in \lambda a u ́ v \in \mathrm{I} \nu$ & to drive out, to expel \\
\hline$\mu \in \gamma a \lambda u ́ v \in t \nu$ & to exaggerate \\
\hline$\delta \hat{\mu} \mu o s,-o v, o$ & democracy \\
\hline 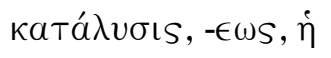 & overthrow \\
\hline 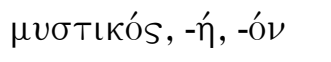 & connected with the mysteries \\
\hline
\end{tabular}


INTERMEDIATE ANCIENT GREEK LANGUAGE

$\tau \grave{\alpha} \mu v \sigma \tau ı \kappa a ́$

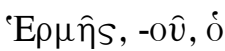

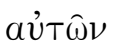

the matter of the mysteries (alluding to an illegitimate private celebration)

(statue of) Hermes

neut.

5. For I know that, wherever I go, the young [men] will listen to me [masc.] talking as I do here.

6. ... they thought that within a few years they would demolish the power of the Athenians, if they kept ravaging their land.

\begin{tabular}{ll}
\hline to demolish & $\kappa a \theta a \iota \rho \in \hat{\imath} \nu$ \\
to keep ravaging & $\tau \epsilon ́ \mu \nu \in \iota \nu$ (Use Imperf. Aspect.) \\
\hline
\end{tabular}




\section{LESSON 22 \\ Result Constructions}

\subsection{Natural Result}

Natural Result is regularly expressed by $\ddot{\sigma} \sigma \tau \epsilon$ with Infinitive (normally Imperf. or Aor.). The construction indicates what is likely to happen as a result of the clause on which the $\tilde{\omega} \sigma \tau \epsilon$ phrase depends. The result may or may not actually happen. If the Subject of the Infinitive is the same as the Subject of the leading verb, it is usually not expressed. If the Subject of the Infinitive is different to that of the leading verb, it is usually expressed in the Accusative Case. The negative is regularly $\mu \eta$. This construction has hardly yet developed in Homer. (To preserve the open nature of the result, it may sometimes be necessary to use a paraphrase in English translation.)

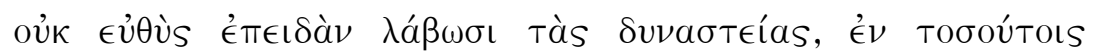

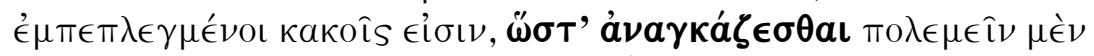

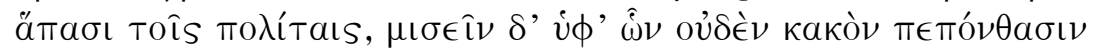
...; (Isoc. 8.111-112.)

Immediately after they have acquired supreme powers, have they not become involved in troubles so serious, as to be compelled to make war on all their fellow-citizens, and to hate those from whom they have experienced no trouble...?

Result Infinitive only, where the Subject of the Infinitive is the same as the Subject of the leading verb $\in i \sigma \iota v$.

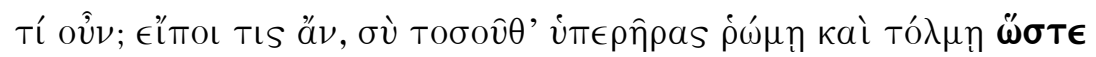

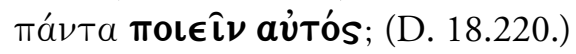

'What, then?' someone might say, 'Were you so superior in strength and daring as to do everything yourself?'

Result Infinitive with Nominative attribute of Subject of leading verb

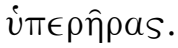




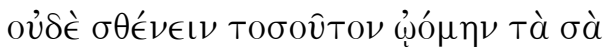

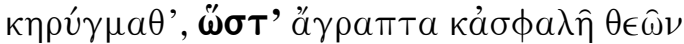

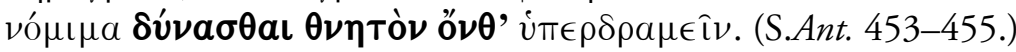

And I did not think that your pronouncements had so much strength, that a mortal being could outrun the unwritten and secure laws of the gods.

Result Infinitive with Accusative Subject, which is different to the Subject of the leading verb œón $\mu \nu$.

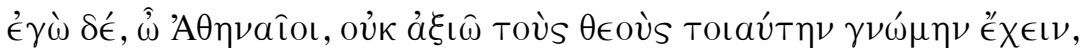

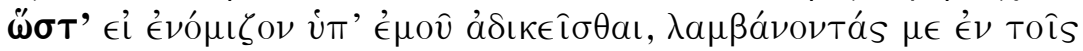

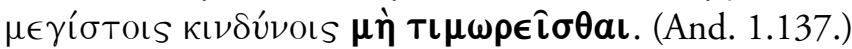

But I, O men of Athens, do not expect the gods to have such an attitude, as not to punish me, when they caught me in the greatest danger, if they thought that they were being wronged by me.

Negative $\mu$ ' with Result Infinitive.

$\dddot{\alpha} \nu$ with the Infinitive after $\ddot{\sigma} \sigma \tau \epsilon$ represents a potential construction, corresponding to $\ddot{\alpha} v$ with Indicative or (as in the following example) Optative.

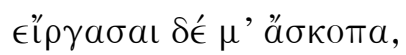

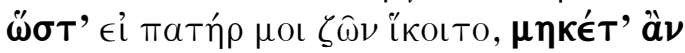

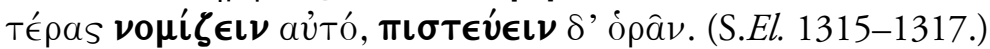

And you have had a strange effect on me, so that, if my father were to come here alive, I would no longer think it a miracle, but would believe that I were seeing him.

Here, the Subject of the Infinitives $\nu \circ \mu i \zeta \in \in \nu$ and $\pi \iota \sigma \tau \epsilon \dot{v} \in \mathrm{L} \nu$ is not expressed, but is the same as the Object of the leading verb ( $\epsilon$ l $\rho \gamma a \sigma a \mathrm{l} . .$. $\mu(\epsilon))$, and is identical with the speaker. 


\subsection{Comparative Result}

After a Comparative adjective or adverb, $\ddot{\eta} \dddot{\sigma} \sigma \tau \epsilon$ with Infinitive is used in the Result construction.

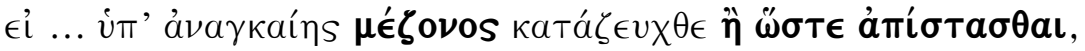

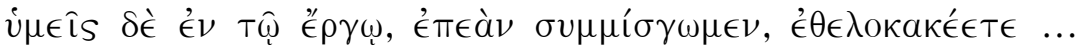
(Hdt. 8.22.1.)

If ... you have been tied down under compulsion too great to revolt from, then you are to be deliberate losers in the action, when we join together in battle...

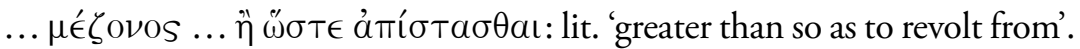

\subsection{Actual Result}

Actual Result is regularly expressed by $\tilde{\sigma} \sigma \tau \epsilon$ with finite Moods, usually Indicative. The Indicative emphasises that the result actually happens. This construction first appears in Sophocles. The negative is ov.

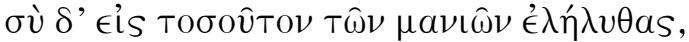

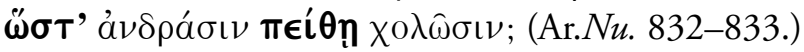

Have you come to so great <a degree $>$ of madness, that you trust provocative men?

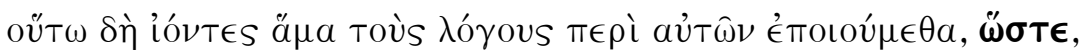

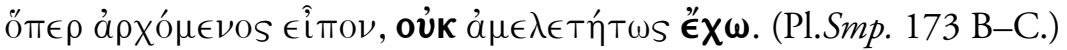

As we were going along at the same time we were conducting the discussion about it in just such a way, that, as I said when I was beginning, I am not unprepared.

Negative ởK in $̋ \sigma \sigma \epsilon$ clause.

Potential Indicative with $\stackrel{a}{v}$ or potential Optative with $\stackrel{\alpha}{v} v$ may also appear in a finite Result clause.

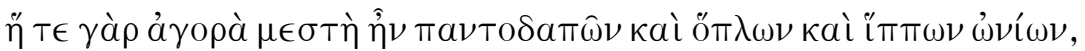

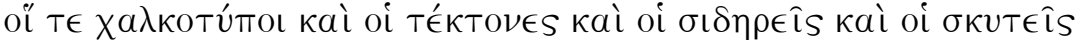

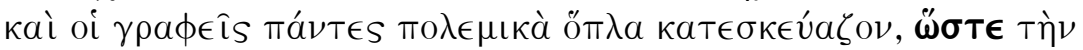

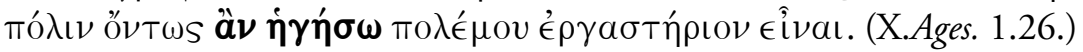


For the market was full of all sorts of weapons and horses for sale, and the coppersmiths, carpenters, ironworkers, cobblers and painters were all manufacturing weapons of war, so that you would have thought that the city was really a factory of war.

$\grave{\alpha} \nu \dot{\eta} \gamma \eta \dot{\eta} \sigma \omega$ is potential Indicative.

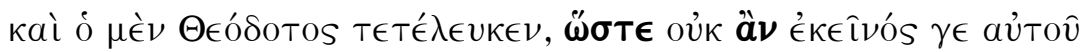

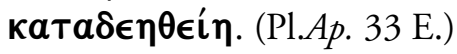

And Theodotus has died, so that he at least would not entreat him.

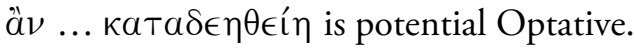

\subsection{Adjectival Clauses of Result}

Adjectival clauses of Result use the Indicative Mood, or potential Optative with $\alpha \nu \nu$, parallel to $\dddot{\sigma} \sigma \tau \epsilon$ clauses with the Indicative. The antecedent of these clauses is mostly negative or interrogative (implying a negative). The indefinite form of the relative pronoun (ö $\sigma \tau \mathrm{TS}$ ) is more common than ös in this construction. The negative is oú.

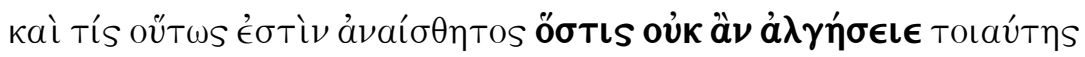

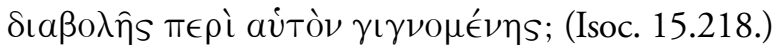

And who is so insensitive that be would not feel pained if such a slander were being made about himself?

\subsection{Provisos}

$\epsilon^{\prime} \phi^{\prime} \hat{\dot{\varphi}}$ and $\epsilon^{\prime} \phi^{\prime} \hat{\dot{\varphi}} T \epsilon$ with the Infinitive (or Accusative and Infinitive) are used in the sense 'on the condition that'. The negative is $\mu$ '

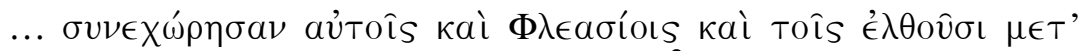

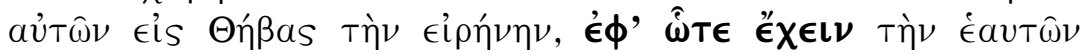
Ékáotous. (X.HG 7.4.10.)

... they granted peace to them and to the Phleasians and to those who had come with them to Thebes, on the condition that each group should keep their own <territory $>$. 


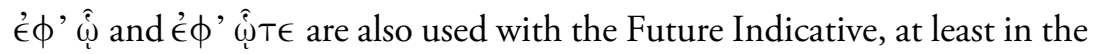
historians Herodotus, Thucydides and Xenophon. Both oú and $\mu$ ń occur as negatives.

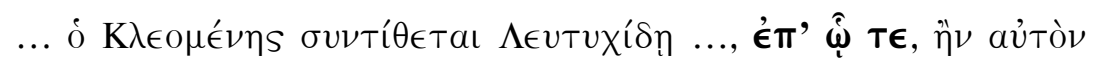

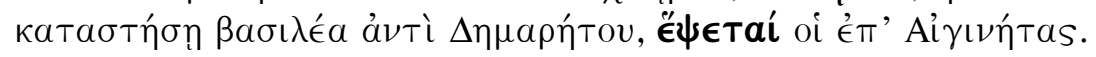
(Hdt 6.65.1.)

... Cleomenes made an agreement with Leutychides ... on condition that, if he [Cleomenes] made him [Leutychides] king instead of Demaretus, he would follow him against the Aeginetans.

$\epsilon^{\prime} \phi^{\hat{Q}}$ or $\epsilon^{\prime} \phi^{\prime} \hat{\dot{Q}} T \epsilon$ sometimes follows a demonstrative antecedent phrase:

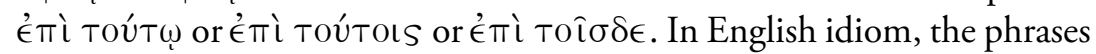
need to be abbreviated to: 'on this/these condition(s), that ...'. In Greek, the plural antecedents Toútoıs and Tỗ $\sigma \delta \epsilon$ are followed by the singular form $\hat{\dot{\omega}}$. Both Infinitive and Indicative constructions occur after these antecedent phrases.

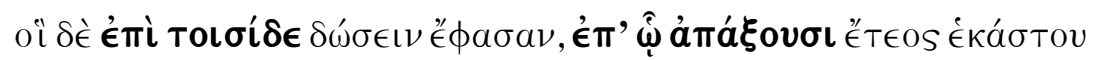

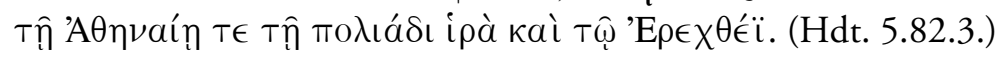

And they [= Athenians] said that they would give <the olive trees $>$ on these conditions, that they [= Epidaurians] would pay each year sacred $<$ offerings > to Athena Polias and to Erechtheus.

$\epsilon \phi$ ' $\stackrel{\hat{\varphi}}{\text { and }} \epsilon \phi^{\prime} \hat{\hat{\varphi}} T \epsilon$ may also express 'for the purpose of'. This usage is not treated in this Lesson and Exercise.

\subsection{Antecedents for Result Constructions}

Result clauses and phrases are frequently preceded by a demonstrative adjective or adverb. The following examples have occurred in the preceding sections.

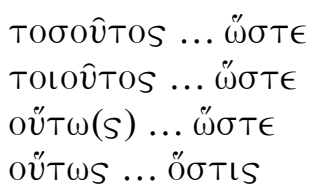




\section{7.}

$\dddot{\omega} \sigma \tau \epsilon$ may introduce a new sentence and have the meaning 'And so'. In this usage, it functions as a coordinating conjunction.

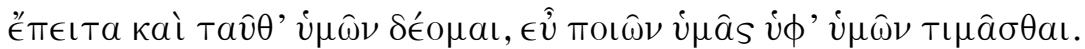

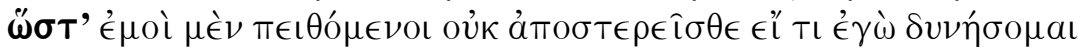
$\dot{v} \mu \hat{a} s \in \hat{v} \pi o t \in \hat{\imath} \nu \cdot$ (And. 1.149.)

Secondly I ask this also of you, that, since I am your benefactor, I be held in honour by you. And so by obeying me you are not <going to be> deprived if I can bestow any benefit on you [OR: deprived of any benefit which I shall be able to bestow on you].

\section{References}

Denniston (1954), The Greek particles, p. 528 (Provisos).

Goodwin (1889), Syntax of the moods and tenses of the Greek verb, \$\$575-610.

Smyth (1956), Greek grammar, \$\$2249-2279, 2556-2559.

\section{EXERCISE 22}

Translate the following passages.

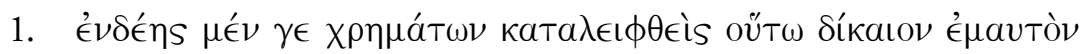

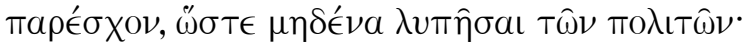

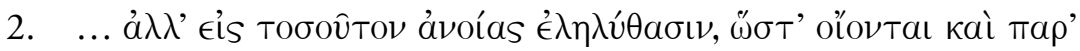

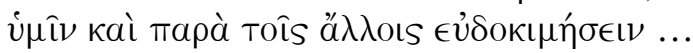

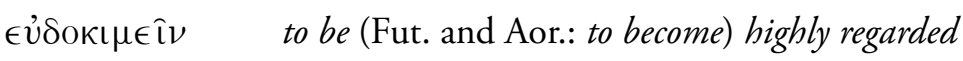

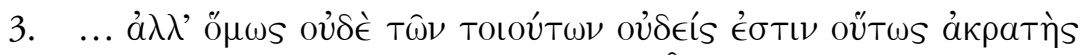

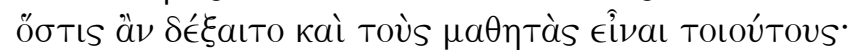

\begin{tabular}{|c|c|}
\hline 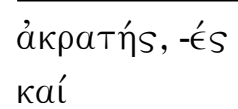 & $\begin{array}{l}\text { uncontrolled } \\
\text { also }\end{array}$ \\
\hline
\end{tabular}




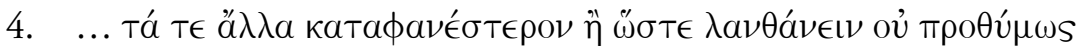
$\xi v \nu \in \pi O \lambda \epsilon ́ \mu \epsilon l$.

\begin{tabular}{|c|c|}
\hline $\begin{array}{l}T a ́ a \ldots ́ a \\
\tau \in\end{array}$ & $\begin{array}{l}\text { Acc. of Respect } \\
\text { Joins this clause to the preceding. }\end{array}$ \\
\hline
\end{tabular}

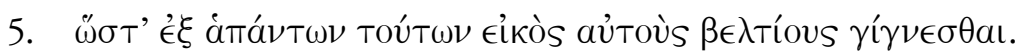

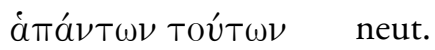

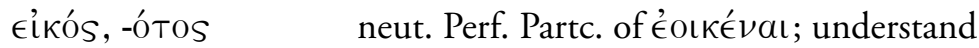

$$
\begin{aligned}
& \text { ÉoTí; + Acc. and Infin. }
\end{aligned}
$$

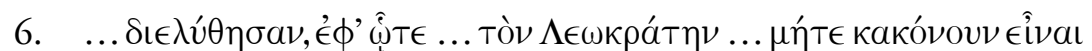

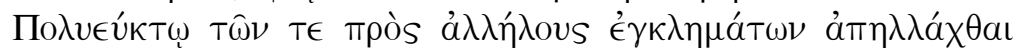
$\pi a ́ \nu T \omega \nu$.

\begin{tabular}{|c|c|}
\hline$\delta ı a \lambda \dot{v} \in \iota \nu$ & to reconcile \\
\hline 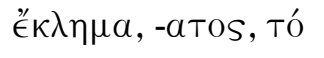 & charge \\
\hline
\end{tabular}

7. ... no one among men would suppose me so completely senseless, as to bear false witness for this [man] ...

\begin{tabular}{ll}
\hline to suppose & $\dot{v} \pi \mathrm{T} \lambda \alpha \mu \beta a ́ v \in \mathrm{L \nu}$ \\
senseless & $\ddot{\alpha} \phi \rho \omega \nu,-\mathrm{O \nu}$ \\
\hline
\end{tabular}

8. And I so strongly dissent from the others who are giving advice, $\mathrm{O}$ men of Athens, that it does not even seem right to me to take thought now concerning the Chersonese nor Byzantium ...

\begin{tabular}{|c|c|}
\hline so strongly & 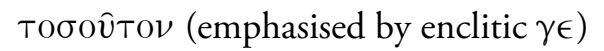 \\
\hline to dissent & 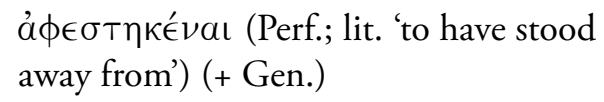 \\
\hline to seem right & 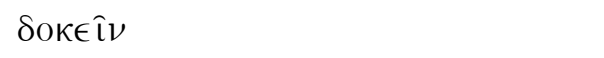 \\
\hline to give advice & $\sigma v \mu \beta o v \lambda \epsilon \dot{v} \in \mathrm{I} \nu$ \\
\hline Chersonese & 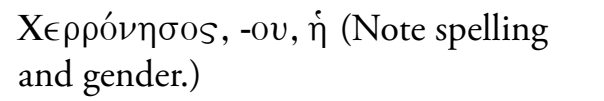 \\
\hline Byzantium & $\mathrm{B} \cup \zeta \alpha^{\prime} \nu \tau \iota \mathrm{O} \nu,-\mathrm{ov}$, Tó \\
\hline
\end{tabular}





\section{LESSON 23 \\ Causal Constructions}

\subsection{Adverbial Clauses of Cause}

Adverbial clauses of Cause are introduced by several subordinating

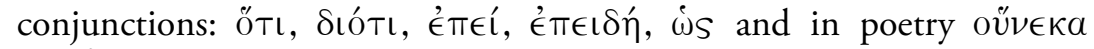

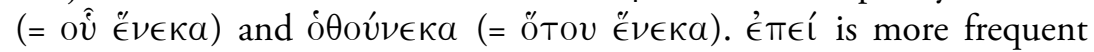

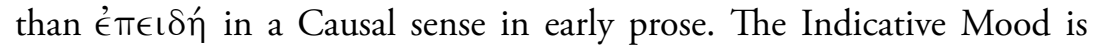
normally used. The negative is ou, which is also used in virtual Causal clauses introduced by $\epsilon \mathfrak{l}$ (with Indic.) or by éá $\nu$ or $\eta^{\prime} \nu$ (with Subj.).

\subsubsection{Indicative}

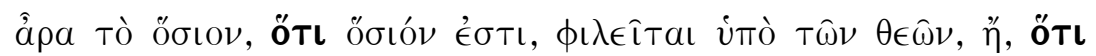

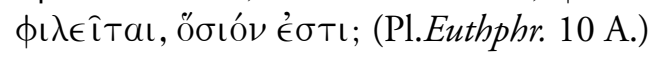

Is holiness loved by the gods because it is holy, or is it holy because it is loved $<$ by the gods $>$ ?

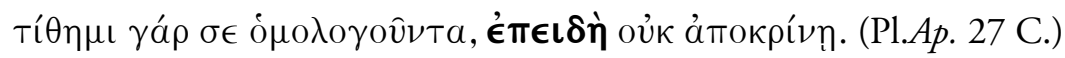
For I regard you as agreeing, since you do not reply.

Negative oú.

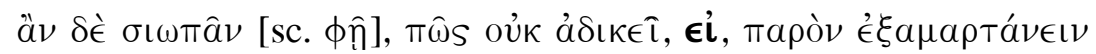

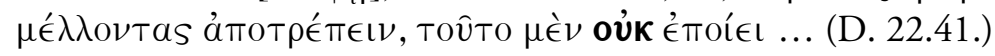

But if <he says> that he kept quiet, how is he not acting unjustly, since [lit. 'if'], although it was possible to turn <them> aside when they were intending to do wrong, he was not doing this...?

Virtual Causal clause introduced by $\epsilon \hat{\imath}$ with negative oủ.

(Cf. Lesson 19.5, last dot point) 


\subsubsection{Potential Indicative or Optative}

Potential Indicative or potential Optative with óv may also appear in a Causal clause.

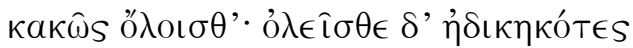

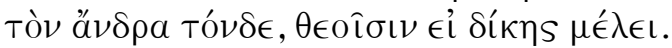

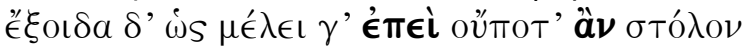

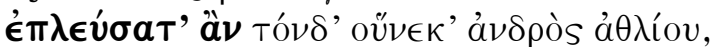

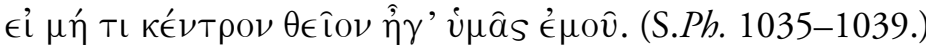

May you perish miserably; and you will perish for having wronged this man, if the gods are concerned about justice.

And I am sure that they are concerned, since never would you have sailed on this voyage on account of a wretched man, if some divine incentive to get me had not been driving you on.

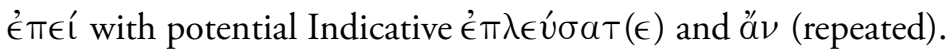

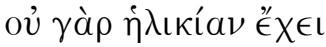

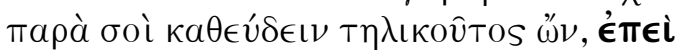

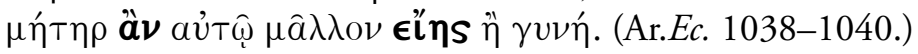

For he is not of an age to sleep with you, being of such a <young > age, since you would be a mother for him rather than a wife!

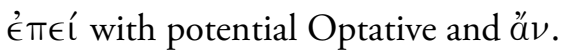

\subsubsection{Optative of Alleged Reason}

In Past sequence, the Optative (without $\alpha^{\prime} \nu$ ) is used in a Causal clause to denote an alleged reason. In the following sentence, $\dot{\omega} s$ with Optative $\dot{a} \pi \circ \chi \omega \rho \eta \tilde{\sigma} \sigma \mathrm{L} \alpha \nu$ expresses the reason of the Athenians in the city, not that of the writer Thucydides.

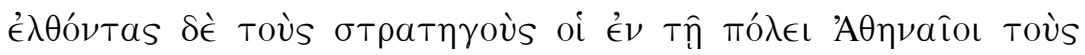

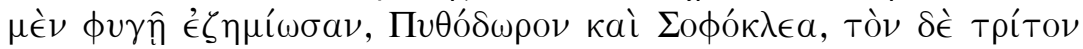

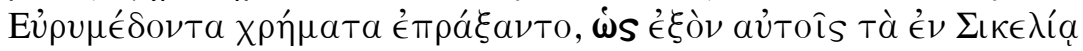

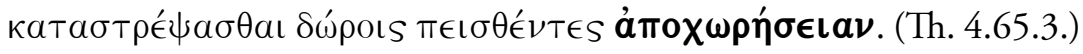

But when the commanders came, the Athenians in the city punished the <first two>, Pythodorus and Sophocles, with exile and exacted money from the third, Eurymedon, on the grounds that, although it had been possible for them to gain control of affairs in Sicily, they had been bribed by gifts and had departed. 


\subsection{4. ö $\tau \epsilon$ with a Causal Meaning}

Ö $T \epsilon$ sometimes has a virtual Causal force, already in Homer, and extending to the classical period. (The practice of distinguishing ö $T \epsilon$ [Temporal] from ö $T \in$ [Causal] in print dates only from the nineteenth century.)

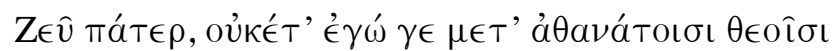

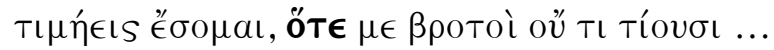
(Hom.Od. 13.128-129.)

Father Zeus, no longer shall I for my part be honoured among the immortal gods, since mortals do not honour me at all ...

Here, ǑT $T$ does not denote a particular time (or particular times) 'when' mortals do not honour Poseidon. Rather, it gives the reason why gods will not honour him, 'since' mortals do not honour him 'at all'. The argument proceeds a minore ad maius (from the lesser to the greater).

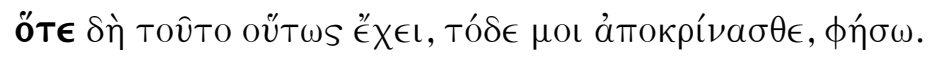
(Pl.Prt. 356 C.)

'Since indeed this is so, answer this for me', I shall say.

Both ÖTı and ÖT€ seem to be derived from the neuter singular relative pronoun Ö. ÖTl is the indefinite form of this pronoun. ÖT€ is simple Ö followed by generalising enclitic $T \epsilon$, primarily an Epic usage (Liddell \& Scott, 1996: $\tau \in$ B.). The basic early meaning of either form could be expressed as: 'with respect to which', or 'with regard to the fact that'.

Many examples, from Homer and Hesiod onwards, are ambiguous because of elision: O๊ $\tau(\mathrm{l})$ or Ö $\tau(\epsilon)$. The usual view is that only ö $\tau(\epsilon)$ allows elision. But two notable Hesiod scholars doubt this.

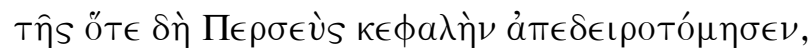

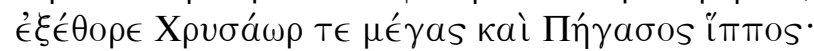

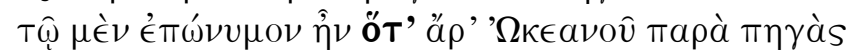

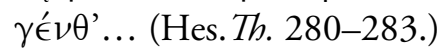

Just when Perseus cut off her head, there leapt out great Chrysaor and Pegasus the horse; the latter had a significant name, because of course he was born beside the waters of Ocean ... 
$\gamma{ }^{\prime} \nu \theta^{\prime}=\stackrel{\epsilon}{ }^{\prime} \mathcal{E}^{\prime} \nu \in T O$

Acknowledging the usual view, West (1966, p. 247) has commented on this passage: 'But if we ask which word we should see if it were not before a vowel, the answer is certainly that we should see öTı ...'. More succinctly, Paley (1883, p. 204) has commented on the same passage: 'Ó $T$ ' for ÖTı, not ÖT $\epsilon$. If elision of the final iota of ÖTı is allowed in general, there will be far fewer instances of Ö $T(\epsilon)$ with a Causal meaning.

\subsection{Adjectival Clauses of Cause}

Cause may be expressed in adjectival clauses. The definite relative adjective ós is more common than the indefinite ö $\sigma$ TIs. The Mood is generally Indicative and the negative is ov่. (Similar clauses with $\mu$ n are probably better classified as Conditional adjectival clauses.)

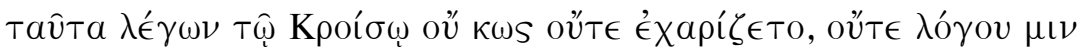

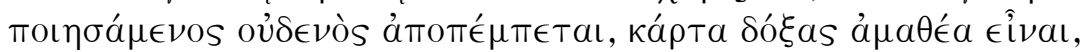

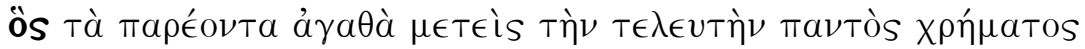

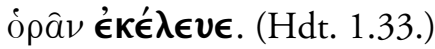

In saying this he was not at all pleasing to Croesus, and <the latter > considering him of no importance sent him away, thinking him to be very ignorant, since, setting aside present benefits, be was telling him to look at the outcome of every matter.

åmoте́ $\mu \pi \epsilon$ tal is Historic Present.

\subsection{Causal Participles}

Participles may express Cause. See Lesson 4 on Participles, Lesson 5 on Genitive absolute and Lesson 6 on Accusative absolute. Such Participles may be reinforced by certain adverbs. is before a Causal Participle indicates that the Cause is expressed on the authority of the main Subject

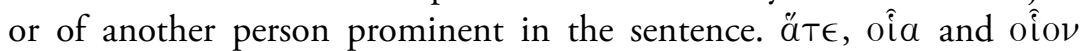
indicate that the Cause is expressed on the authority of the writer (or of the person delivering a speech). Herodotus also uses $\omega^{\prime} \sigma \tau \epsilon$ in a similar way. 


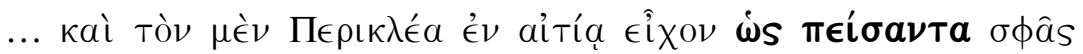
$\pi 0 \lambda \epsilon \mu \epsilon \hat{\imath} \nu$... (Th. 2.59.2.)

... and they held Pericles to blame on the grounds that he had persuaded them to go to war...

The reason introduced by $\dot{\omega}$ is attributed to the Athenians, who are the Subject of $\epsilon \hat{i} \chi O \nu$.

... ăT

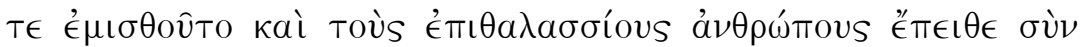

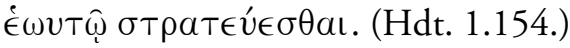

... inasmuch as he held all the gold from Sardis, he was hiring mercenaries and was persuading the men of the coast to go on campaign with him.

The reason introduced by ä $\tau \epsilon$ is that of the author Herodotus.

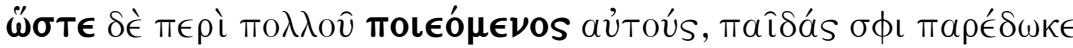

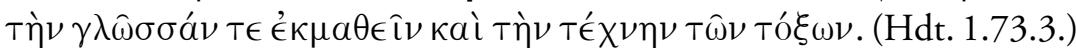

And inasmuch as he regarded them highly, he committed boys to them to learn their language and the technique of the bow.

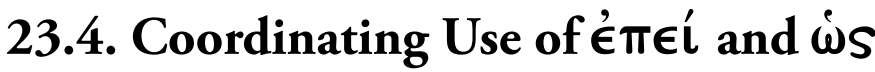

Editors sometimes treat $\dot{\epsilon} \pi \epsilon \dot{l}$ and $\dot{\omega} s$ as introducing a Main clause at the beginning of a sentence, and thus as being equivalent to $\gamma a ́ \rho$. It might be argued that this is a subordinating use in some long sentences. But that

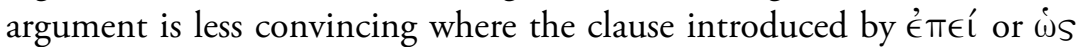
constitutes a question, wish or command rather than a statement.

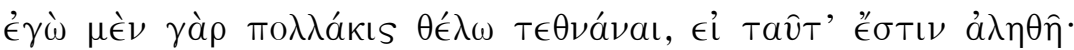

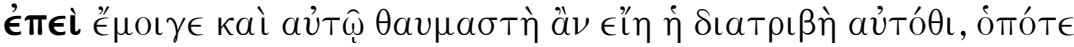

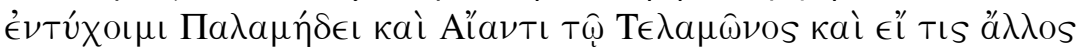

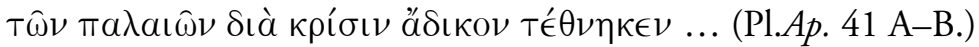

For I am willing to die many times, if this is true. For to me myself at least the lifestyle would be wonderful there, when I met up with Palamedes and Ajax son of Telamon and anyone else among early figures who has died because of an unjust judgment ... 


\section{References}

Goodwin (1889), Syntax of the moods and tenses of the Greek verb, $\$ \$ 580-581$, 712-719, 862-865.

Smyth (1956), Greek grammar, \$\$2085-2086, 2240-2248, 2555.

Paley (Ed.) (1883), The Epics of Hesiod, p. 204.

West (Ed.) (1966), Hesiod: Theogony, p. 247.

\section{EXERCISE 23}

Translate the following passages.

1. є̇те́́ $\sigma \in \mu \alpha \nu \theta \alpha ́ \nu \omega$

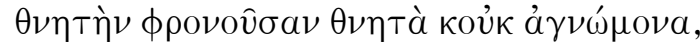

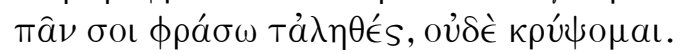

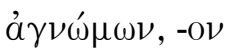
senseless (here Acc. neut. pl., as is $\theta \nu \eta т a ́)$

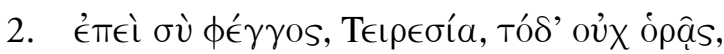

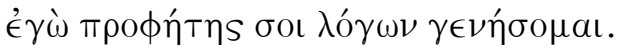

\begin{tabular}{|c|c|}
\hline 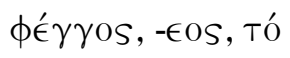 & light (of day) \\
\hline Teı $\rho \in \sigma i ́ a s,-o v, \dot{o}$ & Tiresias \\
\hline$\lambda o ́ \gamma \omega \nu$ & (with)in my words (Gen. of Limits) \\
\hline
\end{tabular}

3.

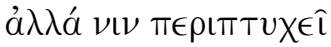

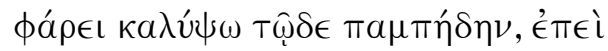

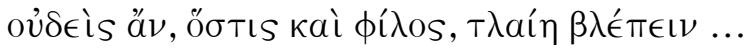

\begin{tabular}{|c|c|}
\hline$\nu \iota \nu$ (enclitic) & him \\
\hline 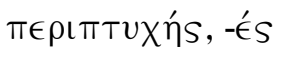 & enfolding, wrapped around \\
\hline âpos, - $\in O S$, Tó & cloak \\
\hline 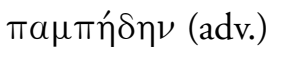 & completely \\
\hline ทิvaı (2nd Aor.) & to endure, to bear \\
\hline
\end{tabular}




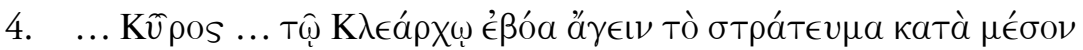

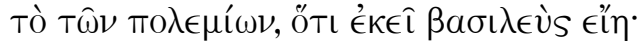

кaTá at

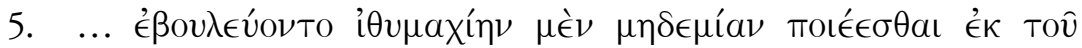

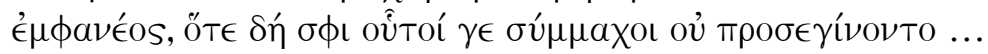

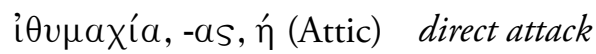

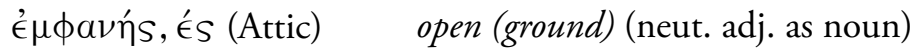

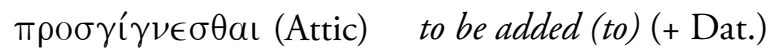

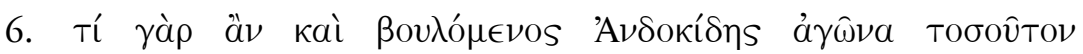

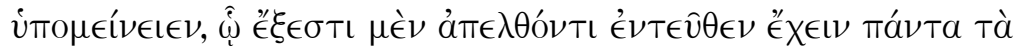
$\dot{\epsilon} \pi เ T \hat{\delta} \delta \in \iota$...;

\begin{tabular}{|c|c|}
\hline$\dot{a} \gamma(\omega) \nu,-\hat{\omega} \nu \mathrm{os}, \dot{o}$ & trial \\
\hline$\dot{v} \pi о \mu \dot{\epsilon} \nu \in \mathrm{I} \nu$ & to submit to (+ Acc.) \\
\hline$\tau \in \hat{v} \theta \in \nu$ (adv.) & from here \\
\hline 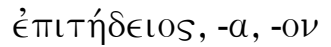 & necessary, requisite \\
\hline
\end{tabular}

7. ... the Sicilian Greeks themselves provided a greater number [of troops] in all categories, inasmuch as they inhabited large cities.

\begin{tabular}{|c|c|}
\hline Sicilian Greek & $\Sigma ı \kappa \in \lambda \iota \omega^{\prime} T \eta S,-o v, \dot{o}$ \\
\hline number & $\pi \lambda \hat{\eta} \theta$ os, -ous, Tó \\
\hline in all categories & катà та́ $\nu T a$ \\
\hline inasmuch as & $\ddot{a} T \in$ (+ Partc.) \\
\hline
\end{tabular}

8. And you [pl.] think that the affairs of the Thebans are in a bad state because they are mistreating their neighbours ...
to be in a (certain) state
ÉX $\chi \mathrm{V} \nu(+\mathrm{adv}$.
to mistreat
$\grave{\alpha} \delta ı \kappa \in \hat{\imath} \nu$ (+ Acc.)
neighbour
$\pi \in \rho i ́$ oıkos, -ov, ó (adj. as noun) 



\section{LESSON 24 \\ Constructions with Verbs of Effort and Caution}

\subsection{Introduction}

The most common construction with verbs of effort and caution is öt with Future Indicative in both Primary and Past sequence. The ötws clause is a noun clause, Object of the verb of effort or caution. Besides the construction with Future Indicative, there are other constructions in Greek. These vary from one verb to another, and from one author to another. Moreover, manuscripts may vary between Future Indicative and Aorist Subjunctive in their reading of the same word. And editors have been inclined to prefer a Future Indicative reading or to emend Aorist Subjunctive to Future Indicative. The negative for all constructions is $\mu \eta$.

\subsection{Primary Sequence}

\subsection{1. ő $\pi \omega s$ with Future Indicative}

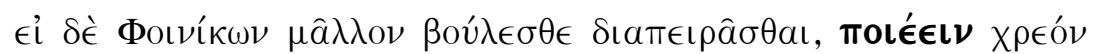

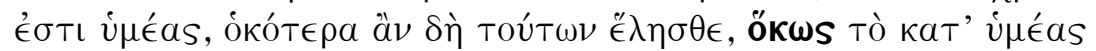

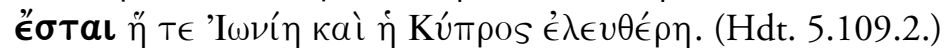

But if you wish rather to try out the Phoenicians, it is right that you should ensure, whichever of these <options you choose, that so far as depends on you, Ionia and Cyprus will be free.

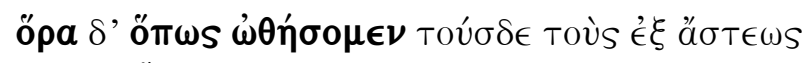

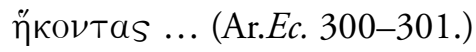

And see to it that we push aside these people who have come from town ... 


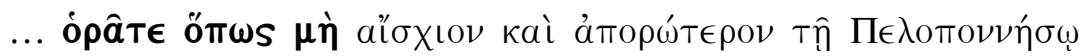
$\pi \rho a ́ \xi o \mu \epsilon \nu$. (Th. 1.82.5.)

... take care that we do not create $<$ a situation $>$ more shameful and more difficult for the Peloponnese.

Negative $\mu \eta \dot{n}$.

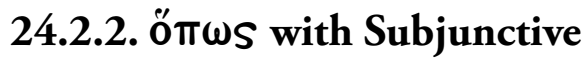

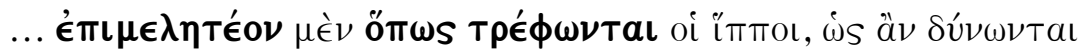

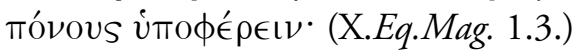

... <it is $>$ necessary to take care that the horses are nourished, so that they can endure hard work.

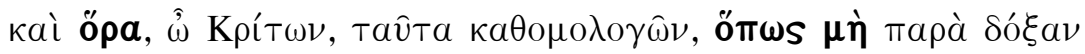

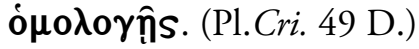

And see to it, Crito, in agreeing to this, that you do not agree contrary to <your real> opinion.

Negative $\mu \eta \dot{n}$.

\subsection{3. $\mu$ ń with Subjunctive}

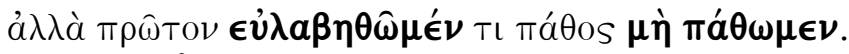

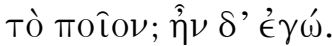

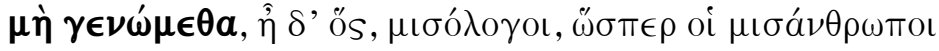

$\gamma \iota \gamma \nu$ ó $\mu \in \nu$ oı. (Pl.Phd. 89 C.)

'But first let us take care that we do not suffer any calamity'.

'What sort <of calamity>?' said I.

'That we do not become', said he, 'haters of argument, just as those who become haters of mankind'. 


\subsection{4. $\epsilon$ ' with Indicative}

Some verbs of effort and caution occasionally have an $\epsilon \dot{l}$ clause as Subject or Object. In the examples, in Primary and Past sequence the Indicative Mood is used. And the leading verb either is negated or is a negative compound.

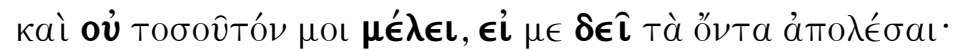
(Lys. 21.12.)

And it is not so great a concern to me, whether I must lose my possessions. $\epsilon \mathfrak{l}$ clause with Present Indicative is Subject of $\mu \in \lambda \epsilon \iota$; lit. 'Whether I must lose ... is not so great a concern ...'.

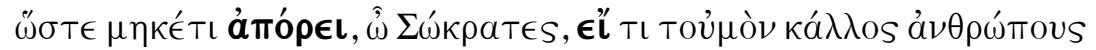
$\dot{\omega} \phi \epsilon \lambda \eta ் \epsilon \mathbf{~} .(\mathrm{X} . \operatorname{Smp}$. 4.16.)

And so no longer be at a loss, O Socrates, <about $>$ whether my beauty will bring any benefit to people.

$\epsilon \mathfrak{l}$ clause with Future Indicative is Object of àmó $\rho \in t$.

\subsection{Past Sequence}

\subsection{1. ö $\pi \omega S$ with Future Indicative}

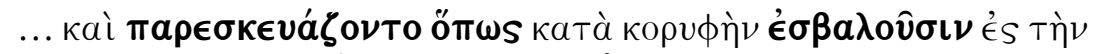

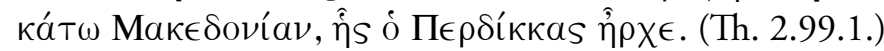

... and they were preparing to <go $>$ over the ridge <and $>$ invade lower Macedonia, of which Perdiccas was ruler.

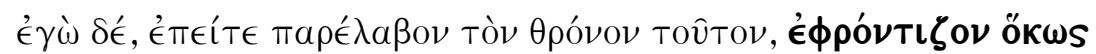

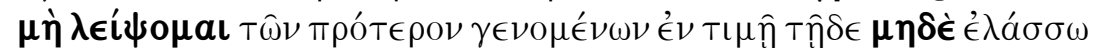

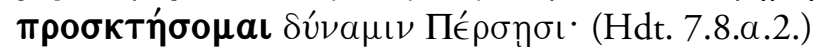

And I, after I had succeeded to this throne, was wondering how I should not be left behind those who had come before in this office, nor gain for the Persians less power [i.e. than they did].

Here, ö $\kappa \omega s$ with Future Indicative is represented by 'how I should...' in English. Negative $\mu$ í and compound. 


\subsection{2. ö $\pi \omega s$ with Subjunctive}

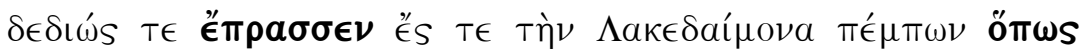

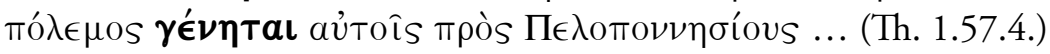

And in trepidation he [= Perdiccas] was trying to bring it about, by sending $<$ agents> to Sparta, that war would break out between them [= Athenians] and the Peloponnesians...

(The second $\tau \epsilon$ anticipates a following $\kappa a i ́$.

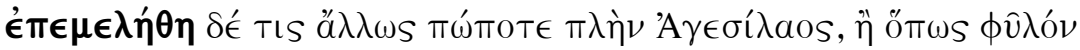

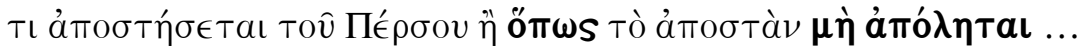
(X.Ages.7.7.)

But did anyone except Agesilaus ever otherwise take care, either that some tribe should revolt from the Persian or that the <tribe $>$ which rebelled should not perish ...?

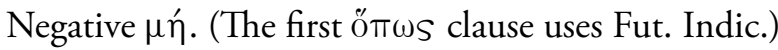

\subsection{3. ötw ws with Optative}

In accordance with the more usual practice of sequence of Moods in subordinate constructions, ö $\pi \omega s$ with Imperfect or Aorist Optative in Past sequence corresponds to Subjunctive of the same Aspects in Primary sequence. Likewise, ő $\pi \omega s$ with Intentive ('Fut.') Optative corresponds to the Future Indicative of Primary sequence.

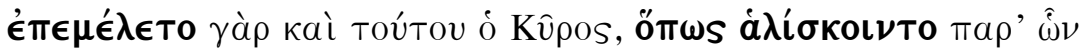

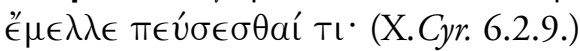

For Cyrus used to be concerned for this also, that <prisoners $>$ should be captured, from whom he was likely to learn something.

Imperfect Optative. The ötm clause is in apposition with Toútov.

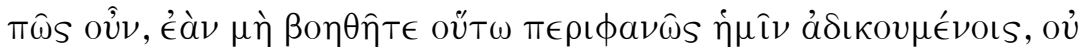

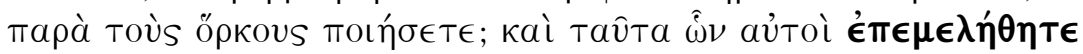

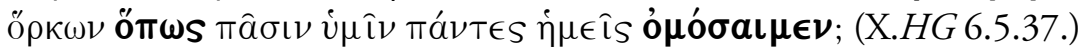

How, then, if you do not help us when we are so obviously being wronged, will you not act contrary to your oaths? And these, oaths which you yourselves took care that we all should swear to you all? 
Aorist Optative.

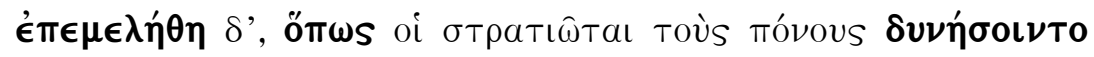
نंтофє́ $\rho \in \mathrm{L} \nu \cdot(\mathrm{X}$. Ages. 2.8.)

And he took care that the soldiers would be able to endure their labours.

Intentive ('Fut.') Optative.

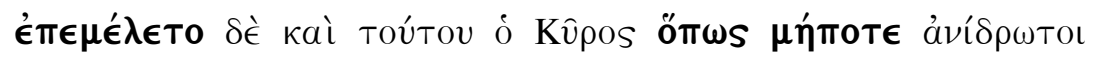

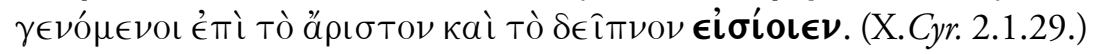

And Cyrus took care of this too, <namely> that they should never go in to lunch and dinner without having raised a sweat.

Negative $\mu \eta ́$ тотє.

\subsection{4. $\mu$ ń with Optative}

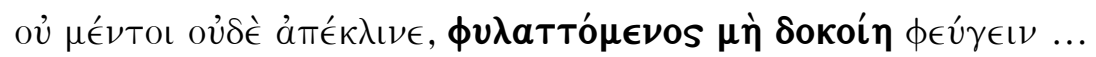
(X.An. 2.2.16.)

However, he was not turning aside either, being careful that be should not seem to be retreating...

\subsection{5. $\epsilon \grave{l}$ with Indicative}

Corresponding to the examples in Primary sequence $(\$ 24.2 .4)$, the following examples have the same structure in Past sequence.

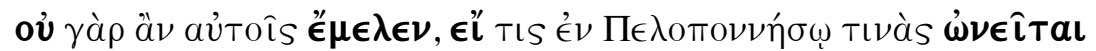

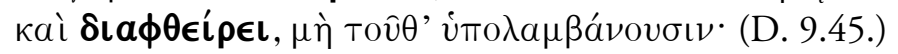

For it would not have been a concern to them, whether any one in the Peloponnese was bribing and corrupting any <persons $>$, if they had not been making this assumption.

$\epsilon \mathfrak{i}$ clause with Present Indicative (Vivid) is Subject of $\epsilon^{\prime} \mu \epsilon \lambda \in \nu$ (in a Past potential Main clause); lit. 'Whether any one ... was bribing ... would not have been a concern ...'. vंто入 $\alpha \mu \beta a ́ \nu 0 v \sigma \iota \nu$ is a Dative plural Participle with Conditional force, agreeing with aưтốs. 


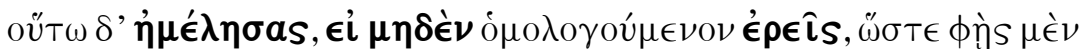

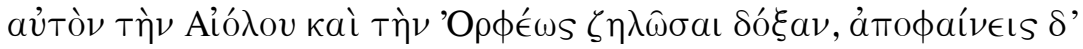

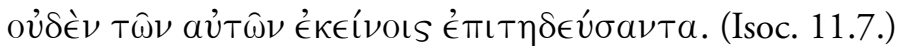

And you were so careless, <about $>$ whether you were going to say nothing consistent, that you say that he emulated the reputation of Aeolus and Orpheus, but you show that he accomplished none of the same <achievements> as they $<$ did $>$.

$\epsilon \hat{l}$ clause with Future Indicative is Object of $\eta \mu \epsilon$ é $\eta \sigma a s$, which is Past Aorist Indicative of negative compound $\grave{\alpha} \mu \in \lambda \in \hat{\imath} \nu$.

\subsection{Variations of the Constructions in $\$ \$ 24.2$ and 24.3}

In some Attic authors (especially Aristophanes, Xenophon and Plato), ă $v$ may be added to ötrws with Subjunctive.

Xenophon mostly uses the common constructions. But in addition, he sometimes uses $\dot{\omega}$ (instead of öt $\pi s$ ) with Future Indicative, Subjunctive and Optative, and $\alpha^{\prime} v$ may be added to $\dot{\omega}$ s with Subjunctive.

With verbs of planning and trying (especially $\phi \rho a ́ \zeta \epsilon \sigma \theta a \mathrm{\iota}, \beta 0 v \lambda \in \dot{\epsilon} \in \iota \nu$,

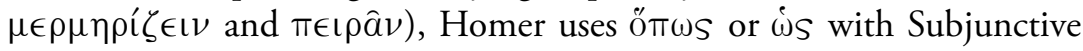
in Primary sequence and Optative (but sometimes Subj.) in Past sequence. $\kappa \in(\nu)$ (enclitic), equivalent to ă $\nu$, is generally used with $\dot{\omega} s$ and

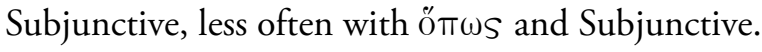

\subsection{Infinitive Constructions}

Besides the constructions with Subordinate clauses, Infinitive phrases are sometimes used with verbs of effort and caution.

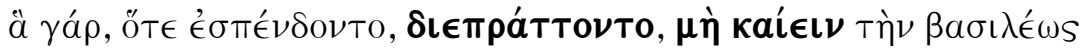

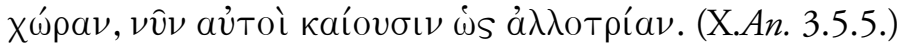

For as to what they were arranging when they were making the truce, $<$ namely $>$ not to burn the king's territory, now they themselves are burning $<i t>$, as <if it were > someone else's. 
The use of $\mu$ in with the Infinitive after a verb of caution may reinforce the idea of caution rather than contradicting it. Compare the following two uses of $\epsilon \dot{u} \lambda \alpha \beta \in \hat{\imath} \sigma \theta a \iota$ with Infinitive.

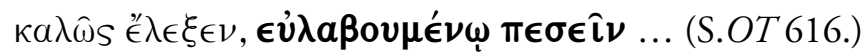

He spoke well, in the judgment of anyone wary of falling ...

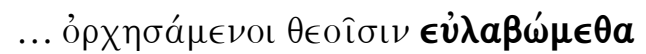

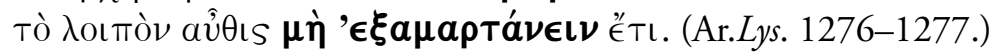

... leading the dance in honour of the gods let us take care

not to offend ever again in future.

\subsection{Omission of Main Clause}

Expressions of effort or caution may be made by means of a ötw clause without any Main clause. However, an imperatival or hortatory verb is always implied as introducing the ö $\pi \omega s$ clause: ' $<$ See to it $>$ that ...', '<Take care> that ... (not) ...'. Consequently, such ö $\pi \omega s$ clauses are always in Primary sequence. Positive clauses use ötws with Future Indicative. Negative clauses use őt $\omega s \mu$ n with Future Indicative or with Subjunctive.

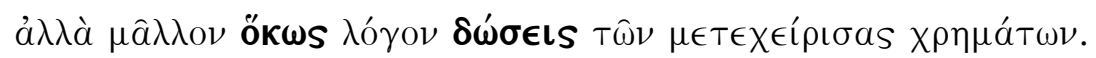
(Hdt. 3.142.5.)

But rather <make sure> that you give an account of the money which you managed.

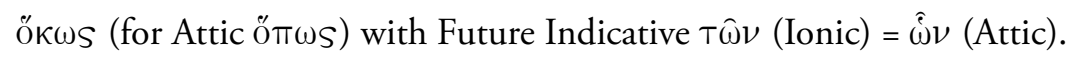

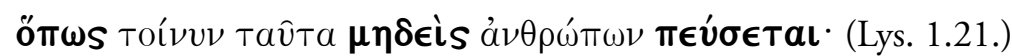

So <make sure $>$ that no one among men learns about this.

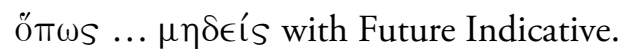

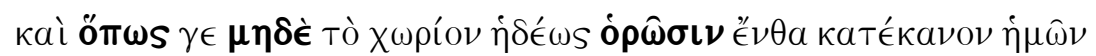

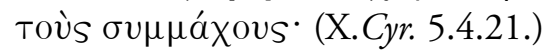

And <let us make> quite <sure> that they will not even see with pleasure the place where they killed our allies.

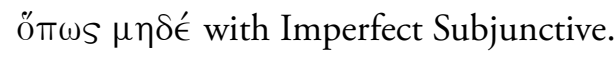




\section{References}

Goodwin (1889), Syntax of the moods and tenses of the Greek verb, $\$ \$ 130,271-278$, 339-354, 361.

Smyth (1956), Greek grammar, \$\$2209-2217, 2220.

\section{EXERCISE 24}

Translate the following passages.

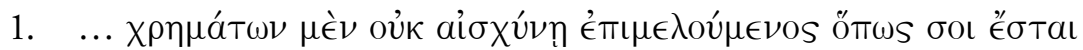

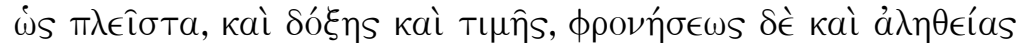

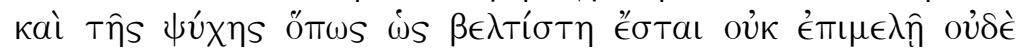
$\phi \rho о \nu т і \zeta \in \mathrm{I}$;

\begin{tabular}{|c|c|}
\hline 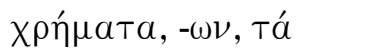 & money \\
\hline 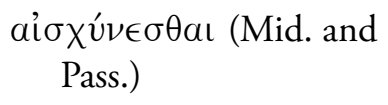 & to be ashamed (of) (+ Partc.) \\
\hline 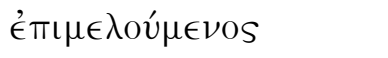 & 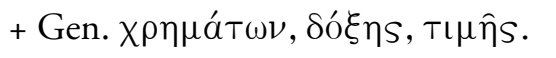 \\
\hline$\pi \lambda \in \hat{\imath} \sigma \top a$ (neut. pl.) & Refers to $\chi \rho \eta \mu a ́ \tau \omega \nu$. \\
\hline$\hat{\epsilon} \pi \iota \mu \epsilon \lambda \hat{n}$ & 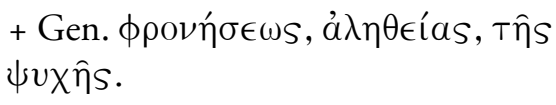 \\
\hline
\end{tabular}

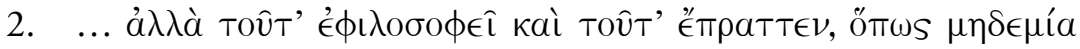

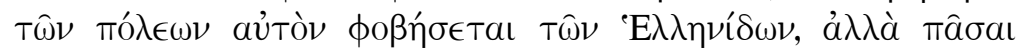

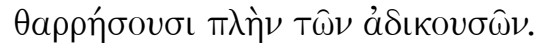

\begin{tabular}{|c|c|}
\hline$\phi ı \lambda о \sigma o \phi \in \hat{\imath} \nu$ & to pursue (an aim or activity) \\
\hline$\pi \rho a ́ T T \in \iota \nu$ & to strive for (+ Acc.) \\
\hline$\theta \alpha \rho \rho \in \hat{\imath} \nu$ & to be confident \\
\hline
\end{tabular}

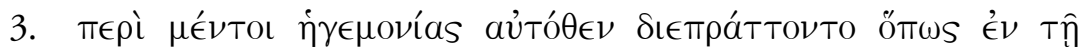

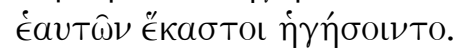

\begin{tabular}{|c|c|}
\hline$\mu \operatorname{é}^{\prime} \mathrm{TOl}$ & $\begin{array}{l}\text { moreover (less common than the } \\
\text { adversative meaning) }\end{array}$ \\
\hline aưTó $\theta \in \nu$ & immediately \\
\hline T⿳亠丷 & Understand $\gamma \hat{\text {. }}$. \\
\hline
\end{tabular}




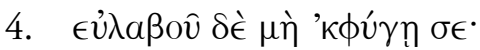

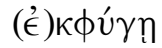
The Subject is masc.

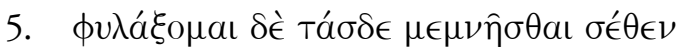

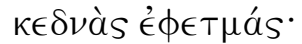

\begin{tabular}{|c|}
\hline 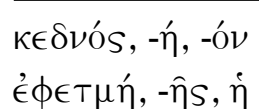 \\
\hline
\end{tabular}

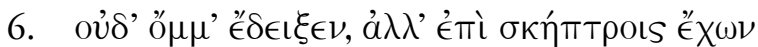

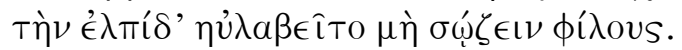

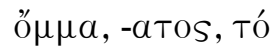
face

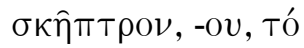
staff; sceptre; (often in pl., as here)

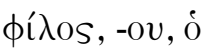
royal power
family member

Orestes speaks ironically to Electra about Menelaus.

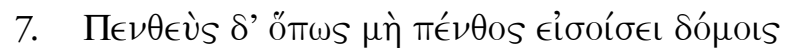
Tôิs $\sigma 0 \hat{\imath} \sigma \mathrm{l}, \mathrm{Ká} \delta \mu \epsilon$.

$\Pi \in \nu \theta \in \dot{s} \quad$ Belongs within ötws clause.

8. ... those who are going to be capable of this ... must see to it that they have a more sensible attitude than the others.

\begin{tabular}{|c|c|}
\hline to be capable of & 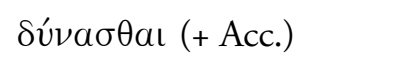 \\
\hline to see to it & $\sigma \kappa O \pi \epsilon \hat{\imath} \nu$ \\
\hline $\begin{array}{l}\text { to have an attitude } \\
\text { sensible }\end{array}$ & 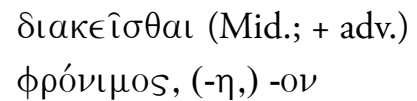 \\
\hline
\end{tabular}

9. And these [men], by canvassing each of the citizens, were trying to ensure that they would make the city revolt from the Athenians.

\begin{tabular}{|c|c|}
\hline to canvass & $\mu \in T l \in ́ \nu a l$ \\
\hline to try to ensure & $\pi \rho a ́ \sigma \sigma \in \iota \nu$ (Use Past Imperf. Indic.) \\
\hline to make ... revolt & 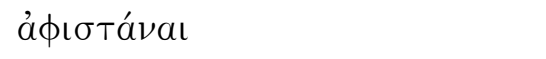 \\
\hline
\end{tabular}





\section{LESSON 25 \\ Adjectival Clauses}

\subsection{Introduction}

An adjectival clause performs the same function as an adjective in qualifying a noun or pronoun. In form, adjectival clauses are introduced by a relative adjective or pronoun and normally contain a finite verb (although this is sometimes only implied in the context). The construction of the adjectival clause may be any of the constructions possible in a Simple sentence or in the Main clause of a Complex sentence-Indicative, Imperative, Jussive (Subjunctive) or potential ( $\alpha v$ with Indicative or Optative). In Greek (as in English), the antecedent noun or pronoun is not always expressed. Thus, oil, for example, may stand for '<those> who'.

The present Lesson is concerned primarily with the distinction in form and function between definite and indefinite adjectival clauses. From this point of view, three main categories of adjectival clause will be considered:

1. Definite clauses introduced by ös

2. Indefinite clauses introduced by ös

3. Indefinite clauses introduced by ö $\sigma \tau \mathrm{Ts}$.

\subsection{Definite Clauses Introduced by ös}

Definite clauses refer to a particular person or thing as antecedent. Provided that the adjectival clause represents a statement, its verb is in the Indicative Mood. The negative within such a clause is oú.

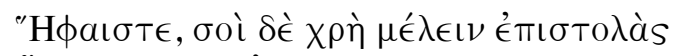

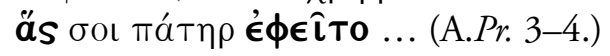

And the commands, which the father laid upon you, should be your concern, Hephaestus...

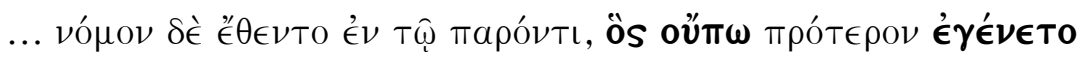
aủTô̂s. (Th. 5.63.4.) 
... but in the present situation they made a law, which did not yet previously exist for them.

Negative oú compound.

However, if the adjectival clause represents a command, its verb is Imperative or Subjunctive. And the negative within such a clause is $\mu$ n.

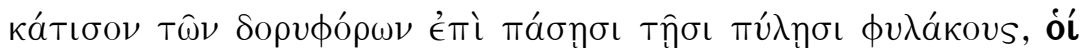

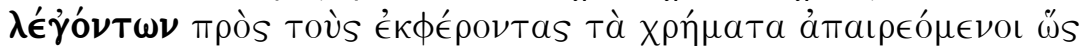

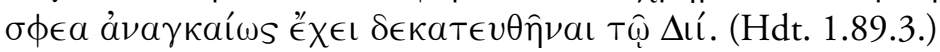

Set at all the gates guards from among the spearmen, who are to say to those carrying out the goods, as they take <them $>$ away, that it is necessary that they be paid as a tithe to Zeus.

Third person plural Imperfect Imperative Active.

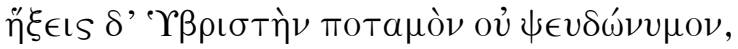

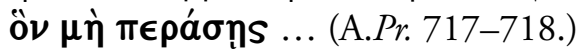

And you will come to the Raging River, not falsely named, which you are not to cross...

A potential Optative may also be used in a definite adjectival clause.

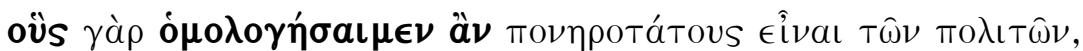

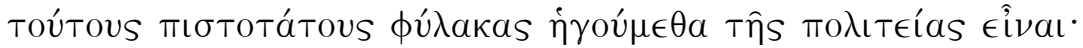
(Isoc. 8.53.)

For we think that these, whom we would agree to be the most wicked of the citizens, are the most reliable guards of the community.

\subsection{Indefinite Clauses Introduced by ös}

Indefinite clauses do not normally refer to a particular person or thing but to 'anyone who' or 'whoever'. Two types of construction occur:

1. Ös äv with Subjunctive in Primary sequence, and ös with Optative in Past sequence

2. Ös with Indicative.

The negative for both these types of construction is $\mu$ n. 


\subsubsection{Subjunctive and Optative}

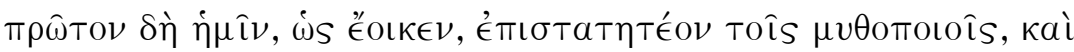

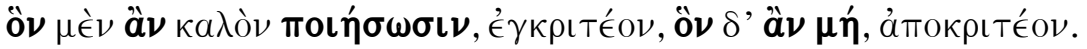
(Pl.R. 377 B-C.)

$<I t$ is $>$ first necessary for us, as it seems, to take charge of the makers of myths, and to accept the one which they make good, but to reject the one which they do not.

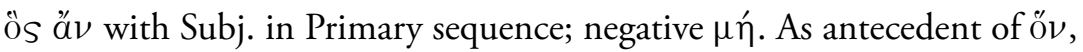
$\mu \hat{v} \theta \mathrm{o} \nu$ is to be understood from $\mu v \theta$ otroloîs.

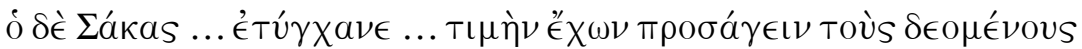

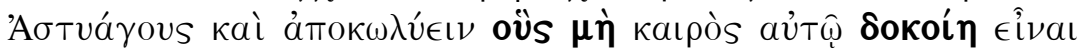

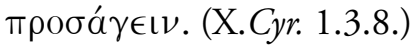

And Sacas ... happened ... to have the duty to introduce those requesting <an audience with> Astyages and to exclude those whom it did not seem to him to be appropriate to introduce.

oüs with Optative in Past sequence; negative $\mu \eta$.

\subsubsection{Indicative}

Positive indefinite clauses with Indicative have the same form as positive definite clauses. Their indefinite reference must be deduced from their context and content. However, negative indefinite clauses with Indicative use $\mu \eta$, whereas negative definite clauses with Indicative use oú.

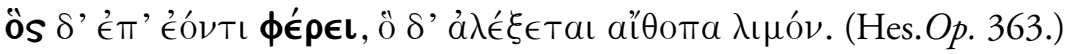

And he, who adds to what is <in stores, [he] then will ward off raging hunger.

Indicative in positive indefinite clause.

ö is masculine; the second $\delta \epsilon \in$ is apodotic ('then'), as if the ös clause were Conditional.

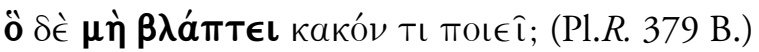

'And does <that>, which does not cause harm, produce any evil?'

$\mu \eta$ with Indicative in negative indefinite clause. 


\subsection{Indefinite Clauses Introduced by öбтls}

Ő$\sigma T I S$, when used as an indefinite relative adjective or pronoun, shows a mixture of the constructions in $\$ \$ 25.2$ and 25.3 above. Its antecedent is generally indefinite or negative or interrogative, and it may be unexpressed.

\subsection{1. ö $\sigma \tau \iota S$ with Indicative and Negative oủ}

In one usage, Ǒ $\sigma \tau \mathrm{TS}$ is treated as containing the notion of indefiniteness within itself. And in texts of Homer it is conventionally written as two words, ös TIS. The negative within the ö $\sigma \mathrm{TIS}$ clause is ov'.

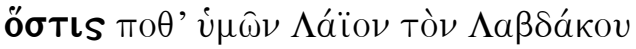

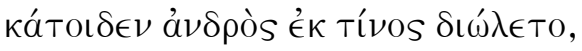

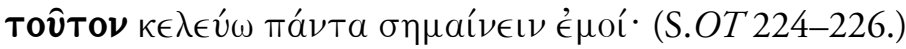

I command this <man $>$, who ever among you

knows by what man Laius son of Labdacus

perished, to reveal all to me.

The grammatical antecedent (Tov̂Tov) of the ö $\sigma$ TIS clause is indefinite.

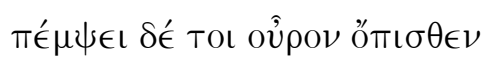

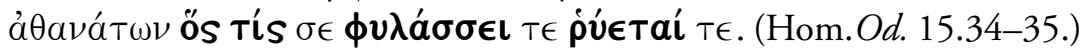

\section{And indeed whichever one of the immortals}

guards and protects you, will send a fair wind behind <you $>$.

The antecedent is indefinite and unexpressed.

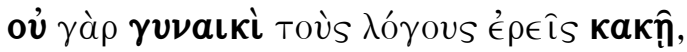

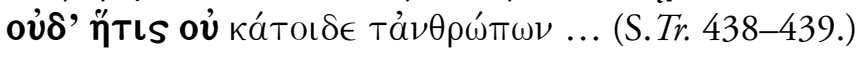

For you will not be addressing your words to an incompetent woman, nor (to one) who does not understand the <ways $>$ of mankind ...

In this sentence, the antecedent clause is negative (ov ... oú $\delta\left(\epsilon^{\prime}\right)$ ), the

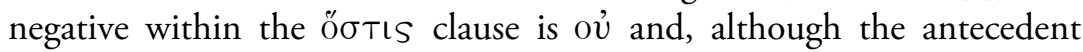
is definite (the speaker refers to herself), the ö $\sigma$ tıS clause is used in a characterising way. (Deianeira claims not to be an incompetent sort of person.) 
o $v$ is used as a negative within a ő $\sigma \mathrm{T}$ IS clause especially in the stereotyped

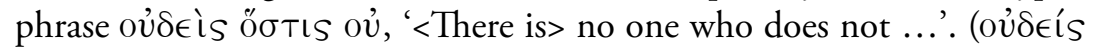
is often attracted to the Case of ö $\sigma$ TIS in Acc., Gen. and Dat.)

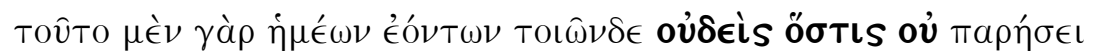
... (Hdt. 3.72.3.)

For on the one hand, since we are such as we are, <there is $>$ no one who will not let $<$ us $>$ pass...

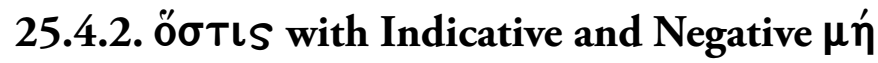

ÖбTIS with Indicative sometimes has $\mu$ ' as its negative, parallel to the use of ôs with the Indicative and $\mu \eta$ in negative indefinite clauses.

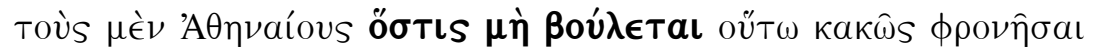

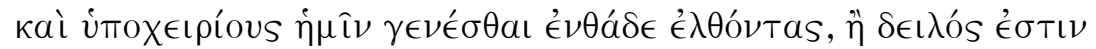

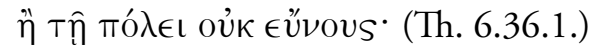

Whoever does not want the Athenians to think so wrongly and to become subject to us when they come here, is either cowardly or not well disposed to the city.

\subsection{3. ÖбTıs with Subjunctive and Optative}

ŐбTIS may also have a construction with ő $\nu$ and Subjunctive in Primary sequence and Optative in Past sequence.

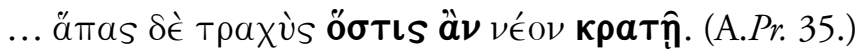

$\ldots$ and everyone, who is new to power, <is $>$ harsh.

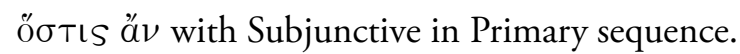

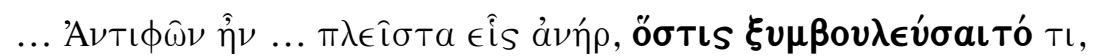
$\delta v v a ́ \mu \in v 0 S$ ì $\phi \in \lambda \in \hat{\imath} \nu$. (Th. 8.68.1.)

... Antiphon was ... the one man most able to help anyone who asked for some advice.

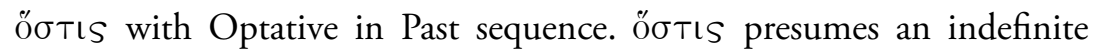
Accusative antecedent, Object of $\dot{\omega} \phi \in \lambda \in \hat{\imath} \nu$. 


\subsection{Coordinating Use of the Relative Adjective or Pronoun}

The relative adjective or pronoun may be used to begin a new sentence. In this situation, ös needs to be translated not as 'Who', but by such phrases as 'And he', 'But he' or 'For he'. To some extent it is a matter of editorial choice whether such occurrences are to be treated as coordinating or subordinating. But certainly some Greek sentences would be artificially long, if this rationale were not adopted.

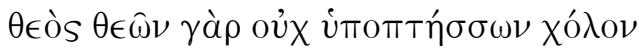

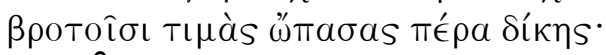

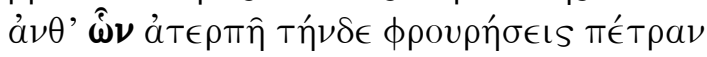

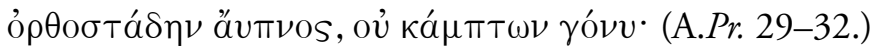

For you, a god, not cowering before the anger of the gods,

bestowed honours on mortals beyond due measure.

And in return for this you will guard this joyless rock, standing upright, unsleeping, not bending the knee.

\subsection{Parenthetic öбтıs Clause}

A clause introduced by ö $\sigma$ TıS may be used parenthetically in Greek, more often with the Indicative ('whoever he is'), but sometimes with Subjunctive and äv ('whatever it may be'). The idiom occurs both with and without an antecedent.

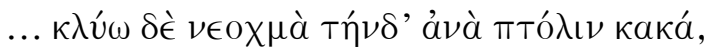

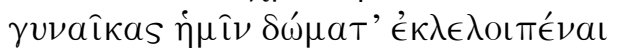

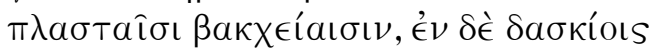

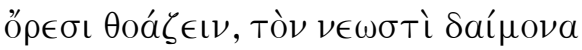

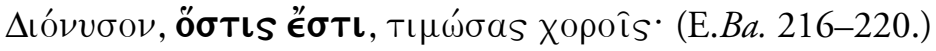

$\ldots$ and I hear of new troubles throughout this city,

that our women have abandoned their homes

in feigned Bacchic rites, and on shadowy

mountains are running around, honouring with dances

this newfound deity, Dionysus, whoever he is.

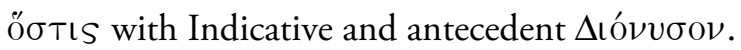




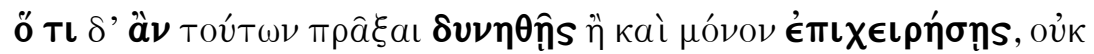

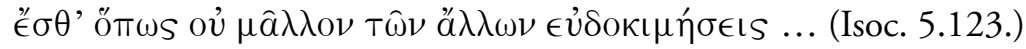

But whatever <part> of this you may be able to accomplish or even may only attempt, it is not possible that you will not become more distinguished than the rest...

Ö Tı with ö $v$ and Subjunctive but no antecedent.

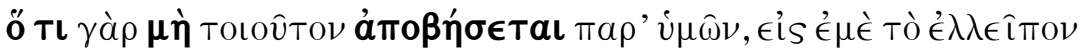
$\eta ँ \xi \in$ I. (X.Cyr. 1.5.13.)

For whatever does not turn out from you $<$ to be> such, the deficiency will fall upon me.

ö $\mathrm{Tl}$ with Indicative and negative $\mu$ ń (cf. $\$ 25.4 .2$ above), but no antecedent.

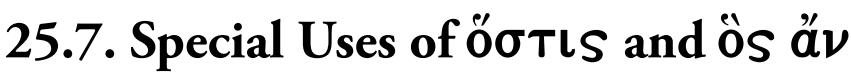

In some sentences, ö $\sigma \tau I S$ and ôs $\alpha$ $\nu$ clauses are not properly related to the Main clause grammatically, but in function they usually serve as Subject for the Main clause. ö $\sigma \tau I S$ and ós may appear in any Gender and may be singular or plural, but they are regularly used in the Nominative Case.

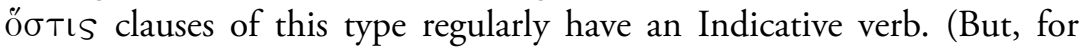
example, the oldest manuscript of Sophocles's Ajax at line 761 has a Subj.

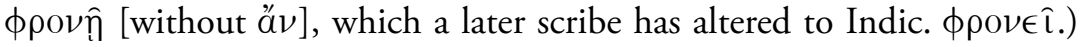
ôs ăv clauses have Subjunctive verbs.

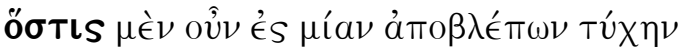

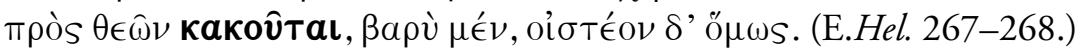

Well then, when any one, focusing on one fortune,

is maltreated by the gods, <that is> burdensome, but still able to be borne.

Structurally: 'Maltreatment by the gods <is> burdensome'. (Subject)

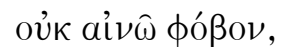

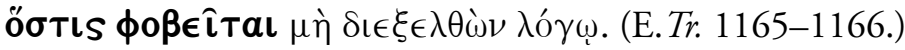

I do not approve fear,

when someone has fear without examining it with reason. 
Structurally: 'I do not approve irrational fear'. (In this passage, the ö $\sigma \tau ı S$ clause serves as Object in apposition with $\phi o ́ \beta o \nu$, the grammatical Object of the Main clause.)

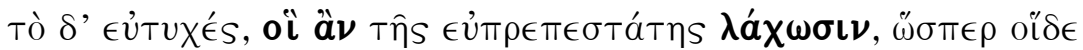
$\mu \grave{v} \nu \nu \hat{v} \nu, \tau \in \lambda \in v T \hat{s}$... (Th. 2.44.1.)

And <it is> good fortune, when <men> obtain a most decent end, just as these $<$ do $>$ now ...

Structurally: 'Obtaining a most decent end <is> fortunate'. (Subject)

\section{References}

Goodwin (1889), Syntax of the moods and tenses of the Greek verb, $\$ \$ 514-564$.

Smyth (1956), Greek grammar, $\$ \$ 2488-2552(-2573)$.

Lesson 25 does not cover all issues in the Sections of Goodwin (1889) and Smyth (1956), and it is not always in agreement with them.

\section{EXERCISE 25}

Translate the following passages.

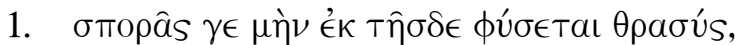

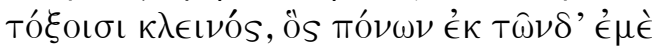
$\lambda \dot{v} \sigma \epsilon \mathrm{l}$.

\begin{tabular}{|c|c|}
\hline бтора́, -âs, $\dot{\eta}$ & origin \\
\hline$\gamma \in \mu \eta_{\nu}$ & but at any rate (Denniston, 1954 , p. 348 ) \\
\hline$\theta \rho a \sigma u ́ s,(-\epsilon \hat{\imath} \alpha,-v ́)$ & (a) courageous (figure) (Subject) \\
\hline$\kappa \lambda \epsilon \iota \nu o ́ s,-\eta ́$, , -ó & $\begin{array}{l}\text { famous (+ Causal Dat.; in apposition with } \\
\text { Subject) }\end{array}$ \\
\hline
\end{tabular}

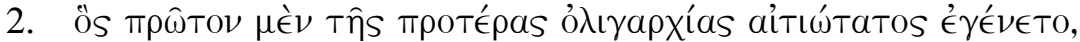

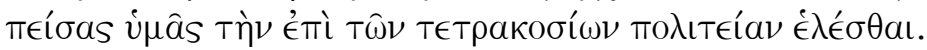

\begin{tabular}{|c|c|}
\hline al̈тıоs, - - , -Ov & responsible (for) (+ Gen.) \\
\hline Ł́mí (+ Gen.) & in the time of \\
\hline 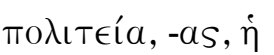 & administration, government \\
\hline
\end{tabular}




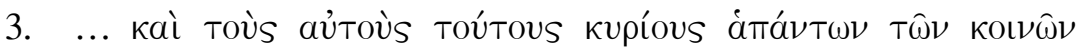

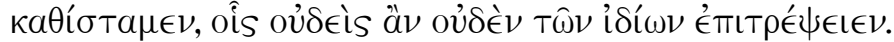

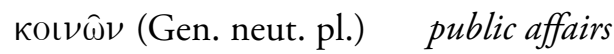

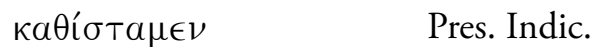

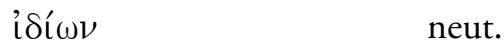

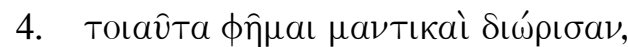

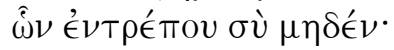

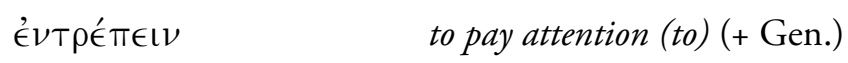

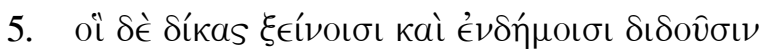

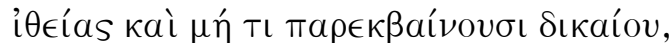

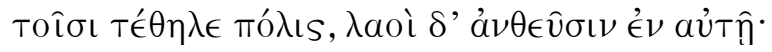

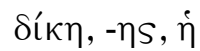

$\xi \in \hat{\imath} \nu 0 S$

$\delta ı \delta o \hat{\sigma ı \nu ~}$

¡̇ús, - $\in \hat{\imath} a,-\hat{u}$

Tôิol

$\theta a ́ \lambda \lambda \in \iota \nu$

$\dot{\alpha} \nu \theta \in \hat{\imath} \nu$ judgment

$\xi \in \dot{\epsilon} \nu \mathrm{S}$

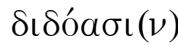

straight (lit. and metaphorical)

demonstrative pronoun, antecedent of ớ

to sprout; (Perf. in Imperf. sense)

to flourish

to bloom (here Ionic 3rd pers. pl.)

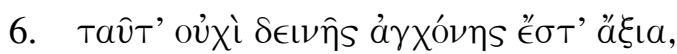

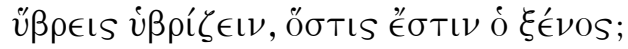

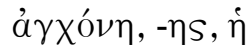

üßpıs, $-\epsilon \omega s, \dot{\eta}$ hanging

(act of) insolence (here internal Acc. with cognate verb)

7. ... I became reconciled on account of this danger with none of my enemies, who more gladly speak ill of me than commend themselves.

\begin{tabular}{|c|c|}
\hline to reconcile (with) & 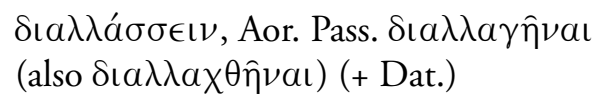 \\
\hline to commend & $\dot{\epsilon} \pi \alpha \iota \nu \in \hat{\imath} \nu$ \\
\hline
\end{tabular}


INTERMEDIATE ANCIENT GREEK LANGUAGE

8. ... but they are sending against me such [men], whom you [pl.] would not rightly trust.

to send (Acc.) against (Dat.) द́ $\pi ı \pi \epsilon ́ \mu \pi \epsilon \iota \nu$

to trust

$\pi \iota \sigma T \epsilon \hat{U} \in \iota \nu$ (+ Dat.) 


\section{LESSON 26 \\ Concessive Constructions}

\subsection{Introduction}

Concession may be expressed by a Participial phrase or by a Subordinate clause. In both constructions ö $\mu \omega s$ ('nevertheless') often appears in the leading clause (that is, the clause on which the Concessive clause or phrase depends).

\subsection{Concessive Participial Phrases}

When a Participial phrase expresses Concession, the Participle itself may carry the Concessive force; or the Participle may be reinforced by каítтє $\rho$ or occasionally by kaí or (mainly in Homer and tragedy) by $\pi \in \rho$ alone. After $\kappa a i m \epsilon \rho$, the Participle of the verb 'to be' may be omitted with an adjective or noun. In Homer, $\kappa a i ́$ and $\pi \epsilon \rho$ are almost always separated by the Participle or by another significant word. A Genitive absolute or an Accusative absolute may have Concessive force. See Lessons 4, 5 and 6 on Participles.

A negated Concessive Participial phrase ('not even if', 'not even though')

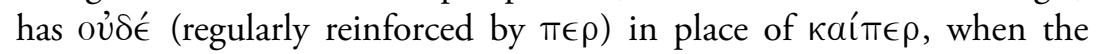
phrase is subordinate to a verb which is (or could be) negated by oú, as with Indicative or potential Optative. In Homer, $\pi \in \rho$ is regularly separated from oủsé.

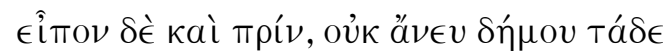

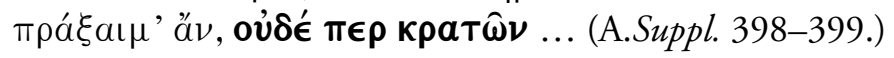

And I said also previously: 'I would not do this without <the consent of $>$ the people, not even though I am ruling ...'

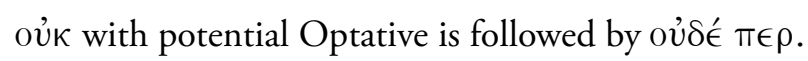




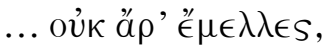

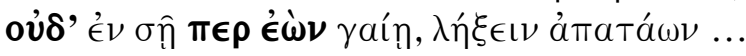

(Hom.Od. 13.293-294.)

... so you were not likely,

not even when you were in your own land, to cease from deceits...

ở火 with Indicative is followed by ở $\delta^{\prime} . . . \pi \epsilon \rho$.

$\mu \eta \delta \in$ is used with a Participle subordinate to a verb which is (or could be) negated by $\mu \eta$, as with Imperative or Subjunctive.

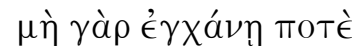

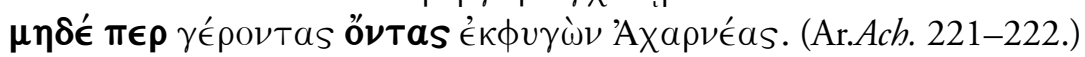

For he is not ever to taunt us

with his having escaped the Acharnians, not even if we are old.

$\mu \eta$ with Jussive Subjunctive is followed by $\mu \eta \delta \epsilon \epsilon \epsilon \rho$.

\subsection{Concessive Clauses}

\subsubsection{The Usual Constructions}

Greek Concessive clauses are, in form, a variety of Conditional clause.

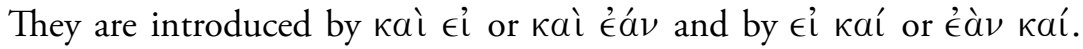
A broad distinction can be made between kaì $\in \hat{l}$ ( $($ á $\nu$ ) meaning 'even

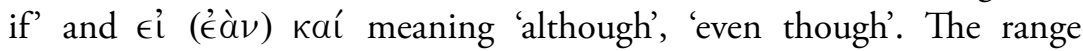
of constructions corresponds to that of other Conditional sentences. The negative within a Concessive clause ('even if ... not', 'although ... not') is $\mu \eta$, as in a Conditional clause. (Contrast $\$ 26.3 .5$ below.)

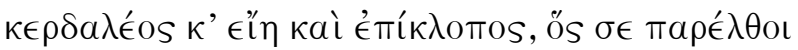

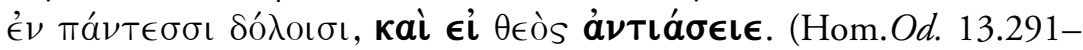
292.)

Crafty would he be and wily, who surpassed you

in all tricks, even if a god were to encounter $<$ you $>$.

kaì $\epsilon i$ with Optative. 


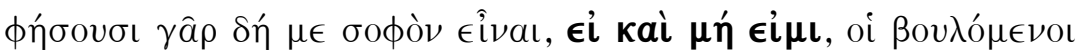
v $\mu \hat{\imath} \nu$ ò $\nu \in \iota \delta i ́ \zeta \in \iota \nu .(P l . A p .38$ C.)

For indeed those, who want to censure you, will say that I am wise, although I am not.

єi kaí with Indicative and negative $\mu$ ń.

\subsubsection{Variations from the Usual Constructions}

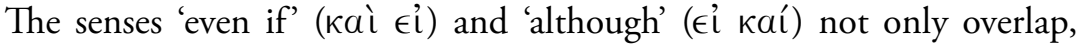
but appear to be reversed in some Greek sentences. This is especially true in verse.

Moreover, not every sentence with kai $\epsilon \hat{l}$ or $\epsilon \hat{l}$ kaí will have the Concessive meanings 'even if' or 'although'. kaí and $\epsilon \dot{l}$, in either order, may function separately at the beginning of a Conditional clause. Thus, kai $\epsilon \mathfrak{l}$ may mean 'and if'. And $\epsilon \grave{l}$ kaí may mean:

a. 'if indeed', referring to the whole clause

b. 'if also/even/actually', referring to a particular item following in the clause.

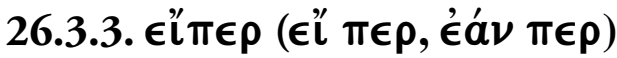

$\epsilon^{\prime \prime} \pi \epsilon \rho$ may have the meaning 'even if'. It is sometimes followed (immediately or later) by other particles such as kaí, $\tau \epsilon, \gamma \epsilon$.

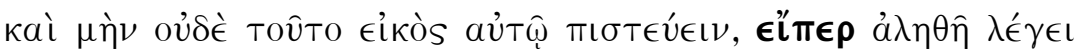

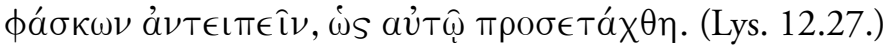

Moreover, even if he is telling the truth in saying that he spoke in opposition, $<i t$ is $>$ not reasonable to believe him in this claim either, that instructions were given to him.

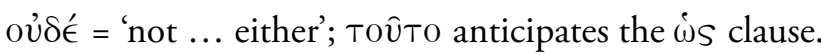




\subsection{4. $\epsilon \grave{l}$ or éáv Alone}

$\epsilon \mathfrak{l}$ or éá $\nu$ alone may have Concessive force.

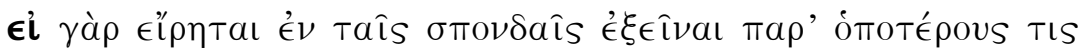

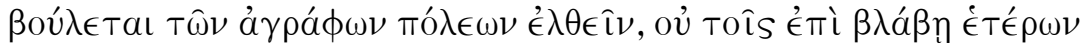

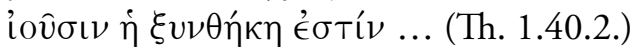

For <even $>$ if it has been stated in the treaty that it is permissible for any one of the unregistered city-states to go to whichever of the two sides it wishes, the clause is not <intended $>$ for those going to harm the others...

\subsubsection{Negated Concessive Clauses}

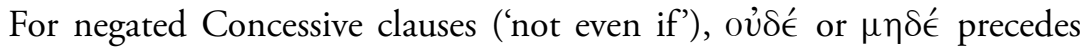

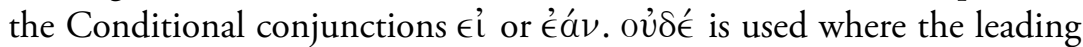
clause requires ớ, as with Indicative or potential Optative. $\mu \eta \delta \epsilon \in$ is used where the leading clause requires $\mu \eta$, as with Imperative, Subjunctive, or Optative in Past sequence representing a Primary Subjunctive. (Cf. $\$ 26.2$ above.) The negative is often repeated within the leading clause.

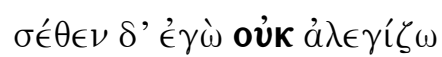

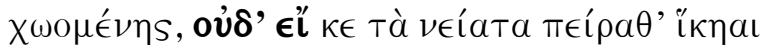

raíns кaì тóvтoı ... (Hom.Il. 8.477-479.)

But I am not worried about you

in your anger, not even if you go so far as the furthest limits of earth and sea...

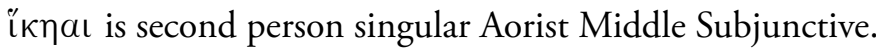

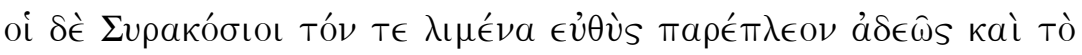

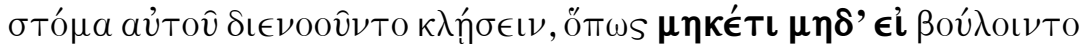

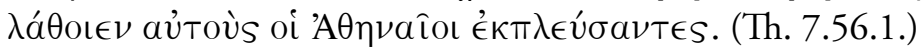

And the Syracusans immediately began to sail along the harbour without fear and were intending to block its mouth, so that the Athenians might no longer escape their notice in sailing out, not even if they wanted to. 


\section{References}

Denniston (1954), The Greek particles, pp. 299-305, 486-487.

Goodwin (1889), Syntax of the moods and tenses of the Greek verb, \$\$842, 859-861 (Participles only).

Smyth (1956), Greek grammar, \$\$2066, 2070.c, 2082-2083 (Participles); 23692382 (clauses).

\section{EXERCISE 26}

Translate the following passages.

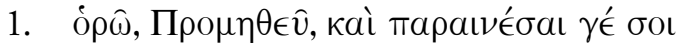

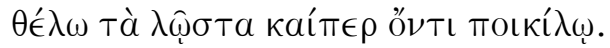

\begin{tabular}{|c|c|}
\hline$\pi a \rho a \iota \nu \in \hat{\imath} \nu$ & to give advice (Acc.) to (Dat.) \\
\hline$\lambda \hat{\omega} \sigma \tau o s,-\eta,-O \nu$ & best \\
\hline 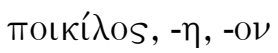 & subtle, ingenious \\
\hline
\end{tabular}

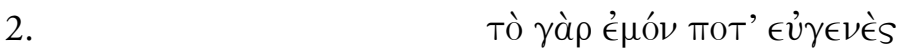

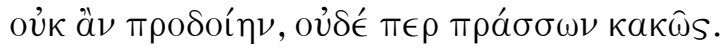

\begin{tabular}{ll}
\hline$\epsilon \dot{v} \gamma \in \nu \eta \dot{s}$, -'́s & of noble birth (here neut. of adj. for \\
& abstract noun) \\
$\pi \rho \circ \delta ı \delta o ́ v a ı ~$ & to betray \\
$\pi \rho a ́ \sigma \sigma \in \iota \nu$ & to fare, to get on \\
\hline
\end{tabular}

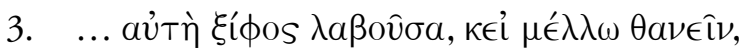
$\kappa T \in \nu \hat{\omega} \sigma \phi \in \ldots$

$\sigma \phi \epsilon \quad$ them (Acc.)

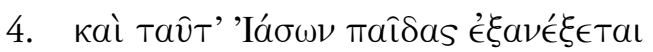

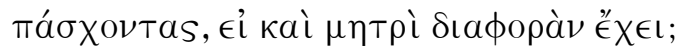

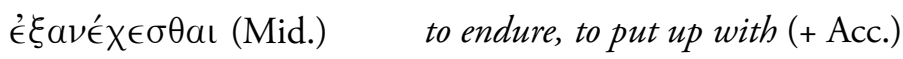

sıaфора́, -âs, $\dot{\eta} \quad$ difference, disagreement 


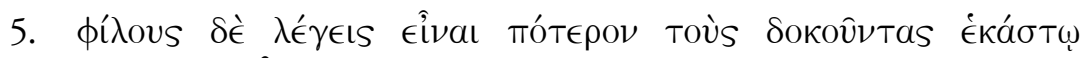

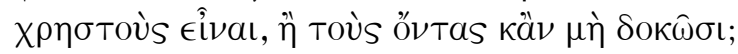

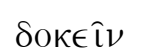

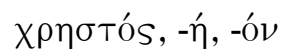

\section{to seem}

good

This sentence is a direct Alternative Question.

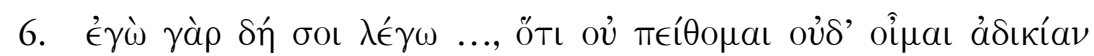

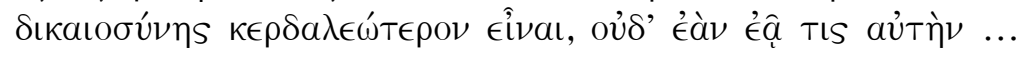

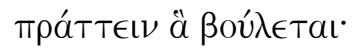

$\kappa \in \rho \delta a \lambda \operatorname{ć}^{\circ},-\alpha,-\mathrm{O \nu} \quad$ profitable

7. For this city must realise fully, even if it is not willing [to], that it is uninitiated in my Bacchic rites ...

\begin{tabular}{|c|c|}
\hline to realise fully & 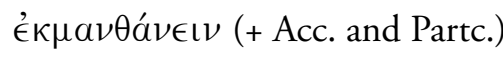 \\
\hline $\begin{array}{l}\text { even if } \\
\text { uninitiated (in) }\end{array}$ & $\begin{array}{l}\text { Use a clause. } \\
\text { áT́́ } \lambda \in \sigma T O S,-o \nu \text { (+ Gen.) }\end{array}$ \\
\hline
\end{tabular}

8. But I think that, although concerning the other [matters] it is appropriate that the [men] of such an age should keep silent, at least concerning going to war or not, it is fitting that these especially should give advice ...

\begin{tabular}{|c|c|}
\hline to think & $\dot{\eta} \gamma \in \hat{\imath} \sigma \theta a \iota$ (Mid.; + Infin.) \\
\hline to be appropriate & $\pi \rho \epsilon ́ \pi \epsilon \iota \nu$ (+ Acc. and Infin.) \\
\hline of such an age & 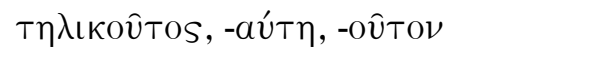 \\
\hline concerning going to war & preposition + articular Infin. $\pi o \lambda \in \mu \in \hat{\imath} \nu$ \\
\hline to be fitting & $\pi \rho о \sigma \eta ́ \kappa \in \iota \nu$ (+ Acc. and Infin.) \\
\hline especially & $\mu a ́ \lambda ı \sigma т a$ \\
\hline to give advice & $\sigma v \mu \beta o v \lambda \epsilon \dot{v} \in t \nu$ \\
\hline
\end{tabular}




\section{LESSON 27 \\ Purpose Constructions}

\subsection{Prepositions}

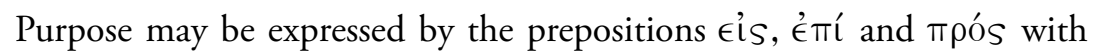
the Accusative, $\epsilon$ mí with the Dative, and $\dot{v} \pi \hat{\epsilon} \rho$ with the Genitive of the articular Infinitive.

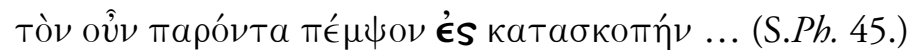

So send the man, who is present, to reconnoitre...

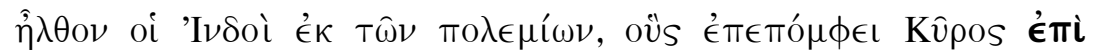
катабкоти́ ... (X.Cyr. 6.2.9.)

the Indians, whom Cyrus had sent to reconnoitre, came from the enemy ...

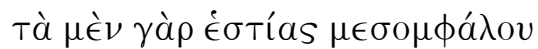

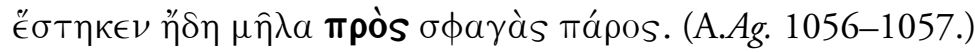

For now the animals

stand <ready $>$ for slaughter before the central hearth.

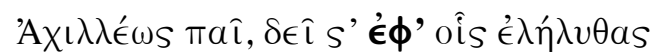

$\gamma \in \nu \nu a \hat{\imath}$ v $\in \hat{\imath} \nu a \mathrm{l}$. (S.Ph. 50-51.)

Son of Achilles, you must be noble <for the purposes> for which you have come.

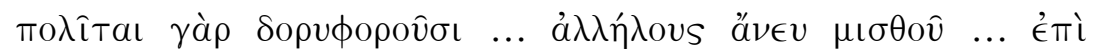

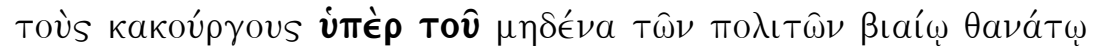

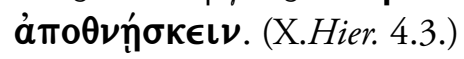

For the citizens guard ... one another without pay ... against evil-doers, so that no one of the citizens may die by a violent death. 


\subsection{Infinitive}

For the Infinitive expressing Purpose with certain verbs, see Lessons 3.4.3.1 and 3.5.3.

\subsection{Participles}

Participles may express Purpose, occasionally in the Imperfect Aspect, but mainly in the Intentive Aspect. $\dot{\omega}$ is frequently used with the Intentive ('Fut.') Participle expressing Purpose. A Participle is used to express Purpose especially with such verbs as 'come', 'go', 'send' and 'summon'.

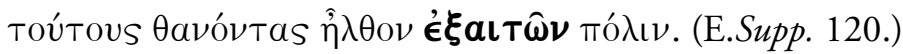

I went to the city to request these dead $<m e n>$.

Imperf. Partc.

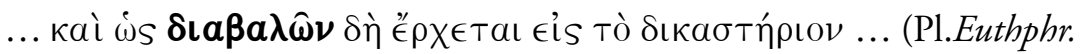
3 B.)

$\ldots$ and he is going to court precisely to slander $<y o u>\ldots$

Intentive ('Fut.') Participle.

\subsection{Adjectival Clauses of Purpose}

Adjectival clauses with the Future Indicative may be used to express Purpose. (Goodwin [1889, \$565], Smyth [1956, \$\$2554, 2705.f.] and other elementary and advanced grammars state that the negative for this construction is $\mu$. . However, they cite no negative examples. Negative examples can be cited for adverbial clauses of Place.)

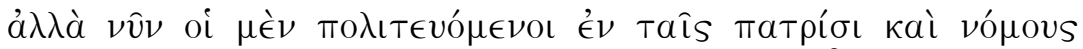

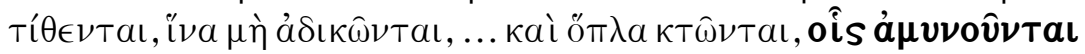

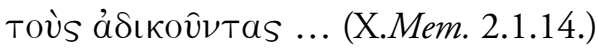

But now those who participate in the government in their fatherlands not only frame laws, so that they may not be wronged, ... but also obtain weapons, with which to ward off wrongdoers... 
In adjectival clauses of Purpose, Homer normally uses the Subjunctive, generally with $\kappa \in(\nu)$, in Primary sequence, and Optative, without $\kappa \in(\nu)$, in Past sequence. The Optative in Past sequence also occurs in Attic literature sometimes.

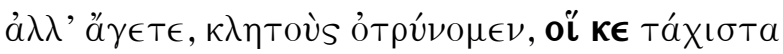

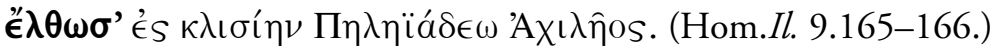

Well come on, let us urge on recruited men, that they may very quickly go to the hut of Peleus's son, Achilles.

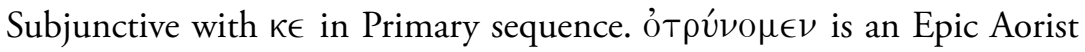
Subjunctive form with short vowel, equivalent to Attic ó $\rho \tilde{\nu} \nu \omega \mu \in \nu$.

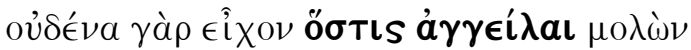

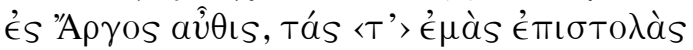

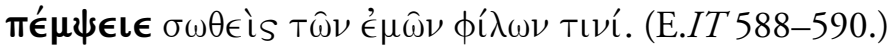

For I had no one to go back

to Argos and report, and, having been saved, to convey

my letter to one of my dear ones.

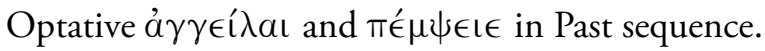

\subsection{Adverbial Clauses of Purpose}

Adverbial clauses of Purpose are introduced by a variety of conjunctions, but mainly ì $\nu a$ and ötw . They regularly have Subjunctive in Primary sequence and Optative in Past sequence. In early Greek, negative Purpose clauses could be introduced by $\mu$ '́ alone. But $\mu \eta$ increasingly came to be used only as a negative within a Purpose clause introduced by one of the other (positive) conjunctions.

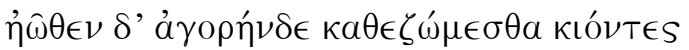

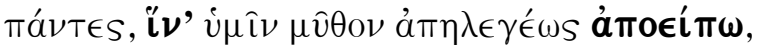

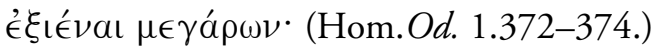

And from dawn let us all go to the place of assembly and sit down, so that I may declare to you my word unrestrainedly, to go out from the halls.

íva with Subjunctive in Primary sequence. 


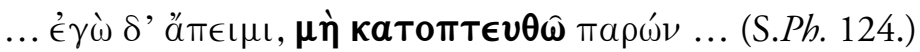

... but I shall go away, so that I may not be observed being present ...

$\mu \eta \dot{a}$ alone with Subjunctive in Primary sequence.

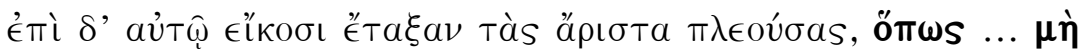

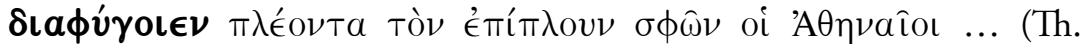
2.90.2.)

And on it [= the right wing] they stationed the twenty <ships> which sailed best, in order that ... the Athenians might not escape through their lineof-attack as it sailed ...

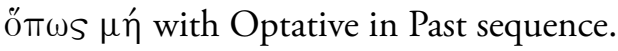

iva is the main Purpose conjunction in Herodotus, Aristophanes, Plato

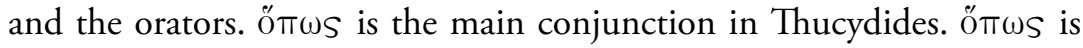

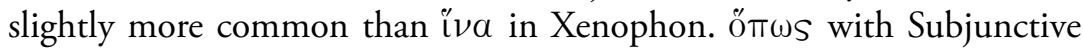
sometimes has ăv in positive clauses.

is with $\kappa \in(\nu)$ or $\alpha$ $\nu$ and the Subjunctive occurs in Homer, Attic poetry and Herodotus (Ionic). ő $\phi \rho a$ is the most common Purpose conjunction in Homer; occasionally $\kappa \in(\nu)$ or $\not \partial v$ is used with ő $\phi \rho a$ and the Subjunctive.

The Vivid construction, with Subjunctive instead of Optative in Past sequence, is used more often than not by the historians Herodotus and Thucydides.

The Future Indicative may be used instead of the Subjunctive especially in poetry, mainly with ö $\pi \omega s$, rarely with ö $\phi \rho \alpha$, $\dot{\omega}$ and $\mu \eta$, but never with ïva.

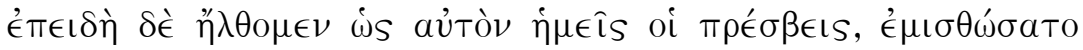

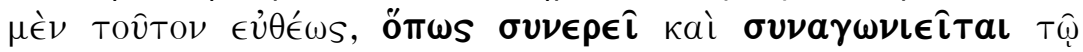

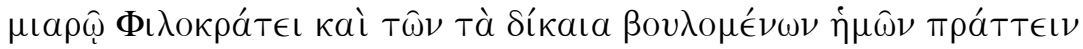

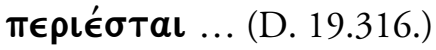

But when we, the ambassadors, had come to him, he immediately hired this $<$ fellow>, so that he might speak with and assist the abominable Philocrates and overtake us who wanted to do the right thing...

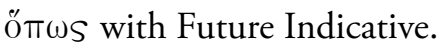




\section{References}

Goodwin (1889), Syntax of the moods and tenses of the Greek verb, \$\$302-338; 802; 840 .

Smyth (1956), Greek grammar, $\$ \$ 1686.1 . d, 1689.2 . c, 3 . d, 1695.3 . c, 1697.1 . b$ (Prepositions); 2065, 2086 (Participles); 2554 (adjectival clauses); 21932206 (adverbial clauses).

\section{EXERCISE 27}

Translate the following passages.

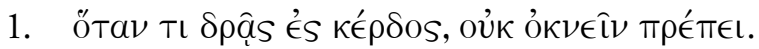

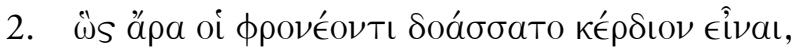

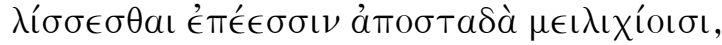

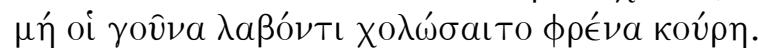

\begin{tabular}{|c|c|}
\hline oi & Dat. masc. sg. \\
\hline 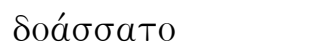 & it seemed \\
\hline 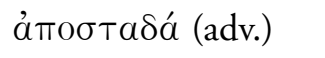 & standing apart \\
\hline$\mu \in ı$ גíxıاos, - $a,-0 \nu$ & gentle, soothing \\
\hline 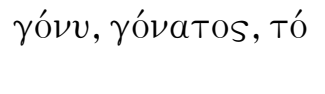 & $\begin{array}{l}\text { knee (here Acc. pl. with alternative } \\
\text { spelling) }\end{array}$ \\
\hline
\end{tabular}

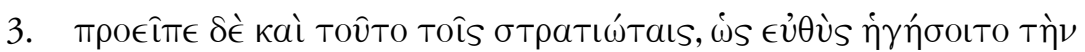

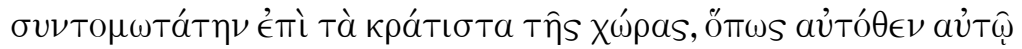

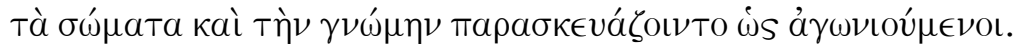

\begin{tabular}{|c|c|}
\hline$\pi \rho \circ \in ı \pi \epsilon \hat{\imath} \nu$ (Aor.) & to say in advance \\
\hline$\sigma u ́ \nu т о \mu о \mathrm{~s},-\mathrm{O \nu}$ & $\begin{array}{l}\text { short (Here understand o̊ } \delta \text { óv, Acc. } \\
\text { of Extent.) }\end{array}$ \\
\hline Tó $\theta \in \nu$ & at once \\
\hline$\gamma \omega \nu \nu^{\prime} \zeta \in \sigma \theta a \iota$ (Mid.) & to take part in the struggle \\
\hline
\end{tabular}




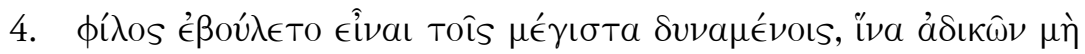

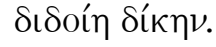

\begin{tabular}{|c|c|}
\hline фídos & Complement of $\epsilon \hat{\imath} \nu a t$ \\
\hline 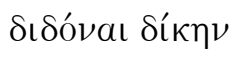 & to pay the penalty \\
\hline
\end{tabular}

5.

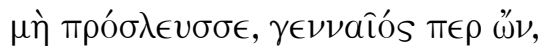

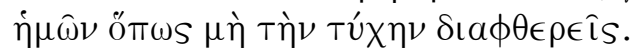

$\pi \rho 0 \sigma \lambda \epsilon \dot{v} \sigma \sigma \epsilon t \nu$ to look at (Understand avंTóv as Object.)

6. For not in order that I may criticise the city of the Spartans in the presence of the rest have I spoken in this way about them, but in order that I may stop those [men] themselves ... [from] having such an attitude.

\begin{tabular}{|c|c|}
\hline in order that & ¿va (both instances) \\
\hline to criticise & $\delta\llcorner\alpha \beta a ́ \lambda \lambda \in \iota v$ \\
\hline Spartan & 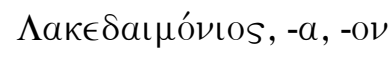 \\
\hline in the presence of & 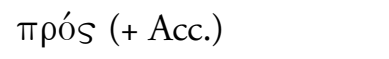 \\
\hline attitude & $\gamma \nu \omega ́ \mu \eta,-\eta s, \dot{\eta}$ \\
\hline
\end{tabular}

7. ... and he was no longer willing to accept payment from me, pushing [me] aside, so that that [man], but not I, might seem to be burying my grandfather.

\begin{tabular}{|c|c|}
\hline to accept payment & åmо $\lambda \alpha \mu \beta a ́ \nu \in \mathrm{t} \nu$ (no Object necessary) \\
\hline to push aside & 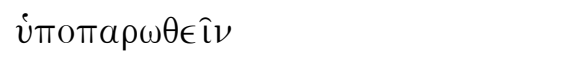 \\
\hline so that & 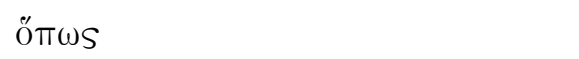 \\
\hline grandfather & та́mாоs, -ov, ó \\
\hline
\end{tabular}




\section{LESSON 28 \\ Clauses of Comparison}

\subsection{Introduction}

Clauses of Comparison are introduced by relative adjectives and by relative adverbs of manner, quality, quantity or degree. The relative adjective or adverb is frequently balanced by the corresponding demonstrative adjective or adverb in the leading clause (on which the clause of Comparison

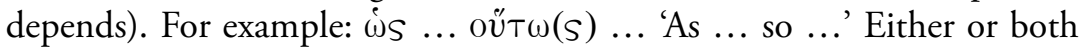
of these adverbs may be reinforced by kaí: $\dot{\omega}$ kaí ... oütw kaí ...: 'Just as ..., even so ...' [OR: 'so too ...']. In Homer, "̈s (accented) frequently stands for oüTws.

\subsection{Definite Comparison}

The simplest form of comparison presents the circumstances of the comparison as factual and uses the Indicative Mood in the clause of Comparison.

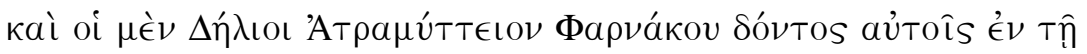

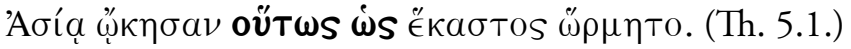

And the Delians settled Atramyttium in Asia, when Pharnaces had granted it to them, in such a way as each <man> had set out.

(There was no organised colony, but settlement was individual and piecemeal.)

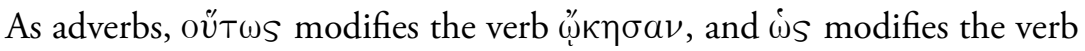
๗̈рипто. 


\subsection{Indefinite Comparison}

An indefinite form of comparison uses the Subjunctive Mood with ăv in Primary sequence. Compare the difference between Open Particular and Open General Conditions, Lesson 19.2.1 and Lesson 19.2.2. In the following sentence, the öt $\omega$ s clause refers to any occasion on which Nicocles influences the attitude of his citizens.

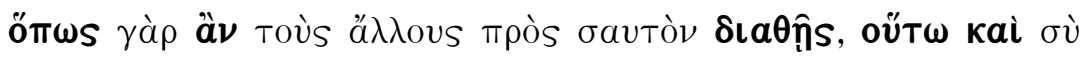

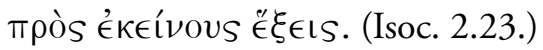

For as you dispose the rest <of the community $>$ towards yourself, so too will you be inclined towards those <people $>$.

The equivalent of this construction in Past sequence has the Optative without ăv. (A Vivid construction, using Subj. with ă $v$, may also occur in Past sequence.)

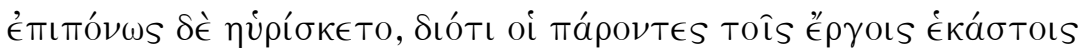

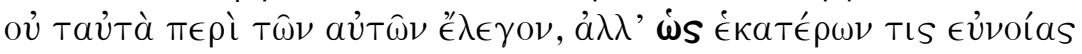

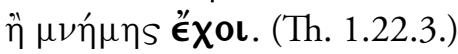

And the discoveries were painstakingly made, because those who had been present at particular actions did not say the same things about the same $<$ <vents>, but <spoke> as any one had some goodwill towards either side or some memory $<$ of what had happened $>$.

(The Partitive Genitives singular $\epsilon \dot{v} \nu o$ á as and $\mu \nu \eta \dot{\eta} \mu \eta$ function as direct Objects of éXol. Cf. Lesson 37.3.4.)

\subsection{Potential, Conditional and Temporal Constructions}

Potential, Conditional and Temporal constructions may occur within a comparison.

\subsubsection{Potential}

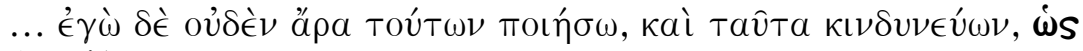

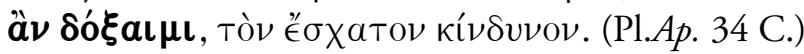


.. but I shall actually do none of these things — and this, when I am running, as I would seem < to be>, the extreme risk.

is with ố $v$ and potential Optative in Primary sequence.

\subsubsection{Conditional}

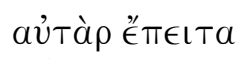

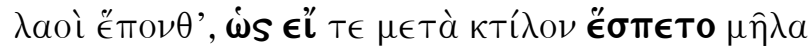

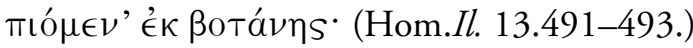

\section{And then}

the men were following, as if sheep $<$ had $>$ followed after a ram from pasture, going to drink.

is $\in \grave{l}$ with Past Aorist Indicative in Past sequence.

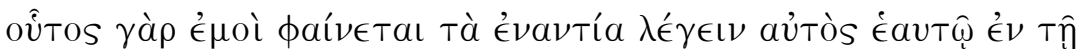

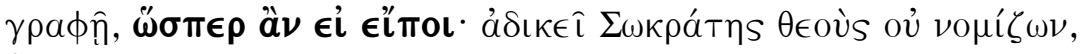

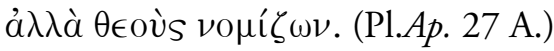

For this <man > appears to me to say the opposite [himself] to himself in his indictment, as (he would) if he were to say: 'Socrates does wrong in not believing in gods but in believing in gods.

$\tilde{\omega} \sigma \pi \epsilon \rho$ àv $\epsilon \dot{l}$ with Optative in Primary sequence.

\subsubsection{Temporal}

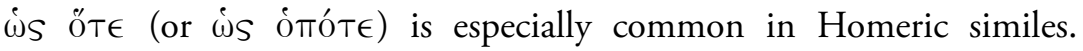
The Mood is sometimes Indicative. But in Homer, an initial Subjunctive without $\stackrel{\alpha}{\nu} \nu$ is often continued by Indicatives. The construction with Subjunctive is indefinite.

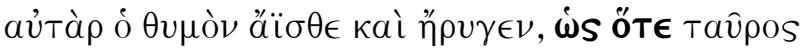

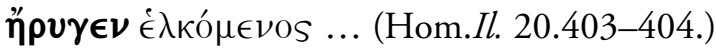

Then he was breathing out his spirit and bellowed, as when a bull

bellows (lit. bellowed; Indic.) while being dragged along ...

is öT€ with Past Aorist Indicative (definite). 


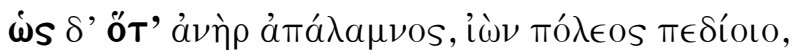

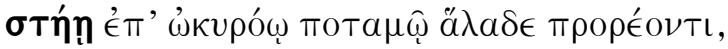

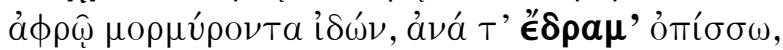

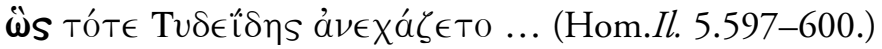

And as when a helpless man, going over a large plain, stops (Subj.) at a swift-flowing river flowing on to the sea, seeing it seething with foam, and runs (lit. ran; Indic.) backwards, so at that time the son of Tydeus was recoiling...

is ÖT€ with Aorist Subjunctive (indefinite) continued by Past Aorist Indicative (definite).

\subsection{Other Correlative Adjectives and Adverbs}

Other correlative adjectives and adverbs also express comparison.

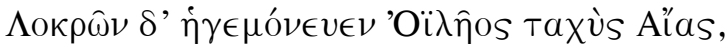

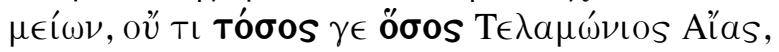

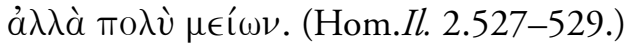

And of the Locrians the leader was Oeleus's <son>, swift Ajax, smaller, not at all so big as Telamon's son Ajax, but much smaller.

\section{References}

Goodwin (1889), Syntax of the moods and tenses of the Greek verb, $\$ \$ 484-485$, 543-549.

Smyth (1956), Greek grammar, $\$ \$ 2462-2487$. 


\section{EXERCISE 28}

Translate the following passages.

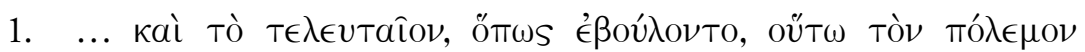

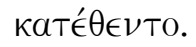

Tò $\tau \in \lambda \in U$ Tầov adverbial

кататі́ $\theta \in \sigma \theta a \iota$ (Mid.) to put an end to (+ Acc.)

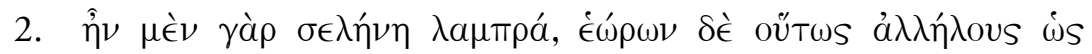

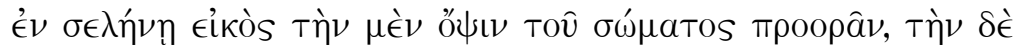

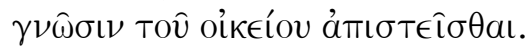

$\sigma \in \lambda \dot{\eta} \nu \eta,-\eta s, \dot{\eta} \quad$ moonlight

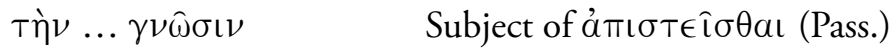

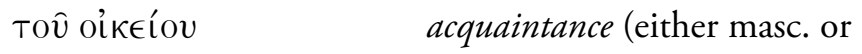

collective neut.)

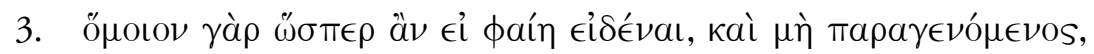

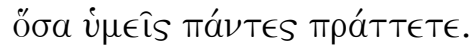

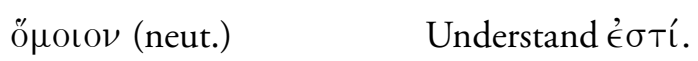

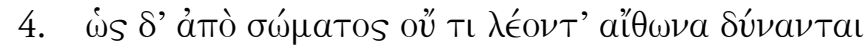

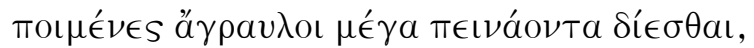

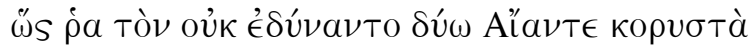

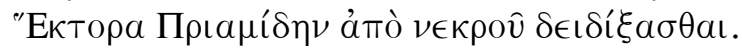

\begin{tabular}{|c|c|}
\hline$\alpha \iota ّ \theta \omega \nu,-\omega \nu 0 s, \dot{o}, \dot{\eta}$ & tawny \\
\hline 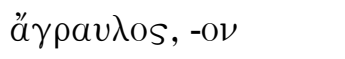 & (living) in the field(s) \\
\hline$\pi \in \iota \nu \hat{\alpha} \nu$ & to be hungry \\
\hline$\delta i ́ \in \sigma \theta a ı$ (Mid.) & to put to flight, to drive away \\
\hline$\hat{\rho} \alpha$ (enclitic adv.) & just (modifying ஸ̈s) \\
\hline корvбти́s, -оर̂, ò & (a) helmeted (man) (here dual) \\
\hline$\delta \in \iota \delta i ́ \sigma \sigma \in \sigma \theta a \iota$ (Mid.) & to frighten, to alarm, to scare away \\
\hline
\end{tabular}




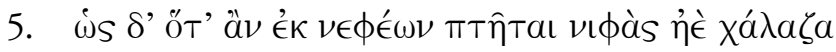

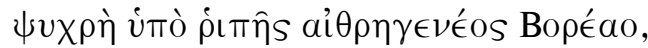

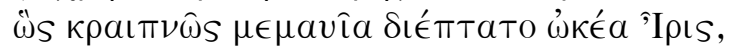

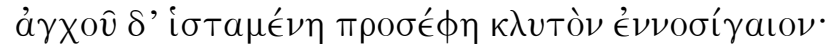

\begin{tabular}{|c|c|}
\hline$\pi \in ́ T \in \sigma \theta a l$ & to fly \\
\hline 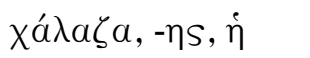 & hail \\
\hline 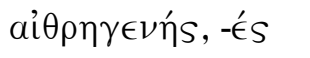 & born in the (bright) sky \\
\hline 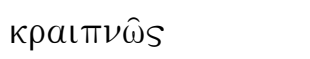 & quickly \\
\hline$\mu \in \mu o \nu \in ́ v a l$ & to be eager (Perf. with Imperf. meaning) \\
\hline$\mu \in \mu a \omega ́ s,-v i ̂ a$, -ós & short form of Partc. of $\mu \epsilon \mu$ ovéval \\
\hline 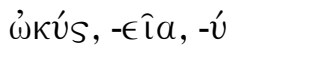 & swift (Epic fem. ஸ่Kéa) \\
\hline àrxô̂ (adv.) & near \\
\hline
\end{tabular}

6. And concerning the mutilation of the statues and the laying of information, just as I promised you (pl.), so too I shall do.

\begin{tabular}{|c|c|}
\hline mutilation & $\pi \epsilon \rho \iota к о \pi \dot{\eta},-\hat{\eta} s, \dot{\eta}$ \\
\hline statue & $\dot{\alpha} \nu a ́ \theta \eta \mu \alpha,-\alpha$ тоs, Tó \\
\hline laying of information & $\mu \eta \dot{\eta} \nu v \sigma ı s,-\epsilon \omega s, \dot{\eta}$ \\
\hline to promise (to someone) & imı $\sigma \chi \nu \in \hat{\imath} \sigma \theta a \iota$ (+ Dat.) \\
\hline
\end{tabular}




\section{LESSON 29 \\ Expressions of Hindering, Forbidding, Denying and Failing}

\subsection{Introduction}

Verbs (and other expressions) of hindering take a direct Object in the Accusative Case. The Object may be a person or a thing. Occasionally, both person and thing occur in the same expression with a double Accusative construction: 'to hinder someone <from $>$ something'. More often the thing, from which someone is hindered, is expressed by a Genitive of Separation with or without a preposition (ámó, é $\kappa)$. When a thing is the direct Object of such a verb, it is most often expressed by an Infinitive without, or less often with, the definite article. And the most common construction for expressing 'to hinder someone from doing something' is technically a double Accusative of person and thing (Infin.): lit. 'to hinder someone to do something'.

In positive and negative expressions of hindering, a redundant negative $\mu$ ń may occur with the Infinitive. And in negative (or interrogative) expressions of hindering, a double redundant negative $\mu \grave{\eta}$ ov may occur with the Infinitive.

Occasionally, an Accusative and Participle (instead of Infinitive) construction is used (cf. Lesson 4.3.3, Supplementary Participle). More rarely, constructions of Result, Effort and Condition are used with the function of a hindering expression; cf. Lessons 22, 24 and 19 respectively. In Passive expressions, the personal Object of the usual construction becomes the Subject and the Infinitive is retained: 'they are hindered from doing something' (lit. 'they are hindered to do something'). In the Passive form of an Accusative and Participle construction, both the Accusative noun or pronoun and the Participle become Nominative. 


\subsection{Direct Object}

\subsubsection{Person}

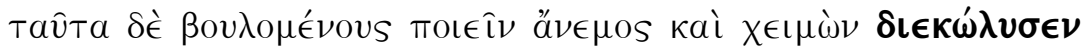

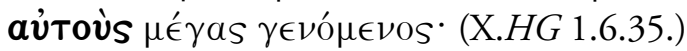

But although they were wanting to do this, a great wind and storm arose and prevented them.

\subsubsection{Thing}

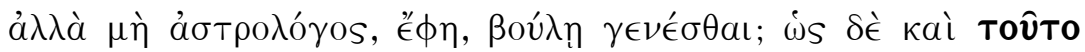

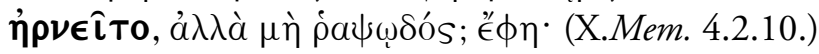

'Well, do you want', he said, 'to become an astronomer?' And since he was denying this also, 'Well', he said, 'a reciter?'

\subsubsection{Person and Thing}

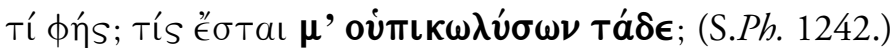

What do you mean? Who will there be who will debar me from this?

\subsection{Genitive of Separation}

\subsubsection{Simple Genitive}

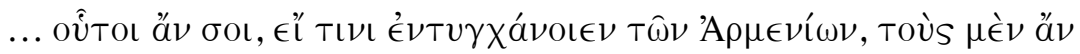

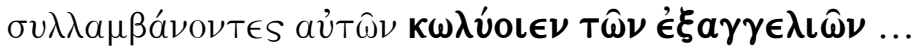

(X.Cyr. 2.4.23.)

... these men, if they encountered any one of the Armenians, would seize some of them for you and would prevent $<$ them $>$ from $<$ making $>$ reports ...

\subsubsection{Preposition with Genitive}

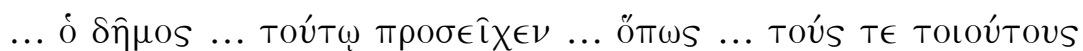

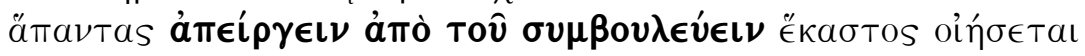
$\delta \in \hat{\imath} \nu$... (Isoc. 12.139-141.) 
... the people ... attended to this ... that each should think that it was necessary to debar all such <men> from giving advice ...

( $\tau \epsilon$ anticipates a following $\tau \epsilon$. )

\subsection{Infinitive after a Positive Expression}

\subsubsection{Infinitive Only}

... тáde кaì $\theta \rho \eta \nu \hat{\omega}$ кámı $\theta \epsilon a ́ \zeta \omega$,

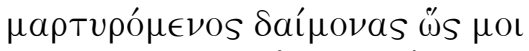

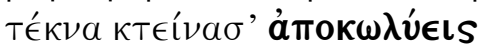

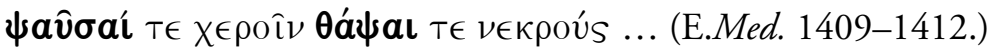

... I both make this lament and invoke the gods, calling the deities to witness that, having killed my children, you are preventing both the touching with one's hands and the burying of their bodies...

\subsubsection{Accusative and Infinitive}

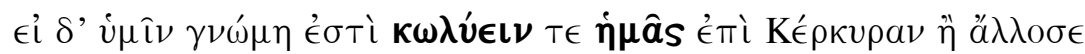

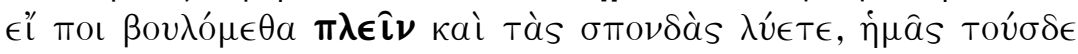

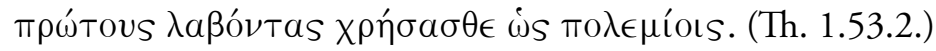

But if you have the intention of preventing us from sailing to Corcyra or to anywhere else that we want to, and (if) you are breaking the treaty, seize us here first and treat <us $>$ as enemies.

\subsubsection{Infinitive with Redundant $\mu$ ń}

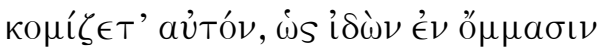

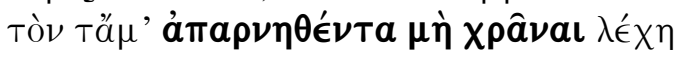

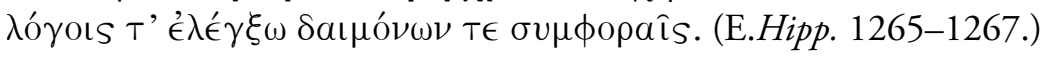

Bring him, so that I may see with my eyes

the one who denied that be polluted my bed

and (so that I) may make a refutation with words and with the disaster from the gods. 


\subsubsection{Accusative and Articular Infinitive}

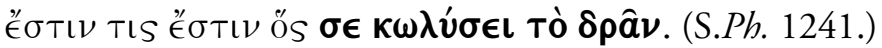
There is, there is someone who will prevent you from acting.

\subsubsection{Accusative and Articular Infinitive with Redundant $\mu$ ń}

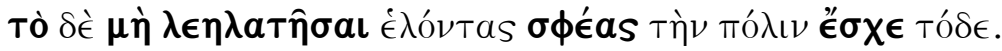
(Hdt. 5.101.1.)

And this kept them from plundering the city when they captured it.

\subsubsection{Accusative and Genitive Articular Infinitive}

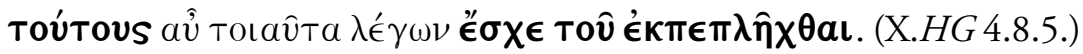

Moreover, by making such statements he kept these men from being [OR: having become] panic-stricken.

\subsubsection{Accusative and Genitive Articular Infinitive with Redundant $\mu$ ń}

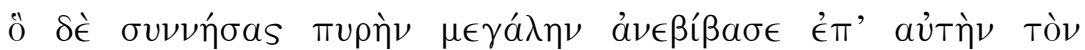

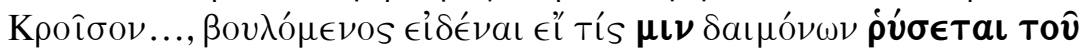

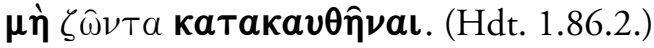

And he, having built a big pyre, made Croesus go up on to it ... wanting to know whether any one of the deities would rescue him from being burned alive.

\section{5. '̇ $\mu \pi 0 \delta \omega ́ \omega$}

The adverb $\epsilon^{\prime} \mu \pi \mathrm{T} \delta \dot{\omega} \nu$ introduces a variety of constructions which express hindering. The basic idea is 'getting in the way', 'blocking'. The grammatical constructions include Infinitive with or without definite article. The definite article may be in the Accusative or the Genitive Case. The Infinitive may have an explicit or implicit Accusative Subject; the implicit Subject may be indicated by an Accusative Participle. Redundant negatives may be used with the Infinitive, with or without the definite article. 


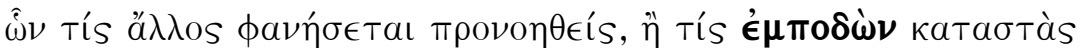

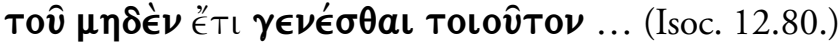

For who else among them will appear as taking precautions, or who as getting in the way of any such thing happening again ...?

Genitive articular Infinitive with Accusative Subject.

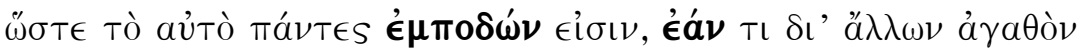

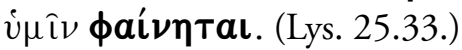

And so all together they are in the way for any good to appear for you through other <people>.

€́áv + Subjunctive: 'in the way if any good should appear'. Conditional construction as in $\$ 29.8$ below.

\subsection{Infinitive after a Negative Expression}

\subsubsection{Infinitive Only}

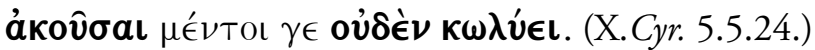

But at any rate nothing prevents listening.

\subsubsection{Accusative and Infinitive}

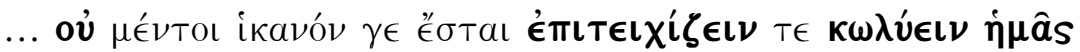

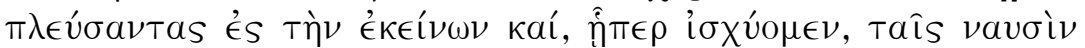
ả $\mu v ́ \nu \in \sigma \theta a \imath \cdot($ Th. 1.142.4.)

... however, it will not be sufficient to prevent us from building-a-fort after sailing to their <territory> and, where our strength lies, defending ourselves with our ships.

\subsubsection{Infinitive with Redundant $\mu \eta \dot{~}$}

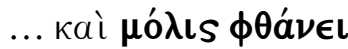

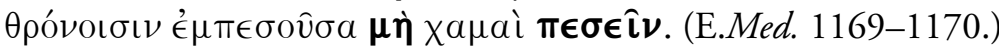

... and, by falling on to her chair,

she scarcely avoided falling to the ground.

$\mu o ́ \lambda ı s$ ('scarcely') is a virtual negative. $\phi \theta a ́ v \in \iota$ is Historic Present. 


\subsubsection{Articular Infinitive Only}

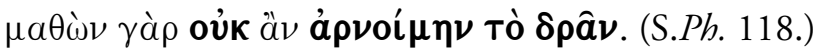

For, if I learned <this>, I would not refuse to act.

\subsubsection{Articular Infinitive with Redundant $\mu$ '́}

тò $\mu$ ทे ả

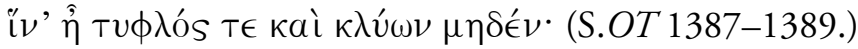

from shutting up my wretched body,

... I would not have kept myself

so that I might be blind and hearing nothing.

$\hat{\eta}$ is Past Indicative in a Purpose clause dependent on the Main clause of an Unfulfilled Conditional sentence (Smyth, 1956, \$2185.c.).

\subsubsection{Accusative and Infinitive with Redundant $\mu \grave{\eta}$ oủ}

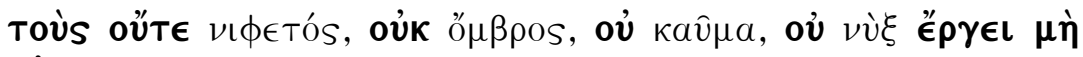

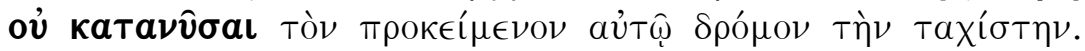
(Hdt. 8.98.1.)

Neither snow nor rain nor heat nor night binder them from covering in the quickest way the course appointed by him.

\subsubsection{Accusative and Articular Infinitive with Redundant $\mu \grave{\eta}$ ov่}

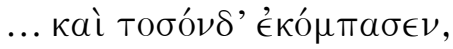

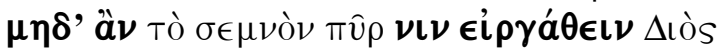

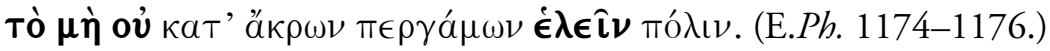

$\ldots$ and he made his great boast, that not even the sacred fire of Zeus would prevent him from capturing the city down from its highest citadel. 


\subsubsection{Genitive Articular Infinitive}

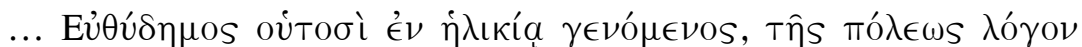

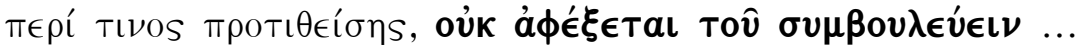
(X.Mem. 4.2.3.)

... Euthydemus here, when he comes of age, <and $>$ when the city is proposing a discussion about something, will not restrain himself from giving advice.

\subsubsection{Genitive Articular Infinitive with Redundant $\mu$ '}

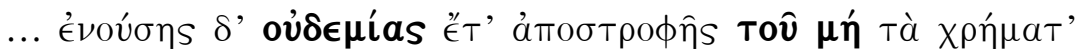

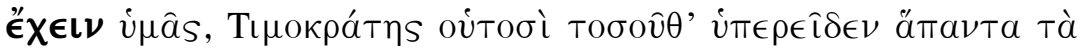

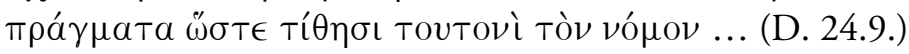

... and when there was no longer any means-of-preventing your having the money, Timocrates here overlooked all the issues to so great an extent that he is proposing this law...

\subsection{Result Construction}

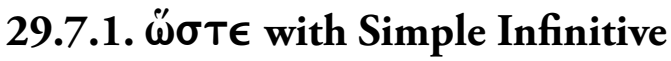

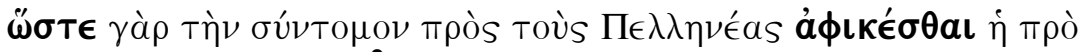

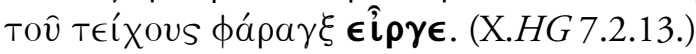

For the ravine in front of the wall was preventing <them $>$ from reaching the Pellenians along the short <route>.

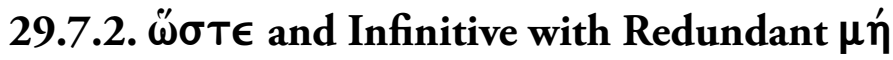

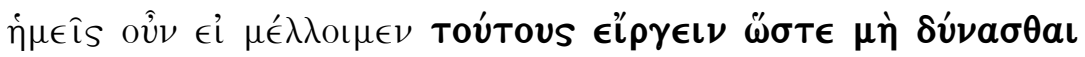

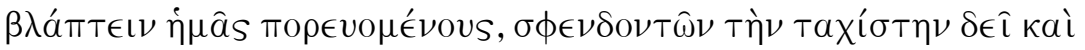

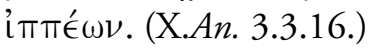

Therefore, if we were going to prevent these <men > from being able to harm us as we proceeded, there would be need of slingers very quickly and horsemen.

$\delta \in \hat{\imath}$, as a modal verb ('need', 'must', 'ought', etc.), is used in the Indicative in Greek, where English uses a potential idiom. 


\subsection{Effort Construction}

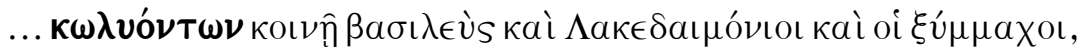

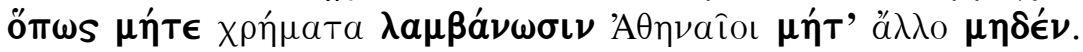
(Th. 8.18.1.)

... let the king and the Spartans and their allies in common prevent the Athenians from receiving either the money or anything else.

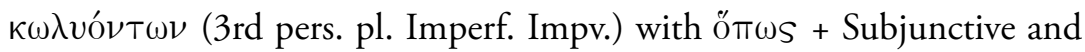
negative $\mu$ ń compounds.

\subsection{Conditional Construction}

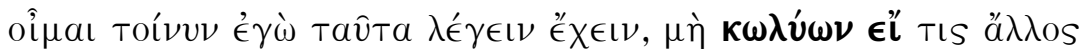

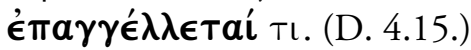

So I think that I can say this without preventing anyone else from making any promise.

$\kappa \omega \lambda \dot{v} \omega \nu$ with $\epsilon \hat{\imath}+$ Present Indicative: 'not preventing that anyone else should be making any promise'. $\epsilon l$ introduces a noun clause (cf. Lesson 34).

\subsection{Participial Construction}

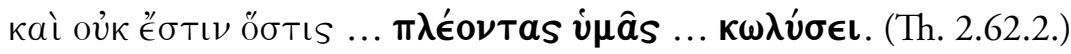
And there is no one who ... will prevent ... you from sailing.

This construction is parallel to the Accusative and Participle with mav́єıv: 'to stop someone from doing something'.

\subsection{Passive Constructions}

\subsubsection{Passive Verb Only}

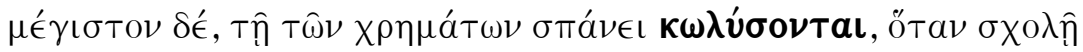

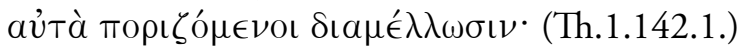

And most important, they will be hindered by lack of funds, when by procrastinating they delay in acquiring them. 


\subsubsection{Passive Verb with Infinitive}

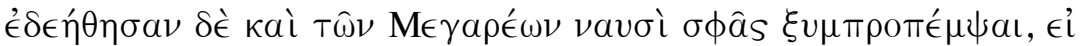
ă $\rho \alpha \boldsymbol{\kappa} \boldsymbol{\lambda} \boldsymbol{\lambda}$ ó

And they asked the Megarians also to join in escorting them with ships, in case they were prevented by the Corcyreans from sailing.

\subsubsection{Passive Verb with Participle}

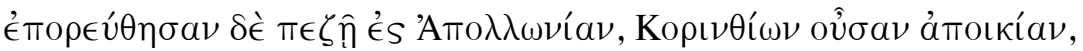

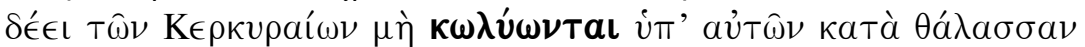
$\pi \epsilon \rho a$ oú $\mu \epsilon \nu$ ol. (Th. 1.26.2.)

And they travelled by land to Apollonia, since it was a colony of the Corinthians, out of fear of the Corcyreans, in case they were prevented by them from crossing by sea.

\section{References}

Goodwin (1889), Syntax of the moods and tenses of the Greek verb, $\$ \$ 807-820$.

Smyth (1956), Greek grammar, \$\$2739-2749.

\section{EXERCISE 29}

Translate the following passages.

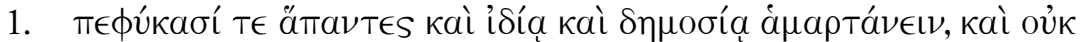

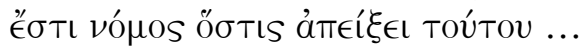

\begin{tabular}{|c|c|}
\hline$\pi \in \phi \cup \kappa \in ́ \nu a \iota$ & $\begin{array}{l}\text { to be inclined(to) (+ Infin.; Perf. with } \\
\text { Imperf. meaning) }\end{array}$ \\
\hline$T \epsilon$ & and (Joins whole sentence to preceding.) \\
\hline Toútou & Refers to ä $\mu \alpha \rho \tau \alpha ́ \nu \in t \nu$. \\
\hline
\end{tabular}

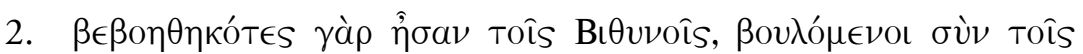

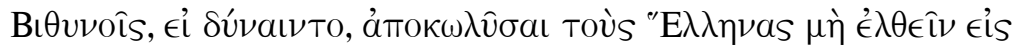

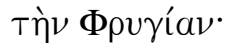




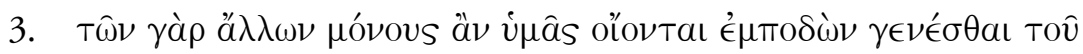
ă $\rho \xi a r$ av่Toùs $\tau \hat{\omega} \nu{ }^{~} \mathrm{E} \lambda \lambda \eta \dot{\eta n} \omega \omega \nu$.

\begin{tabular}{|c|}
\hline$\not ̋ \rho x \in I \nu$ \\
\hline
\end{tabular}

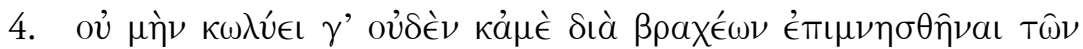

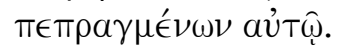
$\mu \eta \dot{v} v$
however
oứćv
Nom.

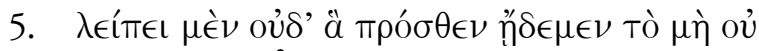

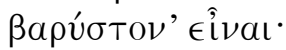

\begin{tabular}{|c|c|}
\hline$\lambda \in i m \in l \nu$ & to fall short of (+ Infin., here articular) \\
\hline$\eta \underline{n ̋ \in \mu \in \nu}$ & 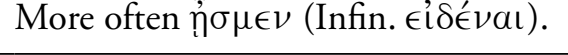 \\
\hline
\end{tabular}

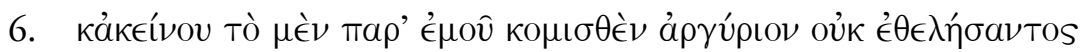

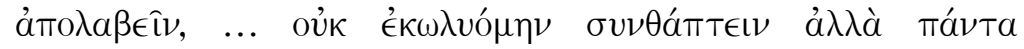

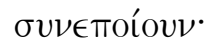
тарá (+ Gen.)
by
$\sigma v \nu \theta a ́ \pi \tau \epsilon \iota$
to join in the burial

7. And these [men] were staying behind and preventing the Athenians from carrying stones and from dispersing further away.

\begin{tabular}{|c|c|}
\hline to stay behind & 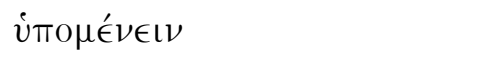 \\
\hline to carry stones & $\lambda_{\imath} \theta о \phi о \rho \in \hat{\imath} \nu$ \\
\hline to disperse (Intr.) & $\dot{a} \pi о \sigma \kappa i ́ \delta v a \sigma \theta a \iota$ (Pass.; a stem) \\
\hline further away & накроте́ $\rho \alpha \nu$ (adverbial Acc.) \\
\hline
\end{tabular}

8. For if I had not been caught off my guard with oaths to the gods, I would not ever have kept from declaring this to my father.

\begin{tabular}{|c|c|}
\hline to catch & 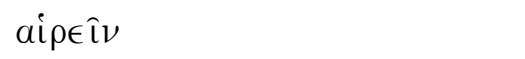 \\
\hline off guard & äфарктоs, -оv \\
\hline oath (to) & ӧркоs, -оv, ó (+ Gen.) \\
\hline to keep (Intr.) (from) & $\begin{array}{l}\epsilon^{\prime} \chi \in \iota \nu, \text { (Aor.) } \sigma \chi \in \hat{\imath} \nu(+ \text { Infin. with } \\
\text { redundant negatives } \mu \grave{\eta} \text { où) }\end{array}$ \\
\hline
\end{tabular}




\section{LESSON 30 \\ Temporal Constructions 1: Clauses in Primary Sequence}

\subsection{Introduction}

Three Lessons will deal with Subordinate Temporal clauses and with the Temporal phrases which use $\pi \rho$ í $\nu$ and the Infinitive. For convenience, all $\pi \rho$ í $\nu$ constructions (clauses and phrases) will be treated together after the other Temporal constructions. Lesson 30 deals with Temporal clauses in Primary sequence-the verbs in the leading clause refer to the present or the future, as do the Temporal clauses themselves.

Some prepositions may have a Temporal force: átó from, since; $\epsilon$ is until; '́લ after. Such prepositions will be considered here, only when they introduce an adjectival clause with Temporal force, for example, $a \phi$ ' ô from what <time>, ever since.

Only the more common Temporal conjunctions and conjunctive phrases will be used in the Lessons and Exercises.

When a Temporal clause refers to a definite time, the Indicative Mood is used; the negative is ou'. When a Temporal clause refers to an indefinite time, the Subjunctive Mood with óv is used in Primary sequence; the negative is $\mu \eta ́$. In Epic, $\kappa \in(\nu)$ (enclitic) is equivalent to ă $\nu$. For the most part, Temporal clauses referring to the future use the indefinite construction, since what is in the future has not yet happened. In indefinite Temporal clauses in Primary sequence, some conjunctions, which end with a vowel, coalesce with ôv.

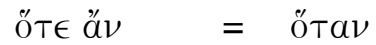

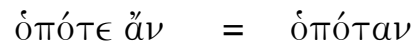

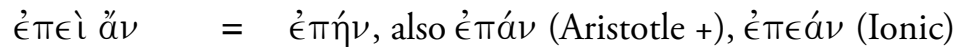

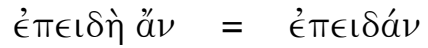




\subsection{Contemporaneous Action in Temporal Clause}

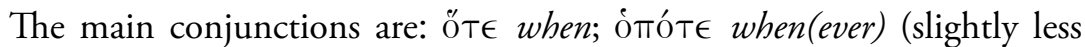

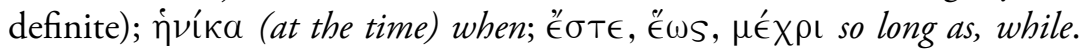
The limits or duration of time may be emphasised in clauses introduced

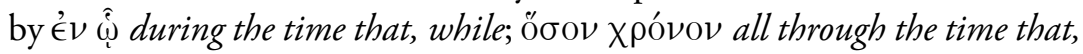
so long as.

\subsubsection{Definite}

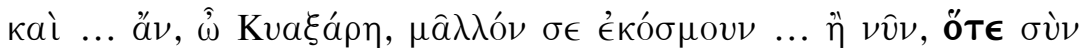

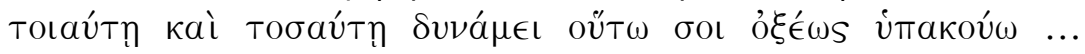
(X.Cyr. 2.4.6.)

And would I be showing you, O Cyaxares, more respect ... than now, when I am obeying you so quickly with a force of such character and size ...?

Ö $T \epsilon$ with Present Indicative in the Temporal clause, contemporaneous with the Present potential Main clause (expressed by Past Imperf. Indic. with ăv).

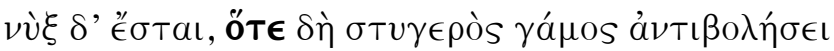

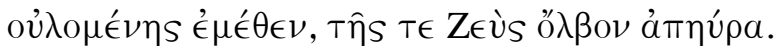

(Hom.Od. 18.272-273.)

And there will be a night, when indeed a hateful marriage will come upon poor me, <the one> whose happiness Zeus took away.

ÖT€ with Future Indicative in the Temporal clause (rare), contemporaneous with the Future Indicative of the Main clause. ( $\tau \hat{\eta} S \tau \in$ : For this 'untranslatable $T \epsilon$ ' see Smyth, 1956, $\$ 2970$; Hom.Od. 13.31, 60).

\subsubsection{Indefinite}

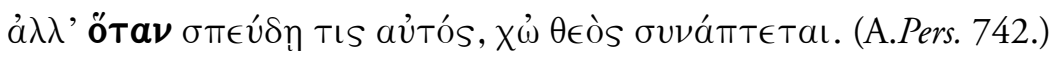
But when someone himself hastens on $<$ to his doom $>$, the god also cooperates.

ÖTa $\nu$ with Subjunctive in the Temporal clause, contemporaneous with the Present Indicative of the Main clause (referring to repeated action). 


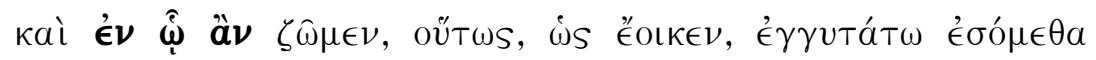

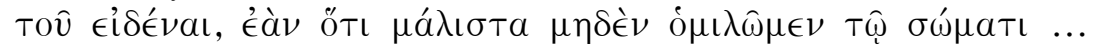
(Pl.Phd. 67 A.)

And while we are alive, we shall on this condition, as it seems, be nearest to knowledge, if as much as possible we have no association with the body...

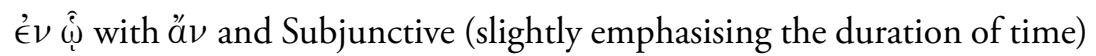
in the Temporal clause, contemporaneous with the Future Indicative of the Main clause.

\subsection{Prior Action in Temporal Clause}

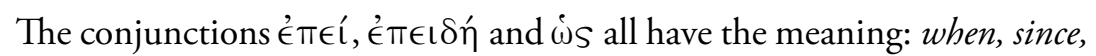

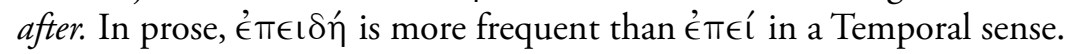

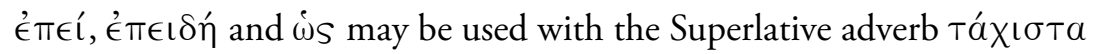
to emphasise immediate priority: as soon as. The adverb táxıбTa is sometimes separated from the conjunction by one or more words. The separation occurs especially with $\dot{\omega}$, to avoid confusion with the

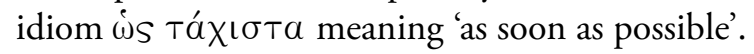

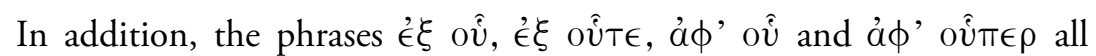
mean: from what $\langle$ time $>$, ever since. These phrases introduce an adjectivalTemporal clause which emphasises a time limit, while the clause on which they depend expresses subsequent duration or repeated action.

\subsubsection{Definite}

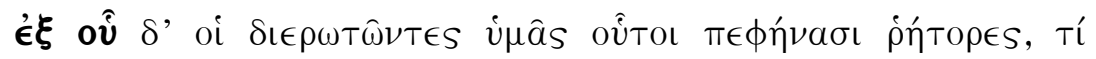

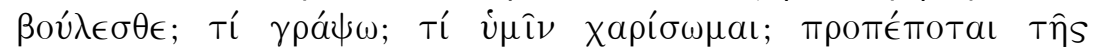

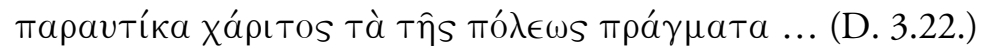

But ever since these orators have appeared, who constantly ask you, 'What do you want? What <law> am I to propose? In what <way> am I to oblige you?', the interests of the city have been squandered for <the price of s momentary gratification.

$\mathfrak{\epsilon}^{\prime} \xi$ o $\hat{\dot{u}}$ with Present Perfect Indicative emphasises a limit (which has been reached), while the Main clause expresses subsequent repeated action. 


\subsubsection{Indefinite}

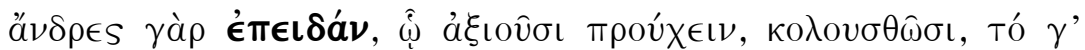

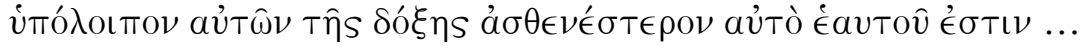
(Th. 7.66.3.)

For, when men are thwarted in that in which they claim to excel, what is left of their reputation is weaker than its former self [lit. 'is itself weaker than itself'] ...

$\epsilon \in \epsilon \in \delta a ́ v$ with Subjunctive in the Temporal clause denotes action prior to the ongoing state expressed by the verb 'to be' in the Main clause.

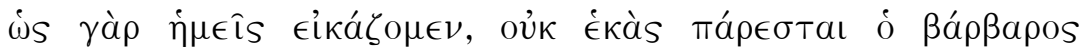

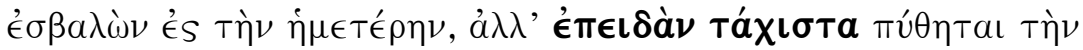

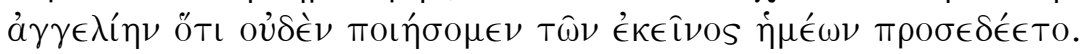
(Hdt. 8.144.5.)

For as we surmise, the foreigner will invade our <country $>$ and will be upon us not in any long time, but as soon as he has heard the message, that we shall do nothing of what that man was asking of us.

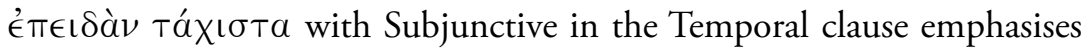
immediate priority in relation to the Future Indicative of the Main clause. $\tau \hat{\omega} \nu$ (Ionic) $=\hat{\omega} \nu$ (Attic).

\subsection{Subsequent Action in Temporal Clause: Indefinite}

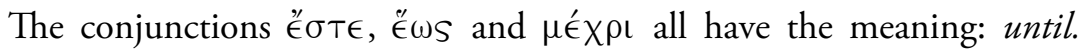
(As noted in $\$ 30.2$, these conjunctions may also express contemporaneous action: while.) Temporal clauses expressing subsequent action in Primary sequence are always indefinite, since it is not known exactly when the time limit ('until') will be reached. Temporal clauses expressing subsequent action may be anticipated by Temporal adverbs such as $\pi \rho i ́ v$ (Epic) or

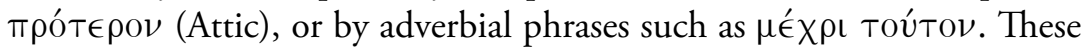
expressions are redundant but emphatic. 


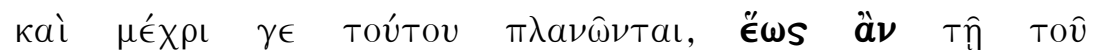

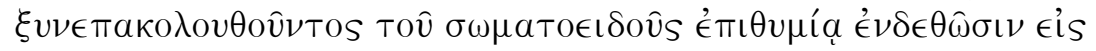

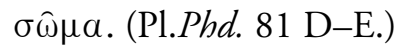

And right up to this <time> they wander around, until, by reason of the desire for the bodily-nature which follows along with <them $>$, they are bound to a body.

ÉwS åv with Subjunctive in the Temporal clause denotes action at any time prior to that of the Main clause. As here, the Subjunctive is most often Aorist.

\section{References}

Goodwin (1889), Syntax of the moods and tenses of the Greek verb, $\$ \$ 514-522$, 529, 532-533, 539-540, 556, 558 (Temporal clauses awkwardly treated as 'Relative' clauses together with adjectival clauses and adverbial clauses of place and manner); 611-612, 613.3-613.5 and 615-620 (Temporal constructions referring to subsequent action, except $\pi \rho(1)$ ).

Smyth (1956), Greek grammar, \$\$2383-2403, 2409-2413.

\section{EXERCISE 30}

Translate the following passages.

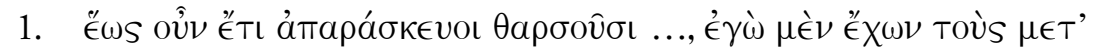

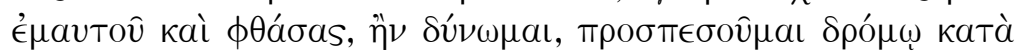

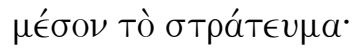

$\delta \rho o ́ \mu \omega$ at a run

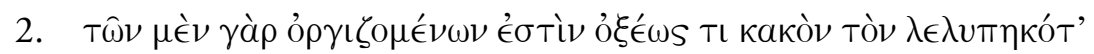

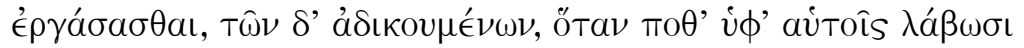

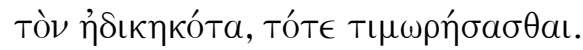

\begin{tabular}{|c|c|}
\hline 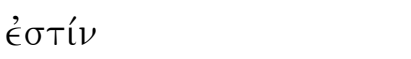 & it is <characteristic of $>(+$ Gen. $)$ \\
\hline نंđó (+ Dat.) & under < the control of $>$ \\
\hline$T \iota \mu \omega \rho \in \hat{\imath} \nu$ (Act. and Mid.) & to punish \\
\hline
\end{tabular}




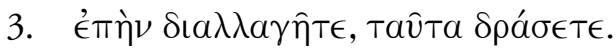

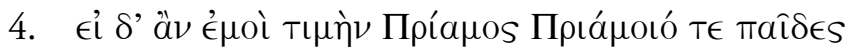

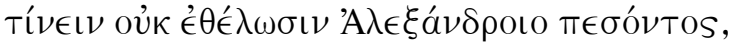

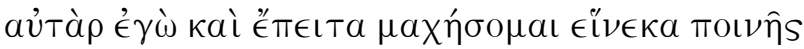

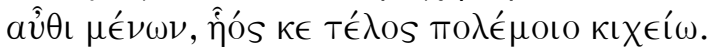

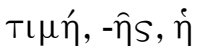

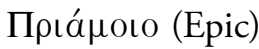

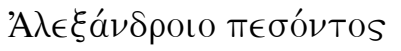
av่Tá $\rho(\mathrm{adv}$.

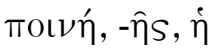
aरें $\iota$ ( (adv.) خेós $\kappa \in$ (Epic) $\kappa \iota(\gamma) \chi \alpha ́ \nu \in \iota \nu$ price

Прıа́ $\mu \mathrm{ov}$ (Attic)

Gen. abs. (Temporal)

then (drawing consequence of a condition) recompense

here

Ëws äv (Attic)

to reach (here 1 st pers. sg. Aor. Subj.)

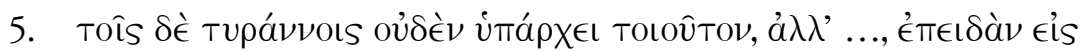

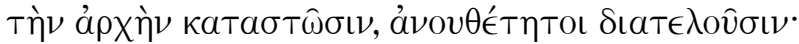

\begin{tabular}{|c|c|}
\hline 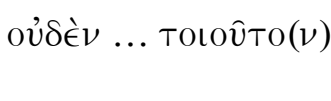 & $\begin{array}{l}\text { Nom. neut. sg.; understand help, } \\
\text { advantage. }\end{array}$ \\
\hline$\lambda \in \hat{\imath} \nu$ & to continue \\
\hline
\end{tabular}

6. Wait until you [sg.] learn the rest in addition.

to learn in addition $\quad \pi \rho 0 \sigma \mu \alpha \nu \theta a ́ \nu \in \mathrm{L} \nu$

7. And when I have accomplished what I want, I shall come fully prepared, in order to lead you [pl.] away to Greece and to go away myself to my own command.

\begin{tabular}{|c|c|}
\hline to accomplish & 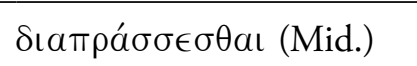 \\
\hline fully prepared & $\begin{array}{l}\text { Aor. or Perf. Mid. Partc. of } \\
\sigma v \sigma \kappa \in v a ́ \zeta \in \mathrm{L} \nu\end{array}$ \\
\hline command & $\dot{a} \rho x \dot{\eta},-\hat{\eta} s, \dot{\eta}$ \\
\hline
\end{tabular}




\section{LESSON 31 \\ Temporal Constructions 2: Clauses in Past Sequence}

\subsection{Introduction}

In Past sequence, when a Temporal clause refers to a definite time, the Indicative Mood is used; the negative is ov. When a Temporal clause refers to an indefinite time, the Optative Mood without ă $v$ is used; the negative is $\mu \eta$. But sometimes the Primary construction is used even in Past sequence ('Vivid' construction). The common conjunctions and conjunctive phrases are the same as in Lesson 30.

\subsection{Contemporaneous Action in Temporal Clause}

\subsubsection{Definite}

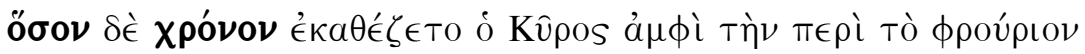

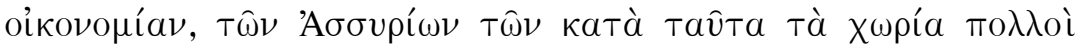

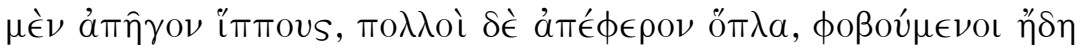

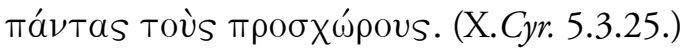

And all through the time that Cyrus remained inactive concerning arrangements about the fort, many of the Assyrians in these parts were withdrawing their horses, and many were handing in weapons, since by now they were in fear of all their neighbours.

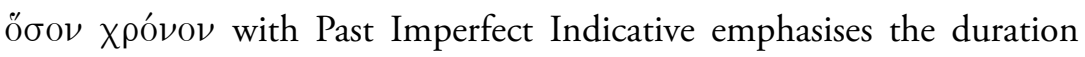
of time. 


\subsubsection{Indefinite}

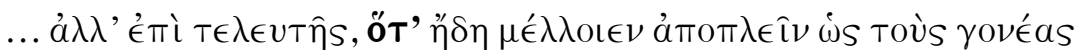

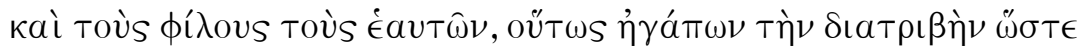

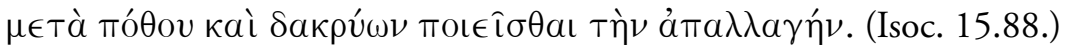

... but at the end, when they were now about to sail away to their parents and their own family members, they were so content with their way of life as to make their departure with regret and tears.

ŐT $(\epsilon)$ and Optative without $\stackrel{\alpha}{\nu} \nu$ denotes any (rather than every) time contemporaneous with the repeated action of the Main clause.

\subsection{Prior Action in Temporal Clause}

With the Past Aorist Indicative, the conjunctions $\epsilon \pi \epsilon \in \dot{l}, \dot{\epsilon} \pi \epsilon \mathrm{I} \delta \dot{\eta}$ and $\dot{\omega}$ usually imply action prior to that of the clause on which they depend. The Past Perfect Indicative is much less common in a Temporal clause, and often implies a past state resulting from completed action.

\subsubsection{Definite}

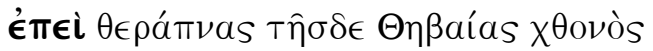

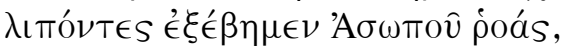

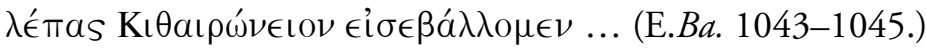

When we had left the dwellings of this Theban

land and had crossed the streams of Asopus,

we began to head into the broken-country of Cithaeron ...

ÉTtí with Past Aorist Indicative denotes action prior to that of the Main clause.

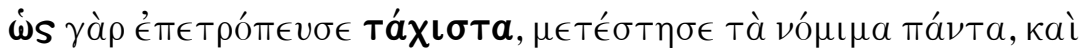

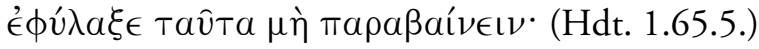

For as soon as he had become guardian, he changed all the customs, and ensured that <people> should not transgress these.

is ... Táxı $\sigma \tau a$ with Past Aorist Indicative emphasises immediate priority. 


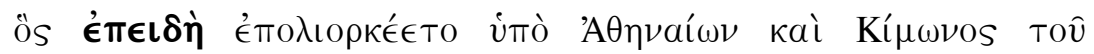

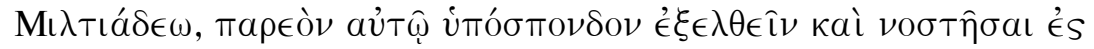

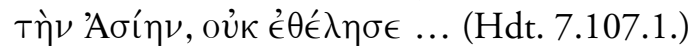

And when he was being besieged by the Athenians and Cimon son of Miltiades, although it was possible for him to go out under truce and to return to Asia, he refused...

$\epsilon \in \epsilon ı \delta \eta ́$ with Past Imperfect Indicative denotes an action that has

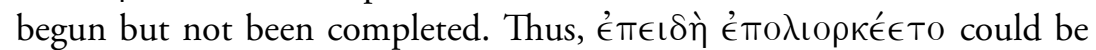
translated: 'after he began [OR: had begun] to be besieged'.

\subsubsection{Indefinite}

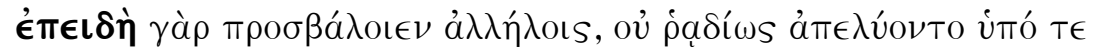

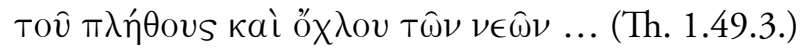

For when (ever) they (had) made an attack on each other, they did not easily extricate themselves due to the number and density of the ships...

$\hat{\epsilon} \pi \epsilon ı \delta \eta ́$ and Optative without $\alpha$ $\nu$ denotes any action in this battle prior to that of the clause. ( $T \epsilon$ anticipates a second kaí in the next phrase.)

\subsection{Subsequent Action in Temporal Clause}

\subsubsection{Definite}

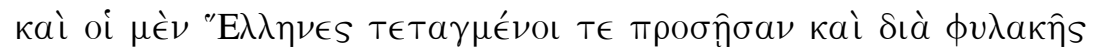

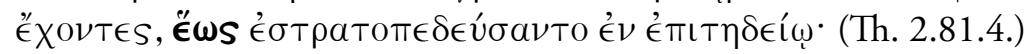

And the Greeks kept advancing, drawn up in ranks and remaining on guard, until they pitched camp in a suitable <place $>$.

ÉwS with Past Aorist Indicative denotes instantaneous action subsequent to the continuous action expressed by the Past Imperfect Indicative of the Main clause. 


\subsubsection{Indefinite}

... Tá $\tau \epsilon \ddot{a} \lambda \lambda a$ X

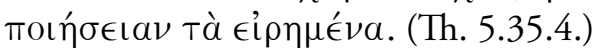

... and they [= Athenians] kept control of the other places, waiting until those $<$ troops $>$ [= Spartans $]$ should have done for them what had been stated. (OR: waiting for those <troops> to do for them what had been stated.)

$\check{\epsilon} \omega S$ and Optative without $\alpha ّ v$ denotes the anticipated but indefinite limit for which the Athenians (Subject of the Main clause) were waiting.

\section{References}

Goodwin (1889), Syntax of the moods and tenses of the Greek verb, \$\$514-522, $532,535,553,613.1-613.2,613.5,614.2,615-619$.

Smyth (1956), Greek grammar, \$\$2388, 2395-2396, 2414-2417.

\section{EXERCISE 31}

Translate the following passages.

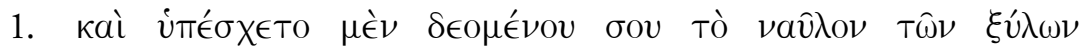

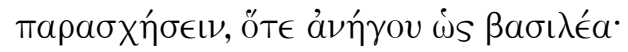

\begin{tabular}{|c|c|}
\hline$\delta \in \hat{\imath} \sigma \theta \alpha \iota$ (Mid. + Aor. Pass.) & to request \\
\hline$\nu a \hat{v} \lambda \mathrm{o \nu ,} \mathrm{-ov,} \mathrm{Tó}$ & freight-payment \\
\hline$\gamma \in \sigma \theta a \iota$ (Mid.) & to set sail \\
\hline
\end{tabular}

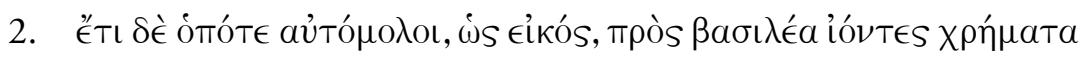

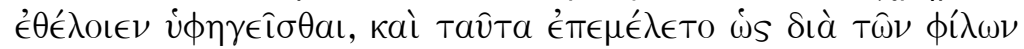

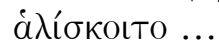

\begin{tabular}{|c|c|}
\hline 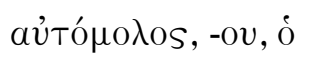 & deserter (adj. as noun) \\
\hline 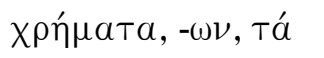 & merchandise \\
\hline$\dot{v} \phi \eta \gamma \in \hat{\imath} \sigma \theta a \iota$ (Mid.) & to show the way to (+ Acc.) \\
\hline кaí & also, modifying тav̂Ta \\
\hline таขิта & $\begin{array}{l}\text { direct Object of } \dot{\epsilon} \pi \epsilon \mu \epsilon^{\prime} \lambda \epsilon T O \text {, } \\
\text { anticipating } \dot{\omega} \text { s clause }\end{array}$ \\
\hline
\end{tabular}




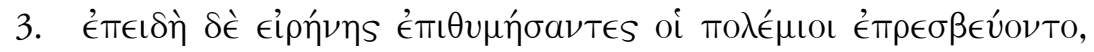

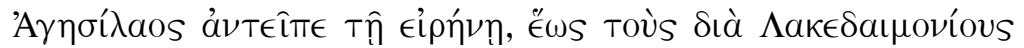

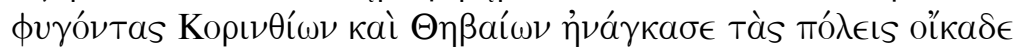

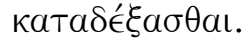

$\pi \rho \in \sigma \beta \in \dot{v} \in \sigma \theta a \mathrm{r}$ (Mid.) to send embassies

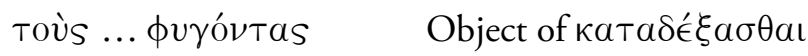

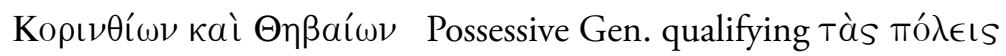

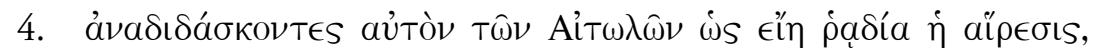

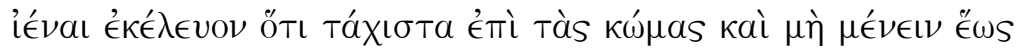

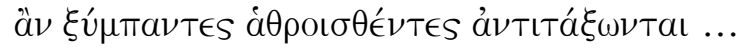

\begin{tabular}{|c|c|}
\hline$a \dot{\nu} \alpha \delta ı \delta a ́ \sigma \kappa \in \iota \nu$ & to explain \\
\hline Ait $\omega \lambda{ }^{\circ},{ }^{\prime},-\hat{\omega} \nu$, oi & $\begin{array}{l}\text { Aetolians (The Gen. pl. qualifies } \dot{\eta} \\
\text { ail } \rho \in \sigma \text { เs.) }\end{array}$ \\
\hline ail $\rho \in \sigma ı s,-\epsilon \omega s, \dot{\eta}$ & capture \\
\hline 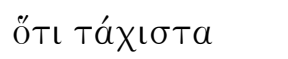 & is Táxı $\sigma \tau a$ \\
\hline
\end{tabular}

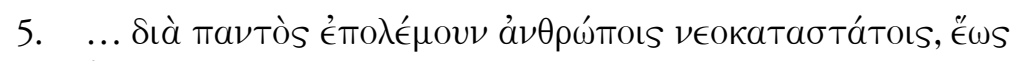

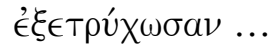

Sı̀̀ TavTós

vєоката́бтатоs, -оv

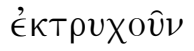

constantly

newly established

to wear (someone) out, to exhaust

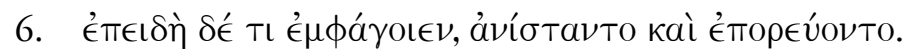

\begin{tabular}{|c|}
\hline$\epsilon^{\prime} \mu \phi a \gamma \in \hat{\imath} \nu$ (Aor.) \\
\hline
\end{tabular}

7. ... and the rest of the foreigners, when they had seen them giving way, no longer held their ground, but took to flight.

\begin{tabular}{|c|c|}
\hline to give way & 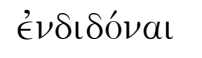 \\
\hline to hold one's ground & $\dot{v} \pi о \mu \epsilon ́ \nu \in \mathrm{I} \nu$ \\
\hline
\end{tabular}


INTERMEDIATE ANCIENT GREEK LANGUAGE

8. Up to this [point] Lasthenes used to be named a friend, until he betrayed Olynthus.

\begin{tabular}{ll}
\hline up to & $\mu \dot{X} \chi \rho \mathrm{l}(+\mathrm{Gen})$. \\
Lasthenes & $\Lambda a \sigma \theta \epsilon ́ v \eta \mathrm{s},-\mathrm{ovs}, \dot{0}$ \\
Olynthus & 'O $\lambda v \nu \theta \mathrm{os},-\mathrm{ov}, \dot{\eta}$ (place) \\
\hline
\end{tabular}




\section{LESSON 32 \\ Temporal Constructions with $\pi \rho^{\prime} \nu$}

\subsection{Introduction}

In classical Attic Greek, $\pi \rho i ́ v$ introduces two basically different constructions, which express action subsequent to that of the leading clause.

When $\pi \rho i ́ v$ functions like a preposition and introduces an Infinitive phrase, it usually means 'before', and usually occurs in a positive sentence.

When $\pi \rho i ́ v$ functions as a conjunction and introduces a clause with a finite verb, it usually means 'until', and usually occurs in a negative sentence. $\pi \rho i ́ v$ may be preceded by a redundant $\pi \rho i v$ (Homer) or by a redundant $\pi \rho{ }^{\top} \tau \in \rho \circ \nu$ or $\pi \rho \sigma_{\sigma} \sigma \in \epsilon$ (Attic) in the leading clause.

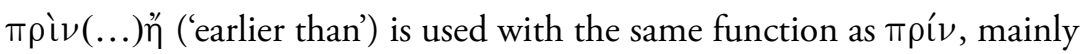
in Herodotus, and mostly with Infinitive; but Herodotus also uses

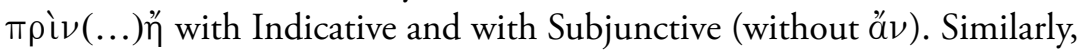

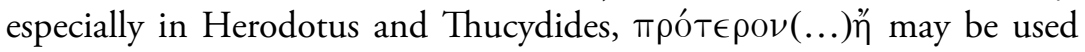
with Infinitive, or with Subjunctive without ăv (mainly in Herodotus), or sometimes with Indicative.

\section{2. $\pi \rho i ́ \nu$ with an Infinitive Phrase}

The Subject of the Infinitive, if it is the same as the Subject of the leading verb, is normally not expressed; and if the Subject of the Infinitive has an adjective agreeing with it, or a Complement referring to it, the adjective or Complement is in the Nominative Case. However, sometimes an unexpressed Subject for the Infinitive is not the same as the Subject of the leading verb, but must be understood from the context. The Subject of the Infinitive, if it is different to the Subject of the leading verb, is normally expressed and is in the Accusative Case. Because $\pi \rho i ́ v$ denotes a chronological limit, it frequently introduces an Aorist Infinitive indicating a point of time. 


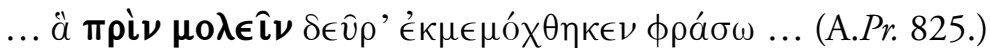
... I shall tell what she has struggled through before she came here...

$\pi \rho i ́ v$ with Aorist Infinitive occurs in a positive sentence. The Subject of $\mu o \lambda \epsilon \hat{\imath} \nu$ is not expressed, since it is the same as the Subject of the leading

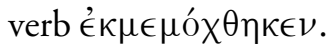

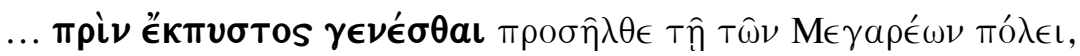

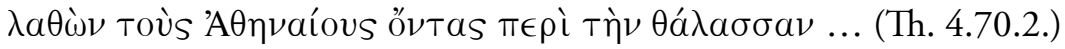

... before he was detected, he approached the city of the Megarians, escaping the notice of the Athenians since they were near the sea...

$\pi \rho i v$ with Aorist Infinitive and Nominative Complement occurs in a positive sentence.

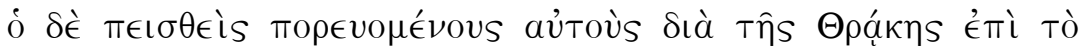

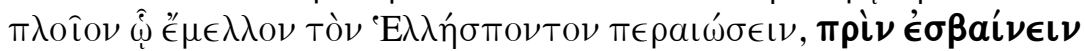
$\xi v \lambda \lambda \alpha \mu \beta \alpha ́ v \in \mathrm{L}$... (Th. 2.67.3.)

And he was persuaded and, as they were travelling through Thrace to the boat on which they were intending to cross the Hellespont, he seized them before they (could) embark...

$\pi \rho i ́ v$ with Imperfect Infinitive, whose unexpressed Subject is not the same as the Subject of the leading verb $\xi v \lambda \lambda a \mu \beta a ́ v \in t$ (Hist. Pres.).

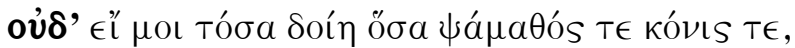

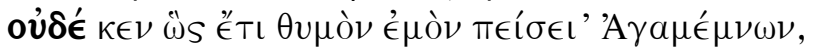

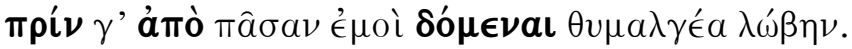
(Hom.Il. 9.385-387.)

Not even if he were to give me so much as the sand and the dust, not even so would Agamemnon yet persuade my spirit, before at least he repaid me (for) all the heart-rending dishonour. $\pi \rho i ́ v$ with Aorist Infinitive occurs in a negative sentence. 


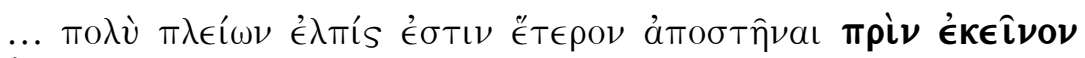

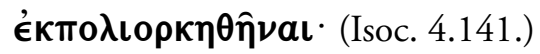

... there is much greater expectation that another <may> revolt before that $<$ man $>$ is forced-to-surrender-under-siege.

$\pi \rho i ́ v$ with Accusative and Aorist (Pass.) Infinitive occurs in a positive sentence.

\section{3. $\pi \rho$ í $\nu$ with a Finite Verb}

\subsubsection{Definite}

When $\pi \rho$ í $\nu$ with a finite verb refers to a definite time, the verb is in the Indicative Mood and is usually in the Past Aorist Tense.

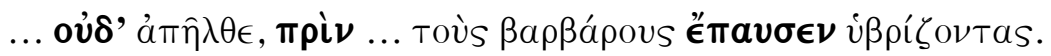
(Isoc. 15.83.)

... nor did he go away, until ... he stopped the foreigners (from) acting insolently.

$\pi \rho i ́ \nu$ with Past Aorist Indicative occurs in a negative sentence.

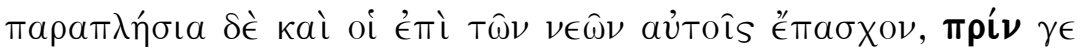

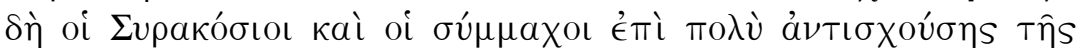

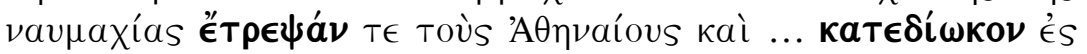

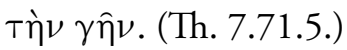

And those on the ships also were experiencing much the same as they <were>, until finally the Syracusans and their allies, after the naval battle had lasted for a long time, put the Athenians to flight and ... vigorously pursued them to land.

$\pi \rho i ́ v$ with Past Aorist Indicative occurs in a positive sentence. This construction is much less common than Indicative in a negative sentence. $\gamma \in \delta$ ' ('finally') is literally 'at least indeed'. 


\subsubsection{Indefinite}

\subsubsection{Primary Sequence}

When $\pi \rho i ́ v$ with a finite verb refers to an indefinite time in Primary sequence, the verb is regularly in the Subjunctive Mood, and in Attic (especially in prose) normally has $\ddot{\alpha} v$.

$$
\sigma \tau \in \rho \in a ́ s ~ \tau^{\prime}
$$

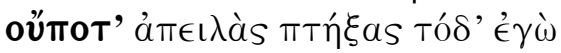

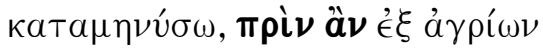

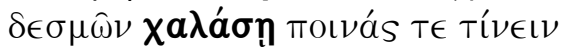

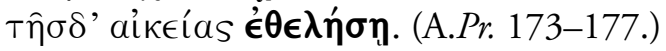

\section{and never,}

cowering before his harsh threats, shall $\mathrm{I}$ make this known, until he releases $<m e>$ from savage bonds and becomes willing to make recompense for this maltreatment.

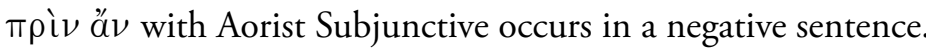

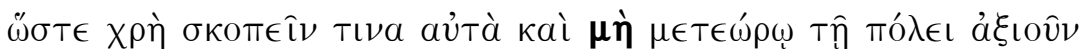

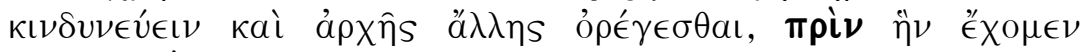
$\beta \in \beta a \iota \omega \sigma \omega \dot{\mu} \mu \in \theta a$... (Th. 6.10.5.)

And so one should examine them [= the points just mentioned] and not think it right to put the city at risk when it is at sea and to reach for another empire, until we make secure the one which we have...

$\pi \rho i ́ v$ and Aorist Subjunctive (without $a ̈ \nu$ ) occurs in a negative sentence ( $\mu$ ๆ́). Homer does not yet use ă $\nu$ or $\kappa \in$ in this construction. The Subjunctive without $\alpha$ $\nu$ occurs occasionally in Herodotus, Thucydides and Attic drama.

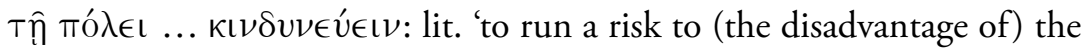
city'. $\mu \in T \epsilon \omega ́ \omega \omega$ is metaphorical.

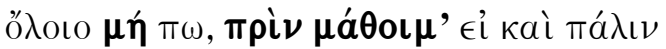

$\gamma \nu \omega ́ \mu \eta \nu \mu \in \operatorname{To}^{\prime} \sigma \in \mathrm{IS}^{\circ} \cdot($ S.Ph. 961-962.)

May you perish—not yet, until I learn whether you will actually change your mind again.

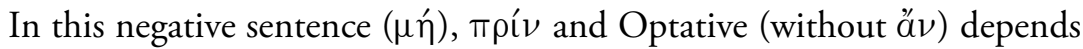
on an Optative of Wish in the Main clause ('assimilation of Mood'). 


\subsubsection{Past Sequence}

In Past sequence, $\pi \rho i ́ v$ and Optative (without $\alpha^{\prime} \nu$ ) occurs only in suboblique constructions - that is, where the Temporal clause is included in reported discourse (whether in a clause introduced by öTı or $\dot{\omega} s$, or in a phrase with Infinitive or Participle), or depends on another Optative clause (cf. \$32.3.2.1. Primary Sequence, last example). Vivid constructions

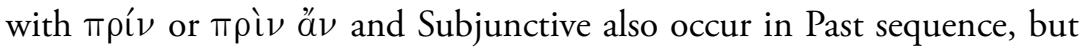
again only in suboblique constructions. All the following passages contain negative expressions antecedent to the $\pi \rho$ í $\nu$ clauses: 'not ... until'.

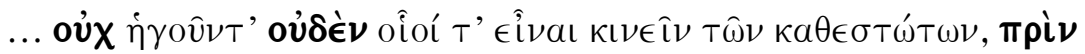

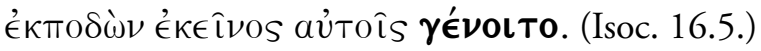

... they did not think that they were able to make any change in the constitution, until that <man> got out of their way.

$\pi \rho{ }^{\prime} \nu$ and Optative (without $\alpha$ $\nu$ ) depends on the Nominative and Infinitive construction of reported thought after a negated Main verb.

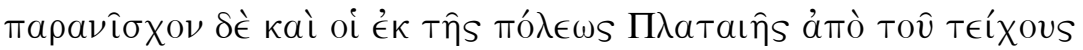

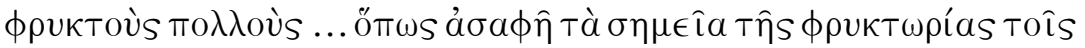

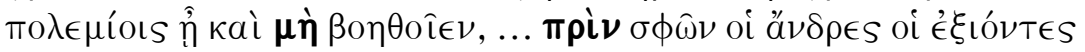

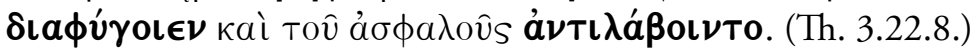

But the Plataeans in [lit. 'out of'] the city also raised-in-answer from the wall many beacons ... in order that the enemy's beacon-signals might be unclear, and that ... they [= Thebans] might not come to help, until their own [= Plataeans'] men who were going out escaped and reached safety.

$\pi \rho\left\{v\right.$ and Optative (without $\alpha{ }^{\prime} \nu$ ) depends on a negative Purpose clause with Optative.

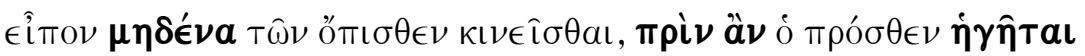
... (X.Cyr. 2.2.8.)

I said that none of those at the rear was to move, until the one in front <of him> led the way...

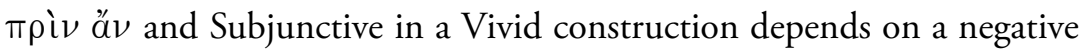
reported command. 


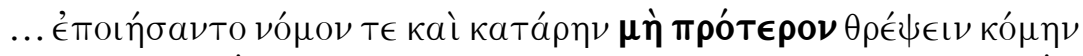

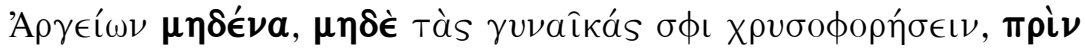

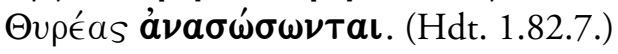

... they made a law and a curse that no one of the Argives would grow his hair, nor their women wear gold any earlier, until they recovered Thyreae.

$\pi \rho i ́ v$ and Subjunctive (without $\alpha$ $\nu$ ) in a Vivid construction depends on a negative reported command with anticipatory $\pi \rho \sigma^{\top} \epsilon \rho 0 \nu$.

\section{References}

Goodwin (1889), Syntax of the moods and tenses of the Greek verb, $\$ \$ 621-661$.

Smyth (1956), Greek grammar, $\$ \$ 2430-2461$.

\section{EXERCISE 32}

Translate the following passages.

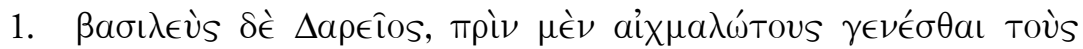

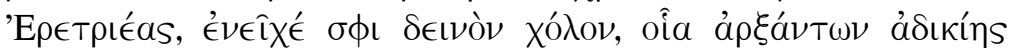

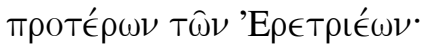

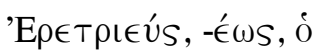

\section{Eretrian}

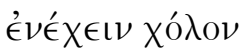

to harbour a grudge (against) (+ Dat.)

$\sigma \phi \mathrm{l}$ (enclitic)

them (Dat. pl.)

oía (adverbial)

inasmuch as (+ Partc. phrase)

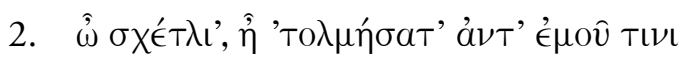

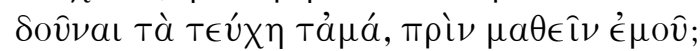

\begin{tabular}{|c|c|}
\hline$\sigma \chi \chi^{\prime} T^{\prime} \lambda_{\mathrm{I}}(\epsilon)$ & scoundrel (Voc.) \\
\hline 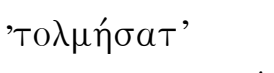 & 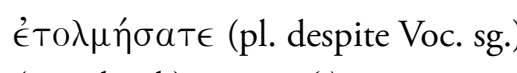 \\
\hline 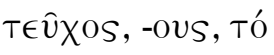 & (mostly pl.) weapon(s) \\
\hline
\end{tabular}




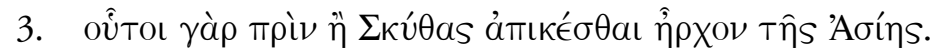

\begin{tabular}{ll}
\hline$\kappa \dot{v} \theta \eta \mathrm{s},-\mathrm{ov}, \dot{o}$ & Scythian \\
$\dot{a} \pi \iota \kappa \nu \in \hat{\imath} \sigma \theta a \iota$ & to arrive (Ionic $\pi$ for Attic $\phi)$
\end{tabular}

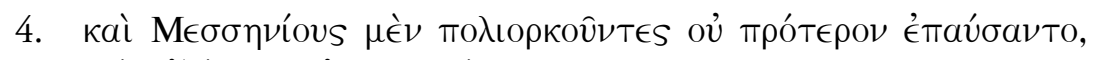

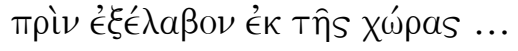

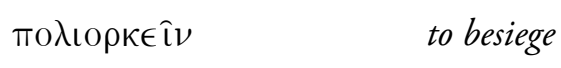

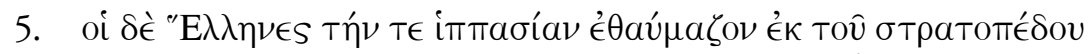

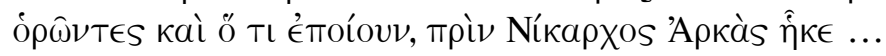

iтாабía, -as, $\dot{\eta}$

$\dot{\alpha} \mu \phi ı \gamma \nu \mathrm{\imath} \hat{\imath} \nu$ cavalry manoeuvre

to be doubtful about (+ Acc.; here with double augment)

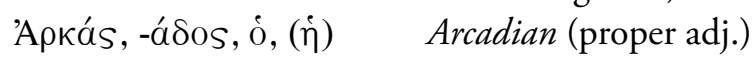

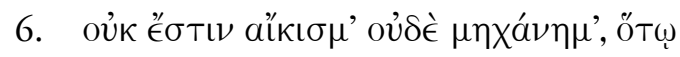

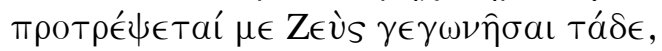

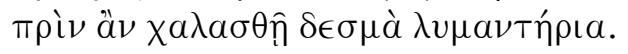

\begin{tabular}{|c|c|}
\hline alı́к $\sigma \mu \alpha,-\alpha \tau o s$, тó & torture \\
\hline 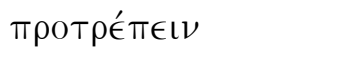 & to impel (Act. and Mid.) \\
\hline$\gamma \in \gamma \omega \nu \eta \hat{\sigma} \sigma a \iota$ & $\begin{array}{l}\text { to declare (Aor. Infin. ending on Perf. } \\
\text { stem with Imperf. meaning) }\end{array}$ \\
\hline 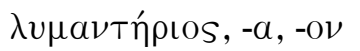 & torturous, excruciating \\
\hline
\end{tabular}

7. Well then, $I$ shall go out of the way of this disaster, before Agaue comes to the house.

\begin{tabular}{|c|c|}
\hline out of the way & 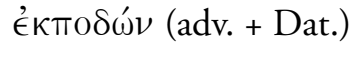 \\
\hline Agaue & 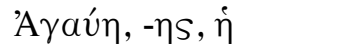 \\
\hline
\end{tabular}

8. Do not groan until you [sg.] learn [this].

to groan $\quad \sigma \tau \epsilon \nu a ́ \zeta \epsilon \mathrm{L} \nu$


INTERMEDIATE ANCIENT GREEK LANGUAGE

9. ... I decided not to make the voyage secretly, until I (had) told you [sg.] ...

\begin{tabular}{|c|c|}
\hline to make & 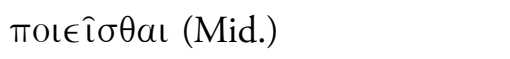 \\
\hline voyage & $\begin{array}{l}\pi \lambda \circ \hat{v} s, \pi \lambda \circ \hat{v}, \dot{o} \text { (contracted from } \\
\pi \lambda \text { óos) }\end{array}$ \\
\hline secretly & бîya (lit. 'in silence') \\
\hline to tell & $\phi \rho a ́ \zeta \epsilon \iota \nu$, Aor. $\phi \rho a ́ \sigma a ı$ \\
\hline
\end{tabular}




\section{LESSON 33 \\ Adverbial Clauses of Place and Manner}

\subsection{Adverbial Clauses of Place}

\subsubsection{Introduction}

Adverbial clauses of Place (or Local clauses) are introduced by relative adverbs which have the function of subordinating conjunctions. These adverbs cover the meanings 'where', 'to where' ('whither') and 'from where' ('whence'). Some of these adverbs may be used in either a definite or an indefinite form. And all forms may be used with either the Indicative Mood or the Subjunctive in Primary sequence, and with either the Indicative Mood or the Optative in Past sequence. There is no established convention for expressing the full range of definiteness in English translation. For convenience, it is suggested that, for example, both ov and ömou when used with the Indicative should be translated as 'where', and that when used with the Subjunctive or Optative they should be translated as 'wherever'. Even so, the '-ever' suffix should be avoided in English translation, if the Greek implies 'any time' something happens, when the English implies 'every time' something happens. In Primary sequence, $a^{\prime} v$ is normally used with the Subjunctive in prose, but may be omitted in verse.

\begin{tabular}{|c|c|}
\hline 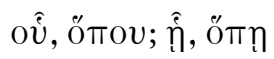 & where \\
\hline oî, öтoเ & to where \\
\hline ö $\theta \in \nu, \dot{o} \pi o ́ \theta \in \nu$ & from where \\
\hline
\end{tabular}

There is also a pair of adverbs which may have a demonstrative meaning as well as their relative meaning.

Év $\nu$ $\theta a$

$\epsilon^{\prime \prime} \nu \theta \in \nu$ where (also 'there'), to where, from where

from where (also 'from there') 
In addition, $\check{~} \nu \alpha$ appears to have been originally a relative adverb of place meaning 'where'. This usage continues into the classical period, but fades out in the Hellenistic period. (However, already in Homer the use of "iva as a Purpose conjunction outweighs its Local meaning.)

The negative is usually ou for the Indicative and $\mu$ in for the Subjunctive and Optative. However, $\mu \eta \dot{n}$ may also be used when the Indicative expresses a general situation, or when the Future Indicative expresses Purpose (see $\$ 33.3$ below).

The relative adverbs may be emphasised by the enclitic particle $\pi \epsilon \rho$. Editorial practice varies in treating this particle as part of the preceding word or as a separate word (e.g. i้ $\nu a \pi \epsilon \rho$ or íva $\pi \epsilon \rho$ ).

Quite often, a Genitive of Limits of Space (a subcategory of the Partitive Genitive) modifies a relative adverb. As the following two examples show, the relative adverbs may be used either in a literal sense, or in a figurative sense.

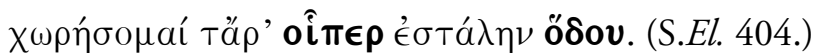

I shall go, then, to that point of my path where I was sent.

Literal reference to place; strictly: 'to where indeed within my path ...'.

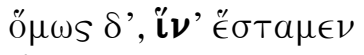

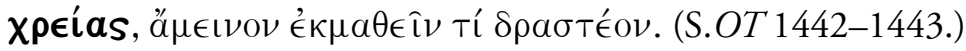

Nevertheless, where (with)in our present need

we stand, <it is $>$ better to learn fully what $<i t$ is $>$ necessary to do.

Figurative reference to place.

\subsubsection{Primary Sequence}

\subsubsection{Definite}

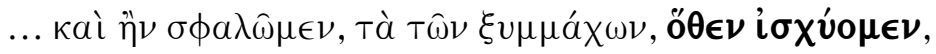
пробато́ $\lambda \lambda u т a l \cdot(T h .1 .143 .5$.

... and if we fail, the <resources> of our allies, from where we draw our strength, are lost as well.

ö $\theta \in \nu+$ Present Indicative. 


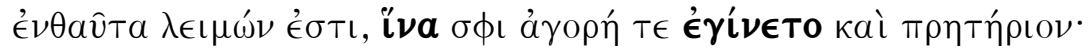
(Hdt. 7.23.4.)

A meadow is there, where an assembly-area and market-place was made by them.

$\check{I}^{\prime \nu} \alpha+$ Past Imperfect Indicative in the context of Present narrative.

\subsubsection{Indefinite}

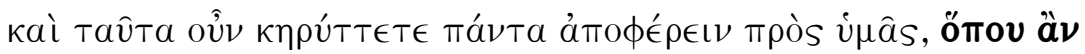

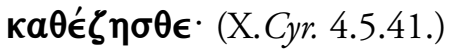

Tell <them $>$, therefore, to deliver all this also to you, wherever you are situated. Öтоv + ăv with Subjunctive in prose.

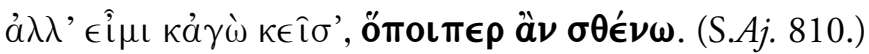

But I too shall go there, to wherever indeed I have the strength.

Öтоเтє $\rho+\not ̈ \nu$ with Subjunctive in verse.

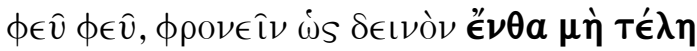

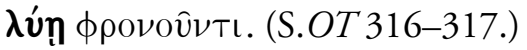

Oh oh, how terrible <it is > to be wise where there is no profit for the wise man.

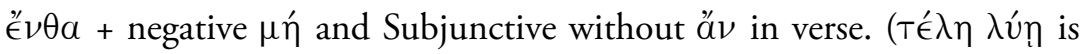
equivalent to $\lambda v \sigma ı t \epsilon \lambda \hat{n}$.)

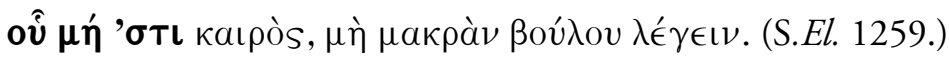

Where it is not the right time, do not wish to speak at length.

ố + negative $\mu \eta ́$ and Indicative. Compare Lesson 25.3.2: indefinite adjectival clauses with negative $\mu \eta \dot{n}$ and Indicative.

\subsubsection{Past Sequence}

\subsubsection{Definite}

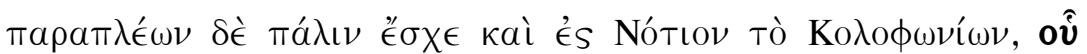

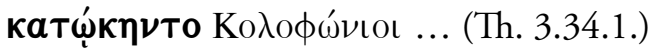

And as he sailed back along the coast he also put in at Notium the <port> of the Colophonians, where the Colophonians had settled ... 
o $\hat{U}+$ Past Perfect Indicative.

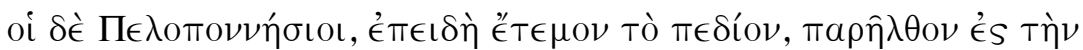

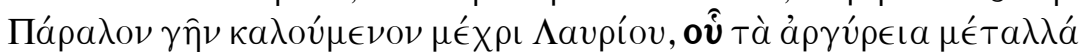

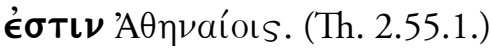

And the Peloponnesians, when they had ravaged the plain, passed on to the region called Paralus, where the Athenians have their silver mines.

o $\hat{v}+$ Present Indicative in the context of past narrative.

\subsubsection{Indefinite}

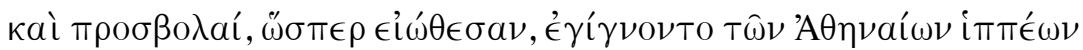
ӧтп тарєі́ко ... (Th. 3.1.2.)

And attacks by the Athenian horsemen, as indeed had been customary, were being made, wherever it was practicable ...

Őாฺฺ + Optative.

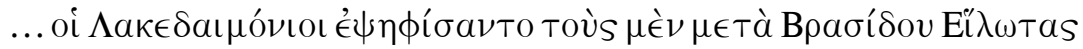

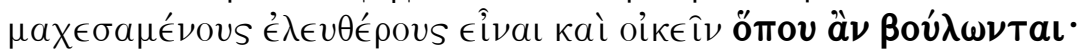
(Th. 5.34.1.)

... the Spartans voted that the Helots who had fought with Brasidas should be free and live wherever they wished.

ömov + ăv with Subjunctive in a Vivid construction.

\subsection{Adverbial Clauses of Manner}

In so far as the conjunctions introducing adverbial clauses of Comparison are 'properly conjunctive relative adverbs of manner' (Smyth, 1956, $\$ 2463$ ), adverbial clauses of Manner have already been treated in Lesson 28. However, that Lesson included adjectival as well as adverbial clauses; and it covered the categories of quality, quantity and degree as well as Manner. On the other hand, the conjunctive relative adverbs $\hat{i}$ and öm ฺ may express Manner ('in what way') as well as location ('in what place', 'to what place', 'by which route'). This section thus provides a link both to Lesson 28 and to the earlier part of the present Lesson. The following examples illustrate the same pattern as with clauses of Place. 


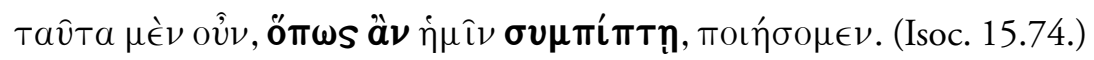
Well then, we shall do this, in whatever way it comes to pass for us.

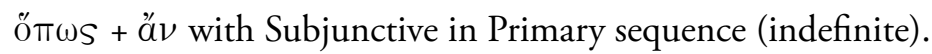

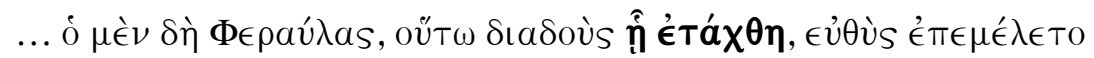

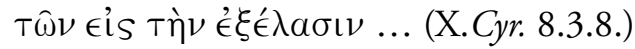

... Pheraulas indeed, having thus made the distribution as he had been instructed, immediately took care of matters relating to the procession ...

$\hat{n}$ with Indicative in Past sequence (definite).

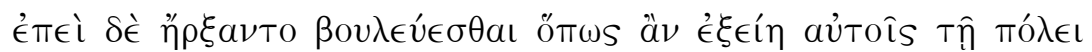

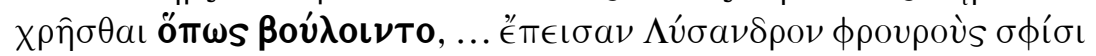
$\sigma v \mu \pi \rho \hat{a} \xi \alpha \iota t e ́ \lambda \theta \in \hat{\imath} \nu$... (X.HG 2.3.13.)

But when they began to consider how it would be possible for them to treat the city however they wished ... they persuaded Lysander to cooperate in getting a garrison to come to them ...

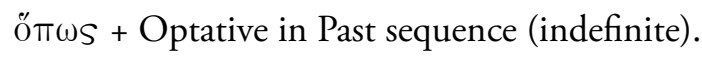

\subsection{Adverbial Clauses of Place Expressing Purpose}

Sometimes adverbial clauses of Place simultaneously express Purpose. The relative adverb of Place is expressed in translation as a Purpose conjunction + demonstrative adverb: 'where you may ...' becomes 'in order that there you may ...'. In Primary sequence, the Mood of the verb in these clauses is either Subjunctive with ôv or Future Indicative; in Past sequence the Mood is Optative. The negative is $\mu \eta$.

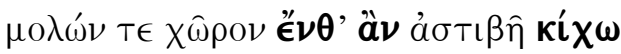

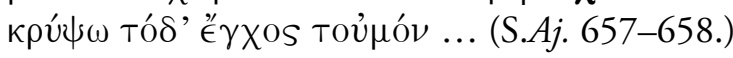

And going where I may find an untrodden place

I shall hide this sword of mine ...

(i.e. 'in order that somewhere I may find ...')

$\check{\epsilon}^{\prime} v \theta a+\stackrel{\alpha}{\nu}$ with Subjunctive in Primary sequence. 


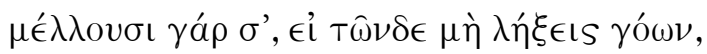

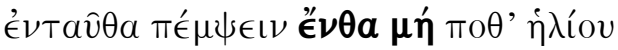

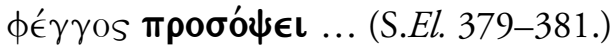

For they intend, if you do not cease from these laments, to send you there where you may not ever look upon the light of the sun ...

(i.e. 'in order that there you may not ever look upon the light of the sun ...')

$\epsilon^{\prime \prime} \nu \theta a+$ negative $\mu \eta ́$ with Future Indicative in Primary sequence.

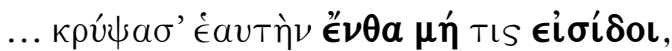

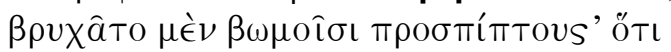

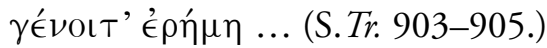

... hiding herself where no one might see,

falling before the altars she screamed that

she had become desolate...

(i.e. 'hiding herself that there no one might see ...')

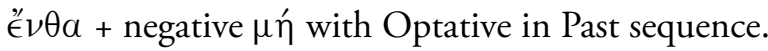

\subsection{Adverbial Clauses Distinguished from Noun Clauses}

The same conjunctive relative adverbs as introduce adverbial clauses of Place or Manner may also introduce certain types of noun clause. Such noun clauses occur especially as reported questions, where the whole clause is the Object of a verb of saying, asking, knowing or seeing. Such a clause may also be the Subject of the verb 'to be', or the Object of a verb of effort or caution.

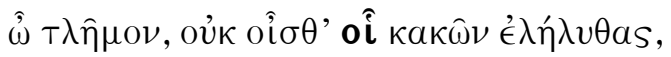
'Iâoov'(E.Med. 1306-1307.)

O poor <man>, you do not know to what point of troubles you have come, Jason.

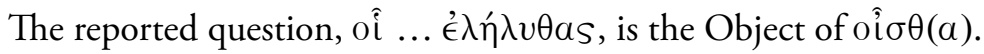




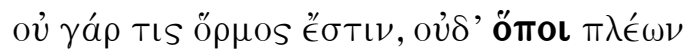

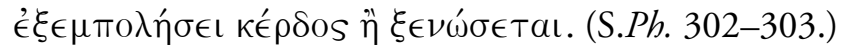

For there does not exist any harbour, nor anywhere one will sail to and make a gainful trade or be welcomed as a guest.

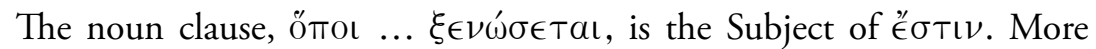
literally: '(the place,) to where (by) sailing one will make a gainful trade ... does not exist'.

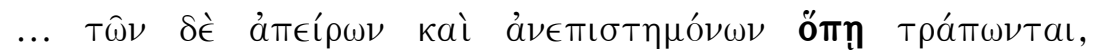

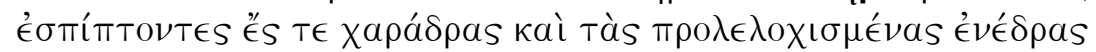
$\delta \mathrm{i} \in \phi \theta \in$ ророто. (Th. 3.112.6.)

... but since they were inexperienced and ignorant of where they were to turn, falling into ravines and ambushes set beforehand they were being destroyed.

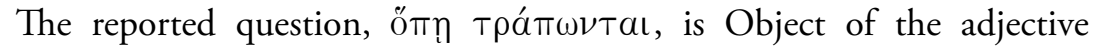
$\dot{\alpha} \nu \in \pi \iota \sigma \tau \eta \mu o ́ \nu \omega \nu$ (with ő $\nu \tau \omega \nu$ understood in an improper Gen. abs.).

\section{References}

Goodwin (1889), Syntax of the moods and tenses of the Greek verb, $\$ \$ 529,540$, 556.

Smyth (1956), Greek grammar, \$\$2498-2499. Cf. 346, 2463 (list of relative adverbs).

\section{EXERCISE 33}

Translate the following passages. (The Exercise does not include any reported questions or clauses of effort or caution.)

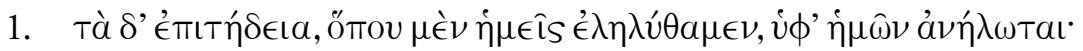

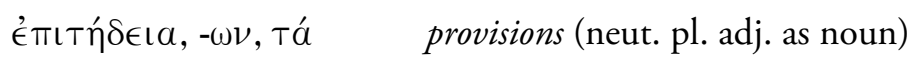

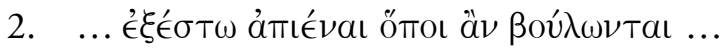

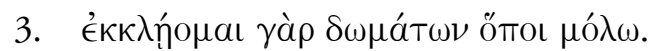

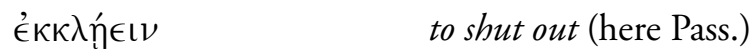




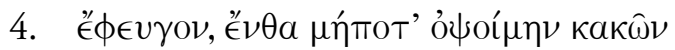

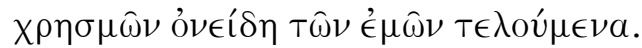

$\phi \in \hat{\gamma} \gamma \in \mathrm{IV} \quad$ to be in exile

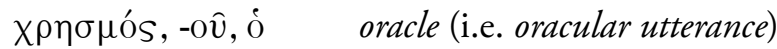

érós, -ń, -óv my (i.e. about me)

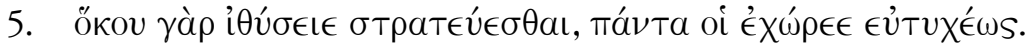

\begin{tabular}{|c|c|}
\hline ӧкоv (Ionic) & ӧтоv (Attic) \\
\hline 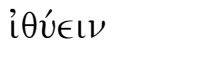 & to strive (+ Infin.) \\
\hline oi & Dat. masc. sg. \\
\hline$\chi \omega \rho \in \hat{\imath} \nu$ & to turn out (Intr.; uncontracted in Ionic) \\
\hline
\end{tabular}

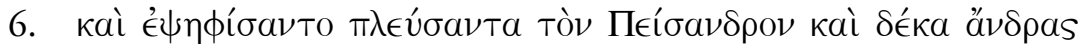

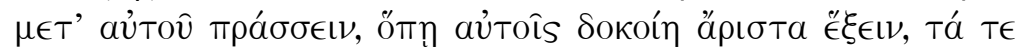

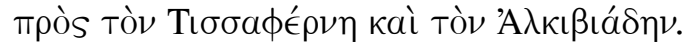

$\pi \rho a ́ \sigma \sigma \in \mathrm{L} \nu$ to negotiate (+ Acc.)

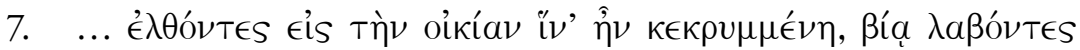

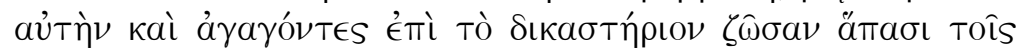

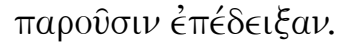

This passage concerns the concealment of a female slave, in order to gain a legal advantage by falsely claiming that she had died.

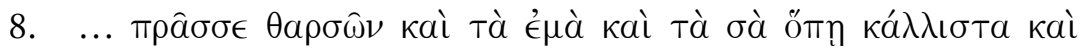

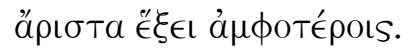

9. And if they were to become subject, all matters would be accomplished as we wish.

$\begin{array}{ll}\text { subject (to authority) } & \dot{v} \pi 0 x \in i ́ p ı s, ~(-\alpha,)-o v \\ \text { as } & \hat{i} \text { (+ Indic.) }\end{array}$

The Conditional clause may be translated by a Gen. abs. 
10. ... they held out for a short time, but then they turned to Panormus, from where indeed they had set sail.

\begin{tabular}{|c|c|}
\hline to hold out & $\dot{v} \pi о \mu \epsilon ́ \nu \in t \nu$ (here referring to a naval battle) \\
\hline to turn (Intr.) & $\tau \rho \epsilon ́ \pi \epsilon \sigma \theta a \iota$ (Mid.) \\
\hline Panormus & Пávopuos, -ov, ó \\
\hline
\end{tabular}





\section{LESSON 34 \\ Noun Clauses with Expressions of Emotion}

\subsection{Introduction}

Noun clauses introduced by ÖTı or $\epsilon \mathfrak{l}$ meaning 'that' are used as the Object of various verbs of emotion, or as the Subject of the verb 'to be' with an adjective of emotion as Complement. Typical emotions are surprise, shame, blame, anger, love, hate, pleasure and pain. Since already in Homer ÖTı may mean either 'that' or 'because', it is necessary to distinguish noun clauses from adverbial clauses of Cause. And likewise, it is necessary to distinguish noun clauses introduced by $\epsilon \dot{l}$ from the common adverbial clauses of Condition introduced by the same conjunction. Other noun clauses, which are introduced by $\epsilon \hat{l}$, are reported questions (Lesson 18), clauses of effort and caution (Lesson 24) and clauses of fearing (Lesson 35).

In order to demonstrate the construction of verbs of emotion with a direct Object, the following sections will contain examples of such verbs with a noun as direct Object, then with a pronoun, and then with a pronoun anticipating a noun clause introduced by ö $\tau \iota$ or $\epsilon \hat{l}$. After that, examples of verbs of emotion with a plain öTı or $\epsilon \hat{l}$ clause as direct Object will be given.

Further sections will provide examples of $\epsilon \mathfrak{l}$ introducing a noun clause as Subject of the verb 'to be' with an adjective of emotion as Complement. Such noun clauses are also sometimes the Subject of certain other verbs.

Finally, the use of negatives in noun clauses introduced by öTı or $\epsilon \dot{l}$ will be considered. 


\subsection{Verbs of Emotion}

\subsubsection{Noun as Direct Object}

Verbs of emotion may have as direct Object a noun which is abstract or concrete and which refers to a person or thing.

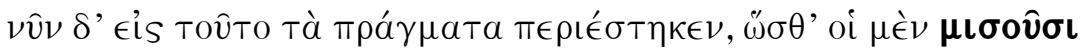

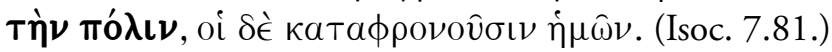

But now circumstances have come around to this <point $>$, that they [= Greeks] bate the city [= Athens], and they [= foreigners] despise us.

The Object is concrete and personal (collective).

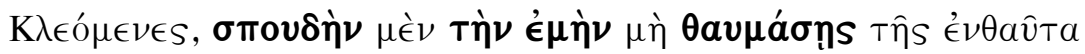
$\dot{a} \pi i \xi_{\operatorname{loS}} \cdot($ Hdt. 5.49.2.)

Cleomenes, do not be surprised at my eagerness for coming here.

The Object is abstract and denotes a thing.

\subsubsection{Pronoun as Direct Object}

The pronoun is regularly neuter singular or plural.

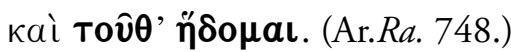

I enjoy this too.

The pronoun is neuter singular.

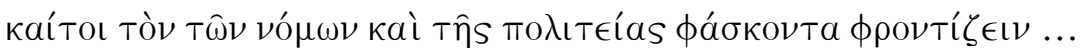

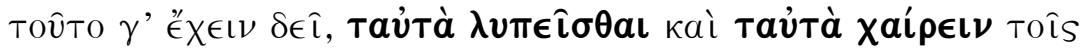

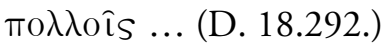

And yet the one who claims to be concerned for the laws and the constitution ... must be capable of this, to feel grief at the same things and to rejoice at the same things as the general public ...

The pronouns are neuter plural. 


\subsubsection{Pronoun Anticipating a öTı Clause}

In the following example, Tav̂Ta refers to the content of the ötı clause: 'my father' is annoyed at 'this', namely, 'that I am proceeding'. ótı does not mean 'because': the ö $T$ c clause expresses what 'my father' is annoyed at, not why he is annoyed. Thus, the ötı clause is the direct Object of

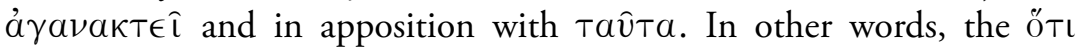
clause is an Objective predicate of the pronoun tav̂ta.

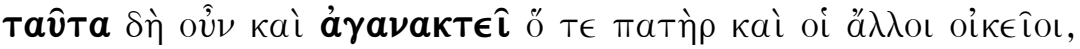

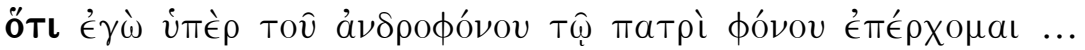
(Pl.Euthphr. 4 D.)

So indeed my father and the rest of the family members are annoyed at this, that I, on behalf of the murderer, am proceeding against my father for murder...

\subsubsection{Pronoun Anticipating an $\in \grave{l}$ Clause}

Similarly in this next example aútò тоиิтo refers to the content of the $\epsilon i$ clause. This clause expresses what the Subject of the leading clause is surprised at, rather than why he is surprised. In function the $\epsilon \hat{i}$ clause is not an adverbial Conditional clause, but a noun clause as direct Object of $\theta a v \mu a ́ \zeta \omega$ and in apposition with av่Tò тоv̂To. In other words, the $\epsilon i$ clause is an Objective predicate of the pronominal phrase aưTò Tô̂To.

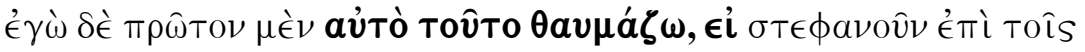

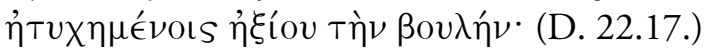

But I in the first place am surprised at this very $<$ point $>$, that he thought it appropriate to reward the council for the unfortunate <events $>$. 


\subsection{5. öTı Clause Alone as Direct Object}

A öTı clause may be the direct Object of a verb of emotion even without an anticipatory pronoun. But again, the öTı clause is a noun clause, not an adverbial Causal clause.

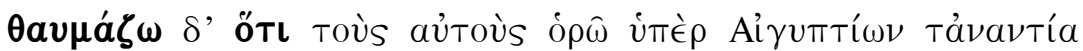

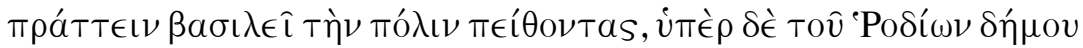

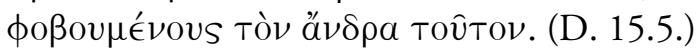

But I am surprised that I see the same <men $>$ trying-to-persuade the city to act in opposition to the (Persian) king where the Egyptians are concerned, but being afraid of this man where the democracy of the Rhodians is concerned.

\subsubsection{El Clause Alone as Direct Object}

Similarly, an $\epsilon \dot{l}$ clause may be the direct Object of a verb of emotion without an anticipatory pronoun. And the $\epsilon \dot{l}$ clause also is a noun clause, not an adverbial Conditional clause.

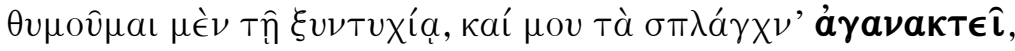

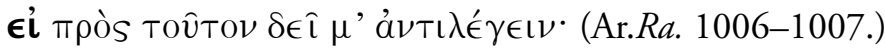

I am angry at the turn of events, and my emotions are annoyed,

that it is necessary that I should speak against this <fellow>.

\subsection{7. $\epsilon \mathfrak{l}$ Clause as Direct Object with an Adjective of Emotion}

An $\epsilon \hat{l}$ clause may be a direct Object in apposition with an adjective of emotion. In the following example, it is appropriate to understand the adjective as an Objective predicate.

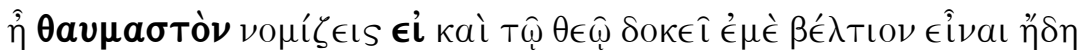
$\tau \in \lambda \in v T \hat{a} \nu ;(X . A p .5$.

Do you think <it> surprising that even to (the) god it seems to be better that I should die now?

English idiom regularly uses the pronoun 'it' anticipating the 'that' clause; compare the Greek anticipatory pronouns in $\$ \$ 34.2 .3$ and 34.2.4 above. 


\subsection{El Clause as Subject}

\subsection{1. $\epsilon \grave{l}$ Clause as Subject of $\epsilon \hat{\imath} \nu a \iota$}

When an $\epsilon \dot{l}$ clause is the Subject of a sentence, it is most commonly the Subject of the verb 'to be' $\epsilon \hat{\imath} \nu a l$ and has an adjectival Complement. Sometimes, the Complement is a full adjectival clause. And sometimes,

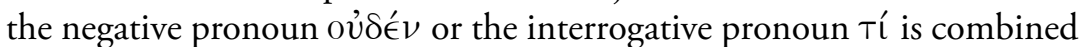
with the adjectival Complement.

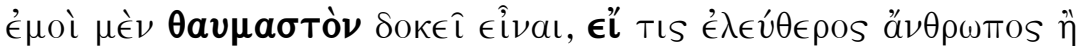

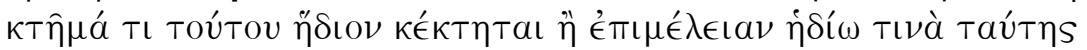

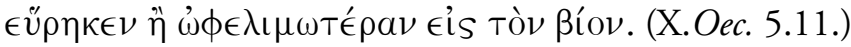

To me <it> seems to be amazing, that any free man has obtained any possession more pleasant than this or has found any occupation more pleasant than this or more helpful for his livelihood.

As in the previous example, English idiom uses the anticipatory pronoun 'it'. More literally: 'That any free man has obtained ... seems to me to be amazing'.

Indicative forms of $\epsilon \hat{\imath} \nu$ a are regularly omitted, as in the following four examples.

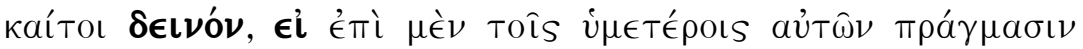

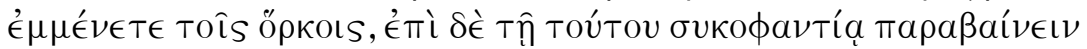

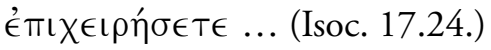

And yet $<$ it is $>$ terrible, that in the matter of your own affairs you abide by your oaths, but in the case of the vexatious prosecution by this <man $>$ you are going to attempt to transgress them ...

More literally: 'That in the matter of your own affairs you abide $\ldots<$ is $>$ terrible'.

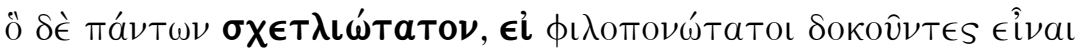

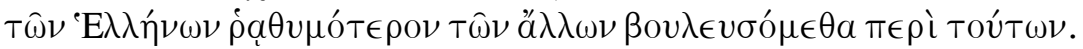
(Isoc. 6.56.)

And what <is $>$ most shocking of all <is $>$ that we, although seeming to be the most energetic of the Greeks, are going to deliberate more lightly than the rest about this. 
In this example, the Complement is a full adjectival clause, $\ddot{0} \ldots$ $\sigma \chi \in T \lambda \iota \omega \cot \alpha \nu$, and the Indicative of the verb 'to be' is omitted both as the Main verb and as the verb of the of clause. Both Greek and English allow a reversal of word order for the sake of emphasis. The order Subject, $<$ verb>, Complement would run: 'And that we are going to deliberate more lightly than the rest about this $<$ is $>$ what $<$ is $>$ most shocking of all'.

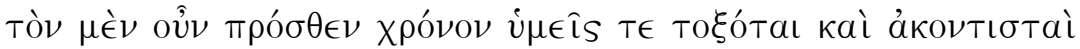

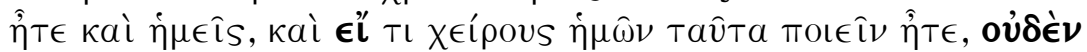

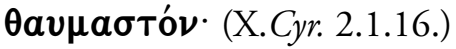

Well then, during the previous time you were archers and lancers and $<$ so were $>$ we, and that you were somewhat inferior to us at doing this, $<i s>$ nothing surprising.

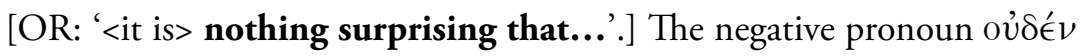
is combined with the adjectival Complement $\theta a u \mu a \sigma \tau o ́ v$.

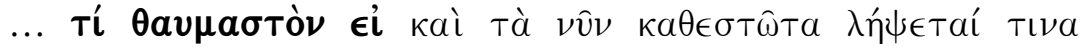
$\mu \in T a ́ \sigma \tau a \sigma ı \nu ;$ (Isoc. 6.40.)

... what $<$ is $>$ surprising < about the idea $>$ that also our present circumstances are going to undergo [lit. 'receive'] some change?

The interrogative pronoun $\tau i ́$ is combined with the adjectival Complement

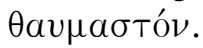

\subsection{2. $\epsilon \mathfrak{l}$ Clause as Subject of Other Verbs}

An $\in \dot{l}$ clause may also be the Subject of a limited number of other verbs of emotion. '́ $\xi \alpha \rho \kappa \epsilon \hat{\imath} \nu$ and $\mu \in T \alpha \mu \epsilon \lambda \in \hat{\imath} \nu$ belong to this group.

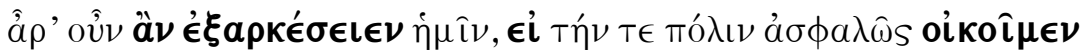

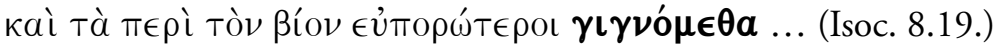

Would <it> satisfy us, then, that we should inhabit the city in safety and should become well provided regarding what concerns our livelihood ...?

Grammatical structure: 'Would <the possibility>, that we should inhabit ... satisfy us?' The Optative oikôิ $\mu \in \nu$ in the $\epsilon$ ' clause corresponds to

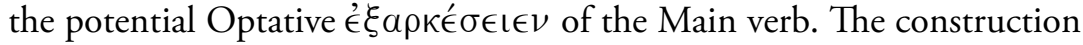
of the whole sentence is analogous to a Future Unfulfilled Conditional sentence. However, the $\epsilon \dot{l}$ clause is a noun clause, expressing $w h a t$ ' would satisfy us', not an adverbial Conditional clause. 
Similarly, an adjective of emotion is sometimes used in apposition with the $\epsilon \hat{l}$ clause as Subject of a non-emotional verb.

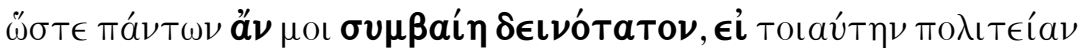

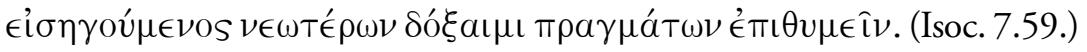

And so the strangest of all things would happen to me, that in introducing such a form of government I should seem to desire revolution.

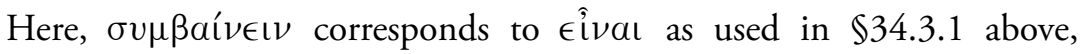
but $\delta \in \iota \nu$ ótatov is part of the Subject not the Complement.

\subsection{Negatives with öTı and $\epsilon i$ Clauses}

ÖTı clauses regularly use ở and its compounds. $\epsilon \hat{\imath}$ clauses sometimes use ov่, but often use $\mu \eta_{\text {and }}$ its compounds. ov and $\mu \eta \dot{n}$ may even occur in the same $\epsilon \dot{l}$ clause, when it is divided by $\mu \epsilon^{\prime} \nu$ and $\delta \dot{\epsilon}$.

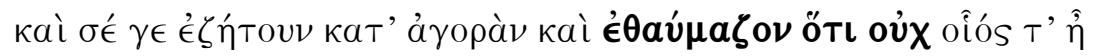
$\epsilon \dot{v} \rho \in \hat{\imath} \nu$. (Pl. Tht. 142 A.)

And I was looking for you (all) over the market-place and I was surprised that I was not able to find <you>.

ÖTı with negative oủ and Indicative.

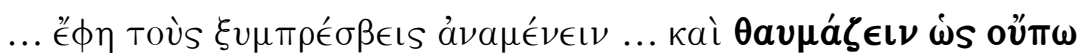

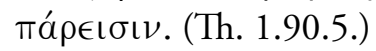

... he said that he was waiting for his fellow-ambassadors ... and that he was surprised that they were not yet present.

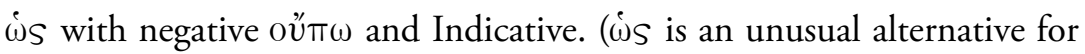
ÖTI. Here it is sometimes regarded as meaning 'how' not 'that'.)

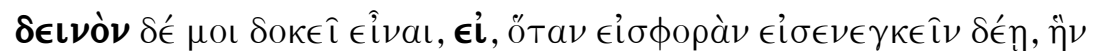

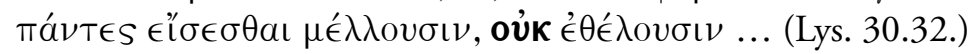

And it seems to me to be terrible, that, when it is necessary to pay a contribution, which all are going to know about, they are not willing...

$\epsilon \mathfrak{i}$ with ov and Indicative, which would not normally occur in a genuine Condition (cf. Lesson 19.5). 


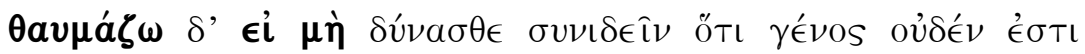

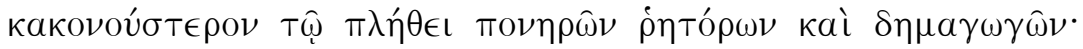
(Isoc. 8.129.)

But I am surprised that you are not able to see that no group is more ill-disposed to the general public than incompetent orators and politicians.

$\epsilon \mathfrak{l}$ with $\mu \eta \dot{~ a n d ~ I n d i c a t i v e . ~}$

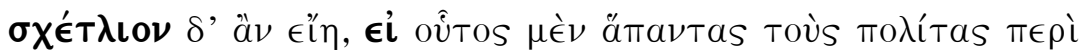

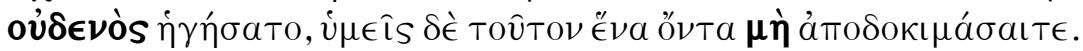
(Lys. 31.31.)

It would be shocking, that this <man> considered all the citizens worth nothing, but <that> you should not disqualify this <man > when he is $<j u s t>$ one $<$ person $>$.

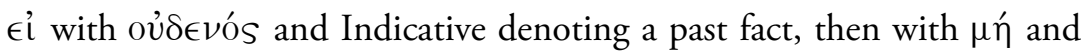
Optative denoting an imminent possibility from which the speaker is dissuading his audience. The $\epsilon \dot{l}$ clause is divided by $\mu \epsilon ́ v$ and $\delta \epsilon ́$.

\subsection{General Comments}

\subsection{1. ‘́áv}

Sometimes, '́áv with Subjunctive is mentioned as having the same function as $\epsilon i$ or ÖTl with expressions of emotion. However, there are few examples. And, it may be that éá $\nu$ should be regarded as introducing a genuine Conditional clause, even with an expression of emotion. Moreover, the classical prose author Isocrates frequently uses $\epsilon \dot{l}$ to introduce noun clauses with expressions of emotion; but all (18) éáv clauses are genuine Conditional clauses, and are not used with expressions of emotion.

\subsubsection{Scholarly Views}

Standard treatments of Ancient Greek grammar in English, French and German differ somewhat in their view of expressions of emotion with clauses introduced by ǑTı and $\epsilon \dot{l}$. In German, Kühner (1890-1904) regards such clauses as noun clauses (Substantivsätze). Schwyzer (1950) appears to agree for öTı and $\omega$ s clauses; for $\epsilon \mathfrak{l}$ (€́á $\nu)$, he merely refers 
to Kühner. In French, Humbert (1954) first discusses Causal clauses introduced by ŐTt or $\dot{\omega}$, then adds Object (completive) clauses with verbs of emotion. "The content of these emotions is expressed by the Causal clause, introduced by $\epsilon \hat{l}$, "if it is true that, since..."' (\$337). This formulation seems deliberately to blur the distinction between adverbial Conditional and Causal clauses on the one hand and noun clauses on the other hand.

In English, Goodwin (1889) treats clauses with expressions of emotion in a separate section in the midst of Conditional clauses. He acknowledges that, with many expressions of emotion, 'a protasis with $\epsilon \hat{l}$ may be used to express the object of the emotion', although 'a causal sentence would generally seem more natural' (\$494). And he maintains, 'These expressions may also be followed by öTı and a causal sentence' (\$496). After treating the usual Causal constructions including ÖTı and is clauses, Smyth $(1956, \$ 2247)$ continues by writing that, 'Many verbs of emotion state the cause more delicately with $\epsilon \dot{l}\left(\mathfrak{\epsilon}^{\prime} \alpha \nu\right)$ if as a mere supposition than by ÖTl'. He acknowledges that öTı clauses are also used with these verbs (\$2248). But he ends with the comment, “ötl after verbs of emotion really means that, not because' (\$2248.a.).

This Lesson follows the view that, with expressions of emotion, clauses introduced by ö $T \iota$, $\dot{\omega} s$ and $\epsilon \dot{l}$ are noun clauses, and that the subordinating conjunctions are appropriately translated as 'that', not 'because' nor 'if'.

\section{References}

Goodwin (1889), Syntax of the moods and tenses of the Greek verb, \$\$494-496.

Humbert (1954), Syntaxe Grecque, $\$ 337$.

Kühner (1904), Ausfübrliche Grammatik der Griechischen Sprache (Vol. 2.2), pp. 369-370.

Liddell \& Scott (1996), A Greek-English lexicon, $\in$ i B. V.

Schwyzer (1950), Syntax und Syntaktische Stilistik (Griechische Grammatik, vol. 2), pp. 645-646, 688.

Smyth (1956), Greek grammar, $\$ \$ 2247-2248$. 


\section{EXERCISE 34A}

Translate the following passages. Both ö $T \iota$ and $\epsilon \dot{l}$, when introducing noun clauses of the type treated in Lesson 34, should consistently be translated as 'that'.

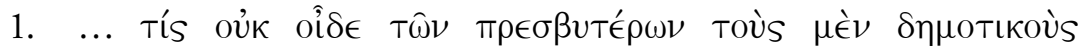

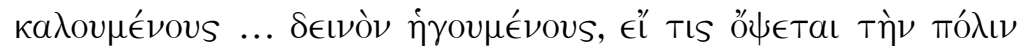

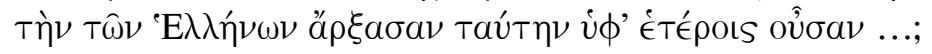

\begin{tabular}{|c|c|}
\hline$\pi \rho \in \sigma \beta \hat{v} \tau \in \rho O S,-$ & older \\
\hline$\dot{\eta} \gamma o u \mu \epsilon ́ v o v s$ & $\begin{array}{l}\text { Reflects Past Imperf. of direct } \\
\text { knowledge: } \dot{\eta} \gamma о \hat{v} \nu \tau o .\end{array}$ \\
\hline
\end{tabular}

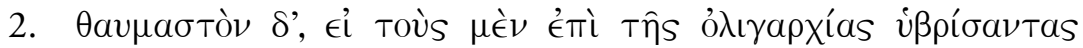

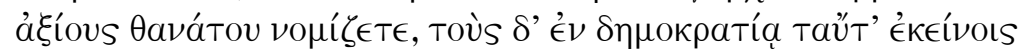

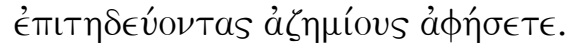

\begin{tabular}{|c|c|}
\hline 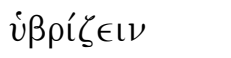 & to act violently \\
\hline$\epsilon^{\epsilon} \pi \iota T \eta \delta \in \dot{v} \in \iota \nu$ & to commit \\
\hline 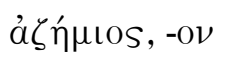 & unpunished \\
\hline
\end{tabular}

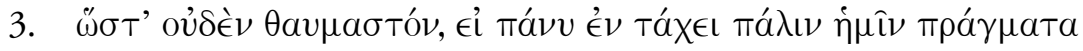

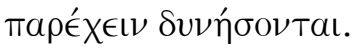

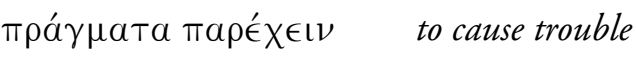

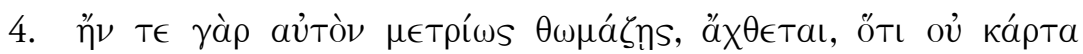

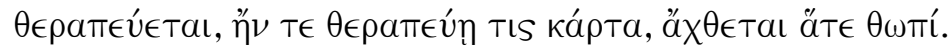

\begin{tabular}{|c|c|}
\hline$\theta \omega \mu a ́ \zeta \in \mathrm{l} \nu$ (Ionic) & to admire \\
\hline$a^{\prime} x \theta \in \sigma \theta a \iota$ & to be annoyed \\
\hline$\theta \in \rho a \pi \in \dot{v} \in I \nu$ & to pay attention to (1st instance Pass.) \\
\hline$\theta \hat{\omega} \psi, \theta \omega \pi o ́ s, \dot{o}$ & flatterer \\
\hline
\end{tabular}

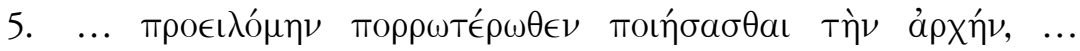

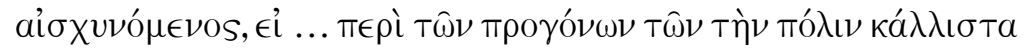

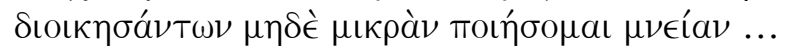


The speaker is referring to the composition of his speech.

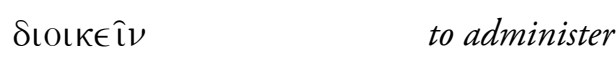

6. And let no one of you be surprised, that we know [this] accurately.

accurately ákpı $\beta \hat{\omega}$

7. For we are able to make also this criticism against them, that for their own city they compel their neighbours to be serfs ...

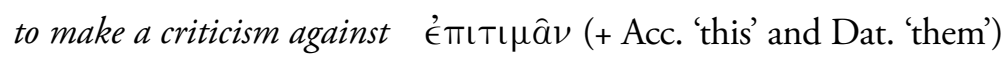

neighbour

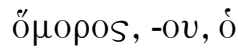

to be a serf

$\epsilon i \lambda \omega T \epsilon u ́ \in \iota \nu$

\section{EXERCISE 34B}

Translate the following passages. Both öTı and $\epsilon \hat{l}$, when introducing noun clauses of the type treated in Lesson 34, should consistently be translated as 'that'.

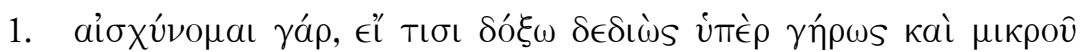

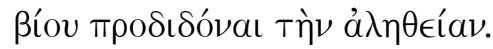

\begin{tabular}{|c|c|}
\hline$a \imath \sigma \chi v ́ v \in \sigma \theta a \iota$ & to be ashamed \\
\hline$\gamma \hat{\eta} \rho a s,-\omega s$ (-aos), Tó & old age \\
\hline$\mu \iota \kappa \rho о \hat{v}$ & $\begin{array}{l}\text { Refers to speaker's remaining, } \\
\text { not total, life. }\end{array}$ \\
\hline
\end{tabular}

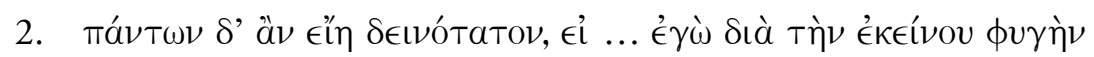
$\zeta \eta \mu \iota \theta \epsilon i ́ \eta \nu$.

\begin{tabular}{|c|c|}
\hline$\phi v \gamma \dot{\eta}^{\prime},-\hat{\eta} s, \dot{\eta}$ & exile \\
\hline$\zeta \eta \mu \iota \mathrm{v} \nu$ & to punish \\
\hline
\end{tabular}

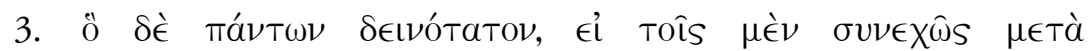

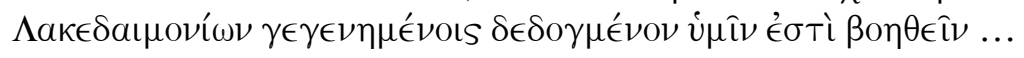




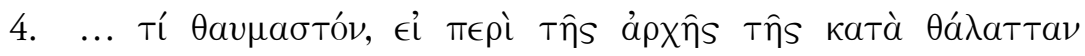

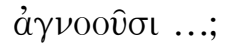

5.

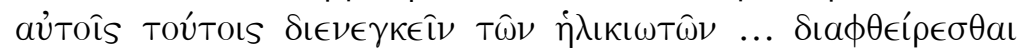
$\psi \eta \phi i ́ \sigma \alpha \iota \sigma \theta \epsilon \ldots$

Toîs aƯToîs Toútols neut.

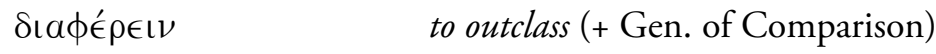

$\dot{\eta} \lambda \iota \kappa \iota \omega ́ t \eta s,-o v, \dot{o} \quad$ comrade

Sı $a \phi \theta \in i ́ \rho \in \mathrm{IV}$ to corrupt

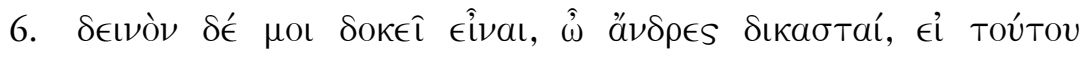

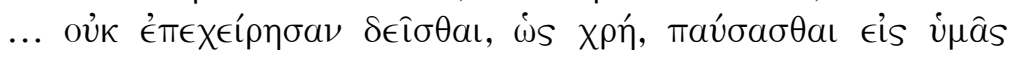

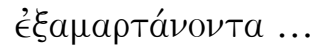

$\delta \in \hat{\imath} \sigma \theta a \mathrm{l} \quad$ to request (of) (+ Gen.)

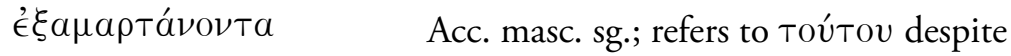
change of Case.

7. For I am ashamed, that, having said so much in advance about the excellence of Agamemnon, I am going to mention nothing of what has been achieved by that $[\mathrm{man}] . .$.

\begin{tabular}{|c|c|}
\hline to have said in advance & 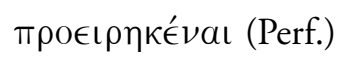 \\
\hline Agamemnon & 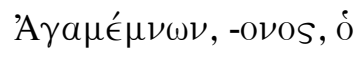 \\
\hline to mention & $\mu \iota \mu \nu \eta ́ \sigma \kappa \in \sigma \theta \alpha \iota$ \\
\hline
\end{tabular}

8. But it seems to me that I would reasonably be annoyed, ... that they were willing to make the mattter equal to the most serious grounds of complaint.

\begin{tabular}{|c|c|}
\hline to make equal with & $\begin{array}{l}\epsilon^{\epsilon} \xi ı \sigma o v \nu \nu \text { (+ Acc. 'matter' and Dat. } \\
\text { 'ground') }\end{array}$ \\
\hline ground of complaint & 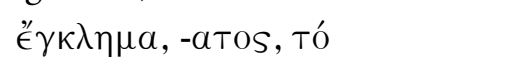 \\
\hline
\end{tabular}




\section{LESSON 35 \\ Expressions of Fearing}

\subsection{Introduction}

Fears are most commonly expressed by a verb of fearing with a direct Object. The Object may be a noun or a pronoun referring to a person or a thing. But the Object may also be an Infinitive phrase, with or without the neuter singular definite article. A verb of fearing may also have as its direct Object a noun clause, which is most commonly introduced by $\mu$ ń.

The following verbs are those which are most often used in expressions of fearing. $\phi o \beta \in \hat{\imath} \sigma \theta a \iota$ is Passive in form, but Active in function, since it has a direct Object. (Coincidentally, 'to be afraid' in English was originally a

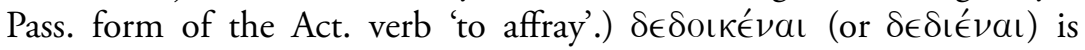
a Perfect form with Imperfect meaning: 'to have become afraid' and hence 'to be afraid' or 'to fear'. $\delta \in \iota \mu a i ́ v \in t \nu$ has the same meaning. $\tau a \rho \beta \in \hat{\imath} \nu$, also synonymous, is mainly restricted to verse. In addition to expressions of fear with verbs, there are various idioms which use nouns such as $\dot{0}$

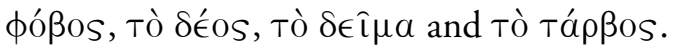

\subsection{Verbs of Fearing with Noun or Pronoun as Object}

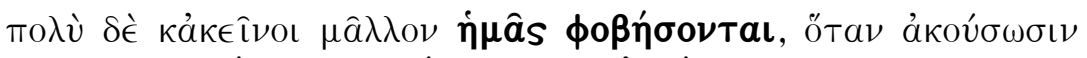

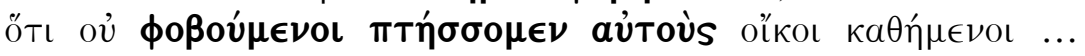
(X.Cyr. 3.3.18.)

And those <men> also will much more be afraid of us, when they hear that we are not cowering in fear before them...

Acc. pronouns (persons) as Object. 


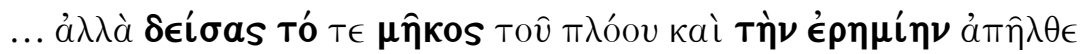
ómí $\sigma \omega \ldots$... (Hdt. 4.43.1.)

... but fearing the length of the voyage and the isolation he went back again ...

Acc. nouns (abstract things) as Object.

\subsection{Verbs of Fearing with Infinitive Phrase as Object}

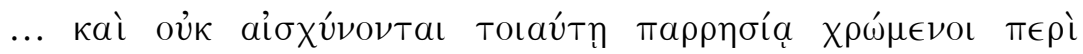

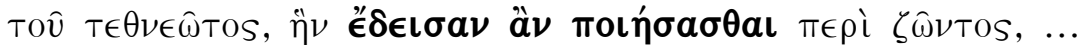
(Isoc. 16.22.)

... and they are not ashamed to employ such outspokenness about him now that he is dead, as [lit. 'which'] they would have feared to use concerning <him when he was > living...

Plain Infin. as Object.

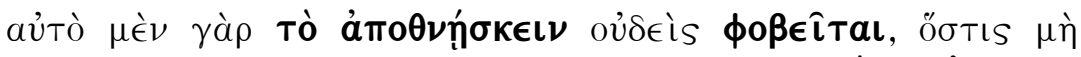

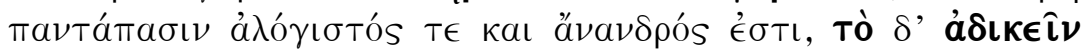
$\phi о \beta \epsilon \hat{\imath}$ таا. (Pl.Grg. 522 E.)

For no one, who is not altogether irrational and unmanly, fears actual dying, but he fears acting unjustly.

Articular Infin. as Object.

[The sentence is slightly illogical. The intended meaning is as follows.

'For any one, who is not altogether irrational and unmanly, does not fear actual dying, but he fears acting unjustly'.

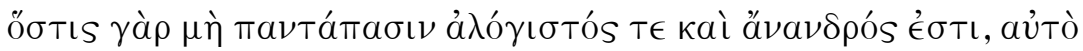

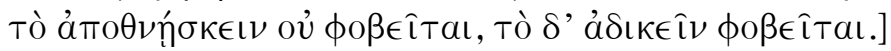




\subsection{Verbs of Fearing with a $\mu$ ' Clause as Object}

\subsubsection{Fears that Something May Happen}

In Primary sequence, fears that something may happen are generally expressed by $\mu \eta$ with the Subjunctive Mood. In Past sequence, the Optative Mood may replace the Subjunctive; but a Vivid construction, retaining the Subjunctive, is also common.

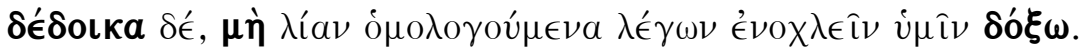
(Is. 8.34.)

But I fear, that I may seem to you to be annoying you by saying what is generally agreed.

Primary sequence with $\mu \eta$ and Subj.

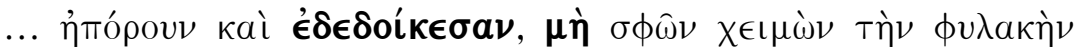

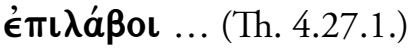

... they were puzzled and were afraid, that winter might overtake their blockade...

Past sequence with $\mu$ í and Optative.

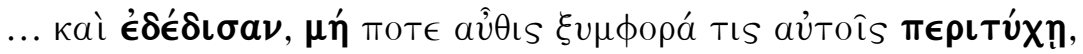

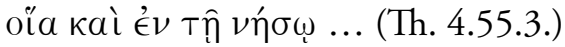

... and they were afraid, that one day some disaster might again befall them, such as <had happened $>$ also on the island ...

Vivid construction with $\mu$ í and Subj.

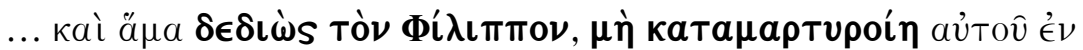

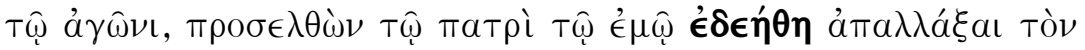

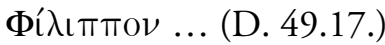

... and at the same time fearing, that Philip might testify against him at the trial, he approached my father and begged <him > to pay off Philip ...

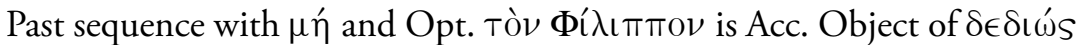

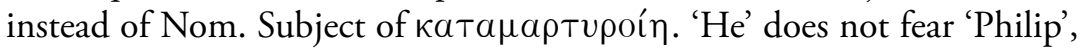
but fears 'that' Philip may testify. 


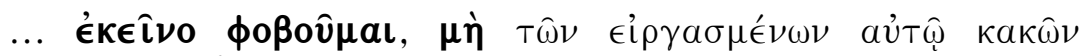

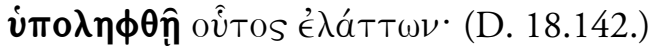

... I am afraid of that, that this <man > may be supposed incapable of the evils perpetrated by him.

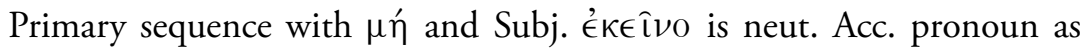

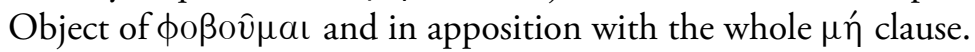

\subsubsection{Fears that Something May Not Happen}

When a fear is expressed that something may not happen, ov and its compounds are used within the $\mu$ n clause. In Primary sequence, the Subjunctive Mood is used. But it is doubtful whether the Optative Mood is ever used in Past sequence. A Vivid construction is used instead, whether the leading verb is Past or Historic Present.

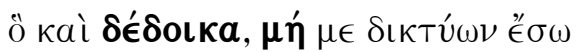

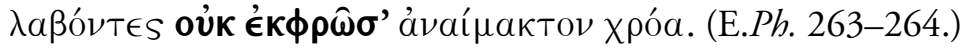

And in regard to this I am also afraid, that having caught me inside the nets they may not let me out with my flesh unstained by blood.

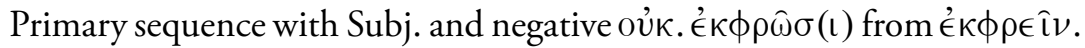

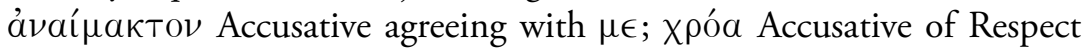

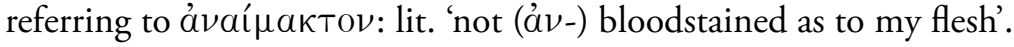

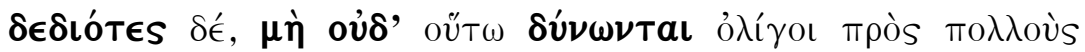

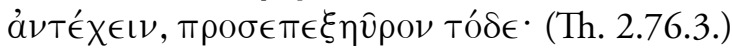

But fearing, that not even so might they be able to hold out, <being $>$ few against many, they contrived this <plan $>$ in addition.

Vivid construction with Subj. and negative oủ $\delta(\epsilon)$.

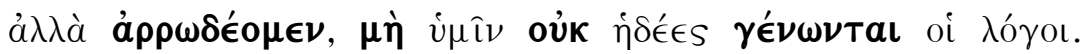
(Hdt. 9.46.3.)

But we were afraid, that our words might not turn out to be pleasing to you.

Vivid construction with Subj. and negative oủk after Historic Pres. leading verb. 


\subsection{Fears that Something is (etc.) Actually Happening}

In order to emphasise a fear that something is actually happening, the Indicative Mood is used in some $\mu \eta$ clauses in Primary sequence. Within the $\mu \eta$ clauses there are examples of Present, Future, Past Aorist and Present Perfect Indicative verbs. In Past sequence, an Optative in the $\mu$ ń clause represents an Indicative of the Primary form of the expression of fear. The negative within the $\mu \eta \dot{n}$ clause is again ov , as in $\$ 35.4 .2$.

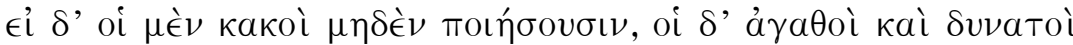

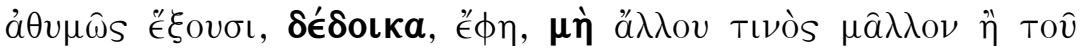

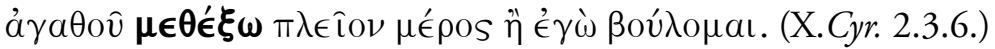

'But if the bad do nothing, and the good and powerful become fainthearted, I fear', he said, 'that I shall have a rather larger share than I wish of something other than good'.

Primary sequence with $\mu \eta \dot{n}$ and Fut. Indic.

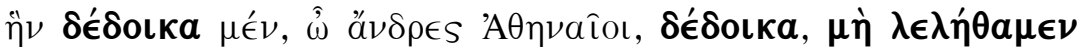

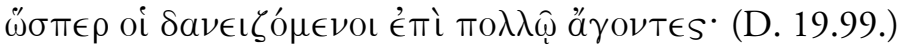

And I fear, O men of Athens, I do fear, that we have missed seeing that we are enjoying it just as those who are borrowing at a high interest rate.

Primary sequence with $\mu \eta \dot{n}$ and Pres. Perf. Indic. $\eta v$ is coordinating relative pronoun: 'And ... it', referring to 'peace' ( $\epsilon i \rho \eta \eta \eta \eta)$ in the previous sentence.

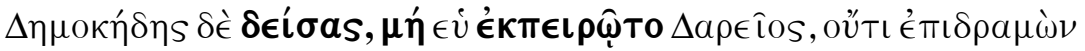

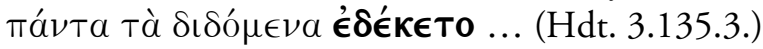

But Democedes fearing, that Darius was testing him, was in no hurry to accept all that was being offered ... [lit. 'not at all rushing was accepting']

Past sequence with $\mu \eta$ and Imperfect Optative, representing Present

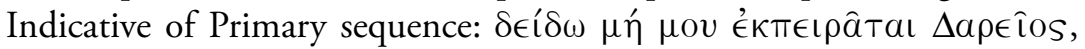
'I am afraid that Darius is testing me'. (A Subj. in Primary sequence would mean: 'I am afraid that Darius may test me'. This would not make sense in the context, despite the ambiguity of the Indic. and Subj.

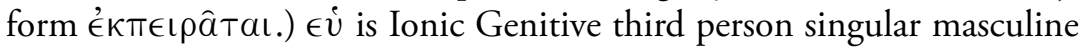
pronoun (enclitic). 


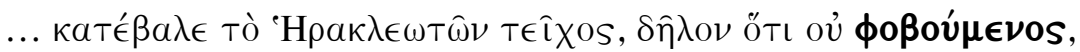

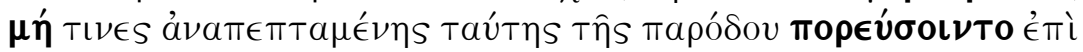

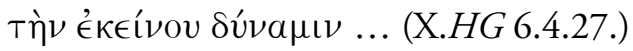

... he overthrew the fortress of the Heracleots, clearly not fearing, that, since this passage had been laid open, certain people would proceed against that $<$ man's $>$ power...

Past sequence with $\mu \eta$ and Intentive ('Fut.') Opt., representing Fut. Indic.

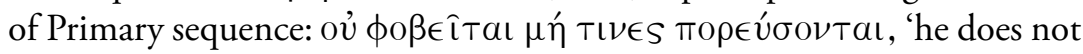
fear that certain people will proceed ....'

\subsection{Fears Expressed with Other Conjunctions}

\subsection{1. ӧ $\pi \omega S \mu \eta ́$}

In this construction, ö $\pi \omega s$ should be translated as 'that'. $\mu$ ń may be regarded as redundant and should not be translated.

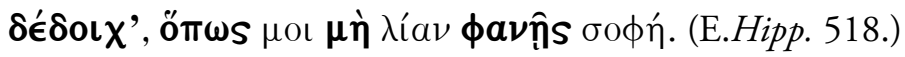

I am afraid, that you may appear too clever for my good.

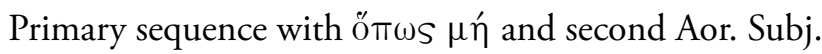

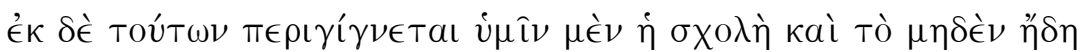

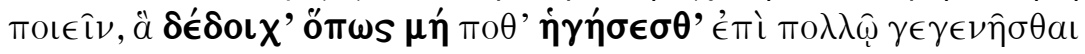
... (D. 8.53.)

But from this there results for you leisure and doing nothing now, which I am afraid that one day you will think has been achieved at a high price...

Primary sequence with öt $\omega S \mu \eta \dot{n}$ and Fut. Indic.

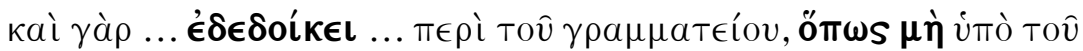

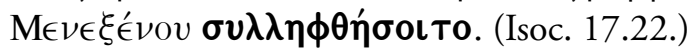

For indeed ... he was afraid ... concerning the document, that it would be seized by Menexenus.

Past sequence with öt $\omega s \mu \eta$ and Intentive ('Fut.') Opt., representing Fut.

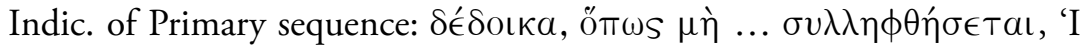
am afraid, that it will be seized .... 


\subsection{2. öTเ}

When a ÖTı clause occurs in relation to an expression of fear, the ÖT clause is usually an adverbial clause of Cause and not part of a fearing construction as such. Moreover, in a construction of the form ठı̀̀ Tov̂To $\phi о \beta \in \hat{\imath} \sigma \theta a \mathrm{l}$, öTl ... 'to fear on account of this, (namely) that ...', the öTı clause is indeed a noun clause, but is in apposition with the pronoun тойто. Cause is here expressed by the preposition Sıá in the adverbial

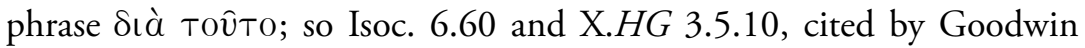
(1889, \$377). However, in the following example, the ötı clause is a genuine noun clause of fearing. And öTı should be translated as 'that', not 'because'.

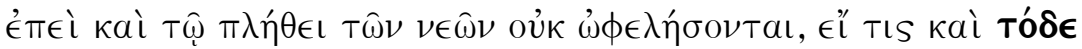

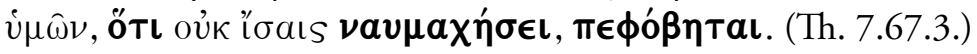

For indeed they will not be helped by the number of their ships, if any one of you has become afraid of this, that he will fight at sea with an unequal number.

In Primary sequence, the öTı clause with Fut. Indic. is in apposition with

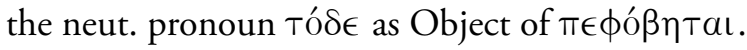

\subsection{3. is}

is may be used in the same way as ötı, and should also be translated 'that'.

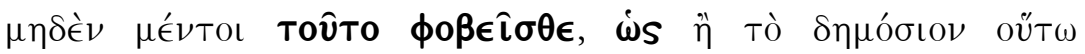

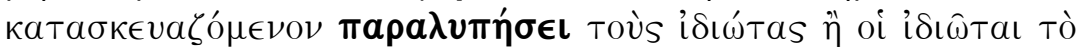

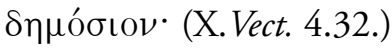

However, do not at all fear this, that either the public company being set up in this way will bother private citizens or private citizens $<$ bother $>$ the company.

In Primary sequence the $\dot{\omega}$ clause with Fut. Indic. is in apposition with

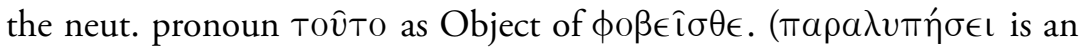
emendation for the impossible readings of the manuscripts, $\pi \alpha \rho \alpha \lambda v \pi \eta \sigma \eta$ or $\pi \alpha \rho a \lambda v \pi \eta \sigma \in \mathrm{L} \nu$.) 


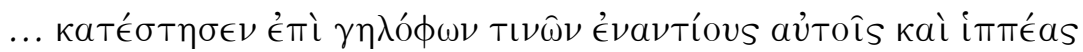

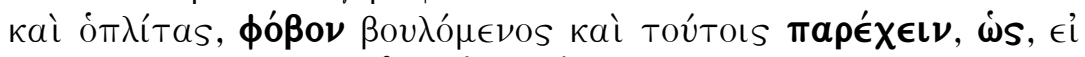

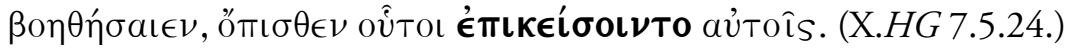

... he set up on some hills both horsemen and infantrymen opposite them, wishing to create fear in these also, that, if they came to help, these would press upon them from behind.

In Past sequence, the $\dot{\omega}$ s clause with Intentive ('Fut.') Opt. represents

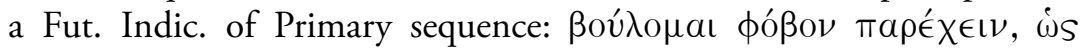
$\epsilon \in \pi \kappa \in$ Í⿴囗⿱一一) (For the introductory noun phrase, cf. $\$ 35.7$ below.)

\subsection{4. $\epsilon \grave{l}$}

In both Primary and Past sequence, a fear is sometimes expressed by an $\epsilon \dot{l}$ clause with Present or Future Indicative. The construction is similar to that of reported questions with $\epsilon \dot{l}$ (= 'whether'). However, in the following example the negative within the $\epsilon \dot{l}$ clause is $\mu \eta$, used as in Conditions, not as in reported questions. (Cf. Lessons 18.1, 19.1 and 19.5.)

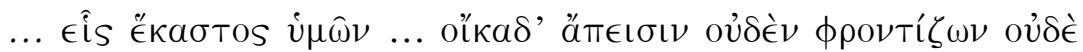

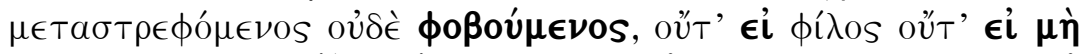

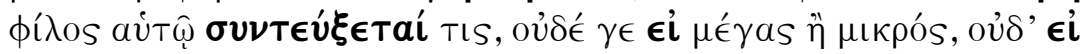

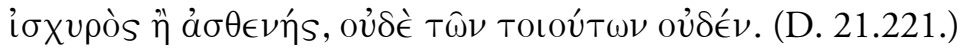

... each one of you ... will go off home not worrying about anything nor looking behind nor fearing, neither whether any friend nor whether any one not a friend is going to encounter him, nor yet whether $\langle$ he is $>$ big or little, nor whether strong or weak, nor any of such <issues>.

Primary sequence with $\epsilon \dot{l} \mu \eta \dot{n}$ and Fut. Indic. (A Pres. or Fut. verb 'to be' may be understood with the subsequent two occurrences of $\epsilon \dot{l}$.) 


\subsection{Introductory Noun Phrases}

Various noun phrases may be used instead of a verb to introduce a clause of fearing. A selection of examples follows.

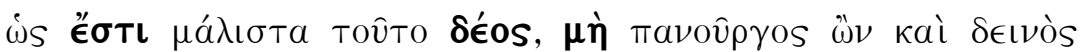

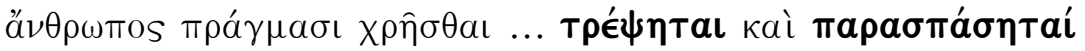

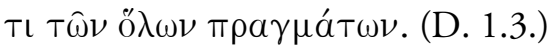

For there exists especially this fear, that being unscrupulous and a person clever at exploiting circumstances... he may turn to his own advantage and wrest aside something of the whole set of circumstances.

$\delta$ '́os (Nom.) with verb éoTl and $\mu \eta$ with Subj. in Primary sequence.

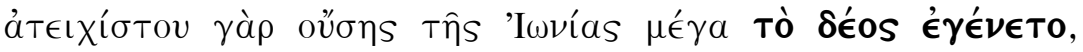

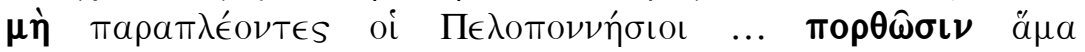

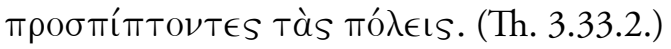

For, since Ionia was unfortified, great <was $>$ the fear $<$ which $>$ arose, that the Peloponnesians ... as they were sailing past might fall upon their cities and ravage $<$ them $>$.

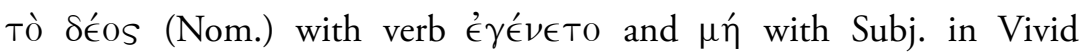
construction.

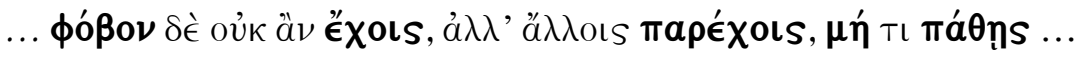
(X.Hier. 11.11.)

... and you would not have fear, but you would create for others $\langle$ fear $>$, that you might suffer something ...

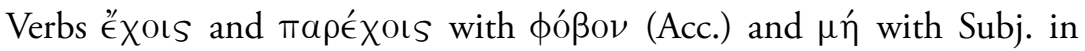
Primary sequence.

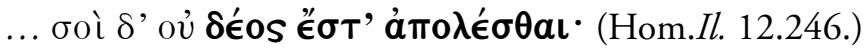

... yet there is no fear that you should perish. [lit. 'there is not fear for you to perish']

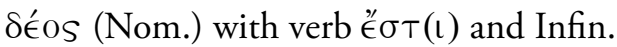




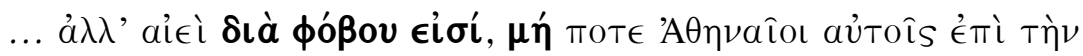
$\pi{ }^{\prime} \lambda \iota \nu \stackrel{\epsilon}{\lambda} \lambda \theta \omega \sigma \iota \nu$... (Th. 6.34.2.)

... but they are constantly in fear, that at some time the Athenians may come against them <and attack > their city ...

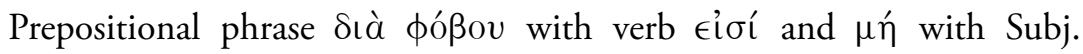
in Primary sequence.

\subsection{Note}

English translations of fearing clauses in the Greek passages in the Lesson observe the following conventions of Tense and Mood, especially where English auxiliary verbs are required:

- 'may' is used in Primary sequence for the Greek Subj.

- 'might' is used in Past sequence for Imperf. or Aorist Opt. or for Vivid Subj.

- 'would' is used in Past sequence for Intentive ('Fut.') Opt.

- Indic. is used for Greek Indic. and for Opt. in Past sequence when it represents a Pres. or Past Indic. of Primary sequence.

It is recommended that these conventions be observed in the Exercise.

\section{References}

Goodwin (1889), Syntax of the moods and tenses of the Greek verb, $\$ \$ 131,365-373$, 376-377.

Smyth (1956), Greek grammar, $\$ \$ 2221-2238$. 


\section{EXERCISE 35A}

Translate the following passages.

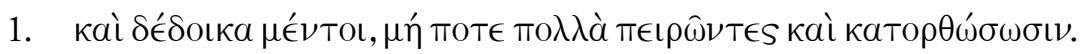

\begin{tabular}{ll}
\hline$\mu \in \operatorname{\nu Tol}$ & moreover \\
$\kappa a \tau о \rho \theta 0 \hat{\nu}$ & to succeed \\
\hline
\end{tabular}

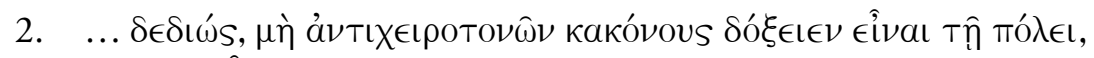

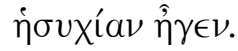

ávTıX

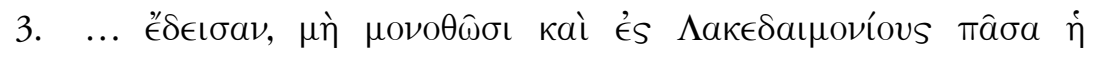

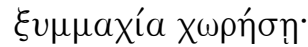

\begin{tabular}{ll}
\hline$\mu$ Hov̂v & to isolate \\
$\chi \omega \rho \in \hat{\imath} \nu$ & to go over \\
\hline
\end{tabular}

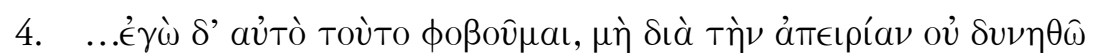

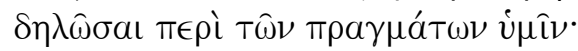

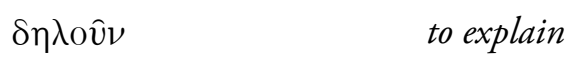

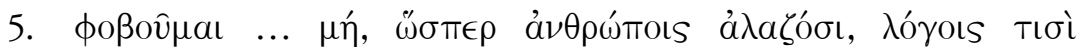

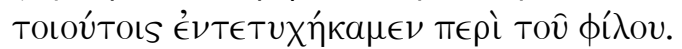

\begin{tabular}{|c|c|}
\hline$\ddot{\omega} \sigma \pi \epsilon \rho$ & (just) as if \\
\hline 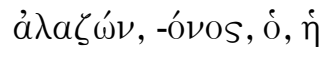 & deceptive \\
\hline$\lambda o ́ \gamma o s,-o v, \dot{o}$ & argument \\
\hline 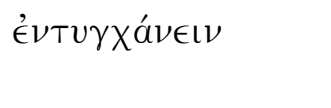 & 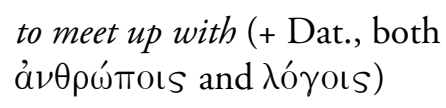 \\
\hline 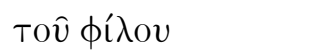 & neut. Adj. for abstract noun \\
\hline
\end{tabular}

6.

$\mu \eta \kappa \hat{\epsilon} T^{\prime} e^{\prime} \kappa \phi o ß o v$,

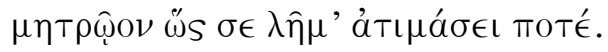

$\lambda \hat{\eta} \mu a,-a$ Tos , тó spirit


7.

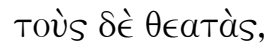

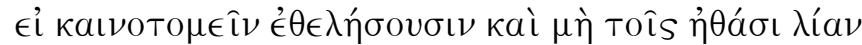

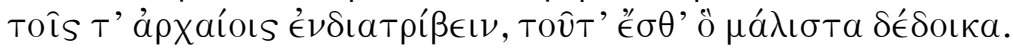

$\theta \in a T \eta ́ s,-o v, \dot{o}$

spectator

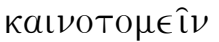

to try something new

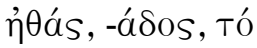

usual <practice $>$ [more often a masc.

or fem. adj.]

$\lambda i ́ a v(\mathrm{adv}$.

too long

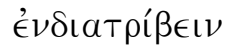

to continue in (+ Dat.)

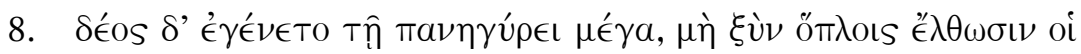

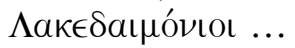

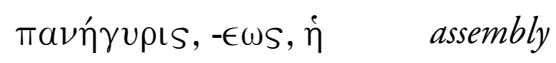

9. ... they are afraid of him, but perhaps they would become willing actually to bear witness for me.

10. For only so many of the twenty men at first appointed did not become afraid to enter.

\begin{tabular}{|c|c|}
\hline twenty & 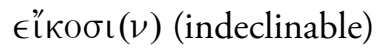 \\
\hline to appoint & Tá $\sigma \sigma \in \iota \nu$ \\
\hline
\end{tabular}

\section{EXERCISE 35B}

Translate the following passages.

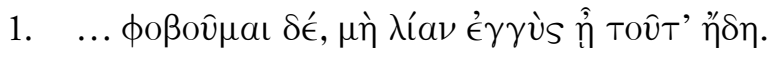

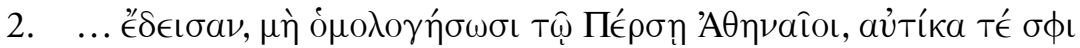

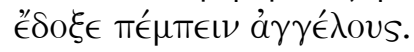

$\sigma \phi \mathrm{i} \quad$ Dat. 3rd pers. pl. masc. pronoun

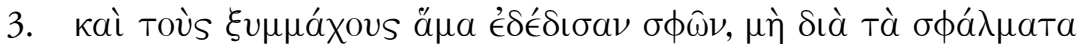

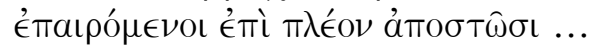




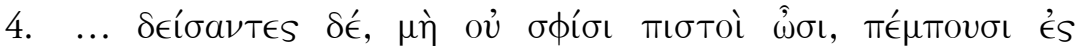

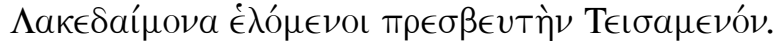

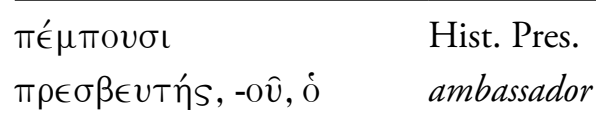

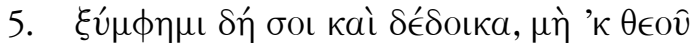

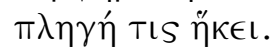

$\pi \lambda \eta \gamma \dot{\eta},-\hat{\eta} s, \dot{\eta}$ blow (lit. and metaphorical)

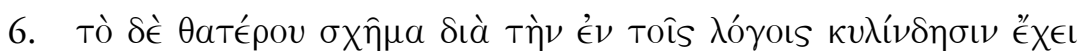

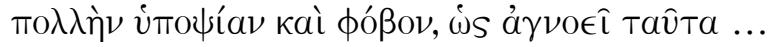

\begin{tabular}{|c|c|}
\hline$\theta a \tau \in ́ \rho o v$ & Tov̂ ÉTÉ $\rho O v$ \\
\hline$\sigma \chi \hat{\eta} \mu \alpha,-\alpha$ тos, тó & character \\
\hline$\kappa v \lambda \iota^{\prime} \nu \delta \eta \sigma \iota s,-\epsilon \omega s, \dot{\eta}$ & involvement \\
\hline ітоні́a, - - ss, $\dot{\eta}$ & suspicion \\
\hline
\end{tabular}

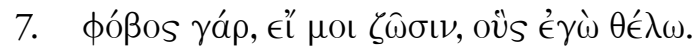

8. So then, are we to fear this [man], whom fortune and the divine demonstrate [to be] an unprofitable friend and an appropriate foe?

\begin{tabular}{|c|c|}
\hline So then, ...; & $\epsilon \hat{\imath} \tau a \ldots ;$ \\
\hline divine & 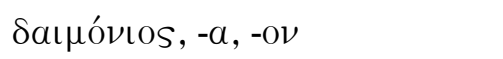 \\
\hline to demonstrate & $\dot{\epsilon} \mu \phi \alpha \nu \nu^{\prime} \zeta \in \iota \nu$ \\
\hline unprofitable & $\lambda v \sigma \iota t \in \lambda \eta \dot{s}$, , -́́s \\
\hline appropriate & $\begin{array}{l}\sigma v \mu \phi \epsilon ́ \rho \omega \nu,-o v \sigma \alpha,-o \nu \text { (Partc. as } \\
\text { ordinary adj.) }\end{array}$ \\
\hline
\end{tabular}

9. $\ldots$ and I would be afraid to follow the guide whom he gave, in case he led us [to a place] from where it will not be possible to go out.

\begin{tabular}{ll}
\hline guide & $\dot{\eta} \gamma \in \mu \omega \dot{\omega} \nu,-o ́ \nu 0 s, \dot{o}$ \\
gave, led & Both terms refer to a future possibility. \\
in case & $\mu \dot{\eta}+$ Subj. \\
\hline
\end{tabular}





\section{LESSON 36 \\ Nominative and Vocative Cases}

\subsection{Nominative as Subject}

The primary function of the Nominative Case is to express the Subject of a finite verb.

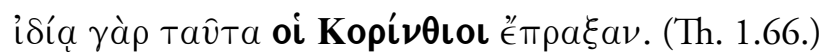

For the Corinthians did this independently.

\subsection{Nominative as Complement}

The Nominative also expresses the Complement of verbs such as 'to be', 'to become', or 'to seem (to be)'. The Complement refers back to the Subject.

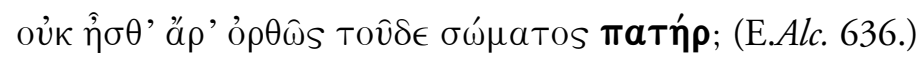

Were you, then, not genuinely father of this person?

The noun Complement refers back to the Subject contained within the verb $\hat{\eta} \sigma \theta a$.

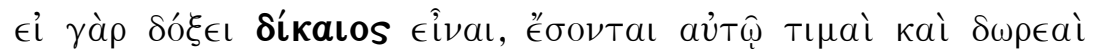

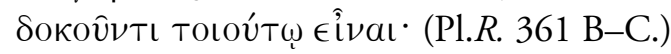

For if he is going to seem to be just, there will be honours and gifts for him as seeming to be such.

The adjectival Complement refers back to the Subject contained within the verb $\delta$ ó $\xi \in \mathrm{l}$. 


\subsection{Predicate Nominative with Passive Verb}

Some verbs in the Active Voice may take a double direct Object, where the second Accusative term is a predicate of the first.

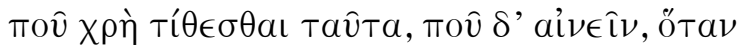

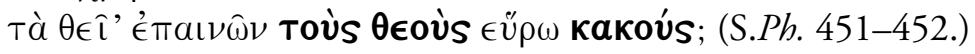

How should I regard this, and how approve, when

while I praise the <actions > of the gods I find the gods nasty?

кakoús (without article) refers back to Toùs $\theta \in$ oús (with article).

If such Active constructions are transposed to the Passive Voice, the first Accusative becomes the Subject and the predicate Accusative becomes a predicate Nominative.

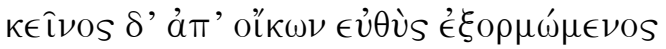

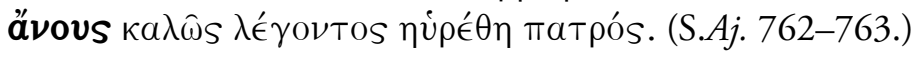

But that <man $>$, as soon as he was setting out from home, was found $<$ to be $>$ senseless, although his father spoke well.

The Active equivalent of this expression would be: 'they found that $<$ man $>$ $<$ to be $>$ senseless'. In the actual Passive expression, the first Accusative ('that $<$ man>') becomes the Subject; and the predicate Accusative ('senseless') becomes a predicate Nominative (ävous).

\subsection{Quoted Nominative}

A term may be quoted in the Nominative, even if the syntax of its clause requires another Case (usually Acc., in practice). Sometimes, the quoted term appears without introduction, or preceded only by the neuter singular definite article Tó (regardless of the Number and Gender of the quoted term itself). Sometimes, a word such as övo $\mu a$ ('term') or $\sigma v ́ \nu \theta \eta \mu a$ ('watchword') introduces the quoted term.

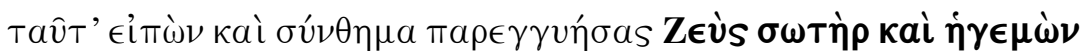

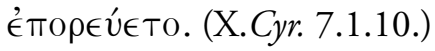

After saying this and passing along the watchword 'Zeus saviour and leader', he moved on. 


\subsection{Nominative Address}

Nominative forms are sometimes used with a Vocative function. (In poetry there may be metrical reasons for this usage.) In the following sentence, $\sigma \tau v \gamma \nu$ ós is unambiguously Nominative: the Vocative form is

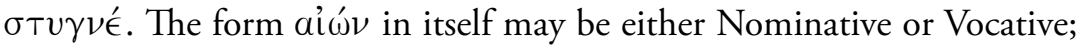
but, following $\sigma \tau u \gamma \nu$ ós, it is to be understood as Nominative. The Main

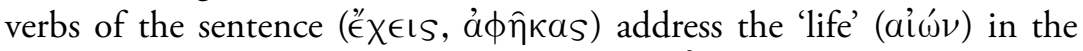

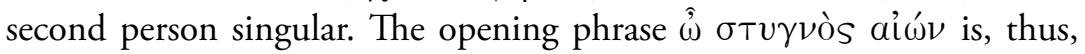
a Nominative address, not an exclamation.

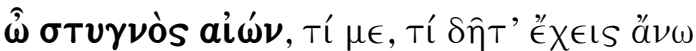

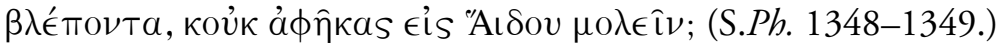

O hateful life, why, why indeed do you keep me up here seeing < the light of day>, and <why> did you not allow me to go to <the house $>$ of Hades?

\subsection{Nominative Exclamation}

In the following quotation, there is no Main verb. In the long opening phrase, all nouns and adjectives, except one, are unambiguously Nominative. The form $\nu v \mu \phi \in \hat{\imath} 0 \nu$, therefore, which could in itself be either Nominative or Vocative, should be understood as Nominative. The opening phrase is thus a Nominative exclamation.

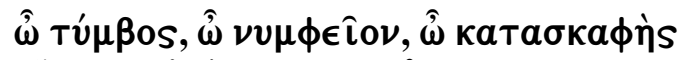

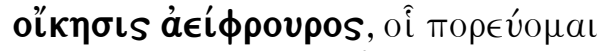

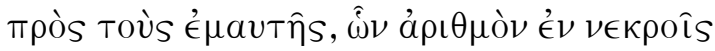

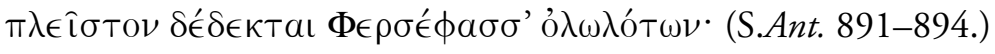

$O$ tomb, $O$ bridal chamber, $O$ deep-hollowed

dwelling ever-guarding, to where I am going

to my own <relatives>, the largest number of whom,

having perished, Persephone has received among the dead. 


\subsection{Vocative}

The Vocative Case is used to address someone or something. It is isolated from the syntax of the sentence in which it occurs. Hence, it has sometimes been regarded as 'not really a case'. However, the forms of the Vocative are just as much a part of the inflexion of nouns and adjectives as the other Cases. But again, the Vocative uses the shortest form of the stem of nouns and adjectives. And, although some subtypes of the three main declensions have separate forms for the Vocative, other subtypes use the same form as the Nominative. For example, $\alpha \nu \theta \rho \omega \pi \epsilon$ (2nd declension

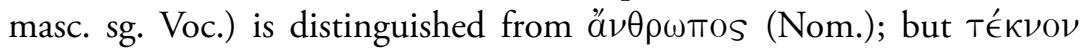
(2nd declension neut. sg.) serves both as Nominative and as Vocative.

Vocative forms are frequently preceded by $\hat{\dot{\omega}}$. (Conventionally, $\hat{\dot{\omega}}$ is used with Vocatives, and $\ddot{\omega}$ with exclamations. But this convention is not consistently observed in manuscripts and printed texts.) Especially where there are not separate forms for Nominative and Vocative, a preceding $\hat{\omega}$ helps to indicate the function of a Vocative phrase.

Typically, a Vocative is placed after the opening phrase of a sentence in order to catch the addressee's attention. However, since the positions of primary and secondary emphasis in a sentence are the beginning and the end, a Vocative may occur first or even last. When a Vocative phrase is placed first in a sentence, a connective particle may be delayed until after the Vocative.

In addition to its basic function, a Vocative phrase may mark the beginning of a new paragraph in speeches. For example, $\hat{\omega} a ̈ \nu \delta \rho \in S$ is used after the opening phrase at Andocides 1.1, 3, 5, 6, 8, 10, etc.

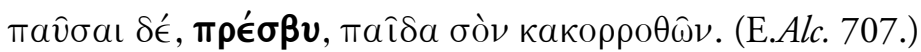

And stop, old man, abusing your son.

Simple Voc. after opening phrase.

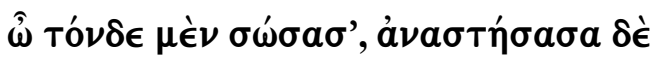

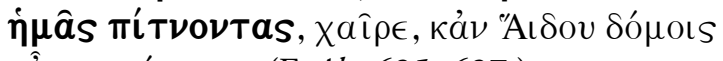

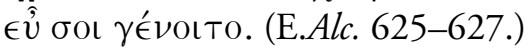

O you who saved this <man>, and raised us up

when we were falling, farewell, and may it go well for you

in the house of Hades.

Elaborate Voc. with $\hat{\omega}$ and Participial phrases at beginning of sentence. 


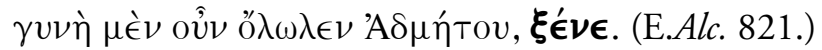

No, <it is $>$ the wife of Admetus $<$ who $>$ has perished, friend.

Simple Voc. at end of sentence (in stichomythia).

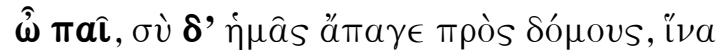

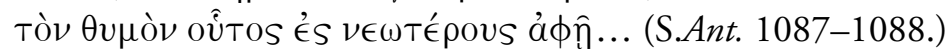

But you, $\boldsymbol{O}<\boldsymbol{m y}>$ boy, lead us away to our home, so that this man may vent his anger on younger people ...

Connective particle $\delta \in ́$ delayed until after opening Voc.

\subsection{Hanging Vocative}

Some Vocative phrases are left 'hanging' without a proper Main clause. This may happen when an opening Vocative phrase is immediately followed either by an explanatory clause with $\gamma \alpha$ á $\rho$, or by an adjectival or adverbial clause.

'Ахє

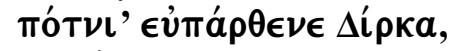

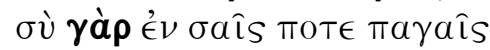

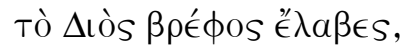

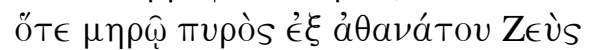

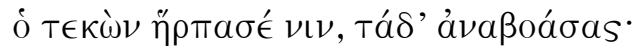

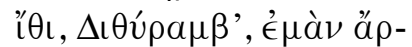

$\sigma \in \nu a$ Tá $\nu \delta \in \beta a ̂ \theta \imath \nu \eta \delta u ́ v$.

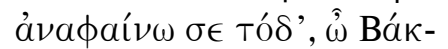

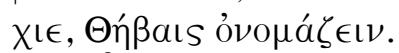

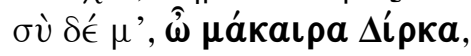

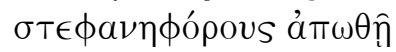

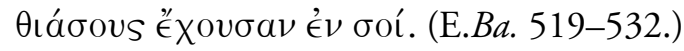

\section{Achelous's daughter,}

virgin queen Dirce, <I invoke you>;

for you once received in your waters

the infant-child of Zeus,

when Zeus who begot him snatched him

from the immortal fire <and put him > in his thigh, letting out this cry:

'Come, Dithyrambos, enter this 
male womb of mine;

I proclaim to Thebes, O Bacchius,

that I call you by this name'.

But you thrust me away from yourself,

O blessed Dirce, when I hold

my garlanded celebrations on you $<r$ banks $>$.

In this passage, the Chorus of Bacchants address the river Dirce and then immediately explain why they are invoking the addressee. The construction drifts away from the Vocative by way of the explanatory clause with $\gamma a \dot{\alpha} \rho$, a Temporal clause with ö $\tau \epsilon$ and direct quotation of the cry of Zeus. At this point, the Chorus state their complaint against Dirce ('But you thrust me away ...') and renew the Vocative in briefer form ('O blessed Dirce').

\section{¡ì $\delta a \hat{\imath} \mu o \nu$,}

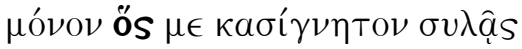

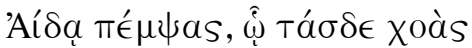

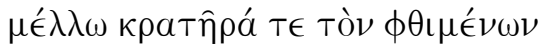

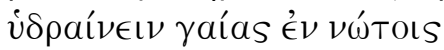

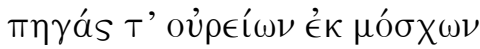

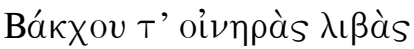

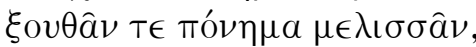

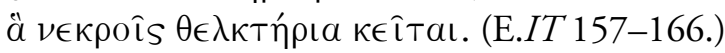

\section{Ah, deity,}

who, by sending <him> to Hades, rob<bed> me

of my only brother, for whom I am going to sprinkle

on the surface of the earth this

bowl of liquid-offerings for the departed:

streams from the mountain heifers

and libations of the wine of Bacchus

and produce of the busy bees,

which are appointed as charms for the dead.

Hanging Vocative with adjectival clause. 


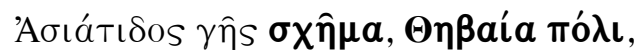

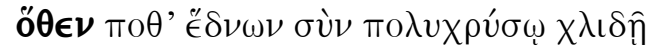

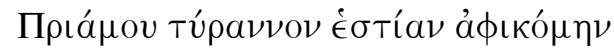

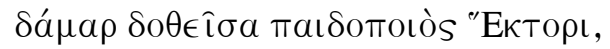

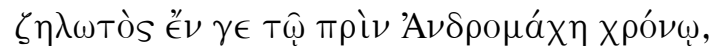

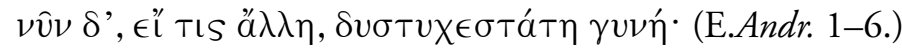

Form of the Asian land, city of Thebe,

from where once with the glory of my dowry rich-in-gold

I came to the royal hearth of Priam

given as wife to produce children for Hector,

Andromache, to be envied at least in that early time,

but now, if anyone else <is>, a most unfortunate woman.

Hanging Vocative with adverbial clause.

\section{References}

Denniston (1954), The Greek particles, pp. lx, 189 (on postponement of connective particles in sentences beginning with a Vocative, exclamation or oath); 60 ( $\gamma a ́ \rho$ clauses explaining what has just been said, including hanging Vocatives).

Smyth (1956), Greek grammar, \$\$907, 917-918, 927, 938-945, 973-974 (Nominative); 949-972 (variations of agreement in Number between Subject and Predicate); 1283-1288 (Vocative).

\section{EXERCISE 36}

1. Translate the following passages.

2. Indicate for each term or phrase printed in bold type:

- whether it is Nominative or Vocative in function

- whether, if Nominative (except Nom. Address), it is Subject, Complement, predicative Nominative or quoted Nominative, and with which verb (citing the form in the text) it is constructed

- whether, if Vocative, it is a particular usage (hanging Voc., initial Voc. with delayed connective particle, etc.)

- whether there are contextual grounds for deciding the function of any examples which are ambiguous in form. 


\section{Example}

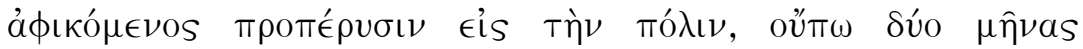

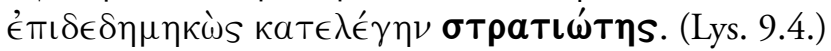

Having arrived the year before last in the city, when I had not yet been in residence for two months I was enlisted <as $>$ a soldier.

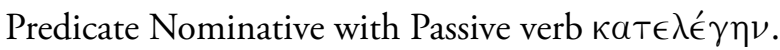

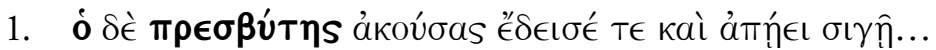

\begin{tabular}{ll}
\hline$\pi \rho \in \sigma \beta u ́ t \eta s,-o v, \dot{o}$ & old man \\
$\delta \in \hat{\imath} \sigma a ı$ (Aor.) & to become afraid
\end{tabular}

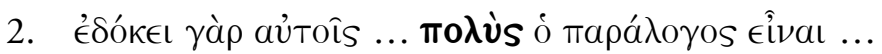

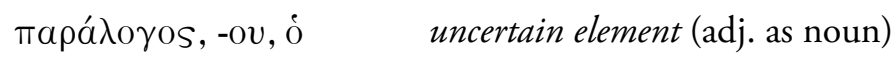

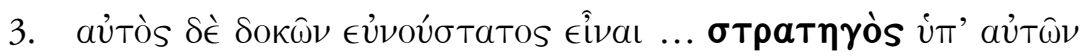

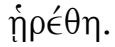

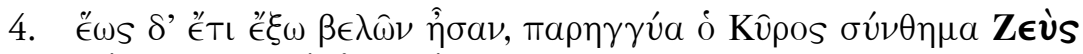

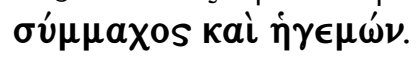

$\epsilon^{\prime} \xi_{\omega} \quad$ outside <the range of

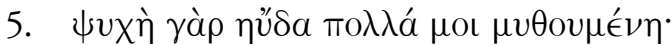

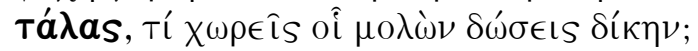

aủઠâv to speak out (here Intr.)

$\mu v \theta \in \hat{\imath} \sigma \theta a \iota$ (Mid.) to converse (+ internal Acc. and Dat.)

6. $\phi \epsilon ́ \rho \in \delta$,

$\phi \epsilon ́ \rho \in \delta \dot{n} \quad$ well now (+ rhetorical question)

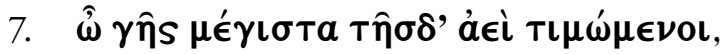

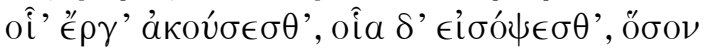

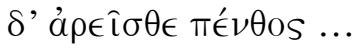

al $\rho \in \sigma \theta a \mathrm{u}$ (Mid.) to take upon oneself 


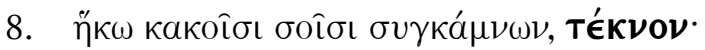

9. ìñ̈

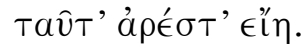

\begin{tabular}{|c|c|}
\hline $\begin{array}{l}\text { ińïos, }(-\alpha,)-o \nu \\
\text { à } \rho \in \sigma \tau o ́ s,-\alpha a,-o ́ v\end{array}$ & $\begin{array}{l}\text { healing } \\
\text { pleasing (accent affected by elision) }\end{array}$ \\
\hline
\end{tabular}

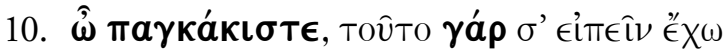

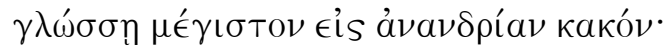





\section{LESSON 37 \\ Accusative Case}

\subsection{Accusative as Direct Object}

\subsubsection{Simple Direct Object}

The most basic function of the Accusative Case is to express the direct Object of a verb.

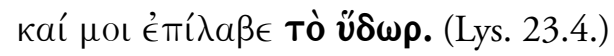

And please stop the water(-clock).

\subsubsection{Predicate Accusative}

A second Accusative term may be added to the simple direct Object after factitive verbs such as 'to make', 'to appoint', 'to think', 'to call' (somebody something). (Cf. Lesson 36.3.)

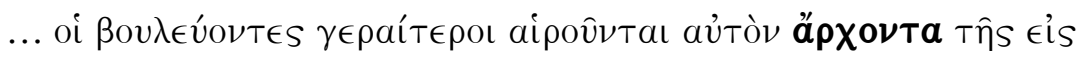

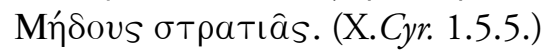

... the elders sitting in council chose [Hist. Pres.] him commander of the expedition to the Medes.

\subsubsection{Double Object}

Some verbs may have a double Object, where the second Accusative is not predicative. Frequently, the first Object is a person, the second a thing, for example, 'to teach' somebody something, 'to ask' somebody something and (in Greek) 'to deprive' somebody (of) something or 'to conceal' something (from) somebody. 


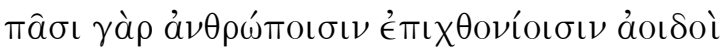

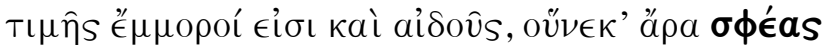

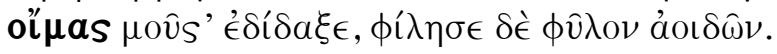

(Hom.Od. 8.479-481.)

For among all people on the earth singers

are participants in honour and respect, just because the muse

taught them the ways <of singing $>$, and loved the race of singers.

The second Object is an ordinary noun.

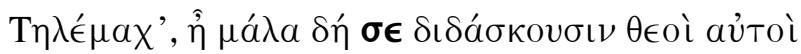

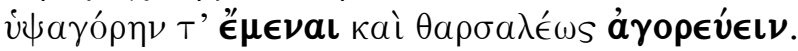

(Hom.Od. 1.384-385.)

Telemachus, assuredly the gods themselves are teaching you to be a boaster and to speak boldly.

The second Object is a pair of Infinitive phrases (i.e. verbal noun phrases).

\subsubsection{Retained Accusative}

When a verb, which may take a double Object of person and thing, is used in the Passive Voice, the person becomes the Subject and the thing is 'retained' in the Accusative.

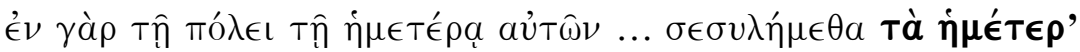

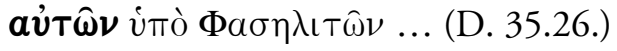

For in our own city ... we have been robbed of our own $<$ possessions $>$ by the people of Phaselis...

Active equivalent: 'The people of Phaselis have robbed us of our own $<$ possessions >’ (double Acc.).

An equivalent Passive construction may be used with verbs, which in the Active take a direct Object of the thing in the Accusative and an indirect Object of the person in the Dative. For example, $\epsilon^{\prime} \pi \iota \tau \epsilon^{\prime} \lambda \lambda \epsilon \iota \nu$ in the Active Voice may mean 'to give instructions (Acc.) to someone (Dat.)'. 


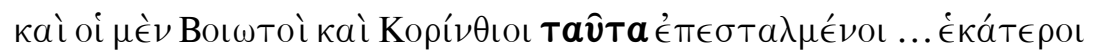
àveXúpovv. (Th. 5.37.1.)

And the Boeotians and the Corinthians, having been given these instructions ... both withdrew.

Active equivalent: 'having given these instructions to the Boeotians and Corinthians' (Acc. and Dat.).

\subsubsection{Accusative with a Phrase Equivalent to a Verb}

An Accusative term sometimes provides a virtual direct Object for a phrase, in which a verb with Object is equivalent to a simple verb.

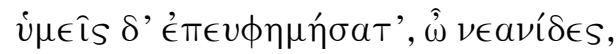

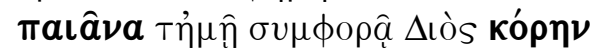

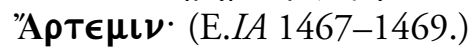

But you, O young women, sing

praise $<$ to $>$ the daughter of Zeus, Artemis, for my

situation.

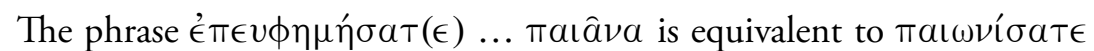
('praise') with direct Object кó $\eta \nu$ 'А $\rho \tau \epsilon \mu \nu$. Some scholars prefer to explain this construction in terms of a noun directly dependent on another noun (of action), without reference to a verb.

\subsubsection{Accusative of Whole and Part}

Sometimes a direct Object is more narrowly defined by a second Accusative in apposition with it. The usage is mainly poetic.

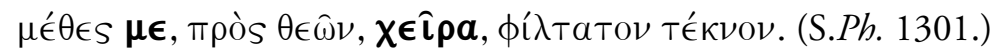

Let me go, by the gods, <let go my> hand, dearest boy.

\subsubsection{Cognate Accusative}

So far in this Lesson, all examples in $\$ \$ 37.1 .1-3$ and 37.5-6 have contained 'external' or 'affected' Objects. The action of the verb is exercised upon an already existing person or thing. An 'internal' or 'effected' Object denotes the content or result of the action of the verb: the grammatical Object 
does not exist until the action of the verb takes place. Usually such an internal or effected Object is a noun either etymologically or conceptually related to (or 'cognate' with) the verb whose Object it is. Otherwise, the cognate Accusative may be a demonstrative or relative adjective used as a pronoun.

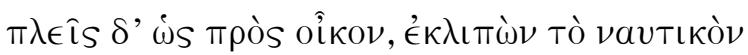

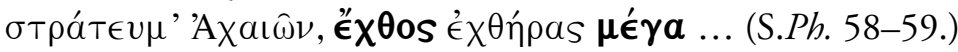

And you are sailing as for home, leaving the naval expedition of the Achaeans, having developed a great hatred ...

The Accusative é $\chi \forall$ os is etymologically cognate with éX

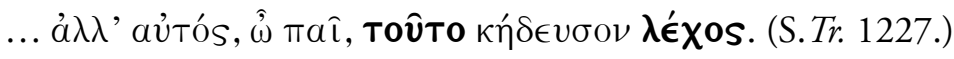

... but you yourself, my boy, undertake this marriage.

The Accusative $\lambda \operatorname{é} \chi O S$ is conceptually cognate with $\kappa \dot{\delta} \delta \in v \sigma O \nu$.

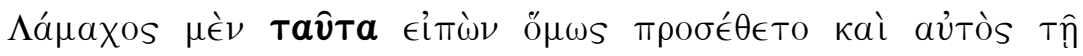

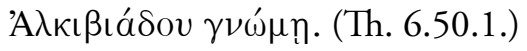

Although having made these statements, Lamachus himself nevertheless sided with the opinion of Alcibiades.

The internal Accusative of the demonstrative adjective Tav̂Ta refers to the content of the verb. (In the second example in $\$ 37.1 .4$ above, Tav̂Ta is a retained internal Acc.)

Verbs sometimes have both an internal and an external Object. Verbs meaning 'to divide, to distribute' belong to this group.

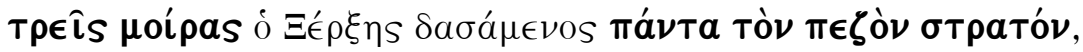

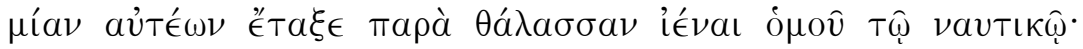
(Hdt. 7.121.2.)

Dividing all the infantry force <into $>$ three parts, Xerxes appointed one of them to go along the sea<-coast> parallel with the fleet.

The 'infantry force' existed before the division was made (external Object), but the 'three parts' did not exist until the division was made (internal Object). 


\subsubsection{Oaths}

Verbs of swearing take various Objective constructions:

1. to swear to do something (mostly Intentive/'Fut.' Infin.), or that one is doing something (Imperf. Infin.), or did something (Aor. Infin.), or would have done something (Aor. Infin. with ö $\nu$ ) or that one has done something (Perf. Infin.). See Lesson 16.3.

2. (a) to swear an oath (internal Acc.).

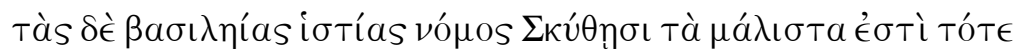

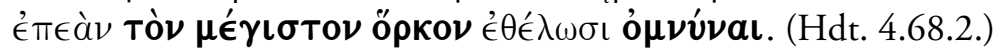

And it is the custom for the Scythians generally to swear by the king's hearth(s) then, when(ever) they want to swear the most serious oath.

(b) to swear to something, to confirm by oath (external Acc.).

єi

For he had sworn to peace.

(c) to swear by someone or something (external Acc.).

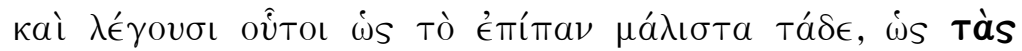

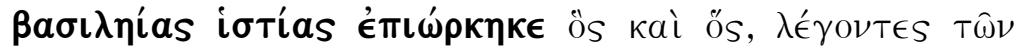

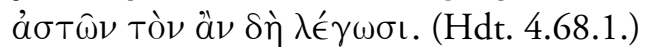

And these [Scythians] for the most part generally say this, that so and so (stating whoever they actually state of the townsmen) has sworn falsely by the king's hearth(s).

3. An oath formula may also be used parenthetically in the Accusative. Various positive, negative or neutral particles may precede the oath.

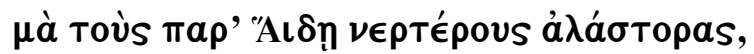

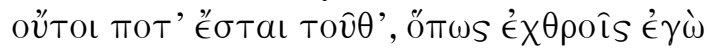

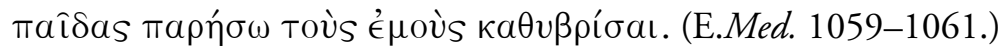

\section{By the avengers below with Hades,}

this will certainly not ever be, that I should give up

my own children for my enemies to maltreat. 


\subsection{Adverbial Uses of the Accusative}

Several uses of the Accusative are more appropriately regarded as adverbial, expressing relationships of space, time, manner, degree and respect.

\subsubsection{Accusative of Goal (or 'motion towards')}

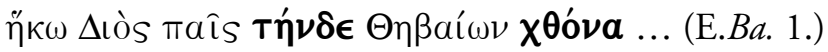

I have come the son of Zeus to this land of the Thebans...

This usage is poetic.

\subsubsection{Accusative of Extent of Space}

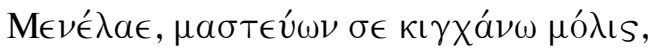

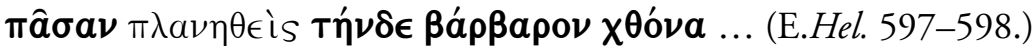

Menelaus, in my search I scarcely <manage to $>$ reach you, after wandering all over this foreign land ...

General area.

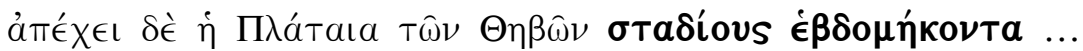
(Th. 2.5.2.)

And Plataea is distant seventy stades from Thebes...

Specific distance. $(70$ stades $=$ c. $13 \mathrm{~km}$.

\subsubsection{Accusative of Extent of Time}

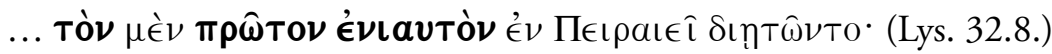

... they lived for the first year in the Piraeus.

\subsubsection{Accusative of Manner}

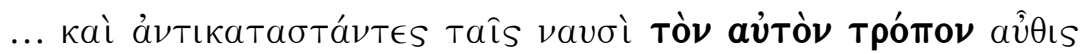

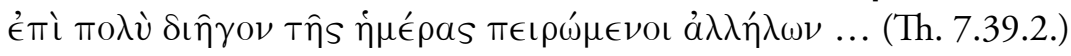

... and taking their stand in opposition with their ships, in the same way they again continued for a large part of the day making attempts on each other... 


\subsubsection{Accusative of Degree}

Degree is often expressed by the neuter Accusative singular or plural of adjectives of size and number, indefinite adjectives or negative adjectives.

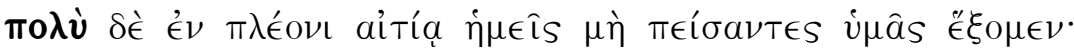
(Th. 1.35.4.)

But we shall hold you much more at fault if we do not persuade you.

moגú (adverbial Acc. of Degree) modifies the Comparative adjective $\pi \lambda \epsilon ́ \mathrm{O \nu}$.

\subsubsection{Accusative of Respect}

With verbs used intransitively or in the Passive Voice or with adjectives, the Accusative may denote the respect in which the verb or adjective is defined. The usage ranges from the completely general ('in all respects'), through spheres of activity or attributes, to the body or especially a part of the body.

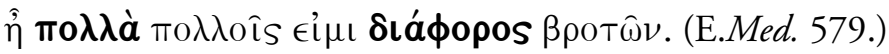

Certainly in many respects I am in disagreement with many among mortals.

General; with adjective.

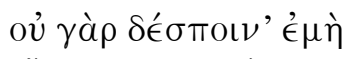

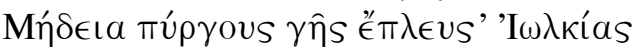

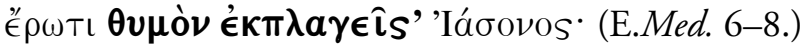

\section{For my mistress Medea}

would not have sailed to the ramparts of the land of Iolcus, struck in her heart with love for Jason.

Particular; with Pass. Partc.

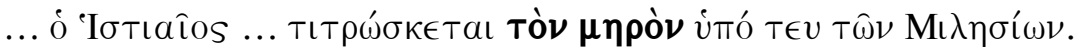
(Hdt. 6.5.2.)

... Histiaeus ... was wounded in the thigh by one of the Milesians.

Here the Accusative of Respect denotes the part of the body of Histiaeus which 'was wounded' (Pass.; Hist. Pres.). Although this usage has been classified as adverbial, it is essentially the Passive form of the Accusative of 
whole and part (classified as direct Object at $\$ 37.1 .6$ above). The Active form of the present sentence would be: 'One of the Milesians wounded

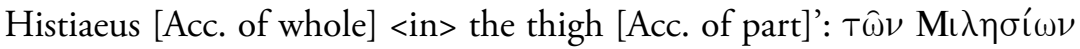

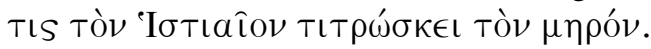

\subsection{Accusative in Apposition to a Sentence}

Sometimes, an Accusative appears to be independent of its sentence and to refer to a phrase, clause or even all the rest of the sentence. For some instances, the rationale of an 'internal Accusative' is plausible. In other instances, the Accusative may be regarded as being in apposition with another Accusative (or Object Infin.). But sometimes these explanations seem strained, except as background to a stereotyped construction.

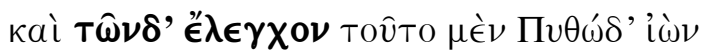

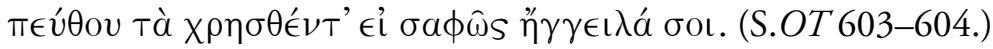

And as proof of this, first go to Pytho

and inquire, whether I clearly reported the oracle to you.

Creon is addressing Oedipus. 'This' is Creon's claim that he has no designs on the kingship of Thebes. 'First' translates tôิTo $\mu$ '́ $\nu$ (an adverbial Acc.). The first item of 'proof' is finding out whether Creon clearly reported the oracle to Oedipus. Thus, the whole content of the sentence after the 'Accusative in apposition' constitutes the 'proof'. '€ $\lambda \epsilon \gamma \chi O \nu$ is not in apposition with any other Accusative in the sentence, and it hardly provides an 'internal Accusative' for any verbal element in the sentence.

\section{References}

Smyth (1956), Greek grammar, \$\$985, 991, 1551-1635, 2894 ( $\mu$ á); 2922 (vaí); 2923 ( $\nu \eta ́)$.

\section{EXERCISE 37}

Translate the following passages. Comment briefly on the function of the Accusative phrases in bold type in each passage, for example, direct Object of what verb (citing the form in the text), Accusative in apposition with (the rest of) the sentence. 


\section{Example}

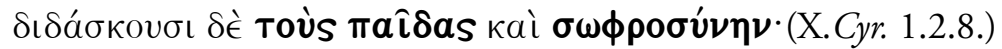

And they teach their children moderation also.

Double direct Object of $\delta ı \delta a ́ \sigma \kappa o v \sigma \iota$, person and thing.

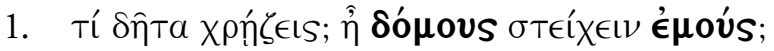

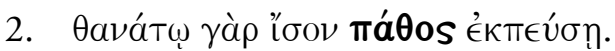

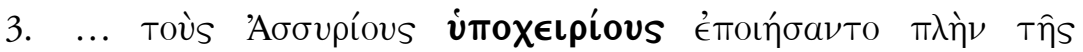

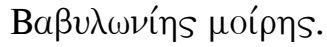

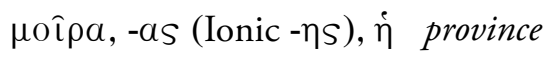

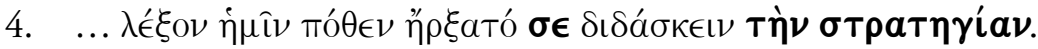

Tó $\theta \in \nu$ how

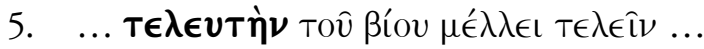

$\mu \epsilon \in \lambda \lambda \in \mathrm{T}$ The Subject is masc.

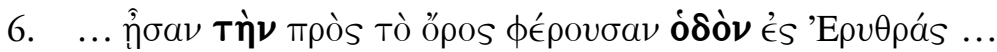

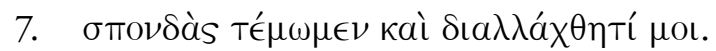

$\sigma \pi \mathrm{o \nu} \delta \dot{\eta},-\hat{\eta} s, \dot{\eta}(\mathrm{pl}$.$) \quad agreement, treaty$

Té $\mu \nu \in \mathrm{IV}$ to make peace

$\delta \iota a \lambda \lambda a ́ \sigma \sigma \epsilon \mathrm{l \nu}$ (usu. mid.) to speak

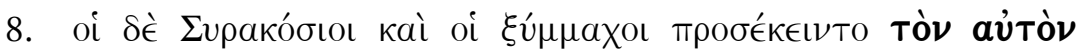

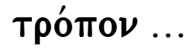

$\pi \rho \circ \sigma \kappa \in \hat{\imath} \sigma \theta a \iota$

to press hard (upon) (+ Dat., when

expressed)

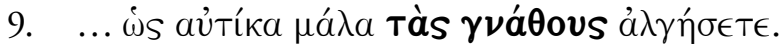

\begin{tabular}{|c|c|}
\hline is & how ...! (exclamatory with $\dot{a} \lambda \gamma \eta \dot{\eta} \sigma \in T \epsilon)$ \\
\hline$\gamma v a ́$ oos, -ov, $\dot{\eta}$ & jaw \\
\hline
\end{tabular}




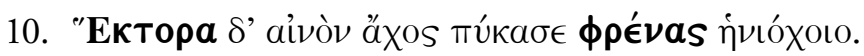

\begin{tabular}{|c|c|}
\hline$\pi u \kappa a ́ \zeta \in ı \nu$ & to cover \\
\hline ウ̇víoxos, -ov (-olo), ó & charioteer \\
\hline
\end{tabular}

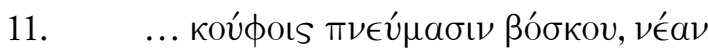

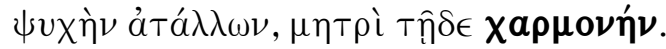

\begin{tabular}{|c|c|}
\hline 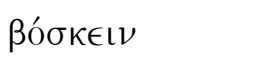 & to feed (here Pass.) \\
\hline$a^{\top} \operatorname{Tá} \lambda \lambda \in \mathrm{\iota} \nu$ & to nurture, to rear \\
\hline 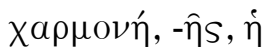 & joy \\
\hline
\end{tabular}

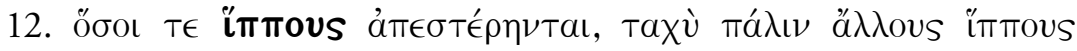

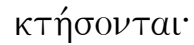

$\tau \epsilon$ Joins this sentence to the preceding

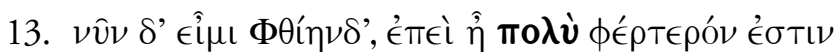

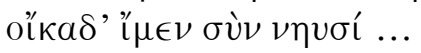

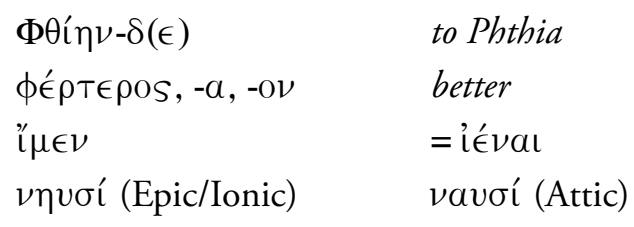




\section{LESSON 38 \\ Genitive Case 1}

\subsection{Introduction}

This Lesson deals with Genitive phrases which qualify a noun or pronoun; hence, they are sometimes called 'adnominal' Genitives. The function of such phrases is similar to that of an adjective; hence, they are also sometimes called 'adjectival' Genitives. All types of usage in this Lesson are basically Possessive.

\subsection{Simple Possessive Genitive}

The qualified noun belongs to the person or thing denoted by the Genitive phrase.

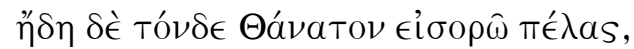

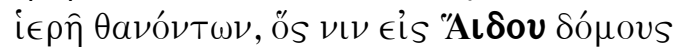

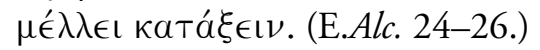

And now I see Death here nearby, priest of the dead, who is going to lead her down to the house of Hades.

The 'house' belongs to 'Hades'.

\subsection{Subjective Genitive}

Many Genitive phrases of a generally 'possessive' type may be subdivided as either 'Subjective' or 'Objective'. The Subjective Genitive corresponds to the Subject of a verb equivalent in meaning to the qualified noun.

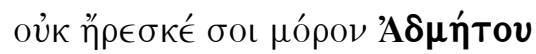

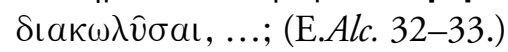


Was it not sufficient for you to prevent the fate of Admetus...?

'Admetus' (Subject) was due to suffer his 'fate'.

\subsection{Objective Genitive}

The Objective Genitive corresponds to the Object of a verb equivalent in meaning to the qualified noun.

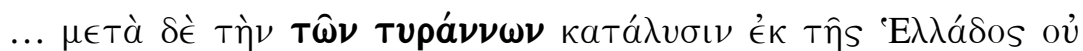

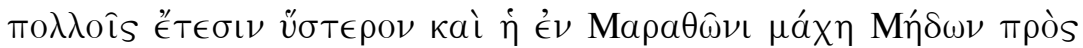

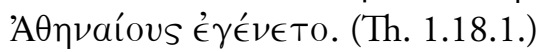

... and after the removal of the tyrants from Greece, not many years later the battle at Marathon of the Persians against the Athenians also took place.

The Spartans 'removed' 'the tyrants' (Object) from Greece.

\subsection{Partitive Genitive}

The Partitive Genitive denotes the whole class of which the qualified noun forms a part.

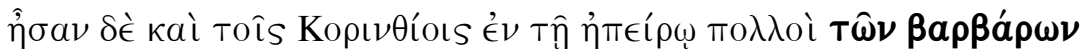

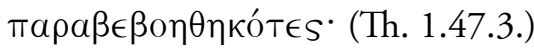

And many of the foreigners, having come to help, were also <available $>$ on the mainland for the Corinthians.

The 'many' constitute a part of the total number of 'the foreigners'.

\subsection{Genitive of Definition (or Apposition)}

The Genitive of Definition is a more specific term which defines a more general word. Since both terms refer to the same reality, this usage is also called the Genitive of Apposition.

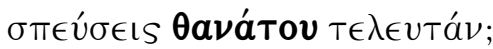

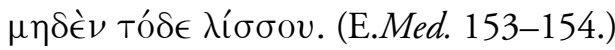


Will you hasten the end that is death?

Make no prayer for this.

The 'end' is more closely defined as 'death'.

\subsection{Genitive of Description (or Quality)}

The Genitive of Description or Quality expresses the character or purpose of the qualified noun.

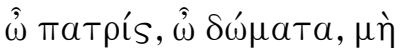

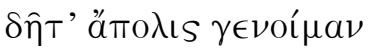

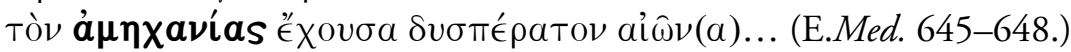

O fatherland, O home, may I certainly

not become city-less,

having that life of helplessness, hard to cross over...

'Helplessness' indicates the character of 'that life'.

\subsection{Genitive of Material}

The Genitive of Material (as also of Measure, and of Price or Value) may be considered a subtype of the Genitive of Description. The Genitive of Material indicates what the qualified noun is made of, or consists of.

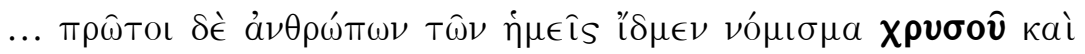

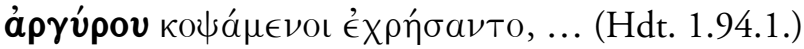

... and they first among men whom we know stamped coinage of gold and of silver and used it ...

The material of the 'coinage' is 'gold' and 'silver'. (Ionic T⿳亠丷⿵ $\nu=$ Attic $\hat{\omega} \nu$,

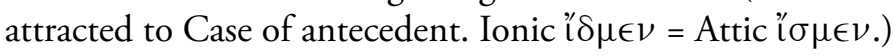




\subsection{Genitive of Measure}

The Genitive of Measure describes the qualified noun by indicating its size or duration.

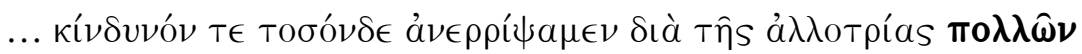

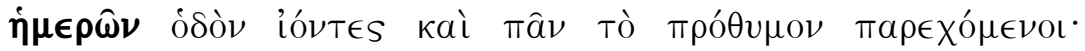
(Th. 4.85.4.)

... we ran so great a risk by travelling on a journey of many days through enemy territory and while showing all eagerness.

The 'many days' indicate how much time the 'journey' takes.

\subsection{Genitive of Price or Value}

The Genitive of Price or Value describes the cost or worth of the qualified noun.

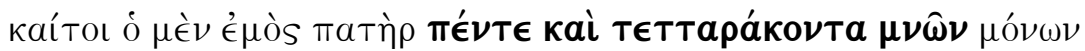

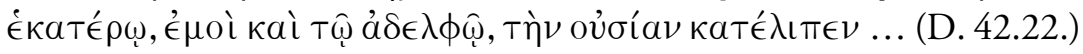
And yet my father bequeathed to each, my brother and me, the estate of forty-five minae only...

The 'estate' was worth 'forty-five minae'.

\section{References}

Smyth (1956), Greek grammar, \$\$1289-1338.

\section{EXERCISE 38}

Translate the following passages. Briefly indicate the particular function of the Genitive phrases in bold type. For example, Partitive Genitive, Genitive of Material, etc. In passages 2 and 3, the Genitive phrases are either Subjective or Objective; briefly indicate the reason for your choice between these two possibilities. 


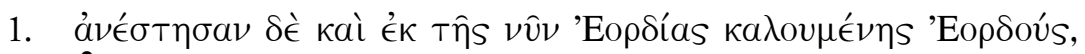

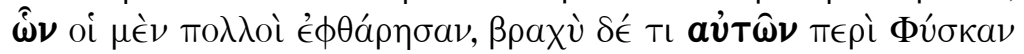

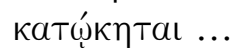

ávıтával to remove (people from a place)

$\beta \rho a \chi v ̀$... Tı (Nom. adj.) Understand a noun such as group.

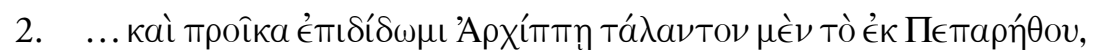

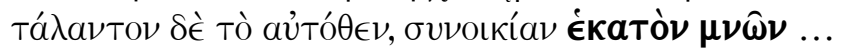

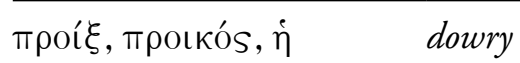

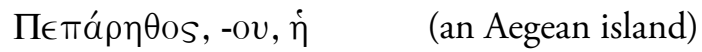

au่тó $\theta \in \nu$ (adv.) from here (referring to Athens)

ovvoเкía, -as, $\dot{\eta} \quad$ tenement house

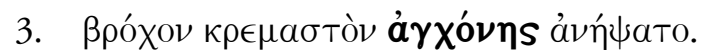

ávíłaто The implied Subject is fem.

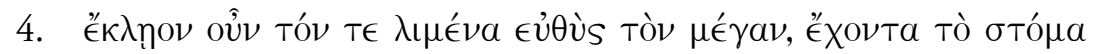

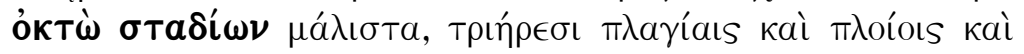
ákátoıs ...

\begin{tabular}{|c|c|}
\hline$\kappa \lambda \eta ̣ \in \in \mathrm{I \nu}$ & to shut up, to block (here 3rd pers. pl.) \\
\hline$T \epsilon$ & $\begin{array}{l}\text { Anticipates a kaí (not quoted); } \\
\text { need not be translated. }\end{array}$ \\
\hline 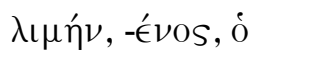 & harbour \\
\hline$\mu a ́ \lambda ı \sigma т a$ & approximately \\
\hline$\pi \lambda a ́ \gamma \cos ,(-a)-,\mathrm{o \nu}$ & placed sideways, broadside on \\
\hline áкaтоs, -оv, $\dot{\eta}(\dot{o})$ & light vessel \\
\hline
\end{tabular}

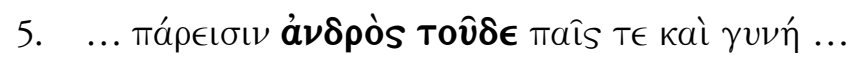

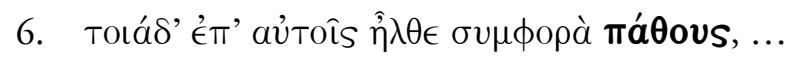

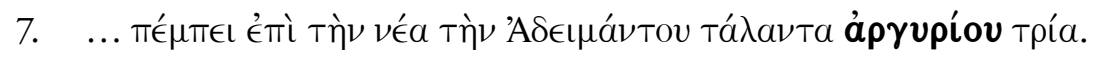

\begin{tabular}{|c|c|}
\hline$\pi \epsilon^{\prime} \mu \pi \epsilon \mathrm{l}$ & Hist. Pres. \\
\hline 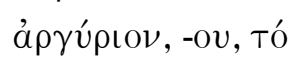 & silver \\
\hline
\end{tabular}


INTERMEDIATE ANCIENT GREEK LANGUAGE

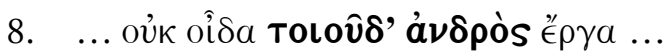

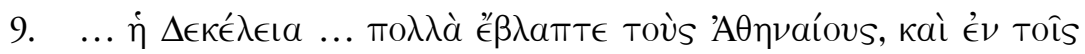

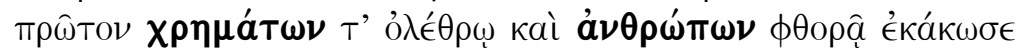
тà $\pi \rho a ́ \gamma \mu \alpha \tau a$.

\begin{tabular}{|c|c|}
\hline 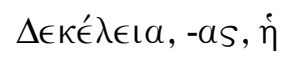 & Decelea (place) \\
\hline то入入а́ & internal Acc. \\
\hline ÉV Tô̂s $\pi \rho \hat{\omega}$ ToV & in the first place \\
\hline$\phi \theta$ o $\rho a ́,-a ̂ s, \dot{\eta}$ & annibilation \\
\hline
\end{tabular}




\section{LESSON 39 \\ Genitive Case 2}

\subsection{Introduction}

This Lesson deals with Genitive constructions which are used with verbs, adjectives and adverbs. The function of such phrases is similar to that of an adverb; hence, they are sometimes called 'adverbial' Genitives. Some of the basically Possessive functions (including Partitive), which were treated in Lesson 38, may also be used predicatively with verbs. In addition, the Genitive of Separation (or Ablatival Gen.) includes a number of other particular functions.

\subsection{Possessive Genitive}

\subsubsection{Complement and Equivalent of Predicate Nominative}

The simple Possessive Genitive may be used predicatively as Complement of verbs meaning 'to be', 'to become', 'to seem'; and, as the equivalent of a predicate Nominative, with the Passive of verbs (whose Act. may take a predicate Acc.), such as 'to be called', 'to be considered'. (Cf. Lesson 36.2 and Lesson 36.3.)

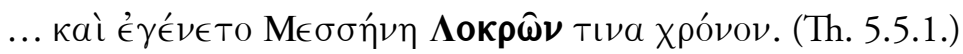

... and Messene became < the possession $>$ of the Locrians for some time.

Complement of É $\gamma$ '́v $\in$ To.

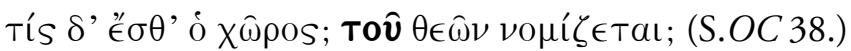

And which is the place? To which of the gods is it regarded <as belonging>?

Equivalent of predicative Nominative, with the Passive verb $\nu$ o $\mu$ í $\zeta \in$ Tl. 


\subsubsection{Complement to an Infinitive Subject}

The simple Possessive Genitive may be used predicatively as Complement of the verb 'to be', where the Subject is an Infinitive phrase. This idiom expresses the idea: 'It is the nature/responsibility/habit etc. of someone to do something'. (Grammatically: 'To do something is <the nature etc.> of someone'.)

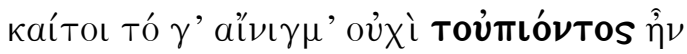

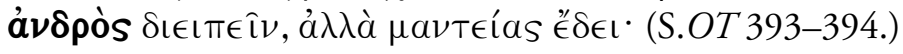

And yet it was not <the responsibility> of any man who came along to expound the riddle, but there was need of prophecy.

\subsubsection{Equivalent of Predicative Accusative}

The simple Possessive Genitive may be used with the Active of verbs meaning 'to think', 'to make', 'to appoint', etc. as the equivalent of a predicative Accusative. (Cf. Lesson 37.1.2.)

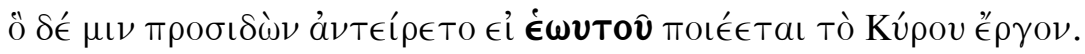
(Hdt. 1.129.2.)

And he, looking at him, asked in turn whether he regarded the action of Cyrus as his own.

\subsubsection{Genitive of Material}

The Genitive of Material may modify a verb and indicate what something is made of. The Genitive may be a Complement of the verb 'to be' or the equivalent of a predicative Accusative with verbs such as 'to make'. (Cf. Lessons 36.2 and 37.1.2.)

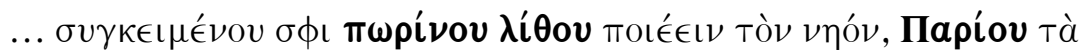

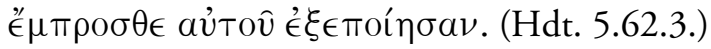

... although it had been agreed for them to make the temple of limestone, they made the front of it of Parian <marble $>$.

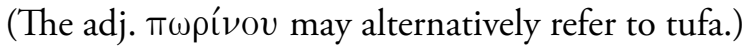




\subsubsection{Genitive of Measure}

The Genitive of Measure may be used as Complement of the verb 'to be'. (Cf. Lesson 36.2.)

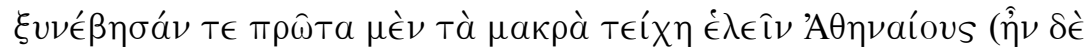

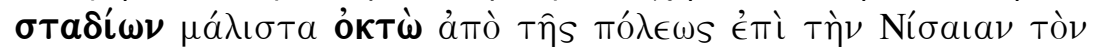

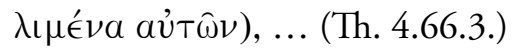

And they agreed that first the Athenians should take the long walls (and they were of approximately eight stades <in length> from the city to Nisaea their harbour),...

\subsubsection{Genitive of Price or Value}

The Genitive of Price or Value may be used adverbially with appropriate verbs (such as 'to buy', 'to value') and with adjectives (such as ä $\xi_{\text {ios, }}$ 'worth', 'worthy of').

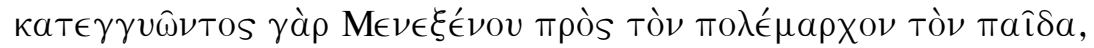

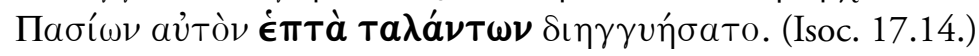

For when Menexenus required Pasion to give security before the polemarch for the slave, he provided security for him $<$ to the amount $>$ of seven talents.

\subsection{Partitive Genitive}

As noted in Lesson 38 and in $\$ 39.1$ above, the Partitive Genitive is properly a subcategory of the Possessive Genitive. The part 'belongs to' the whole.

\subsubsection{Complement of the Verb 'to be'}

The simple Partitive Genitive may form the Complement of verbs such as 'to be' or 'to become'.

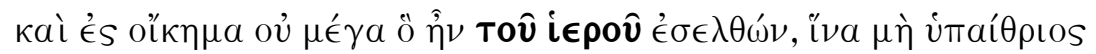

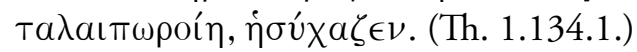

And entering a small room which was <part> of the temple, so that he might not suffer from exposure, he kept quiet. 


\subsubsection{With Verbs Meaning 'to have or give a share of'}

The simple Partitive Genitive may function as the Object of verbs meaning 'to have or give a share of'. This construction is analogous to the basic use of the Partitive Genitive with nouns. In the adnominal phrase 'one of the citizens', 'one' is the part and 'of the citizens' denotes the whole group (Gen. in Greek). So, in the present example, 'to have a share' or 'to take part' $\left(\mu \in T \in \chi_{X} \in I \nu\right)$ is followed by a Genitive phrase denoting the whole group of actions.

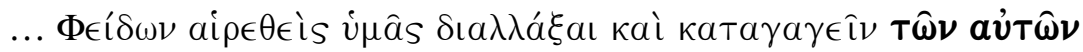

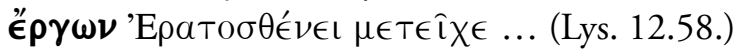

... Phidon, having been chosen to reconcile you and bring you back, participated in the same actions as Eratosthenes...

\subsubsection{With Verbs of Perception}

Verbs of perception may take a Genitive. For example, the common construction with verbs of hearing is Accusative of the sound, voice, etc. and/or Genitive of the person making the sound or possessing the voice. The sound, voice, etc. is part of the person or of the person's activity.

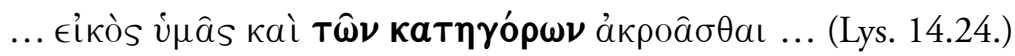

$\ldots<$ it is $>$ reasonable that you should listen also to accusers...

The article $\tau \hat{\omega} \nu$ is used generically.

\subsubsection{Equivalent to a Direct Object}

Sometimes a verb, which otherwise takes a direct Object in the Accusative, may take a Partitive Genitive equivalent to a direct Object. (Cf. Lesson 37.1.1.)

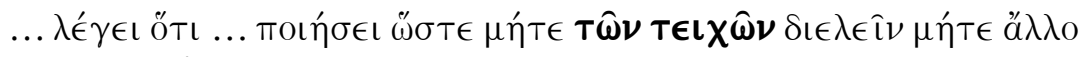

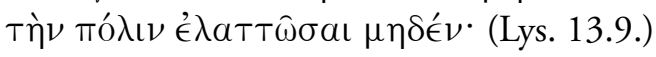

... he said that ... he would see to it that neither <would any one $>$ take down $<$ part $>$ of the walls, nor <would > anything else diminish < the standing of $>$ the city.

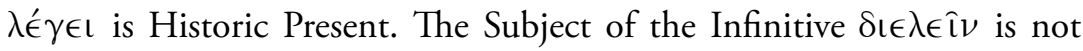
explicit. 


\subsubsection{Genitive of Limits of Time}

The Genitive of Limits of Time is a Partitive Genitive-an action takes place for only part of the time specified by the Genitive phrase.

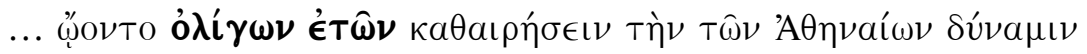
... (Th. 5.14.3.)

... they thought that within a few years they would demolish the power of the Athenians...

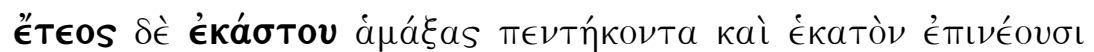
$\phi \rho v \gamma a ́ v \omega \nu \cdot(H d t .4 .62 .2$.

And [within] each year they pile on one hundred and fifty wagon-loads of sticks.

The Genitive of Limits of Time is commonly used to express frequency.

\subsubsection{Genitive of Limits of Space}

Similarly, the Genitive of Limits of Space is a Partitive Genitive-an action takes place with reference only to part of the space specified by the Genitive phrase.

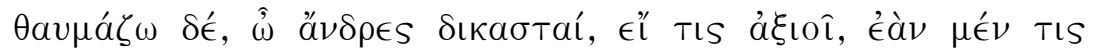

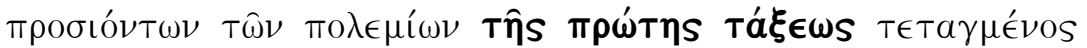

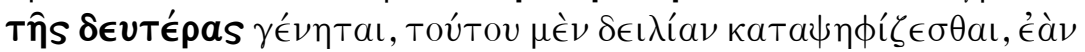

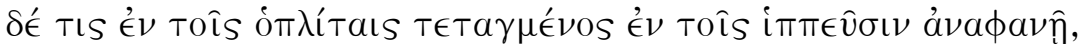

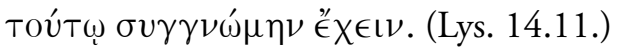

And I am surprised, $O$ men of the jury, that anyone thinks it right, if, as the enemy approaches, someone placed in the first rank turns up in the second rank, to vote this <man> guilty of cowardice, but if someone placed among the infantry appears among the cavalry, to grant pardon to this $<$ man $>$.

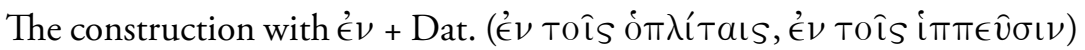
is practically equivalent in meaning to the Genitive construction. 


\subsubsection{Other Partitive Constructions}

The Genitive used with many other verbs (and related adjectives or adverbs) is usually classed as Partitive. The following selected examples show that this classification is not always satisfactory.

In the expressions 'to fill something with water' (verb) or to be 'full of water' (adj.), 'water' regularly appears in the Genitive Case in Greek. The 'Partitive' rationale for this construction is that only some water (not all) is needed for the filling.

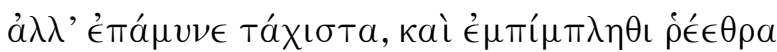

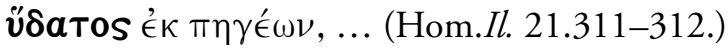

Come, bring assistance very quickly, and fill your streams

with water from your springs, ...

River Scamander addresses River Simois.

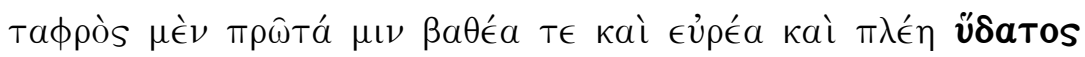
$\pi \in \rho \imath \theta \epsilon ́ \epsilon \mathrm{l}, \ldots$ (Hdt. 1.178.3.)

First a moat runs round it [= Babylon], deep and broad and full of water, ...

It is not so clear that a Partitive explanation can be applied to the group of verbs meaning 'to remember, to forget; to care for, to neglect'.

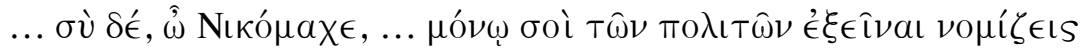

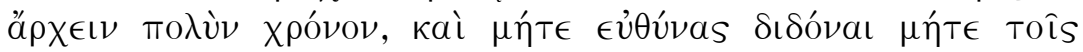

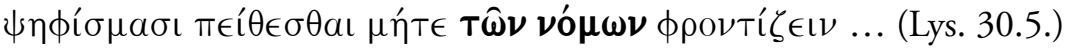

... but you, O Nicomachus ... think that it is permissible for you alone of the citizens to hold office for a long time, and neither to submit to an examination, nor to obey the decrees, nor to take notice of the laws...

$\phi \rho O \nu \tau^{\prime} \zeta \in \mathrm{L} \nu$ may take a direct Object in the Accusative when it means 'to consider'. When this verb takes a Genitive, it is most often negated and has the sense 'not to worry about'. And from Herodotus onwards, the Genitive may be used with the preposition $\pi \epsilon \rho$ í. But it can hardly be said that Nicomachus is 'not worried about' only some of the laws. Thus, a Partitive explanation for the construction seems inadequate. Indeed, a Causal explanation seems more plausible: Nicomachus is 'not worried' because of the laws. The Causal Genitive is basically a Genitive of Separation (see $\$ 39.4 .3$ below). 
The Genitive with adjectives, which are compounded with the negative prefix $\dot{a}-$, is usually classed as Partitive.

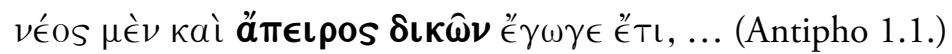

For my part $<I$ am $>$ still young and without experience of lawsuits, ...

Here, the speaker may be regarded as inexperienced 'within the sphere' of lawsuits, in a construction analogous to the Genitive of Limits of Time or Space.

\subsection{Genitive of Separation}

The Genitive of Separation is used with a wide range of verbs, adjectives and adverbs.

\subsubsection{Simple Genitive of Separation}

Most simply, the Genitive of Separation is used with verbs meaning 'to be distant from', 'to separate someone (Acc.) from something (Gen.)' or 'to deprive someone (Acc.) of something (Gen.)'.

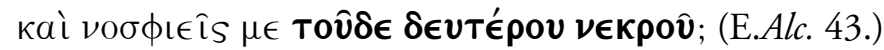

And will you deprive me of this second corpse?

\subsubsection{Genitive of Comparison}

The Genitive of Comparison is a particular type of Genitive of Separation.

\subsubsection{With Comparative Adjectives}

The Comparative adjective qualifies the person or thing being compared; the Genitive indicates the standard of comparison. The idea of 'separation' is involved, in that some people may be, for example, more or less numerous or strong in 'departing from' the standard of others.

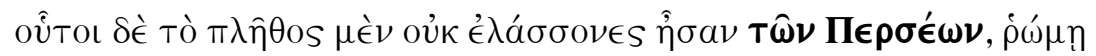

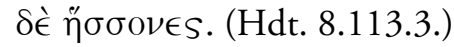

These were not less in number than the Persians, but were inferior in strength. 


\subsubsection{With Verbs Denoting Difference}

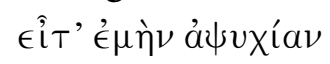

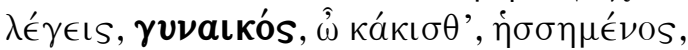

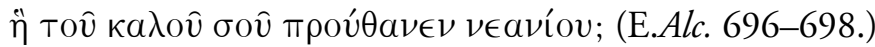

\section{Then do you speak of my}

faintheartedness, $O<$ you scoundrel, having become inferior to your wife, who died for you, her fine young man?

\subsubsection{Genitive of Cause}

The Genitive of Cause is also a particular type of Genitive of Separation.

\subsubsection{With Verbs of Emotion}

The Genitive denotes Cause with verbs of emotion, such as 'to be surprised at' or 'to blame someone (Dat.) for something (Gen.)'. The idea of 'separation' is involved, in that the emotion 'arises from' the thing or person specified in the Genitive.

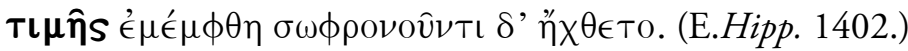

She $[=$ Aphrodite] complained of the honour < which you did not show her $>$ and got annoyed with <you for being restrained.

\subsubsection{In Exclamations}

The following exclamation presents a standard form: first an interjection ('Oh alas'), then an explanation of the interjection, given in the Genitive. The interjection 'arises from' the matter specified in the Genitive.

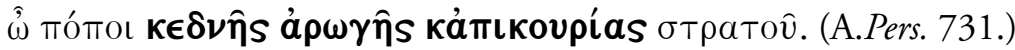
Oh alas for our army's trusty belp and defence!

\subsection{Genitive with Compound Verbs}

The Genitive Case is used with some compound verbs, including multiple compounds (with more than one adverbial prefix). The type of Genitive usage depends on the meaning of a particular simple verb and on the meaning of its prefix(es). Legal terms with the prefix кaтa-comprise

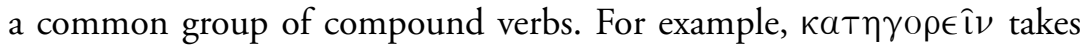
(among other constructions) a Genitive of the person condemned, with or without an Accusative of the charge or crime. 


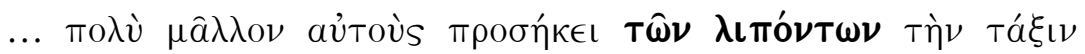

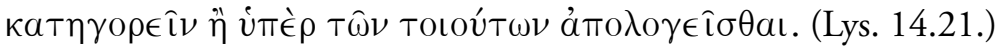

... it is much more appropriate for them to accuse those who desert their post than to make a defence on behalf of such people.

\section{References}

Smyth (1956), Greek grammar, $\$ \$ 1339-1449$.

\section{EXERCISE 39}

Translate the following passages. For each passage, briefly indicate the general and particular function of the Genitive phrases in bold type, for example, Partitive (general), Limits of Time (particular) and modifying which verb, adjective or adverb.

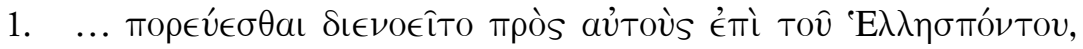

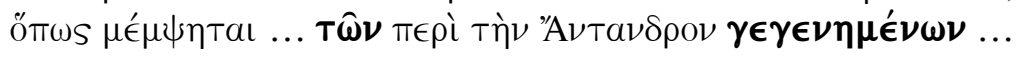

\begin{tabular}{ll}
\hline$\delta ı a \nu o \in \hat{\imath} \sigma \theta a \iota$ (Mid.) & to intend \\
$\pi \in \rho i ́(+$ Acc.) & near \\
\hline
\end{tabular}

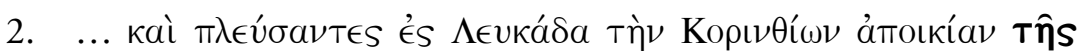

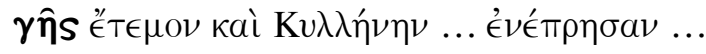

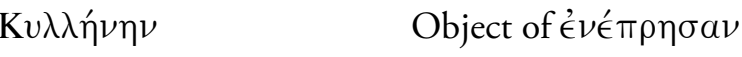

3.

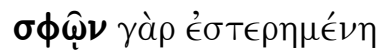

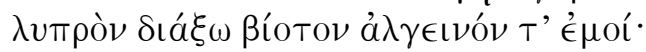

$\sigma \phi \omega \hat{\nu} \nu$

Gen. dual 2nd pers. pronoun

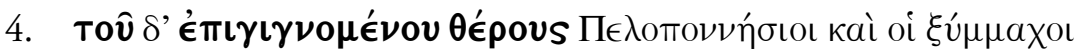

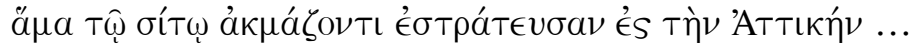

\begin{tabular}{|c|c|}
\hline$\epsilon^{\prime} \pi \iota \gamma^{\prime} \gamma \nu \in \sigma \theta a \iota$ & to follow (chronologically) \\
\hline$\ddot{\alpha} \mu \alpha$ (adv.) & at the same time as (+ Dat. with Partc.) \\
\hline 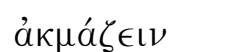 & to be ripe \\
\hline
\end{tabular}




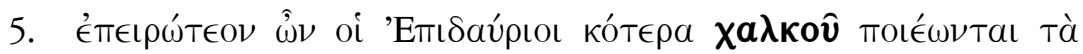

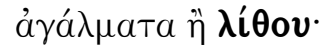

\begin{tabular}{|c|c|}
\hline$\dot{\epsilon} \pi \epsilon \iota \rho \omega \tau T^{\prime} \in I \nu$ (Ionic) & $\begin{array}{l}\text { to inquire (here 3rd pers. pl. Past } \\
\text { Imperf. Indic. Act.) }\end{array}$ \\
\hline$\hat{\omega} \nu$ & oûv (Attic) \\
\hline 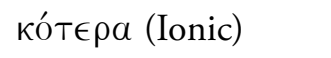 & 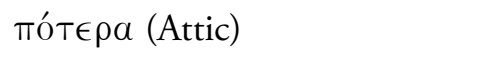 \\
\hline 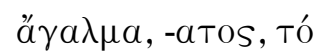 & statue \\
\hline
\end{tabular}

The two Gen. terms have the same function.

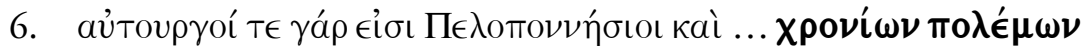

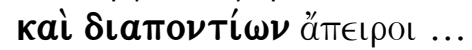

\begin{tabular}{|c|c|}
\hline aủToupyós, -óv & self-employed \\
\hline 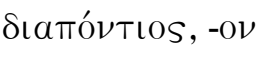 & overseas \\
\hline
\end{tabular}

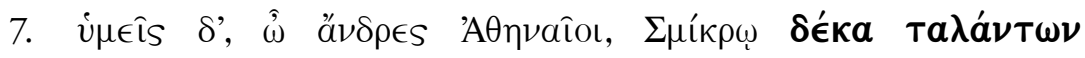

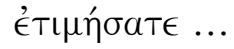

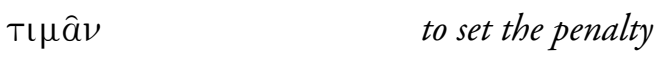

8. $\quad \dot{\epsilon} \pi \epsilon \grave{l} \pi \lambda \epsilon \epsilon^{\prime} \omega \nu$ X

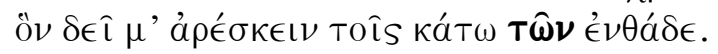

Tô̂s, Tิ̂̀ masc.

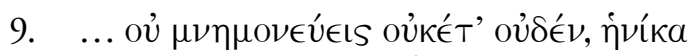

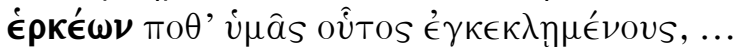

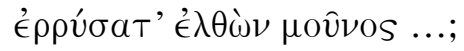

\begin{tabular}{|c|c|}
\hline 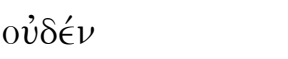 & internal Acc. with $\mu \nu \eta \mu \nu \nu \in \dot{v} \in \mathrm{IS}$ \\
\hline 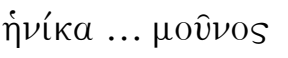 & noun clause, Object of $\mu \nu \eta \mu o \nu \in v \in \in I S$ \\
\hline Ёркоs, -оus, тó & fence, (line of) defence \\
\hline ('́)pú́ $\sigma \theta a \iota$ (Mid.) & to rescue \\
\hline
\end{tabular}




\section{LESSON 40 Dative Case 1}

\subsection{Introduction}

The Dative Case covers two basic functions: denoting the persons whose interests are affected by an action or situation, and indicating accompaniment in the broadest sense. Lesson 40 treats the Dative of Interest and the Dative of Accompaniment in general. Lesson 41 will treat two further and particular categories of accompaniment: location in place or time, and means or instrument. The functions of the Dative Case are predominantly adverbial. However, nouns and adjectives, which are related to verbs, may also take a Dative construction. For example, the verb $\epsilon \dot{U} \nu 0 \epsilon \hat{\imath} \nu$ and the adjective $\epsilon$ Uै $\nu$ ovs used with $\epsilon \hat{\imath} \nu \alpha$ l both mean 'to be well disposed (to)' and take a Dative.

\subsection{Dative of Interest}

\subsubsection{Interest in General}

A wide range of verbs and related nouns or adjectives take a Dative denoting the persons to or for whom an action is done.

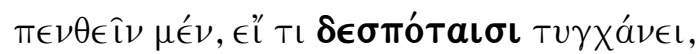

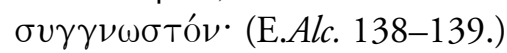

$<$ It is > pardonable to lament, if something happens

to one's masters.

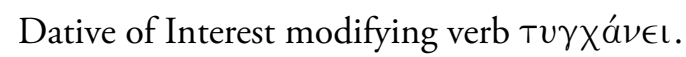

(Grammatically: 'To lament [Subject] <is> pardonable [Complement]'.) 


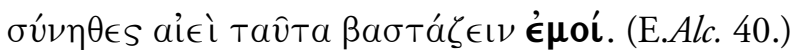

$<$ It is > customary for me to carry this constantly.

Dative of Interest modifying adjective $\sigma u ́ \nu \eta \theta \in S$.

(Grammatically: 'To carry this constantly [Subject] <is> customary [Complement] for me'.)

\subsubsection{Indirect Object}

Verbs of saying, giving, etc. commonly take a direct Object in the Accusative and an indirect Object in the Dative.

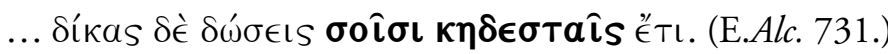

... and you will yet give recompense to your wife's-relatives.

\subsubsection{Possessive}

The Possessive Dative is used with verbs meaning 'to be' or 'to become', where the Subject (concrete or abstract) is or becomes the possession of the person designated by the Dative. A paraphrase with the verbs meaning 'to have' or 'to get' is often used, and the Subject in Greek then becomes the Object in English.

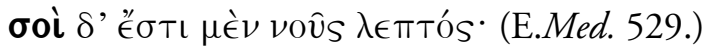

And you do have a subtle mind.

Lit. 'And there exists for you a subtle mind'.

\subsubsection{Agent}

In classical Greek, the Agent of a Passive verb is usually expressed by vंró with Genitive. However, a Dative of Interest is frequently used with Passive verbs in the Perfect Aspect (and rarely with other Tenses). The Dative of Agent is also the normal construction with verbal adjectives ending in -TOS and -TÉOS (Lessons 7.3 and 8.2).

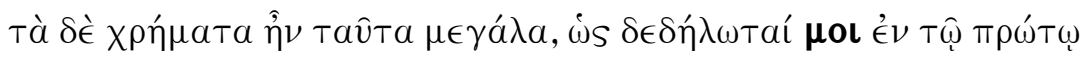
$\tau \hat{\omega} \nu \lambda \hat{\gamma} \gamma \omega \nu$. (Hdt. 5.36.4.)

And this treasure was great, as has been made clear by me in the first of the books. 


\subsubsection{Similarity}

A Dative of Interest is used with adjectives and adverbs expressing similarity, including o aủTós meaning 'the same (as)'.

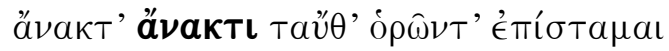

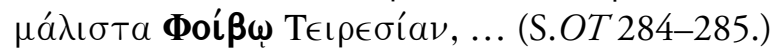

I know that lord Tiresias generally sees the same things as lord Phoebus, ...

\subsubsection{Person Judging (or Reference)}

The Dative denotes the person, from whose point of view something is valid. The Dative term may be a Participle only. The usage is common with topographical directions.

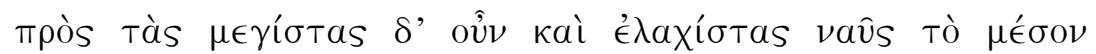

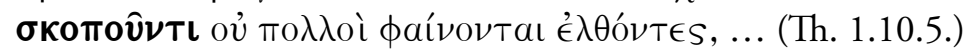

But at any rate for someone examining the midpoint [OR: average] in relation to the largest and the smallest ships, it is clear that not many $<$ men $>$ went, ...

\subsubsection{Purpose}

The Dative, especially of abstract nouns, may be used to express the Purpose for which an action is performed.

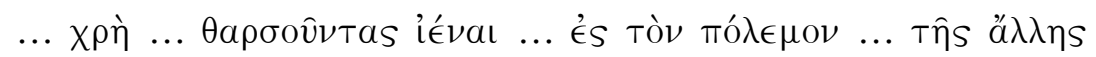

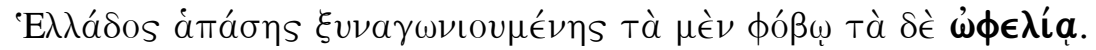
(Th. 1.123.1.)

$\ldots<$ we should ... with high courage go ... into the war ... since all the rest of Greece will join in the struggle partly because of fear and partly for advantage.

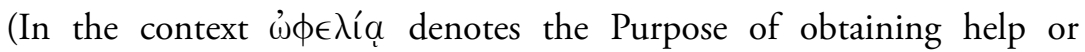
advantage, not the Purpose of helping someone else.)

According to Smyth (1956, \$1473), 'For the dative of purpose (to what end?), common in Latin with a second dative (dono dare), Greek uses

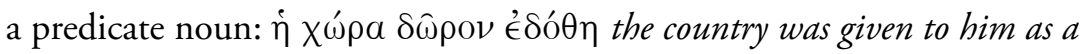


gif' (X.HG 3.1.6.). In this Greek example, the 'predicate noun' ( $\delta \omega \rho \rho \nu)$ is used in the Nominative Case with a Passive verb. But a double Dative may also be used with a Greek Passive verb. In Latin grammars, the 'second dative' is designated 'predicative dative'.

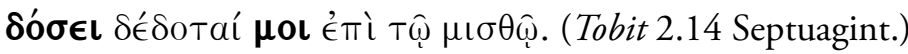

It has been given to me as a gift in addition to my pay.

\subsubsection{Ethic}

The Dative of the personal pronouns (sg. or pl.) is used to express the interest of the first person or to catch the attention of the second person. (The idiom seldom occurs with the third person.) A paraphrase such as 'please' (1st pers.) or 'I tell you' (2nd pers.) is often appropriate. Typically, the pronoun appears near the beginning of a Main clause and, therefore, tends to 'modify' the whole clause. However, it could sometimes be regarded as modifying the verb of a Main clause, especially an Imperative.

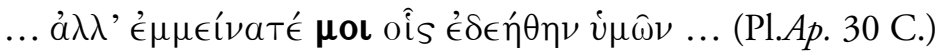

... but please abide by what I asked of you ...

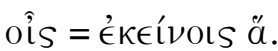

\subsection{Dative of Accompaniment (or Sociative Dative)}

The Dative of Accompaniment in the narrower sense expresses simple accompaniment, attendant circumstances and (with an abstract noun) Manner.

\subsubsection{Simple Accompaniment}

The Dative may simply express the accompaniment of persons, without any particular nuance.

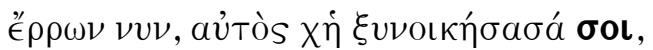

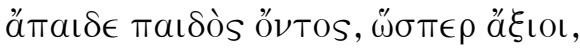

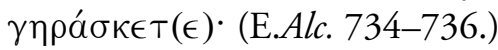

Begone then, you yourself and she who came to live with you, and grow old childless, as you deserve, although you have a child. 


\subsubsection{Attendant Circumstances}

Parallel to the expression of personal accompaniment, the Dative may be used to denote attendant circumstances with things both concrete and abstract.

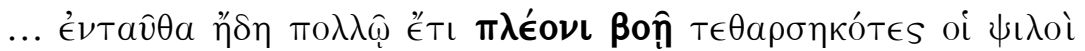
ÉTா́́KEIVTO・ (Th. 4.35.2.)

... then straight away with even much more shouting having taken heart the light-armed troops pressed hard upon <them $>$.

\subsubsection{Dative of aútós with Noun}

The Dative of aútós in agreement with a noun emphasises the inclusion of the Dative phrase in the action of its clause. The Dative phrase may be related to the Subject or the Object of the clause. The Dative of avitós usually agrees with a plural noun, and always precedes it in early and classical Greek.

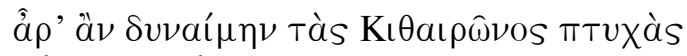

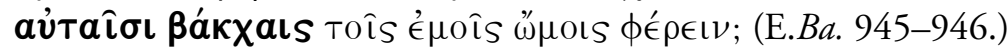

Would I be able to carry the mountain-valleys

of Cithaeron on my shoulders, Bacchants and all?

Dative phrase related to Object, 'the mountain-valleys'.

\subsubsection{Military Accompaniment}

The Dative of Military Accompaniment is merely a particular application of the simple Dative of Accompaniment. It denotes military forces and equipment.

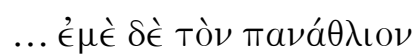

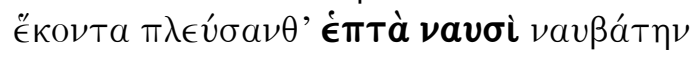

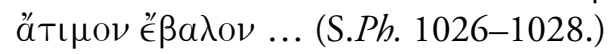
... but me, completely wretched fellow, a seaman having set sail willingly with seven ships, they cast <out $>$ dishonoured ...
} 


\subsubsection{Manner}

The Dative may denote in what Manner an action is performed. The Dative is typically an abstract noun, which is frequently qualified by an adjective.

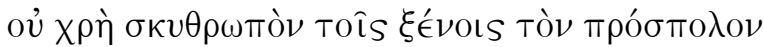

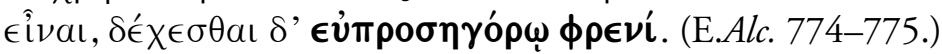

A servant should not be sullen towards guests,

but should receive them with courteous attitude.

The definite articles (Tô̂s, Tóv) are used generically.

\section{References}

Smyth (1956), Greek grammar, $\$ \$ 1450-1502,1521-1527,1529,1544-1545$.

\section{EXERCISE 40}

Translate the following passages. For each passage, briefly indicate the general function (Interest or Accompaniment) and, where applicable, the particular function (e.g. Possessive or Manner) of the Dative phrases in bold type, and state which verb the phrase modifies or how it is otherwise related to its clause.

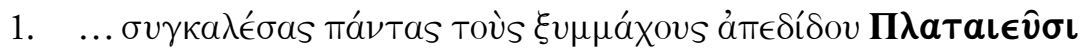

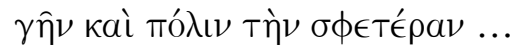

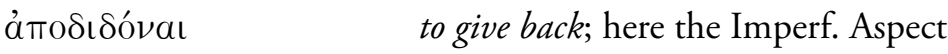
implies 'proceeded to give back'

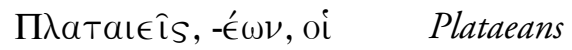

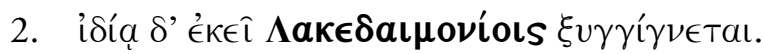

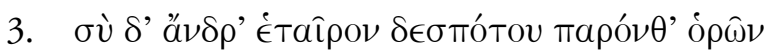

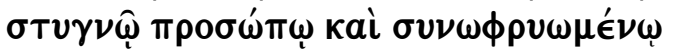
$\delta \in ́ X \eta$...

\begin{tabular}{|c|c|}
\hline 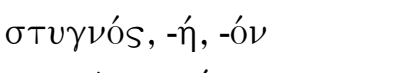 & sullen \\
\hline$\sigma v \nu \omega \phi \rho v \omega \mu \epsilon \cos ,-\eta,-0 \nu$ & frowning, scowling (Perf. Pass. Partc.) \\
\hline
\end{tabular}




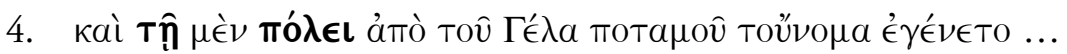

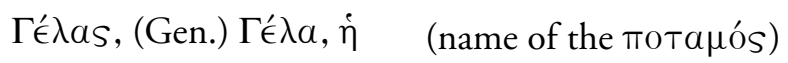

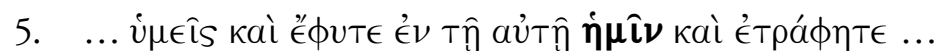

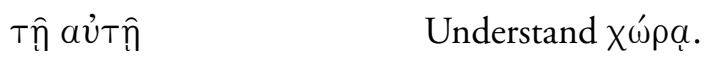

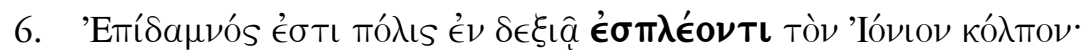

кó $\lambda$ TाOS, -ov, ó gulf

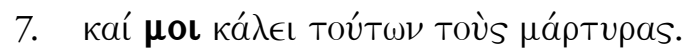

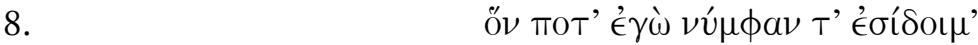

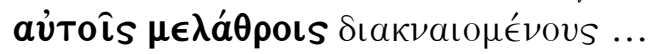

öv coordinating relative pronoun

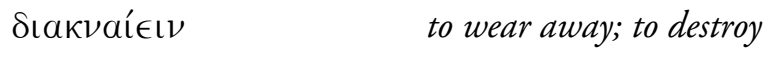

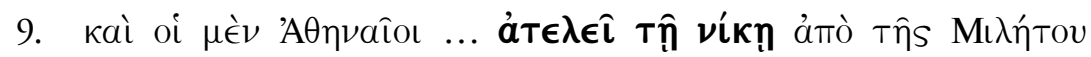

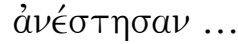

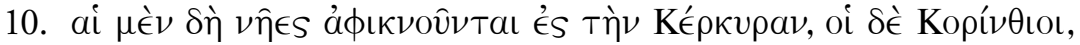

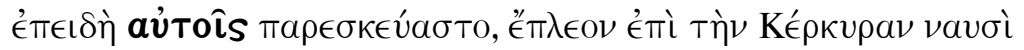

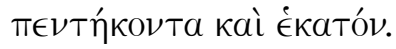

\begin{tabular}{|c|c|}
\hline$\mu \grave{\nu} \nu \delta \dot{\eta} \ldots$... & 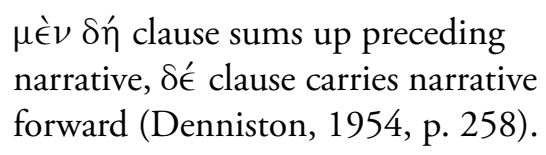 \\
\hline 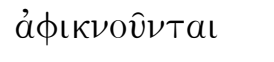 & Hist. Pres. \\
\hline$\pi \alpha \rho \in \sigma \kappa \in \mathcal{\imath}$ & impersonal Pass. \\
\hline
\end{tabular}





\section{LESSON 41 \\ Dative Case 2}

\subsection{Locative}

Locative uses of the Dative Case express the meaning 'in' or 'at' a particular place or time.

\subsubsection{Place}

In classical Attic prose, the Dative denoting location usually requires the preposition $\mathcal{\epsilon}^{\prime} \nu$. However, sometimes in prose and frequently in verse a plain Dative is used.

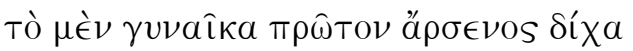

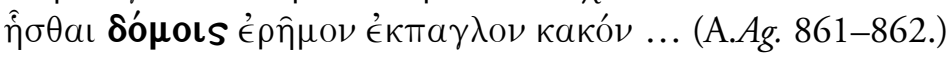

In the first place $<$ it is $>$ a terrible problem that a wife

should sit in the house, deserted, apart from her husband...

Dative of Place with a common noun in verse; proper nouns also occur in verse.

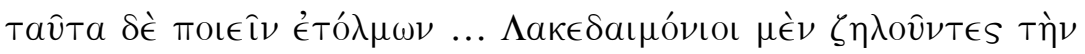

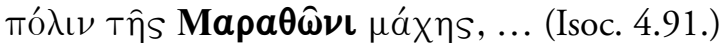

And they dared to do these things ... the Spartans admiring our city for its battle at Marathon,...

Dative of Place with a place name in prose.

Some scholars (including Smyth, 1956, \$1534) have claimed that a Locative Dative without preposition is restricted to proper names of places in prose. Even if this commonly occurs in the classical period, the claim seems not to be universally valid. 


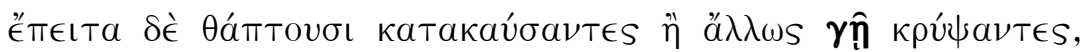

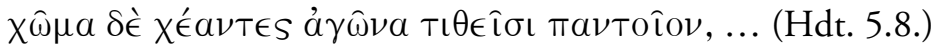

And then they celebrate funeral rites by cremating or otherwise by burying in the earth, and after heaping up a mound they conduct every kind of contest,...

Dative of Place with a common noun in prose.

\subsubsection{Time}

The Dative denotes the time when something happens. This use of the Dative may be regarded as indicating the 'point of time', provided that allowance is made for the 'point' to be as long as an hour, day, month or year.

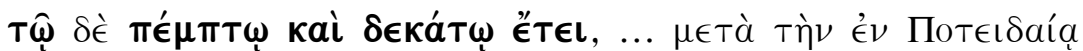

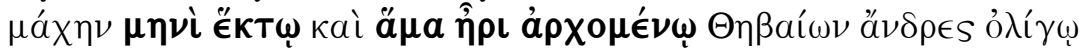

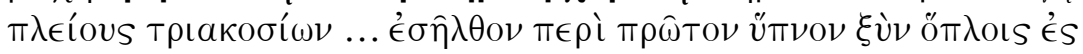

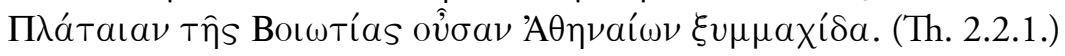

But in the fifteenth year ... in the sixth month after the battle at Potidaea and just when spring was beginning, men of the Thebans, a little more than three hundred ... about the first watch entered with weapons into Plataea in Boeotia, when it was in alliance with the Athenians.

Note the three slightly different Temporal expressions:

1. 'in the fifteenth year'

2. 'in the sixth month after' another event

3. 'simultaneously with spring' plus Participle.

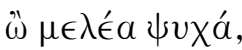

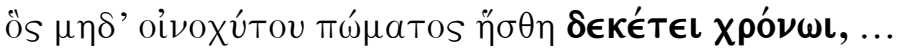
(S.Ph. 714-715.)

Oh, the miserable life <of one $>$, who did not even enjoy a cup of poured wine in a ten-year period, ... (R.G. Ussher, 1990) 
In English idiom, the Temporal phrase after a negative may be translated 'for a ten-year period'. But Accusative of Extent of Time in Greek 'would rather suggest that $\mathrm{Ph}$. had not had ten years continuous enjoyment of wine' (Jebb). The present expression is also to be distinguished from the Genitive of Limits of Time-the emphasis is not on the limits, but on the fact that Philoctetes did not enjoy a drink at any point in the period.

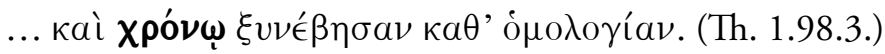

$\ldots$ and after a while they came to terms.

As in English idiom, so in Greek 'I will do this in a while' means 'I will do this after a whileltime'.

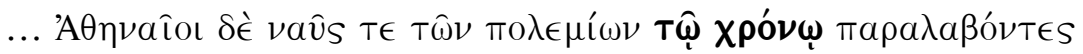

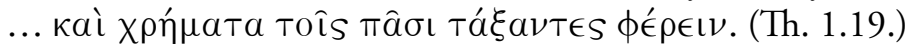

... but the Athenians <controlled their allies $>$ by taking ships from the citystates in the course of time... and by requiring them all to pay money.

This expression is similar to the previous one, but uses the definite article.

\subsubsection{Respect}

The Dative may indicate in what respect something is the case. This usage is equivalent to the Accusative of Respect. And some nouns may be used idiomatically in either construction-for example, both $\gamma^{\prime}$ 'vOS and $\gamma \in \mathcal{\prime} \cup \in \mathrm{L}$ may mean 'with regard to birth/family/race'. The construction occurs with verbs, adjectives, adverbs and nouns.

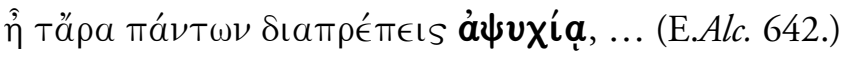

Surely then, you are preeminent among all in faintheartedness, ...

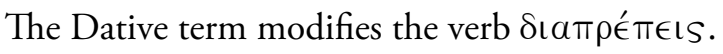

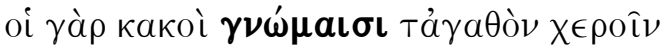

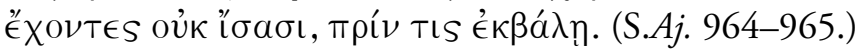

For those who are incompetent in judgments do not know that they have the good in their hands, until someone throws it away.

The Dative term modifies the adjective какоí. 


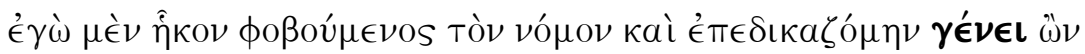

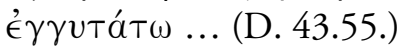

I had come revering the law and I was pursuing the case since I was nearest in family-relationship...

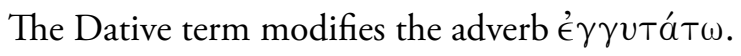

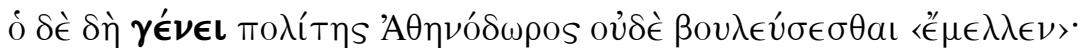
(D. 23.12.)

And Athenodorus indeed, a citizen by birth, <was likely> not even to contemplate <doing so $>$.

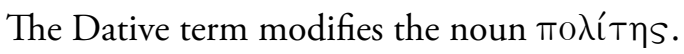

The Dative of Respect is usually treated as a subcategory of the Instrumental Dative. But the classification is made without positive justification and with the qualification that the Instrumental is used in a transferred or weakened sense.

The Dative of Respect might rather be regarded as a Locative usage, denoting the sphere of action, behaviour or existence. In many instances, the sphere is denoted by an abstract noun. Moreover, already in the classical period év may be used with a Dative of Respect. And this usage becomes more noticeable in the Hellenistic period. év supports a Locative function.

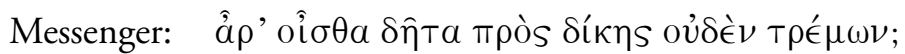

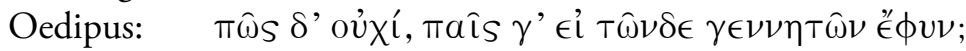

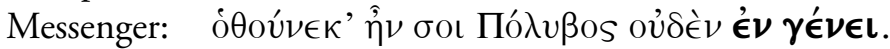

(S.OT 1014-1016.)

Messenger: Do you know, then, that you are not rightly fearing anything? Oedipus: But how not, at least if I was born a child of these parents? Messenger: Because Polybus was nothing to you with regard to family. 


\subsection{Means or Instrument}

\subsubsection{In General}

The Dative Case is widely used to indicate the means or instrument by which an action is performed. The construction occurs both with verbs used transitively and with verbs used intransitively. Many verbs may be used in either way. Either persons or things may implement an action. The construction with a verb used actively is more obvious. But Passive examples occur, where the Dative denotes personal Means and not the responsible Agent. And when $\chi \rho \hat{\eta} \sigma \theta a$ ('to use') has a Dative of the person, the verb may take a second, predicate Dative. The meaning then tends to shift, for example, from 'use someone as a friend' to 'treat or regard someone as a friend'.

\subsubsection{With Verbs used Transitively}

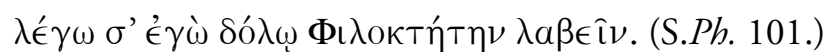

I am saying that you (are to) take Philoctetes by trickery.

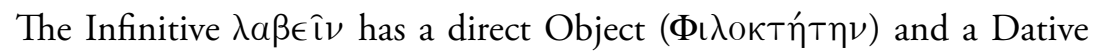

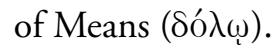

\subsubsection{With Verbs used Instransitively}

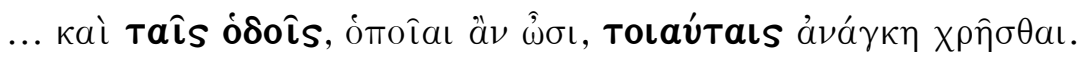
(X.Cyr. 1.6.36.)

... and $<i t$ is $>$ necessary to use such roads as there are.

$\chi \rho \hat{\eta} \sigma \theta a \iota$ is properly Intr.; lit. 'to make use by means of such roads'.

\subsubsection{Personal Means}

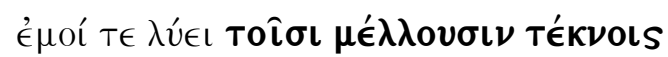

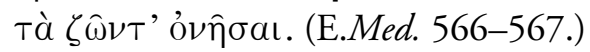

And it is expedient for me by means of the future children

to benefit those who are living.

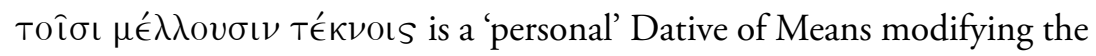
Active Infinitive òvฑิซaı.

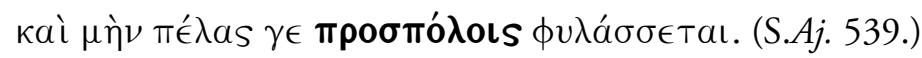


Yes indeed, he is being guarded nearby by means of attendants.

Tecmessa (the responsible Agent) replies to Ajax's request that he may see his young son. $\pi \rho 0 \sigma \pi$ ó $\lambda o s s$ is personal Dative of Means modifying the Passive verb $\phi u \lambda a ́ \sigma \sigma \in T a$.

\subsubsection{Personal Means with Predicative Dative}

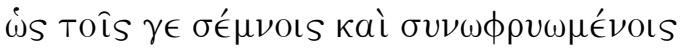

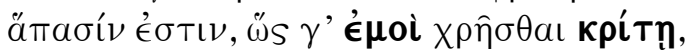

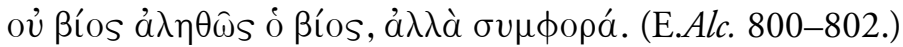

For to these solemn and frowning people at least, all of them, at least to use me as judge, life is not truly life, but calamity.

$\chi \rho \eta \hat{\sigma} \theta$ a here is used with a second, predicative Dative, in the sense 'to use/treat/regard as'. ( $\dot{\omega}$ s + Infin. expresses a parenthetical qualification.)

\subsubsection{Cause}

The Dative may denote the factor, because of which something happens. The usage is very similar to the Causal Genitive, especially since this Dative is likewise often used with verbs of emotion.

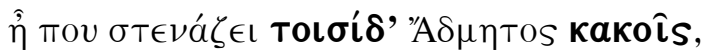

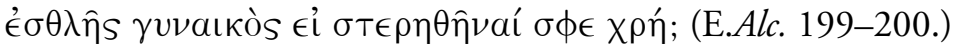

Is Admetus perhaps groaning over these troubles,

that he should be deprived of his good wife?

(For $\epsilon \hat{l}$ meaning 'that' with expressions of emotion, see Lessons 34.2.4 and 34.2.6.)

\subsubsection{Degree of Difference}

The Dative denotes the degree of difference with Comparative and (less often) Superlative adjectives and adverbs, and also with other expressions implying comparison.

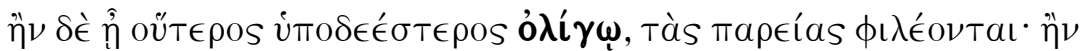

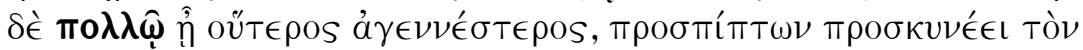

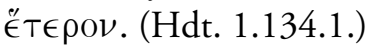


But if the one is inferior <only> by a little, they kiss the cheeks; and if the one is much more ignoble, he falls before the other and does obeisance to him.

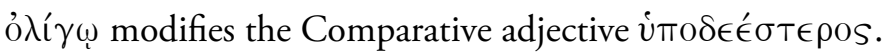

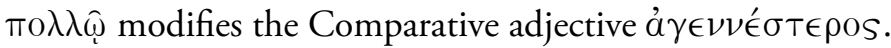

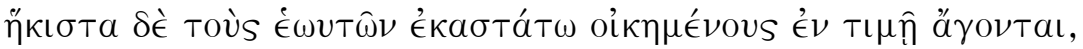

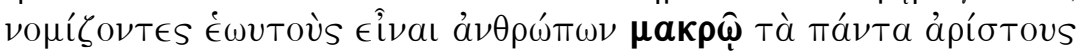
... (Hdt. 1.134.2.)

And they hold in least honour those who live furthest from themselves, thinking themselves to be by far the best of men in all respects...

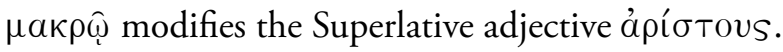

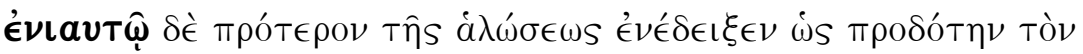

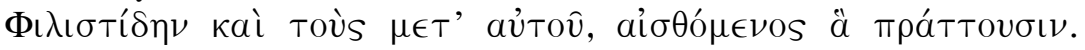
(D. 9.60.)

But a year before the capture he informed against Philistides as a traitor, as well as his associates, after realising what they were doing.

In this construction, $e^{\prime} \nu$ LavT $\hat{\varphi}$ is not a Dative of Time but a Dative of Degree of Difference modifying the Comparative adverb $\pi \rho \sigma^{\prime} \tau \rho \rho \nu$ and meaning 'earlier by a year than the capture'. Other Temporal terms may also be used as Dative of Degree of Difference.

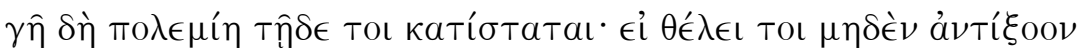

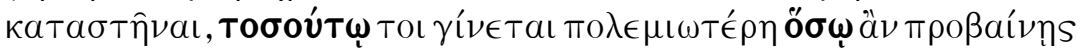

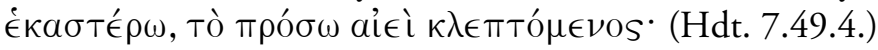

And the land becomes hostile to you in this way: if nothing is likely to become adverse for you, <the land> becomes so much the more hostile to you, the further you progress, being constantly deceived as to what lies ahead.

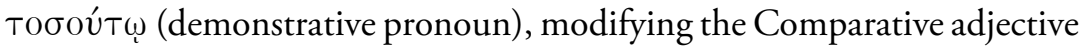
$\pi \mathrm{T} \lambda \epsilon \mu \mathrm{\iota} \omega \tau \epsilon \in \hat{\rho} \eta$, corresponds to ö $\sigma \omega$ (relative pronoun, lit. 'by how much'),

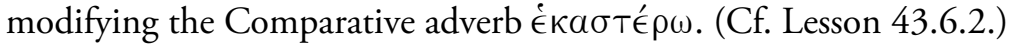

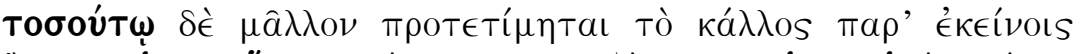

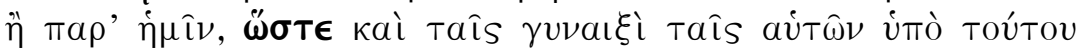

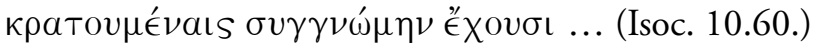


And so much the more has beauty been preferred among them [= gods] than among us, that they pardon even their own wives when they are overcome by it ...

Toбoút $\omega$ (demonstrative pronoun), modifying the Comparative adverb $\mu \hat{\alpha} \lambda \lambda \mathrm{o \nu}$, corresponds to $\ddot{\sigma} \sigma \tau \epsilon$ (relative adverb), introducing the Result clause. (Cf. Lesson 43.6.1.)

\section{References}

Smyth (1956), Greek grammar, $\$ \$ 1503-1543$.

\section{EXERCISE 41}

Translate the following passages. For each passage, briefly indicate the general and particular function of the Dative phrases in bold typefor example, Locative, Time, modifying which verb; Means, Degree of Difference, modifying which Comparative adjective or adverb.

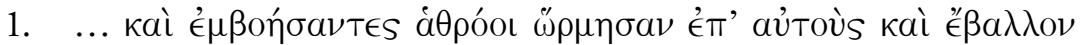

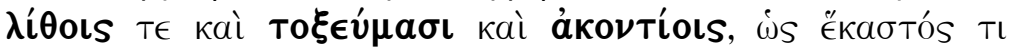

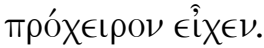

The three Dative terms comprise a single phrase with a single function.

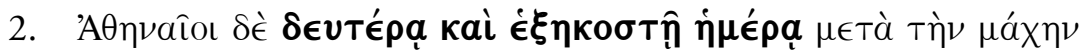

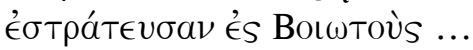

ÉS (+ Acc. of persons) into < the territory of

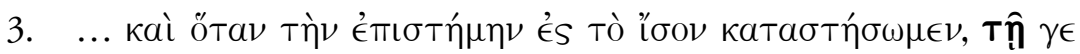

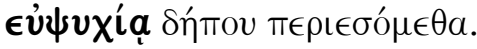

\begin{tabular}{|c|c|}
\hline $\begin{array}{l}\dot{\epsilon} \pi \iota \sigma \tau \dot{\eta} \mu \eta,-\eta S, \dot{\eta} \\
\pi \in \rho \iota \epsilon \hat{\imath} \nu \alpha \iota\end{array}$ & $\begin{array}{l}\text { skill } \\
\text { to be superior }\end{array}$ \\
\hline
\end{tabular}

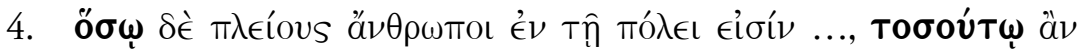

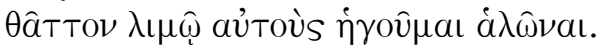




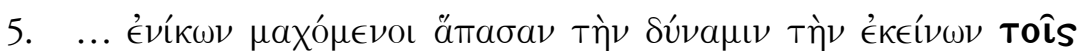

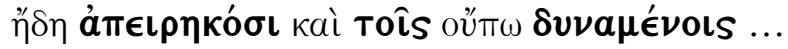

Toîs ... Toîs ... + Partc. masc., referring to persons à $\pi \in I \pi \in \hat{\imath} \nu$ (Aor.) to become tired outlexhausted

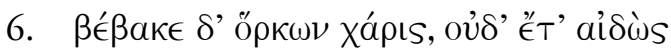

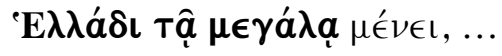

xápıs, -เтоs, $\dot{\eta} \quad$ charm

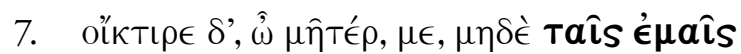

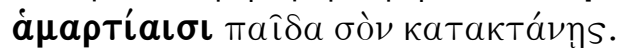

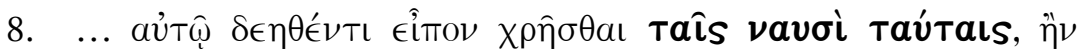

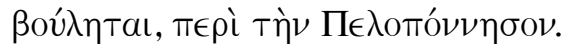

\begin{tabular}{ll}
\hline$\alpha \mathfrak{U} T \hat{\imath}$ & masc. \\
$\delta \in \hat{\imath} \sigma \theta a \mathrm{I}$ (Mid. and Pass.) & to request \\
$\epsilon \hat{i} \pi \circ \nu$ & 3rd pers. pl.
\end{tabular}





\section{LESSON 42 \\ Prepositions}

\subsection{Adverbs}

In the earliest surviving Greek literature, many words, which are regularly used as prepositions in the classical period, are still being used as adverbs.

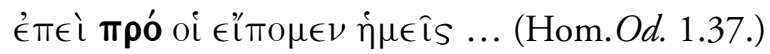

For we told him beforehand...

\subsection{Compound Verbs}

When placed immediately before verbs, these adverbs form compound verbs.

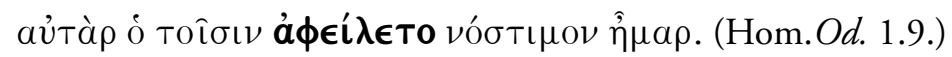

And he took away the day of return for them.

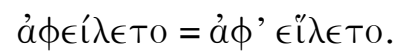

\subsection{Prepositions}

When placed immediately before, in the middle of, or after a noun phrase, these adverbs begin to look like prepositions governing a Case.

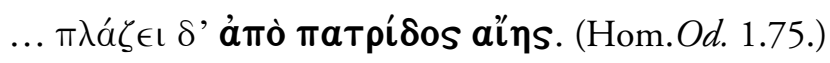

... but he turns <him> away from his native land.

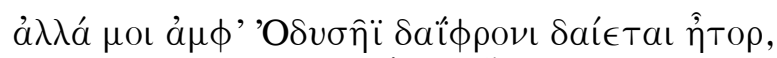

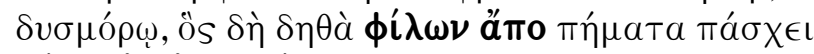

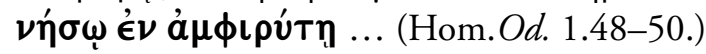

But for me my heart is torn concerning wise Odysseus,

ill-fated man, who indeed has long been suffering miseries away from his dear ones

on an island surrounded by sea ... 


\subsection{Case Functions}

The functions of the Accusative, Genitive and Dative Cases were established before prepositions began to be used with them. In the Lessons and Exercises concerned with those Cases, all the functions of the Cases were expressed without the use of prepositions. In classical Greek, it is often possible to detect the original Case function of a prepositional phrase apart from the preposition itself.

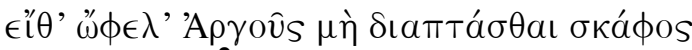

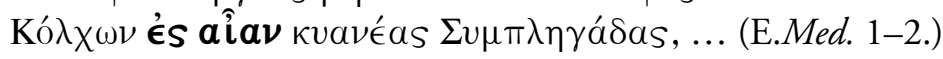

If only the ship Argo had not flown through

the dark Clashing Rocks to the land of the Colchians,...

In the context, aî $\alpha \nu$ is clearly an Accusative of Goal, even apart from the use of the preposition ÉS.

However, the original Case function is not always so clear. For example, there are several passages in the tragedy of Sophocles, Oedipus the King, where the phrase $\pi \rho$ òs $\theta \in \hat{\omega} \nu$ is used in an urgent entreaty with second person Imperative or Subjunctive.

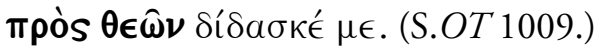

By the gods, instruct me.

A possible rationale for the prepositional phrase is that it is an elliptical request formula. The request is explicit in the following couplet from Theognis.

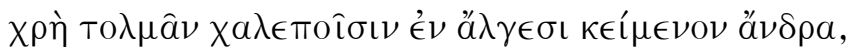

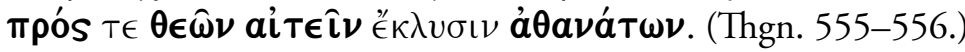

A man when involved in difficult sufferings should endure, and ask from the immortal gods release.

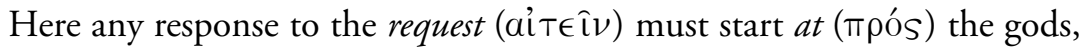
but must proceed from the gods $(\theta \in \hat{\omega} \nu)$. The Genitive of Separation would be the appropriate category. Compare $\delta \in \hat{\imath} \sigma \theta a \iota, \pi \rho \circ \sigma \delta \in \hat{\imath} \sigma \theta a \iota$, $\lambda i ́ \sigma \sigma \in \sigma \theta a l$ and $\chi \rho \eta ́ \zeta \epsilon \iota \nu$, 'to beg, to entreat, to request (from)', with Genitive of person but no preposition. 
The Accusative of Goal without a preposition is limited to phrases denoting Place. However, the Accusative of Goal with a preposition may also express Time.

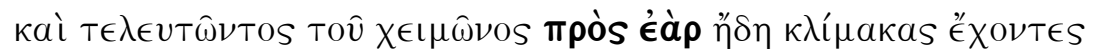

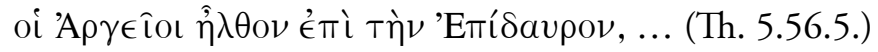

And as the winter was ending, now towards spring, the Argives came with scaling-ladders against Epidaurus, ...

\subsection{Possessive Genitive with Preposition}

In an abbreviated construction, a Possessive Genitive may be used with

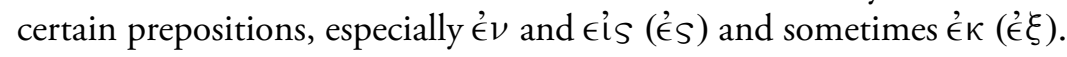

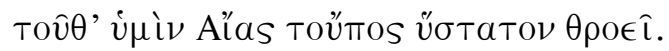

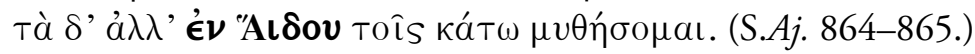

Ajax addresses this last word to you,

and for the rest I shall speak in <the realm > of Hades to those below.

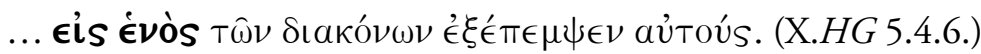

... he sent them off to $<$ the house $>$ of one of the servants.

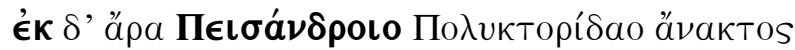

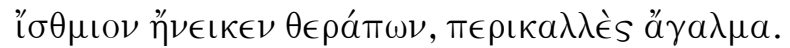

(Hom.Od. 18.299-300.)

And then out of < the house $>$ of lord Pisander son of Polyktor

his assistant brought a necklace, a very beautiful adornment.

\subsection{Compound Verb with Preposition}

In classical prose, an adverbial prefix of a verb is often repeated as a preposition with the appropriate Case. However, this usage also occurs in verse. (But in the classical period poets more often than prose writers rely on the established Case functions without a preposition.) The repetition is normally ignored in English translation. 


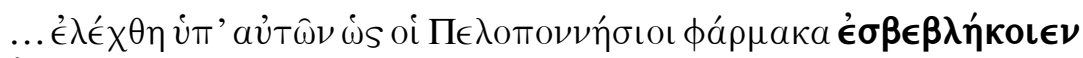

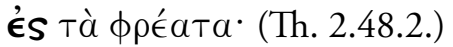

... it was said by them that the Peloponnesians had thrown poison into their cisterns.

Repetition in prose.

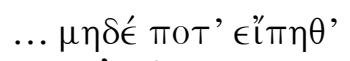

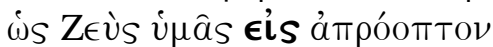

$\pi \hat{\eta} \mu^{\prime} \epsilon \dot{\imath} \sigma \epsilon \in \beta a \lambda \epsilon \nu$... (A.Pr. 1073-1075.)

$$
\ldots \text { and do not ever say }
$$

that Zeus threw you into

unforeseen misery...

Repetition in verse.

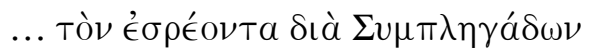

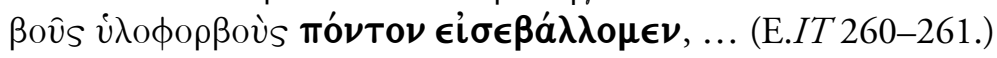

... we had been driving our cattle that feed in woodland into the sea that flows in through the Clashing Rocks, ...

No repetition in verse.

\subsection{Metaphorical Use of Prepositions}

The examples in $\$ 42.3$ and the first example in $\$ 42.4$ above use prepositions with the appropriate Cases in a literal sense: ámó with Genitive of Separation, $\dot{\epsilon} V$ with Dative of Place, $\dot{\epsilon}_{S}$ with Accusative of Goal. In the example from Theognis (\$42.4), $\pi \rho$ ós is used with a Genitive of Separation in a metaphorical sense-no literal, physical movement is involved. This metaphorical usage is quite common, especially when a preposition is used with an abstract noun.

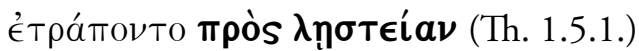

they turned to piracy

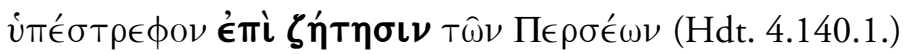

they turned back to search for the Persians 


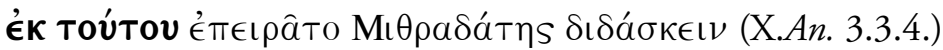

after this Mithradates tried to explain

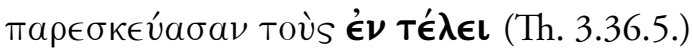

they prevailed upon those in authority

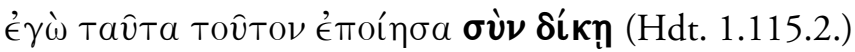

I did this to this <man > with justice

\subsection{Accent and Position of Prepositions}

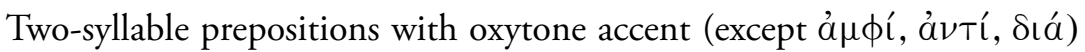
become paroxytone when they follow their Case. Note $\phi i ́ \lambda \omega \nu$ ămo in $\$ 42.3$ above (second example). In classical prose, $\pi \epsilon \rho$ í is the only 'proper' preposition ( $\$ 42.11$ below) which is placed after its Case. É $\nu \in \kappa a$ is regularly placed after its Case, and $̋ \nu \in \cup$ sometimes.

\subsection{Adverbial Accusative as Preposition}

Some nouns are used adverbially in the Accusative and are qualified by a simple Possessive Genitive. These Accusative nouns virtually have the function of prepositions.

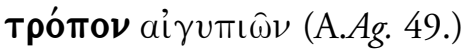

in the manner of vultures

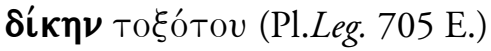

in the manner of a bowman

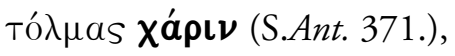

because of his rashness

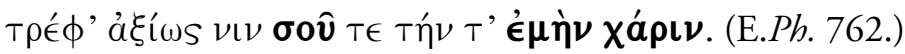

Look after her properly for the sake of yourself and for my sake.

In this and other instances there is a mixture of Genitive Case and

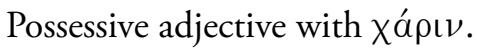




\subsection{Pregnant Construction}

In a so-called pregnant construction, verbs of rest are sometimes used with $\epsilon i s(\dot{\epsilon} S)$ + Accusative when they imply previous motion.

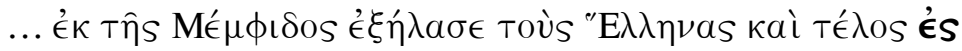

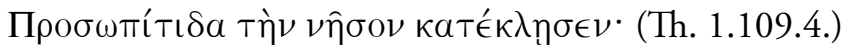

... he drove the Greeks out of Memphis and finally shut <them> up in the island of Prosopitis.

Conversely, verbs of motion are sometimes used with év + Dative when they imply subsequent rest.

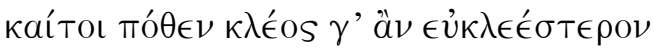

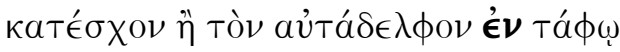

тı $\theta \in \hat{\imath} \sigma \alpha ;($ S.Ant. 502-504.)

And yet from where would I have obtained more glorious

glory than by putting my own brother into

a grave?

\subsection{1. 'Proper' and 'Improper' Prepositions}

The label 'proper' has been applied to prepositions that are used to form compound verbs, and the label 'improper' to prepositions that are not so used. The classification is not very useful. It applies the term 'proper' to the very words which are used in two different ways, either as prepositions or as adverbial prefixes to verbs. It applies the term 'improper' to the very words which are used only as prepositions. It does not apply the term 'improper' to the adverbial Accusative nouns which have the function of prepositions. Nor does it take account of other prepositions which may also originally have been Case forms, such as évTós (Ablative) or $\pi \epsilon \rho i ́$ (Locative). See Smyth (1956), $\$ \$ 1647,1699$ and (for a list) $1700-1702$. 


\subsection{Hellenistic and Later Developments}

Prepositions are more often used (with the appropriate Cases) than in the classical period.

But the distinction between $\epsilon \dot{i} S$ + Accusative and $\dot{\epsilon} \nu+$ Dative becomes further blurred.

Fewer prepositions are being used. And their range of meaning is being restricted. By way of compensation, $\epsilon \dot{L} S, \dot{\epsilon} \nu$ and $\epsilon^{\prime} \kappa$ are used more extensively.

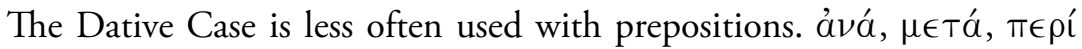
and $\dot{v} \pi$ are no longer used with the Dative at all (except $\dot{v} \pi o ́$ rarely in Polybius).

There is an increasing tendency for each preposition to be used with one Case only.

The Accusative becomes more generally used as the preferred Case with prepositions. In modern Greek, it is the only Case used with prepositions. And only seven prepositions remain in modern Greek.

\section{References}

Leaf \& Bayfield (Eds) (1895), The Iliad of Homer (Vol. 1), \$\$33-35.

Smyth (1956), Greek grammar, \$\$1302, 1636-1702.

\section{EXERCISE 42A}

1. Translate the following passages.

2. For each prepositional phrase in bold type, name the grammatical Case and indicate the particular Case function (apart from the preposition). For the Case functions, see Lessons 37, 38, 39, 40 and 41, and for prepositional expressions of Purpose see Lesson 27.1. Passages for Exercise $42 \mathrm{~A}$ are selected from Herodotus, Thucydides and Xenophon. 


\section{Example}

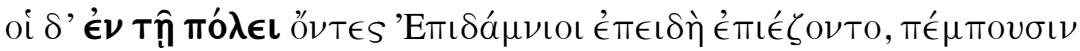

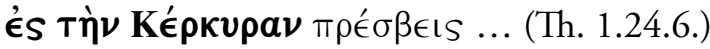

And the Epidamnians who were in the city, since they were being hard pressed, sent [Hist. Pres.] ambassadors to Corcyra...

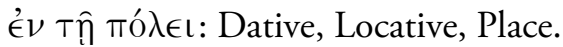

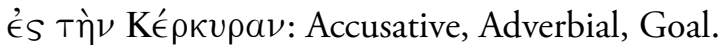

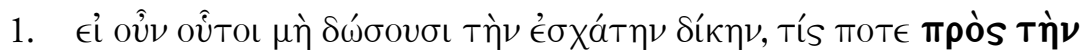

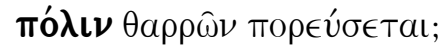

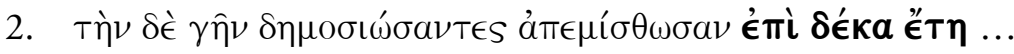

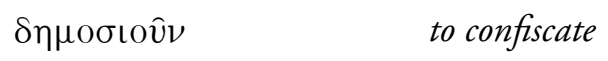

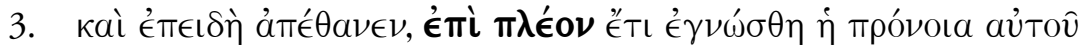
$\dot{\eta} \dot{\epsilon} S$ Tò $\nu \pi o ́ \lambda \epsilon \mu o \nu$.

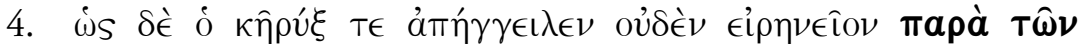

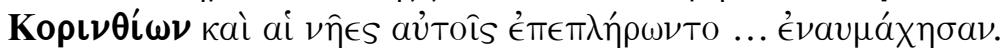

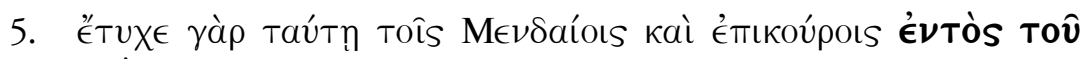

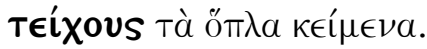

Taúṭฺ here (Dat. as adv.)

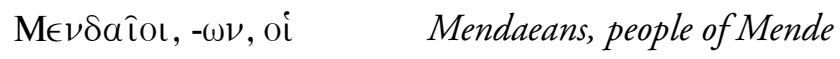

є́тíkoupos, - $a,-\mathrm{O \nu} \quad$ auxiliary (esp. of soldiers)

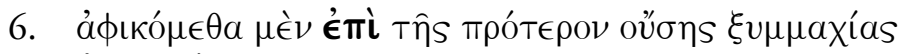

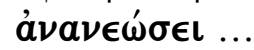

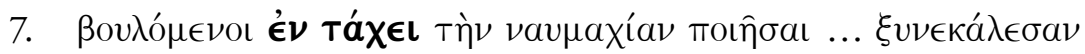
Toùs бтратเі́tas ...

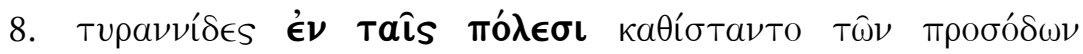

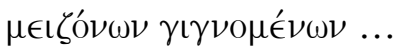

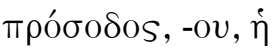

revenue 


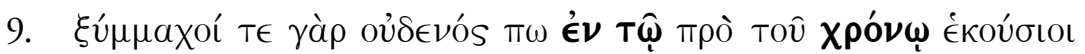

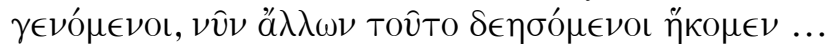

\begin{tabular}{ll}
\hline$\epsilon$ & $\begin{array}{l}\text { anticipates a following kaí and need } \\
\text { not be translated. } \\
\text { this }\end{array}$ \\
$\tau$ Tôे &
\end{tabular}

\section{EXERCISE 42B}

1. Translate the following passages.

2. For each prepositional phrase in bold type, name the grammatical Case and indicate the particular Case function (apart from the preposition). For the Case functions, see Lessons 37, 38, 39, 40 and 41. For prepositional expressions of Purpose see Lesson 27.1. Passages for Exercise 42B are selected from Herodotus, Thucydides and Xenophon.

\section{Example}

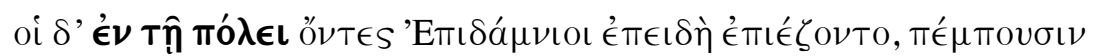

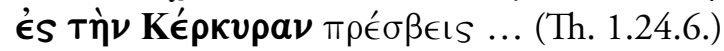

And the Epidamnians who were in the city, since they were being hard pressed, sent [Hist. Pres.] ambassadors to Corcyra ...

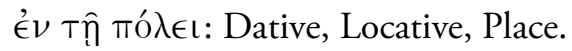

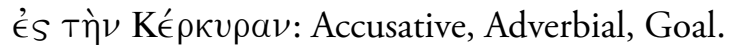

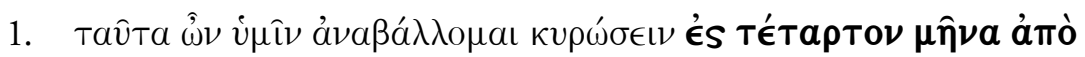

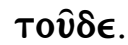

\begin{tabular}{ll}
\hline$\hat{\omega} \nu$ (Ionic) & ởv (Attic) \\
$\hat{\alpha} \nu \alpha \beta a ́ \lambda \lambda \epsilon \sigma \theta a \iota$ (Mid.) & to delay (+ Intentive Infin.) \\
$\kappa v \rho \circ \hat{\nu} \nu$ & to confirm
\end{tabular}

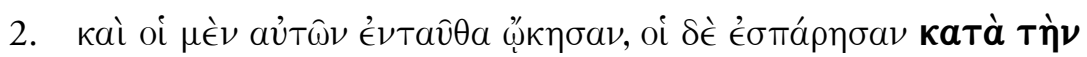

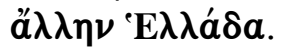




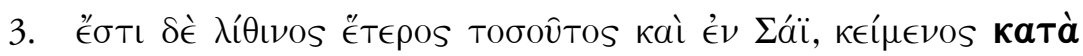

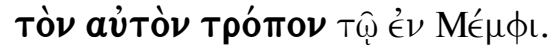

\begin{tabular}{|c|c|}
\hline$\lambda_{i} \hat{\theta} \operatorname{\iota \nu os},(-\alpha,-\mathrm{o \nu})$ & tone (statue) (masc. adj. as noun) \\
\hline kaí & also \\
\hline sáïs & (place name) \\
\hline$T \widehat{\varphi}\left\langle\ldots \lambda_{\imath} \theta^{\prime} \nu^{\prime} \nu \omega\right\rangle$ & Dat. with aưTóv \\
\hline
\end{tabular}

4. $\beta a \sigma ı \lambda \epsilon ́ i ̈ ~ T \hat{~}$

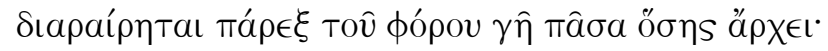

\begin{tabular}{ll}
\hline$\iota \boldsymbol{\iota}-a i \rho \in \hat{\imath} \nu$ & to divide up (here Pres. Perf. Pass.) \\
$\pi a ́ \rho \in \xi$ & apart from (+ Gen.)
\end{tabular}

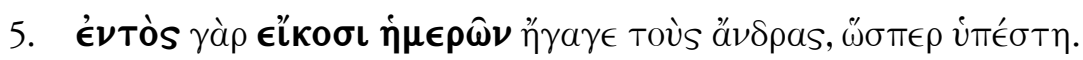
iфıбтávaı to promise (Mid./Pass. and Intr. Tenses)

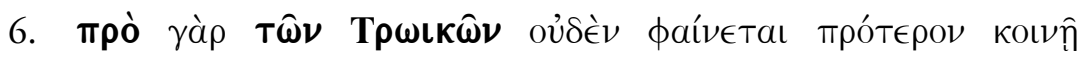

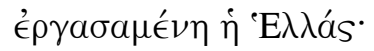

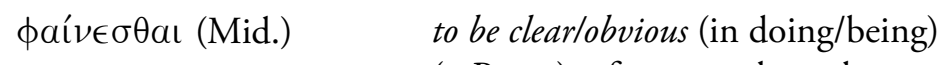

(+ Partc.); often paraphrased as

'It is clear that I (etc.) do/am ...'

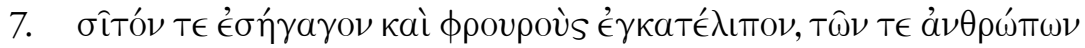

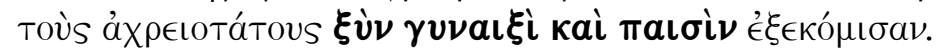
$\grave{a} \times \rho \in \hat{\imath} \mathrm{os},(-\alpha)-,\mathrm{ov}$
unfit

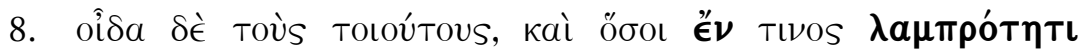

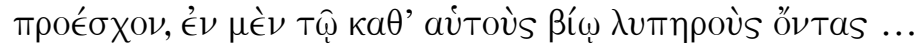

\begin{tabular}{|c|c|}
\hline Tıvos (neut.) & in any <field >, etc. \\
\hline$\lambda а \mu \pi \rho о ́ т \eta s,-\eta т о s, \dot{\eta}$ & distinction \\
\hline$\pi \rho \circ \operatorname{é} \chi \in \mathrm{IV}$ & to excel \\
\hline 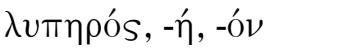 & annoying \\
\hline
\end{tabular}




\section{LESSON 43 \\ Correlative Clauses}

\subsection{Introduction}

Clauses, which are introduced by a relative adjective or adverb, may have as their antecedent the corresponding demonstrative adjective or adverb. The antecedent may appear in the Main clause of a sentence, or in a Subordinate clause or an Infinitive or Participial phrase. The relative term, but not necessarily the demonstrative, always occurs at the beginning of its clause.

\subsection{Adjectival Clauses}

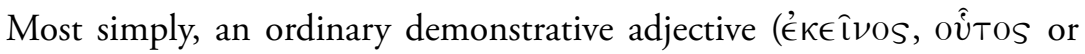
less often ö $\delta \epsilon)$ is antecedent to the definite or indefinite relative adjective (ös or ö $\sigma \tau t S$ ) introducing the relative clause. Both demonstrative and relative adjectives may be used as adjectives qualifying a noun or as pronouns without a noun. All adjectival relative clauses may precede, follow or interrupt the demonstrative clause or phrase. Since relative adjectives agree with their antecedent in Number and Gender but take their Case from the syntax of their own clause, they are not necessarily in the same Case as the corresponding demonstrative term.

In addition there are the special demonstrative adjectives and their corresponding relative adjectives.

\section{Category Demonstrative adjective Relative adjective}

\begin{tabular}{|c|c|c|}
\hline size, number & 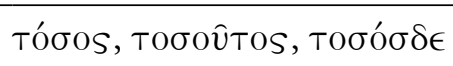 & 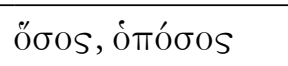 \\
\hline quality & 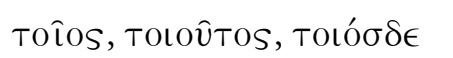 & oíos, ómô̂os \\
\hline age, size, status & 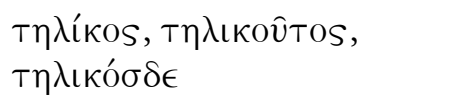 & 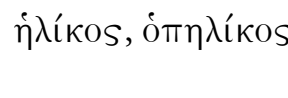 \\
\hline
\end{tabular}


A special demonstrative term may sometimes correspond to an ordinary relative term. And a demonstrative clause may sometimes correspond to an Infinitive construction instead of a clause with a finite verb.

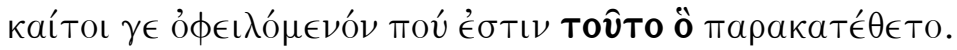
(Pl.R. 332 A.)

And yet this which he entrusted is surely owed.

Tоט̂To (Nom. demonstrative) corresponds to ö (Acc. relative). (Cf. Lesson 25.)

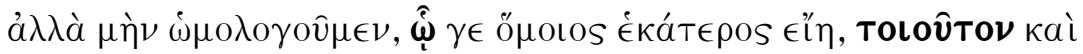

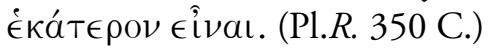

But in fact we agreed that, to what each is like, such also each is.

Toเov̂Tov (Acc. demonstrative of quality) in reported discourse (Acc. and Infin.) corresponds to $\hat{\dot{\varphi}}$ (Dat. ordinary relative).

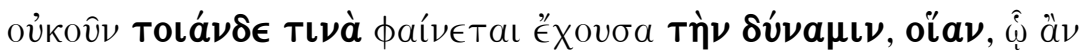

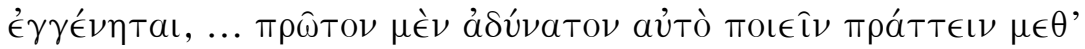

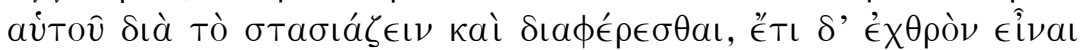

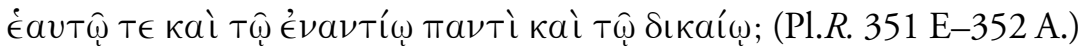

Therefore, does it [= injustice] not clearly have its power of some such sort, as, in whatever it occurs ... in the first place it [= injustice] makes it impossible for it [ = that in which injustice occurs] to deal with itself on account of being at odds and quarrelling, and further it is hostile to itself and to every opponent including the just?

Toıá $\nu \delta \in$ (Acc. demonstrative) corresponds to olia (Acc. relative with Result Infin. construction). (Cf. Lessons 22 and 28.5.)

\subsection{Adverbial Clauses}

Parallel to correlative adjectival clauses, some types of adverbial clause may have a demonstrative adverb as antecedent to a relative adverb introducing the relative clause. These relative adverbs may also be viewed as subordinating conjunctions. The relevant types are adverbial clauses of Time (Temporal), Place (Local), Manner (including Comparison) and Result. 


\subsubsection{Clauses of Time}

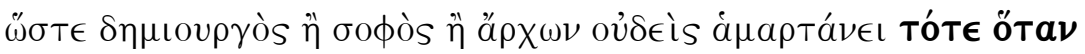

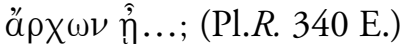

And so no craftsman or scientist or ruler makes a mistake then when he is ruling ...?

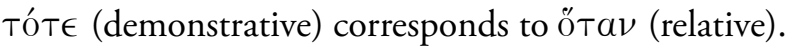

(Cf. Lessons 30 and 31.)

\subsubsection{Clauses of Place}

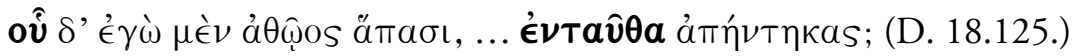
But where I <am> immune in all respects, ... here you have confronted me?

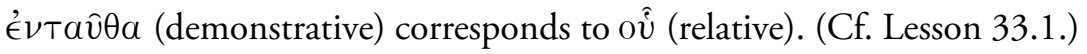

\subsubsection{Clauses of Manner}

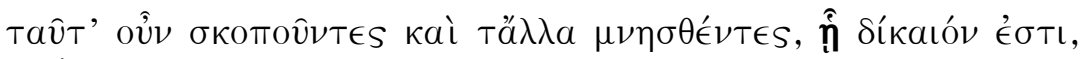

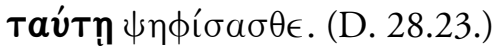

Therefore, considering this and recalling the other <points $\rangle$, in what way it is just, in this way vote.

Taúṭ̣ (demonstrative) corresponds to ị̂ (relative). (Cf. Lesson 33.2.)

\subsubsection{Clauses of Comparison}

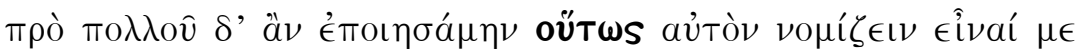
$\delta \in \iota \nu o ́ \nu, \ddot{\omega} \sigma \pi \epsilon \rho \dot{\epsilon} \nu \dot{v} \mu \hat{\imath} \nu \in \ell \not \emptyset \eta \kappa \in \nu$. (Isoc. 15.15.)

And I would have regarded it as important, that he should think that I am so clever, as indeed he has said in your presence.

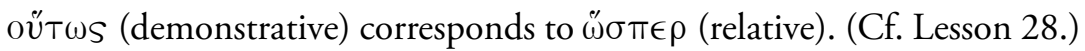




\subsubsection{Clauses or Phrases of Result}

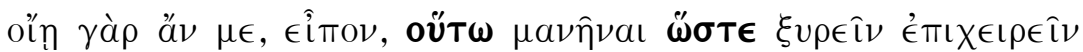

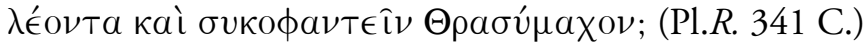

'Do you really think that I', I said, 'would become so mad as to try to beard the lion and outwit Thrasymachus?'

oưt $\omega$ (demonstrative) in reported thought (Acc. and Infin.) corresponds to $\ddot{C} \sigma \tau \epsilon$ (relative) introducing the relative phrase (also Acc. and Infin.). (Cf. Lesson 22.)

\subsection{Interrogative Antecedent}

Correlative sentences, which are questions rather than statements, may have an interrogative pronoun instead of a demonstrative pronoun as antecedent.

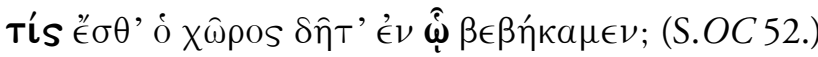

What is the place, then, into which we have come?

\subsection{Mixed Adjectival and Adverbial Construction}

In $\$ \$ 43.2-3$ above, examples have been restricted to sentences either with demonstrative and relative adjectives or with demonstrative and relative adverbs. However, Result constructions may also have a demonstrative adjective as antecedent to the relative adverb $\omega \sigma \tau \epsilon$ introducing a Result clause or phrase.

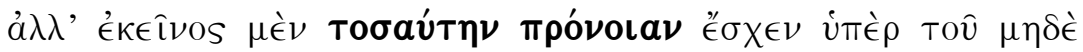

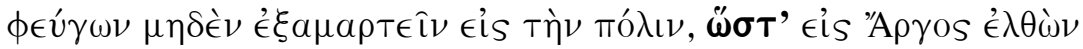

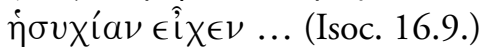

But that man took so much care over doing no wrong against his city even when he was in exile, that he went to Argos and kept quiet ...

(Cf. Lesson 22.1.) 


\subsection{Pronominal Idioms}

\subsubsection{Result}

A particular Result construction has the form: €ís Toбov̂To(v)/Tov̂To (pronoun) + Partitive Genitive + verb of 'coming' (or similar) + $\tilde{\sigma} \sigma \tau \epsilon$ with Result clause or phrase. (The construction also occurs without the Gen. term.)

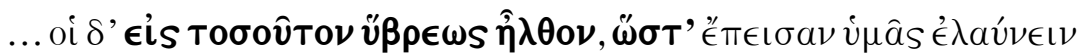

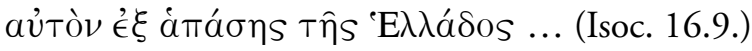

... but they came to so great $<$ a level $>$ of insolence, that they persuaded you to drive him out of all Greece ...

(Cf. Lesson 22.3, first example.)

\subsubsection{Dative of Degree of Difference}

The Dative of Degree of Difference is a pronominal idiom, and is often but not always used in a correlative construction.

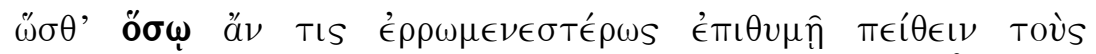

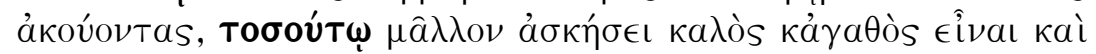

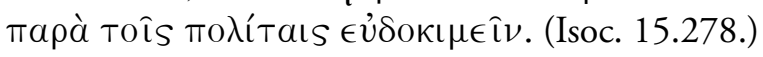

And so the more strongly any one desires to persuade his hearers, (so much) the more he will endeavour to be fine and good and to be in high regard among the citizens.

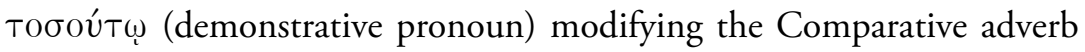
$\mu \hat{a} \lambda \lambda \mathrm{o \nu}$ in the leading clause corresponds to ö $\sigma \omega$ (relative pronoun) modifying the Comparative adverb $\epsilon^{\prime} \rho \rho \omega \mu \in \nu \in \sigma \tau \epsilon \in \operatorname{sis}$ in the relative clause. (Cf. Lesson 41.2.3.)

\subsection{Note}

Since correlative clauses do not receive adequate attention in standard Greek grammars, no references are given for this Lesson. 


\section{EXERCISE 43}

Translate the following passages.

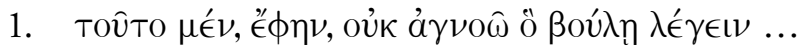

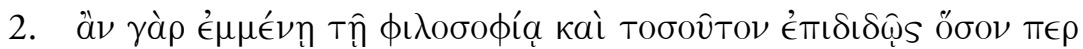

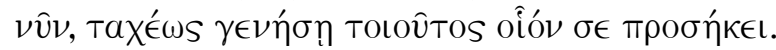

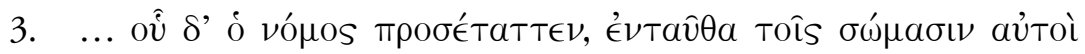

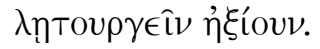

$\lambda \eta ฺ т о u \rho \gamma \epsilon \hat{\imath} \nu$

to perform public service, to serve (later $\lambda \in \iota$ Toup $\gamma \in \hat{\imath} \nu$ )

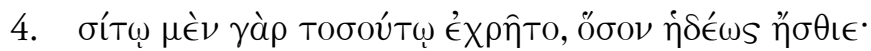

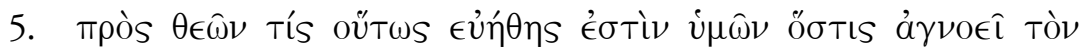

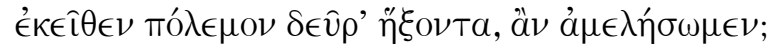

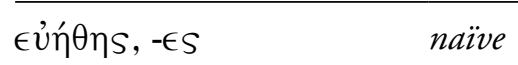

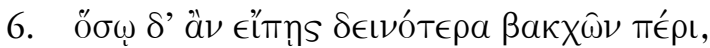

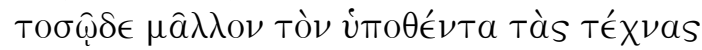

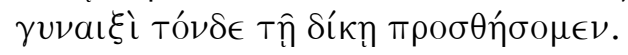

$\delta i ́ \kappa \eta,-\eta s, \dot{\eta} \quad$ punishment

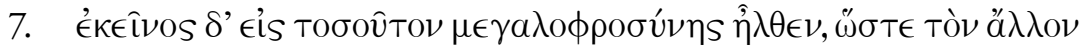

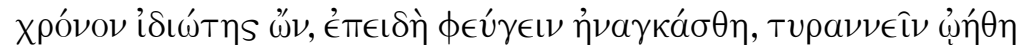
$\delta \in \hat{\imath} \nu$.

8. And they were annoyed then, when we thought it right that we should legally have control over certain people.

\begin{tabular}{|c|c|}
\hline to be annoyed & 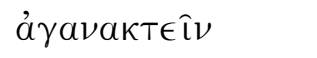 \\
\hline legally & $\nu o \mu i ́ \mu \omega s$ \\
\hline to have control over & $\epsilon \in \pi \alpha ́ \rho \chi \in \mathrm{L} \nu$ (+ Gen.) \\
\hline
\end{tabular}


9. Thus it seems to me at least that, in what way [it is] easiest, in this way also it is best to do this.

\begin{tabular}{|c|c|}
\hline thus & 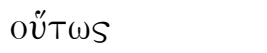 \\
\hline easiest & 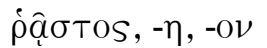 \\
\hline
\end{tabular}





\section{LESSON 44 \\ Exclamations}

\subsection{Exclamatory Cries}

In the English language, a number of terms are used in isolation to express various emotions. These terms often seem to have no etymology, but are merely grunts, cries, screams and so on: 'wow!', 'whew!', 'aha!', 'ugh!', etc. Similarly, in Greek there are numerous terms expressing a range of emotions. Most simply, the terms stand alone and are marked off by a full stop or colon in modern editions of Ancient Greek writings. Alternatively, such terms may interrupt a Greek sentence at the beginning, middle or end, and may be separated only by commas. It may be difficult to find suitable English equivalents for some of these terms. And sometimes transliteration is a better solution than translation.

The English exclamation mark (!) is not normally used in Greek punctuation. (Occasionally, some modern editors have used it.) In Greek verse texts, some exclamatory cries are 'outside the metre' (extra metrum), and may or may not have a line number.

ӧтотототої.

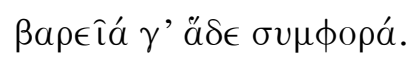

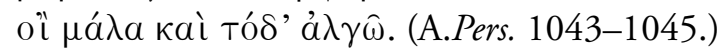

\section{Ototototoi!}

This calamity <is $>$ burdensome indeed.

Alas, I am greatly pained at this too.

о่тототото $̂$ (a cry of pain or grief) stands alone.

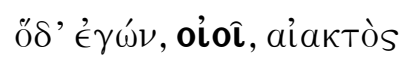

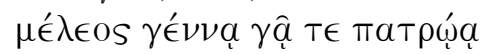

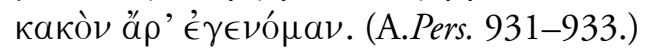


Here I, alas, a lamentable,

wretched <figure>, became a disaster, then,

for my race and my fatherland!

olô̂ (a cry of pain, grief, pity or astonishment) interrupts the sentence.

\subsection{A Cry with First Person Singular Pronoun}

Reflecting the emotional involvement of an individual speaker, the first person singular pronoun may be combined with a cry. Most often the pronoun is a Dative of Interest $(\mu \mathrm{ol})$, which may be repeated. Sometimes the Nominative $(\dot{\epsilon} \gamma(\dot{\omega})$ is added to the Dative.

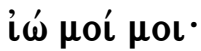

Tí $\phi \hat{\omega} ;($ E.Hipp. 1384-1385.)

Ab me, ab me!

What am I to say?

$i \omega ́$ (a cry of grief, suffering or appeal) is used with $\mu$ o repeated.

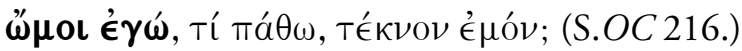

Ab me, ab me! What is to become of me, my child?

$\ddot{\omega}$ (a cry of surprise, joy or pain) with $\mu \mathrm{ol}$ (Dat.) and $\epsilon^{\prime} \gamma \dot{\omega}$ (Nom.).

\subsection{An Exclamation with a Causal Genitive}

The reason for an exclamation may be expressed by a Causal Genitive phrase. Such Genitive phrases may be added either to a mere cry, or to an exclamatory Nominative phrase. (Cf. Lesson 36.6.)

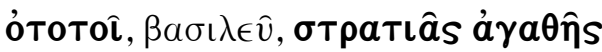

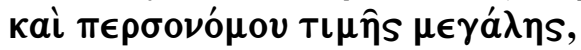

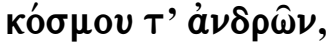

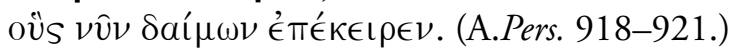

Ototoi, $<O>$ king, for the noble army and for the great honour of Persian rule, and for the splendour of the men, whom now a deity <has > cut down!

The series of Genitive phrases gives the reason for the Chorus's cry, ӧтото $\hat{\imath}$. 
¡́́,

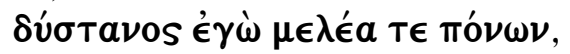

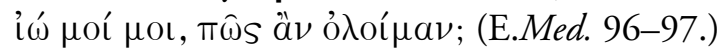

Ah,

unfortunate <am>I and wretched because of my troubles,

ah me, ah me, may I perish!

The Genitive $\pi$ ó $\nu \omega \nu$ gives the reason for Medea's exclamation that she is unfortunate and wretched. (The term '<am>' would be better omitted if English idiom allowed, since the phrase is an exclamatory Nom. rather than a statement.)

\subsection{Exclamatory Infinitive Phrases}

In English, an exclamation may be expressed in an Infinitive phrase.

Oh, to be in England

Now that April's there ... (R. Browning, Home Thoughts from Abroad, lines 1-2.)

Exclamatory Infinitive phrases also occur in classical Greek, mainly in drama. The Infinitive may have an explicit Accusative Subject; otherwise, such a Subject is implied in the context. And the Infinitive may have its own neuter Accusative definite article.

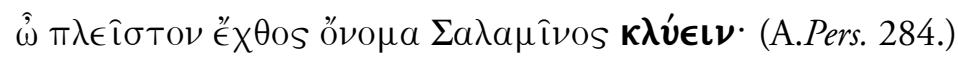

Oh, <even $>$ to hear the name of Salamis, greatest object of hate!

Infinitive phrase without definite article and without Accusative Subject. The Messenger, who speaks the line, could easily be supplied as Accusative Subject of the Infinitive: 'Oh, that $<\mathrm{I}>$ should even hear ...!'

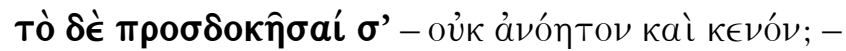

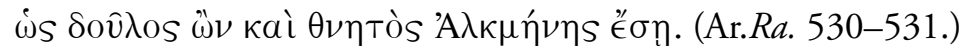

And that you should expect - <is it $>$ not senseless and empty-headed? that, although you are a slave and a mortal, you will be Alcmena's <son>!

Infinitive phrase with definite article and with explicit Accusative Subject $(\sigma(\epsilon))$. (For the sake of clarity, W. B. Stanford's punctuation has been followed.) 


\subsection{Exclamatory Sentences Introduced by oíos, öros or $\dot{\omega}$}

Exclamations may be expressed in a phrase or a full sentence which is introduced by the relative adjectives oîs and öбos or by the relative adverb $\dot{\omega} s$. oíos and öoos may be used alone as pronouns, or may qualify a noun. $\dot{\omega} s$ may modify the verb in its sentence, or an adjective or another adverb.

\subsection{1. oîs}

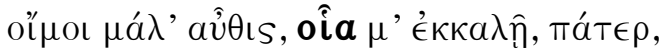

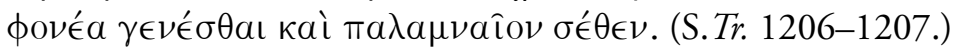

Alas yet again, to what you do summon me, father,

to become your murderer and blood-guilty!

o $\hat{i} \alpha$ is used as a pronoun.

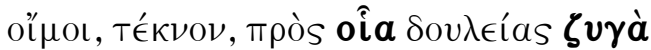

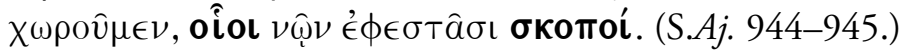

Alas, <my son, to what a yoke of slavery

we are going! What guardians stand over us both!

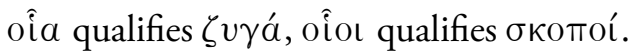

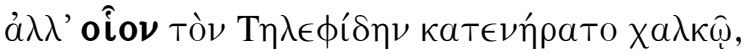

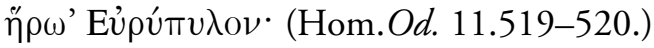

But what <a man was $>$ that son of Telephus <whom > he killed with his bronze spear,

the hero Eurypylus!

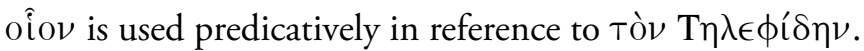

\subsection{2. öбos}

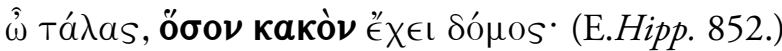

$O$ wretched <man $>$, how great a trouble the house contains!

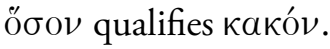




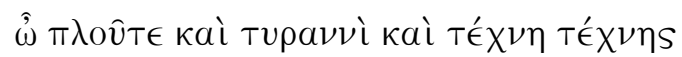

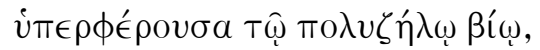

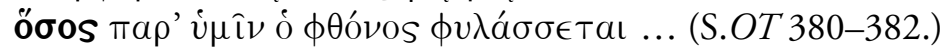

$O$ wealth and royal power and skill surpassing

skill in the greatly-envied life,

bow great $<i s>$ the jealousy $<$ that $>$ is fostered among you ...!

ő $\sigma 0 s$ is used predicatively in reference to ó $\phi \theta$ óvos.

\subsection{3. is}

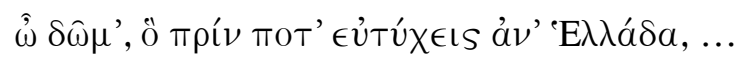

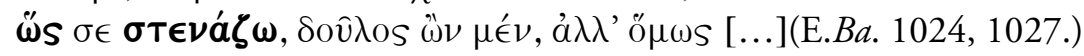

O house, which once in the past were fortunate throughout Greece ...

how I, slave though I am, nevertheless lament for you ...

is modifies the verb $\sigma \tau \epsilon \nu a ́ \zeta \omega$.

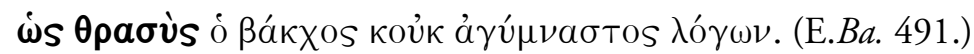

How bold the bacchanal and not unpractised in arguments!

is modifies the adjective $\theta$ parús.

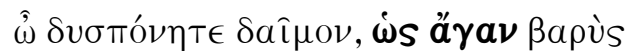

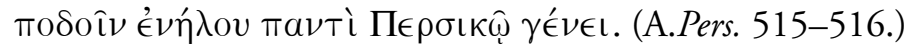

O troublesome deity, how excessively heavily

you leapt with both feet upon all the Persian race!

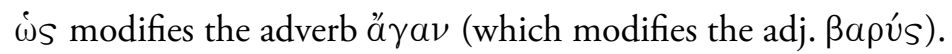

\subsection{Interrogative Adjective or Adverb}

It is sometimes suggested that an interrogative adjective or adverb may introduce an exclamation. However, it seems better to regard such sentences as being rhetorical questions, at least until the end of the classical period. In the Hellenistic period, exclamations may be introduced by an interrogative term. The following examples from early verse, late classical prose and early Hellenistic verse illustrate the usage. 


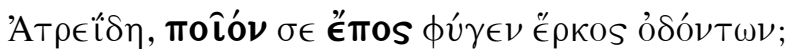

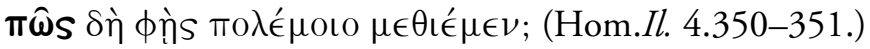

Son of Atreus, what word escaped from you <through $>$ the barrier of your teeth? How indeed do you say that <we > are holding back from war?

Although line 350 has sometimes been treated as an exclamation, it is better understood as a rhetorical question in keeping with line 351. To îv ... Étros (350) corresponds in meaning to $\pi \omega \hat{s}$... $\phi$ ṇs (351).

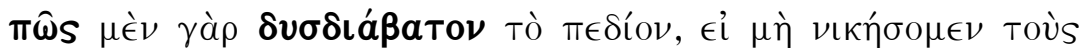

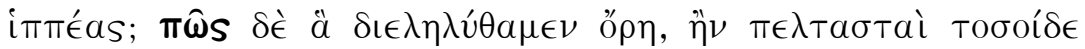

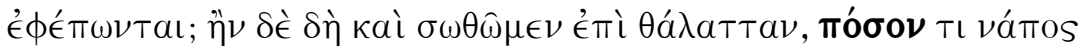
ó Пóvtos; (X.An. 6.5.19-20.)

For how hard to cross <will $>$ the plain <be>, if we do not defeat the cavalry? And how <hard > the mountains which we have passed through, if so many light-armed troops pursue? And if indeed we get safely to the sea, about how big a ravine <is $>$ the Euxine?

Xenophon, in a speech, is exhorting his troops to battle and arguing that the ravine in front of them is no more difficult or dangerous than the terrain or sea over which they have already passed or will have to pass. The questions, on the borderline between literal and rhetorical, would not make sense as exclamations. Xenophon does not want to say: 'How difficult it will be!'

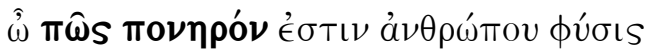

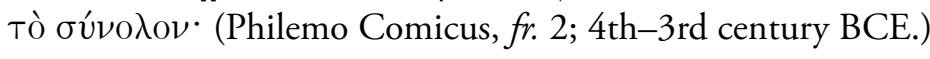

Oh, how evil a thing is the nature of man

in general!

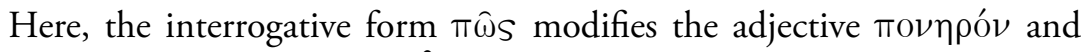
is definitely exclamatory, as $\hat{\omega}$ (or $\dddot{\omega}$ : manuscripts vary) helps to confirm.

\subsection{Reported Exclamations}

Smyth (1956, \$\$2685-2687) classifies some sentences as 'indirect' or 'dependent' exclamations, while acknowledging that it 'is often difficult to distinguish between indirect exclamations and indirect questions' (\$2685). In practice, with one possible exception, all the examples in his $\$ 2686$ can 
be classified as reported questions. And none of the examples in $\$ 2687$ is a reported exclamation. Instead, there are adjectival clauses (Hom.Il. 21.399; Pl.Phd. 117 C-D), a direct exclamation (Ar.Nu. 1206-1211), an ambivalent adjectival clause or reported question (Pl.R. $329 \mathrm{~B}$ ), a Causal clause (Pl.Phd. $58 \mathrm{E}$ ) and an adverbial clause of place (Ar. V. 1450-1452, metaphorical).

The one possible exception is Pl.Tht. 142 B. At this early stage, only Euclides and Terpsion have been involved in the dialogue. Terpsion exclaims:

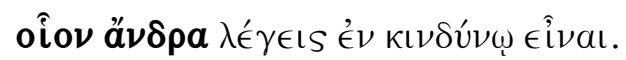

What a man you say is in danger!

The grammatical construction is Accusative and Infinitive of reported speech. And yet, this is not a reported exclamation. For Euclides has not said 'What a man!', he has only said, in different words, that Theaetetus 'is in danger', specifically, that he is severely wounded and has dysentery. Terpsion himself, who is not the Subject of $\lambda \epsilon ́ \gamma \in \mathrm{IS}$, is responsible for the exclamatory component of the sentence. The sentence is an abbreviation of the expression 'What a man <he is, who $>$ you say is in danger!' Euclides immediately confirms this general value judgment with the specific phrase

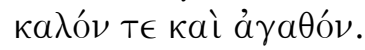

A comment from the Chorus-leader in the Trachineae follows a similar pattern.

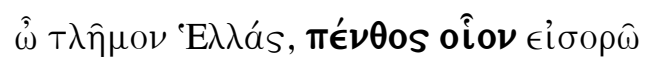

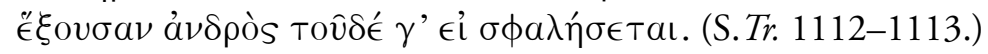

O poor Greece, what grief I see

that it will have if it is (going to be) cheated of this man!

The Vocative phrase is exclamatory, not a genuine address. The following grammatical construction is Accusative Participle of reported mental

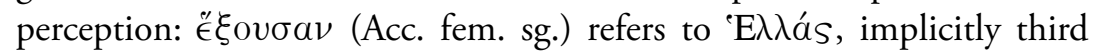
person as $\sigma \phi a \lambda \eta \dot{\sigma} \sigma \epsilon a$ s shows.

If the reading $\dot{\alpha} \lambda \lambda$ ' o $\hat{i}$ ov (rather than $\dot{\alpha} \lambda \lambda$ o $̂ 0 \nu$ ) is accepted, then Hom.Il. 5.638-639 would already provide another example. 


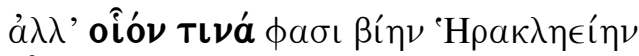
Eival ...

But what a $<$ man $>$ they say that the strength of Heracles was...!

(The phrase 'strength of Heracles' for 'strong Heracles' is a standard idiom; cf. Hom.Il. 2.658; 11.690.)

Each of these three examples occurs in a passage of direct speech. The speaker is responsible for the exclamatory component of each sentence, whether she is reporting her own observation (S.Tr.), or he is reporting an interlocutor's implied comment (Pl. Tht.) or the statements of people in general (Hom.Il.). It is not so much that the sentences themselves are reported (or indirect or dependent) exclamations. Rather, the exclamations occur in a subordinate phrase of the sentences: Accusative and Infinitive or Participle.

\section{References}

Goodwin (1889), Syntax of the moods and tenses of the Greek verb, \$\$787, 805 (Infinitive).

Smyth (1956), Greek grammar, \$\$2015, 2036, 2575.4, 2681-2687.

\section{EXERCISE 44}

Translate the following passages.

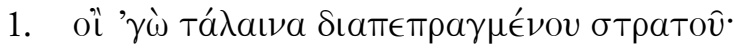

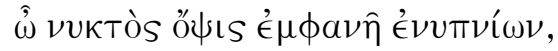

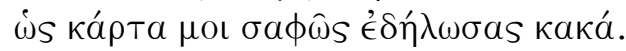
to bring to an end, to destroy (here Pass.)

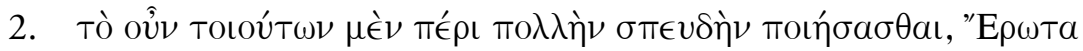

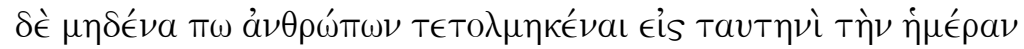
$\dot{a} \xi \hat{i} \omega s \dot{v} \mu \nu \eta \hat{\eta} \sigma a l \cdot$

\begin{tabular}{|c|c|}
\hline oนิ้ & well then \\
\hline 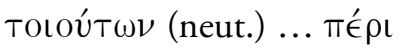 & See Lesson 42.8. \\
\hline
\end{tabular}




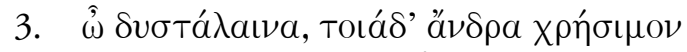

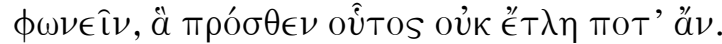

$\hat{\omega} \delta v \sigma \tau a ́ \lambda a \iota v a \quad$ The speaker addresses herself.

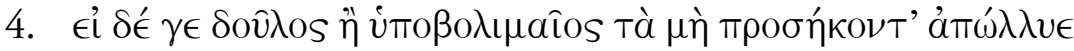

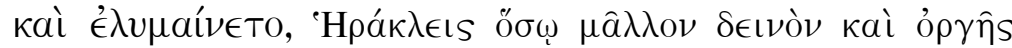

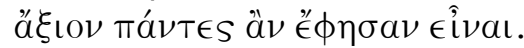

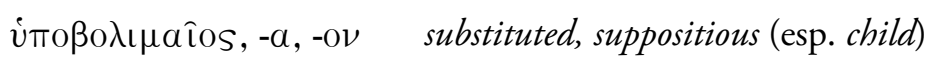

$\lambda v \mu a i ́ v \in \sigma \theta a \mathrm{l}$ (Mid.) to misuse

'Hрák $\lambda \in I S \quad$ exclamatory Voc.

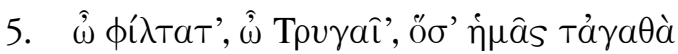

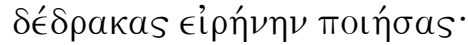

6. ¿̈̋

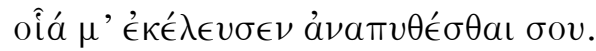

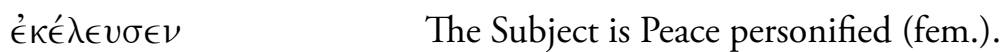

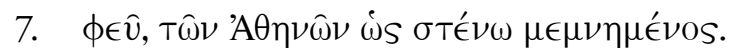

8. O men, how pleasant [it is] to see your faces!

9. And how many cities he captured without crossing the ford of the river Halys

nor rushing off from his hearth...!

\begin{tabular}{|c|c|}
\hline ford & тópos, -ov, ó \\
\hline Halys & "A $\lambda u s,-v o s, \dot{O}$ \\
\hline to rush off & $\sigma \dot{\epsilon} \in \sigma \theta a \iota$ (Pass.), $\sigma v \theta \hat{\eta} \nu a \iota$ (Aor.) \\
\hline
\end{tabular}





\section{Bibliography}

\section{Standard References}

Goodwin, W. W. (1889). Syntax of the moods and tenses of the Greek verb (Rev. ed.). London: Macmillan.

Liddell, H. G. \& Scott, R. (1996). A Greek-English lexicon (9th ed.). (H. S. Jones $\&$ R. McKenzie, Eds.). Oxford: Clarendon Press.

Montanari, F. (2015). The Brill dictionary of Ancient Greek. Leiden \& Boston: Brill.

Smyth, H. W. (1956). Greek grammar (Rev. ed.) (G. M. Messing, Ed.). Cambridge, MA: Harvard University Press.

\section{Other References}

Allen, W. S. (1987). Vox Graeca: A guide to the pronunciation of classical Greek (3rd ed.). Cambridge: Cambridge University Press.

Denniston, J. D. (1954). The Greek particles (2nd ed.). Oxford: Clarendon.

Gildersleeve, B. L. (1900-1911). Syntax of classical Greek from Homer to Demosthenes (Vols 1-2). New York: American Book Company.

Hesiod. (1966). Theogony. (M. L. West, Ed.). Oxford: Clarendon.

Humbert, J. (1954). Syntaxe Grecque. (2nd ed.). Paris: Klincksiek.

Joint Committee on Grammatical Terminology. (1911). On the terminology of grammar: Being the report of the Joint Committee on Grammatical Terminology. London: J. Murray.

Kühner, R. (1890-1904). Ausführliche Grammatik der Griechischen Sprache (Vols 1-2). (B. Gerth, Ed.). Hanover: Hahnsche Buchhandlung.

Leaf, W. \& Bayfield, M. A. (Eds). (1895). The Iliad of Homer (Vol. 1, \$\$33-35). London: Macmillan. 
Masterman, K. C. (1962). On grammatical terminology and aspect in particular. Greece and Rome, 9, 72-86.

Moorhouse, A. C. (1982). The syntax of Sophocles (Mnemosyne Supplement 75). Leiden: Brill.

Paley, F. A. (Ed.). (1883). The Epics of Hesiod. London: Whittaker and Bell.

Palmer, L. R. (1980). The Greek language. London: Faber and Faber.

Probert, P. (2003). A new short guide to the accentuation of Ancient Greek. Bristol: Bristol Classical Press.

Rijksbaron, A. (1994). The syntax and semantics of the verb in classical Greek (2nd ed.). Amsterdam: Gieben.

Schwyzer, E. (1950). Syntax und Syntaktische Stilistik (Griechische Grammatik, vol. 2). (A. Debbruner, Ed.). München: Beck. 


\section{Index of Passages Quoted in the Lessons}

Abbreviations of the titles of the works of Greek authors follow the usage of H. G. Liddell and R. Scott (1996) A Greek-English lexicon. References are made to the Lesson and Section number.

Aeschines

3.2

3.124

Aeschylus

Ag. 49

Ag. 861-862

Ag. 1056-1057

Ch. 195

Eu. 611-613

Eu. 674-675

Pers. 284

Pers. 515-516

Pers. 731

Pers. 742

Pers. 918-921

Pers. 931-933

Pers. 1043-1045

Pr. 3-4

Pr. 29-32

Pr. 35

Pr. 36

Pr. 41

Pr. 48

Pr. 115

Pr. 135

Pr. 153-155
Pr. 160-161

11.4 Pr. 162-163

7.3 Pr. 173-177

Pr. 211-213

Pr. 247

42.9 Pr. 253

41.1.1 Pr. 294-295

27.1 Pr. 299-302

11.2.1.1 Pr. 302-303

18.3 Pr. 377-378

10.4.1 Pr. 485-486

44.4 Pr. 500-504

44.5.3 Pr. 520

39.4.3.2 Pr. 564-565

30.2.2 Pr. 616-617

44.3 Pr. 648-649

44.1 Pr. 717-718

44.1 Pr. 735-737

$25.2 \operatorname{Pr} .764-765$

25.5 Pr. 825

25.4.3 Pr. 997

17.5 Pr. 1073-1075

17.1 Suppl. 398-399

11.2.2.2 Th. 247

17.3 Th. 261

9.4 Th. 550-551

11.2.1.2
17.3

17.5

32.3.2.1

18.4

17.1

17.1

18.4

17.3

17.1

17.1

18.4

17.5

10.3.6

18.4

2.3.3

6.2

25.2

17.1

7.3

32.2

18.1

42.6

26.2

5.2

10.3.6

11.1.2 
INTERMEDIATE ANCIENT GREEK LANGUAGE

\section{Andocides}

1.2

1.12

1.12

1.14

1.17

1.19

1.28

1.41

1.41

1.45

1.51

1.55

1.59

1.64

1.109

1.136

1.137

1.149

3.32

Antiphon

1.1

Aristophanes

Ach. 221-222

Ach. 639-640

Ec. 300-301

Ec. $1038-1040$

Eq. 36

Eq. 698-699

Lys. 1276-1277

Nu. 296-297

Nu. 832-833

Ra. 524-525

Ra. 530-531

Ra. 748

Ra. 1006-1007

V. 37
Demosthenes

5.1.4 1.3

$5.1 .2 \quad 1.12$

$13.3 \quad 3.22$

$15.3 \quad 4.15$

$14.2 \quad 6.28$

$13.3 \quad 8.53$

$2.3 .1 \quad 9.16$

$14.2 \quad 9.45$

$14.3 \quad 9.60$

4.3.2 15.5

2.3.2 18.71 (twice)

$\begin{array}{ll}5.1 .5 & 18.125\end{array}$

5.1.3 18.142

$13.3 \quad 18.220$

$\begin{array}{ll}5.1 .1 & 18.292\end{array}$

$8.4 .1 \quad 19.99$

$22.1 \quad 19.179$

$22.7 \quad 19.316$

$4.3 .2 \quad 21.221$

22.17

22.41

39.3.7 23.12

23.79

24.9

$26.2 \quad 28.23$

$19.4 .3 \quad 33.11$

$24.2 .1 \quad 35.26$

$23.1 .2 \quad 37.45$

$11.5 \quad 42.22$

20.2.2.2 43.55

$24.5 \quad 43.61$

$\begin{array}{ll}10.3 .5 & 49.17\end{array}$

22.3

10.3.4 Euripides

44.4 Alc. 24-26

34.2.2 Alc. 32-33

34.2.6 Alc. 40

2.3.1 Alc. 43

Alc. 138-139
38.2

38.3

40.2 .1

39.4 .1

35.7

4.3.2

30.3 .1

29.9

8.4 .2

35.6 .1

37.1 .8

24.3.5

41.2 .3

34.2 .5

17.2

43.3 .2

35.4 .1

22.1

34.2 .2

35.5

16.3

27.5

35.6 .4

34.2 .4

23.1.1

41.1 .3

18.3

29.6.9

43.3 .3

18.1

37.1 .4

3.5 .3

38.10

41.1.3

18.1

35.4.1

40.2.1 
INDEX OF PASSAGES QUOTED IN THE LESSONS

Alc. 199-200

Alc. 540

Alc. 625-627

Alc. 636

Alc. 642

Alc. 696-698

Alc. 707

Alc. 731

Alc. $734-736$

Alc. $774-775$

Alc. $800-802$

Alc. 821

Alc. 1072-1074

Andr. 1-6

Ba. 1

Ba. 216-220

Ba. 341

Ba. 491

Ba. 519-532

Ba. 718-721

Ba. 945-946

Ba. 1024...1027

Ba. 1043-1045

Ba. 1058-1062

Hel. 267-268

Hel. 462

Hel. 597-598

Hipp. 498-499

Hipp. 518

Hipp. 852

Hipp. 1265-1267

Hipp. 1384-1385

Hipp. 1402

IA 1467-1469

IT 157-166

IT 260-261

IT 588-590

Med. 1-2

Med. 6-8

Med. 95
41.2.2 Med. 96-97

19.4.2 Med. 153-154

36.7 Med. 269-270

36.2 Med. 350-351

41.1.3 Med.352-354

39.4.2.2 Med. 529

36.7 Med. 566-567

40.2.2 Med. 579

40.3.1 Med. 636

40.3.5 Med. 645-648

41.2.1.4 Med. 703

36.7 Med. 1059-1061

11.2.1.1 Med. 1169-1170

36.8 Med. 1271

37.2.1 Med. 1306-1307

25.6 Med. 1409-1412

2.3.2 Ph. 263-264

44.5.3 Ph. 762

36.8 Ph. 1174-1176

11.5 Supp. 120

40.3.3 Tr. 636-637

44.5.3 Tr. 1165-1166

31.3.1

12.2 Herodotus

$25.7 \quad 1.33$

$\begin{array}{ll}7.3 & 1.50 .3\end{array}$

$37.2 .2 \quad 1.65 .5$

$10.3 .4 \quad 1.73 .3$

$35.6 .1 \quad 1.82 .7$

$\begin{array}{ll}44.5 .2 & 1.86 .2\end{array}$

$29.4 .3 \quad 1.89 .3$

$44.2 \quad 1.91 .1$

39.4.3.1 1.94.1

$37.1 .5 \quad 1.115 .2$

$36.8 \quad 1.126 .5$

$42.6 \quad 1.129 .2$

$27.4 \quad 1.134 .1$

$42.4 \quad 1.134 .2$

$37.2 .6 \quad 1.154$

2.3.3 1.178 .3
44.3

38.6

15.4

15.3

19.2 .1

40.2 .3

41.2.1.3

37.2 .6

11.1.1

38.7

7.3

37.1 .8

29.6.3

17.4

33.4

29.4.1

35.4 .2

42.9

29.6.7

27.3

3.5 .3

25.7

23.2

9.3.2

31.3.1

23.3

32.3.2.2

29.4.7

25.2

3.4 .1

38.8

42.7

4.4

39.2 .3

41.2 .3

41.2.3

23.3

39.3 .7 
INTERMEDIATE ANCIENT GREEK LANGUAGE

\begin{tabular}{|c|c|c|c|}
\hline 3.44 .2 & 10.4 .1 & Th. $280-283$ & 23.1.4. \\
\hline 3.72 .3 & 25.4 .1 & Th. 533-534 & 9.3 .4 \\
\hline 3.122 .3 & 15.5 & & \\
\hline 3.135 .2 & 10.4 .2 & Homer & \\
\hline 3.135 .3 & 35.5 & Il. $1.35-43$ & 12.1 \\
\hline 3.142 .5 & 24.6 & Il. $2.80-81$ & 20.3 .1 \\
\hline 4.43 .1 & 35.2 & Il. 2.527-529 & 28.5 \\
\hline 4.62 .2 & 39.3 .5 & Il. 3.39-40 & 11.2.2.3 \\
\hline 4.68 .1 & 37.1 .8 & Il. $4.350-351$ & 44.6 \\
\hline 4.68 .2 & 37.1 .8 & Il. $4.415-416$ & 20.2.2.2 \\
\hline 4.140 .1 & 42.7 & Il. 5.597-600 & 28.4 .3 \\
\hline 5.8 & 41.1 .1 & Il. 5.638-639 & 44.7 \\
\hline $5.15 .1,3$ & 15.5 & Il. 6.345-347 & 11.2.2.3 \\
\hline 5.36 .4 & 40.2 .4 & Il. $8.477-479$ & 26.3 .5 \\
\hline 5.49 .2 & 34.2 .1 & Il. $9.165-166$ & 27.4 \\
\hline 5.62 .3 & 39.2 .4 & Il. 9.385-387 & 32.2 \\
\hline 5.82 .3 & 22.5 & Il. 9.697-699 & 11.2.2.2 \\
\hline 5.101 .1 & 29.4 .5 & Il. 11.386-387 & 20.2.2.2 \\
\hline 5.109 .2 & 24.2 .1 & Il. 11.670-672 & 11.2 .3 \\
\hline 6.4 & 9.3 .2 & Il. 12.246 & 35.7 \\
\hline 6.5 .2 & 37.2 .6 & Il. $13.491-493$ & 28.4 .2 \\
\hline 6.65 .1 & 22.5 & Il. $15.288-289$ & 16.2 \\
\hline 7.8.a.2 & 24.3 .1 & Il. $16.663-665$ & 3.4.3.1 \\
\hline 7.23 .4 & 33.1 .2 .1 & Il. 17.70-71 & 20.3.2 \\
\hline 7.49 .4 & 41.2.3 & Il. $17.556-558$ & 20.2.1 \\
\hline 7.107.1 & 31.3 .1 & Il. 18.107 & 11.1 .3 \\
\hline 7.121 .2 & 37.1 .7 & Il. 20.403-404 & 28.4 .3 \\
\hline 7.147 .1 & 13.3 & Il. $21.311-312$ & 39.3.7 \\
\hline 8.22 .1 & 22.2 & Il. $22.86-88$ & 20.2.2.2 \\
\hline 8.98 .1 & 29.6 .6 & Il. $23.584-585$ & 16.3 \\
\hline 8.108 .2 & 13.3 & Od. 1.9 & 42.2 \\
\hline 8.113 .3 & 39.4.2.1 & Od. 1.37 & 42.1 \\
\hline 8.143 .3 & 11.3 & Od. $1.48-50$ & 42.3 \\
\hline 8.144 .5 & 30.3 .2 & Od. 1.75 & 42.3 \\
\hline 9.46 .3 & 35.4 .2 & Od. $1.372-374$ & 27.5 \\
\hline \multirow[t]{2}{*}{9.117} & 10.4 .2 & Od. $1.384-385$ & 37.1 .3 \\
\hline & & Od. 2.372 & 16.3 \\
\hline Hesiod & & Od. 4.391-392 & 20.2 .2 .2 \\
\hline Op. 363 & 25.3 .2 & Od. 7.204-206 & 20.2.2.1 \\
\hline Sc. 5-6 & 9.3 .4 & Od. 8.221 & 14.4 \\
\hline
\end{tabular}


INDEX OF PASSAGES QUOTED IN THE LESSONS

Od. 8.479-481

Od. 11.519-520

Od. $13.128-129$

Od. $13.291-292$

Od. 13.293-294

Od. $14.274-275$

Od. $14.331-332$

Od. 15.34-35

Od. $15.341-342$

Od. $18.272-273$

Od. $19.589-590$

Od. 22.27-28

Isaeus

2.28

8.34

10.1

18.19

Isocrates

2.23

2.49

4.91

4.129

4.141

5.123

6.40

6.52

6.56

6.92

7.59

7.81

8.19

8.53

8.111-112

8.129

9.7

10.60

11.7

12.80

$\begin{array}{rl}37.1 .3 & 12.112 \\ 44.5 .1 & 12.139-141 \\ 23.1 .4 & 15.15 \\ 26.3 .1 & 15.74 \\ 26.2 & 15.83\end{array}$

$11.2 .2 .3 \quad 15.88$

$16.3 \quad 15.218$

$25.4 .1 \quad 15.278$

$11.1 .2 \quad 16.5$

$30.2 .1 \quad 16.9$

20.3.3 16.9

$10.3 .2 \quad 16.22$

17.14

17.22

$\begin{array}{ll}18.5 & 17.24\end{array}$

$35.4 .1 \quad 18.17$

$11.4 \quad 21.16$

16.3

Lysias

1.21

$28.3 \quad 10.11$

$\begin{array}{ll}7.3 & 12.27\end{array}$

$41.1 .1 \quad 12.74$

2.3.2 12.58

$32.2 \quad 12.86$

$\begin{array}{ll}25.6 & 13.9\end{array}$

$34.3 .1 \quad 14.11$

19.4.3 14.21

$34.3 .1 \quad 14.24$

$\begin{array}{ll}8.3 & 19.32\end{array}$

$34.3 .2 \quad 21.12$

$34.2 .1 \quad 23.4$

34.3.2 24.4

$25.2 \quad 24.15$

$22.1 \quad 25.33$

$34.4 \quad 30.5$

$8.6 \quad 30.32$

\begin{tabular}{ll}
$41.2 .3 \quad 31.15$ \\
\hline
\end{tabular}

24.3.5 31.31

$29.5 \quad 32.8$
9.3.4

29.3.2

43.3 .4

33.2

32.3 .1

31.2 .2

22.4

43.6.2

32.3.2.2

43.5

43.6 .1

35.3

39.2 .6

35.6.1

34.3 .1

10.4.1

13.2

24.6

15.2

26.3.3

21.3

39.3 .2

11.4

39.3 .4

39.3 .6

39.5

39.3 .3

16.2

24.2.4

37.1 .1

14.2

13.2

29.5

39.3 .7

34.4

16.2

34.4

37.2 .3 
INTERMEDIATE ANCIENT GREEK LANGUAGE

Philemo Comicus

fr. 2

Plato

Ap. $17 \mathrm{C}$

Ap. $19 \mathrm{C}$

Ap. $20 \mathrm{E}$

Ap. $21 \mathrm{~A}$

Ap. $27 \mathrm{~A}$

Ap. $27 \mathrm{C}$

Ap. $30 \mathrm{C}$

Ap. $33 \mathrm{E}$

Ap. $34 \mathrm{C}$

Ap. $35 \mathrm{D}$

Ap. $38 \mathrm{C}$

Ap. $39 \mathrm{D}$

Ap. 41 A-B

Cri. $49 \mathrm{D}$

Cri. 51 B-C

Euthphr. 3 B

Euthphr. 4 D

Euthphr. $10 \mathrm{~A}$

Grg. $522 \mathrm{E}$

Hp.Ma. $282 \mathrm{E}$

Leg. 705 E

Phd. $59 \mathrm{E}$

Phd. 67 A

Phd. 81 D-E

Phd. $89 \mathrm{C}$

Phd. 105 E

Phlb. $27 \mathrm{C}$

Prt. $356 \mathrm{C}$

R. $332 \mathrm{~A}$

R. $340 \mathrm{E}$

R. $341 \mathrm{C}$

R. $350 \mathrm{C}$

R. $351 \mathrm{E}-352 \mathrm{~A}$

R. 361 B-C

R. 377 B-C

R. $379 \mathrm{~B}$

\begin{tabular}{|c|c|}
\hline & R. $415 \mathrm{~B}$ \\
\hline 44.6 & R. $526 \mathrm{C}$ \\
\hline & Smp. $172 \mathrm{~A}$ \\
\hline & Smp. 172 B \\
\hline 21.2 & Smp. $172 \mathrm{C}$ \\
\hline 6.2 & Smp. 173 B-C \\
\hline 10.2 & Smp. $173 \mathrm{E}$ \\
\hline 10.2 & Smp. 173 E-174 A \\
\hline 28.4 .2 & Tht. $142 \mathrm{~A}$ \\
\hline 23.1 .1 & Tht. $142 \mathrm{~B}$ \\
\hline 40.2 .8 & \\
\hline 22.3 & Septuagint \\
\hline 28.4 .1 & Tobit 2.14 \\
\hline 3.5 .4 & Sophocles \\
\hline 26.3.1 & Aj. 265-267 \\
\hline 3.5 .3 & Aj. 387-391 \\
\hline 23.4 & $\begin{array}{l}\text { Aj. } 38 /-391 \\
\text { Ai. } 539\end{array}$ \\
\hline 24.2 .2 & \\
\hline $\begin{array}{r}8.7 \\
773\end{array}$ & Aj. 657-658 \\
\hline 27.3 & Aj. 762-763 \\
\hline 34.2 .3 & Aj. 810 \\
\hline 23.1 .1 & Aj. 879-887 \\
\hline 35.3 & Aj. 887-889 \\
\hline 16.1 & Aj. 944-945 \\
\hline 42.9 & Aj. 964-965 \\
\hline 10.4 .2 & Ant. 371 \\
\hline 30.2 .2 & Ant. 453-455 \\
\hline 30.4 & Ant. 502-504 \\
\hline 24.2 .3 & Ant. 678 \\
\hline 17.1 & Ant. 750-751 \\
\hline 17.1 & Ant. 752 \\
\hline 23.1 .4 & Ant. 885-887 \\
\hline 43.2 & Ant. 891-894 \\
\hline 43.3 .1 & Ant. 927-928 \\
\hline 43.3 .5 & Ant. 1087-1088 \\
\hline 43.2 & El. 379-381 \\
\hline 43.2 & El. 404 \\
\hline 36.2 & El. 446-448 \\
\hline 25.3 .1 & El. 814-816 \\
\hline 25.3 .2 & El. 1259 \\
\hline
\end{tabular}

10.4 .2

18.2

4.3 .3

12.4

4.3.1

22.3

3.4 .1

3.4 .2

34.4

44.7

40.2.7

17.2

11.1 .4

41.2.1.3

33.3

36.3

33.1.2.2

11.1 .4

3.4 .1

44.5.1

41.1 .3

42.9

22.1

42.10

8.8

4.3.2

4.3.2

10.3.3

36.6

11.1.1

36.7

33.3

33.1.1

17.1

17.1

33.1.2.2 
INDEX OF PASSAGES QUOTED IN THE LESSONS

\begin{tabular}{|c|c|c|c|}
\hline El. 1315-1317 & 22.1 & Ph. 882-883 & 4.3 .3 \\
\hline El. 1344 & 5.2 & Ph. 961-962 & 32.3.2.1 \\
\hline OC 38 & 39.2 .1 & Ph. 1026-1028 & 40.3 .4 \\
\hline OC 52 & 43.4 & Ph. 1035-1039 & 23.1 .2 \\
\hline OC 216 & 44.2 & Ph. 1241 & 29.4 .4 \\
\hline OC $377-381$ & 6.5 .1 & Ph. 1242 & 29.2 .3 \\
\hline OC 656-657 & 15.3 & Ph. 1301 & 37.1 .6 \\
\hline OC 791 & 17.1 & Ph. 1348-1349 & 36.5 \\
\hline OC 956 & 10.3 .1 & Ph. 1469-1471 & 2.3 .2 \\
\hline OC $1486-1487$ & 17.1 & Tr. 438-439 & 25.4 .1 \\
\hline OT 198-199 & 20.2.2.1 & Tr. 445-446 & 7.3 \\
\hline OT 224-226 & 25.4 .1 & Tr. 706 & 15.3 \\
\hline OT 284-285 & 40.2 .5 & Tr. 903-905 & 33.3 \\
\hline OT 316-317 & 33.1 .2 .2 & Tr. 1112-1113 & 44.7 \\
\hline OT 380-382 & 44.5 .2 & Tr. 1206-1207 & 44.5 .1 \\
\hline OT 393-394 & 39.2 .2 & Tr. 1227 & 37.1 .7 \\
\hline OT 603-604 & 37.3 & & \\
\hline OT 616 & 24.5 & Theognis & \\
\hline OT 838 & 5.2 & $555-556$ & 42.4 \\
\hline OT 863-865 & 11.1.3 & & \\
\hline OT 1009 & 42.4 & Thucydides & \\
\hline OT 1014-1016 & 41.1 .3 & 1.1 .1 & 1.2 .2 \\
\hline OT $1216-1218$ & 11.2.1.2 & 1.5 .1 & 42.7 \\
\hline OT 1255-1257 & 18.5 & 1.5 .3 & 9.3 .4 \\
\hline OT 1367 & 18.5 & 1.6 .5 & 9.3 .4 \\
\hline OT 1387-1389 & 29.6 .5 & 1.7 & 9.3 .4 \\
\hline OT 1442-1443 & 33.1 .1 & 1.8 .3 & 4.3 .2 \\
\hline OT $1455-1456$ & 15.3 & 1.10 .2 & 5.3 \\
\hline $\mathrm{Ph} .45$ & 27.1 & 1.10 .5 & 40.2 .6 \\
\hline Ph. 50-51 & 27.1 & 1.11 .2 & 4.3 .1 \\
\hline Ph. 58-59 & 37.1 .7 & 1.18 .1 & 38.4 \\
\hline Ph. 83-85 & 2.3 .1 & 1.19 & 41.1 .2 \\
\hline Ph. 101 & 41.2.1.1 & 1.20 .1 & 6.4 \\
\hline Ph. 118 & 29.6.4 & 1.22 .3 & 28.3 \\
\hline Ph. 124 & 27.5 & 1.26 .2 & 29.11 .3 \\
\hline Ph. 229 & 2.3 .1 & 1.26 .3 & 21.3 \\
\hline Ph. 302-303 & 33.4 & 1.27 .2 & 29.11 .2 \\
\hline Ph. 451-452 & 36.3 & 1.28 .1 & 6.2 \\
\hline Ph. 714-715 & 41.1 .2 & 1.31 .2 & 9.3 .3 \\
\hline Ph. 734 & 17.1 & $1.31 .4-1.32 .1$ & 12.3 \\
\hline
\end{tabular}


INTERMEDIATE ANCIENT GREEK LANGUAGE

\begin{tabular}{|c|c|c|c|}
\hline 1.35 .4 & 37.2 .5 & 2.84 .2 & 16.2 \\
\hline 1.36 .4 & 12.3 & 2.87 .5 & 3.5 .2 \\
\hline 1.38 .4 & 19.4 .1 & 2.88 .3 & 4.3 .1 \\
\hline 1.40 .2 & 26.3 .4 & 2.90 .2 & 27.5 \\
\hline 1.47 .3 & 38.5 & 2.90 .4 & 16.2 \\
\hline 1.49 .3 & 31.3 .2 & 2.93 .4 & 3.5 .3 \\
\hline 1.53 .2 & 29.4 .2 & 2.93 .4 & 14.7 \\
\hline 1.57 .4 & 24.3 .2 & 2.99 .1 & 24.3.1 \\
\hline 1.64 .1 & 16.1 & 3.1 .2 & 33.1 .3 .2 \\
\hline 1.66 & 36.1 & 3.9 .2 & 19.4 .2 \\
\hline 1.72 .1 & 8.3 & 3.22 .8 & 32.3.2.2 \\
\hline 1.82 .5 & 24.2 .1 & 3.33 .2 & 35.7 \\
\hline 1.86 .1 & 9.3 .3 & 3.34 .1 & 33.1 .3 .1 \\
\hline 1.90 .5 & 34.4 & 3.36 .5 & 42.7 \\
\hline 1.91 .5 & 14.3 & 3.45 .4 & 8.5 \\
\hline 1.98 .3 & 41.1 .2 & 3.60 & 14.3 \\
\hline 1.109 .4 & 42.10 & 3.81 .3 & 9.3 .3 \\
\hline 1.123 .1 & 40.2 .7 & 3.96 .1 & 6.3 \\
\hline 1.134 .1 & 39.3 .1 & 3.112 .6 & 33.4 \\
\hline 1.139 .1 & 6.3 & 4.17 .2 & 6.4 \\
\hline 1.142 .1 & 29.11 .1 & 4.20 .3 & 6.2 \\
\hline 1.142 .4 & 29.6 .2 & 4.23 .1 & 14.2 \\
\hline 1.143 .5 & 33.1.2.1 & 4.27 .1 & 35.4 .1 \\
\hline 1.144 .1 & 3.5 .3 & 4.35 .2 & 40.3 .2 \\
\hline 2.2 .1 & 41.1 .2 & 4.38 .3 & 12.5 \\
\hline 2.5 .2 & 37.2 .2 & 4.55 .3 & 35.4 .1 \\
\hline 2.5 .5 & 14.6 & 4.65 .3 & 23.1 .3 \\
\hline 2.11 .5 & 3.5 .5 & 4.66 .3 & 39.2 .5 \\
\hline 2.20 .1 & 14.7 & 4.70 .2 & 32.2 \\
\hline 2.20 .4 & 3.4.3.3 & 4.80 .1 & 21.3 \\
\hline 2.44 .1 & 25.7 & 4.85 .4 & 38.9 \\
\hline 2.44 .4 & 3.5 .1 & 4.110 .2 & 15.3 \\
\hline 2.48 .2 & 42.6 & 4.128 .2 & 16.1 \\
\hline 2.55 .1 & 33.1 .3 .1 & 5.1 & 28.2 \\
\hline 2.59 .2 & 23.3 & 5.5 .1 & 39.2 .1 \\
\hline 2.62 .2 & 29.10 & 5.11 .10 & 15.2 \\
\hline 2.67 .3 & 32.2 & 5.14 .3 & 39.3 .5 \\
\hline 2.75 .1 & 3.5 .3 & 5.21 .3 & 13.3 \\
\hline 2.76 .3 & 35.4 .2 & 5.29 .2 & 8.5 \\
\hline 2.81 .4 & 31.4 .1 & 5.34 .1 & 33.1.3.2 \\
\hline
\end{tabular}


INDEX OF PASSAGES QUOTED IN THE LESSONS

5.34 .2

5.35 .4

5.37 .1

5.55 .1

5.56 .5

5.63 .4

5.65 .3

5.83 .4

6.10 .5

6.23 .2

6.34 .2

6.36 .1

6.50 .1

7.39 .2

7.47 .4

7.48 .4

7.56 .1

7.66 .3

7.67 .3

7.71 .5

7.77 .6

8.18 .1

8.68 .1

Xenophon

Ages. 1.26

Ages. 1.31

Ages. 2.8

Ages. 3.5

Ages. 7.7

An. 1.9.10

An. 2.1.3

An. 2.1.4

An. 2.2.16

An. 3.3.4

An. 3.3.16

An. 3.5.5

An. 6.5.19-20

An. 7.2.25

Ap. 5
4.3.2 Cyr. 1.2.6

31.4.2 Cyr. 1.2.10

37.1.4 Cyr. 1.3.8

14.5 Cyr. 1.4.17

42.4 Cyr. 1.4.18

25.2 Cyr. 1.4.25

6.5.2 Cyr. 1.5.2

13.3 Cyr. 1.5.5

32.3.2.1 Cyr. 1.5.13

4.3.2 Cyr. 1.6.36

35.7 Cyr. 2.1.16

25.4.2 Cyr. 2.1.29

37.1.7 Cyr. 2.2.8

37.2.4 Cyr. 2.3.6

21.4 Cyr. 2.4.6

21.5 Cyr. 2.4.23

26.3.5 Cyr. 2.4.23

30.3.2 Cyr. 3.2.13

35.6.2 Cyr. 3.3.18

32.3.1 Cyr. 4.2.22

6.3 Cyr. 4.5.41

29.8 Cyr. 5.2.12

25.4.3 Cyr. 5.3.25

Cyr. 5.4 .21

Cyr. 5.5.24

22.3 Cyr. 6.2.9

15.2 Cyr. 6.2.9

24.3.3 Cyr. 7.1.8

12.4 Cyr.7.1.10

24.3.2 Cyr. 8.3.8

21.3 Eq. 12.1

13.4 Eq.Mag. 1.3

11.2.2.1 HG 1.6.35

24.3.4 HG 2.3.13

$42.7 \quad H G 3.1 .6$

29.7.2 $H G 4.5 .18$

$24.5 \quad H G 4.8 .5$

44.6 HG 6.4.27

18.1 HG 6.5.37

34.2.7 HG7.2.13
13.2

18.4

25.3.1

16.1

5.2

15.4

10.4 .1

37.1 .2

25.6

41.2.1.2

34.3 .1

24.3.3

32.3.2.2

35.5

30.2 .1

3.5 .3

29.3.1

18.3

35.2

3.4.3.2

33.1.2.2

18.3

31.2 .1

24.6

29.6.1

24.3 .3

27.1

17.1

36.4

33.2

11.3

24.2.2

29.2.1

33.2

40.2.7

3.4.3.4

29.4 .6

35.5

24.3.3

29.7.1 
INTERMEDIATE ANCIENT GREEK LANGUAGE

$\begin{array}{lr}\text { HG 7.4.10 } & 22.5 \\ \text { HG 7.5.24 } & 35.6 .3 \\ \text { Hier. } 11.11 & 35.7 \\ \text { Hier. } 4.3 & 27.1 \\ \text { Mem. } 1.2 .19 & 13.2 \\ \text { Mem. } 1.2 .41 & 16.1 \\ \text { Mem. } 2.1 .14 & 27.4 \\ \text { Mem. } 4.2 .3 & 29.6 .8 \\ \text { Mem. } 4.2 .10 & 29.2 .2 \\ \text { Oec. } 5.11 & 34.3 .1 \\ \text { Oec. } 7.38 & 8.8 \\ \text { Smp. } 4.1 & 15.4 \\ \text { Smp. } 4.16 & 24.2 .4 \\ \text { Vect. } 4.32 & 35.6 .3\end{array}$

